
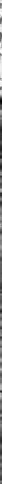

\%

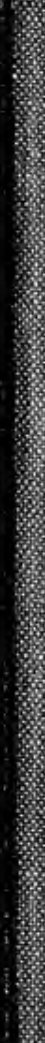

$\%$ 


. 



\title{
Weltbürgertum und Nationalstaat
}

\author{
Studien
}

zur

Genesis des deutschen Nationalstaates

Von

\section{Friedrich Meinecke}

„Grenzpfähle steckest du, um ein Gebiet zu messen; Woch daB dusie nur steckst, das sollst du nichtvergessen.

Der grade Gegensatz setzt grad' die Wahrheit schief,

Weil stets in Wahrheit eins ins andre sich verlief."

Ritckert.

Zweite durchgesehene Auflage

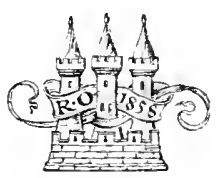

München und Berlin

Druck und Verlag von R. Oldenbourg 


$$
0
$$




\section{Erich Marcks}

zur Erinnerung an die gemeinsamen oberrheinischen Jahre in Freundschaft zugeeignet 



\section{Vorwort zur zweiten Auflage.}

Mein Buch, dessen erste Auflage Ende I907 erschien, versucht in die Genesis des deutschen Nationalstaates dadurch tiefer einzudringen, daß bestimmte große Probleme herausgegriffen und in ihrer Entwicklung durch das letzte Jahrhundert hindurch verfolgt werden. Historischpolitische und ideengeschichtliche Betrachtung mußten dabei überall ineinandergreifen. Ich darf es mit Dankbarkeit aussprechen, daß mein Versuch fast durchweg freundlich und nachsichtig aufgenommen worden ist und die Forschung bereits mehrfach angeregt hat. So habe ich wiederum aus den Bemerkungen meiner Rezensenten, voran G. Küutzels, R. M. Meyers und H. Onckens, und weiter aus manchen Einzelarbeiten der letzten Jahre lernen und der zweiten Auflage eine Reihe von Besserungen und Ergänzungen mitgeben können. Die Veröffentlichung des Gentzschen Briefwechsels hat mich veranlaßt, seine Stellung inmitten der im ersten Buche dargestellten Entwicklungsreihe kurz zu charakterisieren. Meine Auffassung der deutschen und europäischen Politik Steins hoffe ich

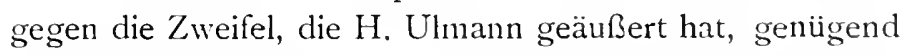
gerechtfertigt zu haben. Im zweiten Buche hat mir dann G. Droysens Biographie J. G. Droysens willkommene Gelegenheit gegeben, die Vorgeschichte seines Programms 
vom Fruhjahr i 848 aufzuhellen. Die Stellung des Königs Friedrich Wilhelm IV. zu dem im zweiten Buche behandelten Probleme konnte ich durch eine im Hausarchive neu aufgefunclene Niederschrift von ihm heller beleuchten. Weitere neue Zeugnisse, die ich inzwischen gefunden, betreffen die Haltung der Erbkaiserlichen. Die Einwendungen, die gegen meine Darstellung der Taktik der katholischen Gruppe von I 849 erhoben worden sind, habe ich nicht unberiicksichtigt gelassen. Schließlich hat H. Onckens Bennigsenbiographie fiir die letzten Kapitel mir wesentliche Ergänzungen geboten.

Mein Buch beruht auf der Meinung, daß die deutsche Geschichtsforschung, ohne auf die wertvollen Uberlieferungen ihres methodischen Betriebes zu verzichten, doch wiederum zu freierer Regung und Fühlung mit den großen Mächten des Staats- und Kulturlebens sich erheben müsse, daß sie sich, ohne Schaden zu nehmen an ihrem eigensten Wesen und Zwecke, mutiger baden dürfe in Philosophie wie in Politik, ja daß sie erst dadurch ihr eigenstes Wesen entwickeln könne, universal und national zugleich zu sein.

Freiburg i. B., 2 I. Mai I9II. 


\section{INHALT.}

\section{Erstes Buch.}

Nation, Staat und Weltbuirgertum in der Entwicklung des deutschen Nationalstaatsgedankens.

Erstes Kapitel. Allgemeines uber Nation, Nationalstaat und Weltbürgertum

Zweites Kapitel. Nation und Nationalstaat seit dem Siebenjährigen Kriege . . . . . . . . . : . . . . 20

Drittes Kapitel. Wilhelm v. Humboldt in den neunziger Jahren des is. Jahrhunderts . . . . . . . . . . . $3^{6}$

Viertes Kapitel. Novalis und Friedrich Schlegel in den Jahren der Frühromantik. . . . . . . . . . 58

Finftes Kapitel. Friedrich Schlegel im Übergange zur politischen Romantik . . . . . . . . . . . . . 79

Sechstes Kapitel. Fichte und die Idee des deutschen Nationalstaates in den Jahren ISo6-1813 . . . . . . . . S9

Siebentes Kapitel. Adam Müller in den Jahren ISoS-1S13. I 21

Achtes Kapitel. Stein, Gneisenau und Wilhelm v. Humboldt in deu Jahren 1\$I2-1SI5 . . . . . . . . . . I55

Neuntes Kapitel. Übergang zur Restaurationszeit; Biick auf die öffentliche Meinung . . . . . . . . . . . . . I99

Zehntes Kapitel. Haller und der Kreis Friedrich Wilhelms 1V. 216 Elftes Kapitel. Hegel . . . . . . . . . . . 271

Zwölftes Kapitel. Ranke und Bismarck . . . . . . . . 280 


\section{Zweites Buch.}

\section{Der preufische Nationalstaat und der deutsche Nationalstaat.}

Erstes Kapitel. Anfänge des preußisch-dentschen Problems; von Moser zu Friedrich v. Gagern . . . . . . . . . 325

Zweites Kapitel. Das preußisch-dentsche Problem vom März bis

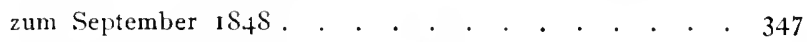

Drittes Kapitel. Heinrich v. Gagerns Werbung um Preußen . 376

Viertes Kapitel. Die Oktroyierung der preußischen Verfassung vom 5. Dezember ${ }_{1} S_{4} S$. . . . . . . . . . . . 399

Fünftes Kapitel. Von der oktroyierten Verfassung bis zur Kaiserwahl. . . . . . . . . . . . . . 448

Sechstes Kapitel. Von Heinrich v. Gagern zu Bismarck . . $4^{6} \mathbf{I}$

Siebentes Kapitel. Foltentwicklung des preuBisch-deutschen Problems . . . . . . . . . . . . . . . . 499

Personenregister . . . . . . . . . . . . . . . . 513 


\section{Erstes Buch.}

Nation, Staat und Weltbürgertum in der Entwicklung des deutschen Nationalstaatsgedankens. 



\section{Erstes Kapitel.}

\section{Allgemeines über Nation, Nationalstaat und Weltbürgertum.}

Wer über die Entstehungsgeschichte des nationalstaatlichen Gedankens in Deutschland etwas sagen will, muß sich zunächst eine klare Vorstellung vom Wesen der Nation und des Nationalstaates und vom Verhältnis beider Begriffe zueinander bilden.

Was sondert innerhalb des universalen Rahmens der Menschheitsgeschichte einzelne Nationen voneinander $a b$ ? Die Antwort kann nur sein, daß es keine Formel gibt, welche allgemeinguiltig die Merkmale dafür angibt. Nationen, so sieht man wohl auf den ersten Blick, sind große, mächtige Lebensgemeinschaften, die geschichtlich in langer Entwicklung entstanden und in unausgesetzter Bewegung und Veränderung begriffen sind, aber deswegen hat das Wesen der Nation auch etwas Fließendes. Gemeinsamer Wohnsitz, gemeinsame Abstammung oder, genauer gesagt, da es keine im anthropologischen Sinne rassenreinen Nationen gibt - gemeinsame oder ähnliche Blutmischung, gemeinsame Sprache, gemeinsames geistiges Leben, gemeinsamer Staatsverband oder Föderation mehrerer gleichartiger Staaten - alles das können wichtige und wesentliche Merkmale einer Nation sein, aber damit ist nicht gesagt, daß jede Nation sie alle zusammen besitzen müßte, um eine Nation zu sein. 
Unter allen Umständen muß irgendeine geschichtlich erwachsene geistige Gemeinschaft und ein mehr oder minder helles Bewußtsein von ihr vorhanden sein, aber wie sie entstanden ist und worauf sie vor allem beruht, dariber belehrt uns kein allgemeines Gesetz, sondern nur die Untersuchung des konkreten Einzelfalls. Wenn allgemeine Gesetze hier walten sollten, so sind sie doch unserer Erfahrung nicht zugänglich. Hier und da glaubt man wohl ein Stück, wenn nicht von allgemeinen Gesetzen, so doch von allgemeinen Tendenzen zu erhaschen und ähnliche Grundziige und Entwicklungsstufen aller oder doch vieler Nationen wahrzunehmen, aber bei strengerer Prüfung hat jede Nation wieder eine ganz individuelle und eigene Seite. Und mag die allgemeine Gesellschaftswissenschaft versuchen, das Typische und Generelle im Wesen der Nationen so viel wie möglich herauszuholen, so wird es den eigentlichen Historiker mehr drängen, das Eigentümliche der Einzelnation so treu und fein wie möglich zu beobachten. So wollen es auch unsere Studien, aber um es tun zu können, bedürfen sie einer wenigstens summarischen Orientierung über das, was man von allgemeinen Typen und Tendenzen im Wesen und Werden der Nationen unterscheiden kann.

Wir fassen die Nationen hier nicht in ihren ersten Ursprüngen, die in der Regel wohl auf ein Zusammen. wachsen aus kleineren Stämmen und Verbänden zurïckgehen, sondern in ihrem entwickelteren Stadium ins Auge. Da ist es denn, trotz aller gleich zu machenden Vorbehalte, ein durchaus fruchtbarer Gedanke, die Nationen einzuteilen in Kulturnationen und Staatsnationen ${ }^{1}$ ), in solche, die vorzugsweise auf einem irgendwelchen gemeinsam erlebten Kulturbesitz beruhen, und solche, die

1) So A. Kirchhoff, Zur Verständigung über die Begriffe Nation und Nationalität (1905), S. 52 ff, und im wesentlichen auch schon. Fr. J. Neumann, Volk und Nation (I888), S. 132 und 149. 
auf der vereinigenden Kraft einer gemeinsamen politischen Geschichte und Verfassung vor allem beruhen. Kulturnationen werden am wirksamsten durch das höchste und stärkste der geistigen Kulturgüter, die Religion, zusammengehalten, und man kann es zumal an ehemaligen Staatsnationen, die ihres Staates vielleicht vor Jahrhunderten schon verlustig geworden sind, mit Händen greifen, wie sie an ihrer nationalen Religion und Kirche einen festen Halt finden können. ${ }^{1}$ ) Aber eben dieser Fall weist schon darauf hin, daß die Staatsnation zugleich Kulturnation sein kann, so daß man oft nicht weiß, was sie stärker zusammenhält, ob das politische, ob das religiös-kirchliche Band. ${ }^{2}$ ) Kann man also innerlich Kultur- und Staatsnationen nicht ganz streng und säuberlich voneinander unterscheiden, so kann man es auch äußerlich nicht tun. Denn innerhalb einer echten Staatsnation können - wie das Beispiel der Schweiz zeigt - die Angehörigen verschiedener Kulturnationen leben, und wiederum die Kulturnation kann in sich - wie das Beispiel der großen deutschen Nation zeigte - mehrere Staatsnationen entstehen sehen, d. h. Bevölkerungen von Staaten, die ihr politisches Gemeingefühl zu kräftiger Eigenart ausprägen, die dadurch zu einer Nation werden, oft es bewußt werden wollen, zugleich aber - sie mögen

1) M. Lenz, Nationalität und Religion. Preuß. Jahrbücher 127; Kleine hist. Schriften (I9IO), S. 234.

2) Man könnte selbst fragen, ob eine Kulturnation rein und ausschließlich aus gemeinsamer Kultur, ohne Mitwirkung eines irgendwelchen politischen Faktors entstehen kann. Das Wort Dahlmann's (Politik, 3. Auflage S. 3): Man kann mehr Volk als Staat sein, aber man kann nicht Volk ohne Staat sein s, enthält, obwohl überscharf formuliert, einen richtigen Kern. Zur Entstehung der italienischen Kulturnation wirkte z. B. die Erinnerung an das römische Reich und wirkte ferner auch die politische Seite des Papsttums und der römischen Kirche mit. Ebenso wird umgekehrt kaum eine Staatsnation je entstanden sein ohne Mitwirkung irgendwelcher religiöser Faktoren. 
es wollen und wissen oder nicht - auch Angehörige jener größeren umfassenderen Kulturnation bleiben können.

Um ein Wollen oder Nichtwollen und um ein stärkeres oder schwächeres Bewußtsein davon kann es sich also hier handeln. Damit stoßen wir vielleicht auf das wichtigste Moment, um die verschiedenen Tendenzen im Verden der Nationen, wenigstens im großen, zu sondern. Man hat wohl geradezu gesagt: Nation ist, was eine Nation sein will. "L'existence d'une nation est un plébiscite de tous les jours. « ${ }^{1}$ ) Aber verlor der Elsässer, der vor I870 der französischen Staatsnation und zugleich auch Kulturnation angehören wollte, darum die tiefen Spuren der deutschen Kulturnation, in der er wurzelte? Er trug sie länger mit sich herum, als er vielleicht wünschte, und er gehörte - historisch gesehen - ihr auch noch an, als er ihr nicht mehr angehören wollte. Und doch behält jenes Renansche Wort, das seine Spitze gerade auch gegen Deutschlands Anspruch auf das Elsaß kehrt, seine Wahrheit, wenn man es richtig beschränkt und auf seine historischen Voraussetzungen zurïckführt. Es ist geboren aus dem Geiste von 1789 , aus dem Gedanken der Selbstbestimmung und Souveränität der Nation, d. h. der Staatsnation, die ihre politische Verfassung selbst gestalten, ihre politischen Geschicke selbst leiten will. Der Wille zur Nation hat damals erst die französische und dann im 19. Jahrhundert auch die deutsche und italienische Nation ergriffen und hat zur Neugestaltung großer Staatsnationen auf dem Kontinente geführt. Aber diesen neueren Zeiten, in denen der Wille zur Staatsnation so mächtig hervorbrach, gingen Zeiten vorher, in denen der nationale Wille noch nicht so bewußt und bestimmt sich regte, in denen von keiner nationalen Selbstbestimmung im vollen Sinne die Rede sein konnte, und in denen doch

1) E. Renan, Qu'est-ce qu'une nation.' (1882) S. 27. 
schon die Franzosen und Engländer eine Staats- und Kulturnation zugleich, die Deutschen und Italiener wenigstens eine Kulturnation waren. Und so treffen wir damit eine Hauptcäsur in der Entwicklung der neueren großen Nationen, sowohl der Staats- wie der Kulturnationen. Wir können eine frühere Periode unterscheiden, in denen die Nationen in ganzen ein mehr pflanzenhaftes und unpersönliches Dasein und Wachstum hatten, und eine spätere, in denen der bewußte IVille der Nation erwacht, in der sie sich selbst - und sei es auch nur durch das Organ ihrer Führer - als große Persönlichkeit, als große geschichtliche Einheit fühlt und das Kennzeichen und Recht der entwickelten Persönlichleit, die Selbstbestimmung beansprucht. ${ }^{1}$ ) Immer aber handelt es sich dabei nur um eine graduelle, nicht um eine radikale Wandlung. Auch in den Zeiten des mehr vegetativen und schlum. mernden Daseins der Nationen fehlte es nicht an einzelnen Momenten, wo sie das Auge aufschlugen, wo sie sprachen und dachten durch das Organ einzelner geistiger Fiihrer, wo sie handelten durch gemeinsame große Kundgebungen und Willensakte. Und ebenso hört auch jene frühere Art des stilleren, unbewußten Lebens keineswegs

I) In der Terminologie abweichend, im Inhalte ibeinsstremmend mit uns sind die Ansichten Eduard Meyers über den Unterschied von Volkstum und Nationalität: ,Erst ganz allmählich . . bildet sich, z ul$n a ̈ c h s t h a l b$ unbewuBt, ein Geftuhl der engeren Zusammengehörigkeit, eine Vorstellung von der Einheit des Volkstums. Die höchste Steigerung desselben, die Idee der $\mathrm{N}$ ationalität, ist dann das feinste und komplizierteste Gebilde, welches die geschichtliche Entwicklung 211 schaffen vermag: sie setzt die tatsächlich bestehende Einheit in einen bewußten, aktiven und schöpferischen Willen ume etc. Die Anfänge des Staats. Sitzungsber, der Berliner Akademie, phil.hist. Klasse 1907, 6. Juni; vgl. auch Meyer, Theorie und Methodik der Geschichte, S. 3 I ff., wo er allerdings in der Reaktion gegen die, welche in den Nationen die Einheiten der Geschichte iberhaupt sehen, wohl etwas zu weit geht. 
auf in den Zeiten der wachen Nationalpersönlichkeiten. Alle Neubildungen, die von dem bewußten Willen der Nationen, d. h. von ihren national empfindenden Regierungen, Parteien und Führern betrieben werden, greifen nur auf und führen nur fort, was leise vorher schon gekeimt hat, was langsam von unten nach oben durchgedrungen ist.

Immerhin ist die graduelle Verschiebung so groß, daß wir die Staats- wie die Kulturnationen in solche älteren und jüngeren Gepräges einteilen können.

Denn was zunächst die Staatsnationen betrifft, so werden sie ja nicht nur geschaffen durch den Selbstbestimmungsdrang der Nationen, sondern auch durch die stillwirkende Arbeit des Staates und durch das politische Zusammenleben in demselben Staatsverbande, also durch ein langsames, säkulares Wachstum. Man kann den Moment nicht angeben, wo sie geboren werden, man kann nur sagen, daß da, wo ein regeres, dauerhaftes, nach innen und außen hin wirksames politisches Gemeingefühl vorhanden ist, die Einwohnerschaft eines Staates zur Staatsnation und der Staat zum Nationalstaat geworden ist. Er kann sich, wie das Beispiel Englands und Frankreichs in ancien rigime zeigt, zugleich auf eine große Kulturnation stützen und sie in ihrer Hauptmasse umfassen, kann aber auch, wie das Beispiel Prcußens in derselben Zeit wenigstens in den Anfängen schon zeigt, eine besondere Staatsnation sich aus Teilen einer größeren Kulturnation heranbilden. Das Entscheidende ist, daß es dic, sei es absolutistische, sei es aristokratisch-parlamentarische Staatsbildung von oben her ist, die, zum guten Teile unwillkiurlich, Staatsnationen und Nationalstaaten dieses älteren Gepräges schafft. Freilich ist der Nationalstaat dieser älteren Zcit, als solcher angesehen, naturgemäß etwas höchst Unvollkommenes. Die ganze wunderbar verschnörkclte und zersplitterte W'elt des ancien régime, 
das ganze System der landschaftlichen, örtlichen und gesellschaftlichen Institutionen wirkt der Nationalisierung von oben her entgegen. Die Patrimonialgewalten und Korporationen zerteilen und absorbieren in hohem Grade den öffentlichen Geist; die Idee des Ganzen kommt nur in mancherlei Brechungen zum Leben. Wohl sind die großen Machtstaaten selbst schon zu kräftigen, autonomen Persönlichkeiten geworden, aber wo schon eine Staatsnation hinter ihnen steht, zeigt sie mehr ein bereitwilliges Folgen als ein selbsttätiges Drängen.

Was aber die Kulturnation dieser älteren Zeit betrifft, so zeigt sich ihr vegetativer Charakter eben schon darin, daß sie nicht von sich aus den Drang hat, Staatsnation zu werden und sich einen sie umfassenden Nationalstaat zu schaffen. Sie konnte sich mit ihrem Dasein als bloßer Kulturnation eher zufrieden geben als die Zeit, die nach möglichst kräftigen Formen und Wirkungsweisen für die Persönlichkeit der Nation suchte. Persönlichkeit heißt nicht nur möglichste Autonomie, sondern auch möglichste Autarkie und harmonische Einheit und Ausbildung aller inneren Kräfte und Anlagen. Doch sehen wir zunächst selbst $a b$ von der doch nur idealen und abstrahierten Vorstellung der Nationalpersönlichkeit, und denken wir nur an die realen Kräfte, aus denen sie sich zusammensetzt, an die Fülle der Einzelpersönlichkeiten, die sie bilden, und an das Gemeinsame in den Einzelwillen. Ist in ihnen erst einmal das volle Bewußtsein einer großen nationalen Gemeinschaft erwacht und zur intensiven Sehnsucht nach ihr gesteigert, so gleicht diese Sehnsucht einer Flut, die sich in alles ergießt, was von ihr erfüllt werden kann, die nicht zufricden ist, bis nicht alles nationalisiert ist, was uberhaupt der Nationalisierung fähig ist. Im Grunde ist dieser Hergang eine großartige Erweiterung der Einzelpersönlichkeit und ihres Lebenskreises. Der Mensch bedarf der Gemeinschaft, sowohl 
um sich von ihr tragen $z u$ lassen, als auch um in sie selbst hineinzutragen, was in ihm lebt, und je autonomer, je individueller er selbst wird, um so weiter und kiihner zieht er die Kreise dessen, was auf ihn wirken soll und worin er sich auswirken will, um so reicheren Inlalt, um so kräftigere Umrisse werden diese Lebenskreise erhalten. Und von allen den größeren Lebenskreisen, in die er sich hineinstellen kann, gibt es wohl keinen, der so unmittelbar zum ganzen Menschen spricht, so stark ihn trägt, so getreu seine ganze natürlich-geistige Wesenheit wiedergibt, so sehr Makroanthropos und potenziertes Individuum selbst ist oder werden kann als die Nation.

Es ist also kein Zufall, daß der Ära des modernen Nationalgedankens eine Ära individualistischer Freiheitsregungen unmittelbar vorangeht. Die Nation trank gleichsam das Blut der freien Persönlichkeiten, um sich selbst zur Persönlichkeit zu erheben. Es machte hierbei auch nichts aus, daß dieser moderne Individualismus in sich selbst gespalten war, indem sein einer Zweig, dem Naturrecht entstammend und demokratisch gerichtet, die Gleichberechtigung aller, sein anderer, aristokratisch in geistigem Sinne empfindend, die Befreiung und Steigerung der Besten erstrebte. ${ }^{1}$ ) Denn der demokratische Individualismus konnte ohne weiteres die Idee der Nation als Mittel benutzen, um alle Störungen der Gleichheit zu bekämpfen, und der aristokratische Individualismus hatte in ihr die Möglichkeit, hier einmal mit den Massen zu empfinden, die in ihnen schlummernden Kräfte herauszufiullen und, wenn nicht das Volk selbst, so doch ein Idealbild des Volkes zu umarmen. Und ob er das nun tat oder nicht, so kam doch alles, was die freie und schöpferische Persönlichkeit schuf, immer sogleich der wirklichen Nation

1) Vgl. Troeltsch, Das Wesen des modernen Geistes. Preuß. Jahrbuicher, April i 907, S. Io ff. Er unterscheidet rationalistischen und irrationalistischen Individualismus. 
zugute, indem es ihr Gesamtleben reicher, eigentiimlicher, individueller machte.

Beide Richtungen des Individualismus also konnten nationbildend wirken. Der größeren Aktivität der Individuen entsprach dann genau die größere Altivität der Nation, und die aktivste Form des modernen Nationalgedankens wurde der moderne Nationalstaatsgedanke. Die älteren Nationalstaaten Frankreich und England verjüngten sich und räumten, der eine rasch und leidenschaftlich, der andere langsam und bedächtig, die Zwischengewalten weg, die der innigeren Vereinigung von Nation und Staat bisher im Wege gestanden hatten. Ganz neue Nationalstaaten erwuchsen aus Nationen, die Jahrhunderte hindurch nur als Kulturnationen gebliiht hatten.

Weil aber das Wesen des modernen Nationalstaates höchstmögliche Alitivität der ihn bildenden Nation ist, so ist es mit seiner äußeren Herstellung und Erhaltung noch lange nicht getan. Es ist damit nur der äußere Wall der Macht gleichsam geschaffen, von dem aus nun die Nation als Staatsnation selbstbewußt und gerüstet in die Welt sieht, und innerhalb dessen sie jetzt ihr inneres geistiges und gesellschaftliches Leben zugleich zu steigern und $\mathrm{zu}$ harmonisieren strebt. Damit kommt nun auch in die Nation als Kulturnation ein neuer Zug, eine größere Aktivität, eine bewußtere Arbeit an sich selbst. Sie stachelt auch solche Nationen an, die auch jetzt noch nur Kulturnation bleiben, und ruhrt zumal diejenigen Teile von Nationen auf, die von ihrer politisch geeinigten Hauptmasse abgetrennt sind und mit ihr nur in Kulturgemeinschaft stehen können. Das Ideal ist allenthalben: Ungebrochene nationale Lebensgemeinschaft in allen wesentlichen Zielen des Daseins. $\left.{ }^{1}\right)$ Die Aufgabe ist un-

1) Sehr schön darüber G. Rümelin, Über den Begriff des Volks (Aufsätze I, I03): , Das eine Motiv kann mich zu diesem, das andere zu jenem Kreise hinziehen; der Glaube kann mich einer Gruppe zu- 
endlich, denn gleichzeitig mit den Mitteln sie zu lösen, wachsen auch ihre Schwierigkeiten. Gleichzeitig indem die Nation erstarkt, erstarken auch alle Lebenskreise innerhalb der Nation. So graben sich nun auch die schon vorhandenen geistigen, politischen und gesellschaftlichen Gegensätze innerhalb der Nation tiefer in sie ein und neue treten hinzu, denn alle Parteien und Gruppen zichen jetzt Nutzen von den regeren individuellen Kräften im Schoße der Nation. Ja, innerhalb der Nation selbst treten sich verschiedene Nationalbegriffe einander gegenuiber, verschiedene Richtungen, deren jede behauptet, die Nation allein echt und recht zu vertreten. Und diese Erscheinung, daß ein Teil der Nation sich unbefangen und gutgläubig als den Kern und die Essenz der gesamten Nation ansieht, liegt sogar im Wesen des Nationallebens selbst begründet, weil es doch immer in erster Linie von den regeren und mächtigeren Elementen, niemals von der ganzen trägen Masse gleichmäßig bestimmt wird, und weil das Idealbild der Nation zugleich auch immer der Spiegel dessen ist, was in den Einzelseelen sich regt. Nation ist also in gewissem Sinne von Natur immer pars fro toto, wobei freilich das Ganze ebensowenig entbehrt werden kann, wie der Kopf den Körper entbehren kann. Im älteren Nationalstaate war es in der Regel nicht zweifelhaft, wer den Kopf und wer die folgsamen Glieder vorstellte. Im juingeren Nationalstaate dagegen, wo die verschiedensten Individualitäten und sozialen Gruppen die Idee der Nation ergreifen und sich in sie hineinprojizieren, ist des

weisen, von der mich der Verband der Gemeinde, des Staats, der Sprache, der Abstammung trennt. Aber unser Gemiit wird jede solche Teilung und Gebrochenheit seiner Stimmung als eine Störung empfinden und beklagen; es wird stets von einer stillen Sehnsucht begleitet sein nach einer vollen, einheitlichen Lebensgemeinschaft. Es wird ihm als ein ideales Ziel die zentrale, alle Lebensziele umschließende Gruppe vorschweben. 
Zweifels und des Kampfes dariiber kein Ende. Wer nur auf diesen Kampf sieht, kann wohl meinen, daß man dem Ziele der vollen Lebensgemeinschaft nicht näher, sondern ferner rücke und daß die Nationen in ihrer friheren vegetativen Periode viel einheitlicher, viel ungebrochener in sich gelebt hätten. Aber es ist ja auch nicht die Einheitlichkeit an sich, die dem modernen Empfinden als höchster Wert erscheint, sondern die mit Leben und Kraft gesättigte Einheitlichkeit; nicht der harmonische Akkord an sich, sondern der möglichst reiche harmonische Akkord. Wohl kann man auch dann noch fragen, ob nicht das an sich wohl inhaltsärmere Nationalleben der älteren Zeit doch größere natürliche Kraft gehabt habe als das durch Reflexion und Zivilisation gebrochene der neueren Zeit. Aber lassen wir uns durch diese stark in das Subjektive gehenden Fragen, die selbst ein und derselbe Betrachter in verschiedener Stimmung oft verschieden beantworten wird, nicht zu weit abziehen. Überhaupt darf man niemals einzelne Eigenschaften des älteren und des modernen Nationallebens für sich miteinander vergleichen, sondern muß dabei immer die gesamte, so enorme Umgestaltung aller Lebensverhältnisse vor Augen behalten. Unfertig und unvollkommen war, wie wir sahen, schon der ältere Nationalstaat seinem inneren Wesen nach. Auch der neuere ist es, aber aus wesentlich anderen Ursachen als der ältere. Diesem fehlte es an spontaner Bewegung aus den tieferen Kreisen der Nation her, jener hat davon eher zuviel und müht sich $a b$, die auseinanderstrebenden und auf ihn eindrängenden Parteiungen zusammenzuhalten. Aber weil dieses Zuviel an Bewegung aus der reicheren Differenzierung der Individuen quillt, so kann auch die Aufgabe des modernen Nationalstaates nicht sein, die Gegensätze zu vernichten, die nationale Kultur zu nivellieren, sondern nur eine Gemeinsamkeit in gewissen Grundanschauungen und eine gegenseitige Duldung und An- 
erkennung dessen, was verschieden und mannigfaltig bleiben darf, zu erreichen, - einen Gottesfrieden gleichsam fiir gewisse Tage des nationalen Lebensjahres. Wird diese Aufgabe auch nur einigermaßen gelöst, so darf der moderne Nationalstaat sich rühmen, ein schwereres und doch wohl auch höheres Werk vollbracht zu haben als der alte Nationalstaat.

Gegen diese Auffassung vom Wesen des alten und des modernen Nationalstaates aber kann sich aus derselben Denkweise heraus, die dem älteren Nationalleben überhaupt eine größere natiirliche Kraft und Frische zuschrieb, noch ein gewichtiger Einwand erheben. Ist nicht, könnte man sagen, überhaupt ein jeder Staat ein Nationalstaat, der in seiner Strulitur ein eigentümliches nationales Gepräge trägt? Es kommt dann nicht darauf an, daß er die Nation, deren Wesen er spiegelt, ganz oder auch nur in ihrer Hauptmasse in sich vereinigt, es kommt dabei ferner auch nicht einmal darauf notwendig an, daß er seine Untertanen zu einer Staatsnation erziehe, - es kommt nur darauf an, daß seine Institutionen möglichst unberihrt von außernationalen Einflüssen seien. In diesem Sinne wäre das alte Rußland vor Peter dem Großen ein reinerer Nationalstaat als das durch heribergenommene westeuropäische Institutionen modernisierte, und wäre das, was wir den modernen Nationalstaat nannten, im Verdachte, iiberhaupt kein Nationalstaat zu sein, weil seine Verfassung so oft nach fremdem Muster gebildet ist. Der echte Nationalstaat geht nach dieser Auffassung vielmehr wie eine eigenartige Blume aus dem besonderen Boden einer Nation hervor, der neben ihm auch noch manche andere staatliche Gebilde von ebenso kräftigem und originellem Gepräge tragen kann, und national ist und wird er nicht durch den absichtsvollen Willen der Regierenden oder der Nation, sondern so, wie Sprache, Sitte, Glaube national sind und werden, durch das stille 
Wirken des Volksgeistes. So war es etwa mit den antiken und den italienischen Stadtstaaten und mit den älteren deutschen Territorialstaaten. Es ist also die Kulturnation, und zwar vorzugsweise die Kulturnation in ihrer mehr vegetativen Periode, die den Nationalstaat in diesem Sinne hervorbringt, und der Staat wird bei dieser Betrachtungsweise überhaupt nur als ein Prodult nationaler Kultur neben anderen angesehen. Also das logische Einteilungsprinzip ist hier ein anderes als das oben angewandte. Jenes ging vom Staate aus, dieses von der Nation, d. h. der Kulturnation. Jenes führte zu dem Urteile, daß es verschiedene Arten von Staaten gibt und diejenigen Staten Nationalstaaten sind, die eine Staatsnation enthalten, d. h. eine Bevölkerung von regerem politischen Gemeingefühl. Dieses dagegen gipfelt in dem Urteile, daß die Nation mancherlei Kinder ihres Geistes hervorbringt, darunter auch Nationalstaaten, d. h. Staaten, die den eigenartigen Charakter einer besonderen nationalen Kultur tragen. Wir werden sehen, daß es sich hier nicht um müßige Distinktionen handelt, sondern um Gegensätze, die gerade in der Entstehungsgeschichte der deutschen nationalstaatlichen Ideale sich bereutend geregt haben.

Wir haben Kulturnationen und Staatsnationen, wir haben Nationalstaaten in politischem Sinne und Nationalstaaten in nationalkulturellem Sinne, wir haben unter den Nationalstaaten im politischen Sinne und ferner auch unter den Staats- und Kulturnationen solche von älterem und modernerem Gepräge unterschieden. Dabei haben wir uns immer zugleich klar gemacht, daß in der geschichtlichen Wirklichkeit diese verschiedenen Typen ineinander übergehen. Überwiegend aber haben wir bisher Nationen und Nationalstaaten in sich und nach ihren eigenen immanenten Eigenschaften und Zielen betrachtet. Eine solche Betrachtungsweise genügt aber noch nicht. Denn Nationen und Nationalstaaten sind nicht - wir deuteten 
es schon oben an - schlechthin nur Exemplare bestimmter, teils rein sich erhaltender, teils untereinander sich mischender Gattungen, sondern tragen, wie alle geschichtlichen Gebilde, zugleich einen in hohem Grade singulären Clarakter. Singulär freilich nicht in dem Sinne, wie es eine von der Romantik beeinflußte Geschichtsauffassung lange gemeint hat, daß alles Besondere einer Nation ausschließlich aus ihrem eigenen immanenten Volksgeiste abzuleiten sei, sondern ihr Wesen bildet sich, ebenso wie das der Einzelpersönlichkeit, auch in und durch die Reibung und den Austausch mit den Nachbarn. So können die Berührungen der Nationen und Nationalstaaten untereinander ihre Einzelentwicklungen aufs tiefste bestimmen. So kann schon der einzelne geschichtliche Moment, das einzelne große Ereignis im Leben der Völker untereinander das Eigenleben der einzelnen Nation und des einzelnen Nationalstaates in Bahnen lenken, die man aus ihren bis dahin wirksamen Entwicklungstendenzen keineswegs schon sicher voraussehen konnte. Wohl kann es nun sein, daß auch diesen von außen her kommenden Einwirkungen bestimmte Grenzen gesetzt sind in der Eigenart der Nation, auf die sie treffen, daß vielleicht nur dasjenige sie wahrhaft $\mathrm{zu}$ befruchten und umzugestalten vermag, was auf einen in ihr schon schlummernden Keim trifft. Aber auch dann würde man bezweifeln können, ob diese schlummernden Keime und Möglichkeiten allen Nationen eigen sind oder nur der einen, in denen sie zur Entfaltung kommen, d. h. ob es Gattungseigenschaften sind oder singuläre Eigenschaften der einzelnen Nation. Nicht zu bezweifeln aber bleibt die Tatsache, daß von außen kommende singuläre Momente den Entwicklungsgang der einzelnen Nation und des einzelnen Nationalstaates wesentlich bestimmen können.

Was sind nun derartige äußere Einwirkungen aber anderes als Akte eines Gemeinschaftslebens der Nationen 
und Staaten untereinander, das wiederum auch seine kausalen Zusammenhänge in sich hat? Freilich sind nun die Grenzen solcher höheren, mehrere Nationen und Staaten vereinigenden Gemeinschaften und diese Gemeinschaften in sich selbst so fließend und unbestimmt, daß sich in der geschichtlichen Forschung der charakteristische Sprachgebrauch herausgebildet hat, der Welt des Nationalen und Einzelstaatlichen sogleich die Welt des Universalen gegenüberzustellen, und das hat dann weiter zu der Auffassung geführt, daß die gesamte Weltgeschichte eigentlich ein großer singulärer Prozeß, eine gewaltige Verflechtung und Durchkreuzung nationaler und universaler Entwicklung sei. ${ }^{1}$ )

Und nun darf man vielleicht sagen, daß die Geschichtsforschung da, wo sie auf diese Verflechtung trifft und sich bemüht, sie nachzuweisen, auf der Höhe des ihr zugewiesenen Gebietes uberhaupt wandelt und die reinste Luft, den klarsten Umblick genießt. Wenn sie, wie wir sagten, mit Vorliebe dem Eigentümlichen zugekehrt ist, so findet sie hier die höchste Art des Eigentümlichen selbst und den unbefangensten Standpunkt, um alles übrige Eigentumliche zu würdigen. Oder will man einwenden, daß das doch unmöglich ihre höchste Aufgabe sein könne, das äußere Grenz- und Berührungsgebiet zwischen Nation und Völkerkreisen, zwischen Staat und Staatensystemen zu bearbeiten? Denn, so könnte man etwa nicht ohne Grund sagen, - so bedeutend, so umfassend und so fernhin wirksam auch diese Berührungen und diese Stöße und Gegenstöße zwischen den Nationen und Völkerkreisen seien, so handle es sich hier doch nur um die Auswirkungen von tiefer und weiter zurückliegenden Kräften, und wer diese an der

1) O. Hintze, Über individualistische und kollektivistische $\mathrm{Ge}$ schichtsauffassung. Histor, Zeitschr. 78, 67 (Histor. und politische Aufsätze 4, I 2 ). 
Quelle fassen wolle, müsse das Individuum studieren in seinen geschichtlichen Wandlungen, und alle die übrigen Objekte historischer Forschung: Gesellschaft, Kultur, Staat, Nation und Menschheit existierten nur in und durch die Vorstellungen, Empfindungen und Handlungen der Individuen, und diese seien die Urzellen geschichtlichen Lebens. Nun wohl, wird man darauf zu erwidern haben, so wollen wir jenes Grenz- und Berihrungsgebiet zwischen nationaler und universaler Entwicklung nicht nur in den Berührungen und äußeren Aktionen der Völker und Staaten untereinander, sondern auch in dem Innenleben der Menschen suchen, denn auch hier entsteht von einer gewissen Kulturstufe an jener eigentümlich-großartige Hergang eines Wirkens und Gegenwirkens von nationalen und universalen Tendenzen. Schon in der geistigen Reibung zwischen Individuum und Umwelt, in dem Emporstreben des Einzelnen aus der Sphäre der Nation in die Sphäre des nur ihm Eigenen liegt oft ein universales Moment, indem die individuellen Güter dem sie Erstrebenden zugleich als rein menschliche Güter erscheinen können, während sie das doch keineswegs schlechthin sind, sondern auch immer noch ein Stiick Wurzelerde der nationalen Sphäre, die er nie ganz verlassen kann, mit sich führen. Sehen wir hier nur auf die Dinge im großen, so taucht sogleich eine Reihe bedeutender historischer Hergänge vor uns auf. Man denke an die antike Kultur und an die innere Auseinandersetzung nationaler und - wir können das entwertete Wort ruhig wieder in seine Ehre einsetzen - weltbürgerlicher Gedanken. Von dem Idealbilde der antiken Humanitas, des reinen Menschentums, hat man zum Beispiel sagen können: »Erst der Konflikt zweier Nationalitäten hat den Begriff und das Wort geschaffen", und es sei "ein erster, noch nicht ganz bewußter Versuch, das Recht des Staates auf das Individuum abzugrenzen, zwischen Nationalität und 
Menschentum zu scheiden. $\left.\ll^{1}\right)$ Man denke dann an die Entstehung des Christentums mit ihrer gewaltigen und fruchtbaren Reibung universaler und nationaler Religion. Man denke weiter, was uns hier besonders nahe liegen muß, an die ersten Spuren eines wirklichen deutschen Nationalbewußtseins im Mittelalter und ihren Zusammenhang mit der universalen Kaiserpolitik. »Es ist nicht bloßer Zufall, daß das erste Auftreten des Namens „Deutsche“ als Bezeichnung für unser Volk fast genau zusammenfällt mit der Errichtung des römischen Kaiserreiches deutscher Nation. ${ }^{2}$ ) Eine universale Aufgabe hat damals auch im Innern des Menschen die nationale Idee mit entzünden helfen. Und schließlich: Ist nicht gerade der erste große Nationalstaat in Europa, der mit vollem Bewußtsein auf der Autonomie der Nation begründet wurde, das Frankreich der Revolution, hervorgebrochen aus dem Mutterschoß des i8. Jahrhunderts, aus einem mit universalen und weltbürgerlichen Ideen durch und durch erfullten Boden:

Das legt die Frage nahe, ob nicht auch in Deutschland die Entstehung der nationalstaatlichen Gedanken aus solcher Spannung zwischen universalen und nationalen Ideen erfolgt ist. Die gemeine Meinung ist, daß allerdings auch in Deutschland eine Epoche weltbürgerlichen Denkens dem Erwachen der nationalen und nationalstaatlichen Idee vorausgegangen ist. Sollten wir in unseren Untersuchungen weiter nichts nachweisen als dieses, so würden wir offene Türen einrennen. Aber jene gemeine Meinung stellt Weltbürgertum und Nationalgefühl zugleich wie zwei sich ausschließende, sich lediglich nur bekämpfende und einander ablösende Denkweisen gegen-

$\left.{ }^{1}\right)$ Reitzenstein, Werden und Wesen der Humanität im Altertum (1907) S. 4. u. 6.

2) Dietr. Schäfer, Deutsches Nationalbewußtsein im Licht der Geschichte (ISS4), S. Io. 
uber. $\left.{ }^{1}\right)$ Das kann einem geschichtlichen Sinne, der an jenen größeren Zusammenliängen geschult ist und nach Darlegung innerlichster Kontinuität in jeder Ideenentwicklung verlangt, nicht genügen. Eine schon feinere und von den Trägern deutscher Bildung immer hochgehaltene Meinung ist die, daß das wahre, das beste deutsche Nationalgefühl auch das weltbürgerliche Ideal einer ubernationalen Humanität mit einschließe, daß es »undeutsch sei, bloß deutsch zu sein «. ${ }^{2}$ ) Diese Meinung kommt der Wahrheit wohl schon näher, aber sie postuliert eine Harmonie zwischen weltbürgerlicher und nationaler Idee, die nicht immer vorhanden war, und sieht hinweg über den schwierigen und dunklen Hergang ihrer inneren Auseinandersetzung und Vereinigung. So sei es eine Hauptaufgabe für uns, das wahre Verhältnis universaler und nationaler Ideale in der Entstehung des modernen deutschen Nationalstaatsgedankens nachzuweisen.

Die Natur des Problems erfordert eine mehr monographische und intensive Behandlungsweise. Die Untersuchung politischer Gedanken darf niemals losgelöst werden von den großen Persönlichkeiten, den schöpferischen Denkern; dort an der hochgelegenen Quelle und nicht in der breiten Ebene der sogenannten öffentlichen Meinung, der kleinen politischen Tagesliteratur muß man sie zunächst zu fassen versuchen. Wir wollen auch die herrorragenderen Denker nur in einer Auswahl und auch diejenigen, die wir auswählen, nicht in ihrer ganzen politischen Ent-

1) Auch die durch ihren Titel an unser Thema erinnernde Schrift Wohlwills, Weltbïrgertum und Vaterlandsliebe der Schwaben (IS75), obwohl sie die Mischung kosmopolitischer und patriotischer Regungen schon treffend bemerkt, geht in der Untersuchung dieses Verhälnisses nicht weit genug.

2) J. E. Erdmann, Das Nationalitätsprinzip (I862); Ernste Spiele (4. Auflage), S. 22r. Ähnlich Zeller, Nationalität und Humanität (1 $S_{73}$ ), Vorträge und Abhandlungen 2, $433 \mathrm{ff}$. 
wicklung, sondern nur da behandeln, wo sie Besonderes und Charakteristisches geleistet haben für die Bildung des deutschen Nationalstaatsgedankens. Dabei gilt es dann allerdings, die besonderen Gedanken und überhaupt das rein Begriffliche soviel wie nur irgend möglich zurückzuführen auf das, was mehr ist als Gedanke und Begriff, auf Leben und Persönlichkeit. Das Schwergewicht wird auf die fruchtbare Zeit der Revolution und der Befreiungskriege fallen, auf Humboldt, Fichte und die Romantiker. An Beispielen aus der deutschen Politik Steins, Gneisenaus und Humboldts wird hier auch die politische Praxis auf unsere Hauptfrage hin untersucht werden. Aus den Beobachtungen, die wir hier einerseits und an der deutschen Politik Friedrich Wilhelms IV. andererseits machten, ist die Idee dieser Untersuchungen überhaupt entstanden. ${ }^{1}$ ) Wollten wir ihre Aufgabe erschöpfen, so müßten wir sie auf alle Hauptverzweigungen der nationalen Idee in Deutschland erstrecken, auf die romantisch-konservative wie auf die liberale und demokratische, und könnten sie selbst mit Erfolg auf die modernen Massenparteien der Sozialdemokratie und des Zentrums ausdehnen. Aber uns genügt es, überhaupt einmal den Weg zu bahnen. So haben wir den romantisch-konservativen Zweig der Entwicklung herausgegriffen, die das eine Große für sich hat, daß er von Stein iiber Friedrich Wilhelm IV., Hegel und Ranke zu Bismarck führt. Auch ist er im ganzen weniger gekannt und gewuirdigt als der liberale Zweig, der wohl zuweilen als der einzige Träger nationalstaatlicher Ideale bis zur Zeit Bismarcks angesehen wird. Wir werden diesen aber auch hier nicht ganz außer acht lassen dürfen und hoffen dann, in der zweiten Untersuchung, die dem Zusammenhange der preußischen und

1) Einiges deutete ich schon in meiner Monographie uber das Zeitalter der deutschen Erhebung (1906) an. 
deutschen Verfassungsfrage gewidmet ist, auch einiges Neue über ihn sagen zu können.

Noch eins. Indem wir die Geschichte bestimmter Ideen durch die monographische Behandlung einzelner Denker aufzuklären versuchen, ist es unvermeidlich, daß manche Beobachtungen sich wiederholen und, obgleich die Objekte der Betrachtung wechseln, einige wenige einfache Gedanken immer wieder ausgesprochen werden muissen. Wir glaubten das nicht scheuen zu dürfen und halten uns an das Wort von Leibniz, daß die Natur zwar einfach in ihren Prinzipien, aber unermel3lich reich in ihrer Anwendung sei. 


\section{'Zweites Kapitel.}

\section{Nation und Nationalstaat seit dem Sieben- jährigen Kriege.}

Werfen wir zunächst einen raschen Blick auf die Hauptrichtungen des nationalen und nationalstaatlichen Denkens in den letzten Jahrzehnten des I8. Jahrhunderts und knüpfen wir dabei an den Gebrauch des Wortes Nation an, der diese Richtungen am besten spiegclt und zugleich die geheimnisvolle Macht der Sprache für die Entwicklung derartiger Ideen beweisen wird.

Seit mehreren Jahrhunderten schon sprach man in Deutschland von "Nation «. Man hatte das Wort wahrscheinlich unmittelbar aus dem Lateinischen, aus der Staats- und Kirchenrechtssprache des I 5. Jahrhunderts uibernommen ${ }^{1}$ ), und es ist interessant, wie in seinem zwiefachen Gebrauche sich unwillkürlich das Gefühl dafür aussprach, daß man von zwei Grundlagen her zu einer Nation werden könne, von der Kulturgemeinschaft oder von der Staatsgemeinschaft. Bald nämlich war es ein Ausdruck für eine Stammes- und Spracheneinheit, bald für die Gesamtheit der Reichsangehörigen. ${ }^{2}$ ) In der Sprache der Reichsabschiede des I6. Jahrhunderts und in der Sprache Luthers insbesondere erhielt das Wort von »teutscher Nation « dann einen noch volleren Klang, der selbst noch in der Wahlkapitulation Karls VII nach-

1) F. J. Neumann a. a. O. S. I39. Werminghoff, Der Begriff: Deutsche Nation in Urkunden des I5. Jahrhunderts. Histor. Viertel. jahrsschrift XI, I $\&_{4}$ ff. (IgOS).

2) F. J. Neumann a. a. O. S. 142 . 
tönte. So hatte es schon lange einen vornehmeren Sinn als das Wort Volk, das man mehr für das Geringe, Gemeine und Massenhafte anwandte, für die niedere Bevölkerung, Soldaten usw. Ähnlich war es auch in den Nachbarländern Frankreich, England, Italien, wo das Wort nation. nawione stolzere Vorstellungen weckte als das Wort peuple, people, popolo. ${ }^{1}$ ) In »Nation «, so darf man vielleicht sagen, hatte man einen Begriff, der zum Lichte, zur Höhe, zur Persönlichkeit empordrängte, in »Volk " mehr den Ausdruck für ein passives und vegetierendes, zu arbeitsamem Gehorsam verurteiltes Dasein. Und man kann nun beobachten, wie seit der Mitte des I8. Jahrhunderts zuerst in Franlireich, dann auch in Deutschland das Wort Nation glänzender und inhalts. reicher wird. Montesquieu widmete in seinem Esprit des lois von 1748 das 19. Buch der Frage, wie die Gesetze sich zu den Prinzipien verhielten qui forment l'esprit gincral, les meurs et les manières d'une nation, und in denselben Jahren entstand das Werk Voltaires, das seit 1769 den Titel Essai sur les mours et l'esprit des nations fuihrte. Beide verstehen unter Nation vorzugsweise die Kulturnation, die durch bestimmte geistige oder moralische Charakterzuige ausgezeichnete Vollisgemeinschaft. ${ }^{2}$ ) Wenig später beginnt auch die politische Aufwärtsbewegung des Begriffs, die nun genau der Aufwärtsbewegung des tiers itat entspricht. Ein Wortfuihrer des dritten Standes erklärte es 1758 für unwürdig, daß man Kaufleute, Gelehrte und Künstler zum peuple rechne; sie gehörten vielmehr zu den höheren Schichten der »Nation«, die

1) Neumann a. a. O. S. I $24 \mathrm{ff}$.

2) Das von Neumann S. I24 angeführte Beispiel aus dem Esprit des lois 28,9 , wo Nation im politischen Sinne, und zwar nur als $\mathrm{Zu-}$ sammenfassung der herrschenden Klassen (la nation ciest-à-dire les seigniurs et les evêques) gilt, bezieht sich auf einen besonderen geschichtlichen Fall, anf die Zustände im alten Frankenreich. 
nach dieser Auffassung zwar auch den peuple mit umfaßte, aber unwillkürlich dann zum Ausdruck für den eigentlichen Kern der Nation werden konnte. Die geistig oder politisch führende Schicht einer Nation hat ja, wie wir schon bemerkten, immer die Neigung, sich selbst mit der Nation zu identifizieren. ${ }^{1}$ ) So strömten denn damals die sozialen, politischen und geistigen Ideen und Ansprüche des dritten Standes in den Begriff der Nation ein und erhielten dann wiederum durch ihn eine ideale Schwungkraft. ${ }^{2}$ ) Wie stark man den Zauber und die Bedeutung des Wortes empfand, zeigen die berühmten Verhandlungen des dritten Standes im Juni I7\$9, wo man lange abwog, ob man sich assemblée nationale oder représentants du peuple français nennen solle. Mirabeau empfahl die letztere Bezeichnung, weil sie die anspruchslosere und unbestimmtere sei, aber der Sinn der Versammlung stand auf das Höhere. Mirabeaus Antrag wollte den Weg offen halten zu einer friedlichen Verständigung, - der Beschluß der Versammlung brach die Bahn zur Revolution. ${ }^{3}$ )

1) Interessant ist der von Neumann S. I24 angefuihrte Satz J. de Maistres: "Qu'est-ce qu'une nation." C"est le souverain et l'aristocratic." In Hans v. Gagerns Schrift „Über Deutschlands Zustand und Bundesver. fassung $18 \mathbf{I} S$ wird zwar auch dem Begriffe, Volke ein edlerer Sinn beigelegt, dann aber heißt es (S. 24): , Spreche ich aber von den An. sichten, den Wünschen, dem Urteil, dem hohen Interesse der Nation, so begreife ich sonder Zweifel nicht jenes Kind des Bettlers . . . sondern ich verstehe vorzugsweise den besseren, denkenden Teil ... den Kern der Nation, ohne weitere Rüchsicht anf Alter, Geschlecht und Stand . - Bekannt ist, wie umgekehrt Jahn in der Einleitung zum , Deutschen Volkstum I I Io die Wörter Volk, Volkstum gegen die Wörter Nation, Nationalität zu Ehren zu bringen suchte.

2) s La nation, c'est la France lettrée ou riches, so hat Aulard die Auffassung derjenigen, die am Vorabend der Revolution am radikalsten dachten, wiedergegeben. Hist. politique de la Rírolution frangaise S. 25.

3) So scharf wie hier wurde der Gegensatz von peuple und nalion allerdings nicht immer empfunden. Vom rein demokratisch-egalitären 
So kerzengrade wuchs damals in Frankreich der Gedanke der Nation, getragen von der sozialen Bewegung des dritten Standes, empor zu dem der Nationalsouveränität und des modernen Nationalstaates. Die ganze tiefe Verschiedenheit der deutschen und französischen Nation zeigt sich nun in der unendlich größeren Verzweigung und größeren Langsamkeit der deutschen Entwiclilung. Zuweilen scheint es, als sei diese Zersplitterung ein Mangel an Kraft, und es wird besonders dort dieser Anschein entstehen, wo man die Einwirkung des französischen Vorbildes und dann oft nur in einer matten Nachahmung spuirt. In Wahrheit aber steht es wohl so, daß der deutsche Nationalgedanke deswegen so langsam und spät reif wurde, weil er so viel und so Heterogenes in sich zu verarbeiten hatte und weil der geschichtliche Boden, auf dem er wuchs, so sehr viel mehr Dickicht noch zu tragen hatte als der wohl vorbereitete der französischen Nation.

Aus solchem Dickicht heraus schlägt uns nun das Wort vom »deutschen Nationalgeist « entgegen in dem Büchlein, das der wackere Friedrich Karl v. Moser i 766

Standpunkte aus konnte man auch das Wort peuple als Schlagwort wählen. Rousseau gebraucht 2. B. in Contrat social vorwiegend feuple, aber zuweilen promiscue mit nation (vgl. z. B. Buch 2, c. 8 Du peuple: $1 l$ est pour le's nations comme four les hommes un temps de jeunisse. . . mais la maturité d'un feuple n'est fos toujours facile a connaîtres usw.) - Für die weitere Entwicklung des Begriffs und der Idee der Nation in Frankreich sind höchst interessant die Gegensätze der Jakobiner und Girondisten im Jahre 1793. Erstere handelten nach dem Grundsatze, daß der Kern der Nation - d. h. sie und das Volk von Paris - die Nation selbst seien. Condorcets Verfassungsentwurf versuchte dagegen die Gesamtheit der Nation auszuspielen und jede Möglichkeit fuir den aktiven und unternehmenden Teil der Nation, die Fiblung an sich zu reißen, zu verhindern - zum guten Teil freilich aus taktischen Gründen, denn die Girondisten hatten von Haus aus genau dieselbe Neigung wie die Jakobiner, sich als melior et sanior pars der Nation und als pars pro toto anzusehen. 
unter diesem Titel in die Welt gehen ließ. Man spürt diesem und anderen seiner Schriften aus diesen Jahren die Bewegung an, die durch Friedrichs des Großen Auftreten und durch den Siebenjährigen Krieg in die Deutschen gekommen war; man spürt in ihnen weiter auch die große Wirkung der neuen Gedanken, die Montesquieu und Voltaire über Völker- und Staatenleben vorgetragen hatten. ${ }^{1}$ ) Beides gab ihm Impuls, uiber die Lage der deutschen Nation nachzudenken, aber der Inhalt seiner Gedanken klammerte sich nicht an Neues, sondern an Altes an. Höchst wahrscheinlich bildete er das Wort Nationalgeist in Anlehnung an Montesquieus Esfrit de la nation und an Voltaires Esprit des nations. ${ }^{2}$ ) Jedoch das neue zukunftsreiche Wort galt einer alten zukunftslosen Sache. Mit seinem modernen Glanze nahm es sich seltsam aus inmitten der verstaubten Umgebung, in die er es stellte, denn die "Spuren eines Nationalgeistes " fand er, so sagt er es selbst, in denjenigen Landschaften Deutschlands, wo man zwanzigerlei Herrschaften binnen einer Tagereise erblicken konnte. $\left.{ }^{3}\right)$ Es war der Reichs-

1) Montesquieu ist für ihn vein Schriftsteller von einem solchen Range, dem man sogar in seinen Fehlern und Mißbegriffen folget und nachahmet $\ll$. ,Beherzigungene, 3. Aufl. I 763 , S. 224. An Montesquieusche Betrachtungsweise erinnert es sofort, wenn er in seinen , Reliquien, (2. Aufl. 1766) unter der Rubrik , Geist einer Nation s sagt: ,Jede Nation hat ihre große Triebfeder. In Deutschland ist's Gehorsam, in England Freiheit, in Holland die Handlung, in Frankreich die Ehre des Königss usw. - Voltaire wird in den , Beherzigungen, S. 362 zitiert als Verfasser des Esprit des nations. Gemeint ist natiurlich der Essai sur les mceurs et l'esprit des nations, der seinen definitiven Titel zwar erst 1769 erhielt, aber schon in einer fruheren Ausgabe von $175^{6}$ das Schlagwort sesprit des nationss im Titel enthalten hatte (vgl. Oeuvres compl. de Voltaire I\$7\$, Bd. II, S. XI).

2) 》Die Franzosen unterscheiden a, heißt es in den , Beherzigungen c S. 362, ,zwischen l'esprit et le génié des nations, wir haben nur Ein Wort zu beydem. In derselben Schrift wird auch das Wort, Nationalgeist a schon gelegentlich (S. 492) gebraucht.

3) S. 51 . 
patriotismus der kleineren und schwächeren Stände, den er pries, und der doch zum guten Teil nur der Ausdruck ihres Schwächegefühls und im übrigen gemischt war aus ständischem Selbstgefühl, konservativem Rechtssinne, Respekt vor dem Kaiser und schließlich auch einem ehrlichen, aber oft nur vagen deutschen Gemeinbewußtsein. Aber immerhin, sein Nationalgeist ist ein politischer Nationalgeist, und so, wie er ihn versteht, ist es zugleich der Sinn für selbständige politische Uberzeugung und freiere politische Tätigkeit. ${ }^{1}$ ) Es ist schon etwas von Steinscher Gesinnung darin. Hat doch auch Stein aus der untergehenden Welt des Reiches und der Reichsritterschaft ein lebendiges Stuick sowohl von nationalpolitischem Gemeingefiihl als von ständischem Unabhängigkeitssinn hinubergetragen in die neuen Zeiten.

So barg dieser alte Reichspatriotismus allerdings ein fruchtbares Samenkorn, das auf neuem Boden, in neuer Luft wieder aufgehen konnte; auf dem Boden des alten Reiches hatte er keine Zukunft mehr. Die Bewegungen der Fürstenbundszeit mochten dann vorübergehend dazu anregen, sich mit dem nationalpolitischen Zustand Deutschlands im ganzen zu beschäftigen und das Zukunftsbild eines einheitlichen, unter einem Herrscher stehenden Deutschlands sich auszumalen -, es war doch nichts weiter als eine interessante These, einer der vielen Spielbälle des Denkens, mit denen man sich unterhielt. ${ }^{2}$ ) Der

1) > Der ganze Begriff von Nationalinteressec, heißt es in seinen s Beherzigungen S. 34I, s setzt ein Volk voraus, welches in dergleichen großen, seinen Ruhe- und Wohlstand betreffenden Angelegenheiten mitzusprechen hätte, wie solches in allen Republiquen und eingeschränckten Monarchien angetroffen wird. In einer unumschränckten Monarchie, wo der Wille und Befehl des Herrn allein entscheidet.... ist es ein bloßes Bild, so dem großen Haufen vorgehalten würde.

2) Vgl. Joh. v. Muiller, Teutschlands Erwartungen vom Fiirstenbunde. Sämtl. Werke, 9, 332; Wenck, Deutschland vor 100 Jahren I, 117 ff.; 2,248 . 
Appell Mosers an den politischen Nationalgeist der Deutschen erscholl, wie man will, zu spät oder zu früh. Aber die Idee eines deutschen Nationalgeistes uberhaupt ging nicht unter und füllte sich mit ganz neuem Inhalt. In Frankreich war es das bürgerliche und das literarische Frankreich vereint, das die neue Nationalidee schuf, in Deutschland war es fast allein das literarische Deutschland. In Frankreich schuf man sie mit vollem Bewußtsein und starker Absicht -, in Deutschland erwuchs der neue Nationalgeist ungesucht und wie nebenher aus der geistigen Arbeit der neuen großen Dichter und Denker. Während Frankreich voranschritt zum modernen Nationalgedanken, dessen Wesen, wie wir sagten, die bewußte Aktivität ist, zeigte Deutschland noch einmal, aber in größter Weise, das Unbewußte und Vegetative im Werden der Nation. Man war beseelt von jungen übermächtigen Lebenstrieben, die aus dem ganzen engbrüstigen Dasein der bisherigen Gesellschaft hinausstrebten. Wer wußte da gleich, wohin der Weg gehen wiirde, aber ehe man sich's versah, stand man auf einer Höhe und gewahrte, daß es zugleich die Höhe der Nation war. War es auch nur die Kulturnation und auch nicht einmal die ganze Kulturnation, sondern nur das literarische Dasein der Nation und ein rein geistiges Gemeingefühl der gebildeten Kreise, was diesen neuen deutschen Nationalgeist jetzt erzeugte, und mochte man auch, während man ihn schuf, immer wieder zweifeln, ob man von einer deutschen Nation im geistigen Sinne reden diurfe ${ }^{1}$ ) - an der Tatsache einer bluhenden, eigenartigen, inhaltsreichen Nationalliteratur ließ sich bald nicht mehr zweifeln, und aus unmittel-

I) Lessing am Schluß der Dramaturgie: ,Über den gutherzigen Einfall, den Deutschen ein Nationaltheater zu verschaffen, da wir noch keine Nation sind! Ich rede nicht von der politischen Verfassung, sondern bloß von dem sittlichen Charakter.s Schiller (Schaubühne als moralische Anstalt): ,Wenn wir es erlebten, eine Nationalbühne 
barstem, frischestem Erlebnis heraus konnte Herder zu Beginn der neunziger Jahre schreiben: »Die beste Kultur eines Volkes ist nicht schnell . . . am schönsten, und ich möchte sagen, einzig gedeiht sie auf dem eigenen Boden der Nation. $\ll^{1}$ )

Die Entwicklung dieses geistigen Nationalbewußtseins von Klopstock und Lessing zu Herder und Schiller zu schildern und wie seine Fäden von Jahrzehnt zu Jahrzehnt dichter werden, ist eine reizvolle Aufgabe für sich. ${ }^{2}$ ) Ebenso liegt es außerhalb unseres Rahmens, zu zeigen, wie damals in der einzigartigen Gedankenwelt Justus Mösers auch das tiefere geschichtliche Erdreich nationaler Lebenszusammenhänge schon bloßgelegt wurde. Wir wollen hier vielmehr nur die Hauptrichtung desjenigen Weges feststellen, der von der neuerwachten Kulturnation zum Staate und der Staatsnation hinüberführte, und werden dadurch sogleich in die neunziger Jahre hineingeführt, wo unter den mächtigen Eindrücken der französischen Revolution nun auch für die deutschen Denker der Staat und das Verhältnis der Nation zum Staate wieder ein Gegenstand, zwar nicht tätiger Teilnahme, aber interessiertester Reflexion werden konnte. Schon Herder konnte gelegentlich Ausblicke in das Politische tun. Obwohl es ihn selbst unendlich mehr lockte, das Werk der

zu haben, so wïrden wir auch eine Nation.s Herder (Briefe zur beförderung der Humanität, 4. Sanmlung n. 53): „Man könne es den Magistern nicht ubelnehmen, wenn sie pro gradu noch bis jetzt ttber das Thema disputieren, swelche Regimentsverfassung Deutschland habe, oder ob die Deutschen eine Nation scien.

1) Briefe zur Beförderung der IIumanität, I. Sammlung n. ro.

2) Uber Lessing vgl. z. B. Baumgarten, War Lessing ein eifriger Patriot? (Hist. und pol. Aufsätze und Reden $217 \mathrm{ff}$.) Vgl. ferner die allerdings sehr matte Arbeit von Behrens, Deutsches Ehr- und Nationalgefühl in seiner Entwicklung durch Philosophen und Dichter (I600-I 8 I 5 ). Leipziger Dissert. IS9I u. im allg. Jastrow, Gesch. d. deutschen Einheitstraumes, 3. Aufl. 
Kulturnation zu treiben und den "großen ungejäteten Garten der Nation « vom Unkraut zu säubern und dabei auch die Torheit der nationalen Selbstuberhebung auszujäten ${ }^{1}$ ), so dachte er doch mit seinem großen Sinne für die Totalität des Lebens mitunter auch schon an die robusteren und männlicheren Aufgaben der Nation. Und es genüge auch nicht, so war seine Meinung, daß der einzelne Deutsche tapfer und ehrlich sei, sondern weiter tue unserem Vaterlande auch not: "Licht, Auflklärung, Gemeinsinn; edler Stolz, sich nicht von anderen einrichten zu lassen, sonderm sich selbst einzurichten, wie andere Nationen es von jeher taten; Deutsche zu sein auf eigenem, wohlbeschützten Grund und Boden $\left.{ }^{2}{ }^{2}\right)$ So forderte er auch schon die politische Autonomie der Nation, in einem Geiste aber, der noch nicht der des modernen autonomen Nationalstaats war. Denn er teilte die Illusion vieler Revolutionsfreunde, daß die Nationalisierung des Staatenlebens den Kriegen der Kabinette ein Ende machen werde: "Kabinette mögen einander betrügen; politische Maschinen mögen gegeneinander gerückt werden, bis eine die andere zersprengt. Nicht so rücken Vat e rländer gegeneinander; sie liegen ruhig nebeneinander und stehen sich als Familien bei. Vaterländer gegen Vaterländer im Blutkampfe ist der ärgste Barbarismus der menschlichen Sprache $\left.\ll{ }^{3}\right)$ Nationalstaat und Weltbürgertum sind hier, ganz im Geiste der ersten französischen Revolutionsjahre, im engsten Bunde als gegenseitig sich bedingende und stützende Mächte gedacht.

1) Briefe zur Beförderung der Humanität, 4. Samml. n. 42.

2) Briefe usw. 5. Sammlung n. 57. „Der natürlichste Staat ist also auch e in Volk, mit ein em Nationalcharakter s, hatte es schon in den Ideen zur Philosophie der Geschichte der Menschheit geheißen (9. Buch, Kap. IV).

3) Briefe a. a. O. am Schlusse. 
Herders Sinn fuir die geschichtliche Welt und damit auch für das IVesen der Nation floß in letzter Linie aus seinem Humanitätsideal und fand in letzter Linie in diesem auch wiederum seine Schranke. ${ }^{1}$ ) Und so versagte seine sonst so wunderbare Kraft des Nachlebens der geschichtlichen Erscheinungen gerade auch gegenüber dem Staate und dessen Machttrieben. Deshalb reichte sein historischer Sinn auch noch nicht aus, um zu erkennen, daß der neue Nationalstaat, dessen Vorbild Frankreich jetzt bot, nur die Fortführung eines alten National- und Machtstaates war. Diese Vorgeschichte und Grundlage des anscheinend neu geschaffenen Staates wurde den Augen der Zeitgenossen verdeclit durch die philosophische, allgemein menschliche Motivierung seiner Rechte und Ansprüche. Was in Frankreich seit I 789 geschah, wurde in Deutschland nicht als das Werk geschichtlich bedingter und ganz konkreter Kräfte, sondern als das Werk des frei schaffenden, sei es zu Recht, sei es zu Unrecht schaffenden Menschengeistes aufgefaßt. Das historische Verstehen trat zurück vor dem Preisen oder Verdammen. Aber unfruchtbar für die Entwicklung der nationalen Idee waren diese Eindrücke nicht. Sie erhielt durch sie einen universalen und rationalen Sinn und empfahl sich eben dadurch den Zeitgenossen, die nach einer solchen Vernunftmotivierung nun einmal verlangten. Wieland führte I79 I sehr charakteristisch aus: Wenn von 25 Millionen Menschen 24, ja nur 20 Millionen einmuitig und standhaft auf einer Un1schaffung ihrer alten Staatsverfassung bestiunden, so machten diese 20 die Nation aus, und nicht sie, sondern die kleine Anzahl, die sich dem Willen der ungleich größeren widersetze, seien die Aufriihrer. Aus den »ersten Grundwahrheiten « aber folge dann auch, daß kein europäischer Staat das Recht habe, der französischen

1) Vgl. Kühnemann, Herders Persönlichkeit in seiner Weltanschauung. S. I2S ff. 
Nation mit Gewalt eine andere Konstitution aufzudrängen, als die sie selbst wolle. ${ }^{1}$ ) Das war die neue fruchtbare Lehre von dem absoluten Selbstbestimmungsrecht der Nation, aber nicht als historisch-politische, sondern als rational politische Wahrheit verkündet. Nit der Selbstbestimmung war dann auch die Persönlichkeit der Nation anerkannt, freilich noch nicht das, was unser historischer Sinn unter der geschichtlich erwachsenen Persönlichlieit der Nation versteht. Nation war hier nicht viel mehr als eine Unterabteilung der Menschheit, ein aus abstrakten Prinzipien gezimmerter Rahmen ohne individuellen Inhalt, und der jeweilige Mehrheitswille, der diesen Inhalt schaffen sollte, bedrohte gerade den echten geschichtlichen Inhalt der Nation. Die tiefen Schwächen und Irrtümer dieser ganz formalistisch gefaßten Lehre von der Nationalsouveränität liegen klar zutage. Aber der historisch-politische Irrtum war zugleich eine große historisch-politische Kraft, und für die Genesis des modernen Nationalstaates war dieser Zustrom rationalistisch-universaler Gedanken auch in Deutschland unentbehrlich. Behalten wir ihn zum Verständnis der späteren Entwicklung im Auge. Denn zunächst bedeutete er für Deutschland nicht viel melhr als eine anregende Theorie, an deren Umsetzung in die Wirklichkeit die Allerwenigsten dachten, und zu der auch die Wirklichkeit selbst noch gar nicht reif war. Solange der Machttrieb von unten her fehlte, war auch kein Bedürnis dazu da, Staat und Nation in ein engeres Verhältnis zueinander zu setzen.

Dafür war der Machttrieb von oben her eben am Verke, die Anfänge einer wirklichen Staatsnation innerhalb der weiteren deutschen Nation zu schaffen. Fr. K. v. Moser fühlte es unwillig, daß sein deutscher Nationalgeist im Norden auf einen Konkurrenten stieß, auf die » Mißgeburt einer militärisch-patriotischen Regierungsform ",

2) Wenck, a. a. O. 2, 209. 
die in den - so drückte er sich reichsrechtlich korrekt aus - ober- und niedersächsischen Landen jetzt emporgekommen sei. Wie überall in dem preußischen Staatswesen die bewußte Absicht und scharfe Berechnung waltete, so hatte Friedrich der Große auch seinen adligen Offizieren, gleichviel aus welcher Provinz sie stammten, einen preußischen Gemeingeist, einen esprit de corps et de nation einblasen wollen. $\left.{ }^{1}\right)$ Ihren Nationalgeist brauchte er unmittelbar und augenblicklich, - so wurden sie, die aktivsten Organe des Staates, auch die ersten Träger seines jungen Nationalgedankens. Selten kann man so handgreiflich beobachten, wie eine Staatsnation entsteht, wie die Nationalisierung da beginnt, wo die Pulse des Staatslebens am stärksten schlagen. Und schon ging sie auch weiter in tiefere Schichten der preußischen Bevölkerung, von denen der König keinen esprit de corps et de nation verlangte. Es stand mit ihrem preußischen Patriotismus, wie mit dem geistigen Nationalbewußtsein, das aus der deutschen Literatur aufblïhte: Ungesucht und unerwartet war er mit einem Male da. Der preußische Staat hatte von seinen Untertanen nur Pflichtgefühl und Anspannung verlangt für höchst nüchterne und hausbackene Aufgaben. Aber weil er dabei den ganzen Menschen beanspruchte, so konnten schließlich auch die Gefühle des ganzen Menschen in Schwingung geraten, als zur Prosa der gewöhnlichen staatlichen Friedensarbeit auch die Poesie eines großen Heldenlebens und eines Kampfes um die staatliche Existenz kam. Zwar war nun dieser neue, aus Gewolltem und aus Ungewolltem zusammenfließende preußische Nationalgeist zum guten Teile nur persönlicher Enthusiasmus für den König und ein Gefühl des Großen, was er und was man mit ihm erlebt, erduldet und erlitten hatte. Aber ohne solche Eindrücke ganz

1) Polit. Testament von I752; Acta Borussica, Behördenorganisation 9,362 . 
persönlichen Inhalts konnte in einem Staate, dessen inneres und äußeres Leben noch in erster Linie von der Persönlichkeit des Herrschers abhing, ein wärmeres Staatsgefühl nicht wohl erzeugt werden. Man konnte nun für den preußischen Staat arbeiten und für den preußischen König schwärmen, und selbst ein weiteres notwendiges Ingrediens eines regen politischen Nationalgeistes war in bescheidenen Anfängen schon da: die freie politische Kritik. Es gibt ein Quantum politischen Mißvergnügens und Besserwissens, das ein gewisses Behagen ausströmt, und dieses konnte man im damaligen Berlin schon finden. In der Presse durfte es sich zwar noch nicht hervorwagen, um so kecker aber im mündlichen Gespräche, und der Berliner war stolz, wenn der Fremde darüber erstaunte und sein dreistes Reden mit englischen Sitten verglich. "Man spricht", so bezeugte ein Schriftsteller, »mit gleicher Freiheit von der Religion wie von den Gebrechen des Staates, beurteilt den König so gut wie seinen Nachbar; und doch ist Patriotismus und Liebe für den König der Grundzug der Nation «. ${ }^{1}$ )

Und nun wuchs in den letzten Zeiten Friedrichs und zugleich unter den Einwirkungen der deutschen Literatur eine Generation von Staatsdienern heran, die sich bemihte, die deutschen Kulturgedanken mit dem preußischen Staatsgedanken zu verschmelzen. So stellt diese Schule von jungen preußischen Beamten und Offizieren, die später auf den öffentlichen Schauplatz trat, ein erstes bedeutendes Beispiel dar, wie sich aus staatlichen und geistigen Quellen ein politischer Nationalgeist modernen Charakters in Deutschland entwickeln konnte. Nur stimmten die einzelnen Teile dieses Nationalgeistes noch nicht so recht zusammen. Die Gedanken des deutschen Kulturlebens, die diese jungen philosophischen Preußen

1) Wenck I, 159 .

Meinecke, Weltbürgertum und Nationalstaat. 2. Aufl. 
ihrem Staate geben wollten, waren ein noch $\mathrm{zu}$ weites Gewand für dessen hageren Körper. Es war zum guten Teile doch Illusion, wenn sie in dem friderizianischen Soldaten- und Beamtenstaat den Träger der Humanitätsidee sahen, es war zum Teile auch nur zufällige Konstellation, daß die Reifezeit der friderizianischen Epoche zusammenfiel mit der ersten Bliitezeit der deutschen Literaturepoche, und so jene umrankt wurde von dieser. Denn obschon es an einer inneren Verwandtschaft zwischen dem rigorosen Geiste des preußischen Staatswesens und dem rigorosen Geiste der Kantischen Philosophie nicht fehlte, so waren deren und der deutschen Humanitätsbewegung zentrale Gedanken doch noch lange nicht imstande, die zentrale Substanz des preußischen Staates selbst zu durchdringen. Freiheit im Sinne von innerer Selbstbestimmung, - Friedrich selbst hatte sie wohl im großen Stile geubt und vorgelebt, aber seinen Staat und seine Untertanen hatte er nicht auf sie gestimmt und stimmen können.

Darum fuihrte dieser preußische Nationalgeist des ausgehenden ancien régime auch ein etwas unsicheres und prekäres Dasein. Schon die Regierungsweise eben des Königs, dem er sein Dasein so wesentlich verdankte, gefährdete ihn und stieß freiere Köpfe von sich ab, und die Regierungsweise seines Nachfolgers tat dies erst recht, ohne dafür das zu bieten, was Friedrich geboten hatte. Die ersten Jahre des jungen Königs Friedrich Wilhelm III. weckten wohl dann von neuem eine Art preußischer Nationalgesinnung und Flitterwochenschwärmerei, aber dies ganze Gemisch von oft edlen, oft trivialen Illusionen und ernsteren, männlicheren Gesinnungen bedurfte erst eines gründlichen Prüfungsfeuers, um das Echte von dem Unechten zu scheiden und die Idee einer preußischen Staatsnation zu einem hohen und unersetzlichen Werte zu steigern. 
Eine Gruncltatsache können wir aus dem bisher Gesagten schon entnehmen. Die eigentumliche Konstellation in Deutschland war die, daß die einzigen brauchbaren Grundlagen zu einem modernen Nationalstaate nicht auf dem Boden der deutschen Nation, sondern auf dem Boden des preußischen Einzelstaates lagen, daß dieser aber die geistigen Kräfte, die er zu seiner Nationalisierung brauchte, nicht aus sich allein schöpfen konnte, sondern aus dem weiten Bereiche der deutschen Kulturnation mit entnehmen mußte. Diese Tatsache ist allbekannt und schier trivial, aber man macht sich selten die eigentümlichen Spannungen und Disharmonien, zu denen sie führte, auch im einzelnen klar. Denn da die deutsche Nationalkultur einen ausgesprochen universalen $\mathrm{Zug}$ hatte, so stand es nun so, daß der preußische Staat, als er sich durch die Kräfte dieser Kultur auffrischte, auch ihren übernationalen, universalen Elementen Einlaß gewährte - eine Nationalisierung also durch zum Teil ubernationale, universale Mittel, ein Fortschritt der Staatsbildung durch Rezeption von zum Teil höchst unpolitischen Ideen. Das war oft so, wie wenn Wasser mit Feuer sich mengt, und die preußische Politik hat bis zur Zeit Bismarclss an diesem Widerspruche zu tragen gehabt. Wir hoffen, daß unsere zunächst ganz abstrakten Sätze allmählich Leben und Farbe gewinnen werden, wenn wir uns nun den einzelnen Denkern zuwenden. 


\section{Drittes Kapitel.}

\section{Wilhelm v. Humboldt in den neunziger Jahren des 18 . Jahrhunderts.}

Gleich in den ersten politischen Schriften Humboldts, den »Ideen über Staatsverfassung, durch die neue französische Revolution veranlaßt «, von I79I und den »Ideen zu einem Versuch, die Grenzen des Staates zu bestimmen ", von I79I und I792, schlägt er das Thema der Nation und ihres Verhältnisses zum Staate an. In der ersten dieser beiden Schriften fesselt er sofort durch den hohen und freien Standpunkt, durch die leidenschaftslose und doch philosophisch interessierte Abwägung dessen, was die französische Nation damals unternahm. Sie hat, meinte er, etwas Unmögliches begonnen, wenn sie eine Staatsverfassung rein nach den Grundsätzen der Vernunft schaffen wollte, denn die Vernunft verlangt Harmonie aller Kräfte. Das Ziel der Menschheit aber ist nicht Harmonie, sondern Einseitigkeit. „Wie mit den einzelnen Menschen, so mit ganzen Nationen. Sie nehmen auf einmal nur einen Gang. Daher ihre Verschiedenheiten untereinander, daher ilrre Verschiedenheiten in ihnen selbst in verschiedenen Epochen. «1) Das lief auf die fruchtbare Erkenntnis heraus, daß die Nationen große geschichtliche, einseitig-kräftige Individualitäten seien, daß sie einer schlechthin rationalen Entwicklung nicht fähig seien. Er

1) W. v. Humboldts Werke, herausg. von Leitzmann $\mathbf{I}, S_{\mathbf{I}}$. 
verfiel nun aber nicht in das andere Extrem, die Vernunft als regulierenden Faktor aus dem Leben der Nationen ganz ausschalten zu wollen. Neben "Zeit und Natur «, die vorarbeiten müssen, ließ er auch den »weisen Gesetzgeber « schaffen, der auf Grund genauester Kenntnis der individuellen Gegenwart, ihre Strömungen fördernd oder hemmend, sich bemühe, aber sich auch begnüge, sie dem Ziele der Vollkommenheit so viel wie möglich zu nähern. Man möchte sagen, er wurde damit dem Unbewußten wie dem Bewußten, dem naturhaften wie dem geistigen Faktor in dem Werden der Nationen gerecht. Und man möchte weiter meinen, daß er bei dieser Auffassung vom Verhältnis des Gesetzgebers zum Nationalleben von der Idee des modernen Nationalstaates, die gerade auch eine genaue Einfiihlung der Regierung in die wohlverstandenen Interessen der Nation fordert, nicht so weit entfernt gewesen sei. Aber da schob sich ihm nun zwischen Nation und Staat sogleich auch die trübe Erinnerung an das Selbsterlebte, an den Druck des aufgeklärten Absolutismus. Es »entstand das Prinzip, daß die Regierung für das Gluick und das Wohl, das physische und moralische, der Nation sorgen muß. Gerade der ärgste und drückendste Despotismus. ${ }^{1}$ ) Diese Erfahrung machte ihn wieder aufs tiefste mißtrauisch gegen den Staat uberhaupt, der die edelsten Kräfte des Menschen lähme durch seine verführerischen Unterdrückungskiinste. Und überhaupt, seine ganze Erkenntnis, daß Einseitigkeit das Los des einzelnen wie der Nationen und die Voraussetzung ihrer Kraft sei, war das Eingeständnis einer schmerzlichen und im Grunde auch nicht vollkommenen Resignation. Nicht die Kraft der Einseitigkeit, die ihn zum tieferen Verständnis und zur gerechteren Wuirdigung auch des Staates gefuihrt haben würde, sondern die »Bildung", die auf vielseitigstes 
Wirken und auf Harmonie aller Kräfte der Persönlichkeit aus war, war sein eigentliches Ideal. Kraft und Bildung aber, mußte er sich gestehen, »stehen ewig in umgekehrtem Verhältnis«. Wohl setzte er gleich hinzu, der Weise verfolge keine ganz, und jede sei ihm zu lieb, um sie der andern zu opfern. Das meinte er wohl aufrichtig als Lebensgrundsatz für sich selbst und für das Individuum ïberhaupt, jedoch für die Kraft, die durch die Zusammenfassung des nationalen Lebens im Staate erzeugt wurde, hatte er wohl ein kühles Verständnis, aber kein wärmeres menschliches Gefühl übrig. Und als er diesem Problem in seiner zweiten Jugendschrift näher nachsann, rückten ihm Staat und Nation noch weiter auseinander als bisher, und indem dabei das Individuum in ihm immer stärker und stolzer sich zu fühlen begann, wurde nun selbst das Bild der Nation, das in seiner ersten Schrift doch so bestimmten geschichtlichen Charakter schon erhalten hatte, ihm wieder blasser und flüchtiger.

Folgendermaßen bestimmt seine Schrift über die Grenzen der Wirksamkeit des Staates sein Verhältnis zur Nation: "Die Staatsverfassung und der Nationalverein sollten, wie eng sie auch ineinander verwebt sein mögen, nie miteinander verwechselt werden. IVenn die Staatsverfassung den Bürgern, sei's durch Ubermacht und Gewalt oder Gewohnheit und Gesetz, ein bestimmtes Verhältnis anweist, so gibt es außerdem noch ein anderes, freiwillig von ihnen gewähltes, unendlich mannigfaltiges und oft wechselndes. Und dies letztere, das freie Wirken der Nation untereinander, ist es eigentlich, welches alle Güter bewahrt, deren Sehnsucht die Menschen in eine Gesellschaft führt. «1)

1) 1, 236 vgl. auch 1, 131: ,Es bleibt immer ein unleugbar wichtiger Unterschied zwischen einer Nationalanstalt und einer Staatseinrichtung. Jene hat nur eine mittelbare, diese eine unmittelbare Gewalt. lei jener ist daher mehr Freiheit im Eingehen, Trennen und Modi- 
Noch oft gebraucht er das Wort Nation, nirgends definiert er den Begriff ausdruicklich. Er spricht wohl von Geist und Charakter der Nation ${ }^{1}$ ), er wünscht, daß der Krieg seinen wohltätigen Einfluß »auf Geist und Charakter durch die ganze Nation « ergießen möge und daß in ihr »der Geist wahrer Krieger oder vielmehr edler Bürger « lebe, welche » für ihr Vaterland zu fechten immer bereit sind «, aber er wünscht nicht, daß der Staat es unmittelbar darauf ablege, die Nation zum Kriege zu bilden. ${ }^{2}$ ) Er verkennt auch richt, daß ein Mittel nötig sei, um Staat und Nation oder, wie er sich - ziemlich entgegenkommend - ausdrückt, »den beherrschenden und den beherrschten Teil der Nation « miteinander zu verbinden. Er erwägt als eines dieser Mittel, das namentlich im Altertume schöne Gestalten hervorgebracht habe, die »Verbreitung eines der Konstitution günstigen Geistes unter der Nation", aber er hält es in der Gegenwart für unratsam, weil es der Ausbildung der Bürger in ihrer Individualität leicht nachteilig sei. $\left.{ }^{3}\right)$ Sieht man freilich genauer $z u$, so verwirft er nicht die Liebe der Nation zu ihrer Konstitution iberhaupt, sondern nur die geflissentlichen Mittel, um sie hervorzubringen. Aber die Konstitution soll denn auch so wenig wie möglich sich fühlbar machen, die Wirlssamkeit des Staates soll so weit wie irgend möglich ersetzt werden durch das verstärkte und vervielfachte Privatinteresse der Bürger. Nicht möglichst stark, sondern möglichst schwach soll der Staat sein. Als Kenner der menschlichen Seele wußte

fizieren der Verbindung. Anfangs sind höchst wahrscheinlich alle Staatsverbindungen nichts als dergleichen Nationalvereine gewesenc, - ein Gedanke, der auf eine eigentümliche Modifikation und zugleich Auflockerung der Vertragstheorie hinausläuft.
1) I, 162 .
2) 1,140 .
3) I, 234 . 
er freilich auch schon damals, daß der Mensch mehr zur Herrschaft als zur Freiheit geneigt sei, und als preußischer Untertan wußte er ferner, daß das Gebäude der Herrschaft nicht bloß dem Herrscher, sondern auch den dienenden Teilen Freude mache durch das Bewußtsein, Glieder eines Ganzen zu sein, das uber die Dauer einer Generation hinausgehe. $\left.{ }^{1}\right)$ Aber sein Ideal war das nicht, den höheren Grad von Kultur sah er nicht in dem herrschenden und dienenden, sondern in dem freien Wirken.

Man sieht daraus, daß nicht nur der alte absolutistische Machtstaat, sondern auch der moderne Nationalstaat, der auf der herrschend-dienenden Teilnahme der Nation am Staate und auf einem kräftigen, Herrschende und Beherrschte verbindenden Verfassungsleben beruht, seinen Wünschen fern lagen. Uberall spürt er die Fesseln für das selbsttätige, rein aus dem Innern herauswirkende Individuum, und auch nicht der leiseste Hauch, der die Freiheit des Innenlebens trüben könnte, entgeht seinem empfindlichen Auge. Dann darf man sich aber auch das, was er sich unter »Nation « und unter »Geist und Charaliter der Nation《 denkt, nur so leicht und körperlos wie möglich vorstellen - keine den einzelnen leitende oder erfullende Lebensmacht, sondern Lebens geist vielmehr, der sich ungesucht entwickelt aus dem zusammenströmenden Hauche der vielen Einzelseelen. Mag er dann auch nach seinem Wunsche wieder zurïckwirken auf die einzelnen, immer ist er doch in erster Linie etwas Erzeugtes, nicht etwas Erzeugendes.

Wir können uns vielleicht die Besonderheit seines Nationalbegriffes noch lilarer machen, wenn wir ihn vergleichen einmal mit demjenigen, den die Lehre von der Volkssouveränität und die Ideen der französischen Revolution ausbildeten, und dann mit demjenigen, den

$$
\text { 1) } 1,240 \text {. }
$$


Wilhelm v. Humboldt in den neunziger Jahren des 18. Jahrh. 4 I

später die Romantik und die historische Rechtsschule hatten. An jene erinnert er durch die Ignorierung der geschichtlichen Mächte, die auch mit beim Autbau der Nation tätig sind ${ }^{1}$, und auch durch die naturrechtlich gefärbte Auffassung des » Nationalvereins « als des Vereins einer augenblicklich miteinander lebenden Vielzahl von Individuen - aber er weiß andererseits nichts von einer volonté génćrale, von einem Gesamtwillen der Nation, der durch die Mehrheit oder deren Repräsentanten dargestellt wird. Er lehnt ihn sogar ab. Wenn auch, sagt er ${ }^{2}$ ), »die Staatsverbindung im engsten Verstande eine Nationalverbindung wäre, so könnte dennoch der Wille der einzelnen Individuen sich nur durch Repräsentation erklären, und ein Repräsentant mehrerer kann unmöglich ein so treues Organ der Meinung der einzelnen Repräsentierten sein. Auch Rousseau liebte, wie man weiß, das Repräsentationsprinzip nicht, aber Humboldt geht uber Rousseau hinaus, wenn er auch die Entscheidung durch Stimmenmehrheit verwirft und die Einwilligung jedes einzelnen für notwendig erklärt. Er hat hier zwar zunächst nur die Frage im Auge, ob der Staat Anstalten schaffen dürfe, die über den Zweck der äußeren und inneren Sicherheit hinausgehen, aber es ist klar, daß er damit die Möglichkeit eines einheitlichen Nationalwillens, der die etwa widerstrebenden Einzelwillen niederwirft, iberhaupt leugnet. "Das meiste", sagt er an anderer Stelle ${ }^{3}$ ), »bleibt immer den freiwilligen einstimmigen Bemühungen der Bürger zu tun übrig «.

Sprachen Rousseau und die französische Revolution dem Willen der Nation einen Grad von Macht uber das

1) Deswegen bedeutet der Nationalbegriff seines Versuches uber die Grenzen der Wirksamkeit des Staates einen Rückschritt gegenüber den Ideen von 1791 (s. oben S. 36).

\footnotetext{
2) 1,131 .

3) $1,517 \mathrm{f}$.
} 
Einzelleben $\mathrm{zu}$, den Humboldt nicht anerkennen wollte, so hat später die historisierende Romantik das Einzelleben bestimmt durch den unbewußt wirkenden Volksgeist. Hier wie dort wurde es unterjocht, nur daß der unterjochende Nationalgeist hier ein anderer war als dort. Humboldt aber läßt überhaupt keinen unterjochenden Nationalgeist gelten, weder den naturrechtlich-demokratisch konstituierten noch den historisch-konservativ verstandenen, weder den bewußt und absichtsvoll herrschenden noch den unbewußt schaffenden. Obgleich er das Wort Nation mit wärmerer Empfindung immer aussprach als das Wort Staat, so tat er es doch deswegen, weil es mehr Freiheit für das Individuum für ihn bedeutete. ${ }^{1}$ ) Wohl niemals ist unter den verschiedenen Faktoren, die das Wesen der modernen Nation ausmachen, die Spontaneität der sie bildenden Individuen so stark, man muß wohl sagen so ausschließlich hervorgehoben worden.

Aber es war doch etwas Großes, daß dieser reine und glühende Individualist überhaupt schon etwas von Nation wußte, daß er nicht zufrieden war mit dem bloßen Selbstgenusse der Persönlichkeit, daß ihm das freie Wirken der Individuen untereinander sogleich zum »freien Wirken der Nation untereinander " wurde. Wohl wurde nun sein Nationalbegriff dadurch so allgemein, daß er ihm unter der Hand zusammenfließen lionnte mit seinem ebenso unbestimmt und weit gedachten Begriffe von der »Gesellschaft « 2 ), und daß ihm »Nation « und » Gesellschaft « überhaupt zu Bezeichnungen für das natürliche Zusammenleben sich $\mathrm{zu}$ verflüchtigen drohten. Aber dafiir hatte

1) Wie ihn die Nation mehr als der Staat, so interessierte ihn der Mensch mehr als die Nation.e Haym, Humboldt S. 51.

2) Vgl. namentlich seine Ausführungen I, I I 3. Haym, S. 55, sagt sehr hiibsch: „Unter dem Bilde einer edlen Gesellschaft stellt sich ihm die ganze in einem Stante lebende Nation dar.e 
er von diesem natiirlichen Zusammenleben und freien Aufeinanderwirken der Menschen eine überaus reiche Vorstellung; es schwebte ihm so mannigfaltig, vollgehaltig und kräftig vor wie nur möglich. Seine Anschauung und Empfindung davon war so lebendig und tief, daß es nur noch weiterer Lebenserfahrungen für ihn bedurfte, um in dieser harmonischen Bewegung der menschlichen Kräfte auch das Rauschen des echten und wahrhaftigen Nationalgeistes heraus zu hören. Wenn man es ihm zum Vorwurf machen wollte, daß er damals noch taub für ihn gewesen sei, so könnte man mit seinen eigenen IVorten antworten: $\gg$ Er streut mehr sich selbst entwickelnden Samen aus, als er Gebäıde aufrichtet, welche geradezu Spuren seiner Hand aufweisen. « Und diejenigen, die Humboldts unkörperlichen Begriff von der Nation dennoch für interessanter halten als manche von den vielen gutgemeinten deutschpatriotischen Ergießungen dieser Jahrzehnte, mögen sich mit einem gleich darauffolgenden Worte trösten: „Es ist ein höherer Grad von Kultur notwendig, sich an der Tätigkeit zu erfreuen, welche nur Kräfte schafft und ihnen selbst die Erzeugung der Resultate überläßt, als an derjenigen, welche unmittelbar diese selbst aufstellt. ${ }^{1}$ )

Wirklich brauchten die Kräfte des Humboldtschen Geistes nur sich selbst überlassen zu werden, um den Weg zur Nation zu finden. Wer so rein und so begierig, so zart und so energisch zugleich in das Geheimnis der Individualität einzudringen versuchte wie er, dem mußte eines Tages es aufgehen, daß auch im Innern des Individuums der Nationalgeist lebte und wirkte, der echte wirkliche Nationalgeist, der nicht bloß aus dem freien geselligen Wirken des einzelnen hervor-

1) Er unterschied damals anscheinend noch nicht, wie später in seinen linguistischen Schriften, zwischen Kultur und Bildung. 
blühte, sondern vor und über ihnen auch als feste geschichtliche Lebensmacht sich ausbreitete. Es wurde ihm namentlich an dem Studium der Griechen, die ihm Vorbilder großer Individualität waren, deutlich, was der Nationalcharakter für sie bedeutete, und das er überhaupt eine wertvolle und notwendige Voraussetzung für die Entwicklung der Einzelcharaktere bilde. "Nun aber geht «, mußte er, auf sie blickend, gestehen, »die Bildung des Menschen in Massen immer der Bildung der Individuen voraus. " ${ }^{1}$ ) Weiter konnte er noch durch eine andere Erwägung, die auch in der ursprünglichen Richtung seiner Gedanken lag, zu hellerem Verständnis und höherer Schätzung der Nation gelangen. Sein Individualismus ging nicht auf Einförmigkeit, sondern auf Mannigfaltigkeit und Eigentümlichkeit des menschlichen Lebens aus. Das Ideal der Menschheit, meinte er ${ }^{2}$ ), tritt nicht in einer Form, sondern in so vielen, als nur immer miteinander verträglich sind, hervor und erscheint nie anders als in cler Totalität der Individuen. IVie wuchs nun aber der Reichtum an Individualität in der Welt, wenn sie nicht nur dem einzelnen, sondern auch den großen Vereinigungen der einzelnen, den Nationen, eigen war. Die Menschheit, sagte er nun ${ }^{3}$ ), bedarf der Vereinigung vieler, vorzüglich auch, sum durch größere Mannigfaltigkeit der Anlagen ihre Natur in ihrem wahren Reichtum und ihrer ganzen Ausdehnung zu zeigen." Väre es nicht schon, fragte er in diesem Zusammenhange, ein Verlust an wertvoller Eigentümlichkeit, wenn auch nur die kleine schweizerische Nation aus der Reihe der europäischen Nationen gestrichen würde?

1) Über das Studium des Altertums und des griechischen insbesondere (1793). Ges. Schriften 1, 276.

2) Plan einer vergleichenden Anthropologie (1795). Ges. Schriften 1,379 .

s) a. a. O. 
Man kann geradezu sagen, daß in den Jahren seit I793 das Problem der Nation ihm obenan stand unter den Aufgaben, die er lösen wollte. Man konnte es schon aus seinen Briefen, namentlich den an Goethe und an Jakobi gerichteten sehen, aber die ganze Tiefe seines Interesses erschließt sich aus den geschichtlichen und geschichtsphilosophischen Entwürfen dieser Jahre, die zum größten Teile erst jüngst durch die akademische Ausgabe seiner Schriften an das Licht getreten sind und unsere Kenntnis der Humboldtschen Gedankenwelt auf das schönste bereichert haben. ${ }^{1}$ ) $\otimes$ Das Studium einer Nation «, heißt es da ${ }^{2}$ ), "gewährt schlechterdings alle diejenigen Vorteile, welche die Geschichte überhaupt darbietet«. Die Vorteile der Geschichte scheint er zwar in etwas utilitarischem Rationalismus nur darin zu sehen, daß sie auf Menschenkenntnis, Beurteilungskraft und Charakter günstig wirke, aber er faßte den Begriff der Menschenkenntnis dabei so umfassend und tief wie möglich als »Kenntnis des Menschen überhaupt « und aller Kräfte und Gesetze, die im menschlichen Leben von innen und von außen her wirken, und das Studium der Nation insbesondere solle, indem es den Zustand und die gänzliche Lage der Nation zu erforschen versuche, gleichsam eine Biographie derselben liefern, die ihren Charakter nach allen Seiten und in seinem ganzen Zusammenhange entwickle, die nicht bloß die gegenseitigen Beziehungen der einzelnen Charakterzïge untereinander,

1) Die verdienstliche, aber gar zu schematische Arbeit Kittels uber W. v. Humboldts geschichtliche Weltanschauung (I90I) hat sie noch nicht benutzen können. Wohl aber ist auf ihnen und auf den weiterhin jüngst veröffentlichten Briefen Humboldts an seine Braut und Gattin das schöne Buch Eduard Sprangers, W. v. Humboldt und die Humanitätsidee (1909), anfgebaut, das zu meiner Freude der von mir entwickelten Auffassung von Humboldts Nationalbewußtsein zustimmt.

2) Über das Studium des Altertums (1793). Ges. Schriften I, $256 \mathrm{f}$ 
sondern auch ihre Relationen in den äußeren Umständen als Ursachen oder Folgen einzeln untersuche. Mit dieser Forderung einer kausal möglichst tiefgreifenden Darstellung des Gesamtlebens einer Nation griff Humboldt schon einer Hauptaufgabe vor, die die Geschichtswissenschaft des 19. Jahrhunderts sich gestellt hat. Hören wir noch andere seiner Sätze, um die Stärke seines Interesses für das Wesen der Nation zu ermessen! „Das Studium des Menschen\&, sagt er in derselben Schrift von I793'), »gewänne am meisten durch Studium und Vergleichung aller Nationen aller Länder und Zeiten." So erwuchs ihm in den nächsten Jahren die Idee, überhaupt eine neue Wissenschaft, die vergleichende Anthropologie, zu begründen, deren Aufgabe es sei, »den Charakter ganzer Klassen von Menschen zu suchen, vorzüglich den der Nationen und Zeiten. « ${ }^{2}$ ) Denn so war der Grundgedanke, von dem dieser großartige Plan ausging: „Der Mensch ist allein genommen schwach und vermag durch seine eigene kurzdauernde Kraft nur wenig. Er bedarf einer Höhe, auf die er sich stellen, einer Masse, die für ihn gelten, einer Reihe, an die er sich anschließen kann. Diesen Vorteil erlangt er aber unfehlbar, je mehr er den Geist seiner Nation, seines Geschlechtes, seines Zeitalters auf sich fortpflanzt. ${ }^{3}$ ) Dieser Plan zu einer vergleichenden Anthropologie trat ihm dann 1796 in den Hintergrund vor dem noch großartigeren eines auf geschichtlicher Grundlage beruhenden Werkes über den Geist der Menschheit uberhaupt, dessen einzelne Teile nach einheitlicher Idee von verschiedenen Händen bearbeitet werden sollten. ${ }^{4}$ ) Er selbst stellte sich die Auf-

1) a. a. O. I, 264 .

2) Plan einer vergleichenden Anthropologie (1795). Ges. Schriften 1, 384 .

3) a a. O. I, $3^{85}$.

4) Vgl. Leitzmanns Bemerkungen in Ges. Schriften 2, 401. 
gabe, Geist und Charakter des I8. Jahrhunderts darzustellen. Sein erster Entwurf dazu, der I 796 und 1797 niedergeschrieben wurde ${ }^{1}$ ), ist freilich im wesentlichen über die Aufstellung der methodischen Grundsätze, man möchte sagen, über eine haarscharfe Schleifung des Messers, mit dem er arbeiten wollte, nicht hinausgekommen und zeigt dadurch vielleicht die Grenzen seines Könnens. Seine Konzeptionen blieben nur zu oft geistige Luftgebilde und nahmen keine Körperlichkeit an, aber sie sprechen zu uns, als lebten sie und stehen uns deutlich Rede und Antwort über unsere Fragen. So tritt es ganz hell hervor, daß er auch die Erfassung des Geistes des is. Jahrhunderts trotz des rationalen und universalen Zuges, der diesem Zeitalter eigen war, von der festen Grundlage einer nationalgeschichtlichen Betrachtung aus versuchen wollte. Im Gegensatz zu den Franzosen Ludwigs XIV., die schlechterdings nur eine Form und Regel für alles gekannt hätten, erklärt $\mathrm{er}^{2}$ ): "Wir hingegen gewöhnen uns jetzt, die Eigentuimlichkeiten jeder Zeit und jeder Nation zu studieren, so viel wie möglich in dieselben einzugehen und diese Kenntnis zum Mittelpunkt unserer Beurteilung zu machen. « Man sieht an seinem Beispiel, wie ein gegen sich selbst ehrlicher und strenger Individualismus ganz durch eigene Kraft und Selbstbesinnung zur Anerkennung der uberindividuellen Mächte des Lebens gelangen konnte, von denen das Einzelleben umgeben und beschränkt, aber auch getragen und befruchtet wird. Wie sehr auch eine ästhetische Freude an der Entdeckung dieser neuen großen Dinge mitspielen mochte, so war sie doch bei Humboldt, wie wir wissen, nicht das Primäre. Wenigstens war sie in ihm untrennbar verschmolzen mit dem, was ihn im Innersten lenkte: mit Gesinnung, die sich und die Welt

\footnotetext{
1) a. a. O. 2, I-II 2 .

2) a. a. O. 2, 72 .
} 
zugleich immer umfassen wollte. Das starke, freiheitsdurstige Individuum in ihm wurde sich seiner Schwachheit, seiner Abhängigkeit von der mütterlichen Nation bewußt und sah mit Dank auf sie zurück. Ergreifend gestand er es an Goethe aus Paris am i8. März 17991): "Wie Sie sogar die Beschränktheit meiner Natur kennen, miissen Sie fühlen, daß mir alles, was mich außerhalb Deutschlands umgeben kann, doch immer heterogen bleibt ... Wer sich mit Philosophie und Kunst beschäftigt, gehört seinem Vaterlande eigentuimlicher als ein anderer an ... Philosophie und Kunst sind mehr der eigenen Sprache bedürftig, welche die Empfindung und die Gesinnung sich selbst gebildet haben, und durch die sie wieder gebildet worden sind. « Und er knüpfte die höchst bedeutende und richtige Bemerkung daran, daß gerade durch die feinere Ausbildung der Sprache, der Philosophie und der Kunst die Individualität und die Verschiedenheit der einzelnen Nationen zunehmen, das innigrere Verstehen verschiedener Nationen schwerer werden würde. So sah er in den höchsten Betätigungen der Menschheit die Lebenswurzel der Nation. Nicht in einer weltbürgerlichen Verschmelzung, sondern in der nationalen Differenzierung sah er die Tendenz einer sich erhöhenden Kultur. Inmitten des aufgeregten französischen Lebens fühlte er eben jetzt mit ruhigem Stolze die Eigentumlichkeit ebensowohl wie die Überlegenheit deutscher Bildung gegenüber der französischen.

So scheint Humboldt in diesen Jahren der historischen und nationalen Denkweise des I9. Jahrhunderts

1) Bratranek, Goethes Briefwechsel mit den Gebrudern v. Humboldt S. 5S. An Jacobi schrieb er am 26. Oktober 179S: ,Ich bin, mitten in Frankreich, nur ein noch viel eingefleischterer Deutscher als vorher geworden.e Leitzmann, Briefe Humboldts an Jacobi S. 60; vgl, daselbst auch S. I20. Ähnlich an F. A. Wolf, 22. Oktober 179S (Ges. Werke 5, 20\$). 
ganz nahe zu kommen. Aber nun gilt es, die Grenze scharf zu ziehen, bis zu der er als Sohn des individualistischen und weltbürgerlichen i 8 . Jahrhunderts nur gelangen konnte, und die er auch mit Absicht nicht iberschreiten wollte. Es gilt jetzt, ein erstes großes Beispiel nachzuweisen, wie der neue nationale Gedanke gerade in seinen geistreichsten Vertretern noch durchwachsen war von den universalen menschheitlichen Idealen der bisherigen Kultur. Man beachte, wie er schon seine im Jahre I793 aufgestellte Forderung eines vergleichenden Studiums der Nationen gleich wieder einschränkt. Abgesehen von der Immensität dieses Studiums, meint er, komme es doch mehr auf den Grad der Intension an, mit dem eine Nation, als auf den der Extension, mit welchem eine Menge von Nationen studiert werde. Und er hält denjenigen Nationalcharakter für besonders erforschenswert, der dem eigentlichen Wesen der Menschheit am nächsten komme. ${ }^{1}$ ) Das war für ihn der Charakter der Griechen; ihre Tendenz war es, »den Menschen in der möglichsten Vielseitigkeit und Einheit auszubilden", es zeigt sich in ihm »meistenteils der ursprüngliche Charakter der Menschheit überhaupt. «²) Das Studium der Nation ist ihm also Mittel zum Zweck, sein menschheitliches Ideal durch die Geschichte bestätigen zu lassen. Auch die moderne Erforschung nationalen Eigenlebens will gewiß im letzten Grunde höchste menschliche Werte aus der Geschichte herausholen, aber sie hält den Weg von der Nation zur Menschheit und von der Erfahrung zum Ideal für weiter und schwieriger, als Humboldt ihn hielt. Sie sucht die Extension in dem Studium der Nationen, die Humboldt noch für entbehrlich hielt, zu verbinden mit der Intension, die er ver-

1) a. a. O. I, 264.

2) I, 270 und 275 .

Meinecke, Weltbürgertum und Nationalstaat. 2. Aut. 
langte; sie schiebt dabei das Ideal der Menschheit selbst, das Humboldt rasch erfliegen wollte, zurück von den Arbeitsstätten selbst, auf denen sie tätig ist, damit sein Glanz das Auge nicht schwäche fuir die Erkenntnis des Wirklichen. Sie gibt es darum nicht preis, aber sie verweist es in andere, höhere Räume und sucht für sich selbst nur so genau, umfassend und voraussetzungslos wie möglich zu bestimmen, wie verschieden der individuelle historische Mensch in der Tat ist. Wie aber stellte Humboldt die Aufgabe der vergleichenden Anthropologie? Gewiß, sie solle die bleibenden Charaktere der Nationen usw. untersuchen mit der Sorgfalt des Naturforschers, aber: "Ob es ihr gleich eigentlich und an sich durchaus nur darauf ankommt, zu wissen, wieverschieden deridealische Mensch sein kann, muß sie den Anschein annehmen, als wäre es ihr darum zu tun, zu bestimmen, wie verschieden der individuelle Mensch in der Tat ist. « Die Nuance gegenüber der modernen wissenschaftlichen Stimmung scheint, rein logisch gesehen, vielleicht nicht gar so groß; psychologisch angeschaut, ist sie ganz bedeutend.

Der moderne Mensch ist eben überzeugt, daß die den verschiedenen 'Grenzen zwischen Betätigungen und Bedürfnissen des menschlichen Geistes schärfer und genauer eingehalten werden muissen, als Humboldt gemeint war, - daß man, um möglichst gute Empirie zu treiben, sie zunächst durchaus als Selbstzweck setzen muß und nicht nur den Anschein davon annehmen, sondern es wirlich entschlossen tun muß. Das bedeutet Gewinn und Verlust zugleich. Er verliert viel von dem inneren Glücke und von der Fluggellsaft, mit der sich Humboldt jederzeit vom wirklichen Menschen zum idealischen Menschen erheben konnte. Er gewinnt dafür, was man durch rationelle Arbeitsteilung nur irgend gewinnen kann. Auch diese Untersuchung ist in erster Linie eigentlich darauf 
Wilhelm v. Humboldt in den neunziger Jahren des IS. Jahrh. $5 \mathrm{I}$ gerichtet, zu zeigen, wie sich in der Entwicklung des nationalen Gedankens im I9. Jahrhundert ein Akt der Arbeitsteilung vollzogen hat, indem er sich allmählich gesondert hat von den ursprünglich mit ihm verbundenen universalistischen und universal-ethischen Idealen und dadurch erst ganz brauchbar geworden ist für die Zwecke des Staates. Noch eine andere Arbeitsteilung, die innerhalb des Wirkungskreises der nationalen Idee vor sich gegangen ist, ist jetzt hier aber zu beachten. Er ist geteilt worden, man möchte sagen in eine theoretische und eine praktische Sphäre. Der Sinn für das Nationale ist einerseits ein wissenschaftliches Erkenntnismittel von höchster Fruchtbarkeit und andererseits eine große moralische Triebliraft für Staat und Gesellschaft geworden. Innerlich hängen diese beiden Strömungen immer noch zusammen und können auch nie ganz getrennt werden, ohne sie beide zu gefährden in ihren Quellen, aber in ihrer Betätigung verhalten sie sich getrennt, und ein kräftiger nationalpolitischer Egoismus kann innerhalb derselben Individualität schiedlich einhergehen neben einem liebevollen Verständnis aller fremden nationalen Eigenart. Humboldt aber ist darin noch ungeschiedene Ganzheit, enges Ineinanderweben von Schauen und Wollen, indem er - so sahen wir es - das Studium der Nationen kontemplativ und ethisch zugleich meinte, - denn was ist sein Suchen nach dem idealischen Menschen anderes als höchste Ethik und höchste geistige Anschauung zugleich? Auf dem Wege der Erforschung des Nationalen suchte er das Übernationale, das höchste ihm erreichbare geistige und sittliche Gut. Wie aber stand es, wird man fragen, mit derjenigen ethischen Wirkung seines Studiums der Nationen, die dem modernen Menschen am nächsten liegt und am selbstverständlichsten dünkt, - wie stand es mit der Belebung seiner deutschen Empfindungen? 
Wir sahen, daß er sich in Paris dankbar bewußt wurde, was er von seinem Vaterland empfangen hatte, wie er sich selbst deutscher als je fuihlte inmitten der fremden und ihm fremdartigen Nation. Aber zunächst war schon die deutsche Nation, mit der er sich verbunden fühlte, nicht die ganze und volle Nation bis in die Tiefen ihres Daseins hinunter, sondern nur eine kleine, ganz kleine Auslese aus ihr. "In Deutschland", schreibt er an Jacobi ${ }^{1}$ ), "vergißt man gerne die Masse, um bei einigen Individuen stehen $\mathrm{zu}$ bleiben. « Und noch deutlicher an Goethe ${ }^{2}$ ): »Was mich an Deutschland knuipft, was ist das anderes, als was ich aus dem Leben mit Ihnen, mit dem Kreise schöpfte, dem ich nun schon seit beinahe zwei Jahren entrissen bin. « Goethe und seine Welt, das war ihm Deutschland. Gewiß fühlte er, daß auch das Goethesche Deutschland nicht bloß ein Kreis von freien, schöpferischen Menschen sei, sondern daß in ihm jene »innere Triebfeder", jene »lebendige immer rege Kraft " wirke, die nach seiner Meinung nicht nur jedem Menschen, sondern auch jeder Nation unentbehrlich sei. $\left.{ }^{3}\right)$ Sicher hatte er den Sinn für das Nationale, aber ob auch schon nationalen Sinn?

An dem deutschen Nationalcharakter fand er eben das schön und groß, daß er die naturhaften Schranken anderer Nationalcharaktere nicht kenne, sondern reiner und freier zum allgemein Menschlichen sich erhebe. So heißt es in seinem Essai über das I8. Jahrhundert ${ }^{4}$ ): »Der Deutsche, tadelt man gemeinhin, ahmt, mit Verleugnung seiner inneren Originalität, ancleren Nationen zu sklavisch nach und gibt ihnen selbst, indem er den

1) Leitzmann S. 64 .

2) Bratranek S. 58 .

3) Leitzmann S. $6 \mathbf{r}$.

4) a. a. O. 2, 43, vgl. dazu auch Humboldts Brief an F. A. Wolf, 20. August 1797, Gesammelte Werke 5, 194. 
Kampf mutwillig auf ein ihm fremdes Gebiet versetzt, einen leichten Sieg in die Hände. Für den gegenwärtigen Augenblick ist nichts gegen diesen Vorwurf zu sagen. Aber bei einem weiter aussehenden Blick zeigt sich diese Nachahnung als eine vorubergehende Erscheinung und als ein Extrem einer sonst Bewunderung und Nacheiferung verdienenden Eigenschaft und erscheint vielmehr, da sie nicht aus Mangel an Kraft, sondern nur aus Mangel an einer entscheidenden Naturbestimmung entsteht, welcher der Beurteilung des Verstandes und der Stärke des Willens ein wohltätiges Ubergewicht erlaubt, als ein edles Streben nach idealischer Vielseitigkeit."

Solche Gesinnung war noch weit davon entfernt, in politisches Ethos umgesetzt zu werden, und selbst nur zur Erkenntnis dessen, was Nation und Staat für einander bedeuten können, für ein rein wissenschaftliches, leidenschaftsloses Interesse an diesem Problem reichte sie noch nicht aus. Inmitten des großen Phänomens, das der nicht nur revolutionierte, sondern auch nationalisierte französische Staat ihm bot, und eifrig sogar darauf gerichtet, den französischen Nationalcharakter in seinen feinsten Zügen $\mathrm{zu}$ erfassen, schrieb er an Goethe: „Um das Politische, wissen Sie, bekümmere ich mich nicht. «1) Das Politische rechnete er zu jenen »Umständen des Tages « und »äußeren Begebenheiten«, die man beiseite lassen müsse, wenn man das bleibende Wesen einer Nation erkennen wolle. »Ich rede«, schrieb er aus Paris an Jacobi am 26. Oktober 1798, »überhaupt nicht von der politischen Stimmung, ich beschränke mich bloß auf das, was eigentlich national ist, auf den Gang cler Meinungen und des Geistes, die Bildung des Charakters, die Sitten usf. «²)

So hielt ihn vom Politischen noch fern der hohe Ehrgeiz, daß die Deutschen eben jetzt berufen seien,

1) Bratranek S. 49 (1798 Frühjahr).

2) Leitzmann, Briefe Humboldts an F. H. Jacobi S. $6 \mathbf{I}$ 
das eigentliche Menschheitsvolk, den reinsten Spiegel der Menschheit zu bilden, wie ihn einst die Griechen, so meinte er, gebildet hätten. Man weiß, daß dieser Gedanke in den mannigfachsten Ausdrucksweisen, von der trivialsten bis zur erhabensten, das damalige gebildete Deutschland beherrschte. Niemand hat ihn wohl größer ausgedrückt als Schiller in dem Fragment zu einem Gedicht, das aus der Zeit nach dem Frieden von Lunéville stammt, und dem der späte Herausgeber ungezwungen den Titel »Deutsche Größe « geben konnte. ${ }^{1}$ ) Da heißt es in der Prosaskizze des Gedankenganges: „Darf der Deutsche in diesem Augenblicke, wo er ruhmlos aus seinem tränenvollen Kriege geht, wo zwei übermitige $\checkmark$ ölker ihren Fuß auf seinen Nacken setzen und der Sieger sein Geschick bestimmt - darf er sich fühlen?... Ja, er darf's! Er geht unglücklich aus dem Kampfe, aber das, was seinen Wert ausmacht, hat er nicht verloren. Deutsches Reich und deutsche Nation sind zweierlei Dinge. Die Majestät des Deutschen ruht nie auf dem Haupte seiner Fürsten. Abgesondert von dem Politischen, hat der Deutsche sich einen eigenen Wert gegründet, und wenn auch das Imperium unterginge, so bliebe die deutsche Würde unangefochten. Sie ist eine sittliche Größe, sie wohnt in der Kultur und im Charakter der Nation, der von ihren politischen Schicksalen unabhängig ist . . . indem das politische Reich wankt, hat sich das geistige immer fester und vollkommener gebildet. " Wenn anders die Welt einen Plan hat, fährt die Skizze fort, so muß dem, der den Geist bildet, beherrscht, zuletzt die Herrschaft werden. Die anderen Völker waren dann die Blume, die abfällt, während die goldene Frucht

1) Deutsche Größe. Ein unvollendetes Gedicht Schillers I Sor \&. Herausgegeben von B. Suphan, Weimar 1902 (Schriften der Goethegesellschaft) und in der Cottaschen Säkularausgabe von Schillers Werken, 2, 386 . 
übrigbleibt. Während der Brite nach Schätzen und der Franke nach Glanz lüstern späht, ist dem Deutschen das Höchste bestimmt: »Er verkehrt mit dem Geist der Welten. « "Jedes Volk hat seinen Tag in der Geschichte, doch der Tag des Deutschen ist die Ernte der ganzen Zeit."

Es liegt ein eigener Zauber über diesen Worten, der vielleicht mit daher rührt, daß erst die späten Nachkommen diesen Blick in Schillers Mappe tun durften und er ihnen nun gleichsam im vertrautesten Gespräche Rede und Antwort steht uber eine Angelegenheit, die ihnen selbst nicht nur eine Sache des Wissens, sondern auch des Herzens ist. Man fühlt so den Hauch seiner Seele stärker, als wenn er schon damals diese Gedanken in seine schimmernden Verse gekleidet hätte, die bei ihm so leicht das Unmittelbare verhüllen. Die Wirkung seiner Worte aber beruht auf noch Tieferem, auf der Ahnung, daß es sich hier um ein keusches Geheimnis unserer nationalen Geschichte handelt, um ein Etwas in der Denkweise unserer großen Vorfahren, das dem Splitterrichter als Verblendung oder als geistiger Hochmut erscheinen könnte, und das doch dem zarteren Verständnis sich als reinste Gesinnung und zugleich als geschichtlich notwendige und heilsame Gesinnung dartut. Daß Deutsches Reich und deutsche Nation zweierlei Dinge seien, daß Kultur und Charakter der deutschen Nation unabhängig sei von ihren politischen Schicksalen, wird manchem heute eine vermessene Rede dünken, und doch war dieser Gedanke, der für das heutige Geschlecht einen Irrtum bedeutet, für viele damalige Deutsche eine lebendige Wahrheit und für die Ernstesten unter ihnen eine Wahrheit von religiöser Kraft. $\left.{ }^{1}\right)$ Wer das Reich des Geistes aufrichten will in dieser Welt, muß

1) Ich darf hier wohl auch auf meine parallelen und ergänzenden Betrachtungen in meinem „Zeitalter der deutschen Erhebung , S. 2S, hinweisen. 
zunächst damit beginnen, zu sagen: Mein Reich ist nicht von dieser Welt. Er muß sie fliehen, um sie hinterher mit mächtigerer innerer Kraft zu beherrschen. Höchste geistige und sittliche Werte schafft man, indem man sich zunächst über das Wirkliche erhebt. So hat hier der Gedanke der Nation in Deutschland einen neuen und tieferen Inhalt bekommen dadurch, daß man alles Politische und wieviel Morsches und Welkes war damals darunter - zunächst einmal aus ihm ausfegte und dafür alle die geistigen Guiter, die man gewonnen hatte, in ihn hineintat. Dadurch erhob man ihn in die Sphäre des Ewigen und der Religion. Dadurch nationalisierte man die bisherige universale Bildung, und so, daß man nicht sagen konnte und wollte, wo das Universale aufhöre und das Nationale begönne. So schlug man sich die Brücke von einem zum andern hinüber, und wenn dann in der Folge die derart vergeistigte Nationalidee zum Staate wieder kam, dann brachte sie ihm eine Mitgift, die auch ihn erst instand setzte, seine höchste Mission zu erfüllen und in der Reihe der großen menschlichen Güter den Platz einzunehmen, den die Entwicklung der Menschheit ihm zuweist. Denn auch der moderne Nationalstaat 'bedarf, wenn er verjüngungsfähig bleiben soll, einer universalen Lebensader und einer steten Rechtfertigung vor :dem Richterstuhl des höchsten menschlichen Ideals.

In großen, einfachen Zügen liegt dieser Entwicklungsgang heute vor uns, der von der Menschheit uber die Nation zum Staate führte, in dem zunächst das Universale national und das Nationale universal wurde, in dem dann der Staat nationalisiert und die Nation politisiert wurde, jedoch so, daß auch der universale Gedanke lange noch mitschwang. Aber die Geradlinigkeit dieser Entwicklung im großen löst sich bei näherer Betrachtung in ein wunderliches und krauses Zickzack und in mancherlei scheinbare Irr- und Nebenwege auf. Der echte 
Wilhelm v. Humboldt in den neunziger Jahren des 18. Jahrh. 57

historische Sinn darf das eine nicht über dem andern vergessen, muß bald in die Höhe steigen und bald hinunter, wo der einzelne Wanderer mühselig seinen Weg sucht. Denn nur durch die Brechung des reinen Lichtstrahls entstehen die Farben des wirklichen Lebens, das wir kennen lernen wollen. Und wer allgemeine $\mathrm{Zu}-$ sammenhänge aufstellt, wird, wenn er sie an der Einzelerscheinung nachzuweisen versucht, bescheiden sich gestehen, daß die Individualität auch immer noch anderen verborgeneren Gesetzen folgt, die auch da möglicherweise mitwirken zum einfacheren Endergebnis, wo sie es scheinbar hemmen. Wie mancher wird meinen, daß auch Schiller, wenn er die Jahre nach I 806 erlebt hätte, ein Redner an die deutsche Nation geworden wäre, und er wird sich auf Schillers Persönlichleit, auf den Geist seines letzten Dramas, schließlich auch auf das, was durch seine Zeilen über »Deutsche Größe" hindurchlilingt, berufen, Denn durch alle Verneinung des politischen Gedankens spuirt man doch seine schmerzliche Unruhe uiber den tatsächlichen politischen Zustand Deutschlands und einen Stachel, der ihn reizte, hindurch. So mag es wohl sein, daß er dem Beispiel Fichtes gefolgt sein würde. Aber nur eine triviale Auffassung wird behaupten, daß er gar nicht anders gekonnt und daß er Goethes Quietismus beschämt haben würde. Denn es gab ja eben nicht nur einen Weg, der aus der universalen Welt des I8. Jahrhunderts in die nationale und nationalpolitische Welt des I9. Jahrhunderts hinuberführte, und die großen Persönlichkeiten dieser Zeit waren auch zu eigentümlich und zu selbständig, um nur auf einen Weg sich weisen zu lassen. Der Reichtum und die Kraft der universalen Menschheitsidee, von der sie alle ausgingen, zeigt sich eben auch darin, daß so verschiedene Wege von ihr aus eingeschlagen wurden, - denn dieser Universalismus war zugleich kräftigster Individualismus. 


\section{Viertes Kapitel.}

\section{Novalis und Friedrich Schlegel in den Jahren der Frühromantik.}

Es war ein Wort von Novalis, an das der Schluß des letzten Kapitels erinnern sollte. Von Humboldt und Schiller kommen wir damit zu dem Kreise der Romantiker, um auch hier zu fragen, wie sie in den Jahren ihrer fruchtbarsten Gedankenproduktion, in den ausgehenden 9o er Jahren des I8. Jahrhunderts, das Wesen der Nation und ihres Verhältnisses zum Staatsleben aufgefaßt haben. Aus den subtilen, aber in sich geschlossenen Gedankengängen Humboldts treten wir hier in die Welt der Aphorismen und Fragmente, in eine verwirrende Fülle von Anregungen und Einfällen. Bei Humboldt führte der Weg, von dem aus er auf Nation und Staat Blicke warf, immer deutlich und geradeaus auf das ihm vorleuchtende Ziel des »idealischen Menschen «. Bei den Romantikern öffnet sich eine Unzahl von Wegen und Pfaden, und kaum hat man sich einem von ihnen anvertraut, so sielit man den Führer, dem man zu folgen glaubt, leichtfüßig entweichen nach anderer Richtung, und man käme sich selbst pedantisch vor, wollte man den einmal beschrittenen Weg zu Ende gehen und systematische Strenge da suchen, wo sichtlich oft nur eine vibrierende Einbildungskraft ihr Spiel treibt. Dennoch muß der Versuch gewagt werden, so viel feste Punkte wie möglich zu bestimmen, denn bei den Frühromantikern insbesondere darf man die ersten Spuren der späteren 
politischen Romantik vermuten, zu der unsere Untersuchung hinführen soll. Den bitteren Ernst und die dolstrinäre Strenge, die deren Ideen in dem Kreise Friedrich Wilhelms IV. annehmen sollten, wird man freilich in dem übermütigen Durcheinander der Frühromantik nirgends begründet finden. Wohl aber wird man vielleicht erkennen können, in welchem Zusammenhange, mit welchen Nachbarideen verbunden sie hier zuerst auftauchen, und man wird ferner dem großen zeitgeschichtlichen Hintergrunde dieser Jahre, den Einwirkungen der französischen Revolution und der Napoleonischen Zeit auf das deutsche Geistesleben, einige erklärende Momente entlocken können. Die Untersuchung soll sich auf diejenigen Vertreter der Frülıromantik beschränken, deren Gedanken über Nation und Staat am reichsten entwickelt sind. Das ist in erster Linie Novalis, in zweiter Linie Friedrich Schlegel.

So schillernd und proteusartig das Spiel ihrer Einfälle zunächst erscheint, so gibt es doch eine sie zusammenhaltende Zentralidee, die gerade durch ihren Inhalt es auch erklärt, weshalb das Spiel so bunt und tausendgestaltig ausschaut. Das ist der Gedanke, daß das Weltall in sich eine unendliche Fïlle von Indiviclualität birgt, daß seine Einheit dadurch nicht etwa aufgelöst und gesprengt, sondern gerade bekräftigt wird, so daß es selbst für sich Individualität und Persönlichkeit ist. ${ }^{1}$ ) »Die Individualität in der Natur ist ganz unendlich. Wie sehr belebt diese Ansicht unsere Hoffnungen von

1) Wir berühren diese Zentralidee hier nur so weit, als es zum Verständnis unserer Probleme nötig ist, lassen also ihre weiteren philo. sophischen Zusammenhänge, ihr Verhältnis zu den philosophischen Systemen der Zeit, vor allem Schellings, bei Seite. Für das Verständnis der romantischen Weltanschauung iiberhaupt liefern reiche Anregung die bekannten neueren Schriften von Ricarda Huch, Marie Joachimi, Kircher, Poetzsch (Studien zur frühromantischen Politik und Geschichtsauffassung 1907) und Walzel, Deutsche Romantik 1908. 
der Personalität des Universums. «1) Demnach ist Gott auch für Friedrich Schlegel einerseits ein 》Abyssus von Individualität $\ll^{2}$ ), andererseits $»$ das Individuum selbst in der höchsten Potenz $« .^{3}$ )

Alte pantheistische und mystische und neue individualistische, mit Goethe und Humboldt nahe verwandte Tendenzen waren in diesen Gedanken miteinander verschmolzen. Die ganze philosophische Bewegung der Zeit drängte seit Kant auf sie hin, und insbesondere war es Schelling, der mächtig hier einwirkte. So entstand ein neues Lebensgefühl von verführerischem Reize, indem es quietistisch-sehnsuichtige Hingabe an alle $\mathrm{Zu}$ sammenhänge des Universums mit intensivem Genusse fremder und eigener Individualität verband. Aber uns hat hier nicht die geistesgeschichtliche Herkunft dieser Ideen und auch nicht ihre Wirkung auf das persönliche Leben zu beschäftigen, sondern ihre Anwendung auf das nationale und staatliche Leben. Zunächst wird es verständlich, daß die Ideen der Frühromantiker insgesamt so unendlich flüssig und beweglich wurden, daß sie gottund welttrunken werden konnten bei dem Hinabschauen in den "Abyssus von Individualität «. Sie machten Ernst damit, jede Lebensregung als Individualität aufuffassen. »Man kann sagen, " meint Novalis, »daß jeder Gedanke, jede Erscheinung unseres Gemiits das individuellste Glied eines durchaus eigentuimlichen Ganzen ist. ${ }^{4}$ ) Indem alles, aber auch alles aufgelöst werden konnte in Individualität, wurde das Auge wohl hell für jede besondere Einzelerscheinung auch im geschichtlichen und staatlichen Leben und ohne weiteres geneigt, es anzuerkennen in seinem Sonderrecht, aber wer alles anerkennen will, steht in Ge-

1) Novalis Schriften (herausgeg. v. Heilborn) 2, 37 I und 653 .

2) Minor, Prosaische Jugendschriften Fr. Schlegels 2, 289.

3) Narie Joachimi, Weltanschauung der Romantik S. 39.

4) Schriften 2, 343 . 
fahr, nichts davon wirklich fest und rund zu bejahen. Wieviele Gegenstände ihrer geistvollen Betrachtung entrinnen ihnen noch aus den Händen, weil sie die Kraft des Zupackens und Festhaltens nicht hatten. Allerdings aber stießen sie auch mit ihrer mächtigen Expansionslust nun rasch und summarisch okkupierend auf Gebiete vor, die dem klassischen Idealismus noch gleichguiltig waren. Höchst ergriffen und tief spricht Novalis schon oft vom Staate und von dem Verhältnis des Einzelnen zu ihm: "Je geistvoller und lebendiger die Glieder sind, desto lebendiger, persönlicher ist der Staat. Aus jedem echten Staatsbürger leuchtet der Genius des Staats hervor, so wie in einer religiösen Gesellschaft ein persönlicher Gott gleichsam in tausend Gestalten sich offenbart. Der Staat und Gott sowie jedes geistige Wesen erscheint nicht einzeln, sondern in tausend mannigfaltigen Gestalten. «1) Man spürt es hier schon durch, wie die Elemente, die hier eben zusammentreten, um das Bild einer lebendigen Staatspersönlichkeit uns vorzuzaubern, sogleich auch wieder auseinanderfließen können zu neuem, unendlichem Gaukelspiel. Aber immerhin, er sah den Staat in der Tat schon als geschlossene Individualität, - »der Staat ist immer ein Makroanthropos gewesen $\left.\ll^{2}\right)$ - und zwar als eine Individualität im geschichtlichen Sinne, nicht im rationalistischen Sinne derer, die den vollkommenen Normalstaat wollten, denn, so sagt er, »die Staaten werden verschieden bleiben, solange die Menschen verschieden sind $\ll^{3}$ ), und er schalt diejenigen armselige Philister, die nirgends Heil statuierten als in der neuen französischen Manier. ${ }^{4}$ ) Insbesondere fesselte schon

1) Schriften 2, 543 .

2) a. a. O. 2, $217 ;$ vgl. 2, 291 .

3) 2, 291 ; vgl. 2, 526 .

4) 2,42. Sein Verbältnis zur französischen Revolution, für die er in seinen ersten Jünglingsjahren geschwärmt hatte (Heilborn, Novalis S. 45; 
Preußen seinen Blick in dem Momente, wo das jugendliche Königspaar Friedrich Wilhelm III. und Luise dort eine neue, gliickverheißende Ära heraufzuführen schienen. Er vertiefte sich in die beseelenden Wirkungen, die von einem solchen Königspaare ausgingen, und wob um sie die Ranken einer symbolisierenden Betrachtung, in denen schon die Stimmungen der preußischen Erhebungszeit, aber auch die der darauffolgenden Restaurationszeit vorausgenommen werden. ${ }^{1}$ ) Der schlicht patriarchalische Royalismus der einen und der mystisch patriarchalische Royalismus der andern klingt hier schon an, aber in einer noch ganz freien und flussigen, poetischen Weise, denn wenn er sich auch von dem Gedanken der Volkssouveränität deutlich abkehrt, so leuchtet doch die Souveränität des Individuums noch überall durch.. ${ }^{2}$ ) Da war es denn wohl möglich, von einer idealen Monarchie zu träumen, die zugleich echte Republik sei - weil ihm echter Republikanismus so viel bedeutete wie »allgemeine Teilnahme am ganzen Staate, innige Berühung und Har-

Friedrich v. Hardenberg [Novalis]: Eine Nachlese, S. 5S), ist auch nachher keineswegs schlechthinnige Abneigung. Das trennt ihn von Burke sowie der späteren politischen Romantik. Von Burke sagt er fein $(2,3 \mathbf{I})$, daß er sein revolutionäres Buch gegen die Revolution geschrieben habe und rechnet ihn vermutlich zu jenen ygenievollsten Gegnern der Revolutions, die sauf Kastration drangene. s. Sie merkten wohl, daß diese angebliche Krankheit nichts als Krise der eintretenden Pubertät sei (a. a. O., vgl, auch 2, 660 und seinen Aufsatz über die Christenheit 2, 4iS, wo er ein bemerkenswertes nachempfindendes Verständnis für das revolutionäre Pathos zeigt). Das schließt iibrigens nicht aus, daß er auch von Burke gelernt haben könnte in seiner Empfindung für die gemiitlichen und ästhetischen Reize der alten Monarchie.

1) Haym, Romant. Schule, S. 344, betont etwas einseitig nur das letztere, wenn er sagt: „Alle Hauptgesichtspunkte der späteren restaurativ-romantischen Staatstheorie sind in diesen .. Aphorismen .. bereits niedergelegt. $c$

2) Vgl. z. B. Schriften 2, 40: > Man hat sehr unrecht, den König den ersten Beamten des Staates zu nennen. Der König ist kein Staatsbürger, 
Novalis und Friedr. Schlegel in den Jahren der Frühromantik. 63

monie aller Staatsglieder $\left.{ }^{1}{ }^{1}\right)$ Er konnte verlangen, daß der Staat ganz anders als bisher in das Leben des einzelnen hineinwachse. „Der Staat wird zu wenig bei uns verkü digt. Es sollte Staatsverkündiger, Prediger des Patriotism geben. Jetzt sind die meisten Staatsgenossen auf einem sehr gemeinen, den feindlichen sehr nahe kommenden Fuße mit ihm «.2) Immer höher wuchs ihm unter solchen Betrachtungen der Wert und die lebenzeugende Potenz des Staates. „Alle Kultur", so wagte er schon zu sagen, »entspringt aus den Verhältnissen eines Menschen mit dem Staate. $\left.\ll^{3}\right)$ Immer klarer wurde zugleich seine Uberzeugung, daß in dem Staate eine bisher mißachtete und vernachlässigte Kraftquelle für die Erhöhung und Stärkung des Einzeldaseins läge: »Der Mensch hat den Staat zum Polster der Trägheit zu machen gesucht, und doch soll der Staat gerade das Gegenteil sein, - er ist eine Armatur der gesamten Tätigkeit; sein Zweck ist, den Menschen absolut mächtig und nicht absolut schwach, nicht zum trägsten, sondern zum tätigsten Wesen zu machen. Der Staat überhebt den Menschen keiner Müle, sondern er vermehrt seine Muihseligkeiten vielmehr ins Unendliche; freilich nicht ohne seine Kraft ins Unendliche zu vermehren. ॥ $^{4}$ )

mithin auch kein Staatsbeamter. Das ist eben das L'nterscheidende der Monarchie, daß sie auf den Glauben an einen höhergeborenen Menschen, auf der freiwilligen Annahme eines Idealmenschen beruht .... Der König ist ein zum irdischen Fatum erhobener Mensch. Diese Dichtung drängt sich dem Menschen notwendig auf. Sie befriedigl allein eine höhere Sehnsucht seiner Nalur. Alle Menschen sollen thronfähig werden. Das Erziehungsmittel zu diesem fernen Ziel ist ein König. Er assimiliert sich allmählich die Masse seiner Untertanen. Jeder ist entsprossen aus einem uralten Königsstamm. Aber wie wenige tragen noch das Gepräge dieser Abkunft?s V'gl. auch S. 2. 659 f.

1) 2,49 ; vgl. überhaupt $2,35 \mathrm{ff}$.

2) 2,393 .

3) 2, 543 .

4) 2,528 . 
So ist auch dieser träumerische Poet und Philosoph, der, mit dem reinen Idealismus seiner großen Zeitgenossen nicht zufrieden, ihn noch ins Magische zu steigern unternahm, zugleich auch ein beredter Zeuge jener stillen Umwandlung im damaligen deutschen Geistesleben, jenes Autkeimens ethisch-politischer Bedürfnisse aus einem bis dahin ganz unpolitischen Boden, das in diesen Jahren so wunderbar und eigen sich zeigte. Man mag einwenden, daß es mit dieser Staatsverkündigung noch nicht so weit her sei, daß dieser Prediger des Patriotismus und der Staatsgesinnung in Wahrheit noch kein Prediger, sondern ein Dichter sei, ein überaus reizbarer und empfänglicher Künstlergeist, der die Entdeckung machte, daß auch der Staat und das Leben im Staate seine Schönheit habe. Lassen wir den Einwand gelten und suchen wir vielmehr in dem, was als eine Schwäche erscheinen kann, auch eine Stärke zu entdecken. Haben wir hier nicht vielleicht wieder einen der verborgenen Wege vor uns, auf denen der deutsche Geist zum deutschen Staate gekommen ist, - eine vielbedeutende Anwendung des Schillerschen Grundsatzes von der ästhetischen Erziehung? Das Morgentor des Schönen sollte ja nicht nur in das Land der Erkenntnis, sondern auch in das Land des sittlichen Handelns führen. Nun kann man wohl die Kraft und den Willen des damaligen Dichters bezweifeln, dieses Land, das er erblickte, wirklich zu betreten und den Staat, den er pries, wirklich zu ergreifen, - schon das war doch etwas, daß er ihn schaute nicht nur im Glanze, sondern auch in der Stärke seines Waffenschmuckes. Der neue lebendige Staat, den er verlangt, ist doch, mag sein Verlangen noch so ästhetisch gefärbt sein, derselbe, den auch ethischere Naturen wie er, Schleiermacher, Arndt und Fichte, damals und in den folgenden Jahren verlangt haben. Und weiter fehlt dem Novalisschen Staatsideal auch eine sehr konkrete Wurzel nicht, insofern 
es ja, wie wir bemerkten, anknuipfte an die Gesinnungen des altererbten patriarchalischen Royalismus. So sehen wir hier also, wie man von dieser geschichtlichen Grundlage aus und indem man dem ästhetisierenden und romantisierenden Zug der Zeit folgte, zu einem wirklichen und echten Nationalstaate kommen konnte. Denn das ist der Novalissche Staat, der auf der aktiven Beteiligung der Bürger am Gemeinwesen und auf einer bewußten gegenseitigen Durchdringung birgerlichen und politischen Lebens beruhen soll. Auch darin dachte er nationalstaatlich, daß er Front machte gegen den maschinenhaften Staat der friderizianischen Monarchie. »Kein Staat «, sagte er ${ }^{1}$ ), »ist mehr als Fabrik verwaltet worden als Preußen seit Friedrich IVilhelms I. Tode. " Das war ein Vorwurf, der seit Mirabeau von vielen, von Freunden der französischen Freiheitsideen sowohl wie von Freunden der alten ständischen und patriarchalischen Ordnungen erhoben worden ist, und Novalis kann, als er ihn aufnahm, vielleicht von beiden beeinflußt gewesen sein. Ganz gerecht war der Vorwurf nicht, aber er gehörte zu den geschichtlichen Ungerechtigkeiten, die man begehen muß, um selbst geschichtlich vorwärts zu kommen. Das Große und Fruchtbare war, daß er den größten deutschen Einzelstaat nicht nur kritisierte, sondern auch idealisierte, daß er in ihm den Beruf und die Fähigkeit zu einem echten Nationalstaate erkannte.

Bei noch kräftigerer Einseitigkeit wäre Novalis vielleicht auch als politischer Denker noch weiter gekommen, als er schon kam. Aber eben auch, weil sie ihm fehlte, ist sein Nachdenken über den Staat über ein bloßes Philosophieren, ein bloßes Prägen bedeutender Grundsätze nicht hinausgekommen. Auf seine eigenen revolutionären Jugendstimmungen sah er jetzt zurück als auf etwas

1) 2,47 .

Meinecke, Weltburgertum und Nationalstaat. 2. Autl. 
Uberwundenes. „Diese Jahre gehen bei den meisten voriber - und wir füllen uns von einer friedlicheren Welt angezogen, wo eine Zentralsonne den Reigen führt, und man lieber Planet wird, als einen zerstörenden Tanz um den Vorkampf mitkämpft. «1) So siegte in ihm wieder der echt romantische Hang, sich selig-beschaulich wiegen $z u$ lassen von den Kräften des Universums, so wurde er politisch tolerant und relativistisch gestimmt, so lobte er sich die »Unabhängigkeit eines reifen Geistes von jeder individuellen Form, die ihm nichts als notwendiges Werkzeug ist. $\left.\ll^{2}\right)$ Und so hat er, - eben auch infolge dieser erhabenen Indifferenz gegen die individuellen Formen des Staatslebens - auch seine fruchtbaren Ansätze zur Theorie des Nationalstaates nicht weiter entwickelt. Er, der sonst überall Persönlichkeit und Individualität sieht und herausfühlt, weiß eigentlich von der Persönlichkeit der Nation im ganzen auffallend wenig zu sagen. Die Belebung und Verherrlichung des Staates fordert er mehr vom individualistischen, als vom gesamtnationalen Beduirfnisse aus. Und insonderheit hat er das Element der deutschen Nationalität noch nicht nutzbar 'gemacht fuir den Staat. Nation in politischer Hinsicht ist ihm, wie aus seinen Aphorismen uber die preußische Monarchie deutlich hervorgeht, die Staatsnation im engeren Sinne, also hier das preußische Volk. ${ }^{3}$ ) Die deutsche Nation aber ist für ihn, wie für Humboldt und alle großen Denker dieser Jahre, ausschließlich Kulturnation.

Und als solche verfließt sie ihm sogleich ins Universale und allgemein Menschliche. »Deutsche gibt es

1) 2,660 .

2) a. a. O.

s) So spricht er 2, 49 von dem Wunsche des Königs von Preußen, s der wahrhafte Reformator und Restaurator seiner Nation und seiner Zeit zu werden \&. 
überall. Germanität ist so wenig wie Romanität, Gräcität oder Brittanität auf einen besonderen Staat eingeschränkt. Es sind allgemeine Menschencharaktere die nur hie und da vorzüglich allgemein geworden sind. Deutschheit ist echte Popularität und darum ein Ideal « " ) - Ahnlich an A. WV. Schlegel"2): 》Deutschheit ist Kosmopolitismus mit der kräftigsten Individualität gemischt." »Die instinktartige Universalpolitik und Tendenz der Römer liegt auch im deutschen Volk. Das Beste, was die Franzosen bei der Revolution gewonnen haben, ist eine Portion Deutschheit. $\left.\ll^{3}\right)$ — In energischer Universalität kann keine Nation gegen uns auftreten. $\left.{ }^{4}\right)$ Diese Uberzeugung von dem Universalberuf der deutschen Nation und daß sie die eigentliche Menschheitsnation sei, teilte der Romantiker ja mit dem Schiller-Humboldtschen Kreise, aber er gab ihr nun noch eine eigentumlich romantische Färbung. Spezifisch romantisch war es, das Universale und das Individuelle sich immer in- und miteinander vorzustellen und eine Art Feinschmeckerei darin zu treiben, jedes der beiden Elemente im anderen immer kräftig herauszufühlen. »Alles Nationale, Temporelle, Lokale, Individuelle läßt sich universalisieren . . . dieses individuelle Kolorit des Universellen ist sein romantisierendes Element. $\ll^{5}$ ) Novalis gab ein andermal noch eine andere Definition des Romantisierens: »Die Welt muß romantisiert werden... Indem ich dem Gemeinen einen hohen Sinn, dem Gewöhnlichen ein geheinnisvolles Ansehen, dem Bekannten die Würde des Unbekannten, dem Endlichen einen unendlichen Schein gebe, so roman-

1) 2,16 .

2) 30. November 1797. Friedr v, Hardenberg (Novalis): Eine Nachlese, S. 169; Raich, Novalis' Briefwechsel mit F. u. A. W., Charl. u. Carol. Schlegel, S. 41 .

3) 2,15 .

4) 2,70

5) $2,129$. 
tisiere ich es. «1) So strahlend und groß diese Forderung war, so mächtige Antriebe sie der modernen Geisteswissenschaft auch zu geben vermochte, so begreift man doch, daß sie auch zum geistreichen Spiele verführte, daß der »unendliche Schein « schließlich über das Endliche, das Universale über das Individuelle und konkret Bestimmte, der Menschheitsgedanke über den Gedanken der Nation den Sieg davontragen konnte.

Wir begreifen es weiter, daß dann auch in seiner Anschauung vom Staatenleben ein universalistischer Zug zum Durchbruch kam, der die unbedingte Autonomie und damit die unbedingte Individualität der einzelnen Staaten nicht mehr recht anerkennen und gelten lassen konnte. "Die Staaten ", sagt er, »müssen endlich gewahr werden, daß die Erreichung aller ihrer Zwecke bloß durch Gesamtmaßregeln möglich ist. Allianzsysteme. Näherung zur Universalmonarchie. $\ll^{2}$ ) Wie er das meinte, hat er zusammenhängend ausgeführt in seinem merkwürdigen Aufsatze von 1799 iber »Die Christenheit oder Europa $\left.\ll^{3}\right)$, in dem wir nun auch noch deutlicher als bisher die Bindeglieder zwischen der subjektivistischen Frühromantik und der späteren politischen Romantik der Restaurationszeit sehen können.

Novalis gab hier Geschichtsauffassung und Zukunftsideal zugleich. Er entwirft ein leuchtendes Bild der christlich-europäischen Kultur des Mittelalters, er läßt auf die Reformation und auf die ihr folgende geistige und politische Entwicklung dunkle Schatten fallen, aber er

1) 2,304 .

2) 2,285 .

3) 2, 399. Er war für das Athenaeum bestimmt, wurde aber auf Goethes Rat nicht aufgenommen. Vgl. Dilthey, Das Erlebnis und die I)ichtung, S. 231; 3. Aufl., S. 298 ; Haym, Romant. Schule, S. 462 ff.; Raich, Novalis Briefwechsel, S. 145 ff.; Spenlé, Novalis (Paris 1903), S. $274 \mathrm{ff}$, der darauf hinweist, daß Novalis selbst trotzdem an eine andere Art der Veröffentlichung dachte (vgl. Raich S. 133). 
glaubt, daß der Morgen nummehr graue für einen neuen herrlichen Lebenstag Europas, daß die schöne Zeit des christkatholischen Mittelalters in verjüngter, neuer Gestalt wieder auferstehen werde. Fast scheut man sich aber, seine Gedanken auf eine so einfache und greifbare Formel zu bringen, denn ihre Umrisse lösen sich bei näherer Betrachtung in Duft und Glanz auf. Die Sprache dient hier dem Unaussprechlichen, der Gedanke dem, was nicht gedacht, sondern nur empfunden und geschaut werden kann. Er spricht in überschwenglichen Tönen von der katholischen Kirche des Mittelalters und ihrem Kultus, von der »heiligen, wunderschönen Frau der Christenheit ", selbst von dem Ewigkeitswert des Jesuitenordens, aber wer möchte es wagen, diese Worte zu pressen und an seine katholisierende Gesinnung ernsthaft zu glauben, wenn ihm schließlich Schleiermacher als einer der Vorboten der neuen Zeit gepriesen wird und wenn er von einer vollgiiltigen Form des Christentums hört, die nichts weiter sei, als 》Glaube an die Allfähigkeit alles Irdischen, Wein und Brot des ewigen Lebens zu sein". Darum ist ihm auch alles Irdische und Geschichtliche nur ein Gleichnis oder ein Annäherungsmittel zum Unsichtbaren und Unendlichen, zum Unbegreiflichen und Wunderbaren, zu den Tiefen, wo Menschheit und Weltall zusammenströmen. Er nimmt seinen Standpunkt über der eigentlichen Geschichte so hoch, daß er Erde und Himmel ineinander fließen sieht, und eben dieses erhabene Schauspiel ist es, was ihn dann wieder duldsam, irenisch, mitverstehend stimmt gegen die einzelne geschichtliche Erscheinung. So löst sich denn auch sein Verdikt uiber den Protestantismus und dessen üble religiöse und politische Folgen schließlich wieder auf in einen Bruderkuß fur die ganze Welt.

Dennoch aber bleibt das Verdikt mit seinen daraus erwachsenden Folgerungen bestehen und will gewürdigt sein. 
Da ist es denn für uns sehr lehrreich zu sehen, wie seine Sympathie für das Mittelalter vor allem eine Sympathie für dessen universalistischen Grundcharakter ist. Er stellt den »allgemeinen christlichen Verein « dieser Epoche der Zerrissenheit der neueren Staatenwelt gegeniber und macht fuir diese Zerrissenheit die Reformation verantwortlich, durch die das Weltliche und Irdische die Oberhand gewonnen habe. "Die neuere Politik entstand erst in diesem Zeitpunkt, und einzelne mächtige Staaten suchten den vakanten Universalstuhl, in einen Thron verwandelt, in Besitz zu nehmen. «1) Das Emporliommen der großen Machtstaaten der neueren Zeit, ihr Ausdehnungs- und Selbstbestimmungsdrang, liurz die Säkularisierung der Politik erscheint ihm als Abfall und Usurpation. Er will es nicht gelten lassen, daß der Staat sich mit festen, markigen Knochen auf den Boden seiner eigensten Interessen stelle. "Alle Eure Stützen sind zu schwach, wenn Euer Staat die Tendenz nach der Erde behält. Aber kniipft ihn durch eine höhere Sehnsucht an die Höhen des Himmels, gebt ihm eine Beziehung aufs Weltall, dann habt Ihr eine nie ermüdende Feder in ihm und werdet Eure Bemühungen reichlich belohnt sehen. $\left.\ll^{2}\right)$ Er versteht es wohl vom höchsten Standpunkte aus, daß auch der mörderische Kampf der Staaten und Nationen untereinander seinen höheren geschichtlichen Zweck habe, indem nämlich ihre nähere und mannigfaltigere Beriihrung untereinander nur eine Vorstufe sei für eine neue Gemeinschaft Europas und einen "Staat der Staaten". Aber die Aufgabe, diesen zu stiften, könne nicht den Staaten selbst, sondern nur einer uiber ihnen stehenden universalen Macht, die weltlich und überirdisch zugleich sei, d. h. der Hierarchie

\footnotetext{
1) 2, f06.

2) 2, 4I2.
} 
Novalis und Friedr. Schlegel in den Jahren der Frühromantik. 71

und Kirche, zufallen, denn »es ist unmöglich, daß weltliche Kräfte sich selbst ins Gleichgewicht setzen .... Nur die Religion kann Europa wieder auferwecken und die Völker versöhnen «. ${ }^{1}$ )

Das ist in flüchtiger, aber nicht mißverständlicher Skizze das Programm eines religiös-kirchlichen Kosmopolitismus ${ }^{2}$ ) und seines Primates auch auf politischem Gebiete. Es ist ein Vorspiel und Seitenstuick zu den Theorien de Maistres, Bonalds und - so hat schon Dilthey erkannt - der heiligen Allianz. ${ }^{3}$ ) Immer ist es ja noch etwas anderes, wenn die Katholiken Bonald und de Maistre und wenn der zwar katholisierende, aber in letzten Grunde pantheisierende Protestant Novalis von Kirche und Hierarchie und von ihrem Berufe zur Leitung der christlichen Staatenwelt sprechen. Denn so sehr auch Novalis dem Protestantismus und der Aufllärung gram war, auf ihre beste Errungenschaft, die innere geistige Freiheit, wollte er doch keineswegs verzichten. Er träımte von einer Harmonie individueller Freiheit und universaler Einheit. ${ }^{4}$ ) Aber derartige aufs höcliste gespannte, aufs äußerste vergeistigte Ideale können sich selten in so reiner Höhe halten. Man verlangt bald wieder nach dem Greifbaren und Sinnlichen. Auch Novalis war mit der unsichtbaren Kirche der Zukunft nicht zufrieden, sondern wünschte, daß die Christenheit »sich wieder eine sichtbare Kirche ohne Rücksicht auf Landesgrenzen bilde«,

1) 2, 4 I $7 \mathrm{ff}$.

2) Er spricht direkt einmal von dem $\gg$ religiösen kosmopolitischen Interesse $\ll$, S. 405 .

3) Es ist das die unhistorische Anschauung, welche der heiligen Allianz ein christliches Gewand lieh. \& Das Erlebnis und die Dichtung, S. 232. 3. Aufl., S. 298.

4) sKeiner wird dann mehr protestieren gegen christlichen und weltlichen Zwang, denn das Wesen der Kirche wird echte Freiheit sein.c 2, 420 . 
verlangte ein »ehrwürdiges europäisches Konzilium « zur Verwirklichung seines Traumes. Da war dann schließlich der Weg zur Rückkehr nach Rom nicht mehr allzu weit und konnte muide werdende Geister verlocken. Das zeigte Friedrich Schlegel.?

Greifen wir jetzt auch aus dessen Entwicklung das heraus, was für unser Problem in Betracht kommt. ${ }^{1}$ ) Die Ausbeute ist freilich gerade fuir die interessantesten und reichsten Jahre seiner Gedankenprodultion - wiederum sind es die ausgehenden neunziger Jahre des Jahrhunderts - nicht so ergiebig wie für Humboldt und Novalis. Aber seine dominierende Stellung in der Frühromantik und seine eigene weitere Entwicklung, die zur politischen Romantik der Restaurationszeit unmittelbar hinuberleitet, erfordert es, auch auf seine politischen und nationalen Jugendgedanken einen Blick zu werfen. Unzweifelhaft hatte dieser universale Kopf auch ein leidenschaftliches Interessse für politische Dinge. „Ich werde glücklich sein, wenn ich erst in der Politik schwelgen kann«, schrieb er 1796 seinem Bruder. ${ }^{2}$ ) Aber dies politische Interesse galt noch nicht dem Staate, wie er war, sondern dem Staate, wie er sein sollte nach der Idee des Denkers. Sein "Versuch über den Begriff des Republikanismus" $\left.(1796)^{3}\right)$ steht in der Hauptsache noch auf demselben rationalistischen und ungeschichtlichen Boden, wie die Schrift Kants vom ewigen Frieden, zu der er hier Stellung

1) Über die hierher gehörigen Gedanken seines Bruders Angust Wilhelm, vgl. Haym, Romant. Schule, S. So4 ff, 824, $850 \mathrm{ff}$.

2) Walzel, F. Schlegels Briefe an seinen Bruder August Wilhelm, S. $27 \mathrm{~S}$.

3) In der Zeitschrift :Deutschland ‘ veröffentlicht. Minor, F. Schlegel, seine prosaischen Jugendschriften, 2, $57 \mathrm{ff}$. Vgl. über ihn das charakteristisch zustimmende Urteil des Franzosen Rouge: Fr. Sihlegel et la sénèse du romantisme allemand (I904), S. I69ff. - Über die Ansätze Schlegels zu historischen und politischen Interessen ijberhaupt vgl. auch Haym, Romant. Schule, S. SS I ff. 
nimmt. Und sie ist vielleicht noch theoretischer und weltfremder wie diese, in der man den heiligen Ernst des Staatsreformers doch immer wohltuend durchspürt, während Schlegels Politisieren mehr ein Versuch ist, auch dieses Gebiet seinem geistigen Weltbilde einzuverleiben. So konnte er den französischen Revolutionsideen sogar noch weitere Zugeständnisse machen, als der bedächtigere un $!$ erfahrenere Kant. ${ }^{1}$ )

Eine der Ideen, in denen er sich mit Kant berührt und über ihn noch hinausgeht, muß uns fesseln. Kant hatte, um zum dauernden Frieden zu gelangen, einen Föderalismus der freien Staaten, einen Friedens- und Völkerbund verlangt. Damit wollte Kant zufricden sein und lehnte die Idee einer Weltrepublik als undurchführbar ab. Schlegel dagegen hielt auch den Völkerstaat für sehr wohl denkbar und anscheinend auch für möglich. „Die Idee einer Weltrepublik hat praktische Gültigkeit und charakteristische Wichtigkeit. $\ll^{2}$ ) Innerhalb dieses Völkerstaates dachte auch er sich, wie Kant, die einzelnen Völker als politisch selbständig und autonom. Aber diese Art von Autonomie war nicht diejenige, die wir bei unserem Problem im Auge haben. Es ist nicht die Autonomie der konkreten, geschichtlichen Staatspersönlichkeit, sondern die Autonomie, die Souveränität des Volkes im Sinne Rousseaus und des Naturrechts, die auf allgemein menschlichen Vernunftpostulaten beruhte ${ }^{3}$ ), die aus den einzelnen Staaten nur Unterabteilungen der Menschheit machte. Da war denn der Gedanke begreiflich, sie wiederum zu vereinigen zu einer Weltrepublik. Hatten wir bei Novalis einen religiös-kirchlichen Kosmopolitismus konstatiert, so sehen wir hier bei Schlegel den

1) Doch finden sich in Schlegels Aufsatz auch einige Ansätze zu einer historisch-empirischen Behandlung der Politik (a, a. O. S. 69 f.).

2) a. a. O. S. 59 .

$\left.{ }^{3}\right)$ Siehe oben S. 30. 
naturrechtlich-demokratischen Kosmopolitismus noch einmal wieder auftauchen.

Als politischer Denker gehörte er damals also merkwürdigerweise noch der unromantischen Welt an, während er als Dichter und Ästhetiker doch die »Seele und Stimme der Nation, ${ }^{1}$ ) der echten, historischen Nation schon lange kannte und hörte. Als junger Dichter hatte er schon I 79I den Wunsch, 》alles aus der immensen Eigentiumlichkeit unserer Nation zu nehmen", und er glaubte damals »entdeckt zu haben, daß unser Volk einen sehr großen Charakter hat. ${ }^{2}$ ) Es berührt eigen, aber man atmet damit die Luft jener Jahre, wenn er sich I793 bald für »deutschen Wert und Geist « und bald für » französische Freiheit « begeistert. ${ }^{3}$ ) Er hatte aber auch noch eine besondere Schule für das Verständnis des Nationalen durchgemacht, dieselbe, in die auch Humboldt und vor ihm schon Herder sich begeben hatten - das war die begeisterte Betrachtung der hellenischen Kultur. An der griechischen Poesie wurde es ihm vor allem klar, daß sie ihre Kraft ganz eigentlich und ausschließlich aus dem Boden der Nation zog ${ }^{4}$ ), während die moderne Poesie, so meinte er, dadurch eine künstliche Poesie wurde, daß sie sich von diesem Boden entfernte und einen allgemeinen europäischen Charakter annahm. ${ }^{5}$ ) Er konnte schließlich, indem er das Phänomen der griechi-

1) Uber das Studium der griechischen Poesie (I795/96), Minor I, $175 \mathrm{t}$.

2) An seinen Bruder, Walzel a. a. O. S. 26.

3) Walzel, S. 132 u. $1+5$.

4) ,Die griechische Bildung überhaupt war durchaus originell und national, ein in sich vollendetes Ganzes, welches durch bloße innere Entwicklung einen höchsten Gipfel erreichte und in einem völligen Kreislauf auch wieder in sich selbst zurïcksank.... ihre Poesie war nicht nur im ersten Anfange sondern auch im ganzen Fortgange be. ständig nazional.c Minor $\mathbf{r}, \mathbf{1} 43$.

5) Minor 1, 94 . 
schen Kultur im ganzen sich vor Augen führte, nicht bei der Kulturnation stehen bleiben, sondern mußte sie auch als politische Nation würdigen und den Zusammenhang ihres geistigen und staatlichen Lebens sehen. Griechenland bot ihm zwar nicht das Schauspiel des nationalen Gesamtstaates, aber das in seinen Augen vielleicht noch großartigere Schauspiel eines nationalen Staatenlebens, einer Vielheit innerlichst verwandter und verbundener, aber in sich autonomer und freier Staaten. Nicht jede Nation, so führte er in der 1798 geschriebenen Geschichte der Poesie der Griechen und Römer aus ${ }^{1}$ ), hat einen Stil oder Charakter im höheren Sinne des Wortes. 》Dazu gelangt ein Volk nur durch eine gewisse gliuckliche Ubereinstimmung der sittlichen und geistigen Anlage und äußeren Umgebung und durch Gleichartigkeit der ursprünglichen Bestandteile beim Anfange der eigentlichen Bildung, wenn das gemeine Wesen zur Selbständigkeit fähig geworden ist; durch unbeschränkte Freiheit im Entwickeln und Bestimmen seiner selbst und durch heftigen Kampf mit einem Volke von entgegengesetzter Art; durch Gesellschaftlichkeit und Gemeinsamkeit aller einzelnen, durch Verbindung und Verbrüderung der freien Staaten《 . . . und endlich: »durch Streben nach Allgemeinheit und Vollständigkeit der Ausbildung mit weltbürgerlichem Sinn und ohne unbildende Annahme des Fremden zu verschmähen.«

Durch das Idealbild des griechischen Volkes, das er hier zeichnet, scheinen seine Wünsche und Ideale für die eigene Nation hindurch; mit dem Sinn für das spezifisch Nationale kann er hier sogar ungezwungen eine

1) a. a. O. I, 358 ; vgl. auch daselbst 361 : , Wie unauslöschlich aber der Charakter dauerte, wenn sich einmal ein solches Gemisch von wandernden und einheimischen Stämmen, ähnlichen aber nicht gleichen Ursprungs zu einer Nation oder gar $z \mathfrak{u}$ einem System von Republiken gebildet hattes etc. 
Reminiszenz seines Traumes von Völkerstaat und Weltrepublik verschmelzen, und die Autonomie des einzelnen Freistaates sowohl wie der Nation im ganzen ist hier auch viel konkreter und geschichtlicher gefärbt als diejenige, die er in seinem politischen Versuche von 1796 meinte. So entwarf er also das Bild einer großen, selbständigen, eigenartigen Kulturnation, deren Boden eine Mehrzahl von selbständigen, eigenartigen, aber untereinander verwandten und verbrüderten Staatsgebilden trägt. Wir werden später sehen, wie bedeutend dieser Gedanke ausgestaltet werden konnte. Aber er selbst führte ihn jetzt noch nicht weiter aus. Uber alles Nationale und Politische hinaus drängte es ihn doch immer wieder zum rein Geistigen. "Nicht in die politische Welt «, schrieb er I799, »verschleuclere du Glauben und Liebe, aber in der göttlichen Welt der Wissenschaft und der Kunst opfre dein Innerstes in den heiligen Feuerstrom ewiger Bildung ". ${ }^{1}$ ) Und mit seiner Deutschheit steht es ebenso wie mit der von Novalis und Humboldt. Sie ist das erhebende Bewußtsein, reiner als andere Nationen den höchsten Zwecken der Menschheit zu dienell. „Nur bei den Deutschen ist es eine Nationaleigenheit, die Kunst und die Wissenschaft bloß um der Kunst und der Wissenschaft willen göttlich zu verehren. ${ }^{2}$ ) . . Nicht Hermann und Wodan sind die Nationalgötter der Deutschen, sondern die Kunst und die Wissenschaft. $\ll^{3}$ )

Damit nahen wir uns wieder der stärksten Quelle der Ideen, die uns bisher beschäftigten. Wir fanden bei Novalis wie bei Schlegel Ansätze sowohl zu einer tieferen Würdigung des von nationalem Leben erfüllten Einzelstaates wie zu einem politischen Universalismus, der die Autonomie des Einzelstaates wieder beschränken mußte.

1) Ideen (Athenaeum), Minor 2, 3oo.

2) a. a. O. 2, 302 .

3) a. a. $0.2,304$. 
Bei Novalis war dieser Universalismus angeknüpft an den mittelalterlichen theokratischen Universalismus, bei Friedrich Schlegel an die weltbürgerlichen Ideen der RevoJution - aber eben nur angeknüpft, nicht entscheidend beeinflußt durch sie. Tiefer und stärker als Mittelalter und Rousseau wirkte hier doch der Grundcharakter der damaligen deutschen Bildung, ihre hochgespannte Geistigkeit, ihre ausschließliche Wertschätzung der idealen Guiter des Lebens, ihre energische Wendung ins Innere des menschlichen Geistes, ihre Neigung, nur das aus der Außenwelt auf sich wirken zu lassen, was die Innerlichkeit am besten und leichtesten nährte. Darin waren diese Frühromantiker noch die echten Söhne der Generation, die das Humanitätsideal geschaffen hatte, der Herder, Goethe, Schiller und Kant. Mochten sie auch schon Keime einer neuen, reicheren Auffassung vom Staatsleben und einer kräftigeren Hinwendung zur Wirklichkeit in sich tragen, so schlug doch noch die spirituelle Tendenz immer wieder durch. Man konnte sich in dem einen Augenblick vielleicht begeistern für den Staat, der den Menschen zum kraftvollen und handelnden Wesen mache, und im anderen Augenblick sich wieder zurückgestoßen fühlen von dem Anblick, den das Leben der Staaten untereinander bot, von diesem wilden Ringen der politischen Egoismen untereinander, in dem man nichts von innerem Menschheitswert entdecken konnte. Während die anderen europäischen Länder, meinte Novalis, durch Krieg, Spekulation und Parteigeist beschäftigt sind, bildet sich der Deutsche mit allem Fleiß zum Genossen einer höheren Epoche der Kultur. ${ }^{1}$ ) Das geistige Neuland, um das doch auch, wie der Nachlebende leicht erkennt, in eben diesen Kriegen schon gestritten wurde, war noch verdeckt durch den Staub des Kampfes. Der politische Boden aber

1) Dilthey, Das Erlebnis und die Dichtung S. 224, 3. Aufl, S. 291 . 
des eigenen Vaterlandes taugte noch zu wenig für die hohen Ideale, denen man diente. Da war es begreiflich, daß Novalis und Schlegel, wenn sie über einen wünschenswerten politischen Zustand der europäischen Menschheit nachsannen, ihren geistigen Universalismus in politischen Universalismus umsetzten und von Völkerfrieden, Völkerbund, Völkerstaat und Weltrepublik träumten. 


\section{Fünftes Kapitel.}

\section{Friedrich Schlegel im Übergange zur politischen Romantik.}

Novalis' Leben, Dichten und Denken gleicht einem wundervollen und in sich abgeschlossenen Traume, und sein früher Tod erscheint wie ein ästhetisch notwendiger Abschluß dieses Traumes. Friedrich Schlegels Los dagegen war es, seine Feuer- und Geniezeit um beinahe drei Jahrzehnte zu uberleben. Es ist hier nicht der Ort, die Gründe für den Niedergang seines Geistes zu erörtern, sondern uns interessiert hier allein die Frage nach der Weiterbildung seiner Gedanken über Nation und nationalen Staat in einer Periode, in der er selbst, durch seinen Übertritt zur katholischen Kirche ( I SOS) und durch seinen Anschluß an Osterreich, die individualistische und freie Romantik hinüberentwickelte zur politisch und kirchlich gebundenen Romantil. Innere geistige, individuelle Ursachen trieben wohl vor allem, aber ohne Zweifel wirkte auch der politische Wandel der Zeiten mit. Das sieht man an seiner veränderten Stellung zu den nationalen und internationalen Problemen. Die Uppigkeit und Ungebundenheit der Frühromantil hatte gutes Spiel in den Jahren nach dem Baseler Frieden, wo Norddeutschland zuriickgezogen war aus der Region der Stürme, und ihre Träume von Völkerfrieden und Völkerbund hingen gewiß auch mit der optimistischen und doch nur aus Weltentfremdung optimi- 
stischen Stimmung dieser Jahre zusammen. Aber als zu Anfang des neuen Jahrhunderts das alte Reich zusammenbrach, war es aus mit diesem Optimismus. Jetzt, wo die politische Selbständigkeit der Staaten und Nationen bedroht war, erhob sich die bange Frage, wie es mit der bisher so unbefangen genossenen geistigen Freiheit und Selbständigkeit der eigenen Nation werden würde. So war die Lage dieser Jahre von I80 I ab das stärkste äußere Reizmittel für die Weiterentwicklung der nationalen Idee, und Friedrich Schlegel ließ es vielleicht um so bereitwilliger auf sich einwirken, weil er neuer Zufuhr an Stoffen für seinen allmählich nachlassenden Geist bedurfte. Denn wenn er jetzt — vor allem in den philosophischen und politischen Vorlesungen der Jahre I804 bis $1806^{1}$ ) und dann in den Wiener Vorlesungen über neuere Geschichte von $18 \mathrm{IO}^{2}$ ) - in den Kampf für die Sache der freien Nationalität gegen die Ubermacht Frankreichs eintrat, so spürt man zwar überall einen lebhaft interessierten Kopf und zuweilen auch den Hauch einer warmen Gesinnung, aber nicht eigentlichen Kämpfergeist, nicht jenen übermächtigen Drang wie bei Fichte und Arndt. Es fehlt eben doch jenes Ethos bei ihm, das uns von der inneren Notwendigkeit des Neuen, was er jetzt vorzutragen hatte, zu überzeugen vermöchte. Überzeugend und ganz. echt berührt eigentlich nur das in diesem Neuen, was unmittelbar aus seiner früheren Gedankenrichtung hervorgeht, und das war der entschiedene Sinn für den unvergleichlichen geistigen Wert eigentümlicher und freier Nationalentwicklung und die Meinung, daß der Reichtum und die Lebendigkeit der europäischen Kultur gerade

1) Philosophische Vorlesungen aus den Jahren $1 \mathrm{SO}_{4}$ bis I806, herausgegeben von Windischmann, $1836 / 37,2$ Bände, vgl. namentlich 2,385 .

2) ¿Über die neuere Geschichte. Vorlesungen, gehalten i. J. I 8 Ioc, Wien I 81 I. 
auf ihr beruhe. ${ }^{1}$ ) Indem er jetzt aber weitergeht und auch die politische Seite des Nationallebens genauer betrachtet als früher, wird man bald gewahr, daß er unsicher umhertastet und seinen Halt schließlich bei derjenigen politischen Verfassungsform sucht, die mit der kirchlichen Gebundenheit des katholischen Systems am besten zusammenstimmte.

Er wirft zunächst die höchst radikale Idee hin, daß das würdigste Prinzip für die Finteilung der Staaten die Sprache sei, nicht nur, weil sie das geistige Verbindungsmittel sei, sondern auch weil sie den Beweis des ähnlichen Ursprungs liefere; Einheit der Sprache beweise gemeinschaftliche Abstammung, und »je älter, reiner und unvermischter der Stamm, desto mehr Sitten, und je mehr Sitten und wahre Beharrlichkeit und Anhänglichkeit an diese, desto mehr wird es eine Nation sein. ${ }^{2}$ ) Dieser Nationalbegriff sollte hochgeschichtlich sein und litt doch an dem schweren geschichtlichen Irrtum, daß die Nation immer in erster Linie auf Blutsreinheit beruhe. Und was wurde nun dabei aus der von ihm so hoch gepriesenen Freiheit und Eigentuimlichkeit des Nationallebens? Die Freiheit wurde nativistisch vergröbert zur Fernhaltung alles fremden Blutes, die Eigentümlichkeit lief hier hinaus auf möglichste Erhaltung des Uberlieferten, auf Stagnation und Altertiumlichkeit der Nationalcharak-

1) Vgl. seine Vorlesungen von i 8 Io, S. I I : , Wäre es den deutschen Völkern nicht gelungen, das römische Joch aufzulösen, wäre vielmehr auch der noch ubrige Norden von Europa Rom einverleibt, auch hier die Freiheit und Eigentümlichkeit der Nationen vertilgt ..., so würde jener herrliche Wettkampf, jene reiche Entwicklung des menschlichen Geistes bei den neueren Nationen gar nicht stattgefunden haben. Und doch ist es eben dieser Reichtum, diese Mannigfaltigkeit, was Europa zu dem macht, was es ist, was ihm den Vorzug gibt, der vorzüglichste Sitz des Lebens und der Bildung der Menschheit zu sein. Ähnlich S. I I6; vgl. auch die Vorlesungen von ISo4/6 2, 358 .

2) Vorlesungen von ISo4/6 2, 357, 359. 
tere. Wir begegnen hier wohl zum ersten Male in Deutschland der spezifisch konservativen Ausdeutung des Nationalitätsprinzips. Je konservativer eine Nation ist, wird uns gesagt, um so mehr ist sie Nation, und es liegt Schlegel in der Tat auch viel mehr am Herzen, die alten gesellschaftlichen Ordnungen und Sitten zu rechtfertigen und zu preisen, als die nationalen Sprachgemeinschaften etwa zu nationalen Staatswesen zu erheben. Der eigentlich nationale Staat ist für ihn demnach der ständische Staat, wie man ihn, so meint er, gerade bei den edelsten Nationen finde ${ }^{1}$ ), und die Grundkraft des Staates sieht er in dem Adel, der zugleich auch der nationale Stand

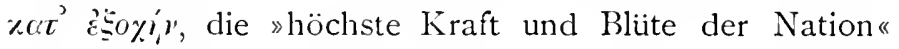
sein müsse. ${ }^{2}$ ) Adelsherrschaft ist für ihn tatsächlich beinahe gleichbedeutend mit Nationalität. Das prägt sich am schärfsten darin aus, daß er den Adel zur Kriegerkaste macht, der die Verteidigung der Nation in erster Linie übernehmen und leiten müsse ${ }^{3}$ ), daß er die allgemeine Wehrpflicht der Nation nur im Notfalle gelten lassen will, als allgemeines Prinzip aber entschieden verwirft. Schlegels Nationalstaat trägt also jetzt, als Nationalstaat im politischen Sinne genommen, durchaus den Typus des älteren Nationalstaates, aber wir haben in ihm zugleich auch wieder das, was wir frïher Nationalstaat im national-kulturellen Sinne nannten, in dem er vom Staate ja verlangt, daß er aus dem reinen, unverfälschten, ursprünglichen Boden der Nation hervorgehe, - wobei er freilich, wie wir sahen, nur denjenigen Staat für rein und ursprünglich national erklärte, der die ständische

1) Wo die Nation treu an ihren Sitten und an ihrer Verfassung hängt, da werden auch nicht leicht die ständischen Verhältnisse verwirrt werden, und wo dieses geschieht, ist es auch immer schon ein Beweis von Korruption und Verfall.c

2) Vorlesungen von is ro S. 56r, 563.

3) Vorlesungen von $1804 / 62,360 \mathrm{ff}$ 
Verfassung konserviert habe. Dadurch vergewaltigte er nun aber den Begriff der nationalen Eigentümlichkeit und Ursprünglichkeit, indem er ihr vorschrieb, worin sie zu bestehen habe, und jede Abweichung davon für Korruption und Verfall erklärte. Und er kanonisierte und dogmatisierte damit nur eine bestimmte Entwicklungsstufe des politischen Lebens, die überdies nicht eigentümlich für die einzelne Nation, sondern eigentümlich für den ganzen romanisch-germanischen Völkerkreis gewesen war. Man darf eher die Behauptung wagen, daß sich die Eigentümlichkeit, der individuelle Genius der einzelnen Nationen gerade in der Art gezeigt hat, wie sie, die eine früher, die andere später, die eine revolutionär, die andere reformerisch, die ursprüngliche gemeinsame feudal-ständische Verfassung überwunden und umgebildet haben. Und wer die ständische Verfassung zur Normalverfassung der Nationen erhob, handelte im Prinzip nicht anders, wie derjenige, der den demokratischen Konstitutionalismus dafür hielt. Das heißt, er stellte, mochte er sich nun dessen bewußt sein oder nicht, eine ubernationale universale Norm für das politische Leben der einzelnen Nation auf. Verfolgen wir diese überaus wichtige Erscheinung, die zum Grundthema unserer Untersuchungen gehört, noch etwas weiter. Gewiß war dieses Aufstellen allgemeiner Verfassungsideale für die einzelnen romanischgermanischen Nationen kein bloßer Doktrinarismus. Es ließ sich geschichtlich und national damit rechtfertigen, daß diese Nationen eben unter sich in hohem Grade verwandt und gleichartig waren, und das Auftauchen und Aussprechen dieser universalistischen Gedanken, mochten sie nun aus aristokratischem oder demokratischem Lager rühren, war selbst schon ein Symptom, eine Wirkung dieser Kulturgemeinschaft und Verwandtschaft zwischen den einzelnen Nationen. Aber, wo war nun die Grenze zwischen dieser, man möchte sagen, europäischen $\mathrm{Al}$ - 
mende und dem Einzelbesitz der Nation, zwischen dem, was dem besonderen Charakter und der besonderen Entwicklungsstufe der einzelnen Nation entsprach und dem, was sie auch mit anderen Nationen teilen oder von ihnen rezipieren konnte? Auf eine solche rein empirische und im eigentlichen Sinne erst historisch-politische Prüfung der Verfassungsformen einer Nation war Friedrich Schlegel nicht gestimmt, war auch seine und waren die nächstfolgenden Generationen meist noch nicht gestimmt, denn universale und nationale Sphäre flossen ihnen durcheinander. So glaubten sie nur $\mathrm{zu}$ oft ganz treuherzig dem nationalen Gedanken zu dienen, wo sie in Wahrheit universalistisch dachten.

Und Friedrich Schlegel war voll nicht nur von unbewußtem sondern auch von bewußtem Universalismus. Das zeigt sich nun in der Art, wie er das Verhältnis der einzelnen Staaten zueinander bestimmt. Wir sahen, daß er in seinen Anfängen, als er von Völkerstaat und Weltrepublik träumte, einem naturrechtlich-demokratischen Kosmopolitismus gehuldigt hatte. Jetzt taucht er nun auch in jenen religiös-kirchlichen, mittelalterlich-romantischen Universalismus ein, wie ihn Novalis vertreten hatte. Zwar fordert er zunächst mit scheinbar jeden Zweifel ausschließender Bestimmtheit die Autonomie der Staatspersönlichkeit. »Jeder Staat ist ein selbständig für sich bestehendes Individuum, ist unbedingt sein eigener Herr, hat seinen eigentümlichen Charakter und regiert sich nach eigentümlichen Gesetzen, Sitten und Gebräuchen. «1) Er verwirft jetzt auch ausdrücklich die früher von ihm selbst vertretene rationalistische Idee eines Völkervereins. Aber nur, um dafür die romantische Idee eines universalen Kaisertums zu empfehlen: „Das Kaisertum, als spezifisch verschieden von dem Königtum genommen,

1) Vorlesungen von ISO4 62,382 . 
als ein Königtum über die Könige. Hierbei wird vorausgesetzt, daß die Nation, welche durch das Kaisertum eine bestimmte Oberherrschaft über die Nachbarvölker ausuibt, eine starke, wo nicht die stärkste sei. Sodann auch muß sie sich durch ihre politische und moralische Verfassung dazu eignen. Die Idee des Kaisertums ist viel kräftiger, um ein sittliches Verhältnis unter den Nationen einzuführen, als jene eines Völkervereins. Das beweist schon die Vergleichung des Mittelalters mit der neuern Zeit. Auch paßt dieses System viel besser zu dem natülichen Verhältnis, in welchem die Nationen rücksichtlich der 'großen Verschiedenheit ihrer Bildung stehen. $\left.{ }^{1}\right)$ Man darf wohl vermuten, daß sich in solchen Gedanken auch das große Zeitereignis, die Begründung des napoleonischen Kaisertums, widerspiegelt, aber dann wollten sie eben, so führen es die Vorlesungen von I 8 Io dann weiter aus²), dem falschen Kaisertum Napoleons das wahre Kaisertum, dem auf egoistischer Herrschsucht und totem Mechanismus beruhenden Universalsystem. Napoleons ein auf sittlichen und religiösen Ideen beruhendes Universalsystem entgegensetzen.3) Immer klarer werden uns dabei die geistigen Wurzeln und Voraussetzungen der heiligen Allianz und der Restaurationszeit. Ganz in deren Sinne ist es auch schon gedacht, daß die ständische Verfassungsform ein Band unter allen $\mathrm{Na}$ tionen, die sie besäßen, bilden müsse, und der katholisierende Romantiker hatte es dann leicht, in der Hierarchie noch ein weiteres universales Band unter den Nationen zu finden und zu fejern. So glaubte er nun den Nationalismus und Universalismus im schönsten Einklang.

1) a. a. $0.2,3 S_{3}$.

2) S. 350 .

$\left.{ }^{3}\right)$,So wollte Schlegel alsoc, sagt schon Gervinus, Gesch. des 19. Jahrhunderts I, $35 \mathrm{~S}$, richtig, , die eine Universalmonarchie, Massenherrschaft und Dynastie mit der andern bekämpfen.` 
"Durch das Kaisertum mit durchgehender ständischer Verfassung und die Hierarchie werden beide Forderungen der Absonderung und Verbindung der Nationen befriedigt. $\left.\ll^{1}\right)$

Aber diese Lösung war nur möglich auf Kosten der echten politischen Autonomie der Staaten und Nationen. Wir sahen es schon bei Novalis, daß sein christlicher Universalismus ihm das Verständnis verschloß für die großen Machtkämpfe der letzten Jahrhunderte, für die Entstehung der modernen Staaten. Genau so abfällig, wie er, urteilte auch Schlegel über sie. Die Herrschsucht der Staaten, meinte er, zerriß das Band zwischen den christlichen Nationen und zerstörte die nationalen Ständeverfassungen im Innern. Er wußte dabei schon sehr gut, daß die Anfänge dieser modernen Politik im Italien der Renaissance ${ }^{2}$ ) zu suchen waren. IVohl pries er die Kultur der Renaissance als einen Segen für Europa, aber ihre Politik sei ein schlimmes Vorbild für die europäischen Höfe gewesen, in dem sie den Krieg aller gegen alle hervorgerufen habe. $\left.{ }^{8}\right)$ So sank bei dieser romantisch-universalistischen Geschichtsauffassung die ganze politische Seite der neueren Geschichte in Schatten. Und selbst der Einheits- und Freiheitsdrang der Nationen mußte es sich da gefallen lassen, in Schranken gewiesen

1) Vorlesungen von I $804 / 62,387$. Auf die weiteren phantastischen Ausführungen seiner Idee (Verbindung des gelehrten Standes mit der Hierarchie, Schaffung eines Mittelgliedes zwischen Hierarchie und Adel durch einen geistlichen Ritterorden, aus dem dann, um die höchste weltliche und geistliche Macht zu vereinigen, der Papst-Kaiser gewählt werden könne, etc.) brauchen wir nicht einzugehen.

2) Das erst in den folgenden Jahrzebnten in Frankreich aufkommende Schlagwort \& Renaissance k kennt er natürlich noch nicht.

3) Vorlesungen von 18 ro S. 235: Karl V. und die österreichischen Herrscher dagegen seien svon dem viel höheren Begriff einer christlichen Republik, eines freien und friedlichen europäischen Staaten- und Völkervereins geleitet a worden. S. 272 u. 337. 
zu werden. Die älteren italienischen Patrioten aus der Zeit Dantes, die nur einen starken, Ruhm und Gerechtigkeit liebenden Kaiser wünschten, waren, so meint er, "auf einem richtigeren Wege als der falsche Patriotismus der späteren Florentiner, welche immer nur die Befreiung Italiens im Munde führen. «1)

So also war es mit dem Kampfe dieses Romantikers für nationale Freiheit gegen französische Universaldespotie beschaffen. Der Gedanke der Nation und ihrer Selbstbestimmung war hier umrankt und umsponnen von Ideen, die ihn zu ersticken drohten. So tief steckte das universale, weltbürgerliche Denken dieser Generation im Blute, daß es auch da wieder durchschlug, wo die weltbürgerliche Aufklärung durch den romantischen Sinn für das Nationale überwunden schien. IVir nennen weltbïrgerliche und universale Ideen, was zugleich, nach ihrem Inhalte betrachtet, ethische und religiöse Ideen waren. Ethischen und - cum grano salis - religiösen Inhalts war schon die weltbürgerliche Aufklärung gewesen. Ethisch und par excellence religiös war auch der romantische Universalismus. Das Ethos selbst war hier und dort grundverschieden, aber einen gemeinsamen Gegner hatten Aufklärer und Romantiker in dem nach ihrer Meinung unethischen Staate des ancien rígime - eigentlich aber im Machtstaate uberhaupt. Beide schalten das als blinde Herrschsucht, was im Wesen des Staates selbst begründet lag, was Ausfluß seiner Selbsterhaltung und Selbstbestimmung war. Sie moralisierten von außen her, statt das Wesen des Staates von innen heraus sich verständlich zu machen, sie machten es sich nicht klar, daß das Sittliche überhaupt neben seiner universalen auch eine individuell bestimmte Seite hat und daß von dieser Seite

1) a. a. O. S. 275 ff. Daß sein Urteil hier zugleich eine spezifisch österreichische Färbung hatte, braucht wohl kaum gesagt zu werden. 
her auch die scheinbare Unmoral des staatlichen Machtegoismus sittlich gerechtfertigt werden kann, denn unsittlich kann nicht sein, was aus der tiefsten individuellen Natur eines Wesens stammt.

Diese Betrachtung liegt von unserem Thema nicht so weit $a b$, wie es vielleicht scheinen mag. Die Idee des vollen, echten Nationalstaates konnte nur erobert werden, wenn zuvor die Autonomie des Staates iuberhaupt wieder erobert war und anerkannt wurde, wenn jenes Ranken- und Schlinggewächs universaler ethischer Ideen, das ihn zu uiberwuchern suchte, zerrissen wurde und die Eigenkraft des Staates sich den Denkern wieder mit ihren mächtigen Wurzeln enthüllte. 
Sechstes Kapitel.

\section{Fichte und die Idee des deutschen National- staates in den Jahren I806-I8r3.}

Friedrich Schlegels Beispiel zeigte, daß zu den universalen und nationalen Gedanken, die sich gegen das System Napoleons erhoben, auch früh schon sehr begrenzte und partikulare Interessen - denn das waren doch die des feudalen Ständestaates - hinzukamen. Um den weiteren Verlauf dieser Entwicklung, die zum Kreise Friedrich Wilhelms IV. hinführte, tiefer zu verstehen, müssen wir aber noch wiederholt zurückkehren zu den großen Hauptströmungen des neuen nationalen Denkens in Deutschland, die von jenem partikularen Interesse frei sind, dafür aber auch die Mischung universaler und nationaler Gedanken aufweisen. Von den mannigfachen Wegen, die hier aus der kosmopolitischen Welt des IS. Jahrhunderts in die nationalstaatliche des I9. Jahrhunderts herüberführen, sollen uns auch nicht die kürzesten, sondern mehr die komplizierten und verschlungenen interessieren. Will man die kürzesten Wege sehen, so muß man sich an einen Patrioten wie Ernst Moritz Arndt halten, der schon 1802 in seiner Schrift »Germanien und Europa « die Forderung der »Einheit des Volkes und des Staates «wenigstens ideell erhoben hat, um sich freilich mit Trauer zugleich zu sagen, daß Deutschland nur durch ganz ungeheuere Ereig. nisse zur »Einheit eines Volkes « werde gelangen 
können. $\left.{ }^{1}\right)$ Ihn führte ein natürlicher, bauernhafter Instinkt und ein warmes und volles Herz auf diesen Weg. Obgleich auch ihn das individualistische Humanitätsideal des ausgehenden I 8. Jahrhunderts innerlich ergriffen hatte, so protestierte er doch mit Kraft gegen den Hang seiner Zeitgenossen, es loszulösen von irdischer Schwere und Ballast. Nicht im Äther des reinen Denkens, sondern unten am Erdboden, in der vielgestaltigen Wirklichkeit des Völker- und Menschenlebens suchte er den Raum für die Übung der menschlichen Kräfte und fand so, wenn auch nur in unbestimmter Zulkunftsahnung, den nationalen Staat, und zwar einen solchen, der auf der innigen Durchdringung nicht nur der Staatsnation, sondern auch der Kulturnation mit dem Staate beruhen sollte. ${ }^{2}$ ) Es war auch kein bloßes, leeres, abstrakt ersonnenes Idealbild eines freien Volksstaates, was ihm vorschwebte. Es muß ihm hoch angerechnet werden, daß er ein, wenn auch nur dunkles und allgemeines Gefühl für die derben Realitäten des Staatslebens hatte. Aus irdischer Notwendigkeit, aus irdischen Elementen, sagte er, ist der Staat zusammengesetzt und kann nur durch diese erhalten werden; einfältige, irdische Gesetze gelten für ihn. IVie aber, warf er ein, »wenn diese irdischen Gesetze die ewigen wären, zur Gestaltung und Erhaltung der IVelt und der Staaten hinreichend?" Es käme ihm das

I) S. 420,426 .

2) Wie sich dabei das Doktrinäre und das Praktische in ihm vermischt, zeigen seine Ansichten über das Verhältnis von Sprachgrenzen und geographischen Grenzen der von ihm postulierten Nationalstaaten. ఎ Die erste Naturgrenze ist, daß jedes Land sein Meer bekomme, die zweite die Sprache (S. 385 ). Daraus folgert er aber z. B., daB Polen, falls es noch ein Staat wäre, die Deutschen in Preußen und Kurland beherrschen müßte, ,weil es seine Meergrenze dort besitzen müßte، (S. 355). Andererseits aber: ,Das Land, was jetzt Teutschland heißt, muß den Rhein allein besitzen und das Meer zu beiden Seiten des Rheins als seine Naturgrenze.c 
freilich, setzte er hinzu, nur wie eine Ahnung, wie ein Blitz in der Nacht. ${ }^{1}$ ) So stand er vor dem Wege, den Ranke später gegangen ist, das Ewige im Irdisch-Empirischen, die beherrschenden Mächte der Geschichte und des Staates nicht über ihnen, sondern in ihnen selbst zu suchen. Nicht ohne Bewegung wird man hier ein frühes Autleuchten des historisch-politischen Realismus bemerken, den das I9. Jahrhundert ausgebildet hat.

Arndt hatte allerdings nicht geistige Konzentration genug, war überhaupt nicht Denker genug, um diese fruchtbare Ahnung weiter zu verfolgen. Darum liegt sein unvergängliches Verdienst um die Entwicklung der Idee des Nationalstaates mehr auf praktischem als auf theoretischem Gebiete, - während es Fichte beschieden war, auf beiden Gebieten das Größte zu wirken, und zwar auf theoretischem, trotzdem, oder vielmehr eben weil er zuvor erst einen sehr viel schwierigeren Weg dafür zurückzulegen hatte als Arndt. Die größere und reichere Denkarbeit, die er erst zu leisten, die Hemmnisse, die er zu überwinden hatte, um der Idee des Nationalstaates sich zu nähern, sie sind es, die seine Gedanken darüber so interessant machen.

Arndt konnte deswegen so schnell und sicher zur Idee seines Nationalstaates gelangen, weil er viel von dem besaß, was Fichte nicht hatte oder, richtiger gesagt, nicht haben wollte, den erdenhaften Patriotismus, der an »der Erdscholle, dem Fluße, dem Berge « haftete. Auf diesen Schollenpatriotismus hat Fichte noch I 804 in seinen »Grundzügen des gegenwärtigen Zeitalters « hinabgesehen und dem »sonnenverwandten Geiste« vielmehr die Aufgabe zugewiesen, sich abzukehren von seinem Staate, wenn dieser gesunken sei, und sich dorthin zu wenden,

1) S. 260,263 . 
»wo Licht ist und Recht«.1) Der Weltbürger von I SO4 wurde dann der Redner an die deutsche Nation von I807. Oft hat man darin die große Sinneswandlung angestaunt und sie sich erklärt aus dem Drange der Not und der Schule der Erfahrung. ${ }^{2}$ ) Tiefere Kenner Fichtes aber haben schon das Verständnis dafür erschlossen, daß der Sprung so groß gar nicht war, daß das Weltbürgertum von I $\mathrm{SO}_{4}$ und der Nationalismus von I $\mathrm{So} 7$ ganz eng zusammenhängen. »Der Kosmopolitismus der Wissenschaftslehre und der Patriotismus der Reden sind ein und derselbe Begriff «, heißt es bei Kuno Fischer ${ }^{3}$ ), und Windelband urteilt: "Dieser Patriotismus der Reden an die deutsche Nation gleicht dem Kosmopolitismus wie

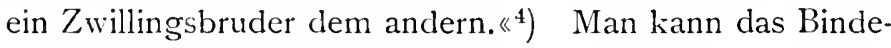
glied zwischen dem Ideal von $\mathrm{I} 804$ und dem von $1807 / 8$ noch erkennen in den Dialogen über den Patriotismus, deren erster schon im Sommer I 806 entstand. ${ }^{5}$ ) Er entwickelte hier die Meinung, »daß es gar keinen Kosmopolitismus überhaupt wirklich geben könne, sondern daß in der Wirklichkeit der Kosmopolitismus notwendig $\mathrm{Pa}$ triotismus werden müsse. « Aber das bedeutet eben, daß ihm beide Gesinnungen zusammenflossen, und sieht man auf die wesentlichen Elemente dessen, was er jetzt den wahren Patriotismus nannte, so begreift man das auch vollkommen. Denn er ist durchaus universal; sein Zweck ist der des Menschengeschlechtes iberhaupt, wie ihn Fichtes Wissenschaftslehre verstand. Ein auf dies Ziel gerichteter Wille muß und kann naturgemäß, so lehrt er, unmittelbar nur auf eine unmittelbare Umgebung

\footnotetext{
1) Sämtl. Werke 7, 212.

\$) Zeller, Vorträge und Abhandlungen I ${ }^{2}$, I 84 ; Lasson, Fichte im Verhältnis zu Kirche und Staat (IS63), S. 200.

3) Fichte, 3. Aufl. (1900), S. 627.

4) Fichtes Idee des deutschen Staates S. I1.

s) Nachgelassene Werke 3,223 ff.
} 
wirken, d. h. sein Wirkungskreis ist die Nation. Dadurch wird er Patriot, bleibt aber Kosmopolit, »indem der letzte Zweck aller Nationalbildung doch immer der ist, daß diese Bildung sich verbreite iber das (menschliche) Geschlecht. «1 Diese Nationalbildung ist also noch gar nichts Individuelles, ist noch keine Nationalbildung in geschichtlichem Sinne, sondern ist nichts mehr und nichts weniger als höchste menschliche Bildung uberhaupt. Die deutsche Nation ist es allerdings gewesen, die die Kraft hatte, sie zu erzeugen, aber sie ist darin, so dürfen wir Fichtes damalige Meinung deuten, nur gleichsam das auserwählte Volk, und ihr Kind ist der Menschen Sohn.

Von dieser Anschauungsweise aus waren dann konsequenterweise die deutschen Einzelstaaten in der Hauptsache nichts weiter als gegebene Wirkungskreise, innerhalb deren der einzelne Deutsche für die Ausbreitung der Nationalbildung, d. h. also der Menschheitsbildung zu arbeiten habe. ${ }^{2}$ ) In diesem Sinne erhob er nun wohl den Anspruch, deutsch-preußischer Patriot zu sein, aber tiefere Wurzeln gestand er dem preußischen Staate und überhaupt dem deutschen Einzelstaate nicht zu: „Die Absonderung der Preußen von den ubrigen Deutschen ist künstlich, gegründet auf willkürlich und durch das Ungefähr zustande gebrachte Einrichtungen; die Absonderung der Deutschen von den ibrigen europäischen Nationen ist begründet durch die Natur $\left.\ll^{3}\right)$, d. h. durch gemeinschaftliche Sprache und Nationalcharakter. Er

1) a. a. O. S. 229, ähnlich S. 233.

$\left.{ }^{2}\right)$, Der in der preußischen Staatseinheit lebende und wirkende Deutsche wird nur wollen und wirken, daß in dieser Staatseinheit zunächst und am allervollendetsten der deutsche Nationalcharakter hervortrete; daß derselbe ron hier aus sich verbreite über die verwandten deutschen Stämme und von diesen aus erst . . . allmählich iber die gesamte Menschheit.c a. a. O. S. 233.

s) a. a. O. S. 232 . 
hätte vom Boden dieser Meinung aus leicht zum Postulate eines einheitlichen deutschen Nationalstaates gelangen können, aber er hat anscheinend kein Bedürfnis nach ihm. Er ist zufrieden, wenn in dem Einzelstaate die neue Bildung zur Herrschaft gelangt, und will im ubrigen, aber als ein sekundäres Interesse, es wohl gelten lassen, daß der Preuße auch für die Integrität, die Rangstellung und den Wohlstand des preußischen Staates wirke. $\left.{ }^{1}\right)$ Jedenfalls wird, so betont er, der Deutsche zum Preußen nur hindurchgehend durch den Deutschen zum Preußen, "so wie nur der rechte wahre Deutsche ein rechter Preuße ist. « Es ist fast die genaue Umkehrung des kühlen Bismarckschen Wortes: daß »deutscher Patriotismus in der Regel, um tätig und wirksam zu werden, der Vermittlung dynastischer Anhänglichkeit bedarf. « ) Fichte wäre wohl zurückgeschaudert vor dieser Art von Patriotismus. »Dafür aber ist denn auch ", sagt Windelband ${ }^{3}$ ), » in der Tat das, was er wahren Patriotismus nennt, ohne allen Erdgeschmack, und sein Deutschland liegt in Utopien."

Wollte man den in diesen beiden Dialogen sich aussprechenden Nationalgedanken kleinlich interpreticren, so würde man sagen, daß er in erster Linie ein Vehikel für die Verbreitung Fichtescher Philosophie sein sollte, daß sein Bild der Nation im Grunde nichts anderes sei als der erweiterte Philosoph Fichte selbst. Er leiht, wie man edler sagen dürfte, sein eigen Fleisch und Bhut dem Bilde der Nation, und er konnte es nicht anders, wenn er den tiefsten Gedanken seiner Philosophie treu bleiben wollte. Auch hier galt es, daß das schöpferische Ich sich selbst das Nicht-Ich setzte. Das einzig wahrhaft Reale, sagte er damals ${ }^{4}$ ), ist das unmittelbare Leben selber, das

1) a. a. O. S. 233 .

2) Gedanken u. Erinnerungen r, 290.

3) a. a. O. S. 12 .

4) ล. ล. O. 257 . 
da lebt. Darum war von dem Wesen der deutschen Nation nur das ihm zugänglich, was in ihm selbst lebte. Der Gedanke der Menschheitsbildung, den er als ihr W'esen ansprach, umfaßte nicht das ganze Wesen der Nation, aber es war das echte, erstgeborene Kind der damaligen deutschen Nation. Und schließlich, wie sollte es bei ihm anders gewesen sein als bei Humboldt und bei Schiller: Unter dem weltbürgerlichen Nationalgedanken regte sich auch bei ihm viel mehr wirkliches und erdenhaftes Vaterlandsgefuihl, als er selbst Wort haben wollte. Als große, ihm selbst nicht bewußte Kraft nährte es in der Tiefe seine neuen Gedanken, aber diese selbst waren $z \mathrm{u}$ herrisch und spröde, um das zuzugestehen. "Selten vielleicht ist die Theorie so weit hinter der instinltiven Wirklichkeit zurückgeblieben. «1)

Und doch ist er nicht lange darauf der Wirklichkeit des politischen und selbst des nationalpolitischen Lebens so nahe gekommen, wie es nur entweder einer hohen praktischen Erfahrung oder einer unbefangenen geistigen Erfassung des Erfahrenen gelingen kann. Das geschah in seinem Aufsatze uber Machiavell, den er $\mathrm{I} S 07$ in Königsberg schrieb und veröffentlichte. ${ }^{2}$ )

Es ist eine ganz merkwürdige und, auf den ersten Blick wenigstens, aus dem Zusammenhange seiner Entwicklung herausfallende Schrift. Denn wir werden es noch sehen, daß die Gedanken seiner Dialoge uiber den Patriotismus, die uns eben beschäftigten, unmittelbar hinüberführen zu den Reden an die deutsche Nation und diese wiederum $\mathrm{zu}$ den politischen Ideen seines letzten Lebensjahres und daß auf allen diesen Stufen das Unpolitische den Primat behauptet vor dem Politischen.

1) Windelband, a. a. O. S. 12.

2) Nachgelassene Werke 3, 40 Iff. 
Hier aber spricht ein Mann, der Machiavellische Realpolitik tief verstanden hat, der einen harten, aber gesunden Kern in ihr findet und seiner Zeit wieder einpflanzen will. Bis zu gewissem Grade kann man das wohl begreifen aus dem Charakter Fichtes einerseits, aus dem Momente, wo er den Blick auf Machiavell richtete, andererseits. Ein großer Willensmensch sah hier dem andern ins Auge, ein radikaler Wahrheitssucher dem andern. Es war die Unerbittlichkeit und Selbstverständlichlieit, mit der Machiavell seinen Gedankenweg verfolgte und alles Störende bei Seite stieß, ohne es auch nur zu nennen, - was ihn so überaus vertraut anmutete. »Was da folgt, das sagt er und sieht sich nach allen Seiten um, was da noch folgt, und sagt es alles; besorgt einzig um die Richtigkeit seiner Schlüsse und durchaus keine andere Rücksicht kennend." Und der Moment, wo Fichte von ihm zu lernen geneigt war, konnte wohl auch den Gedanken eingeben, den Ranke dem Machiavell zugeschrieben hat, daß nämlich für den verzweifelten $\mathrm{Zu}$ stand seines Vaterlandes nur noch Gift als Heilmittel möglich sei. Denn Fichtes Schrift ist zugleich eine strenge Anklage wider die Weichlichkeit und Schlaffheit der jetzt so schwer gestraften preußischen Politik. Weiter aber - Fichte hat nie den Zwang als Mittel zur Freiheit verschmäht, hat in den »Reden " eine gewaltsame Nationalerzieliung, in den politischen Schriften von I 8 I 3 einen Zwingherrn zur Deutschheit verlangt - dem Despoten in ihm konnte das System des rationellen Despotismus, das Machiavell entwarf, imponieren.

Aber damit ist immer noch nicht der letzte und innerste Grund seiner Neigung für Machiavell und der Grund, weshalb es keine vollständige und dauernde Neigung war, aufgedeckt. Wir meinen, er liegt in der ungeheuren Spannung, die zwischen dem Fichteschen Lebensideal und der Wirklichkeit bestand. Sein Ziel war die radikale 
Vergeistigung und Versittlichung der Menschen, ihr Zustand aber, den er - kurz vor der Epoche, wo seine nationalpolitischen Ideen einsetzen - vorzufinden glaubte, war - so entwickelte er es in den "Grundzügen des gegenwärtigen Zeitalters " $\mathrm{I} \mathrm{SO}_{4}$ - der der vollendeten Suindhaftigkeit. So leuchtend ihm das Endziel vorschwebte, so abstoßend war ihm der Anblick der ihn umgebenden Menschheit. Eben weil er ein so gliihender Zulsunftsoptimist war, war er ein so strenger Pessimist gegenüber seiner Zeit. Der Idealist, bemerkt Schiller ${ }^{1}$ ), »denkt von der Menschheit so groß, daß er darüber in Gefahr lommt, die Menschen zu verachten." Es ist vielleicht eine ähnliche Kontrasterscheinung, wie zwischen dem iibersinnlichen Ideale der mittelalterlichen Kirche und ihrer pessimistischen Beurteilung des wirklichen Menschentreibens, und so wie diese konnte auch er die Konsequenz daraus ziehen, daß man die Menschen als böse behandeln, daß man sie beherrschen und zwingen müsse. Ausdruicklich billigte er den Satz Machiavells: "Jedweder, der sich eine Republik oder überhaupt einen Staat errichtet und demselben Gesetze gibt, muß voraussetzen, daß alle Menschen bösartig sind. $\aleph^{2}$ ) Um aber dieses trostlose Axiom mit seinem Glauben an die Bestimmung der Menschleit vereinigen zu können, konstruierte er weiter: Es komme dabei gar nicht darauf an, ob die Menschen wirklich so beschaffen seien; vielmehr stuinde es so, daß der Staat als eine Zwangsanstalt sie notwendig so voraussetze und nur diese Voraussetzung das Dasein des Staates begründe. Und diese selbe Voraussetzung müsse man nun auch dem Verhältnisse der Staaten untereinander zugrunde legen und auch hier annehmen, daß jeder jede Gelegenheit ergreifen werde,

1) Über naive u. sentiment. Dichtung.

2) a. a. O. S. 420 .

Meinecke, Weltbürgertum und Nationalstaat. 2. Aufl. 
um dem andern zu schaden, wenn er seinen Vorteil darin zu finden glaube. Denn immer sei es wenigstens doch möglich, daß es sich so verhalte. Nachdem aber einmal Fichte unter dem Eindruck der Zeitereignisse in diesen Gedankengang sich hineingedacht hatte, ging er mit der ganzen Kraft und Unerschrockenheit seines Geistes in ihm weiter. Die Sicherheit des Staates gründet sich, fuhr er fort, nicht nur auf sein eigenes Territorium, sondern »überhaupt auf alles, wohin du deinen Einfluß erstrecken und womit du in der Folge dich vergrößern kannst. «1)

So sah er mit einem Male mit großer Hellsicht das europäische Staatenleben in seiner wahren Gestalt, das Bild der lebendig sich regenden und dehnenden Staaten und Nationen. Er vergaß in diesem Augenblicke der pessimistischen Voraussetzungen, von denen er ausgegangen war, und folgte dem stärkeren Drange, den Simn und die Vernunft dieses Treibens der anscheinend nur egoistischen Kräfte zu finden und es mit seinen höchsten menschheitlichen Idealen in Ubereinstimmung zu bringen: „Überdies will jede Nation das ihr eigentiimliche Gute so weit verbreiten als sie irgend kann und soviel an ihr liegt, das ganze Menschengeschlecht sich einverleiben, zufolge eines von Gott den Menschen eingepflanzten Triebes, auf welchem die Gemeinschaft der Völker, ihre gegenseitige Reibung aneinander und ihre Fortbildung beruht. *

Das ist eines der bedeutendsten und tiefsten Worte aus dieser Zeit, es bringt das Wesen der alten staatlichen Machtkämpfe und der neuen nationalen Volkstriebe in Harmonie mit den weltbuirgerlichen und universalistischen Idealen des bisherigen deutschen Geistes. Von hier aus eröffnet sich eine Perspelitive unmittelbar hinüber zu der Rankischen Geschichtsauffassung. Der

1) a. a. O. S. 423 . 
entscheidende Schritt war hier getan, der Machttrieb des Staates als natürlicher und heilsamer Lebenstrieb anerkannt und in den Zusammenhang einer sittlichen Weltanschauung gestellt. Was Machiavell gelehrt und was Antimachiavell einst dagegen gesagt hatte, war hier teils überwunden, teils gesteigert und miteinander versöhnt. Das war nur möglich, weil jetzt zu Staat und Menschheit der neue Begriff der Nation hinzugeliommen war und nun auch über den Staat ein neues Licht verbreitete. Wenn der Staat nicht bloß durch den Willen des Fürsten, auch nicht bloß durch das kalte Interesse seiner eigenen Selbsterhaltung getrieben, sondern von einer lebendigen Volksgemeinschaft getragen wurde, dann wurde auch seine Pleonexie geadelt und versittlicht. Lassen wir Fichtes Hauptsätze selbst sprechen ${ }^{1}$ ): 》Die Völker sind ja nicht ein Eigentum der Fürsten, so daß er deren WVohl, deren Selbständigkeit, deren Würde, deren Bestimmung in einem Ganzen des Menschengeschlechts als seine Privatsache betrachten könne . . . . der Fürst gehört seiner Nation ebenso ganz und vollständig an, als sie ihm angehört; ihre ganze Bestimmung im ewigen Rate der Gottheit ist in seine Hände niedergelegt, und er ist dafür verantwortlich.« Er ist in seinem Privatleben an die allgemeinen Moralgesetze, in dem Verhältnisse zu seinem Volke an Gesetz und Recht gebunden, in dem Verhältnisse aber zu anderen Staaten "gibt es weder Gesetz noch Recht, außer dem Rechte des Stärkeren, und dieses Verhältnis legt die göttlichen Majestätsrechte des Schicksals und der Veltregierung, auf die Verantwortung des Fürsten, nieder in seine Hände und erhebt ihn über die Gebote der individuellen Moral in eine höhere sittliche Ordnung, deren materieller Inhalt enthalten ist in den Worten: Salus et decus populi

1) a. a. O. S. 426 . 
suprema lex esto." Es war noch nicht alles, was über das Wesen des neuen werdenden Nationalstaates gesagt werden konnte, aber ein großer Hauptzug seines Wesens wurde festgestellt: Sein Recht und seine Pflicht zur kraftvollen, riicksichtslosen Selbsterhaltung und zur Selbstbestimmung dessen, was seiner Selbsterhaltung diente.

Mit dieser »ernsteren und kräftigeren Ansicht der Regierungskunst " erreichte damals Fichtes Geist auf seiner Bahn den Punlit der größten Erdennähe, der ihm möglich war. Wer nach diesem Aufsatz über Machiavell die »Reden an die deutsche Nation « liest, spürt sich wohl in manchem noch in derselben Richtung weitergeführt, um schließlich doch mit einem Male in einer ganz anderen Welt sich wiederzufinden.

Richten wir unser Augenmerk zunächst auf diejenigen Gedanken der »Reden «, die in der Linie seiner Machiavellbetrachtungen liegen, also einen Fortschritt seines nationalen und politischen Denkens gegeniber den »Dialogen « bedeuten. Man spürt einen solchen zunächst darin, daß er die Fäden zwischen Nation und Staat, - d. h. deutscher Nation und deutschem Einzelstaate - dichter schlingt. In den »Dialogen " hatte er für das Wirken im deutschen Einzelstaate, d. h. in Preußen, zwei Grade unterschieden, das Wirken in deutsch-preußischem, d. h. in letzter Linie menschheitlichem Sinne, und das Wirken in rein preußischem Sinne, das auf ein untergeordnetes Ziel ging. Von dieser Wertabstufung des Wirkens im Staate und damit auch der staatlichen Zwecke ist in den »Reden « nur noch wenig zu spirren. ${ }^{1}$ ) Die Kreise des Einzelstaates und der Nation sind jetzt kon-

1) Etwa darin, daß̧ er (Sämtl. Werke $7,3^{84}$ u. 386 ) den s nächsten ‘ und sgewöhnlichen Zweck des Staates (Erhaltung des inneren Friedens, des Figentums, der persönlichen Freiheit, des Lebens und des Wohlseins aller) von scinem shöheren Zwecks unterscheidet. 
zentrisch zusammengeriickt. Der Staat, sagt er jetzt ${ }^{1}$ ), hat seine bewaffnete Macht 》allein und in keiner andern Absicht " als für denjenigen $\mathrm{Zweck}$, den ihm die Vaterlandsliebe setzt. So scheint er denn wirklich die in dem Machiavellaufsatz ergriffene Idee des Nationalstaates festzuhalten, dessen Macht ausschließlich in Dienste der Nation steht. Und das ungeschichtliche rationale Staatsideal der Aufklärung scheint überwunden zu sein, wenn wir die Worte lesen ${ }^{2}$ ): »Der vernunftgemäße Staat läßt sich nicht durch kiinstliche Vorkehrungen aus jedem vorhandenen Material autbauen, sondern die Nation muß zı demselben erst gebildet und herauferzogen werden. « »Der Staat der Zukunft «, so formuliert Windelband ${ }^{3}$ ) den Grundgedanken seiner » Reden《, »kann nur der Nationalstaat sein, insonderheit der deutsche Nationalstaat. Das ist, so weit es die Philosophie formulieren konnte, das Programm der politischen Geschichte des 19. Jahrhunderts, in der die Konsolidierung der nationalen Staatengebilde das Hauptinteresse ausmacht und deren sachlicher Mittelpunkt, deren beherrschendes Ereignis zweifellos die Grïndung des Deutschen Reiches ist. "Sagen wir noch etwas genauer, es war dies Programm, soweit es die Fichtesche Philosophie formulieren konnte, und achten wir schon hier auf die Reste des Alten, die in dieser Konzeption des Nationalstaates noch steclien.

Bei näherer Prüfung jener oben angefïhrten Worte sieht man, daß er den »vollkommenen Staat ", den vvernunftgemäßen "Staat an sich ja noch nicht aufgegeben hat. Er warf nur den Aufliärern vor, daß sie eben zu bauen versucht hätten ohne die notwendige Grundlage einer dafür geeigneten Nation. Daß er das neue Mittel der Nation jetzt einschob, war an sich ein immenser

1) 7, 386 .

2) 7,353 .

3) a. a. O. S. S. 
Fortschritt des Denkens. Aber weil er das alte Ziel des Vernunftstaates nicht aufgab, konnte auch das neue Mittel der Nation nicht die wirkliche Nation, sondern auch nur eine Art Vernunftnation sein: \$Nur diejenige Nation, welche zuvörderst die Aufgabe der Erziehung zum vollkommenen Menschen durch die wirkliche Ausübung gelöst haben wird, wird sodann auch jene des vollkommenen Staates lösen. ${ }^{1}$ )

So bildete er das eben ergriffene Neue sogleich wieder zurück in das Alte. Dasselbe kann man beobachten an der Art, wie er das im Machiavellaufsatz aufgestellte Prinzip der Autonomie von Staat und Nation in den »Reden" weiter entwickelt. Als ein wirklicher Staat, heißt es hier stolz und hoch, muß der Staat »ursprünglich und selbständig sich bewegen und etwas beschließen können. $\ll^{2}$ ) Allenthalben, heißt es ein ander$\mathrm{mal}^{3}$ ), wo eine besondere Sprache angetroffen wird, ist auch eine besondere Nation vorhanden, »die das Recht hat, selbständig ihre Angelegenheiten zu besorgen und sich selber zu regieren." Sprache und Literatur eines Volkes, so wird in demselben Zusammenhange dargetan, würden entarten durch den Verlust politischer Selbständigkeit. So erkannte er also, wird man freudig konstatieren, den Zusammenhang nationaler Kultur und politischer Selbständigkeit. Nur beachte man auch das eigenartige Hauptmotiv dafür. ${ }^{4}$ ) $\gg$ Was kann denn das für eine Literatur sein, die Literatur eines Volkes ohne politische Selbständigkeit? Was will denn der vernünftige Schriftsteller und was kann er wollen? Nichts anderes, denn eingreifen in das allgemeine und öffentliche Leben und dasselbe nach seinem Bilde gestalten und umschaffen ;

1) 7, 354 .

2) 7,432 .

3) 7,453 .

4) 7,452 . 
er will denken für die Regierenden, »er kann deswegen nur in einer solchen Sprache schreiben, in der regiert wird, in der eines Volkes, das einen selbständigen Staat ausmacht. "Wohl klingt auch das modern nationalstaatlich, denn wir können uns keinen echten modernen Nationalstaat denken ohne eine große und freie nationalpolitische Literatur. Aber was Fichte im Auge hat, ist nicht eigentlich das, was wir unter nationalpolitischer Literatur verstehen, sondern das, was die Philosophen des I 8 . Jahrhunderts trieben, wenn sie sich mit dem Staate befaßten: Aufstellung von Normen für die Regierenden, Regierung der Regierenden durch die Philosophen, um, wir lassen Fichte selbst wieder reden, »das allgemeine Leben und die ganze menschliche Ordnung der Dinge zu gestalten. ${ }^{1}$ ) Dazu also braucht und verlangt er die politische Selbständigkeit der Nation. Sie ist ihm die Voraussetzung für die Herrschaft der Wissenschaft im Staate, - der nationalen Wissenschaft, wird man vielleicht sagen, aber wie wenig würde das den tieferen Sinn dessen, was Fichte eigentlich unter Wissenschaft verstand, treffen. Es ging hinaus über die Sphäre des Nationalen, wie über die engere Sphäre der Wissenschaft überhaupt. Es bedeutete ihm »Umwandlung des IVissens, der Vernunft, der Weisheit in das Leben selbst und in dessen höchsten Quell und Antrieb. $\ll^{2}$ )

Von erhabenstem Punkte her also, aber von einem durchaus unpolitischen und übernationalen her, hat er die Forderung der politischen Selbständigkeit begründet. Ihre eigentlich politische Seite, die er in dem Machiavellaufsatze schon erfaßt hatte, hat er nicht weiter entwickelt, weil ihn das Wesen des Machtstaates auf die Dauer nicht fesseln konnte. Zum Wesen des Macht-

1) Vgl. auch 7,492 .

2) Rede an seine Zuhörer vom 19. Februar IS $_{3}$. Sämtl. Werke 4,604 . 
staates gehört, wie wir oben sagten, die lebendige Bewegung nach außen hin, Berührung mit den Nachbarn in Freundschaft oder Feindschaft und eine gewisse Pleonexie. Hierzu mit in erster Linie gebraucht er seine Selbständigkeit und Unablängigkeit. Nach Fichte soll er sie jetzt gerade umgekehrt dazu gebrauchen, sich abzuschließen von den Machtkämpfen der übrigen Staaten. ${ }^{1}$ ) Sein »geschlossener Handelsstaat « liegt ihm immer noch im Sinne. Wozu bedarf der Deutsche der Freiheit der Meere? 》O möchte doch nur den Deutschen sein günstiges Geschick ebenso vor dem mittelbaren Anteile an der Beute der andern Welten bewahrt haben, wie es ihn vor dem unmittelbaren bewahrte. ${ }^{2}$ ) Und er schneidet aller Realpolitik die Wurzel ab, wenn er am Schlusse die große Forderung erhebt: »Das bunte und verworrene Gemisch der sinnlichen und geistigen Antriebe durcheinander soll überhaupt der Weltherrschaft entsetzt werden, und der Geist allein, rein und ausgezogen von allen sinnlichen Antrieben, soll an das Ruder der menschlichen Angelegenheiten treten. $\left.\ll^{3}\right)$ Alle übrigen Feuer der Welt sollen gleichsam ausgelöscht werden, damit nur dic eine Flamme seines ethischen Ideals, gehütet von der deutschen Nation, als dem Urvolke, dem auserwählten Volke übrig bleibe. Er wünscht ihm politische Selbständigkeit und Macht für den Zweck der Verwirklichung dieses Ideals. Wie seine Plilosophie schon immer eine

1) Auf die Unterscheidung zwischen naturgemäßer und unnatür. licher Eroberung, die er in der I3. Rede macht, brauchen wir nicht einzugehen, da sie zu kraß ist, um für reale Politrk etwas zu bedeuten. Nur eben als unsichere Vermutung mag man es aussprechen, dati der Wechsel der Stimmung gegenüber der des Machiavellaufsatzes (in dem doch gerade eine energische Machtpolitik verlangt wurde), auf die Ab. wandlung der politischen Situation zurückgeht: Damals der frische Eindruck des Krieges, jetzt clie Resignation der Geschlagenen.

\footnotetext{
2) 7,466

3) $7,+96$.
} 
Umwandlung der Individuen in Geistesmenschen verlangt hatte, so verlangt er jetzt eine radikale Umwandlung und Vergeistigung des Staaten- und Völkerlebens.

Das war also die Funktion, die er dem deutschen Staate zuwies. Hat man sich diesen durch alles hindurchgehenden Grundgedanken einmal klar gemacht, so wird man nicht mehr daran denken, den Nationalstaat seiner »Reden « für ein politisches Gebilde zu halten und wird vielleicht gar eine weitere Untersuchung seiner politischen Ideen für überflüssig halten. Fichtesche Ideale und Illusionen aber bleiben unter allen Umständen denk- und untersuchenswürdig auch in ihren Verzweigungen und Konsequenzen, und für unsere Absicht, die Invasion der unpolitischen Ideen in das politische Leben Deutschlands zu veranschaulichen, gibt es unter den reinen Denkern kein bedeutenderes Beispiel als das Fichtesche. Fragen wir also weiter, wie er über Form und Verfassung des deutschen Staates dachte. Wie stand er jetzt vor allem zu der Frage, ob Einheitsstaat, Bundesstaat oder Staatenbund?

Er erwog in der neunten Rede den Fall, daß ein deutscher Einzelstaat hätte darauf ausgehen können, die ganze deutsche Nation unter seiner Regierung zu vereinigen und statt der hergebrachten Völkerrepublik Alleinherrschaft einzuführen. "Jeder Edle über die ganze Oberfläche des gemeinsamen Bodens hinweg hätte sich dagegen stemmen muissen, ${ }^{1}$ ) - nicht etwa aus irgendwelchen dynastischen oder partikularistischen Skrupeln, sondern deswegen, weil er in dem, was wir Viel- und Kleinstaaterei und was er »republikanische Verfassung « nannte, die vorzüglichste Quelle deutscher Bildung und das erste Sicherungsmittel ihrer Eigentimlichkeit erblickte, und weil er fürchtete, daß die Allein- 
herrschaft eines Gewalthabers irgend einen Sprof ursprünglicher Bildung in Deutschland für die Dauer seines Lebens hätte zerdrücken können. Hoffnungslos und ganz unerträglich erscheint ihm ja eine solche Alleinherrschaft nicht, da doch immer Deutsche über Deutsche würden regiert haben, und die deutsche Nation im Dasein verblieben sein würde, aber wünschenswert dünkt ihm der monarchische Einheitsstaat für Deutschland doch ganz und gar nicht. Einen Einheitsstaat in republikanischer Form will er, wie aus seinen Worten klar hervorgeht, wohl schon gelten lassen ${ }^{1}$ ), aber er legt, wie man stark betonen muß, auf die Form des Einheitsstaates überhaupt keinen entscheidenden Wert. Er sagt vielmehr von dem »deutschen Staate" schlechthin: „Ob er nun als einer oder mehrere erscheine, tut nichts zur Sache, in der Tat ist es dennoch Einer." Es ist klar, daß er hier grundsätzlich die äußere Erscheinung des Staatslebens von seinem inneren Wesen unterscheidet. Der eine deutsche Staat kann sich in der Form des Einheitsstaates, kann sich aber auch in der Form der Vielstaaterei zeigen. Das Wesentliche ist vielmehr, so lauten seine unmittelbar vorhergehenden Worte, »daß die deutsche Nationalliebe selbst an dem Ruder des deutschen Staates entweder sitze oder doch mit ihrem Einflusse dahin gelangen könne. ${ }^{2}$ ) Man sieht, daß hierbei auch der deutsche Einzelstaat in seinen Daseinsbedingungen

1) $7,397:$,... . so wäre, falls die vorausgesetzte Einheit der Regierung nicht etwa selbst die republikanische, sondern die monarchische Form getragen hätte, .. es allerdings ein großes Mißgeschick .. gewesen.،

2) 7,397, vgl, auch $7,384,396,428$. Man könnte zwar vielleicht geltend machen, daß er in der 1 . Rede $(7,266)$ und in der Inhaltsangabe zur 13. Rede $(7,464)$ die Vielstaaterei Deutschlands beklagt und von ihrem abgesonderten Dasein sagt, daß es sgegen alle Natur und Vernunft strittec. Wir dürfen aber nach den Ausführungen der 9. Rede annehmen, daß er die Einheit nicht in der äußeren Form 
nicht allzu gut wegkommt. Er rühmt wohl die deutsche Vielstaaterei als Quelle deutscher Bildung, aber die Anhänglichkeit an den Einzelstaat, den territorial-dynastischen Patriotismus läßt er auch jetzt nicht gelten. Einzelstaaten diurfen wohl sein, aber die tieferen Wurzeln in den Gesinnungen ihrer Angehörigen gönnt er ihnen nicht.

Es brauchte weiter, so können wir aus seinen eigenen Prämissen schließen, dann nicht einmal ein äußeres föderatives, sei es staatenbündisches, sei es bundesstaatliches Band zwischen den Einzelstaaten da zu sein, wenn nur das eine, was not tat, da war, nämlich daß der nationale Geist im deutschen Staatsleben entweder herrsche oder zur Herrschaft gelangen könne. So konnte er auch den $\mathrm{Zu}-$ stand Deutschlands vor I 806 ganz erträglich finden, wo Staat und Nation, »wie nur noch bei den Griechen der alten Zeit, " äußerlich voneinander gesondert, aber, so meinte er wenigstens, in Harmonie und Eintracht miteinander gelebt hätten. So konnte er urteilen, daß jeder Verständige die Fortdauer des bisherigen Zustandes hätte wünschen müssen. ${ }^{1}$ ) Man mag einwenden, daß or hier nicht an das Wünschenswerte, sondern an das Erträgliche im Gegensatze zur Unerträglichkeit des momentanen Zustandes denke und daß er hier nur Minimalforderungen für das deutsche Staatsleben stelle. Man wird ferner vielleicht sagen, daß es heikel gewesen sei, damals mehr zu verlangen. Aber Fichte war ein viel zu unerschrockener Denker, um seine prinzipiellen Anschauungen nicht wenigstens durchschimmern zu lassen, und immer

sucht und daß er demnach nicht die Form, sondern den Geist der Vielstaaterei, des sabgesonderten Daseinss verurteilte. Vgl. auch die I1. Rede $(7,437)$ : Wohl uns hierbei, daß es noch verschiedene und voneinander abgetrennte deutsche Staaten gibt. Was so oft zu unserem Nachteile gefuhrt hat, kann bei dieser wichtigen Nationalangelegenheit (der Erziehung) vielleicht $z \mathfrak{u}$ unserem Vorteile dienen.

1) 7, 392, $396 \mathrm{f}$. 
bleibt es also charakteristisch, daß er auf ein solches Minimum herabgehen konnte. Er konnte es, weil ihm die Form politischer Gliederung verhältnismäßig gleichgültig war, weil ihm alles auf die Einheit des Geistes im deutschen Staatsleben ankam. Diese ideelle Einheit von Staat und Nation war als solche so hoch gespannt, wie möglich, aber auch sie »lag in Utopien ", und nur eine prästabilierte Harmonie hätte es fertig bringen können, daß sie Wirklichkeit geworden und daß alle Einzelstaaten nur eines Geistes gewesen wären. Sein deutscher Staat, wie sein Staat iiberhaupt, gehorcht nicht seinen eigentümlichen Lebensbedingungen, sondern empfängt sein Gesetz, so will er es jetzt, von dem nationalen Geiste, aber dieser nationale Geist ist und soll, auch nach der Auffassung der $\gg$ Reden«, nur sein der wahrhaft menschliche Geist, das höchste und reinste Kulturideal. Staat und Nation sind hier wohl schon aufs innigste verbunden, aber nur unter dem herrschenden Primat universaler Ideen.

In diesem Universalismus begegneten sich, wie wir sahen, Auflklärung, klassischer Idealismus und Romantik. Die Romantiker hielten, wie wir bisher schon gesehen haben und auch noch weiter sehen werden, den Zug zum Universalen auch dann fest, als sie tiefer in die Welt des Nationalen eintauchten, und wie Fichte vielleicht schon bei seiner Hinwendung zur Nation unter romantischen Einfliissen mitgestanden hat, so berührt er sich auch mit dem spezifisch romantischen Universalismus einmal so nahe, daß es schwer ist, hier nicht an eine unmittelbare Einwirkung zu denken. Wir erinnern uns, mit welcher Begeisterung Novalis und Friedrich Schlegel von dem Zustande des europäischen Staatenlebens vor dem Aufkommen der großen Einzelmächte sprachen, wie sie die Einheit der Christenheit im Mittelalter rühmten und ihre Zerspaltung durch die Machtliämpfe der neueren 
Jahrhunderte beklagten. Man höre nun Fichte: Indem er die Lehre vom europäischen Gleichgewicht bekämpft, fährt er fort: "Wäre das christliche Europa eins geblieben, wie es sollte und wie es ursprünglich war, so hätte man nie Veranlassung gehabt, einen solchen Gedanken zu erzeugen; das eine ruht auf sich selbst und trägt sich selbst und zerteilt sich nicht in streitende Kräfte, die miteinander in ein Gleichgewicht gebracht werden müßten; nur für das unrechtlich gewordene und zerteilte Europa erhielt jener Gedanke eine notdürftige Bedeutung. "1) Gegenüber der Differenzierung Europas spielt er so den Universalisten, aber freilich gegeniiber dem Gedanken der Universalmonarchie, der damals schreckhaft nahegerückt wurde, spielt er gleich darauf wieder die ldee der Nation aus. Hassenswürdig und vernunftlos war ihm das Traumbild der Universalmonarchie. "Die geistige Natur vermochte das Wesen der Menschheit nur in höchst mannigfaltigen Abstufungen an einzelnen und an der Einzelheit im großen und ganzen, an Völkern, darzustellen. Nur wie jedes dieser letzten, sich selbst überlassen, seiner Eigenheit gemäß . . sich entwickelt und gestaltet, tritt die Erscheinung der Gottheit in ihrem eigentlichen Spiegel heraus. $\left.\ll^{2}\right)$ So wollte er also doch wieder die Völker $»$ sich

2) 7,464. Ähnlich auch schon in den, Grundzügen des gegenwärtigen Zeitalters von $1 \mathrm{SO} 4$ (7, 197 1. 200), wo er mit ganz romantischer Polemik gegen diejenigen, die sich nicht in den Geist anderer Zeiten hineinzudenken vermögen, die Kreuzzüge rühmt als die sewig denkwürdige Kraftäußerung eines christlichen Ganzen, völlig unabhängig von der Einzelheit der Staaten, in die es zerfallen war.. Fester (Rousseau u. d. deutsche Geschichtsphilosophie, S. I4I) betont mit Recht, daß Fichte der erste deutsche Philosoph ist, der dem Mittelalter wieder gerecht wurde und daß dies um so mehr ins Gewicht falle, als gerade er den reaktionären, katholisierenden Bestrebungen der Romantiker ganz und gar fern gestanden habe; aber das schließt eine Einwirkung der Romantiker auf ihn in obigen Punkten natürlich nicht aus

2) 7,467 . 
selbst überlassen «. Der Widerspruch zu dem kurz vorher Gesagten wiurde unerträglich sein, wenn man sich nicht wieder klar machte, daß es ihm immer nur auf den Geist, nicht auf die äußeren staatlichen Formen des Völkerlebens ankommt. Ihm schwebte als wünschenswertes Ideal offenbar ein Zustand Europas vor, der Einheit und Brüderlichkeit im ganzen mit selbständiger Entwicklung der einzelnen Nationen vereinigte; aber freilich lionnte dann von seinen Voraussetzungen aus die Selbständigkeit und Autonomie der Nationen und Nationalstaaten keine wirklich und wahrhaft politische sein. Sie war beschränlit und bestimmt durch die gemeinsamen menschheitlichen Aufgaben.

Die "Reden an die deutsche Nation " enthalten, wie man weiß, noch nicht das letzte Wort, was Fichte uiber Nation und nationalen Staat gesprochen hat. Die Lebenserfahrungen der folgenden Jahre konnten, so wird man erwarten, ihn tiefer hineinführen in diese neue Welt, die er fast wie Kolumbus entdeckt hatte, ohne zu ahnen, daß es eine ganz neue Welt war. Wir haben aus seinem letzten Lebensjahre, das mit dem großen Jahre I 8 I 3 zusammenfiel, seine Staatslehre und vor allem den Entwurf zu einer politischen Schrift vom Frihjahr i 8 I3, den man wohl als sein nationalpolitisches Testament bezeichnen darf. Hier, so rief mit einem gewissen Jubel Heinrich v. Treitschke im Jahre I 862 , tritt uns Fichte entgegen »als der erste namhafte Verkündiger jener Ideen, welche heute Deutschlands nationale Partei bewegen . . . . Hier zuerst verliundet ein bedeutender Mann mit einiger Bestimmtheit den Plan, den König von Preußen als einen „Zwingherrn zur Deutschheit « an die Spitze des gesamten Vaterlandes zu stellen, und wenn er auch, wie Treitschke zugibt, als höchstes Ziel immer noch die »Republik der Deutschen olme Fürsten und Erbadel " vor Augen ge- 
habt habe, so habe er doch gleichzeitig begriffen, daß dieses Ziel in weiter Ferne liege. ${ }^{1}$ )

Für die Frage, die wir uns hier stellen, würde es an sich von seliundärer Bedeutung sein können, ob Fichte sich damals fuir die republikanische oder die monarchische Einheit Deutschlands entschied, denn wir wollen ja wissen, wie nahe Fichte der Idee des modernen Nationalstaates uberhaupt gekommen ist, und dieser konnte sowohl republikanisch als monarchisch gedacht sein. Immer aber bedeutete jeder Schritt weiter zum Nationalstaat hin für Fichte zugleich einen Schritt weiter hinein in die wirkliche politische Welt und hinaus aus der Welt abstrakter Vernunftionstruktionen, und es würde ein hoher Beweis seines gewachsenen politischen Sinnes sein, wenn er in der Tat damals seine republikanischen Ideale vertagt und das preußisch-deutsche Kaisertum als das Ziel der Gegenwart verkündet hätte. Freilich wird man diese fragmentarischen Aufzeichnungen, diese Federproben und Skizzen von Gedankengängen, die einander zum Teil noch widersprechen, nur mit Vorsicht als Quelle für Fichtes endguiltige Uberzeugungen benutzen können. Immerhin gewinnen scine Gedanken, die zuerst sehr pessimistisch und zweifelvoll über die Zukunft der Deutschen anheben, im Verlaufe der Aufzeichnung an Bestimmtheit und Wucht, und während er anfangs auch von Preußen nichts für die deutsche Nation zu erwarten scheint ${ }^{2}$, so hellt sich doch sein Auge bald auf $z u$ der Erkenntnis, daß in Preußen schon ein »eigentlich deutscher Staat " da sei, der durch den Geist seiner bisherigen Geschichte gezwungen sei, »fortzuschreiten in der Freiheit, in den Schritten zum Reiche; nur so kann es fortexistieren. Sonst geht es zugrunde. $\left.\ll^{8}\right)$ Das war ein großes

1) Histor. u. polit. Aufsätze, I, I 36 .

2) 7, 549 .

s) 7,554 . 
Wort, in dem sich der alte Fichtesche Hang zum apodiktischen Postulate aufs gluicklichste verband mit tiefer realer Einsicht, aber man darf nicht übersehen, daß sein apriorisches Postulat doch immer noch stärker war als seine empirische Einsicht. Ein preußisch-deutsches Kaisertum ist ihm, wenn wir die dahinter folgenden Ausführungen damit vergleichen, doch nur ein vorübergehendes Mittel zum Zwecke, und das Ziel der Republik, das er das eine $\mathrm{Mal}$ in weiter Ferne nur sieht ${ }^{\mathrm{T}}$ ), riickt $\mathrm{ihm}$ im weiteren Fortgange seiner Gedanken und wohlgemerkt bei weiterem Anschwellen seiner Hoffnungsstimmung wieder so nahe, daß er die Erblichkeit des deutschen Kaisertums oder, wie er sich ausdrückt, einer deutschen Zwingherrschaft durchaus verwirft. „Also her einen Zwingherrn zur Deutschheit! Wer es sei; mache sich unser König dieses Verdienst! Nach seinem Tode einen Senat, - da kann es sogleich im Gange sein. " Dieses "es" aber ist die Erziehung zur Freiheit, die er dem Zwingherrn als erste Pflicht zuweist. Der Weg zur Republik soll also, so diurfen wir interpretieren, unmittelbar nach dem Tode des preußisch-deutschen Kaisers oder Zwingherrn beschritten werden. ${ }^{2}$ )

Ist nun aber die deutsche Republik, die er will, als wirlilicher deutscher Nationalstaat in unserem Sinne gedacht? D. h. findet in ihr, wollen wir noch genauer fragen, die konkrete Nation den politischen Ausdruck

1) 7,553 .

2) Die Stellen über das preußische Kaiser- bezw. Zwingherrentum sind 7,554 u. 7,565 . Ihnen folgen $7,570 \mathrm{f}$. Äußerungen, die ihnen widersprechen und von Prenßen fir das deutsche Volk nichts erwarten ( Wenn nun z. B. Österreich oder Preußen Deutschland eroberte, warum gäbe dies nur Österreicher, Preußen, keine Deutsche?\& . . . . , Kein bestehender Landesherr kann Deutsche machen; es werden Österreicher, Preußen usw. \&) Entweder wäre danach Fichte hinterher wieder zweifelhaft geworden über Preußea oder aber, was wahrscheinlicher ist, der S. 565 beginnende Abschnitt (der dem Passus ïber den Zwing- 
ihrer eigentiimlichen Art? In der Frage liegt eigentlich schon die verneinende Antwort, denn das Sonderwesen der deutschen Nation war es ja gerade, daß der Stammesund Territorialgeist sich mit der gesamtnationalen Idee vertrug und vertragen mußte. Immerhin muß man zugeben, daß Fichtes Einsicht in die realen Faktoren der Nationalität überhaupt und insbesondere in die der deutschen Nationalität erheblich gewachsen ist. "Völker sind Individualitäten mit eigentümlicher Begabung und Rolle dafür", sagte er, ähnlich wie schon in den » Reden « ${ }^{1}$ ) Aber er findet darüber hinaus auch für den geschichtlichen Ursprung der Nationen und Nationalcharaktere verständnisvolle Worte: »Gemeinschaftliche Geschichte oder trennende entscheidet für die Bildung zum Volke ... gemeinschaftliche Geschichte besteht also in gemeinschaftlichen Taten oder Leiden .... auch im gemeinsamen Regentenhause, welches sinnlich die Einheit repräsentiert: Vaterlandsliebe und Liebe des Regenten vereinigen sich sehr oft . . . . Eine reichere und glänzendere Geschichte gibt einen haltsameren Nationalcharakter (dies erhebt den Preußen über den Sachsen): ebenso wenn man dem Volke mehr Anteil an der Regierung gibt, es zum freien Miturteilen läßt; es nicht als stumme Maschine, sondern als bewußten und gerühmten Mitwirker gebraucht (das hebt Preußen iuber Ósterreich).

herrn folgt) entstammt einem früheren Stadium der Arbeit. Ohne Prüung des Manuskriptes wird sich die Frage, wieweit die Reihenfolge der Abschnitte im Drucke auch der zeitlichen Entstehung entspricht, kaum entscheiden lassen, da auch innerhalb der einzelnen Abschnitte Gedankendivergenzen vorliegen. Vgl. z. B. die sich widersprechenden Äußerungen über die nationale Bedeutung der deutschen Literatur S. 565,568 u. 572 , von denen jedenfalls S. 568 die früheste Stufe darstellt, während die (auch im Drucke eingeklammerte) Stelle S. 565 hinzugefügt $z u$ sein scheint, nachdem die Ausführungen S. 572 geschrieben waren.

1) 7,563 vgl. 7,467 .

Meinecke, Weltbuirgertum und Nationalstaat. 2. Aufl. 
Nationalstolz, Ehre, Eitelkeit heftet sich daher, wie bei den Individuen, an alles und dient, das Band zu befestigen. «1) Ja, noch einen weiteren wesentlichen Schritt zur Erkenntnis des Nationalen tat er am Schlusse seines Fragmentes. Vir unterscheiden, um an früher Gesagtes zu erinnern, unter den Momenten, die das Wesen einer Nation ausmachen, diejenigen politischen Charakters von denen, die auf gemeinsamer Kultur beruhen. Eben diese Scheidung nahm auch Fichte schon vor. Indem er feststellt, daß der merkwürdige Zug im bisherigen Nationalcharakter der Deutschen veben ihre Existenz ohne Staat und über den Staat hinaus, ihre rein geistige Ausbildung " sei, fährt er fort: „Da wird nun tiefer zu unterscheiden sein das Nationale, was nur durch den Staat gebildet wird (und seine Bürger darin verschlingt) und dasjenige, welches uber den Staat hinausliegt. ${ }^{2}$ )

Wer will sagen, wie tief Fichte noch ferner in das Wesen des Nationalen gedrungen sein würde, wenn es ihm beschieden gewesen wäre, in jenen großen Lehrjahren der deutschen Nation auch seine eigene Lehrzeit zu Ende zu führen? Er scheint zuweilen selbst zu fühlen, daß seine Kategorien nicht ausreichen, um den Inhalt des neuen Wunders der Nation, das seine Empfindung überflutete, zu fassen, und es ist ein großes Schauspiel, wie er es doch zwingen will. Mit aller Gewalt versuchte er seine alte Willensfrage: »Wie kommt es zum Vernunftreiche?» zu verschmelzen mit seiner neuen Empfindungsfrage: 》Wie kommt es zu einem deutschen Volke?« Aber weil sein Wille sich die Herrschaft über die Empfindung nicht entreißen ließ, so möchte man vermuten, daß er den

1) 7,567 .

2) 7,572. Er hatte am Anfang der Fragmente $(7,549)$ das Wesen des Nationalen nur auf politischem Gebiete gesucht als ,gegenseitiges Verstehen zwischen Repräsentierten und Repräsentanten und darauf gegründetes Wechselvertrauens. 
kosmopolitschen und rationalistischen Boden, in dem seine Ideen nun einmal wurzelten, niemals ganz verlassen haben würde. In den politischen Fragmenten und der Staatslehre von I 8 I 3 schimmert er jedenfalls noch uberall durch.

Er zog vor allem aus jener Einsicht in die geschichtlichen, territorial-dynastischen Bedingtheiten des wirklichen deutschen Nationalgefuihls nicht diejenige Konsequenz, die wir erwarten kïnnten. Der Nationalstolz der Preußen, der Sachsen, der Osterreicher ist ihm »versessener Bauernstolz «, der, so meint er, mehr als jeder andere Umstand die Herzen der Deutschen unter sich entvölkert habe. $\left.{ }^{1}\right)$ Er kann sich zwar der Einsicht nicht verschließen, daß derartige irrationelle Klammern unentbehrlich seien für ein Volksbewußtsein: »Aber ein Volk will es immer und kann es gar nicht lassen; außerdem bleibt die Einheit des Begriffs in ihm gar nicht rege. « Und doch will er das hinterher wieder nicht gelten lassen. Es genugt ihm nicht, diese territorialen Gesinnungen zu iberbauen durch ein gemeinsames deutsches Nationalbewußtsein, sondern diese Fundamente eines geschichtlich erwachsenen Nationalbewußtseins sollen überhaupt aus dem Boden heraus. Der Einheitsbegriff des deutschen Vollies werde vielmehr, so heißt es am Schlusse ${ }^{2}$ ), $\gg$ nicht irgend eine gesonderte Volkseigentümlichkeit zur Geltung bringen, sondern den Bürger der Freiheit verwirlklichen «. Er will es darum auch nicht zugeben, daß eine bloße Föderation ein Volk zum Volke bilden könne. ${ }^{3}$ ) Vielmehr, so heißt es in der Einleitung und dann wiederum in der Staatslehre: Die Einzelstaaten, in die Deutschland zur Zeit zerfalle, müßten als bloße Mittel zum höheren Zweck

1) 7,568 .

2) 7,573 .

3) $7,565,569$. Die Aufzeichnungen von $\mathrm{I}_{13}$ sind also unitarischer als die 2 Reden (s, oben S. I08), indem ihm jetzt auch die Form der Einheit nicht mehr gleichgiiltig ist. 
künftig wegfallen. $\left.{ }^{1}\right)$ Vor allem aber: Der deutsche Nationalgeist, den er predigte, war keine Frucht geschichtlichen Lebens, sondern ein Postulat der Vernunft. Fassen wir das näher ins Auge.

Er konstatiert, daß die Deutschen bisher noch keinen Nationalcharakter, keinen Nationalstolz haben. Andere Völker, führt er aus, haben ihn durch ihre Geschichte. Die Deutschen haben als solche in den letzten Jahrhunderten keine Geschichte gehabt. „Welches Band haben wir denn gehabt und welche gemeinschaftliche Geschichte $\left.{ }^{2}{ }^{2}\right)$ Man kann an einigen Stellen wohl eine Klage darüber heraushören, daß dem so sei, aber daneben blitzt gerade auch wieder eine gewisse Befriedigung darüber hindurch. Dieser Widerstreit der Empfindungen war zugleich ein Widerstreit der Denkweisen des I8. und I9. Jahrhunderts. IVelche von beiden in ihm die stärkere war, kann nicht zweifelhaft sein. Dem großen Idealisten, der im Zeitlichen immer nach dem Ewigen strebte, lachte das Herz ob der Entdeckung eines Nationalgeistes, der eben noch keine Geschichte hinter sich habe, und ob der Aufgabe, mitzuschaffen an einem Nationalgeiste, der ganz das Werk der bewußten Vernunft und der Freiheit sein werde. Gerade seine Gesichtslosigkeit scheint ihm die Aufgabe zu erleichtern; jedenfalls ist sie ihm ein Beweis dafür, daß in dem, was von deutschem Charakter uberhaupt sich erhalten habe, etwas "schlechthin

1) $7,547,573 ; 4,423$. Lask, Fichtes Idealismus und die Geschichte (1902) meint S. 267 , daß man in Fichtes Verwerfung des Territorialstaates , nicht ein blindes Eifern wider den Schollenpatriotismus erblicken dürfec, sondern vielmehr daraus eine tiefgehende Einsicht erkennen müsse, ১daß jeder Staat im tiefsten Grunde krankt, bei dem politische Organisation und "Volksgeist" sich nicht deckenc. Das ist richtig, nur muß man dann nur gleich hinzusetzen, daß sein ,Volksgeist، eben nicht der historisch-konkrete deutsche Volksgeist war.

9) $7,565,568$. 
Ursprüngliches «, etwas Ubergeschichtliches vorliege. ${ }^{1}$ ) Eben diese »Ursprünglichkeit" hatte er schon in den "Reden« für die deutsche Sprache und die deutsche Nation, das einzige »Urvolk", das »Volk schlechtweg" in Anspruch genommen. Man sieht, daß sein Begriff der „Ursprïnglichkeit " etwas ganz anderes bedeutet, als was wir etwa im Sinne haben, wenn wir von dem »ursprünglichen"Wesen einer Nation sprechen. Wir meinen damit die naturhafte Frische einfacher Kulturverhältnisse, aber immer etwas geschichtlich Bedingtes. Fichte meinte damit gerade das geschichtlich nicht Bedingte. $\left.{ }^{2}\right)$ Die Konsequenz muß dann sein, daß die geschichtlich gewordenen Nationalcharaktere überhaupt minderwertig sind, daß sie der Welt der Unfreiheit angehören. Auch diese Konsequenz zog Fichte. Die Franzosen, sagt er, »haben gar kein eigen gebildetes Selbst, sondern nur, durch die allgemeine Ubereinstimmung, ein rein geschichtliches, dagegen hat der Deutsche ein metaphysisches « ${ }^{3}$.)

1) Die Deutschen ... sind gewachsen ohne Geschichte.\& 7, 565, vgl. $7,57 \mathrm{I}$.

2) Auf das deutlichste zeigen das die ,Redenc, 7, 374: , Der eigentliche Unterscheidungsgrund (für das Wesen des Deutschen) liegt darin, ob man an ein absolut Erstes und Ursprüngliches im Menschen selber, an Freiheit, an unendliche Verbesserlichkeit ... glaube oder ob man an alles dieses nicht glaube ... Jetzt wird endlich dieser Nation durch eine in sich selbst klar gewordene Philosophie der Spiegel vorgehalten, in welchem sie mit klarem Begriffe erkenne, was sie bisher ohne deutliches Bewußtsein durch die Natur ward., Vergl. Kuno Fischer a. a. O. 7IS: ,Fichte hat den Ursprung und Anfang der Kulturgeschichte auf die den Gesetzen der Entwicklung widerstreitende Hypothese eines Ur. und Normalvolks gegrïndet...., d. h. er setzt an die Stelle der Entwicklung die Offenbarung und macht damit die Geschichte zum Rätsel.، Über den Zusammenhang der Idee des Normalvolkes mit Rousseau vgl. Fester a. a. O. S. I33 ff., I46, I 53. - Lask a. a. O. 257, verkennt den prinzipiellen Gegensatz, den Fichte selbst $(7,565)$ zwischen dem , Ursprünglichen, und dem, Geschichtlichen, statuiert.

3) 7,566 . 
Es findet sich allerdings noch ein anderes Wort in diesen Aufzeichnungen, wonach es scheint, als ob Fichte wenigstens die zukünftige Entwicklung der deutschen Nation dem Strome der Geschichte anvertrauen wolle. Der Charakter der Deutschen, sagt er ${ }^{1}$ ), »liegt in der Zukunft: - jetzt besteht er in der Hoffnung einer neuen und glorreichen Geschichte. Der Anfang derselben daß sie sich selbst mit Bewußtsein machen. Es wäre die glorreichste Bestimmung. Grundcharakter der Deutschen daher: 1. Anfangen einer neuen Geschichte. 2. Zustandebringen ihrer selbst mit Freiheit .. 3. Deshalb sollen die Deutschen auch nicht etwa Fortsetzung der alten Geschichte sein: Diese hat -eigentlich fuir sie gar kein Resultat gegeben." Aber ist diese »neue Geschichte , die der deutschen Nation vorbehalten ist, Geschichte in unserem Sinne? Wir meinen, daß schon die tiefe Zäsur, die er zwischen die alte und neue Geschichte der Nation hier legt, dem widerspricht. Wir können keine solchen Sprünge der Entwicklung anerkennen, wir können nicht zugeben, daß ein Volk eine darart geschiedene alte und neue Geschichte haben könne, daß die eine ganz resultatlos verlaufen ist, und die andere in lieinerlei Zusammenhang mit der Vergangenheit stehen soll. Fichte konnte an einen solchen Sprurg uiber den Abgrund nur glauben, weil seine neue Geschichte eben nicht die echte Geschichte ist. Ihr Anfang soll ja sein, daß die Deutschen »sich selbst mit Bewußtsein machen ", sich selbst »mit Freiheit zustandebringen«. Es fehlt in dieser Geschichte das, was zum Wesen der echten Geschichte nun einmal gehört: der Faktor der Unfreiheit und des Irrationellen. Demnach hat er hier zwei ganz verschiedene Geschichtsbegriffe vor Augen, von denen der eine, in der »alten "Geschichte der Deutschen und

1) $7,57 \mathbf{1}$ 
in der Geschichte der anderen Völker wirksam, dem unseren sich nähert, aber eben wegen seiner sozusagen unreinen, unedlen Bestandteile von Fichte mißachtet und beiseite geschoben wird, während der andere, ausschließlich auf den Faktor des bewußten freiheitlichen Schaffens gegruindet, jenseits der Sphäre des wahrhaft Geschichtlichen liegt. ${ }^{1}$ )

Die »neue Geschichte《 ist also eine Vernunft- und Idealgeschichte, wie sein Staat ein Vernunftstaat und seine Nation eine Vernunftnation ist. Es ist immer noch die Sprache der Menschenrechte und der ersten Revolutions. jahre, die aus seiner großen Verheißung spricht: „Und so wird von ihnen (den Deutschen) aus erst dargestellt werden ein wahrhaftes Reich des Rechts, wie es noch nie in der Velt erschienen ist, in aller der Begeisterung für Freiheit des Bürgers, die wir in der alten WVelt erblicken, ohne Aufopferung der Mehrzahl der Menschen als Sklaven, ohne welche die alten Staaten nicht bestehen konnten: Für Freiheit, gegründet auf Gleichheit alles dessen, was Menschengesicht trägt. $\aleph^{2}$ ) Zwar wirken solche Worte auf uns unendlich inhaltsreicher als die an sie anklingende Phraseologie der Girondisten und Jakobiner, aber nur deswegen, weil sie in Fichtes Munde einen tieferen Sinn haben, weil alle seine so abstrakt lautenden Gedanken von Freiheit und Recht das heiße Erlebnis einer großen Seele sind, weil seine Freiheitsforderung nichts anderes als die Forderung der sittlichen Autonomie ist, der Wurzel aller echten und großen Kultur. Der größere Gehalt an persönlichem Leben und das

1) Wir können also der Meinung von Lask, S. 269, nicht beitreten, der in den oben zitierten Worten Fichtes den suntrüglichen Beweis، dafur sieht, daß er einen die , Vergangenheit und Zukunft umfassenden, fur das IS. Jahrbundert völlig unbegreiflichen Begriff von "Geschichte" auch wirklich vertreten hat.

2) Staatslehre 4,$423 ; 7,573$. 
größere Maß an geschichtlich vorwärts treibender Kraft ist es, was uns Fichtes Ideen von Nation und Nationalstaat moderner und geschichtlicher erscheinen läßt, als sie wirklich sind.

So denken wir, daß unsere Vorbehalte und Einschränkungen die unermeßliche Leistung Fichtes für die Entwicklung der nationalen und nationalstaatlichen Idee in Deutschland nicht schmälern werden. Vielleicht im Gegenteil. Das Schauspiel der Entwicklung dieser neuen Idee wird nur bedeutender, wenn man sieht, wie stark und lebendig noch das Alte war, aus dem sie hervorging. Es war nicht so, wie man sich oft und bequem die Sache vorstellt, daß der Kosmopolitismus fade und abgelebt am Boden lag und der junge nationale Gedanke nun leicht und siegreich emporstieg, sondern Kosmopolitismus und Nationalismus standen noch geraume Zeit in einer engen Blut- und Lebensgemeinschaft. Und wenn auch die Idee des echten Nationalstaates in ihr noch nicht voll gedeihen konnte, so war sie doch für die nationale Idee selbst nicht unfruchtbar. Alles kam ja darauf an, daß überhaupt ein bestimmter, kräftiger und energischer Inhalt in sie hineinströmte, daß sie nicht bloß interessiert und beschaulich hin und her erwogen wurde, sondern rund und fest bejaht wurde und ein großes Pathos erhielt. Von dem zerrissenen Boden der damaligen nationalen Wirklichkeit aus war es für Geister wie Fichte zu schwer, ein solches Pathos zu gewinnen, - so tat er es von der Höhe eines universalen ethischen Ideals aus. 


\section{Siebentes Kapitel.}

\section{Adam Müller in den Jahren I808-I8I3.}

Fichte hat seine schon einmal eroberte Erkenntnis vom Wesen des Machtstaates wieder fallen lassen, weil die Macht der sittlichen Idee in ihm selbst zu gewaltig war, als daß sie die Autonomie einer anderen Macht neben sich auf die Dauer hätte anerkennen können. Sein sittlicher Wille, der ihn in die Welt des Staates und der Nation hineingeführt hatte, richtete zugleich die Schranke auf, die ihm den Anblick des ganzen IVesens jener Mächte wieder entzog. So ist es einem Geiste von viel geringerer Kraft, aber von größerer Empfänglichkeit beschieden gewesen, tiefer in die Erkenntnis des Nationalstaates einzudringen, als Fichte. Dies war Adam Müller, der ein Jahr nach Fichtes Reden im Winter ISOS/O9 in Dresden Vorlesungen hielt uber die Elemente der Staatskunst. ${ }^{1}$ ) Fichte hatte zur deutschen Nation geredet, und das zufällige Publikum, das er hatte, vertrat sie ihm. Adam Miiller, damals weimarischer Hofrat, sprach vor einer Versammlung von Staatsmännern und Diplomaten und in Gegenwart eines weimarischen Prinzen. Er sagte diesem aristokratischen Publikum auch Dinge, die ihm gefallen konnten. Nach seines Freundes Gentz Meinung und Rat hätte er sich damals durch ein Buch zur Verteidigung des Geburtsadels eine höchst angenehme Existenz gründen können. $\left.{ }^{2}\right)$ Es kommt

1) 1809 in 3 Bänden erschienen.

2) Gentz an Müller ISoS. Briefwechsel zwischen Gentz und Muller S. 140. 
hier nicht so viel darauf an, ob Adam Müller solchen materiellen Motiven damals zugänglich war oder nicht. Sicher ist, daß wir, von Fichte zu Müller übergehend, aus der reinen Luft der unbedingten ethischen Absicht in eine Umgebung von bestimmtem sozialen Charakter hinubbertreten, in der sich der Autor selbst wohl fühlte, und die sich auch in seiner Theorie nicht verleugnet.

$\mathrm{Ob}$ Müller tiefere geschichtlichere Studien gemacht hat, läßt sich aus seinen Schriften allein nicht mit Sicherheit erkennen. Sein geschichtlicher Sinn war auch nicht von der Art, wie ihn ein im Leben stehender politischer Schriftsteller gewinnen kann. Er hatte wohl zeitweise schon mit Eifer Politik getrieben und als Tagespublizist Fühlung mit Staatsmännern gehabt ${ }^{1}$ ), aber er hat sich den politischen Bewegungen der Zeit niemals geistig so anschmiegen können, wie dies Gentz in seiner besten Zeit vermocht hat. Er hatte wohl eine überaus starke Richtung zum Wirklichen, aber auch einen träumerischen spelsulativen Hang und verband beides so eng miteinander, daß auch seine realsten Einsichten zugleich immer ein Stuick phantasievoller Anschauung sind. Man begreift die Begeisterung einer solchen Natur fiir Heinrich v. Kleist, von dessen Dichtung man Ähnliches sagen könnte, nur daß Kleist nicht allein ungleich kraftvoller und origineller war, sondern auch strenger an sich gearbeitet hat als Adam Müller. Müllers beste Zeit war jedenfalls die der Freundschaft und des Umganges mit Kleist und fiel so mit der ernsten Zeit nach dem Tilsiter Frieden zusammen. ${ }^{2}$ ) So stark aber dadurch auch Müllers Denken im ganzen befruchtet worden ist, so war doch auf dem eigentlich politischen Gebiete er von vornherein

1) So 1803 . Briefwechsel Gentz-Mïller S. 18 und Wittichen, Briefe von und an Gentz 2, 4 ro.

2) Vgl. Steig, H. v. Kleists Berliner Kämpfe und Kayka, Kleist und die Romantik S. 120 ff. 
der interessiertere von den beiden, und es ist wohl möglich, daß er den Dichter, der schon die Not des Vaterlandes zu empfinden begann, vollends in die vaterländischen Dinge hineingezogen hat. $\left.{ }^{1}\right) \quad \mathrm{Zu}$ der großen patriotischen Leidenschaft, die Kleist dann entwickelte, war Müllers sensitive Natur selbst nicht fähig, aber sie war reich und fein genug, um das Bild der ringsum erwachenden nationalen Triebe in sich aufzunehmen und eine Theorie des nationalen Staatslebens zu versuchen, die einen ersten glücllichen Griff in ein neues Leben bedeutet, - einen ersten aber nur, und darum keinen erschöpfenden Griff.

Müller verband nicht zufällig und willkürlich die künstlerisch-ästhetischen und philosophischen Interessen mit den politischen. Ich habe, schrieb er an Gentz am 6. Februar $\mathrm{I} 808^{2}$ ), in eine Trennung der sogenannten heiteren Kunst von dem ernsten Leben nie eingehen wollen. »Meine Ansicht der Welt ist eine ganze und vollständige. "Er wollte auch davon nichts wissen, und darin war er der echte Freund Kleists, daß sich die ideale und reale Ansicht des Lebens voneinander ausschlössen. „Innerhalb meiner Ansicht und - was dasselbe ist - innerhalb meiner ist alles, wie Sie es nennen, idealisch, aber vollständig idealisch. Wenn nun andere sehr gescheite, nur in anderen Standpunkten befindliche Menschen zugeben, ich sei vollständig realisch, über meinen Realismus klagen, so werden sie mir, so wenig ich auch einer solchen Probe vor mir selbst bedarf, erlauben, es für eine Probe zu halten, daß ich das Rechte sei. « Er dachte dabei zunächst an seine Kunstansichten, aber er hatte den gleichen Ehrgeiz, auch in der politischen Wissenschaft eine Lehre

1) Kayka, a. a. O. u. S. 178 .

2) Briefwechsel S. 126. 
zu begründen, die man ebensowohl »idealisch" als »realisch « nennen konnte, die dem Philosophen und dem Staatsmann zugleich den Weg zeigen sollte in den Mittelpunkt des Staates. »Totalität « ist eines seiner Lieblingsworte, und ein großer Zug zu einer allumfassenden Anschauung des bürgerlichen und staatlichen Lebens war in der Tat in ihm, ein Sinn vor allem für die Bewegung des Lebens und für den Zusammenhang seiner Schwingungen, für die Wechselwirkung aller Teile eines Ganzen, eine lebhafte Empfindung auch dafür, daß hinter den äußeren Erscheinungen des geschichtlichen Lebens noch unsichtbare Mächte wirkten. ${ }^{1}$ ) Er tat sich viel zugute auf seine Unterscheidung von Idee und Begriff. Idee war ihm eben das Lebendige, Begriff das Tote. Man sieht hier in eine der größten Wirkungen der Kantschen Erkenntnistheorie hinein. Der Allzermalmer hatte das Vertrauen, daß der Begriff das Wesen der Dinge ausdrücken könne, zermalmt und hatte dadurch, ohne es selbst zu wollen, der neuen Methode genialer Intuition und Spekulation den Weg geöffnet zu ihrem Versuche, das Wesen der Dinge zu erfassen. Begriffe sind, sagt Müller, steife Formen ${ }^{2}$ ), wie die gemeinen Wissenschaften vom Staate, vom Leben, vom Menschen sie umherschleppen. "Vom Staate aber gibt es keinen Begriff. "Wenn aber »der Gedanke, den wir von einem solchen erhabenen Gegenstand gefaßt haben, sich erweitert, wenn er sich bewegt und wächst, wie der

1) Sehr hübsch, aber zugleich mit einigem Protest gegen die Geister, die die Frühromantil einst selbst gerufen hatte, kritisierte F. Schlegel Müllers Art als seinen gewissen Pantheismus des Gefühls, der so gern möglichst alles in Harmonie auflösen will. Besprechung von Müllers Vorlesungen iiber die deutsche Wissenschaft und Literatur I807. Deutsche Nationalliteratur 1Bd. 143 (A. W. und F. Schlegel, hg. von Walzel), S. 4I5.

2) Elemente 1, $27 \mathrm{f}$. 
Gegenstand wächst und sich bewegt, dann nennen wir den Gedanken nicht den Begriff von der Sache, sondern die Idee der Sache, des Staates, des Lebens. « So verlangte er von der Staatswissenschaft, wie von allen höheren Wissenschaften überhaupt, daß sie erlebt, nicht bloß erkannt und erlernt wiirden. ${ }^{1}$ )

Er hätte mit einem solchen Vorhaben einer der größten politischen Denker werden können, wenn es ihm gelungen wäre, das »Idealische " und » Realische* in der Politik ebenso zu verschmelzen, wie es Kleist in der Kunst gelungen ist, wenn er die große Allgemeinanschauung vom Staate, die er hatte, auf eine Fiille konkreter Erfahrung hätte gründen können ${ }^{2}$ ) und wenn er nicht nur dem, was er $\gg I d e e \ll$, sondern auch dem, was er »Begriff " nannte, an seiner Stelle gerecht geworden wäre und es an Schärfe und Klarheit des Denkens nicht zuweilen fehlen ließe. Er kann noch heute ungemein anregen und durch einzelne geniale Einfälle und überhaupt durch das Beflügelte seiner Gedanken die höchsten Erwartungen zuweilen erregen, aber er sättigt nicht in gleichem Grade, und das Fliegende bei ihm verfliegt zuweilen in das Unfaßliche.

Man wird ihm nicht unrecht tun, wenn man ihm die wahre geistige Originalität abspricht und auch in dem Originellsten und Besten, was er gesagt hat, mehr eine glückliche Anwendung und Weiterbildung dessen

1) Elemente I, 22.

2) Gleich damals vermißte sie Rehberg an ihm, ein politischer Denker, der ihm in der konservativen Grundrichtung wohl nahe stand, aber ganz anders, wie er, in der Erfahrung wurzelte. ,Wissenschaftliche Werke, c heißt es in Rehbergs Rezension der Mullerschen Elemente (Sämtl. Schriften 4, 245), ১über Gegenstände, welche die rechtlichen und sittlichen Verhältnisse unter den Merschen angehen, sind wahrhaftig nicht schlechter, wenn sie von dem Erdreiche, auf dem sie gewachsen sind, einen recht merklichen Geschmack angenommen haben. * 
sieht, was er in einer großen Zeit ${ }^{1}$ ) und von Größeren als er gelernt hatte. ${ }^{2}$ ) Wir greifen aus den Einfluissen, denen er sich hingab, diejenigen heraus, die in den $\mathrm{Zu}-$ sammenhang unserer Probleme vor allem gehören: Edmund Burke, die Frühromantik und Fichte. ${ }^{3}$ )

Nennt man Burke, so muß man freilich vor ihm und zuerst den Einfluß des Mannes nennen, der zugleich der erste Interpret Burkes in Deutschland und der nächste politische Freund und Lehrer Adam Müllers war: Friedrich Gentz. Ihm verdankte Müller nach seiner eigenen Aussage $\left.{ }^{4}\right)$ die Richtung auf das wirkliche, körperliche gesellschaftliche Leben, die Welthändel, den Staat und damit die Uberwindung der reinen Spekulation. In Gentzens politischer Gedankenwelt dominieren auch alle die Fragen, die

1) Vgl. seine eigenen Worte, Elemente 1, 9: , So ist die Zeit, in der wir leben, eine große Schule der Staatsweisheit,

2) Für den zwiespaltigen Eindruck, den Müller auf seine Zeitgenossen schon machte, ist sehr bezeichnend das Wort Wilhelm Grimms

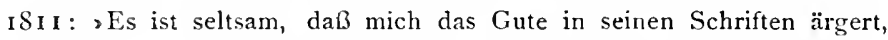
weil ich meine, er habe es auf Borg.s Steig S. 506 und das daselbst, S. 296, angeführte Urteil Humboldts über M. (Bratranek S. 236).

8) Für Müllers philosophische Grundlage käme noch vor allem in Betracht der Einfluß Schellings (vgl. Wittichen, Briefe von und an Gentz 2, 347, Anm. 2; Stahl, Gesch. d. Rechtsphilosophie, 3. Aufl. S. 569). Die noch unbeantwortete Frage, inwieweit er schon von den französischen Schriftstellern der Kontrerevolution berührt war, glaubte ich von der Untersuchung ausschließen zu können, weil das Nationalitätsproblem bei diesen keine entscheidende Rolle spielt. In seinen Vorlesungen iiber Friedrich II. (S. 109) preist er Bonalds Traití sur le divorce. In den Vermischten Schriften, I, 3 I I ff., behandelt er Bonald austührlicher, gibt aber ausdriicklich an, daB er Bonalds Législation primit.ve erst im Frühjahr ISIo kennen gelernt habe.

4) Wittichen, Briefe von und an Gentz 2, 348. -- Die Arbeit von A. Gerhardt, Romant. Elemente in d. Politik u. Staatsanschauung Fr. Gentz', Leipziger Dissertation 1907, ist ihrer Aufgabe nicht ganz gewachsen. 
uns hier beschäftigen. Er entwickelte den feinsten Sinn für den Zusammenhang von Nationalkultur und Nationalstaat und konnte diesen, als er ihn in England vor Augen sah, ergreifend lebendig darstellen. Er kämpfte für Eigenleben und Eigenrecht der Nationen und Staaten und hat das Problem, wie dieses Eigenrecht wieder einzuschränken sei durch das Gesamtrecht der europäischen Staatengesellschaft, ernst erwogen. Er sah in seinen besten Tagen in dem universalen Kampfe gegen Frankreich das Mittel für Deutschlands künftige Nationalgröße ${ }^{1}$ ) und fühlte sich dabei zugleich als der Träger »weltbefreiender und welthistorischer Plane«, innerlich mehr als Weltbürger, der für eine Sache kämpft, denn als Diener eines bestimmten Staates. $\left.{ }^{2}\right)$ So gehören die Ideen, die er mit Geist und Wirkung vertrat, ihrem Inhalte nach durchaus in den Zusammenhang der Entwiclilung, die wir untersuchen, - aber der Mensch, der hinter ihnen stand, gehört nicht ganz hinein. Man hat mit Recht bemerkt, daß er durch seine Entwicklung zum Realpolitiker »sich geschieden hatte von dem Entwicklungsprozeß, den das deutsche politische Leben bis zum Auftreten Bismarcks durchlaufen hat. $\left.\ll^{3}\right)$ Er war, darf man hinzusetzen, zugleich zu sehr Genußmensch, der auch den tieferen Inhalt seines Lebens und selbst die politische Leidenschaft mehr genoß als erlebte. Er hatte, um ein Wort zu variieren, das iiber sein Verhältnis zur Religion gesagt worden ist, mehr Gefühl für den Wert der Ideen als Ideen selbst in sich. Darum fehlte den von ihm vertretenen Ideen ein Etwas, was sie erst ganz homogen machen würde mit denen seiner Zeitgenossen. Und darum fehlte auch seinem

1) ISof, Wittichen, 2, 251 .

2) Das. 2, 244 (ISO4).

3) F. C. Wittichen, Gentz' Stellung zum deutschen Geistesleben vor ISo6. Histor. Vierteljahrsschrift 14, 55. 
Kampfe für die Freiheit der Nationen das wahrhaft nationale Ferment und das innerste Pathos. ${ }^{1}$ )

Wohl ergänzten sich nun Müller und Gentz insofern aufs gluicklichste, als der eine immer hatte, was der andere nicht hatte und doch schätzte. Den einen drängte die eigenste Natur zur idealen Anschauung der Wirklichkeit, den anderen zu ihrer realen Anschauung. Die Ideen aber, die Müller von Gentz hätte entnehmen können, waren nur der Abglanz des stärkeren Lichtes, das von Burke ausging und zu dem Müller sogleich den unmittelbaren Zugang fand.

Burkes Betrachtungen über die französische Revolution waren für ihn eine Offenbarung. Er nannte ihn den letzten Propheten, der auf diese entzauberte Erde gekommen sei. ${ }^{2}$ ) Hier ist, jubelte $\mathrm{er}^{3}$ ), praktisches Leben, hier ist Geist und Theorie, hier erscheinen Staatsmann und Staatsgelehrter in einer Person. „Seine Werke lassen sich nicht destillieren; es lassen sich von ihnen keine Begriffe abziehen, in versiegelten Flaschen aufbewahren . . . ebensowenig lassen sich praktische Kunstgriffe von ihm lernen. Begreift man aber den wirklichen historischen Fall, von dem er spricht, so hat man zugleich seinen Geist begriffen; begreift man den Gedanken, der ihn bewegt, so sieht man denselben zugleich ausgedrückt im wirklichen Leben, richtig und gewaltig ausgedrückt. Burke hat ja nicht nur auf Adam Müller so

1) a. a. O. S. 52. Über die kritischen Zweifel, die sein merkwürdiger, angeblich aus dem Spätherbst I Sog stammender, über das $\mathrm{Na}$ tionalitätsprinzip handelnder Brief an Müller erweckt, vgl. jetzt Wittichen, Briefe etc. 2, $4 \mathrm{I} 8$.

2) Über König Friedrich II. (I 8 IO) S. 52 .

3) Elemente I, 26; andere Stellen iiber Burke in der shehre vom Gegensatze (1804) S. XIIf., den, Vorlesungen über die deutsche Wissenschaft und Literature (2. Aufl. ISo7) S. 27 u. 149; den ,Elementen , I, 86 und Vermischten Schriften (1812) I, 120, 252 ff. 
tief gewirkt. Er hat nicht nur den Gegnern der Revolution die stärksten geistigen Waffen geliefert, er hat, was mehr noch sagen will, den naturrechtlichen Staatsauffassungen des i 8 . Jahrhunderts den ersten entscheidenden Stoß versetzt und allem Denken über den Staat Elemente zugefügt, die niemals wieder ausgeschieden werden können. Er hat die irrationellen Bestandteile des Staatslebens, die Macht der Tradition, der Sitte, des Instinktes, der triebartigen Empfindungen tiefer würdigen und verstehen gelehrt. Man kann nicht sagen, daß er sie geradezu entdeckt habe, denn jeder Realpolitiker der neueren Jahrhunderte, von Machiavell an, kannte und benutzte sie schon. Aber sie waren dem Praktiker nur als die einmal vorhandene, je nachdem auszubeutende oder zu schonende Schwäche der Menschen, dem rationalisierenden Theoretiker mehr als ein Pudendum bisher erschienen. WVenn der Denker sie anerkannte, erkannte er sie mit Resignation auf das eigentliche Ideal der Vernunft an. So Montesquieu, so auch noch, wie wir sahen, IVilhelm v. Humboldt. Aber dieser bloß negativ historischen Denkweise ${ }^{1}$ ), zu der die einsichtigsten, man möchte sagen, die aufgeklärtesten Aufklärer des I 8 . Jahrhunderts schon gelangten, fehlte die eigentliche Freude an der Geschichte und das innere Herzensverhältnis zu ihr. Erst wer ein solches gewann, entdeckte die wahren Werte der Geschichte. Auf dem Gebiete der staatlichen und gesellschaftlichen Institutionen war es vielleicht zuerst Möser, der den neuen Freudenquell auffand. Aber an Tiefe des politischen Verständnisses und an breiter IVirkung ubertraf ihn Burlee, dem jetzt die Gunst der Zeit, das Schauspiel des Zusammenbruchs der reinen Vernunft in Frankreich so sehr zustatten kam. So lehrte er die höhere Zweckmäßigkeit

1) Der glückliche Ausdruck snegativ historische Richtunge ist von Gunnar Rexius, Zur Staatslehre der historischen Schule (in der Hist. Zeitschrift demnächst erscheinend), geprägt worden. 
vieles dessen, was bisher nur als Schwäche oder $\mathrm{Un}^{*}$ vernunft gegolten hatte, verstehen und den Kern der Weisheit in der Hülle des Vorurteils erkennen; er lehrte Achtung und selbst Liebe für dieses ganze Geflecht des natiurlich und halbwild Gewachsenen, das sich durch das Privatdasein des einzelnen ebenso sichtbar-unsichtbar hindurchschlingt wie durch die Gesellschaft und den Staat im großen, das eine wohlige Hülle und einen verborgenen Halt zugleich für alle bildet. Überall, im Großen und im Kleinen, konnte man nun, wenn man nur das Auge dafür hatte, den "ganzen Schmuck der köstlichen Nebenideen" gewahr werden, "welche das Herz umfaßt und selbst der Verstand billigt, weil er ihrer bedarf, um die Mängel unserer nackten, gebrechlichen Natur zu bedecken. ${ }^{1}$ ) So fiel durch Burke ein neues warmes Licht auf eine ganze IVelt von Tatsachen, die man bisher entweder nicht beachtet oder mißachtet hatte. Das gesellschaftliche und politische Leben erschien sehr viel komplizierter, aber auch sehr viel reicher und durch seinen Reichtum schöner als bisher, wo man es in einige wenige Begriffe zu fassen gewohnt war. „Die Natur des Menschen ist verwickelt, "sagt Burlie, »die Gegenstände des gesellschaftlichen Lebens unendlich zusammengesetzt. $\left.\ll^{2}\right)$ Die erste Wirkung dieser Einsicht war bei Burke, wie bei seinem Schüler Adam Müller, tiefer Respekt vor der verborgenen Weisheit dessen, was die Lebenden als Erbe der Vergangenheit übernommen hatten, tiefes Mißtrauen dafür gegen die Weisheit derer, die das Band mit der Vergangenheit zerschneiden wollten. Das Natur- und Vernunftrecht trat in Schatten gegeniber dem positiven Rechte, und dieses stieg auf zum Range eines wahren Naturrechtes. „Wir dürfen«, sagt Müller ${ }^{3}$ ),

1) Burkes Betrachtungen, übers, v. Gentz (Neue Aufl. 1794), I, roS.

2) a. a. O. I, $S_{4}$.

3) Elemente 1, 75. 
》getrost alles Naturrecht außer oder uber oder vor dem positiven Rechte leugnen; wir dürfen alles positive Recht für natürliches anerkennen, cha ja alle die unendlichen Lolialitäten, welche das positive Recht herbeiführen, aus der Natur herfließen."

Eine weitere Wirkung des neuen Sinnes für das komplizierte und tief verwurzelte Wesen des Staates war es, daß man auch das Verhältnis zwischen öffentlicher und privater Sphäre mit anderen Augen ansah. Es ging nicht mehr an, sie säuberlich und streng nach ihrem verschiedenen Begriffe und Zwecke voneinander zu sondern. Man spürte hier wie dort das Wirken eines und desselben Geistes, der nicht von heute war, der die Lebenden miteinander und mit den Vorfahren verband und aus den kleinsten wie aus den höchsten Gütern des Lebens sprach. So lehrte Burke den Staat nicht als Zweckverband, uberhaupt nicht als reine rationale Einrichtung, sondern als eine über die Spanne der Einzelgeneration weit hinausgehende Lebensgemeinschaft auffassen. „Es wäre frevelhaft, den Staatsverein wie eine alltägliche Kaufmannssozietät . . . zu betrachten, die man treibt, solange man Lust hat, und aufgibt, wenn man seinen Vorteil nicht mehr absieht. Ein Staat ist eine Verbindung von ganz anderer Art und von ganz anderer Wichtigkeit .. . er ist eine Gemeinschaft in allem was wissenswuirdig, in allem was schön, in allem was schätzbar und gut und göttlich im Menschen ist. «1) Man erkennt, wie viel Müller Burke zu verdanken hat, wenn man die Definition des Staates, die er selbst aufstellte, danach liest ${ }^{2}$ ): »Der Staat ist nicht eine bloße Manufaktur, Meierei, Assekuranzanstalt oder merkantilische Sozietät; er ist die innige Verbindung der gesamten physischen und geistigen

1) a. a. O. I, I39 f.

2) Elemente I, 5I; ähnliche Definition in seinen Vermischlen Schriften I, 22 I. 
Bedürfnisse, des gesamten physischen und geistigen Reichtums, des gesamten inneren und äußeren Lebens einer Nation zu einem großen, energischen, unendlich bewegten und lebendigen Ganzen. " »Der Staat ist eine Allianz der vorangegangenen Generationen mit den nachfolgenden und umgekehrt. «1) Vielleicht noch bewußter als Burke hob er auch die Schranken zwischen privatem und öffentlichem Dasein auf. So lange Staat und Bürger zweien Herren dienen, sagt er, sind auch die Herzen innerlich zerschnitten. ${ }^{2}$ ) Es muß dahin kommen, daß »das Privatleben nichts anderes ist als das Nationalleben von unten auf betrachtet und das öffentliche Leben zuletzt nichts anderes als dasselbe Nationalleben von oben herab angesehen. $\ll^{3}$ )

Wie weit sind wir hier schon von den Humboldtschen Ideen der neunziger Jahre abgeführt. Damals Primat des Individuums gegenüber Staat und Nation, oder doch, so war der spätere Standpunkt, die Nation ein Boden und Bildungsmittel für das Individuum und interessant durch ihre Beziehungen zu diesem, - jetzt aber, bei Müller, ist das individuelle Dasein nur noch Teil und Glied eines großen, mächtigen Ganzen, das aus Vergangenem und Gegenwärtigem zusammengesetzt ist, und in dem das Einzeldasein und die Gegenwart durch das Uberindividuelle und das Vergangene beschränkt werden. Demnach ist der Mensch das »vielarmige, nach allen Seiten in die Natur eingesponnene, an tausend physischen und moralischen Fäden mit Vorzeit und Nachwelt zusammenhängende Wesen. $\left.\ll^{4}\right)$ Das Volk aber ist: »die erhabene Gemeinschaft einer langen Reihe von vergangenen, jetzt lebenden und noch kommenden Ge-

1) Elemente I, $S_{q}$.

2) Über Friedrich II. S. 37 .

3) a. a. O. S. 45.

4) Vermischte Schriften I, $1+5$. 
schlechtern, die alle in einem großen innigen Verbande zu Leben und Tod zusanmenhängen. «1) So fesselt und hebt ihn dieser Anblick der säkularen Lebenseinheiten, der Dauer im Wechsel, des Zusammenhanges der Generationen untereinander, wo dann der einzelne Mensch auch immer, so meint er, in der Voraussetzung handeln muß, daß nicht er allein, sondern die ganze umgebende Natur auch handle.

So spürt man neben Burke immer deutlicher die Ideen der Frühromantik hindurch. Burke lehrte ihm vor allem den Blick für das Säliulare, für die Ketten zwischen den Generationen, die Frühromantik den Blick für die unendliche Bewegtheit des Alls, für die in ihm durch und miteinander wirkenden Kräfte und für die Individualität einer jeden dieser Kräfte. Diese beiden Einflisse lassen sich nicht genau trennen, umsoweniger, da vielleicht auch schon die Frühromantik von Burke her Einwirkungen erfahren hat. ${ }^{2}$ ) Auch Novalis hatte bereits, wie wir sahen, die verloren gegangene Kontinuität mit dem Mittelalter wiederherstellen wollen, hatte ferner auch schon den Staat als "Armatur der gesamten Tätigkeit" des Menschen gepriesen. Und wiederum konnte man auch von Burke lernen, was der Lieblingsgedanke der Frühromantik war, daß das Wesen der Individualität nicht auf das menschliche Individuum beschränkt sei, daß man sie überall in Geschichte und Natur finden könne. »Burke und einige Deutsche waren es, « sagt Müller ${ }^{3}$ ), die »das Geheimnis von der Persönlichkeit der Besitztümer, der Gesetze der Menschen, der Staaten und der ganzen Natur« ahnten. Dabei zeigt aber Müller schon eine wichtige

1) Elemente 1, 204 .

2) S. oben S. 62 .

9) Vermischte Schriften 1, 120. Vgl. auch über Novalis: ,Lehre vom Gegensatze S. 27 u. 77, Norlesungen über deutsche Wissenschaft und Literature S. 73 . 
Abwandlung gegenüber der Frühromantik. Bei Novalis leuchtete, bei aller Hingabe an die Zusammenhänge des Alls, doch immer noch, wie wir sagten, die Souveränität des Individuums - der Gedanke, der die Frülıromantik mit dem klassischen Idealismus verband - hindurch. Bei Müller aber ist ihr Schimmer schon in Verblassen, und es hat, wenn man so sagen darf, die Individualität der iiberindividuellen Mächte den Sieg über das Individuum schon davongetragen, und dieses hat seine Souveränität verloren an die geschichtlichen Lebensmächte, von denen es umgeben ist.

Deswegen ist der Graben zwischen Müller und Fichte schon tiefer wie zwischen Fichte und der Frühromantik, und deswegen kann der Einfluß, den Fichte auf Müller nach unserer Meinung ausgeuibt hat, auch kein zentraler mehr sein. Aber man kann ihn immerhin in einigen Zügen erkennen. Handelt es sich doch in dieser ganzen Zeit um ein Zusammendrängen verschiedener Geister von verschiedenen Ausgangspunkten her, wo dann die Wege sich zum Teil unentwirrbar zuletzt kreuzen konnten. Und Vereinigung bisher getrennter Lebenssphären war überhaupt eines ihrer Grundbedürfnisse dabei. So sollten, nach Müllers Meinung, vor allem die Wissenschaften sich nicht mehr absondern von der Gemeinschaft des Staatsund Nationallebens. Er wollte zeigen, daß sie »verderben und verdunsten, daß ihnen alles Leben, dessen sie bedürfen, und alle Gemuitlichkeit, aller Kern, alle Kraft abgeht, sobald sic aus dem Verein mit dem Staat heraustreten und für sich selbst herrschen und bedeuten wollen." Keine einzelne Wissenschaft könne bestehen, wenn sie nicht eingreife in das gesellschaftliche Leben.")

Diese Auffassung vom Verhältnis der Wissenschaft zu Statat und Gesellschaft war im damaligen Deutschland noch verhältnismäßig neu. Das Staatsleben des I 8. Jahr-

1) Elemente 1, $63 \mathrm{ff}$. 
hunderts hatte wohl auch schon seine wissenschaftlichen Beihelfer gehabt in den gelehrten Juristen und Kameralisten, aber mehr als eine Hilfstruppe, die vom Zentrum der Wissenschaften aus detachiert war. Und die aus dem neuerwachten geistigen Leben hervorgegangenen jungen Vissenschaften hatten sich zunächst mehr vom Staate abals ihm zuentwickelt. Das wurde anders seit der Wende des Jahrhunderts, teils unter den Einwirkungen der großen Zeitereignisse, teils aus immanenten Bedürfnissen der Wissenschaften selbst oder, richtiger gesagt, der den Wissenschaften lebenden Menschen. So hatte kurz vor Adam Müller Fichte schon sagen können: „Selbst das Schweben in höheren Kreisen des Denkens spricht nicht los von dieser allgemeinen Verbindlichkeit, seine Zeit zu verstehen. Alles Höhere muß eingreifen wollen auf seine Weise in die unmittelbare Gegenwart, und wer wahrhaftig in jenem lebt, lebt zugleich in der letzteren." Als Gentz diese Stelle in den Reden an die deutsche Nation ${ }^{1}$ ) las, fiel ihm die Ubereinstimmung mit seines Freundes Adam Müller Denkweise auf: »Es muß doch in den eigentlichen echten Tiefen der Menschheit zuletzt alles zu einem Resultat führen; wie könnten sonst Köpfe, die von so durchaus verschiedenen Anfangspunkten ausgehen, wie Sie und Fichte, einander endlich wieder, sogar in einzelnen entscheidenden Außerungen und Worten begegnen: $\left.: 2^{2}\right)$

Sieht man freilich genau auf diese Begegnung, so sieht man auch in ihr noch eine charakteristische Diffe-

1) $7,4+7$.

2) 27. Juni rSoS. Briefwechsel, S. I4S. Diese Úbereinstimmung kann sich natiulich nicht auf das oben den, Elementen der Staatskunst entnommene Zitat beziehen, da diese Vorlesungen ja erst im Winter I $80 \$ / 9$ gehalten worden sind, sondern auf frühere, ähnlich lautende Worte Müllers in den sorlesungen über dentsche Wissenschaft und Literatur: (IS07) S. I I 6 u. I 36. 
renz. Fichte wollte wohl auch die Wissenschaft aus ihrer Isolierung herausreißen und $\mathrm{zu}$ innigster Gemeinschaft mit Nation und Staat führen. »Was wollen denn zuletzt alle unsere Bemühungen selbst um die abgezogensten Wissenschaften?" Offenbar sei es ihr letzter Zweck, 》zu rechter Zeit das allgemeine Leben und die ganze menschliche Ordnung der Dinge $z u$ gestalten ${ }^{1}{ }^{1}$ ) Solch unbedingtes Herrscheramt konnte ihr Adam Müller nicht zugestehen. Bei Fichte stehen Wissenschaft und Staat zueinander wie der Gebende zum Nehmenden. Bei Müller ist Geben und Nehmen auf beiden Seiten, und im Grunde sind sie eine untrennbare Einheit. "Wissenschaft und Staat sind, was sie sein sollen, wenn sie beide eins sind - wie die Seele und der Körper eins sind in demselben I.eben. $\ll^{2}$ ) Das hätte wohl auch Fichte sagen können, aber in anderem Sinne, im Sinne eines unbedingten Primates der Wissenschaft.

Andererseits erinnert wieder der Kampf, den Müller gegen den toten "Begriff « und fiir die lebendige 》Idee" des Staatsgedankens führt, an Fichtes schon frühe hervortretendes Streben, den Formalismus der Begriffe zu uiberwinden und ein Vereinigungsband des Staatsganzen aufzuzeigen, das "außer dem Begriffe liegt. $^{3}$ ) Freilich scheiden sich auch hier sofort wieder die Wege in dem, was dies Vereinigungsband und diese Seele des Staates sein sollte. Bei Fichte ist es immer nur der reine ethische Wille seiner Wissenschaftslehre, und die Freiheit, d. h. die Lebendigwerdung des Sittengesetzes, so daß es aufhört Gesetz zu sein, ist ihm Ziel aller Ziele. Einen so rein aus der Tiefe des eigenen Innern geschöpften Freiheitsgedanken sucht man bei Müller vergebens. Er erkennt wohl auch eine Idee der Freiheit an, die als eine große,

1) 7,453 .

2) Elemente I, 64.

3) Lask, S. 250 und 256. , Reden, 7, 386 . 
nie nachlassende Kraft der bürgerlichen Gesellschaft wirken muisse. $\left.{ }^{1}\right)$ Aber diese Freiheitsidee definiert er nur als eine »Begierde, seine Eigenheit zu behaupten, sich, seine Ansicht, seine Handlungsweise, seinen Gang, seine ganze Lebensform bei den ubrigen geltend zu machen. " Dieser zentrifugalen Freiheitsidee wirke auch als ewig gegenstrebende Zentripetalkraft die Idee des Rechts entgegen, und so sehr er die Lebendigkeit und Beweglichkeit auch dieser Rechtsidee betont, leidet es doch keinen Zweifel, daß sie in erster Linie das historische Recht, die von den vergangenen Generationen geschaffenen Daseinsformen, wahren soll gegenuber dem Freiheitsdrang der Individuen. Denn er ist durchdrungen davon, daß in diesem Werke der Jahrtausende von vornherein eine geheime Vernunft, ein dunkler Instinkt des Rechtes gewaltet habe. Fichte hatte in seinen Vorlesungen von I $\mathrm{SO}_{4}$ über das gegenwärtige Zeitalter die Entwicklung der Menschheit eingeteilt in das Zeitalter des unbewußt wirkenden Vernunftinstinktes, das der Sündhaftigkeit und das der bewußten Vernünftigkeit. Von diesen drei Zeitaltern läßt der Romantiker Müller sozusagen nur das erste, das des unbewußt schaffenden Vernunftinstinktes gelten, aber in ihm lebt und webt er nun auch ganz und gar. Fichtes Idee vom nationalen Staate war ganz nach vorwärts gerichtet, beruhte auf der Vorstellung von einer ganz neuen Art des geschichtlichen Werdens und mißachtete das bloße Beharren und Erhalten des Hergebrachten. $\left.{ }^{2}\right)$ So gläubig wie sein Zukunftsoptimimus, so gläubig ist Müllers Vergangenheitsoptimismus, der dann in den Jahren der Restauration immer

1) Elemente I, 209.

2) עIn der Erhaltung der hergebrachten Verfassung, der Gesetze, des bürgerlichen Wohlstandes ist gar kein rechtes eigentliches Leben und kein ursprünglicher Entschluß.s 7, 386. 
stärker wurde und zur quietistischen Anerkennung des Gerrordenen schlechthin und zur Unterordnung der Vernunft unter den Glauben fuihrte. ${ }^{1}$ )

Dann konnte er sich auch der tiefen Kluft ganz bewußt werden, die ihn von Fichte trennte, aber damals, in den Jahren nach 1807 , war sein Konservatismus und Historismus noch nicht so abgeschlossen, um nicht auch von dem damaligen Fichte zu lernen und vielleicht sogar einen Tropfen Blutes von ihm in sich aufzunehmen. Welchen starken Eindruck die "Reden" auch auf ihn machten, sieht man aus seinem Briefwechsel mit Gentz. ${ }^{2}$ ) "Was ist ", so heißt es dann in Miillers Berliner Vorlesungen uber Friedrich II. ${ }^{3}$ ), »das Anziehende an Fichte, das mit Recht Unwiderstehliche für seine Schiiler: Gewiß nicht die Konsequenz des Stoffes, der objelitive Wert der Lehre, sondern die unaufhörliche militärische Disposition des Gemüts, die Selbstverteidigung bis dahin und weit darüber hinaus, wo gar kein Mensch mehr anzugreifen scheint. « Daß bei Fichte sich alles Gedachte in Leben, Energie und Bewegung umsetzte, das war es, was auf Müller wirkte, was die denkwürdige Berïhrung zwischen zwei sonst feindlichen geistigen Welten ${ }^{4}$ ) möglich machte. Fichtes Tat war es gewesen, den Rationalismus in das Dynamische zu steigern

1) Vergleiche den Brief an Gentz vom 2. Mai is I9 (Briefwechsel, S. 279), wo er sich auch mit Fichtes Rationalismus und Intellektualismus auseinandersetzt: , Wer den Glauben des Gehorsams hat, wer an die Gesetze Gottes glaubt und an seine positiven Weltordnungen, nicht weil sievernünftig sind, sondern weil ihm alle Jahrhunderte sagen, daß sie von Gott herriihren... der ist orthodox; er ist ein Christe etc.

z) a. a. O. S. $14^{S}$.

5) S. 317 .

$\left.{ }^{4}\right)$ Müller hatte schon ISoI (Berliner Monatsschrift, Dez. ISoI, vgl. Vermischte Schriften 1, 324) gregen Fichtes geschlossenen Handels. staat polemisiert. 
und die Dynamik der Vernunft und des freien sittlichen IVillens hinuberzuführen auf das Gebiet des Staates, das er zwar dadurch nicht wirklich erobern und umwandeln, aber doch mit einer inneren Lebendigkeit erfüllen konnte, wie er sie bis dahin noch niclit gehabt hatte. Die Dynamik des Staats- und Gesellschaftslebens, die Müller uns klar machen will, ist von anderer Beschaffenheit, aber auch von höchster innerer Lebendigkeit. Leben erzeugt Leben, und so kann man die Vermutung wohl wagen, daß in dem Bilde des energisch bewegten Staatsund Nationallebens, das Müller vor Augen stand, einige kräftige Farben aus Fichtes Staatsideal stammen.

Dieses erschien uns durchaus ungeschichtlich und überempirisch, Müllers Staat dagegen geschichtlich-konkret. Aber so einfach ist der Gegensatz doch nicht. Indem Fichte uberhaupt die Möglichkeit einer Fortentwicklung und Steigerung des Staates durch Vernunft und sittliche Kraft lehrte, gehörte er zu denen, die von ethisch-rationalistischem Ausgangspunkte aus dem modernen Entwicklungsgedanken Bahn gebrochen haben. Adan Müller dagegen kennt auf dem Gebiete des staatlichen Lebens weder einen ethischen, noch den modern-historischen Entwicklungsgedanken. Er kennt im wesentlichen, von einzelnen historisch anmutenden Urteilen abgesehen, nur den Gegensatz und Dualismus von echtem und entartetem, von organisch-natürlichem und mechanisch-liunstlichem Staatsleben, das in Wahrheit für ihn freilich kein wirkliches Leben, sondern nur Schein des Lebens ist, während in den Tiefen doch die Natur der Dinge aller gewaltsamen Staatskunst zum Trotz weiterwirke. Aber erinnert nicht auch diese dualistische Entgegensetzung von echtem und unechtem Staatsleben wiederum ganz an Fichte und alle seine schroffen Zäsuren zwischen Ursprünglichem und Entartetem, alter und neuer Geschichte, wahrem Sein und scheinbarem Sein? Beide also, der Romantiker Miiller 
wie der aus der Autklärung hervorgegangene Fichte, stehen auf dem Grenzgebiete zwischen I8. und I9. Jahrhundert, zwischen geschichtlicher und absolutierender Denkweise, beide beharren bei einer dualistischen Einteilung der Erscheinungen des Staatslebens, beide vermögen es noch nicht, diejenigen geschichthichen Erscheinungen, die ihnen unsympathisch sind, mit geschichtlichem Verständnis zu durchdringen. Indem Müller zwar die geschichtlichen Mächte im allgemeinen dem unhistorischen Rationalismus gegenüber zur Geltung bringt, verkennt er die geschichtliche Macht, die auch in diesem steckte, und beginnt also ein geschichtliches Denken mit einem höchst ungeschichtlichen Akte.

IVir sahen, daß auch Novalis und Schlegel nicht anders verfahren waren. Das neu erschlossene geschichtliche Leben war ihnen an sich eine Musik voll Energie und Harmonie, der sie sich hingaben, aber von der sie zunächst nur die Harmonien und nicht die Dissonanzen gelten lassen wollten. Aber auch das war schon ein Großes und Fruchtbares, und die romantische Konzeption von dem unendlichen Reichtum des Weltalls an Individualität mußte mit der Zeit auch den Veg öffnen zum historisch-politischen Realismus des I9. Jahrhunderts, mußte schließlich die Vorstellung vom Normal- und Idealstaat, die jetzt in romantischen wie unromantischen Köpfen noch lebte, überwinden. Denn das Prinzip der Individualität, auf den Staat ubertragen, führte doch eben dazu, in jedem Einzelstaate eine Persönlichkeit zu sehen, die man von ihrem eigenen Boden aus und nach ihren eigenen inneren Gesetzen zu verstehen habe. Der erste Schritt dazu aber war, den Staat überhaupt als Individualität, als geschlossene, lebensvolle und eigenartige Einheit zu betrachten. Wir sahen, daß Novalis darin vorangegangen war; wir haben nun Müllers bedeutende Ansichten hierüber zu würdigen. 
Gleich zu Beginn seines Werkes uber die Staatskinst schlägt er dies Thema an ${ }^{1}$ ) und rückt der Lehre von Adam Smith vor, daß sie zu wenig Rücksicht nehme »auf die geschlossene Persönlichkeit der Staaten, auf ihren abgerundeten Charakter«. »Betrachtet man ", sagt

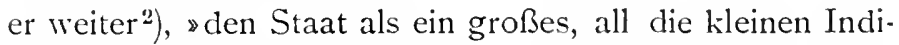
viduen umfassendes Individuum, sieht man ein, daß die menschliche Gesellschaft im ganzen und großen sich nicht anders darstellen kann, denn als ein erhabener und vollständiger Mensch - : so wird man niemals die inneren und wesentlichen Eigenheiten des Staates, die Form seiner Verfassung, einer willkürlichen Spekulation unterwerfen wollen. »nicht bloß ein Spielwerk oder Instrument in der Hand einer Person, eines Friedrichs, sondern er ist eine Person selbst, ein freies, in sich durch unendliche Wechselwirkungen streitender und sich versöhnender Ideen bestehendes wachsendes Ganzes«. Diese Art von Staatspersönlichkeit ist etwas ganz anderes, als was fruher etwa schon einzelne naturrechtliche Denker meinten, wenn sie eine juristische oder moralische Person des Staates oder Volkes konstruierten ${ }^{4}$ ), - sie ist ein Lebewesen, das in allen seinen Gliedern und Funktionen von Vitalität und Geist iiberquillt und auch nur wieder im Zusammenhang des ganzen, von Persönlichkeit durchdrungenen Weltalls steht. Alles im Staate, Gesetze, Einrichtungen, Sachen, gewinnt Leben für ihn. Das ist eben das große »Geheimnis von der Persönlichkeit der Besitztümer, der Gesetze, der Menschen, der Staaten und der ganzen Natur. $\left.\ll^{5}\right)$

1) Elemente I, IS.

2) 1,256 .

3) Vermischte Schriften I, 221 .

4) Vgl. Gierke, Althusius, 2. Aufl., S. I 5 ff. und IS9 ff.

5) Vermischte Schriften I, I 20. 
Aus dieser Beseelung und wahrhaften Personifizierung des politischen Lebens, aus dieser Verwandlung aller politischen Begriffe und Kategorien in lebendige konlirete Mächte ergeben sich die wichtigsten Folgerungen. Zunächst eine neue und tiefere Ansicht vom Verkehr und Kampf der Staaten untereinander. Die Vorstellungen von Völkerrecht und Gleichgewicht sind ihm, im gewöhnlichen Sinne gebraucht, viel zu formal und äußerlich, viel zu sehr toter Begriff, um eine Ahnung des Wirklichen zu geben. Vielmehr könne man das Wort Gleichgewicht nur gelten lassen, wenn man darunter verstehe »gleichmäßiges WVachstum, gegenseitiges Sichsteigern und erheben der Staaten ${ }^{1}$ ) Geraten sie in Kampf miteinander, so ist »dieser Rechtsstreit zu groß, als daß der einzelne Mensch weiter darin Richter sein könnte; denn wie vermöchte er das Leben dieser gewaltigen Individuen allgegenwärtig zu durchdringen?«. Eben, weil sie Individuen sind, stoßen sie aneinander an. »Alle diese Staaten, die wir als große Menschen, menschlich an Körperbau, Gemïts- und Denkart, Bewegung und Leben dargestellt haben, sollen unabhängig und frei sein wie das Individuum im einzelnen Staate... In ihrer eigentiimlichen nationalen Form und Manier sollen sie wachsen und leben und sich einander geltend und fühlbar machen. $\ll^{2}$ ) Und wiederum entwickeln sie durch diese Reibung gegeneinander auch sich selbst.

Damit fällt auch auf den Krieg ein besonderes Licht. Er gehört, so stellt sich nun heraus, zum Wesen des Staates, er ist die große Schule des Charakters und der Eigenart des Staates. Er ist es, »der den Staaten ihre Umrisse, ihre Festigkeit, Individualität und Persön-

1) Elemente 1, $2 s_{3}$.

2) a. a. O. 283,285 . 
lichkeit gibt. $\left.{ }^{1}\right)$ Dann verlangten auch die politischen Interessenkämpfe der Staaten untereinander nach anderen Maßstäben beurteilt zu werden als sie das moralisierende Publikum bisher anzulegen gewohnt war. »Es waren nicht sowohl die Ansichten der Kabinette, welche den Krieg bestimmten; es war niemals der Eigensinn der Regierenden, wie ein verweichlichter, verderbter Pöbel sich die Sache denken mochte: es waren immer tieferliegende, in der notwendigen Konstruktion der gesamten Staatenverhältnisse liegende Gründe. Ein innerer, der gegenwärtigen Generation völlig unbewußter, aus dem Anstoße fruherer Generationen herrührender Drang nach lebendigen IVachstum war auch das eigentliche Mobil der Kriege, die in den vorletzten Jahrhunderten einzelne Staaten für ihre Vergrößerung unternommen haben. $\left.\ll^{2}\right)$ IVie Ranke'sch mutet das alles schon an: der Staat als geschichtlich gewordene Individualität, die Konstanz und Kontinuität seines Wesens und Lebens über die Spanne des Einzeldaseins hinausreichend, die neue Würdigung der Maclit- und Interessenkämpfe der Staaten untereinander als ihrer aus innerer Notwendigkeit geübten Lebensfunktionen, kurz, die tiefere Begründung und Bewertung der großen Politik. Bei Ranke hat das freilich alles noch viel mehr Klarheit und Durchsichtigkeit, bessere empirische Begriindung und iiberhaupt erst eigentlich wissenschaftliche Form. Aber die romantische Herkunft gerade einiger seiner Haupt- und Lieblingsgedanken wird hier ganz klar, und es ist nicht unmöglich, daß er insbeson-

1) 3,6; vgl, auch $\mathrm{I}, 15$ und 107 .

2) Elemente I, 287 f.; ähnlich I, I07. Ganz schief ist also das Urteil Dombrowskys : , Gegen die Politik der Kabinette . . . hatte er den Widerwillen der Weltanschauung usw, s (Ad. Muiller, d. histor. Weltanschauung u. die polit. Romantik; Zeitschr. f. d. gesamte Staatswissenschaft 1909, S. 389 ). 
dere von Adam Müller stärkere Anregungen erhalten hat, als man bisher gewußt hat. ${ }^{1}$ )

Alle diese fruchtbaren Ideen Müllers gipfeln nun aber in dem Gedanken, daß das eigentliche Lebensprinzip der Staaten die »Nationalität« sei. Das Wort war damals ganz jung ${ }^{2}$ ) und hatte damals noch weniger wie später einen konstanten und eindeutigen Sinn, so daß derjenige, der etwas Besonderes damit sagen wollte, allen Grund hatte, diesen Sinn erst zu fixieren. Dies tat

1) In Rankes ausgewähltem Briefwechsel (Zur eigenen Lebensgeschichte, S. 173) begegnet nur einmal (1827) der Name Müllers in rein persönlicher Sache.

2) Vgl. F. J. Neumann, Volk und Nation (I888), S. $5_{2}^{2}$ ff, und Kirchhoff, Zur Verständigung iiber die Begriffe Nation und Natio. nalität (1905), S. 59 ff. Letzterer meint wohl mit Recht: ,Das Wort Nationalität ... scheint nicht weit iber den Anfang des I9. Jahrhunderts zurïckzureichen. Am frühesten fand ich es bei Gelegenheit dieser Studien gebraucht von Novalis I798 (Athenaeum I, I, 87; Schriften hg. von Heilborn 2, I5): ,Unsere alte Nationalität war, wie mich dünkt, echt römisch $=$ natürlich, weil wir auf eben dern Wege wie die Römer entstanden etc, " - dann I $\$ 00$ bei Wilbelm v. Humboldt (Briefwechsel mit Goethe, S. I68), der über die Staël sagte: ,Es ist ein wunderbares Phänomen, mitten in einer Nation manchmal Menschen zu finden, die einen fremden Geist in diesen Banden der Nationalität tragen. Im gleichen Jahre (I800) auch bei Görres (Polit. Schriften, 57 und 201). Fr. Schlegel gebraucht es wiederholt in den philosophischen Vorlesungen von I $804 / 6(2,358,386)$, Ad. Müller I 805 bei Maurer-Constant, Briefe an Joh. v. Müller 3, ro3. Gentz I 806 in der Vorrede zu den Fragmenten aus der neuesten Geschichte des politischen Gleichgewichts in Europa (Ausgew. Schriften, hg. v. Weick 4, I9), Fichte in den Reden $(7,485)$ und in der Statslehre von I $S_{1} 3$ (4, 429). Um diese Zeit war es schon sehr verbreitet. Vgl. Heerens Aufsatz von ISIo, Über die Mittel der Erhaltung der Nationalität besiegter Völker (Histor. Werke II); Heinichen, Die Staatsweisheitslehre oder die Politik von Johann v. Mitller (IS10), S. I 22 ff.: \# Wodurch wird die Nationalität einer Nation bewahrt?s; Stein ISO7 (Pertz I, 437), i Si I, s. unten Kap. S; Savigny, Vom Beruf unserer Zeit usw., 2. Autlage, S. 37; Niebuhr in seiner unten Kap. 9 behan. delten Schrift von ISI+. 


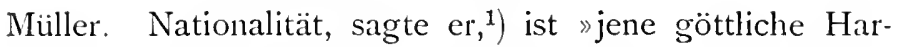
monie, Gegenseitigkeit und Wechselwirkung zwischen dem Privat- und öffentlichen Interesse. « Dasselbe meint er offenbar, wenn er ein andermal ${ }^{2}$ ) Nationalität »die Ausbildung, die Befestigung des bürgerlichen Gemeinwesens" nennt, wenn er die »Sehnsucht nach Nationalität « gleichsetzt mit der »Sehnsucht nach Verbindung und Wechselwirkung unter den Menschen. « ${ }^{3}$ ) In den Vorlesungen über Friedrich II. ${ }^{4}$ ) setzt er zwar »eigentliche Nationalität " mit »wahrer Freiheit und Unabhängigkeit « gleich, aber eines wie das andere könne nicht stattfinden, 》so lange Staat und Bürger zweien Herren dienen ... so lange die Herzen innerlich zerschnitten sind in ein doppeltes Verlangen, das eine, in bürgerlicher Ordnung im Staate zu leben,... das andere, sich von der ganzen bürgerlichen Ordnung wieder auszunehmen, sich mit seinem Hauswesen und seinem ganzen Privatleben und den heiligsten Empfindungen, ja selbst mit seiner Religion, wieder herauszuschneiden aus demselben Staate.

Danach ist es ganz klar, daß sein Nationalitätsbegriff durch und durch politisch ist und die innige Verbindung und Durchdringung von Staat, Volk und Individuum, öffentlichem und privatem Dasein bedeutet. So berührt er sich mit dem geistreichen Nationalstaatsgedanken von Novalis, während er grundverschieden ist von dem Fichteschen Nationalbegriff. Denn dieser ging ja aus von der Kulturnation, von der Sprach- und Kulturgemeinschaft des gesamten deutschen Volkes, die er sich zum Repräsentanten der Menschheit steigerte, während er den deutschen Einzelstaat mißachtete und den Staat

1) Elemente, 2 I 66 .

2) Daselbst 2, 2.40 .

3) Daselbst 3, 253,

4) S. 37 .

Neinecke, Weltbürgertum und Nationalstaat. 2. Aufl. 
überhaupt nur als Kulturstaat, - auch dieses Wort hat Fichte vielleicht zuerst geprägt $\left.{ }^{1}\right)$ - als Mittel zum Vernunftreich schätzt. Adam Müller dagegen geht, wie Novalis und schließlich auch Friedrich Schlegel, von den geschichtlich gegebenen Staatsgemeinschaften aus. In Fichtes Nation dominiert das universale Element, in Muillers Nation das Element der historisch-politischen Besonderheit. ${ }^{2}$ ) Er spricht ausdrïcklich von einer » preußischen ", von einer »österreichischen "Nation. ${ }^{3}$ ) Besonders instruktiv ist, was er über die preußische Nation und Nationalität sagt. Sie ist ihm ein Ergebnis historisch-politischer Vorgänge. "Die preußische Nationalität war größtenteils nur Frucht siebenjähriger Anstrengungen «4), und weil sie auf zu schwachen Grundlagen beruhe, so habe die bewußte Arbeit diese ergänzen müssen. Und er sah darin nicht schlechthin, wie so viele andere, die vor ihm und nach ihm ähnlich urteilten, einen Mangel, sondern der Mangel bedeute zugleich eine hohe Aufgabe. "Die preußische Monarchie, wie anders ihr Beruf scheinen möge, ist von der Natur vor allen anderen europäischen Staaten und zuerst dazu bestimmt, jene Nationalität, welche die

1) $\mathrm{Er}$ gebraucht es $\mathrm{ISO}_{4}$ in den Grundzïgen des gegenwärtigen Zeitalters (Werke 7,200 ) und $\mathbf{1} S 06$ in den Dialogen über den Patrio. tismus (Nachgel. Werke 3, 230).

2) Daraus erklären sich auch die oben S. 139 angedeuteten modernhistorisch anmutenden Einzelurteile Müllers, auf die Dombrowsky a. a. O. S. $390 \mathrm{ff}$. hinweist. Es handelt sich hier namentlich um Muillers Spott iiber die Nachahmer des von ihm selbst höchlichst bewunderten Englands. Er ist noch nicht, wie D. meint, schlechthin modern-historisch empfunden, sondern fließt, von seiner politischen Tendenz abgeseben, aus dem romantischen Sinn fur die unübertragbare Individualität der geschichtlichen Einzelerscheinung, der gerade recht unhistorisch werden konnte, wenn er die Übertragbarkeit von Einrichtungen der einen Nation. auf die andere überbaupt leugnete.

9) Vermischte Schriften I, 268.

$\left.{ }^{4}\right)$ Elemente 3, 193. 
Natur ihr versagen will, durch wahre Kunst und mit Bewußtsein zu erzeugen. «1) So konnte doch auch dieser Romantiker einmal der bewußten und planmäßigen Tat ihr Recht im geschichtlichen Leben lassen und sich darin mit Fichte innerlich berihhren.

Man kann gespannt sein, wie sich Müller bei solchen Anschauungen über clas IVesen der Nation zu dem Problem der deutschen Nation stellt. Da sie keine staatliche Einheit bildete, lionnte er sie kaum als eine Nation in seinem Sinne, als eine geschlossene politische Individualität anerkennen. Es ist merkwürdig, wie er trotzdem, als Beobachter des wirtschaftlichen Lebens in Deutschland und seiner Bedürfnisse, in den Elementen der Staatskunst den Satz zu vertreten wagt, daß Deutschland für seine ökonomische Existenz die politische Einheit brauche. Gewiß spiegeln sich darin auch die großdeutschen Stimmungen vom Vorabend des österreichischen Krieges von I 809. Gewiß waren es dann wieder die deprimierenden Erfahrungen von ISo9, die ihm dies Ideal wieder raubten, so daß er in seinen Vorlesungen uber Friedrich II. erklärte: "Auch ich habe viel von einer Verbindung jenes größeren Volkes geträumt, zu dem wir gehören, wie der Zweig zum Stamme gehört, Revolutionen erwartet und Helden und mancherlei Veränderungen in den Gesinnungen der Völker, die kommen und den Traum begünstigen sollten. $\ll^{2}$ ) Jetzt indes, so schließt er, komme es darauf an, für das Nächste zu sorgen und sich zu begeistern für das besondere Vaterland, den besonderen Herrn und seine hundertjährige Krone.

In demselben Zusammenhange aber und mitten dazwischen entwickelte er Ansichten über das Verhältnis von deutschem und europäischem Dasein, die uns sofort

\footnotetext{
1) Über König Friedrich II., S. 16.

2) S. 58 .
} 
bekannt anmuten und an alle früher behandelten Denker erinnern werden: „Der große Föderalismus europäischer Völker, welcher dereinst kommen wird, so wahr wir leben, wird auch deutsche Farben tragen; denn alles Große, Gründliche und Ewige in allen europäischen Institutionen ist ja deutsch. - Das ist die einzige Gewißheit, die mir unter allen jenen Hoffnungen verblieben ist. Wer kann das Deutsche noch herausscheiden und schneiden aus dem Europäischen! Der Same des deutschen Lebens ist ja in diesen letzten Völkerstürmen nur immer weiter und weiter verbreitet worden über den Boden unseres Weltteils: Er wird fortwuchern und von ganz unscheinbaren Anfängen zu gewaltigen Wirkungen allmählich fortschreiten; sein Wachstum überlasse man der ewigen Natur, «1) So teilte also auch er jene Vorstellung von der hohen universalen Aufgabe des deutschen Volkes, die uns in mannigfacher Ausprägung bei Humboldt, bei Schiller, bei Novalis und Schlegel und zuletzt bei Fichte begegnete. So sehen wir denn die weltbürgerlichen Ideale der bisherigen deutschen Kultur auch in die romantische, historisch-politische Gedankenwelt Müllers hineinragen. Und hatte Müller, im Anschluß an Novalis und im Gegensatz zu Fichte, den Schritt nach vorwärts getan, den deutschen Einzelstaat als Nationalstaat im politischen Sinne zu würdigen, so tat er hier, wo es sich um das Problem der deutschen Nation im ganzen handelte, sogar wieder einen Schritt zurück hinter Fichte. Denn dieser faßte zwar auch die deutsche Nation als Menschheitsvolk auf, wollte sie aber doch zunächst geschlossen und rein für sich erhalten, während Müller vielmehr den Beruf des deutschen Geistes darin sieht, auseinanderzuströmen über Europa, aufzugehen in ihm, um

Ahnlich schon die , Vorlesungen uber deutsche Wissenschaft und Literaturs Seite 54. 
es zu befruchten, so daß deutsches und europäisches Leben eine untrennbare geistige Einheit bilden.

Und dieses weltbürgerliche Kulturprogramm blieb nicht der einzige Rest weltbürgerlicher Ideen. IVohl sahen wir Müllers historischen Realismus in seiner IVürdigung der europäischen Machtkämpfe, in seiner lebendigen Vorstellung von den großen Staatspersönlichkeiten Europas so bedeutend hervorbrechen; wohl machte er es sich selbst zur Aufgabe, den weltbürgerlichen Sinn der Deutschen zu bekämpfen, »indem ich ", so sagt er einmal, จ das Wesen des nationalen und staatsbürgerlichen Charakters rechtfertige, welcher der schalen, iber den ganzen Erdball zerfließenden Weltbürgerlichkeit erst Haltung gibt. $\left.\ll^{1}\right)$ Er wußte wohl ganz deutlich, wie schwer es seinen Zeitgenossen wurde, aus dem alten, allgemeinen und absoluten Staatsideal hinüberzutreten auf den Boden des individuellen Nationalstaates. „Gegen diese Idee des besonderen Staates oder der Nationalität lehnt sich unser Zeitalter auf, wie es noch kein früheres getan hat $\left.\ll^{2}\right)$, und er konnte sich nicht mit Unrecht etwas darauf zugute tun, daß er gründlicher als sonst irgend jemand die Notwendigkeit abgesonderter Staaten zur Entwicklung: der Menschheit dargetan habe. ${ }^{3}$ ) Aber sein eigenes politisches Denken und Streben ging eben doch noch nicht im abgesonderten Nationalstaate auf. Die von ihm selbst mitgefundenen neuen Wahrheiten genuigten ihm noch nicht, er bedurfte neben der neuen nationalen Speise auch noch etwas von der alten universalen Nahrung. "In dem Herzen des einzelnen Menschen, in wie gliucklichen Verhältnissen er auch als Bürger lebe, wie mächtig das Vaterland alle seine Neigungen auch fessele.... bleibt

1) Elemente 3, I7 I.

2) Daselbst 3, 223.

3) Daselbst 3, 212 . 
dessenungeachtet eine unausgefüllte Seele zurïck: unter aller nationaler Befriedigung noch Raum zur Sehnsucht. «1) Aus dieser Sehnsucht entsprang jene Idee eines zukünftigen europäischen Föderalismus, die wir als ein Inventarstiick weltbiirgerlicher Politik kennen gelernt haben, und es war ihm mit ihr nicht minder ernst, als mit seinem Nationalstaate. „Entschließt euch, an zwei Dinge zu glauben, kräftig mit Aufopferung alles dessen, was ihr Euer nennt! Zuerst an den Staat, an die nationale, von den Vätern ererbte . Form eines bürgerlichen Gemeinwesens, eines Vereins auf Tod und Leben für eine bestimmte lokale und nationale Idee des Reiches... zweitens, was aus dem ersten Glaubensartikel folgt: an eine rechtliche Gemeinschaft wahrer Staaten, und sollten es auch vorläufig nur zwei oder drei untereinander sein. $\left.\ll^{2}\right) \quad 》 W$ ir fühlen, « heißt es an anderer Stelle, $\left.{ }^{3}\right)$ »es gibt keinen bloßen, reinen Patriotismus mehr, wie ihn die Alten nährten, ein gewisser Kosmopolitismus geht ihm zur Seite und mit Recht; denn es kommt auf zwei Dinge an: auf das Vaterland und auf den Staatenbund, deren eins, abgesondert für sich, ohne das andere nicht mehr begehrt werden kann.*

Man konnte gewiß, wir erinnern an friher Gesagtes, $\left.{ }^{4}\right)$ auch von rein historischen und empirischen Beobachtungen aus zu der Uberzeugung kommen, daß das Staatsleben der romanisch-germanischen Völkerwelt nicht ausschließlich aufgeht im Selbsterhaltungstrieb der einzelnen Staatspersönlichkeiten und in ihrem Kampfe um das Dasein, daß große Gemeinsamkeiten vorhanden sind nicht nur in ihren geschichtlichen Grundlagen,

1) Elemente 3, 234.

2) Daselbst 3, 234.

3) Daselbst 3, 296.

4) Oben S. 83 . 
sondern auch in ihren natürlichen Interessen und Zielen. Man konnte zumal in der damaligen Weltlage ihrer inne werden und, wie das Beispiel seines Freundes Gentz zeigt ${ }^{1}$ ), sie gerade deswegen kräftig betonen, weil es galt, durch ihre Hilfe die bedrohte Autonomie der Einzelstaaten zu schiitzen. Man kann ferner auch vom Standpunkt moderner Erfahrungen aus noch hinzufuigen, daß die zunehmende individuelle Differenzierung der einzelnen Großstaaten und die innere kräftigere Herausarbeitung ihrer Eigenheiten diesen Bestandteil an Gemeinsamkeiten keineswegs gemindert, sondern eher gemehrt hat. Aber solcher rein realistischen Abschätzung der internationalen und nationalen Güter war Adam Müller noch nicht fähig. Sein Ideal der europäischen Staatengemeinschaft entsprang nicht einer rein historisch-politischen, sondern einer zugleich auch religiösen Weltbetrachtung. Nicht Gesetze und Traktaten fur sich, meint $\left.\mathrm{er}^{2}{ }^{2}\right)$ können diese erhabene Gemeinschaft schließen. Die Kirche ist es, die sie einst geschlossen hatte; sie nur kann sie wieder herstellen. „Es muß ein Gesetz geben, das noch höher ist, als die Selbsterhaltung des individuellen Staates, einen Bund zu gegenseitiger Garantie unter den individuellen Staaten, und dieses Gesetz muß mit seiner Notwendigkeit jeden einzelnen Staat bis in seine geheimste Stelle, es muß jeden einzelnen Bürger durchdringen. Woher anders könnte dieser Geist zu schöpfen sein, als aus der Religion der Gegenseitigkeit,

1) Vgl. Gentz, Über den Ursprung und den Charakter des Krieges gegen die französische Revolution (ISor), Ausgew. Schriften, hg. von Weick, 2, 195 ff., und seine Fragmente aus der neuesten Geschichte des politischen Gleichgewichts in Europa (1805 bezw. 1806), daselbst 4, Is u. 66 ff. Über Gentz' Verhältnis zur Romantik vgl. auch Varrentrapp, Histor. Zeitschr. 99, 50, Anm. 2 u. F. C. Wittichen, Gentz' Stellung zum deutschen Geistesleben vor ISo6, Histor. Vierteljahrsschrift 14, ++ ff.; s. auch oben S. $126 \mathrm{ff}$.

2) Elemente 3, $224 \mathrm{f}$. 
die schon einmal Völker von den mannigfachsten Sprachen und Sitten innig miteinander verband $\ll .^{1}$ )

Adam Müller war schon I 805 zur katholischen Kirche iibergetreten, und man muß es anerkennen, daß dieser Schritt für ihn etwas anderes bedeutete, als für manchen Anderen der romantischen Konvertiten. Wohl entsagte er damit einem ungefesselten Subjektivismus, aber nicht aus innerer Erschöpfung, auch nicht in forciertem Bruche mit einer bisherigen friedlosen Freiheit. Seine fruchtbarste und interessanteste Gendankenarbeit hat er viel. mehr gerade in den Jahren nach seinem Ubertritt geleistet, und er blieb auch in der selbstgewählten Gebundenheit frei genug, um in dem preisgegebenen Protestantismus das »heilige, unveräußerliche Prinzip der Freiheit und demnach der Allgegenwärtigkeit der Religion " rundweg anzuerkennen. ${ }^{2}$ ) Aber man sieht daraus, daß auch sein Katholizismus noch einen höchst romantischen und subjektiven Charakter trug, und auch das war echt romantisch an ihm, daß er sogleich hinuberfloß auf das politische Gebiet und nach innerer Vereinigung religiöser und politischer Sphäre strebte. Er hielt es geradezu für das große Gebrechen der Zeit, daß die politischen Beziehungen der christlichen Religion vergessen seien, er bestritt die Meinung, daß die Religion mit den sogenannten weltlichen Dingen nichts zu schaffen habe, er forderte, daß das unsichtbare und doch so mächtige, so bewegliche Gesetz der Religion « den Verkehr der großen Staaten Europas untereinander regulieren misse ${ }^{3}$ ). Und die Geistlichkeit insbesondere - wir erinnern uns der ganz ähnlichen Ideen Friedrich Schlegels - habe die große Bestimmung, die Staaten untereinander und den Einzel-

1) Elemente 3, 226.

2) Daselbst 3, 323. Er rühmt z. B. auch den Tiefsinn von Schleiermachers Reden iuber die Religion. Daselbst 3, 255.

y) Daselbst I, 297. 
nen im Staate mit der Gesellschaft zu verknüpfen, »alle ausschweifende Größe durch die Macht der Idee wieder in die gerechte Bahn zurückzuführen und endlich den Geist einer gewissen sittlichen Gleichheit und christlichen Gegenseitigkeit in allen bürgerlichen Verhältnissen aufrecht zu erhalten $\ll^{1}{ }^{1}$ ) Wenn solche Meinung irgendwie greifbaren politischen Sinn bekommen sollte, so konnte es nur auf eine Erneuerung der ultramontanen Herrschaftsansprïche hinauslaufen. Wir glauben nicht, daß Müller selbst damals diese ultramontane Konsequenz seiner luftigen Ideen sich klar gezogen hat. Vielmehr entsprangen sie noch dem Bedürnis des Romantikers nach Totalität und Einheitlichlieit des Weltganzen. Aber so kam er nun schließlich dahin, sich aufzulehnen gegen die Durchführung seines eigenen Realismus. Denn er fürchtete, wenn er ihm zu weit nachgäbe, in einen unlösbaren Konflikt, in einen unerträglichen Riß zwischen christlicher und heidnischer Lebensauffassung $z u$ gelangen. Er wollte es schließlich also doch nicht zugeben, daß die absolute Selbsterhaltung die erste Pflicht des Staates sei ${ }^{2}$ ). IVer nichts kenne als sie, der könne, wenn er an die Erfahrungen der Geschichte und an den IVechsel der Staatenschicksale denke, nicht zur völligen inneren Ruhe über das Schicksal eines Staates kommen und müsse eine Art von politischer Todesfurcht empfinden. Aber sei denn nicht, meint er halb geistreichelnd, halb ernst, Christus in die Welt gekommen, um auch die Staaten von ihrem Tode zu erlösen? Bedürfe nicht auch die Staatenpersönlichkeit eines Mittlers?

Lassen wir solche romantisierende Mystik auf sich beruhen. Hier galt es festzustellen, daß die höchst bedeutenden Ansätze zu einem historisch-politischen Rea-

1) Elemente 2, 106.

2) Daselbst 3, 233 ff. und 226 . 
lismus im Sinne Rankes, die wir bei Muiller wahrnahmen, in ihrer Entfaltung zurückgehalten sind durch universalistische Träumereien, in denen das romantisch-mystische und das katholische-hierarchische Element durcheinander spielen. $\left.{ }^{1}\right)$

1) Wie sich seine Gedanken iiber europäische Föderation und die Rolle der römischen Kirche dabei im Sinne de Maistre's weiter entwickelten, zeigt sein Briefwechsel mit Gentz aus den Jahren 1820/21. 


\section{Achtes Kapitel.}

\section{Stein, Gneisenau und Wilhelm v. Humboldt in den Jahren $1812-1815$.}

Aus zwei großen Quellen flossen, - das wird aus den bisherigen Erörterungen sich aufgedrängt haben -. die Ideen, die wir behandelten; aus zwei Hauptursachen ist die eigenartige Legierung von nationalen und universalen, politischen und unpolitischen Bestandteilen in ihnen zu verstehen: Aus den inneren Tendenzen des geistigen Lebens einerseits, aus den großen Eindriicken und Antrieben der Weltlage andererseits. Der deutsche Geist in seinem neuen Bedurfnisse, die Ideen auch in der Wirklichkeit und als lebensvolle Individualitäten wiederzufinden und die Wirklichkeit nach den Ideen zu gestalten, ergriff den Gedanken der Nation in einer noch hochuniversalen Stimmung und durchdrang das Eine mit dem Anderen. Die Weltlage aber stellte an die Nationen und Staaten die Forderung, sich dadurch selbst zu erhalten, daß sie sich eng aneinanderschlossen. Nationale Autonomie und universale Föderation trieben einander wie zwei ineinander verzahnte Räder. So ist es wohl leicht begreiflich, daß die ungeheure Wucht der Erlebnisse, die auf solch Zusammenwirken hindrängten, das Denken und Empfinden der Zeitgenossen noch tiefer in die Richtung hineinfuilurte, in der sie schon waren. Wie aber stand es, wird man nun fragen, mit den Gedanken und Entschliissen der handelnden Staats- 
männer selbst: Handelten auch sie, wenn sie jetzt nationale und europäische Interessen zugleich wahrnahmen, unter jenem Doppeldrucke geistiger Ideale und politischer Notwendigkeiten des Momentes? Letzteren wird man ohne weiteres bei ihnen zu vermuten haben, aber eben deswegen wird man den ersteren um so schwerer nachweisen können, und wozu, wird man einwenden, bedarf es auch der ideengeschichtlichen Motivierungen, wo man mit realpolitischer Zweckmäßigkeit die Dinge einfacher und natïrlicher erklären kann? Dic Schwierigkeit, die einer methodischen Erkenntnis bereitet wird, liegt also darin, daß die rein politische Aufgabe des Einzelstaates und der Einzelnation zum großen Teil zusammenfiel mit der universalen Aufgabe, Europa zu einigen und zu befreien, daß gesunder staatlicher Egoismus und Universalismus im Sinne der politischen Romantik zum großen Teile dasselbe wollten. So wird man. wenn man auch hier auf Spuren der Wirkung jener geistigen Ideale zu stoßen glaubt, nur mit größter Vorsicht operieren müssen. Man wird vor allem die Persönlichkeiten genauer zu sondern haben. Die Männer von geringerem Stoffe, die politischen Eklektiker, aber auch die Staatsmänner der reinen Staatsund Machtraison wird man mit anderem Maßstabe zu behandeln haben, als diejenigen, in denen neben dem Staatsmann auch der Mensch und die geistige Persönlich. keit stärker mitsprechen. In den einen ist die Herrschaft der Idee enger begrenzt als in den anderen, und wo sie auf den ersten Blick vielleicht zu herrschen scheint, dient sie doch oft nur dazu, das reale Interesse zu verkleiden. Wer wollte es wagen, aus den Noten der Diplomaten, aus den préambules der Staatsverträge innerste ideale Motive und Impulse herauszulesen:

Anders steht es aber mit den drei Männern, deren Gedanken uiber die zukünftige Gestaltung Deutschlands in den kritischen Jahren I8I2-ISI5 wir untersuchen 
möchten. Für sie waren die geistigen Ideale ihrer Zeit nicht bloßer Schmuck der Rede, auch nicht bloß ein Bildungsmittel, wie es wohl auch der reine Staatsmann auf sich wirken lassen kann, sondern eine stete Lebensnahrung, deren sie auch im Drange des Handelns nie ganz entraten konnten. So ließen sie sich so tief von ihnen durchdringen, daß sie nicht nur zu bewußten moralischen Uberzeugungen, sondern auch zu unbewußten Voraussetzungen ihres Tuns und Denkens werden konnten. Auch wird jeder, der nur etwas von ihnen weiß, dies zugeben für ihre nationalen Ideale, freilich nur, um in der Regel hinzuzusetzen, daß sie damit dem weltbürgerlichen Geiste sich entgegengeworfen hätten. Und insbesondere wird dies von der hergebrachten Auffassung dem Freiherrn v. Stein nachgesagt. Wir wissen nun schon, wie es in Wahrheit mit diesem Gegensatze beschaffen war, wissen ferner, daß auch die Romantik, deren Einfluß auf Stein durch seinen neuesten und bedeutendsten Biographen überzeugend nachgewiesen worden ist, nicht nur Nationalismus, sondern auch Kosmopolitismus mit neuen Vorzeichen war, und wagen nunmehr die Behauptung, daß der Freiherr vom Stein in eben den Jahren, in denen er am stärksten gestrebt und gedacht hat fuir die Zukunft der deutschen Nation, zugleich auch beigetragen hat zur Entwicklung jenes Systems der politischen Romantik, das man später das der heiligen Allianz genannt hat. Er schaute, sagt Lehmann'1), im Geiste bereits den deutschen Nationalstaat, aber noch nicht, müssen wir hinzusetzen, den autonomen Nationalstaat, sondern den durch universale Prinzipien gebundenen. ${ }^{2}$ )

1) Stein 3, 19I.

2) Die Einwände, die Ulmann (Über eine neue Auffassung des Frh. vom Stein, Histor. Vierteljahrsschrift r9ro, $153 \mathrm{ff}$.) dagegen erhoben hat, haben mich nicht uberzeugt, wohl aber hier und da zu einer schärferen Fassung und Rechtfertigung meiner Argumente veranlaßt. 
Man muß dafür ausgehen von der Beobachtung, daß Stein die politische Befreiung Deutschlands nicht als eine rein deutsche Angelegenheit, sondern zugleich auch als eine europäische und mit europäischer Hilfe durchzuführende behandelt hat. Wir haben allerdings das große und starke Wort von ihm aus dem Jahre i So9: NDeutschland kann nur durch Deutschland gerettet werden ${ }^{1}$ ), aber dies Ideal der reinen nationalen Autarkie, das in einem gehobenen Momente allerdings sein Inneres erfuillen konnte, hat er I8I2 nicht festgehalten. Er meinte im September dieses Jahres zum Grafen Münster ${ }^{2}$, daf Deutschland sich jetzt in einer ähnlichen Lage befincle, wie zur Zeit Gustav Adolfs. Er hoffte auf einen Befreier aus dem Auslande, er hoffte vor allen damals auf England, das des Beistandes sowohl von Rußland wie von Schweden sicher sei und sich eines großen Vertrauens in Deutschland erfreue, da man überzeugt sei, daß sein und Deutschlands wahrer Nutzen übereinstimme. Dieser Gedanke, wird man einwenden, sei schon rein aus der damaligen politischen Situation heraus verständlich als das einzige Rettungsmittel, das damals einem deutschen Patrioten noch übrig geblieben sei. Deutschland selbst trug die Waffen für Napoleon, und Zar Alexander betrieb eben damals jene Pläne auf Wiederherstellung Polens, die Stein für absurd und gefährlich hielt, weil sie Europa beunruhigen und insbesonders Osterreich, die größte deutsche Macht, abschrecken würden, sich auf die Seite der Gegner Napoleons zu schlagen. Eben deswegen, meinte er am I2. November I8 I 2 zu Pozzo di Borgo ${ }^{3}$ ), müsse England jetzt leading poiver sein. In dem Zusammen-

1) An Gneisenau, 20. Februar I So9. Lehmann 3, 25; es klingt an Adam Miillers Wort (Elemente 2, 148) an: Allein und durch sich selbst müssen sich die Nationen retten.

2) Io. Sept. Lehmann 3, 157; Pert $z$, Stein 3, $152 \mathrm{f}$.

3) Lehmann 3, 193; vgl. Pertz 3, 208 u. 2 Io. 
hange dieses selben Briefes stellte er auch die berühmte Forderung auf, daß Deutschland und Italien zu großen Massen umgestaltet werden miißten; das sei eine der ersten Bedingungen für die Ruhe Europas gegen das französische Ungestim. Es war eine große Idee, die zerstiickelten Nationen Mitteleuropas gemeinsam zum selbständigen Leben $z u$ wecken, aber auf festem und dauerhaftem Grunde ruhte sie bei ihm nicht. Lehmann muß es später, bei den Verhandlungen in Paris, mit Bedauern konstatieren, daß er sie wieder preisgeben konnte: ${ }^{1}$ ) "Jetzt mutete er den Italienern das zu, was er im Namen des eigenen Volkes mit Heftigkeit ablehnte. Er nennt es eine unerträgliche Inkonsequenz. Wir meinen, man kann sie ertragen, wenn man in Stein eben noch nicht den Vertreter des spezifisch modernen Nationalgedankens sieht. Er hat ihn, wie nur einer, mit schaffen helfen, aber er selbst hat ihn noch nicht in seiner Reinheit erfaßt. Schon in dem Augenblicke, wo er die nationale Organisierung Deutschlands und Italiens zugleich forderte, forderte er sie von einer zugleich universalen Tendenz aus. Europa erscheint ihm als eine in nationale Organismen gegliederte oder zu gliedernde Gemeinschaft gegenuber dem Unruhestifter Frankreich, und England ist in diesem Augenblicke die Vormacht dieser Gemeinschaft. Bei einem Durchschnittsdiplomaten wirde man kaum auf solche Worte achten: man würde meinen, daß sie dem hergebrachten Floskelschatze diplomatischer Sprache entstammten. Im Munde Steins, der solche Floskeln verachtete, haben sie einen andern Klang. Hätte er England durch solche Phrasen nur in dem Sinne gewinnen wollen, in dem der Vertreter einer selbständigen Macht die Allianz eines anderen Staates gewinnen will, so würde er ihm in den zu befreienden Teilen Deutsch- 
lands nicht Rechte eingeräumt haben, die, um mit Lehmann zu sprechen, eine Diktatur bedeuteten. England solle, meinte er in dem Briefe an Münster vom ı. September, in den von seinen Landungstruppen besetzten Teilen Deutschlands es so machen, wie in Portugal, wo es auch eine Diktatur ausuibte. Ein Verwaltungsrat solle gebildet werden, in dem Graf Münster als Beauftragter des Prinzregenten von England, Stein als der des Zaren Alexander, außerdem vielleicht noch einige hervorragende Deutsche, ein russischer und ein englischer Minister sitzen sollten. England solle auch den Fuihrer des aus der befreiten deutschen Bevölkerung aufzustellenden Heeres ernennen.

Das zeugt von einem Vertrauen auf Englands politische Uneigennützigkeit, wie es bei einer Auffassung verständlich ist, die nicht nur an eine voribergehende Allianz der Gegner Frankreichs, sondern an ihre dauernde europäische Solidarität glaubte. ${ }^{1}$ )

Von demselben Geiste ist seine Denkschrift über die deutsche Verfassung vom I 8 . September I \& 2 erfüllt. »Die Ruhe Europas erheischt, daß Deutschland so eingerichtet sei, daß es Frankreich widerstehen, seine Unabhängigkeit behaupten, England in seine Häfen zulassen und der Möglichkeit französischer Invasionen in Rußland zuvorkommen kann. Die zukünftige Bewahrung der nationalen Unabhängigkeit ist hier eng verknüpft mit der Vorstellung, daß diese nur im engsten Bunde mit England und Rußland werde verteidigt werden können. Daß

1) , Mit dieser Auffassung «, bemerkt Ulmann S. I58, , diurfte doch kaum stimmen, daß kurz vor jener Äußerung Stein Rußland eine ähnliche Rolle zugedacht hatte (Lehmann 3, 146)". Stein spricht da aber nicht von Rußland schlechthin, sondern von $₫$ RBland und seinen Verbündeten.\& Natiirlich sollte die ausländische Diktatur einem hochnationalen $Z$ wecke dienen, sie war auch damals das einzige disponible Mittel zu ibm, aber daß Stein an diesem unvermeidlichen Übel das Übel nicht empfand, das ist das Auffallende. 
Deutschland je andere Verbuindete als diese, je einen anderen Gegner als Frankreich haben könne, scheint er nicht anzunehmen.

Allerdings, diese Denkschrift war für den Zaren bestimmt. "Stein redet", sagt Lehmann ${ }^{1}$ ), »mit einem Nichtdeutschen, der nicht für Deutschland allein, sondern für die Unabhängigkeit der abendländischen Nationen überhaupt das Schwert führt. « Das muß man gewiß beachten, und man kann also hier, wie oben, die Beweiskraft des einzelnen Zeugnisses bezweifeln. Stößt man aber immer wieder auf die optimistische Illusion, daß Deutschlands nationales Interesse bei England und Rußland wohl aufgehoben sei, so wird man aufmerksam. Gleich in einer weiteren Denkschrift über Deutschlands Zukunft, die er am I. November 1812 dem Lord Walpole nach Wien mitgab, findet man die Nachdenken erregenden Worte: „Die deutschen Angelegenheiten müssen durch England, Osterreich, Rußland geordnet und Preußen mit fortgerissen werden. $\left.k^{2}\right)$ Das antifranzösische Europa also hat den Deutschen zu sagen, was ihre Verfassung sein solle.

Auch solche, die uns zugeben, daß alle diese Äußerungen nicht bloß auf den Adressaten berechnet waren, sondern aus echter Uberzeugung Steins stammten, möchten vielleicht einwenden, daß es eben eine durch die pressende

1) 3,160 .

2) Pertz 3, 202. Der Ausdruck, fortreißen \&, meint Ulmann S. I60, könne sich nur auf eine Nötigung zum Anschluß an die antifranzösische Koalition beziehen. Der strenge Wortlaut des Satzes und seine Stellung am Schlusse des von ihm entworfenen Zukunftsbildes von Deutschland widerlegen das. Ulmann meint nun freilich, diese Verfassung sei für Preußen so günstig gewesen, daß es nicht nötig gewesen sei, Preußen zu ihr zu swingen $\propto$; das glaube ich natürlich auch nicht, aber sfortgerissen werden $<$ ist auch nicht identisch mit , gezwungen werden \&, und die Tatsache wird nicht aus der Welt geschafft, daß das Verfassungswerk und damit auch das Geschenk, das Preußen erhalten soll, von England, Österreich und Rußland ausgehen soll.

Meinecke, Weltbürgertum und Nationalstaat. 2. Auf. 
Not des Augenblickes hervorgetriebene Überzeugung gewesen sei, jedoch keineswegs schon eine feste Doktrin, vergleichbar derjenigen, zu der später die Gerlachs den Gedanken der heiligen Allianz steigerten. Aber wer die Ursprünge solcher Doktrin untersucht, muß gefaßt darauf sein, sie zunächst nur als Ausdruck momentaner Erfahrung zu finden, - allerdings, so vermuten wir, einer Erfahrung, die in gewisse, schon vorhandene Kategorien seines Denkens hineinströmte und durch dessen dolstrinäre apriorische Bestandteile bestimmt wurde. Verfolgen wir unsere Spuren weiter in der Hoffnung, allmählich auf immer festeren Boden zu gelangen.

In derselben Denkschrift vom I. November I 8 I 2 finden wir auch Ideen über die politische Gestaltung des außerdeutschen Europas, die in der Tat auf ein solches doktrinäres a priori im Geiste Steins deutlich hinweisen; Ideen, die, wenn sie auch dem nationalen Interesse Deutschlands zugute kommen sollten, doch aus einer noch ganz unnationalen Gedankenwelt herstammen und jedenfalls der Achtung vor fremder Nationalität und historischer Staatspersönlichkeit zuwider sind. Dänemark sollte zur Strafe für sein Festhalten an Napoleon ganz aufgelöst werden; Norwegen und die Inseln sollten an Schweden, Jütland an England fallen, Schleswig und Holstein mit Deutschland vereinigt werden. Holland aber müßte mit England vereinigt werden, das sich mit Deutschland über die Freiheit der Rhein- und Maasmündungen zu verständigen hätte. Lehmann findet diese Revision der Karte Europas etwas antiquarisch und erinnert, was das Schicksal Dänemarks betrifft, an die Pläne Karls X. und seines Freundes Cromwell. Aber ihre historische Erläuterung darf wohl etwas tiefer greifen. Wir haben hier zunächst nicht bloß eine antiquarische Reminiszenz, sondern ein genuines Uberlebsel aus der Gedankenwelt des Absolutismus, jene wohlbekannte Meinung, daß es möglich und 
durchführbar sei, die Länderbestandteile Europas ohne Rücksicht auf ihre historisch-politischen Zusammenhänge und auf die Wünsche ihrer Bevölkerungen auf bestimmte Zwecke hin neu zu gruppieren, jene mechanisch-teleologische Auffassung von der Formbarkeit des europäischen Staatensystems, die, aus der naiven Praxis des erobernden und begehrenden Machtstaates zuerst entsprungen, auch der naturrechtlich-rationalistischen Denlsweise wohl zusagen konnte. »Man kam, « sagt Sorel ${ }^{1}$ ) »durch eine logische Entwiclilung der Ideen und Tatsachen dazu, die Zerstuickelung eines Staates nicht bloß als eine Transaktion zwischen den rivalisierenden Anspruichen und als eine gezwungene Wirkung der Sukzessionskriege, sondern als eine 》ressource normale der Diplomatie zu betrachten, als ein Mittel zur Vcrhütung von Kriegen, um die Ambitionen, die aufeinander zu sturzen drohten, von vornherein $z u$ befriedigen. « Man hat so oft und durchaus mit Recht den Staatsmännern des Wiener Kongresses dieses willkürliche Umspringen mit den Nationen zum Vorwurf ge. macht. Es ist von höchstem Werte, festzustellen, daß auch die Staatsmänner und Denker der preußischen Reformzeit, die Vorlämpfer nationaler Regenerierung und spontanen Lebens im eigenen Staate, das Herumkünsteln und Klügeln an fremden Staatskörpern nicht lassen konnten. Die künstliche und absichtsvolle Schöpfung des neuen Königreichs der Niederlande ist gewünscht und gefordert worden von Gneisenau, von Boyen und bis zu gewissem Grade selbst von Niebuhr..2) Boyen hat die sonderbarsten Pläne über Schaffung von allerlei Zwitterund Zwischenstaaten ersonnen ${ }^{3}$ ). Von Gneisenau aber haben wir Gedanken aus dem Herbste IS I 2, die unmittel-

\footnotetext{
1) L'Europe et la rízolution frangaise I, 39.

2) Histor. Zeitschr. 95, 448 .

3) Mein Leben Boyens I, 380; 2, 70.
} 
bar zur geistigen Deutung der aus demselben Momente entsprungenen Steinschen Ideen dienen können. Er lehnte in einem Schreiben an Münster vom 2. November IS I $2^{1}$ ) jenen oben erzählten Vorschlag Steins zur Bildung eines vielköpfigen Verwaltungsrates in Deutschland zwar ab, aber nicht deswegen, weil er den englischen Einfluß in Deutschland bedenklich fand, sondern weil ihm die Form, in der er wirken sollte, unpraktisch und unmöglich erschien. 》Wir müssen, nun die Dinge so sich gewendet haben, auf etwas anderes denken. England muß für sich erobern und allen Eroberungen seine Konstitution geben, dieselben mit sich vereinigen als einen integrierenden Teil des britischen Reichs. Die so mit Britannien vereinigten Völker werden sich unter einer freien Verfassung höchst glücklich fühlen, und daß durch eine solche Amalgamation die britische Regierung selbst an exekutiver Gewalt gewinnen würde, darf ich Ew. Exzellenz nicht erst sagen. «²)

Vielleicht möchte man wieder versuchen die Bedeutung dieses merkwürdigen und uns ebenso undeutsch wie unpreußisch berührenden Gedankens durch den Hinweis auf die Lage, in der er geäußert wurde, und auf den Adressaten, für den er bestimmt war, abzuschwächen. Man könnte etwa geltend machen, daß Gneisenau damals angesichts der preußisch-französischen Allianz an Preußens Zukunft verzweifeln konnte, daß er, trotz der Kunde vom Brande Moskaus, noch recht skeptisch in die Zukunft sah und auf ein Versagen der russischen Widerstandskraft und der Energie des Zaren sich gefaßt machte. ${ }^{3}$ ) Aber er hielt seinen Gedanken, mit geringer Variation, auch fest, als der ganze Umfang der Katastrophe in Rußland ihm bekannt wurde und als er hoffen durfte, daß auch Preußen sich wieder

\footnotetext{
1) Pertz, Gneisenau 2, 423.

2) Pertz, Gneisenau 2, $423 \mathrm{f}$.

3) a. a. O. 2, 422.
} 
erheben werde. Die Variation bestand jetzt darin, daß er nicht eine unmittelbare Vereinigung Nordwestdeutschlands und Englands, sondern die Grüdung eines großen nordwestdeutschen Welfenreiches empfahl, das der welfischen Dynastie auch dann bleiben wiirde, wenn sie - wie es damals nicht ausgeschlossen schien - die englische Krone verlieren wïrde. ${ }^{1}$ ) Die Idee soll schon I809 die englischen Prinzen beschäftigt haben, schon damals hat auch Gneisenau es für zweckmäßig gehalten, sie zu begünstigen ${ }^{2}$ ), und es ist allbeliannt, daß vor allem Graf Münster sie dann vertreten hat ${ }^{3}$ ). Dicses nordwestdeutsche Welfenreich konnte dann allerdings wohl einmal von England sich trennen und, wie man geltend machen wird, zu einem rein deutschen Staate wieder werden. Aber

1) Die damalige präsumtive Thronerbin war die Tochter des Prinzregenten, die durch Verheiratung eine neue Dynastie hätte nach England ziehen können.

2) Pertz, Gneisenau I, 469; Hist. Zeitschr. 62, 502.

3) Pertz, Stein 3, 238, teilt tinen Auszung aus einem an den Prinzregenten gerichteten Schreiben vom 7 . Dez. I I $2_{2}$ mit, in dem der erwähnte Plan entwickelt wird, und schreibt es dem Grafen Münster zu; im Leben Gneisenaus (2, 439 ff.) aber gibt er den vollständigen Text des Schreibens, und zwar mit $\mathrm{G}$ ne is en a us Unterschrift und bemerkt auch a. a. O. S. 674, indem er seine frühere Angabe der Autorschaft Münsters ausdrücklich widerruft, daß er den vollständigen Text jetzt ๖den eigenbändigen Papieren « Gneisenaus entnommen habe. Er dürfte danach das eigenhändige französische Konzept Gneisenaus vor sich gehabt haben, und man wird danach auf die Autorschaft Gneisenaus sich verlassen können, um so mehr als auch der Stil des Schreibens ihm ganz entspricht. Ein Satz in ihm (,Es sind bereits drei Jahre, daß ich [diese Entwürfe] der britischen Regierung vorlegtes) würde auch wohl ungezwungener für ihn als für Münster passen. Nun befindet sich allerdings im Nassauer Archive eine Abschrift, anonym, aber von der Hand des Sekretärs ron Münster und mit der Randbemerkung Steins versehen: "Von Graf Münster an Regenten (Stern bei Schmidt, Geschichte der deutschen Verfassungsfrage I $\$$ I 2-18 I 5, S. 43, Anmerkung, und Lehmann, Stein 3, 263, Anmerkung), und ferner lıat auch Stein schon am I6. März I8I3 das Schreiben dem Grafen Münster zuge- 
mit Sicherheit war es doch nicht zu erwarten, und vor allem Gneisenau selbst war nicht der Meinung, daß dieser Welfenstaat sich einmal völlig von England werde emanzipieren können. 》Ich habe, « schrieb er dem Staatskanzler Hardenberg aus London am 6. Januar i $S$ I $3^{1}$ ), 》auf diesen Plan hier hingearbeitet, weil solcher teils ein mächtiges Motiv abgibt, um die tätige Mitwirkung Englands für unsere Kontinentalangelegenheiten zu sichern, teils weil ein solcher Staat, von England geschützt, selbst für Preußen eine Schutzwehr sein und ewig verhindern würde, daß Frankreich uns angreifen könnte«. Schließlich hat er sogar noch einmal, einige Tage vor seiner Ende Januar I 8 I 3 erfolgten Abreise aus England, in einer Eingabe an Castlereagh die ursprüngliche Formulierung des Gedankens wieder aufgenommen und es England frei stellen wollen, die zu erobernden Länder zwischen den alten Grenzen Frankreichs und der Elbmindung entweder $\gg z u$ einer Sekundogenitur für das jetzt regierende Haus zu bestimmen oder sie seinem Reiche einzuverleiben und Vorteile davon zu ziehen. ¿2) $^{2}$

Es ist begreiflich, daß Gneisenau von dieser zweiten Alternative nur zu englischen oder zu englich-hannoverschen, aber nicht zu preußischen Ohren gesprochen hat.

schrieben (Hist. Zeitschr. 59, 298), aber das genügt doch nicht, um darauf hin, wie Stern es tut, die ausdriickliche, auf archivalischen Befund gestiitzte Angabe von Pertz im Leben Gneisenaus zu verwerfen. W'ir meinen also, daß Stein sich geirrt haben muB, als er den Brief, dessen Abschrift er jedenfalls durch Vermittlung Münsters erhalten hat, nun auch diesem zuschrieb. - Die Eingabe Gneisenaus an das Foreign offiee vom 14. Dezember 1812, in dem das obige Projekt abermals ent. wickelt und der britischen Regierung plausibel gemacht wird, ist unvollständig und in Übersetzung bei Pertz, Gneisenau 2, 454 ff., im vollständigen französischen Originaltext von Stern in den Forsch. zur brand. u. preuß. Gesch. I3, ISo ff. mitgeteilt.

1) Histor. Zeitschr. 62, 514.

2) Pertz, Gneisenau 2, 493. 
Indessen, das ist hier ganz nebensächlich, und ebenso würde man auch nur eine ganz selbstverständliche Nebensache betonen, wenn man uns entgegenhalten wollte, daß Gneisenau mit diesem Luftschlosse des nordwestdeutschen Welfenreiches die englischen Streitkräfte nach Deutschland locken wollte. Gewiß war, wie schon Pertz bemerkt hat ${ }^{1}$ ), für Gneisenau dieser Plan nur Mittel und nicht, wie für die englischen Prinzen und für Münster, Zweck und Ziel. Aber daß er, der Vorkämpfer des preußischen Nationalstaates, der das Jahr darauf von einer nationalen Vereinigung Deutschlands mit Preußen träumen konnte, überhaupt zu einem solchen Mittel greifen konnte, ist das Erstaunliche und bedarf dringend einer genaueren historischen Interpretation, als es bisher erfahren hat. Man sieht, daß das preußische wie das deutsche Nationalgefihl Gneisenau's von anderer Strulktur war, wie das heutige, daß es beweglicher und umgestaltungsfähiger war wie das unsere, welches enger an eine bestimmte, historisch und politisch erwachsene Gemeinschaft gebunden ist. Hier sehen wir das Individuum noch in größerer Freiheit seinem ursprünglichen Staate und seiner ursprünglichen Nation gegenuberstehen - Staat und Nation erscheinen vielmehr fast als etwas, was der Mensch sich schaffen oder sich suchen kann nach seinem Gedankengebilde und Beduirfnisse. Man wird aufs stärkste wieder an die berühmten Worte Fichtes von ISO4 erinnert: 》Mögen die Erdgeborenen Bürger des gesunkenen Staates bleiben. Der sonnenverwandte Geist wird unwiderstehlich angezogen werden und hin sich wenden, wo Licht ist und Recht.《

Wir verkennen gewiß nicht, was zwischen dem Fichte von ISO4 und dem Gneisenau von ISI 2 schon liegt. Was Gneisenau für Preußen und Deutschland

1) Gneisenau 2, 674 . 
erlebt und getan hatte, knupfte ihn durch Bande an sie, die wohl im Grunde schon unzerreißbar waren, die aber immer noch elastischer und dehnbarer, mehr geistig-persönlich und weniger naturhaft waren, als diejenigen, welche die großen Patrioten der zweiten Hälfte des I9. Jahrhunderts an ihr Vaterland fesselten. Gneisenau glaubte durch Mitarbeit an der Begründung eines englisch-deutschen Staatswesens gewiß nicht der Sache seiner Nation untreu zu werden - er wollte ihr ja gerade dadurch dienen. Aber Nation war ihm, so wagen wir es zu deuten, in erster Linie der Inbegriff von Freiheit, selbständiger Gesittung und Bildung, war ihm ein geistiges Fluidum, das nicht notwendig an die Grenzen einer Gemeinschaft gebunden war, war ihm ein Feuer, das im äußersten Notfalle übertragbar schien auf einen andern Herd, wenn der ursprüngliche Herd erkaltete. Und wer uiberhaupt Sinn hat für die Auswirkung großer geistiger Tendenzen im einzelnen, der wird auch unschwer die Herkunft dieser Ideen aus dem individualistischen und kosmopolitischen Geiste des I 8 . Jahrhunderts erkennen. Venn Gneisenau das Glikck der von Britannien eroberten und mit ihm vereinigten Bevölkerungen ausmalt, so wird man an ein charakteristisches Wort erinnert, das Ewald v. Kleist während des Siebenjährigen Krieges einmal aussprach: "Wie glücklich würden die Länder sein, die der König eroberte. Das war die, so hat man richtig interpretiert ${ }^{1}$ ), mit weltbürgerlichem Denken zusammenhängende Neigung, »in der Begluickung der eroberten Lande die Rechtfertigung des Eroberers zu finden. « Zum Erobern und zum Begluicken war nun wohl inzwischen auch das Befreien hinzugekommen, aber hatte nicht auch der Gedanke der Befreiung in diesen Jahrzehnten oft eine sehr weltbürgerliche Seite? Gneisenaus

1) Wenck, Deutschland vor hundert Jahren I, I 4 . 
Vorstellung eines freien und glücklichen britisch-deutschen Verfassungsstaates steht im Grunde genommen auf demselben Boden, wie der Traum der Mainzer Klubisten von einem französisch-deutschen Freistaate. Nochte der Inhalt dessen, womit man den Staat zu füllen gedachte, damals und jetzt noch so verschieden sein, darin stimmte man überein, daß man von universalen Gesichtspunliten ausging, daß man in Weltfreiheit und Weltknechtschaft den Gegensatz sah. Gneisenau sprach es im Herbst I 12 deutlich aus: "Die Welt scheidet sich ab in solche, die gezwungen oder freiwillig für Bonapartes Ehrsucht oder dagegen fechten. A uf das Gebiet der Länder scheint es hierbei weniger anzukommen, als auf das der Grundsätze. $\ll^{1}$ )

Oder will man noch einwenden, daß Gneisenau, wie wir sahen, die Begründung eines großen Welfenstaates zwischen Schelde und Elbe für wohlverträglich mit dem preußischen Staatsinteresse, nicht nur mit dem jetzigen, sondern mit dem dauernden, gehalten und sogar auf die stillschweigende Genehmigung Hardenbergs und des Königs gerechnet habe? Sollte er das wirklich getan haben, so würde es nur zeigen, daß Gneisenau iber dieses Staatsinteresse anders dachte, als ein auf dem realen Boden dieses Staates stehender oder selbst schon als ein an Preußens deutsche Zukunft denkender Politiker nach unseren heutigen Begriffen tun durfte. Die Elbgrenze war eine Grenze gegen das Wachstum Preußens in Deutschland hinein, warf Preußen nach Osten, in die slawische Welt zuruick. Der Glaube aber an eine dauernde Harmonie englischer, englisch-welfischer und preußischer Politik trägt wieder einen kosmopolitischen Zug. Er ver-

1) Pertz, Gneisenau 2, 369; Gneisenau knüpft die Bemerkung an das Schicksal Tiedemanns, der auf russischer Seite im Gefechte gegen seine eigenen preußischen Landsleute gefallen war und, wie Gneisenau meinte, absichtlich den Tod gesucht hatı. 
kennt den Wechsel der Weltverhältnisse und Staats. interessen, der heute England und Preußen einigen, morgen wieder trennen konnte, er macht den augenblicklichen Weltgegensatz zu einem dauernden System, zu einem dualistischen System, wo Feinde und Freunde der Weltfreiheit sich einander gegenüberstehen und letztere brüderlich nebeneinander und für ihre gemeinsame Hauptaufgabe leben können.

Diesen dominierenden Dualismus, der alle Sonderstaatsinteressen absorbiert, hat Lehmann bei einem anderen Denker dieses Kreises, bei Ernst Moritz Arndt, sehr schön beobachtet. Arndt hatte in der ersten Ausgabe des Soldatenkatechismus vom Oktober I 8 I 2 die radikale Lehre gepredigt, daß der Fahneneid die Soldaten der Fürsten, dic jetzt Napoleon folgten, nicht bände. Als eine Lösung des Rechtsverhältnisses zwischen Fürsten und Vasallen »erschien dem Autor des Soldatenkatechismus der Abfall zum Reiche des Bösen, wie es sich ihm darstellte im Staate Napoleons; wenn man die Schilderung liest, die Arndt von diesem entwirft, so wird man geradezu an die cizitas terrena von Augustinus erinnert. «1)

Das war also der gemeinsame politische Boden, auf dem im Jahre 1812 und zu Beginn des Befreiungsjahres I 8 I 3 die drei großen Patrioten Stein, Gneisenau und Arndt standen. Gemeinsam war ihnen, daß sie Europa einteilten in die Sphäre der Freiheit und die Sphäre der Unfreiheit, daß sie sub specie dieses Prinzips die Besonderheiten des deutschen und preußischen Staatslebens beurteilen konnten, daß ihnen preußische und deutsche Nationalität, universale Freiheit und zugleich — im innersten Kerne - Freiheit des Individuums in eine einzige goldige Wolke zusammenflossen. Begreiflich genug, wird man sagen, als Wirkung der außerordentlichen, singulären

1) Lehmann 3, 182. 
Schicksale dieses Jahres, die sie abdrängen konnten von dem Boden eines bestimmten Staates, aber ganz verständlich doch nur, wenn man den Untergrund kosmopolitisch-individualistischen Gedankengutes beachtet, der in ihrer Bildung lag und auf den die Geschicke dieses Jahres sie nun trieben.

Gemeinsamkeit der Grundanschauung schloß Mannigfaltigkeit der Wege und Mittel nicht aus. Im Gegenteil, sie schloß eine solche bunte Mannigfaltigkeit hier notwendig in sich, weil durch die Loslösung vom festen Boden eines Staates die politische Phantasie flügge wurde und sich in allerlei Kombinationen ergehen konnte. Abgesehen von der einen scharfen Scheidelinie, die durch die Heerlager Europas lief, wurden die Grenzen der Staaten nun variabel, wie sie variabel gewesen waren für die Politiker und Philosophen des I8. Jahrhunderts. Wir sahen es vorhin schon an den nordeuropäischen Projekten Steins, man sieht es auch an seinen deutschen Plänen dieses Jahres. Am I8. September empfahl er die Teilung Deutschlands zwischen Österreich und Preußen, am 2. November hatte er nichts gegen die Auflösung Preußens einzuwenden, wenn sie ausführbar sei. ${ }^{1}$ ) Diese Sprunghaftigkeit war auch Gneisenau zu stark, aber was er Stein zur Kritik entgegenhielt, zeigt, bei Licht besehen, zum Teil wenig-

1) Ich halte dieses Umspringen mit den Grenzen deutscher Staaten noch nicht, um auf Ulmann S. $157 \mathrm{zu}$ antworten, für Universalismus schlechthin, aber für sehr verwandt mit ihm, weil es mit ihm ïbereintrifft in der Verkennung des historischen Eigenlebens der Staaten und in der Handhabung allgemeiner vernüntiger Normen. Die Kabinetspolitik des IS. Jahrhunderts, aus der Ulmann es herleitet, war, um wieder an Sorels Wort (s. oben S. 163) zu erinnern, durchaus nicht un. berïhrt geblieben von den geistigen Strömungen des I $S$. Jahrhunderts, und die Jakobiner, an die Ulmann noch erinnert, bekanntlich auch nicht. Seine Meinung, sie seien die Verfechter eines smodernen französischen Nationalgedankens gewesen, verkennt ganz, daß auch ihr Nationalismus noch recht stark mit Kosmopolitismus amalgamiert war. 
stens, wieder dieselbe Grundanschauung, von der aus Stein experimentierte. Gneisenau schrieb ihm Ende Dezember

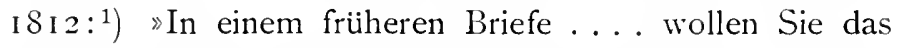
ganze nördliche Deutschland an Preußen geben; in Ihrem jüngsten wollen Sie ganz Deutschland zur Einheit unter Ósterreich organisieren. Bei dem ersten Ihrer Entwürfe würden wir in dem hiesigen (englischen) Ministerio und selbst in den verschiedenen deutschen Völkerschaften den heftigsten IViderstand finden und uns noch obendrein des Undankes schuldig machen. Gerade die Idee der alten besseren Zeit soll die öffentliche Meinung für uns gewinnen, und nur an dieser öffentlichen Meinung kann sich unser Preußen wieder aufrichten. Dieser Staat ist ein kranker Körper mit niedergeschlagener Seele, der nur durch Pflege und gütige Behandlung seiner Nachbarn wieder Kraft erhalten kann, und der Kranke solle damit anfangen, seine Nachbarn aus ihren Wohnungen zu treiben. Das ist ebenso unausführbar, als es ungerecht ist. $\mathrm{Zu}$ dem zweiten Ihrer Entwürfe muß wenigstens ich meine Mitwirkung verweigern. Die Ausführbarkeit einer Zerstuickelung Preußens ist wohl vorhanden, aber ob das Verschwinden eines Staates von der Bedeutung als Preußen nicht das Gleichgewicht auf andere Weise zerstören würde, mögen diejenigen berechnen, die eine solche revolutionäre Maßregel anraten und unterstuitzen."

Der Protest gegen das revolutionäre Umspringen mit Preußen und Norddeutschland, die Anrufung der Idee der alten besseren Zeit «, das atmet wohl schon den Geist der Restaurationszeit und Verständnis für die Erhaltung der geschichtlichen Staats- und Volksindividualitäten. Auch dies Verständnis ist ihm damals durch den Moment und die Umgebung, durch die Luft der englischhannöverischen Interessen, die ihn damals umgab, geweckt

1) Um den 22. Dez. herum, Pertz, Gneisenau 2, 467; Lehmann, Stein 3, 279, Anmerkung $\mathbf{1}$. 
worden. Er hatte die Kraft, das zu verstehen, worin er lebte, und es war mit seine Größe, daß er aus jedem fruchtbaren Erdreich, in das er versetzt wurde, etwas Lebendiges entnehmen und in sein eigenes Wesen umsetzen konnte. So hat er auch bald, in preußischen Boden zurückverpflanzt, viel tiefer wieder seine Wurzeln in ihn hineintreiben können, als es der sprödere Stein je vermochte. Damals aber sah er den preußischen Staat von außen an und nicht nur mit den Augen des Realpolitikers, sondern auch des, ja man darf wohl sagen, philanthropischen Erziehers, des nach Rezepten arbeitenden Staatskünstlers, der von universalen Gesichtspunkten aus und unter universaler Beteiligung der Nachbarstaaten den schwachen preußischen Organismus wieder aufrichten möchte. Preußen soll nicht zerstört werden, soll aber auch nicht zu groß werden, weil das deutsche und europäische Gleichgewicht es so und gerade so verlangt, da hat man wieder den echten Geist des künstlichen Machens. Allerdings ja wiederum nicht bloß ihn allein. Auch echtes persönliches Erlebnis, trübe Erfahrungen seiner preußischen Jahre, Enttäuschung und doch nicht erloschene innere Teilnahme sprechen aus dem pessimistisch-mitleidigen Urteile, das er iiber Preußen in diesem Augenblicke hatte. Uberlebsel und eigenes neues Leben fließen so durcheinander.

Daß auch Preußen eigenes neues Leben reichlich in sich habe, wußten Stein und Gneisenau damals nicht, obwohl sie es doch selbst ihm mit gegeben hatten. Beide erkannten es freudig an, als es sich dann I 8 I 3 entfaltete. Gneisenau kehrte, wie wir sagten, wieder zurück zum preußischen Nationalstaate. Wie aber stand es nun mit Stein? Fassen wir jetzt seine deutschen Verfassungspläne aus den Jahren I8I3/I 5 auf unsere Frage hin ins Auge.

Hatte ein Jahr zuvor die Idee des Befreiungskampfes ihre Zuflucht notgedrungen beim Ausland suchen müssen, 
so gewann sie jetzt den Mutterboden der eigenen Nation wieder; immer noch in enger Umschlingung mit den verbündeten Mächten des Auslandes, aber doch getragen und gesteigert durch die spontanen Kräfte der Nation. Jetzt hätte, sollte man meinen, der Ehrgeiz eines nach voller nationaler Autonomie strebenden Staatsmannes sich ein höheres Ziel stecken können, als in den Bedrängnissen der Vorjahre. In der Tat finden wir auch in der Steinschen Denkschrift vom August is $13^{1}$ ) schöne und hohe Worte. Als das wenn auch jetzt unerreichbare Ideal stellt er hier hin 》ein einziges selbständiges Deutschland «, die Erhebung der Nation »zu einem mächtigen Staate, der alle Elemente der Kraft, der Kenntnisse und einer gemäßigten und gesetzlichen Freiheit in sich schlösse.« Eine besondere Steigerung seiner Nationalstaatsidee aber bedeutete das nicht. Er hatte schon im Oktober I 8 I I eine Verfassung für Deutschiand »auf Einheit, Kraft, Nationalität gegründet $\ll^{2}$ ) und im September I 8 I 2 ein Reich gewünscht, 》welches alle sittlichen und physischen Bestandteile der Kraft, Freiheit und Aufklärung enthielte. $\left.\ll^{3}\right)$ Aber wie damals, so glaubte er auch jetzt der Mitwirkung des Auslandes hierbei nicht entraten zu können. Er appellierte an Europa, an $\gg$ Ehre und Pflicht der die großen Angelegenheiten der Nationen leitenden Staatsmänner", daß sie das deutsche Verfassungswerk mit allem Ernste und tiefster Besonnenheit erwögen. Ende i 8 I 2 hatte er sich England, Rußland und Ósterreich als die Ordner Deutschlands gedacht, die Preußen mit fortreißen müßten. Jetzt, im September I8I3, hatte er das Vertrauen auf Ósterreich einigermaßen verloren, das Vertrauen auf Preußen wieder gewonnen, aber sein Vertrauen auf England und Rußland

1) Schmidt, S. 59 ff.

2) Pertz, Stein 3,46.

3) a. a. O. 3,4 IS. 
war geblieben. Da von Metternich nichts zu erwarten sei, schrieb er an Münster am I6. September I8 I3, so muß $\gg$ England mit Rußland und Preußen ernstlich auf die Erhaltung und Griindung einer festen Ordnung der Dinge in Deutschland bedacht sein. "Wiederum wünschte er in den letzten Tagen des Jahres I $\&$ I 3 eine deutsche Verfassung, 》die gegen das Ausland Kraft zum Widerstand verschafft ${ }^{1}$ ) und in demselben Atem beinahe die Hilfe des Zaren dafür; er möge, meinte er, schon jetzt die deutsche Verfassung durch eine Kommission vorbereiten lassen, in der außer Stein, dem Preußen Humboldt und dem Ósterreicher Stadion auch der Russe Rasumowsky sitzen sollte. »Ein Gesuch, * sagt Lehmann mit Recht ${ }^{2}$ ), »das für sich betrachtet gerade vom nationalen Standpunkte aus die stärkste Kritik herausfordern mußte. « Verständlich, meint er, sei es nur durch die großen Verdienste des Zaren um Europa und Deutschland und durch die politische Nichtigkeit der beiden anderen fürstlichen Häupter der festländischen Koalition. Man muß diese Momente gewiß gelten lassen, aber doch nicht nur sie allein. Sie hätten, so vermuten wir, nicht wirken können, wenn nicht Steins Nationalismus von vornherein ein anderer gewesen wäre, als der moderne Nationalismus, wenn er nicht noch eingebettet gewesen wäre in europäischen Universalismus.

Diese Vermutung wird wieder geweckt durch die Aufgaben, die er dem Wiener Kongresse stellen wollte. »Die großen Mächte sind es, « sagt seine für das russische Kabinett bestimmte Denkschrift vom 17 . September I $S$ I 4,3$)$ ) welche ihr sittliches und physisches Dasein aufs Spiel gesetzt, welche unermeßliche Anstrengungen gemacht, deren Völker Ströme Bluts vergossen haben .. . Es ist daher

1) 25. Dez. I $\mathrm{I}_{3}$, Histor. Zeitschr. So, 260.

2) 3, 350 .

3) Pertz 4, I IO ff. 
den großen verbündeten Mächten durch ihre Ergebenheit an die gute Sache und den Sieg das Schiedsrichteramt überwiesen und das Recht des Ausspruches über die großen Interessen, welche noch $\mathrm{zu}$ entscheiden bleiben. " Ganz fern gehalten werden sollte nur Frankreich von einer Teilnahme an den deutschen Angelegenheiten. Diese selbst sollten nach seinem Wunsche allerdings entschieden werden durch die drei deutschen Mächte Hannover, Preußen und Ósterreich. Aber »der Erfolg würde in letzter Stufe zu Kenntnis der verbündeten Mächte gebracht werden, damit sie diesen Erfolg nach den Grundsätzen des europäischen Gleichgewichts beurteilen. «1)

Es ist bekannt und braucht hier nicht weiter ausgeführt zu werden, daß Stein dann auch noch wiederholt, vor, wie während des Wiener Kongresses, die Unterstützung und Intervention des Zaren für die deutsche Verfassungssache angerufen und benutzt hat. Er mußte sie benutzen, wird man wieder sagen, weil er keine andere Macht hinter sich hatte. Wohl würde in der schweren Lage, in der er war, auch ein Staatsmann strengster nationalpolitischer Observanz die Hilfe des Auslandes nicht verschmäht haben. War, diese Frage erhebt sich jetzt, die Anrufung des Auslandes nur ein taktisches Augenblicksmittel, oder war sie behaftet mit der universalistischen Illusion einer dauernden Interessenharmonie zwischen Deutschland und den angerufenen Auslandsmächten? IVir glauben deutliche Spuren einer solchen Illusion schon gezeigt $\mathrm{zu}$ haben, aber geben ausdrücklich $z u$, daß sie wohl dringenden Verdacht erregen, aber einen ganz durchschlagenden Beweis noch nicht erbringen können. So miissen wir denn, um zum Ergebnis zu kommen,

1) Schon allein durch diesen Schlußsatz wird die Meinung Ulmanns S. 163 , daß das Schiedsrichteramt der großen Mächte nicht für deutsche, sondern fur allgemeine Interessen gemeint sei, widerlegt. 
nicht nur nach der Augenblickslage jener Jahre, wo die Steinsche Nationalpolitik die Auslandshilfe nicht entbehren konnte, sondern nach dem Ziele und dem Endzustande Deutschlands, den Stein vor Augen hatte, fragen. Hat er für alle Zukunft den ausländischen Einfluß fernhalten wollen von den höchsten Angelegenheiten der deutschen Nation? Wir räumen auch hier von vornherein ein, daß der stolze Mann jeden Zweifel an dieser Absicht vermutlich mit Zorn zurückgewiesen haben würde. Gentz hatte Ende Oktober I 8 I 4 dem Kronprinzen von Württemberg eine Denkschrift gezeigt, wonach Osterreich sich mit dem suidlichen Deutschland und Frankreich zur Erhaltung des Gleichgewichts gegen Rußland verbünden müsse, da dieses immer Preußen und das nördliche Deutschland in sein Interesse verwickeln werde. "Ich machte ihm, « schrieb Stein daruber in sein Tagebuch ${ }^{1}$ ), »das Verderbliche eines Systems bekannt, welches die Einigkeit in Deutschland .... vernichte, das südliche Deutschland dem Einflusse Frankreichs, das nördliche dem Einflusse Rußlands preisgebe und einen unseligen Zwiespalt zwischen Preußen und Ósterreich erhalte. E Er wollte an sich die nationale Autonomie, aber es kommt nun, um das Problem an seiner letzten Wurzel zu erfassen, darauf an, ob die nationale Autonomie, die er wollte, identisch ist mit derjenigen, die das aus den Entwicklungen des I9. Jahrhunderts hervorgegangene Nationalbewußtsein verlangt. Wir antworten mit einem unbedingten Nein. Z wei schlagende Beweise dafür gibt es, daß Stein die nationale Autonomie mit ausländischen Servituten hat belasten wollen, die wir für unverträglich mit ihr halten.

Humboldt hatte in seiner Denkschrift vom Dezember I 8 I 3 vorgeschlagen, daß diese Garantie von den großen

1) Histor. Zeitschr. 6o, 396. 
Mächten Europas, namentlich von Rußland und England, ibernommen würde. Stein bemerkte dazu11): »Die auswärtige Garantie hat sehr was Bedenkliches, auf jeden Fall würde man nur England oder Rußland daran teilnehmen lassen. " Diese Garantie sollte sich nach Humboldts Meinung nur auf die Beschuitzung Deutschlands gegen auswärtige Angriffe beziehen und zu keiner Einmischung in die inneren Angelegenheiten Deutschlands führen dürfen, aber es ist klar, daß auch eine derart beschränlite Garantie immer noch Handhaben zu Ubergriffen bot und unverträglich war mit einer echten nationalen Unabhängigkeit. Wohl sieht man, daß Stein solche Bedenken schon empfand, aber man sieht zugleich, daß er auf halbem Wege stehen blieb, wo cler moderne Nationalismus den Weg zu Ende gehen und jede, schlechthin jede verfassungsmäßige Möglichkeit, die freie Bewegung der eigenen Machtpolitik durch das Ausland gestört zu sehen, verurteilen wird.

Der zweite Beweis ist, daß Stein, als er in der Denkschrift vom März I 8 I 4 den Vorschlag eines Viererdirektoriums als oberster deutscher Bundesbehörde machte ${ }^{2}$ ), es zusammensetzen wollte aus Ósterreich, Preußen, Bayern und Hannover. Hannover aber, das hieß England. „England also und Bayern, « folgert Delbriick richtig $\left.{ }^{3}\right)$, 》sollten gleiche Rechte über Deutschland haben wie Preußen." Auch diese Aussicht hatte demnach nichts Abschreckendes fuir Stein. $\left.{ }^{4}\right)$

1) Histor. Zeitschr. So, 264.

2) Pertz, Stein 3, 719; Schmidt, S. I3I.

3) Die Ideen Steins ïber deutsche Verfassung. Erinnerungen, Aufsätze und Reden, S. 95.

4) Ulmann S. I62 beruft sich darauf, daß Stein die IJerrschaft Undeutscher in unserer Mitte als einen Schimpf für die Nationalehre verworfen habe. Gewiß, er wollte keinen undentschen Geist, aber daß er den durch Hannover doch tatsächlich einströmenden englischen Einfluß hat zulassen können, beweist eben, daß er die Grenze zwischen 
Er hat, wir wiederholen es, nicht unnational damit $\mathrm{zu}$ denken geglaubt. Er hat die Verknüpfung der englischen und russischen mit der deutschen Politil in den Grenzen, die er zuließ, nicht für schädlich, sondern eher für nützlich gehalten. Aber dieser Glaube eben ist es, den wir heute überwunden haben, den wir als fremdartiges, als universalistisches Gedankengut empfinden. Er war entstanden aus Idee und Wirklichkeit zugleich, aus der Wirklichkeit des durch Not und Kampf gehärteten Interessenbandes zwischen Deutschland, England und Ruß. land, aber aus dieser zeitgeschichtlichen Erfahrung nun

Deutsch und Undeutsch anders zog als wir. Wenn Ulmann weiter meint, sein Nationalgefiuhl sei autonomer als das hente noch gültige Recht, das fremden Seitenlinien deutsche Throne offen hält, so ist darauf zu erwidern: $\mathbf{I}$. daß dieses Recht heute nur positives, uberliefertes $\mathrm{Recht}$, aber nicht Ausdruck heutiger Rechtse mp find ung ist, und 2. daß man es dulden kann, weil man historischer Erfahrung gemäß anf die fruher oder später erfolgende Nationalisierung fremder Seitenlinien hofft. - Gegen Ulmann S. 165 bemerke icb noch, daß ich keineswegs in Stein schlechthin einen sinnerlichen Kosmopoliten s sehe. Nur einen, nicht in jedem Momente wirksamen, aber in gewissen wichtigen Momenten allerdings wirksamen Beisatz von Vorstellungen kosmopolitischer Provenienz behaupte ich. - Die Beispiele Bismarckscber Konzessionen an ausländische Einflüsse, auf die Ulmann S. 166 weist, kann ich nicht als Analoga zu den Steinschen Konzessionen gelten lassen. Daß Bismarck I $_{50} 0$ den Ausspruch der Garanten von ISI5 uber Deutschland hat zulassen wollen, ist iberhaupt nicht uberliefert. Ulmann hat schon früher, in der Kontroverse mit Fester uiber die Olmützrede (Histor. Vierteljahrsschrift I902 S. 55) sich den Bismarck von 1850 konservativer vorgestellt, als er wirklich war und ist inzwischen durch das von Ludwig v. Gerlach 2, 116 iiberlieferte Wort Bismarcks vom 21. Nov. I 850 (,Friedrich II. I 740 sei sein Mustere) schlagend widerlegt worden. Damals wie jeizt hat Ulmann die Verflechtung verschiedenartiger Gedankenfäden innerhalb derselben historischen Persönlichkeit nicht zu erkennen vermocht. Bismarcks Preisgebung Luxemburgs I $\$ 67$ betraf ein innerlich nur noch halbwegs deutsches Land und war ein realpolitisches Mittel autonomer Nationalpolitik, die docb einen ganz anderen Charakter trug als die Politik Steins und Friedrich Wilhelms IV. 
eine dauernde Hoffnung zu machen, war das Werk einer Ideologie, welche die egoistischen Grundkräfte der Politik verkannte und die europäischen Gemeinsamkeiten überschätzte.

Auch Steins bekannte Ansichten über das Verhältnis Preußens und Osterreichs zu Deutschland und zum deutschen Bunde wird man nunmehr unter diesen Gesichtspunkt stellen dürfen. Wenn Deutschland und das antifranzösische Europa ein gemeinsames, dominierendes Grundinteresse haben, wieviel mehr nicht Österreich, Preußen und Deutschland? Die Formen, in denen er diese drei Mächte zusammenhalten wollte, wechselten in seinen Entwïrfen, aber die optimistische Grundvoraussetzung, daß sie zusammenhalten wuirden, blieb. Preußens glaubte er für Deutschland jetzt ganz sicher zu sein. ${ }^{1}$ ) Osterreichs allerdings weniger. Er sah sehr wohl die mannigfachen Scheidewände zwischen Osterreich und Deutschland; er charakterisierte sie in seiner Denkschrift vom I7. Februar I \& I 5 mit einer ganz realpolitisch berührenden Nüchternheit: $\gg$ Das Interesse, das Osterreich an Deutschland nimmt, wird immer untergeordnet sein à ses convenances momentanées. "Aber der Realpolitiker räumte sofort dem Ideologen das Feld, wenn er nun eben deswegen Osterreich an Deutschland ketten wollte durch Ubertragung der Kaiserwürde. Durch sie sollte es zurückgeführt werden zu seinem deutschen Beruf und erzogen werden für Deutschland. Er muß von dem Glauben durchdrungen gewesen sein, daß das Erziehungswerk gelingen werde ${ }^{2}$ ), und es steckt in diesem Glauben

1) Denkschrift vom August I 8 I $3, \S 28$ u. 30 , Schmidt, S. 65 f. ; Denkschrift vom I7. Februar ISI5, Pertz 4, 744; vgl. Lehmann 3, 439.

2) Vgl. seine Tagebuchaufzeichnung uiber die Unterredung init Hardenberg vom II. Febr. (Histor. Zeitschr. 60, 430.) s Hardenberg äußerte seine Abneigung (gegen die Übertragung der Kaiserwürde an Österreich) und gründete sie auf die Geistlosigkeit der österreichischen 
nun gewiß auch noch ein Stück Aufklärung des I8. Jahrhunderts, jenes politisch angewandten Rationalismus, der durch einige zweckmäßig gewählte Institutionen das Leben der Staaten regulieren und ihre immanenten naturhaften Sondertriebe korrigieren zu können glaubte. Er kannte die egoistischen Sondertriebe des österreichischen Staatswesens, aber er ignorierte sic dann doch, weil er auf den schließlichen Sieg der Gemeinsamkeiten, die zwischen Deutschland und Osterreich bestanden, vertraute. Nur das richtige Organ für sie geschaffen, und Österreich wird sein inneres Wesen wandeln und ein deutscher Staat wieder werden.

Uberaus merkwürdig aber verschlingen sich mit dem rationalistischen Faden in dem Gedanken des österreichisch-deutschen Kaisertums noch andere geistesgeschichtliche Fäden. Natürlich war bei Stein auch noch historische Romantik und Reichserinnerung im Spiel, wenn er dem Hause Habsburg auch "wegen des langen Besitzes und der Gewohnheit der Völker ${ }^{1}$ ) die Kaiserkrone zurückgeben wollte. Die historische Romantik verurteilte das Machen in politischen Dingen und pries dafür das geschichtliche Werden, richtiger gesagt, das Gewordene als Grundlage des Staatslebens. Hier sehen wir Stein als Rationalisten und Romantiker, als Fürsprecher des Machens und des Gewordenen zugleich. Und die dritte, gemuitlich weitaus wirksamste Wurzel seines Gedankens hat schon Lehmann gluicklich betont. $\left.{ }^{2}\right)$ 》Wir berühren «, sagt er, 》den stärksten Fehler seiner Argumentation, der freilich auch der menschlichste und verzeihlichste war: er nahm an, daß im Grunde jeder Deutsche ein Stück von der Vaterlandsliebe im Herzen trage, die ihn und

Dynastie und Regierung. Ich bemerkte ihm: diese Unvollkommenheiten seien vorübergehend, es käme hier auf Verfassungseinrichtungen an "usw.

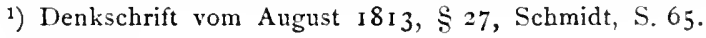

2) 3, 44I. 
seine Mitarbeiter beseelte. « So sieht man hier die nationale Idee in ihrer innerlichsten Form als sittliche Macht und als Glauben an ihre Macht auch im ganzen Leben des Volkes, aber zugleich umschlungen und durchwachsen mit anderen Ideen, die sie verhindern, wahrhaft politisch zu werden, sich mit dem Realen $z u$ verbinden und dadurch in die Realität des autonomen Nationalstaats umzusetzen.

Man könnte die Analyse noch fortsetzen, man könnte insbesondere zeigen, daß auch seine wunderlichen Gedanken aus dem Sommer I 8 I4, die auf eine Zertrennung des preußischen und österreichischen Staatsverbandes durch Einordnung der linkselbischen preußischen und der nach Suiddeutschland gravitierenden österreichischen Provinzen in den deutschen Bund gingen, auf einer Staatsauffassung beruhten, die das Wesen der Staatspersönlichkeit noch nicht voll erfaßt hatte. Achtete er in den fruher besprochenen Fällen ihre Autonomie nicht, so achtete er in diesem Falle ihre innere Einheit und Geschlossenheit nicht. Daß der Staat in erster Linie Macht und eine sich nach ihren eigenen Trieben bewegende Macht ist, hat er nicht gelten lassen wollen. Gewiß verlangte er auch Macht des Staates und insbesondere des geträumten deutschen Nationalstaates, aber die weitaus dominierende Hauptaufgabe dieser Macht sah er in der Abwehr des französischen Erbfeindes und in dem Schutze innerer Freiheit.

Er gebraucht nicht gerade, so weit wir sehen, das Wort „Erbfeind « für Frankreich, aber er nennt es den "ewigen, unermüdlichen, zerstörenden Feind « der Deutschen. $\left.{ }^{1}\right)$ In dem Worte »Erbfeind « prägt sich auch ein mehr nativistisches Nationalgefühl aus. Auch Stein hatte nicht wenig davon in sich und nährte es durch die ge-

1) Denkschrift vom August 1813, Schmidt, S. 59. 
schichtlichen Erinnerungen der letzten Jahrhunderte, aber sein Begriff des »ewigen Feindes", wie er ihn gebraucht, geht zugleich auch in das Gebiet des Sittlichen über und steigert den nationalen Gegensatz zu einem universalen, zu jenem Dualismus des guten und bösen Prinzips, den wir kennen. Durch Frankreich ist nach ihm auch das Böse in Deutschland jetzt hineingekommen: 》Man verfolge die Geschichte der Staatsverwaltung in Bayern, Württemberg und Westfalen, um sich zu überzeugen, wie es einer Neuerungssucht, einer tollen Aufgeblasenheit und einer grenzenlosen Verschwendung und tierischer Wollust gelungen ist, jede Art des Glücks der beklagenswerten Bewohner dieser einst blühenden Länder zu zerstören. $\left.\otimes^{1}\right)$ Die deutsche Verfassung soll, so fordert er, die Mauern, die Deutschland einst schiitzten, wieder aufrichten. So hängen äußere und innere Aufgaben Deutschlands ihm eng zusammen. Die deutsche Verfassung ist ihm nach außen hin eine Vormauer zum Schutze der äußeren, nicht nur nationalen, sondern auch universalen Unabhängigkeit, nach innen eine Vormauer gegen den durch Frankreich erweckten Despotismus der Fürsten, - Deutschland eine Grenzmark Europas zugleich und eine Provinz in Reiche der sittlichen Freiheit.

Diesen Primat des ethischen vor dem realpolitischen Gedanken hat sein Biograph kräftig und mit innerster Sympathie, zuweilen wohl mit etwas schroffem Pathos, aber doch auch nicht ohne die nötige Kritik herausgearbeitet. "Ihm erschien das Ganze, "sagt er z. B. von Steins Auffassung des Wiener Kongresses, »nicht als ein Ringen um die Macht, sondern als ein Kampf zwischen dem Bösen und dem Guten. $\ll^{2}$ ) Auch das Weltbürgerliche in Stein ist ihm nicht entgangen. Er nennt ihn »das Kind einer Zeit, die in der Idee der Menschheit lebte, « den

1) a. a. $\mathrm{O}$.

2) $3,+47$. 
》Kämpfer einer Epoche, welche die Völker gelehrt hatte, zusammenzustehen. $\ll^{1}$ ) Seinen Widerspruch gegen die polnischen Pläne des Zaren leitet er sehr treffend weniger aus einer spezifisch preußisch-deutschen Gesinnung, als aus "Erwägungen universaler Art《 ab. »Die Mächte des Abendlandes sollten sich zusammenfinden in der Bekämpfung jedweder Universalmonarchie, und die Forderung, an den Grundsätzen des Gleichgewichts festzuhalten, richtete er auch an Preußen. ${ }^{2}$ ) In der Tat erlebte der altc Gedanke des europäischen Gleichgewichts, der so oft zur Phrase gemißbraucht worden war, in Stein jetzt eine Auferstehung, in der das in ihm steckende ethischkosmopolitische Samenkorn sich wirklich einmal ganz rein entfaltete. Und eben das, was wir meinen, daß das Sittliche und das Kosmopolitische sich in Stein mit dem Nationalen verschmolz, spricht Lehmann auch aus mit seinem Worte von den »ethisch-religiösen Ideen, halb nationaler, halb universaler Tendenz. ${ }^{3}$ ) So glauben wir mit unserem Versuche nur einen Weg zu gehen, den er selbst gebahnt, aber nicht weit genug beschritten hat. Denn es klafft noch in seiner Auffassung eine Lücke, um nicht zu sagen ein Widerspruch, zwischen dem Stein, der der Vorkäınpfer der nationalen Staatsidee, und dem Stein, der der Vorkämpfer des universalen Gleichgewichts wurde. Er war beides, aber nicht unvermittelt nebeneinander, sondern so, daß sein nationaler und nationalstaatlicher Gedanke leise und oft halb unbewußt gelenkt und cingeschränkt wurde durch die weltbürgerliche Idee.

Wer von Stein und Gneisenau zu Wilhelm v. Humboldt kommt und nun auch an ihn dieselben Fragen richtet, die wir an jene stellten, wird vielleicht von vorn-
1) 3,484 .
2) $3,423 \mathrm{f}$.
3) $3,37+$ vgl. 2,81 . 
Stein, Gneisenau und W. v. I Humboldt in den Jahren I 8 I2-ISI5. I 85

herein darauf gefaßt sein, das weltbürgerliche Element bei ihm noch penetranter zu finden. Stein und Gneisenau, groß geworden im preußischen Staats- und Heeresdienst, Humboldt groß geworden in der Welt der klassischen Dichtung und Philosophie und im Protest gegen die Expansionslust der Staatsgewalt und auch das Nationale, wie wir früher sahen, in rein menschlicher Gesinnung ergreifend, - man sollte meinen, daß er als Staatsmann nun ganz besonders darauf aus hätte sein können, das national regenerierte Preußen und Deutschland unter universale Gebote zu stellen und die Selbstbestimmung der Staatsgewalt und der politisch geeinigten Nation zu binden. Aber es stellt sich, wenn man seine deutschen Verfassungsgedanken aus den Jahren I $\$$ I 3 - I $\$$ I 6 daraufhin mustert, sogleich das überraschende Ergebnis heraus, daß er der Idee des autonomen Nationalstaates in diesen Jahren viel näher gekommen ist als Stein. Wir sahen, daß Stein die Aufgabe der auswärtigen Machtpolitik Deutschlands instinktiv beschränkte auf die Abwehr des 》ewigen Feindes « Frankreich, daß ihm diese Aufgabe Deutschlands zugleich eine universale Funktion war, indem er Europa einteilte in die Zonen der Freiheit und der Unfreiheit. Eben deswegen, weil er unwillkürlich universal, man möchte sagen übersichtig, dachte, war er, was Deutschlands Machtpolitil betraf, kurzsichtig; und diese Kurzsichtigkeit hat Humboldt erkannt. Ohne es zu sagen, polemisiert er tatsächlich gegen Stein, wenn er in seiner an ihn gerichteten Denkschrift vom Dezember I $S$ I 3 schreibt ${ }^{1}$ ): „Wenn man über den zukinftigen Zustand Deutschlands redet, muß man sich wohl hüten, bei dem beschränkten Gesichtspunkte stehen zu bleiben, Deutschland gegen Frankreich sichern zu wollen. Wenn auch in der Tat der Selbständigkeit Deutschlands nur von dorther

1) Gesammelte Schriften XI, 96; Schmidt, S. Io.. 
Gefahr clroht, so darf ein so einseitiger Gesichtspunkt nie zur Richtschnur bei der Grundlegung zu einem dauernd wohltätigen Zustand fiur eine große Nation dienen. Deutschland muß frei und stark sein, nicht bloß, damit es sich gegen diesen oder jenen Nachbarn oder iiberhaupt gegen jeden Feind verteidigen könne, sondern deswegen, weil nur eine auch nach außen hin starke Nation den Geist in sich bewahrt, aus dem auch alle Segnungen im Innern strönen; es muß frei und stark sein, um das, auch wenn es nie einer Prüfung ausgesetzt würde, notwendige Selbstgefühl zu nähren, seiner Nationalentwicklung ruhig und ungestört nachzugehen und die wohltätige Stelle, die es in der Mitte der europäischen Nationen für dieselben einnimmt, dauernd behaupten zu können."

Das ist eines der großartigsten politischen Worte, nicht nur Humboldts, sondern dieser Zeit uberhaupt, eines der Worte, die auf der Höhenscheide zweier Zeitalter stehen, die den Weg wohl noch erkennen lassen, der aus der vergangenen Zeit zu ihr herauf führte, aber zugleich einen offenen und weiten Blick auf das Kommende eröffnen. Die universale Aufgabe Deutschlands inmitten der europäischen Nationen ist nicht vergessen, aber sie hemmt nicht, wie bei Stein, seine freie politische Bewegung nach allen Seiten hin, und diese Bewegungsfreiheit und Selbstbestimmung dient nicht nur, wie in der autonomen Politik des Absolutismus, dem Gewinne von Macht, sondern die Macht wird in den höheren Dienst des Geistes gestellt; und wiederum der Geist, den er hier meint, ist nicht mehr der rein individualistische, sondern der mit dem Gesamtleben der Nation verbundene. Macht und Geist, Individuum, Nation und Menschheit, Politik und Kultur, diese Falitoren, die in diesen Jahren in den Köpfen der Menschen so stark erregt waren und deswegen so stark auch hin und her zitterten, liegen hier einmal in den Wagschalen in idealem 
Gleichgewichte zueinander. Man kann nicht schlechthin sagen, daß Humboldt hier schon Staat und Nationalstaat in ihrer nackten Gestalt gleichsam, in jener reinen Autarkie und Autonomie, in jener unbedingten Auswirkung ihrer immanenten Machttriebe sah, wie sie später Ranke und noch' stärker Bismarck sahen. Es liegt noch ein leichter aber fester Schleier von ethisch. geistigen Postulaten über ihnen, der aber, so wie hier die Sache formuliert ist, der Natur des Staates und der Macht keinen Zwang antut, der sie veredelt, aber nicht unterbindet.

So drang Humboldt in das Wesen des nationalen Machtstaates tiefer ein als Stein, obgleich ihm der Staat als solcher weniger am Herzen lag als diesem, - vielleicht aber eben deswegen. Der mehr Schauende sieht oft, demselben Gegenstande zugekehrt, mehr als der mehr Verlangende und Handelnde. Aber Humboldt schaute jetzt doch auch mit einem starken Herzensanteil auf das politische Schicksal der deutschen Nation, und auch dieses $\mathrm{MaB}$ von innerer, aber von eigentlicher Leidenschaft freier Neigung trug dazu bei, sein Verständnis dafür zu schärfen. Seine erste und bleibende Liebe war dem Individuum zugewandt. Dann sah er, schon in den neunziger Jahren, über dem Individuum die Nation sich erheben, und immer tiefer hatte er seitdem den ursprünglichen und naturhaften Zusammenhang zwischen beiden begreifen gelernt. 》Es liegt in der Art, « sagt er in derselben Denkschrift, swie die Natur Individuen zu Nationen vereinigt und das Menschengeschlecht in Nationen absondert, ein überaus tiefes und geheimnisvolles Mittel, den Einzelnen, der für sich nichts ist, und das Geschlecht, das nur in Einzelnen gilt, in dem wahren Wege verhältnismäßiger und allmählicher Kraftentwicklung $\mathrm{zu}$ erhalten. « Und nun wagen wir zu vermuten, daß er jetzt auch deswegen die Spontaneität und 
Autonomie der politisch geeinigten Nation erkennen und fordern konnte, weil er sie einst für das Individuum gefiuhlt und gefordert hatte. Wo stammt ïberhaupt unsere historisch-politische Denkweise, unser Sinn für die Individualität auch der überindividuellen menschlichen Verbände her? Doch wohl ganz wesentlich mit aus einem Individualismus, der seine ursprünglich flache Ansicht vom Wesen des Individuums im Laufe einer säkularen Arbeit immer mehr vertieft hat, bis er zu seinen Wurzelschichten gelangte und damit zu den Zusammenhängen. die das Eigenleben des einzelnen mit dem Eigenleben der höheren menschlichen Verbände und Ordnungen verknüpfen. Individualität, Spontaneität, Drang nach Selbstbestimmung und Machtausdehnung uberall, und so auch im Staate und in der Nation. „Die Nationen, « sagt Humboldt jetzt auch noch, 》haben, wie die Individuen, ihre durch keine Politik abzuändernden Richtungen. « Das war zugleich ein Protest gegen den, wie wir sahen, auch noch in Stein und selbst in Gneisenau nachwirkenden Rationalismus, der mit seinem künstlichen Machen diesem Eigenleben zu nahe trat. Wir lassen hier die eigentlich transzendente Frage, wie sich das autonome Leben der verschiedenen Stufen vom Individuum bis zum Staat herauf mit ihrer gegenseitigen Abhängigkeit voneinander vertragen kann, ganz beiseite. Hier galt es nur, zu verstehen, wie gerade Humboldt, unbeirrt von dem universalistischen Idealismus seiner Zeitgenossen, dem Nationalstaate geben konnte, was des Nationalstaates ist, wie er auf dem Wege von den Ideen zu den Realitäten in dieser Frage den Freiherrn vom Stein überholen konnte.

Aber endguiltig hat auch er nicht das Ziel behauptet, und Ruickfälle und Inkonsequenzen sind ihm nicht erspart geblieben. Wir sahen, daß Steins optimistische Zuversicht auf das harmonische Zusammenleben Preußens und Osterreichs in Deutschland aus jenem selben ethischen 
Idealismus floß, der auch seinen politischen Universalismus nährte. Auch Humboldts deutsche Verfassungspläne rechneten immer auf das Zusammenwirken der beiden deutschen Großmächte. »Die feste, durchgängige, nie unterbrochene Ubereinstimmung und Freundschaft Ósterreichs und Preußens ist allein der Schlußstein des ganzen Gebäudes«, heißt es in der Denkschrift vom Dezember I8I3. „Das Wahre und Eigentliche wäre, * sagte er auch in seiner großen Denkschrift iber den deutschen Bund vom 30. September I $\left.8 \mathbf{1}^{1}\right)$, 》daß PreuBen und Osterreich gemeinschaftlich den Bund leiteten, « und er erklärte den Bund »als eines der sichersten Mittel, ihr Einverständnis zu bewahren.« Aber ganz wohl scheint ihm bei dieser Konstruktion von vornherein nicht gewesen zu sein. Wenn man seine Worte vom Dezember I 8 I 3 liest, daß dieser feste Punkt der österreichischpreußischen Ubereinstimmung eben von vornherein gegeben sein müsse, um den Bund uberhaupt zu schließen, daß er ein durchaus politischer sei und auch auf einem rein politischen Prinzip beruhe, so sieht man sehr deutlich und schön wieder, daß er, anders als Stein, wohl alles Un- und Uberpolitische aus diesem Verhältnisse ausscheiden wollte und sich selbst zur Nüchternheit ermahnte. Aber ob er daran geglaubt hat, daß die reine Politik schon dafür sorgen werde, Ósterreichs und Preußens Freundschaft zu erhalten? Die Gründe, durch die er sich davon zu überzeugen versuchte, klingen gequält. ${ }^{2}$ ) Hätte er an die Möglichkeit einer dauernden, auf rein politischer Grundlage beruhenden Interessenharmonie Osterreichs

1) Gesammelte Schriften XII, 82; Zeitschrift für preuß. Gesch. 9, 109.

2), Gerade aber indem man in das Verhältnis Österreichs und Preußens schlechterdings nichts mehr Verpflichtendes bringt, als jedes Bündnis enthält, und dieselbe (die Übereinstimmung Österreichs und Preußens) zur Grundlage der Wohlfahrt des gesamten Deutschlands macht, 
mit Deutschland und Preußen wirklich fest geglaubt, so würde er I 15 gegen das deutsche Kaisertum Ósterreichs wenigstens das nicht geltend gemacht haben, daß man dadurch noch keine Garantie gegen eine undeutsche Politik Ósterreichs schaffe. „Si l'on croit que l'Autriche ne se décidera pas à des transactions misibles à l'Allemagne précisément à cause de la dignité Impériale, on oublic qu'une puissance doit toujours agir ainsi que son intérêt réel l'exige impérieusement."1) Er machte es sich auch I $\$$ I 6 auf Grund der jüngsten Erfahrungen wieder klar, daß Preußen auf Ósterreich dann gewiß nicht zählen könne, »wenn es Pläne geben sollte, wo es darauf ankäme, etwas gegen die Mehrheit der anderen mit großer Energie durchzusetzen. $\ll^{2}$ )

So hat er also über den Geist der österreichischen Politik in Deutschland und uber die Möglichkeit eines österreichisch-preußischen Zusammenwirkens wohl skeptischer gedacht als Stein, ohne doch den Mut der Konsequenz zu haben und die Lebensfähigkeit des Bundes, der auf einer solchen gebrechlichen Grundlage beruhte, uiberhaupt zu leugnen. ${ }^{3}$ )

Wie die Dinge lagen, blieb ja freilich damals gar kein anderer Ausweg ubrig, als es mit dem Bunde und

welche ihre eigene in sich begreift, verstärkt man sie durch das Gefühl der Freiheit und Notwendigkeit, wozu sich die Abwesenheit alles Grundes zu einem ausschließenden Interesse gesellt, da zwischen beiden Mächten weder Unterordnung noch Teilung der Gewalt gestattet wird.e schmidt, S. Io8.

1) Denkschrift vom 23. Febr. 1815, Gesammelte Schriften XI, 300, Schmidt, S. 420.

2) Gesammelte Schriften XII, 65.

3) Treitschke, D. G. 2, 144, geht zu weit und sieht in Humboldt zu sehr den Vertreter seiner eigenen Auffassung, wenn er Humboldts Ansicht vom deutschen Bund, wie sie in der Denkschrift vom 30. Sept. I 816 entwickelt wird, yhoffnungslos nennt. Es finden sich neben den pessimistischen Äußerungen, auf die sich Treitschke beruft, 
mit dem österreichisch-preußischen Zusammenwirken in ihm wenigstens zu versuchen, und man versteht es, daß gerade auch ein real gerichteter Staatsmann wie Humboldt das, was die Notwendigkeit diktierte, von seiner besten Seite zu nehmen sich bemuihte und gute Miene zum wenig versprechenden Spiele machte. Aber ganz frei von dem Verdachte, daß sich auch noch etwas unpolitischer Idealismus mit hineinmengt, ist Humboldt darum doch nicht, und zwar deswegen nicht, weil wir an anderen Punkten ganz deutliche Spuren eines solchen an ihm auftauchen sehen. Wir bemerkten schon friher, daß gerade er in dem Verfassungsplane vom Dezember I 8 I 3 den ungliuckseligen Vorschlag machte, die Garantie für den deutschen Bund den großen Mächten Europas, namentlich England und Rußland, zu übertragen. Wohl suchte er gleich dahinter diese Garantie wieder einzuschränken und unschäcllich zu machen, indem er alle Einmischung der fremden Mächte in die inneren Angelegenheiten Deutschlands fern gehalten wissen wollte ${ }^{1}$ ),

doch auch bemerkenswerte optimistische Urteile, S. 65: Die unerfreuliche Lage wird, Preußen doch nie hindern, dasjenige durch den Bund zu erlangen, worauf es mit Recht Anspruch machen kann\&, und S. 67: \Alle Maßregeln der gemeinschaftlichen Verteidigung werden [bei richtiger Haltung Preußens] auch mit Erfolg durchgesetzt werden können. ‘

1) Demnach sollten sie auch einen direkten Anteil an der Herstellung der Verfassung, qui ne peut être qu'un ourrage national, nicht erhalten. Denkschrift vom April ISI4, Gesammelte Schriften XI, 207. Schmidt, S. 146. Hinterher wurde ihm selbst eine beschränkte Garantie der fremden Mächte bedenklich, denn während er im April I $\$ 14$ noch von puissancis garantes de la constitution gesprochen hatte, versuchte er in der Denkschrift vom 30. Sept. ISI6 nachzuweisen, daß die Einrückung der Bundesakte in die Kongreßakte keine eigentliche Garantie bedeute. ,Im wahren und eigentlichen Verstande des Worts gibt es daher jetzt gar keinen Garant des Deutschen Bundes und seiner Verfassung, außer dem Bunde selbst, \& (a.a. O.S. 97) eine, wie Treitschke, 2, I 40 schon hervorhebt, sleider keineswegs unanfechtbare Rechtsansichte. S. auch unten Kap. 9, S. 200 f. 
aber in den großen Macht- und Daseinsfragen der äußeren Politik sollte Deutschland, - so müssen wir doch seinen Gedanken interpretieren - eine verfassungsmäßige Hoffnung auf den brüderlichen Beistand der beiden großen Auslandsmächte setzen dürfen.

Humboldt teilte mit Stein nicht nur diesen Irrgedanken, sondern auch jenen zweiten, oben hervorgehobenen, daß man der englischen Regierung via Hannover einen verfassungsgemäßen Einfluß selbst auf die Leitung des deutschen Bundes gewähren könne. Ja, jene Idee Steins vom März I8I4, ein Viererdirektorium, gebildet aus Osterreich, Preußen, Hannover und Bayern, zu errichten, ist nur eine Weiterentwicklung dessen, was Humboldt schon im Januar I 8 I4 vorgeschlagen hatte. $\left.{ }^{1}\right)$ Wenn man, so meinte er zu Gentz, Bedenken fände, das Recht der Kriegserklärung nur Osterreich und Preußen anzuvertrauen und Bayern und Hannover davon auszuschließen, »so könnte diese Schwierigkeit leicht dadurch gehoben werden, daß man sie an diesem Rechte teilnehmen ließe, ob ich gleich dies nicht ganz billigen würde. " Diese Mißbilligung traf nicht etwa EnglandHannovers Teilnahme. Im Gegenteil, denn er fährt fort: 》Unbequemlichkeit aber könnte daraus wenig erwachsen, da England, welches mit Hannover zusammenfällt, doch immer seine Stimme dabei haben würde, und Bayern, wenn es auch, dem Namen nach, mitspräche, sich dennoch den größeren Mächten fügen müßte. ${ }^{2}$ ) Da er kurz vorher erklärt hatte, daß Deutschland nicht nur gegen diesen oder jenen Nachbarn, sondern gegen jeden Feind gerüstet sein müsse, so hat er an die Möglichkeit, daß England jemals Deutschlands Feind werden könne, offenbar nicht gedacht.

\footnotetext{
1) Richtig erkannt von Gebhardt, Humboldt als Staatsmann 2, I I 4.

2) Gesammelte Schriften XI, II3 (Humboldt an Gentz, 4. Januar I 8 I4).
} 
Also auch er hat den großen Gedanken der nationalen Autonomie für Deutschland, den er als einer der ersten zur begrifflichen Schärfe brachte, nicht konsequent festgehalten, auch er ist von dem Glauben nicht ganz losgekommen, daß es uibernationale Gemeinsamkeiten im Staatsleben gebe, auf die man politisch bauen, auf die man auch das Dasein der eigenen Nation mit gründen könne.

Um ihn ganz zu verstehen, müssen wir das vorhin über ihn Gesagte ergänzen und teilweise einschränken Wir sagten, daß die ethisch-geistigen Postulate, die er für die nationale und politische Existenz Deutschlands aufstellte, dem Wesen des Staates und der Macht keinen Zwang anzutun brauchten. Aber er ist sich auch darin nicht konsequent geblieben. Das zeigen seine Gedanken iiber die Gestaltung Deutschlands und über den Grad von politischer Einheit, den er ihm geben wollte. Er rühmte in derselben Denkschrift vom Dezember ISI3, in der er das Ideal der autonomen Nation aufstellte, zugleich die Zerstückelung Deutschlands als eine Voraussetzung für die Mannigfaltigkeit seiner geistigen Bildung, und er wiinschte deshalb nicht, daß sie ganz authöre. Diesen Wunsch unterstiitzte freilich zugleich auch sein zuweilen so großartig hervorbrechender Wirklichkeitssinn, denn er setzte hinzu: "Der Deutsche ist sich nur bewuft, daß er ein Deutscher ist, indem er sich als Bewohner eines besonderen Landes in dem gemeinsamen Vaterlande fühlt." Das sind Worte, die unmittelbar an Bismarcks berühmtes Kapitel von den Dynastien und Stämmen erinnern, und so darf seine Meinung, daß Deutschland zum geschlossenen Einheitsstaate nicht geschaffen sei, auch vor dem Forum strengster realpolitischer Kritik wohl bestehen. Es fällt nun freilich auf, daß er in diesem Zusammenhange die natürliche Richtung Deutschlands auf das bescheidene Ziel beschränkt, »ein Staaten- 
verein zu sein«, - im Gegensatz zu Frankreich und Spanien, die »in eine Masse zusammengeschmolzen« seien. Er kennt also hier nichts Mittleres zwischen Staatenverein und Einheitsstaat, er kennt oder er erstrebt doch nicht den Bundesstaat, der Mannigfaltigkeit im Inneren mit geschlossener Einheitlichkeit und Kraft nach außen verbindet. Aber er hatte allerdings, wie wir wieder zugeben müssen, einen von höchster realer Einsicht zeugenden Grund dafür, auf den Bundesstaat zu verzichten. 》Die Wahrheit ist, « sagte er einige Jahre später in seiner Denlsschrift vom 30. September ISI6, 》daß ein eigentlicher Bundesstaat da nicht mehr möglich ist, wo Zwei Glieder desselben (der ubrigen nicht zu gedenken) so mächtig geworden sind. ${ }^{1}$ ) Und doch wird ueu, wenn man eben diese Denkschrift vom 30. September i 8 i 6 . liest, sich dem Eindrucke nicht entziehen können, daß auch noch andere als realpolitische Gründe seine Ziele für Deutschland bestimmt und beschränkt haben. „Man muß auf keine Weise, « sagt er hier ${ }^{2}$ ), »den wahren und eigentlichen $Z$ weck des Bundes vergessen, insofern er mit der europäischen Politik zusammenhängt. Dieser Zweck ist Sicherung der Ruhe; das ganze Dasein des Bundes ist mithin auf Erhaltung des Gleichgewichts durch innewohnende Schwerkraft berechnet; diesem wiirde nun durchaus entgegengearbeitet, wenn in die Reihe der europäischen Staaten, außer den größeren deutschen einzeln genommen, noch ein neuer kollelitiver in einer, nicht durch gestörtes Gleichgewicht aufgeregten, sondern gleichsam willkürlichen Tätigkeit eingeführt würde, der bald für sich handelte, bald einer oder der anderen größeren Macht zur Hilfe oder zum Vorwande diente. Niemand könnte dann hindern, daß nicht Deutschland als Deutschland auch ein erobernder Staat würde, was kein echter

1) Gesammelte Schriften Xil, $S_{3}$

2) a. a. O. S. 77 . 
Deutscher wollen kann; da man bis jetzt wohl weiß, welche bedeutende Vorzüge in geistiger und wissenschaftlicher Bildung die deutsche Nation, so lange sie keine politische Richtung nach außen hatte, erreicht hat, aber es noch unausgemacht ist, wie eine solche Richtung auch in dieser Rücksicht wirken würde. «

Man sieht, daß auch das Ziel im ganzen hier für Deutschland merklich niedriger gesteckt ist als in den schönen Worten von I \& 13. "Sicherung der Ruhe", als einziger Zweck des Bundes nach außen hin, wie bescheiden klingt das nach dem stolzen Aufblick zu dem freien und starken, von Selbstgefühl gehobenen Deutschland! Was zwischen den Dezembertagen des Jahres $I_{1} I_{3}$ und den Septembertagen des Jahres i $\$$ I 6 geschehen war, macht wohl die Herabstimmung seiner Hoffnungen in vielem verständlich. Nachdem die deutsche Bundesverfassung einmal so sehr viel schwächer und schlechter ausgefallen war, als Humboldt es gewünscht hatte, waren auch die Voraussetzungen für eine auswärtige Gesamtpolitik Deutschlands andere geworden. Ein Bund, wie ihn sich Humboldt im Dezember I 8 I 3 dachte, wo die Entscheidung uber Krieg und Frieden Deutschlands in die Hände der beiden leitenden Großmächte gelegt war, konnte und durfte Deutschland nach außen hin kräftiger vertreten als ein Bund, dessen radikaler Fehler, wie Humboldt jetzt sagte, »gänzlicher Mangel aller exekutiver Gewalt ist «. Einem Bunde mit so dürftigen Organen durfte man keine große nationale Politik zumuten, denn es drohte dabei doch nur Blendwerk oder Intrigue herauszukommen. Man versteht es darum, wenn Humboldt jetzt davor warnte, dem Bundestage »einen zu weitgehenden Begriff von Einheit beizulegen * und dadurch Hoffnungen zu erwecken, die der Bund, wie er war, nun einmal nicht erfüllen konnte. So urteilte er als nüchterner Arzt, der die schwachen Kräfte seines 
Patienten richtig einschätzte, so urteilte er auch jetzt als spezifisch preußischer Staatsmann, der es nicht dulden konnte, daß die preußische Selbständigkeit durch einen Bund ohne Zentrum, durch eine Politik der Kleinen und Vielen sich Fesseln anlegen ließ. So war sein jetziger Verzicht auf eine selbständige und starke Vertretung Deutschlands gegenüber dem Ausland wohl wiederum zum großen Teile eine verständige Anpassung an die reale Lage, aber hält man clas I 8 I 3 und i 8 I 6 Gesagte zusammen, so wird man nicht leugnen können, daß er auch um seines Kulturideals willen die Entwicklung Deutschlands zu einem autonomen Machtstaate in vollem Sinne nicht gewünscht hat, daß sein nationalpolitisches Ideal gedämpft wurde durch Ideen, die aus der weltbürgerlichen Bildung des I 8 . Jahrhunderts stammten, durch jene Vorstellung von dem Berufe der Deutschen zur Kultur- und Menschheitsnation. Oder will man einwenden, daß er nur das eine verhindern wollte, daß Deutschland ein erobernder, d. h. ein seine Machtpolitik überspannender Staat würde? WVir meinen, daß derjenige, der den Mißbrauch einer IVaffe dadurch verhiiten will, daß er sie versteclit, ein Mißtrauen gegen sie überhaupt hat. Er fand es überhaupt bedenklich, daß die deutsche Nation eine spolitische Richtung nach außen« nähme. Das ging über das hinaus, was er als preußischer Staatsmann und als nuichterner Kritiker der Bundesverfassung gegen eine auswärtige Politils des Bundestages mit Grund einzuwenden hatte.

So enthält diese Denkschrift vom 30. September I 8 I 6 eine feine und strenge politische Einsicht eng verwoben mit Forderungen, die ganz unpolitischen Ursprungs waren. Die Schrift übt überhaupt einen seltsamen Reiz aus durch die bei näherer Betrachtung immer noch wachsende Subtilität ihres Inhalts. Heben wir hier nur noch einen fur unser Thema bedeutenden zug in diesem Gedankenzusammenhange hervor. 
Es war realpolitisch durchaus richtig gedacht, sagten wir, daß er die Tätigkeit des Bundestages, so wie er einmal geformt war, beschränken wollte derart, daß er immer nur sfür eine mehr abwehrende, negativ einwirkende, Unrecht verhindernde, als für eine zu vielem positiven Einwirken und aus ihm selbst hervorgehender Tätigkeit bestimmte Behörde gelte. «1) Man wird, wenn man dem weiter nachdenkt, zu einem milderen Urteil über die geschichtliche IVirksamkeit des Bundestages uberhaupt vielleicht gelangen, man wird aus der Stimmung des Klagens oder Verspottens in die des Verstehens geraten und die Unproduktivität des Bundestages als das natüliche und normale Ergebnis der I 8 i 5 in Deutschland geschaffenen Lage ansehen. Aber hat sich das Humboldt auch in allen seinen Konsequenzen schon klar gemacht? Wir glauben, nein. Er hat sich in einen furchtbaren inneren Widerspruch dadurch verstrickt, daß er einmal dem Bunde und Bundestage die Fliigel beschneiden wollte und dann doch wieder erwartete, daß er wenigstens zu einer gewissen Höhe wieder fliegen könne. Es war eine unausgleichbare Antinomie, daß der Bundestag auf der einen Seite Unrecht verhindern, auf der andern Seite sich aber einer aus ihm selbst hervorgehenden positiven Tätigkeit enthalten sollte, und daß ferner der Bund zwar Deutschlands Unabhängigkeit sichern und seine Verteidigung organisieren und doch eine selbständige auswärtige Politik nicht treiben sollte. Wer wirksam hindern soll, muß auch wirksam schaffen können, und wer wirksam verteidigen soll, muß wenigstens die Möglichkeit haben, auch wirksam angreifen zu können. Ein Staatswesen, und sei es auch nur ein Staatenbund, bedurfte, wenn es auch nur das leisten sollte, was Humboldt von ihm erwartete, größeren Spielraumes, als er

1) a. a. O. S. 77 . 
ihm einräumen wollte. Er machte es sich nicht klar, daß man dem Baume nicht Nahrung entziehen und dann doch, wenn auch noch so bescheidene Frucht von ihm erwarten konnte. Der Bund sollte - und damit mündet diese Betrachtung in unser Thema wieder ein - nationalpolitische Funktionen ausüben, ohne nationalpolitische Autonomie zu genießen.

Auf anderen und verschlungeneren Wegen als Stein gelangte Humboldt zu solchem Irrtum. Sehr viel subtiler greift bei ihm das Politische und Unpolitische ineinander über. Aber eine letzte Quelle des Irrtums liegt auch bei ihm in den Resten einer unstaatlichen Ansicht vom Staate, die er bei aller Schärfe politischer Erkenntnis nicht ganz überwinden konnte. 
Neuntes Kapitel.

\section{Übergang zur Restaurationszeit; Blick auf die öffentliche Meinung.}

Zwei Ideen waren es hauptsächlich, die aus der bisherigen universalistischen Bildung in die neu sich regenden nationalen Ideen mit hinüberflossen und mit diesen sich verschmolzen. Einmal die Vorstellung, daß die deutsche Nation als reinste Geistes- und Kulturnation die eigentliche Menschheitsnation sei, und sodann das Postulat einer universal-europäischen Staatenverbindung. Den ersten Gedanken hegten die Vertreter des klassischen Humanitätsideals, beide Gedanken zusammen Novalis und Friedrich Schlegel in den Jahren der Frühromantik; ferner auch Fichte wohl, aber mit viel stärkerer Betonung des ersten dieser beiden Gedanken, während umgekehrt Adam Müller und Friedrich Schlegel in seiner weiteren Entwicklung den Schwerpunkt auf den zweiten Gedanken verlegten. Beide Gedanken haben anspornend und hemmend zugleich auf das nationale und politische Leben gewirkt. Durch die hinreißende Kraft, die Fichte dem Gedanken der Menschheitsnation gab, half er den politischen Enthusiasmus der Erhebungszeit mit entzünden. aber wir sahen eben an Humboldts Beispiel, daß dieser Gedanke zugleich auch den politischen Machtdrang der Nation mit dämpfen half. Noch unmittelbarer griff, so sahen wir bei Stein, der zweite Gedanke in das politische Leben ein, noch unmittel- 
barer wirkten in ihm geistige Bewegung und Weltlage zusammen. Und weil es sich hier um ganz große und weithin reichende Ideenzusammenhänge handelt, so ist es lklar, daß alle von uns bchandelten Beispiele eben nur Beispiele von etwas Umfassenderem und weiter Verbreitetem sind, und es fällt nun vielleicht auf manche Erscheinung Licht, die ohne das isoliert, singulär und darum befremdend sich ausnimmt. Wie wunderlich berihrt es z. B., wenn der Heidelberger Jurist Thibaut, als er ISI 4 seine berihmte Forderung nach einem einheitlichen Gesetzbuch für ganz Deutschland stellte, in einem Atem ihren »echten germanischen Sinn pries und sie durchzuführen vorschlug durch $»$ Völkervertrag unter feierlicher Garantie der auswärtigen großen alliierten Mächte ${ }^{1}$ ) Wir wissen jetzt, daß dieser für uns heute unerträgliche Gedanke einer auswärtigen Garantie für eine nationale Sache den damaligen Nationalgefühl nicht so unerträg= lich sein konnte, weil man die Stellung Deutschlands in Europa mit anderen Augen ansah als wir. So wird man es iberhaupt nun besser verstehen, daß die elf ersten grundlegenden Artikel der deutschen Bundesalite der Wiener Kongreßakte einverleibt und damit, wenn auch keine ganz zweifellose Garantie, so doch bedenkliche Ansprüche auf eine Garantie der deutschen Verfassung durch die europäischen Signatarmächte und auf ihr Einmischungsrecht geschaffen wurden. Metternich selbst hat, als er die Einverleibung betrieb, an eine wirkliche Garantie gedacht. »So müssen, "heißt es in seiner Erklärung in der deutschen Konferenz vom 5. Juni 1 \& I 5 , »die österreichischen Bevollmächtigten vorzüglich verlangen, die Bundesakte noch vor Beschließung des Kongresses unter die Garantie der europäischen Mächte,

1) Lber die Notwendigkeit eines allg. bürgerl. Rechts für Deutschland. Zivilistische Abhandlungen $\left(\mathbf{I} \mathbf{S}_{4}\right.$ ), S. 4+3. Ich verdanke den Ilinweis meinem Freiburger Kollegen Alfred Schultze. 
gleich anderen Kongreßbeschliissen gestellt zu sehen. ${ }^{1}$ ) Er selbst dachte dabei natülich an nichts anderes als an das Interesse Osterreichs, wie er es verstand, aber daß er diese Forderung überhaupt erheben, und daß die Einreihung der Bundesakte unter die Beschlüsse des europäischen Kongresses dann anstandslos erfolgen konnte, deutet auf eine Auffassung vom Wesen des Deutschen Bundes, die in ihm eine Einrichtung von nicht nur nationalem, sondern auch von europäischem Charakter sah, von sozusagen verfassungs- und stiftungsmäßig europäischem Charakter. IVir sahen, wie sich selbst Humboldt hiernach den »wahren und eigentlichen Zweck « des Bundes zurechtmachte und werden nicht erstaunt sein, ähnliche Gedanken in der Schrift des Göttinger Historikers Heeren: "Der deutsche Bund in seinem Verhältnis zu dem europäischen Staatensystem « wiederzufinden. $\left.{ }^{2}\right)$ Der deutsche Bund, heißt es hier, steht in der innigsten Ubereinstimmung mit den allgemeinen und den besonderen Interessen von Europa. Darum kann es auch den fremden Mächten nicht gleichguiltig sein, wie der 》Zentralstaat von Europa « geformt ist. Wäre dieser Staat eine große Monarchie mit strenger politi-

1) Kliiber, Akten des Wiener Kongresses 2, 523. In dem Konferenzprotokoll wird statt "Garantie der Ausdruck , Schutz gebraucht (S. 5II). Es wäre erwünscht, diese ganze Frage und die wiederholten Versuche des Auslandes in den folgenden Jahrzehnten, auf Grund des beanspruchten Garantierechtes sich einzumischen in die inneren Angelegenheiten Deutschlands, eingehender zu untersuchen. - Lnter den Außerungen dieser Jahre, in denen der Gedanke, Deutschland unter die Garantie der großen Mächte zu stellen, empfohlen wird, nenne ich noch die richt uninteressante Schrift: ,Uber Deutschlands und Europens Staats. und Nationalinteresse bey und nach dem Congreß zu Wien.، Germanien ISI4. Auch den Gedanken des europäischen Staatenbundes, der alle unabhängigen Nationen umfassen sollte, wurde vertreten z. B. von Mallinckrodt, , Was thun bey Teutschlands, bey Europens Wieder. geburt? ISI3.

2) I 817 . Histor. Werke 2, $423 \mathrm{ff}$. 
tischer Einheit, ausgeriistet mit allen den materiellen Staatskräften, die Deutschland besitzt, - welcher sichere Ruhestand wäre für sie möglich? Würde ein solcher Staat lange der Versuchung widerstehen können, die Vorherrschaft in Europa sich zuzueignen? Das habe man schon lange in der praktischen Politik gefühlt, deswegen sei seit dem westfälischen Frieden die $»$ Erhaltung deutscher Freiheit « nicht bloß die Aufgabe für Deutschland, sondern für Europa gewesen. So habe die Weisheit der alliierten Mächte jetzt erkannt, daß ein Staatskörper gebildet werden muß, der schwach zum Angriff, aber stark zur Verteidigung sei, - der $\gg$ Friedensstaat von Europa.

Dieser europäische Zentral- und Friedensstaat ist als genaues logisches Gegenstuick zur Universalmonarchie gedacht, auch er hat universale Funktionen, nur mit umgekehrten Vorzeichen. »Er muß der Verteidiger des Prinzips des rechtmäßigen Besitzstandes sein, weil ohne dieses für ihn selber bald gar keine Sicherheit mehr wäre"; und so liege es also keineswegs geradezu außer seiner Sphäre, für die Erhaltung dieses rechtmäßigen Besitzstandes und der rechtmäßigen Dynastien Europas einzutreten. Wie Europa ihn, so hilft er Europa schützen und erhalten.

So konnte ein Mann konstruieren und phantasieren, der ein nüchterner und das Wesen autonomer Machtpolitik schon erfassender historischer Denker und ein in seiner Art treuer und uberzeugter Verteidiger deutscher Nationalität in den Jahren, wo sie am schwersten bedroht war, gewesen ist ${ }^{1}$ ). Man sieht nur wieder von neuem, wie stark die politische Luft dieser Jahre mit universalistischen Bestandteilen geschwängert war - derselben Jahre, die den europäischen Nationen ihre Unabhängig-

1) Vgl. seinen Aufsatz ১Über die Nittel zur Erhaltung der Nationalität besiegter Völker , greschrieben und erschienen ISIO in Perthes' Vaterländ. Museum. Histor. Werke 2, I ff. und Marcks, Bismarck I, Ioo f. 
keit und auch ein Gefühl ihrer Unabhängigkeit, aber freilich eben nicht die ganze Unabhängigkeit und insbesondere nicht den Deutschen das Gefühl der unbedingten Unabhängigkeit zurückgegeben hatten. Die Deutschen fühlten sich eben zu sehr als Welt- und Universalnation. Andere Nationen leiten daraus den Anspruch auf Weltherrschaft ab, im damaligen Deutschland aber war man imstande, daraus eine Art von Weltdienstbarkeit abzuleiten und das Joch mit Freuden zu tragen.

Diese Weltdienstbarkeit, diese Neutralisierung der deutschen Nationalkraft durch den deutschen Bund und die ihn freundlich-gönnerhaft umstehenden europäischen Großmächte ist eine der Hauptvoraussetzungen für die europäische Geschichte der folgenden Jahrzehnte geworden. Man sieht schon in Heerens Schrift die Gedanken der legitimistischen Interventionspolitik, der Kongresse von Troppau, Laibach und Verona auftauchen. Das Schlinggewächs des legitimistischen Universalismus war nicht auf Deutschland allein beschränlit, es wucherte ja uberaus stark auch in der französischen Schule der politischen Romantik, der de Maistres, Bonalds usw. Aber es hätte sich nicht so weit verbreiten und nicht so viel bedeuten können, wenn nicht im Zentrum von Europa der Geist des autonomen Nationalstaats noch im Schlummer gelegen hätte.

Dieser Zustand des Schlummers war wenigstens der vorherrschende Zustand. Denn es fehlte nicht an einzelnen wachen Regungen, an vereinzelter Aussprache derjenigen politischen und nationalen Wahrheiten, die in dem modernen Nationalstaate verwirklicht worden sind. Eine deutliche Ahnung z. B. der Gefahren, die von der Solidarität der europäischen Höfe, der Politik der europäischen Kongresse für das Eigenleben der einzelnen Nationen drohten, hatte merkwürdig frühe schon Fried- 
rich Gottlieb Welcker. ${ }^{1}$ ) 》Der Stand aller Verhältnisse verändert sich, wenn eine neue einseitige Gewalt, eine ubbersouveräne Souveränität in einem Kongreßstaat sich bildet; wenn ,Gesetze von ganz Europa sanktioniert" werden können ohne Wissen und Willen von Europa, oder doch der meisten und größten Völker Europas. " Wenn jetzt die Deutschen keine Verfassung als Nation, wenn sie nicht eimmal die Grenzen erhalten hätten, die sie mit unbestreitbarem Rechte begehren konnten, so rühre das allein daher, daß sie, die im Verhältnis zu ihren Regierungen wieder anfangen sollten etwas zu sein, »dem Ausland gegeniber nichts waren, sondern die großen Höfe alles". So antizipierte er schon den Gedanken, der in den folgenden Jahrzehnten die Regierungen und Völker bewegen und gegeneinander führen sollte: Wenn die Fürsten unter sich eine Verbindung aufrichten, die auf einer von der Natur und der Verfassung der einzelnen Staaten ganz verschiedenen Grundlage ruht, «so muißten notwendig die Völker eine Geneigtheit erhalten, sich unter sich zu verstehen und zu verbinden für die angefochtenen Interessen. « Die Völker würden dann zuletzt nicht ihren Fürsten, die Fürsten nicht ihren Völkern angehören. ${ }^{2}$ ) So war dann - und man weiß, bis zu welchem Grade diese Prophezeiung eingetroffen ist - Europa wieder geteilt in zwei universale Heerlager: der Solidarität der legitimen Regierungen auf der einen, der nach Freiheit und Selbstbestimmung trachtenden Nationen auf der anderen Seite.

So lange diese Situation dauerte, war der individuelle Nationalstaat, der Regierung und Volk zur Einheit

1) Über die Zukunft Deutschlands, greschrieben im Dezember I $S_{5}$, mit einigen späteren Zusätzen. Kieler lilätter 2, 345 ff. (IS I6). - Andere Stimmen, die den Einfuß des Auslandes auf Veutschland fürchten, bei IIagen, Öffentl. Meinung in Deutschland etc. Historisches Taschenbuch N. F. VII, 639 f., 696.

2) a. a. O. S. 364 . 
verband, unmöglich, und der Gedanke der nationalen Autonomie, auf den sich die unterdrückten Völker beriefen, war dann eben kein wahrhaft nationaler Gedanke, sondern ein universales und rationales Axiom, in dem der Geist des IS. Jahrhunderts wieder zur Herrschaft lam. Das Nationalitätsprinzip erhielt dann jenen formalen und schablonenhaften Charakter, den man aus den Theorien Napoleons III. kennt und den man auch in der populären Nationalgesinnung des vormärzlichen Deutschlands häufig genug findet. $\mathrm{Da}$ war man imstande, für die Freiheit, Unabhängigkeit und Macht aller Nachbarnationen zu schwärmen und sich gewiß auch für die cler eigenen Nation ehrlich zu begeistern, ohne zu ahnen, daß die Verbruiderung der freien Nationen, von der man träumte, keine nationale, sondern eine weltbürgerliche Idee war. Es ist aber wieder ganz deutlich, daß diese politischen Irrtimer auf einer idealen und realen Ursache zugleich beruhten. Die reale Ursache war die innere Spannung zwischen Regierenden und Regierten, hervorgerufen clurch den Kampf um die Freiheitsrechte, durch das Emporstreben der bürgerlichen Klassen, das heißt durch soziale und politische Gegensätze, die zunächst zwar nur innerhalb eines Staates und Volkes spielten, aber ihre Analogien fast allerwärts hatten. So daß schon dadurch ein internationaler Zug in diese Kämpfe lam, den dann eben das ideale Element des fortwirkenden weltbürgerlichen Geistes mächtig verstärkte.

Es fehlte aber, wie wir aus Velckers WVorten sahen, schon an der Schwelle dieses Zeitalters nicht an der Ahnung, wie ungesund dieser Zustand der universalen Spannung zwischen Regierenden und Regierten war. Was er negativ ausdriiclite, sprach Luden positiv aus, wenn er ISI4 schrieb ${ }^{1}$ ): "Immer und überall streben

1) Das Vaterland oder Staat und Volk. Nemesis I., S. I0 f., I $S_{\text {I }}$. Dals Luden selbst der Verfasser ist, ergibt sich aus S. 2 II. 
Staat und Volk, man möchte sagen mit liebevoller Sehnsucht zu einander, um sich einander zu halten oder zu gewinnen ... Sind Staat und Volk eins, so ist der höchste Wunsch und das heiligste Streben des Menschen, diese Einheit zu bewahren; sind sie getrennt, so ist, wenn nicht immer der Wunsch, so doch gewiß das Bestreben da, diese Einheit zu erringen. Die Volksgenossen suchen sich in einem Staat zu vereinen, die Bürger eines Staates suchen ein Volk zu werden: Bald überwiegen diese, bald jene, und die gewaltigsten Bewegungen und die interessantesten Erscheinungen im Leben unseres Geschlechts gehen aus diesen Bestrebungen hervor. Ruhiges Gedeihen aber, fester Friede, kräftige Bildung und allgemeines Glück wird nur da gefunden, wo die Einheit von Volk und Staat erreicht ist." Freilich zeigte er zugleich schon durch diese idealisierende Ausmalung des nationalstaatlichen Zukunftsdaseins, daß sein politisches Denken noch im Unpolitischen und Doktrinären stecken blieb.

Denn nicht Friede und Ruhe, sondern Kampf, Sorge und Reibung ist das Schicksal des echten Nationalstaates. Wie ganz anders beruhren uns die Worte eines jungen energischen Denkers, den schon Treitschke mit Recht sehr hoch gestellt hat, Ottokar Thons, des Adjutanten Karl Augusts von Weimar $\left.{ }^{1}\right)$ : „Es ist an sich unmöglich, daß sich die Staaten anziehen, die Natur will, daß sie sich abstoßen." Darum erkannte er die Unmöglichkeit dessen, was Stein und Humboldt doch immer wieder für möglich zu halten sich bemühten, daß nämlich zwei so unabhängige Staaten wie Österreich und Preußen je ein und denselben Weg nebeneinander hergehen könnten.

1) , Was wird uns die Zukunft bringen ?s Wien, März ISI5. Veriffentlicht u. d. T. , Aus den Papieren eines Verstorbenenc, als Manuskript gedruckt (1S67). Vgl. Treitschke I ${ }^{5}, 6 S 2$ und meine Schrift , Die deutschen Gesellschaften und der Hoffmannsche Bund،, S. 5 I. 
"Sie werden ihn gehen, so lange es ihr beiderseitiger Vorteil will, sie werden ihn verlassen, so bald sich ihre Ansichten und Interessen teilen. « Und, was dieses Urteil doppelt wertvoll macht, es kam von einem Manne, der nicht nur das Wesen des Machtstaates, sondern auch die Kraft der Nationen kannte und wußte, »was ein Volk kann, wenn es etwas bestimmt und kräftig will ". Wenige haben so bündig und scharf wie er den Gang der deutschen Geschicke im I9. Jahrhundert, die Verdrängung und Verweisung Osterreichs nach Osten, die Niederbeugung der deutschen Mittelstaaten und die Aufrichtung des deutschen Nationalreiches durch das siegreiche preußische Schwert vorausgesagt.

Noch höher hinauf steigen wir bei unserer raschen Auslese von Stimmen der öffentlichen Meinung, wenn wir Niebuhrs berühmte Schrift »Preußens Recht gegen den sächsischen Hof « (I \& I 4) auf unsere Probleme hin mustern. Da finden wir wiederum wie bei Thon, nur in tieferer und gedankenreicherer Begründung, Staatsverständnis und Nationalgefühl vereinigt, eben die beiden Ideen, die durch ihre Vereinigung zur Idee des autonomen Nationalstaates hinführen mußten. „Ein Staat kann nur heißen, was in sich Selbständigkeit hat; fähig ist, den Willen zu fassen, sich zu behaupten und sein Recht geltend zu machen; nicht was einen solchen Gedanken gar nicht hegen kann; was sich einem fremden Willen anschließen und unterordnen muß und diesen ergreifen, wo er der eigenen Lebensfristung am günstigsten scheint. ॥ $^{1}$ ) Höher als das formale geschriebene Recht stand ihm das ungeschriebene Recht der großen in der Geschichte sich regenden Kräfte, und wiederum erkannte er dieses an, ohne damit das brutale Recht des Stärkeren an sich zu prolilamieren, ohne den Boden des sittlichen Ideals preiszugeben: "Was die

1) S. $29 \mathrm{f}$. 
Kraft erobert und sich aneignet, bildet ein neues Leben; schlimm oder gut, segensvoll oder verderblich, wie der Geist ist, der in dem Kräftigen wolnnt. «1) Nicht das Recht des Stärkeren, sondern das durch keinen Sieg des jeweils Stärkeren zu vertilgende Recht des Lebendigen erkannte er an, und, so erfüllt von dem Lebendigsten der letzten großen Jahre, zauderte er nicht, selbst den Finzelstaat zu beugen unter das Recht und das Beduirfnis der Nation. »Die Gemeinschaft der Nationalität ist höher als die Staatsverhältnisse, welche die verschiedenen Völker eines Stammes vereinigen oder trennen. Durch Stammart, Sprache, Sitten, Tradition und Literatur besteht eine Verbrüderung zwischen ihnen, die sie von fremden Stämmen scheidet, und die Absonderung, die sich mit dem Auslande gegen den eigenen Stamm verbindet, zur Ruchlosigkeit macht ..2)

Aber wurde nicht durch diesen Satz zugleich die Autononie des Einzelstaates wieder eingeschränlit zugunsten einer uberstaatlichen Idee? Ganz gewiß, denn das Nationalitätsprinzip, das er dem Einzelstaate überordnet, ist, wenn man seine Sätze im Zusammenhange priff, noch mehr das der Kulturnation als das der Staatsnation. $\left.{ }^{3}\right)$ Es ist ein »unsichtbares Einheitsband $\ll^{4}$ ), zusammengewebt aus großen natürlichen und geistigen Gemeinsamkeiten und von ihm so umfassend gedacht, daß es selbst Holländer und deutsche Schweizer, ja sogar

1) S. 70 .

2) S. 19 .

3) Er unterscheidet $S .77 \mathrm{f}$. genau zwischen s Nationalitäte und spolitischer Individualitätc, wenn er sagt: „Es gibt keine sächsische Nationalität, so wenig wie eine pommersche oder märkische. Nur von der Aufopferung der politischen Individualität kann die Rede sein.є Wenn er daneben gelegentlich von der, sächsischen Nation a spricht, so ist das also nur ein lequemer Sprachgebrauch.

4) S. $2 \mathrm{~S}$. 
bis zu gewissem Grade die Engländer mit umfaßt. ${ }^{1}$ ) Wohl erkennt er nun innerhalb der großen deutschen Nation mit Stolz und gehobenem Herzen auch das Dasein einer vechten preußischen Nation« an, also einer Staatsnation im engeren Sinne innerhalb einer umfassenderen Kulturnation, aber dadurch wird der Primat der Kulturnation gegenuiber dem Einzelstaate ja keineswegs aufgehoben, und vor allem, was höchst charakteristisch ist, diese preußische Staatsnation ist ihm keine geschlossene Staatsnation und sonach kann ihm auch Preußen kein geschlossener autonomer Nationalstaat sein. Vielmehr ist »Preußen kein abgeschlossenes Land; es ist das gemeinsame Vaterland eines jeden Deutschen, der sich in Wissenschaften, in den Waffen, in der Verwaltung auszeichnet $\left.\ll^{2}\right)$ So wird ihm Preußen tatsächlich zu einer Quintessenz Deutschlands und zum Vorkämpfer der deutschen Nationalität, deren Rechte, so sagt er es ausdrücklich einmal, auch dann nicht verloren gehen, »wenn nicht der größere, sondern nur ein minderer Teil der ganzen Nation es erkemnt und in Kraft zu setzen Herz und Geist besitzt « $\left.\cdot^{3}\right)$

1) "Von einer sehr großen Nation, wie die deutsche, kann ein eingewanderter Stamm, wie die Engländer, angesiedelt in einem ent. fernten und ganz getrennten Lande, zu einer abgesonderten Nation heranwachsen; dennoch geht die urspriingliche Verwandtschaft nicht unter, und obwohl die Verhältnisse sich verwickeln, so dauert ein natiirliches Bündnis des Ganzen zum Ganzen, des Einzelnen zum Einzelnen im andern Staat und zu seiner Gesamtheit fort, dessen Verletzung sich immer straft. \& Von Holländern und deutschen Schweizern heißt es: , Die Rechte der Nation, der sie sich entziehen wollen, können sie nicht aufheben. I Yierauf gründet sich das Vermittlungsrecht der Verbündeten für die Schweiz.s S. $20 \mathrm{f}$. Niebuhr steht mit diesen groß- und alldeutschen Gedanken nicht allein da. Vgl. z. B. W. v. Humboldts Gesammelte Schriften I I, I36. Ihre Verbreitung und vor allem ihre Begründung zu antersuchen, wäre eine lohnende Aufgabe.

2) S. 79 .

3) S. 22.

IIeinecke, Weltbïrgertum und Nationalstaat. 2. A 1 H. 
Wenn man die Konsequenzen dessen erwägt, was er vom Wesen des Staates an sich, und dessen, was er vom Wesen und Rechte der Nation, d. h. der deutschen Kulturnation, sagt, so sieht man leicht, daß hier ein Dualismus, eine Spannung zweier verschiedener Prinzipien vorliegt, die er sich selbst nicht klar machte, weil er nun einmal von dem Gedanken ganz erfüllt war, daß sie notwendig und harmonisch zusammengehörten. Und dieser Gedanke zwang ihn weiter dazu, auch die Geschichte des preußischen Staates anders zu sehen, als sie wirklich gewesen war. Sie war die Geschichte eines ehrgeizigen, nach Autonomie strebenden Machtstaates gewesen. Er aber meinte, daß wenigstens bis 1740 kein Fürstenhaus größere "Treue für die allgemeine deutsche Sache geubt habe, als Brandenburg-Preußen. ${ }^{1}$ ) So ist er der erste bedeutende Vertreter dessen, was man die borussische Geschichtsauffassung genannt hat, der Vorläufer Droysens und Treitschkes. Das nationale Postulat verdunkelte seine politische Erkenntnis. Es verdunkelte sie ihm zumal für den damaligen Moment, wo es galt, die Ansprüche Preußens auf Sachsen zu rechtfertigen, Ansprüche, die doch nicht nur auf der deutschen Idee und auf der deutschen Mission des preußischen Staates, sondern vor allem auf dessen eigensten, real-egoistischen Interessen beruhten. Das verliannte Niebuhr, aber dieser sein Irrtum war der genaue Ausdruck der Lage, in der man war, und der Tendenzen, die sich regten. Man strebte aus der bloßen, unpolitischen Kulturnation heraus zu einem nationalstaatlichen Dasein. Aber das Ziel, das am Ende des eingeschlagenen Weges lag, der autonome deutsche Nationalstaat, war verborgen und konnte gerade auch denen sich verbergen, die mit statlichen Dingen am vertrautesten waren und darum ahnten, daß die einfachste Lösung des

1) S. 68 . 
Problems auch die schwierigste war. $\left.{ }^{1}\right)$ Weil sie aber doch den Drang, es zu lösen, nicht lassen konnten, so war nun ihr Bemühen, Staat und Nation miteinander zu vereinigen, doch nur ein Bemühen, zwei noch nicht vereinbare Dinge miteinander zu vereinigen. So also kam es, daß auch der große historische und politische Denker Niebuhr hier strauchelte. Indem er die Nation über den Staat und den preußischen Einzelstaat in den Dienst der deutschen Idee stellte, wies er wohl den Weg, der in die Zukunft führte, aber vergewaltigte für Vergangenheit und Gegenwart das Wesen der autonomen preußischen Staatspersönlichkeit. Zwei Linien sah er gleichsam vor sich, die erst in weiter Ferne zusammenlaufen sollten und die er schon jetzt zusammenlaufen sah und nur zusammendrängen konnte durch die Beugung der einen von ihnen.

Wir schlagen damit schon das Thema an, das uns im zweiten Buche beschäftigen wird. Hier mußten wir es berühren, weil wir ja klar machen wollten, wie eng verbunden die Entstehungsgeschichte der Nationalstaatsidee in Deutschland mit der Invasion der unpolitischen Ideen in den Staat ist. Unter den Beispielen dieser Invasion aber ist Niebuhrs Versuch, das Verhältnis von Staat und Nation festzusetzen, an sich schon bedeutend durch Geist und Tiefe und durch seine, man möchte sagen, Kongenialität sowohl mit der staatlichen wie mit der unstaatlichen Lebenssphäre, - er gehört der staatlichen Sphäre entschieden tiefer, beiden Sphären aber gleichmäßiger an als Humboldt. Und nun fehit schließlich auch in Niebuhrs National- und Staatsgedanken jenes Element der universalen Ideale und Postulate nicht, durch die das natürliche Eigenleben sowohl der Staaten

1) Vgl. Delbriick, Die Ideen Steins über deutsche Verfassung, Erinnerungen, Aufsätze und Reden, S. 93 ff. 
wie auch selbst der nach seiner Meinung ihnen ibergeordneten Nationen eingeschränkt wurde.

Denn auch er vertritt den Gedanken, daß die christlichen Staaten Europas eine Einheit bilden, die zu verletzen ebenso ruchlos sei wie der Verrat, den der Einzelstaat an seiner Nation ube. "Sich mit Mohammedanern zum Angriff gegen Christen verbinden, galt immer fiir ein unverzeihliches Verbrechen, nach dem Urteile der Protestanten wie der Katholiken." Er ging so weit, sogar den legitimistischen Kreuzzug gegen die französische Revolution im Prinzip zu billigen. »Wäre die Koalition gegen die französische Revolution nur nicht so matt und gedankenlos geführt worden, daß auf dem Wege augenscheinlich kein Heil zu hoffen war, so ließe sich gegen die Lehre mit Fug nichts einwenden, welche der ersten Verbindung zugrunde lag, daß eine Gesamtheit der europäischen Staaten, wiewohl durch keine faktische Föderation geleitet, darum nicht minder bestehe und jeder Staat an der Sache Europas teilzunehmen verpflichtet sei. $\left.{ }^{1}\right)$ So sah auch er, wie die Romantiker und wie Stein die universale Sache Europas und die Sache der Nationen unauflöslich miteinander verkniipft. ${ }^{2}$ ) Und so berihrten sich in ihm nun die Geister zweier Epochen, der Revolution und der Restauration. Denn sein kühner Satz, daß die Nationalität über dem Staate stünde, wäre ja vor I 789 undenkbar gewesen und wurde jedenfalls nach I I 5 von den Staatsmännern der Restauration als höchst revolutionär empfunden. Und doch wollte Niebuhr selbst kein revolutionärer, sondern ein konservativer Staatsmann sein, und wenn er auch den von der Revo-

1) S. $20 \mathrm{f}$.

2) Höchst charakteristisch ist es, daß er den Fall der Republik Genua als Strafe ansieht für die Unterstiitzung des sallyemeinen Feindes ‘, die zugleich sein Vergehen gegen die Nationalität Italiens gewesen sei. S. 2 I. 
lution entbundenen Kräften der Nation seine Brust geöffnet hatte, so glaubte er doch eben mit der Nationalitätsidee, wie er sie verstand, die Revolution bekämpfen zu können.

Diese Niebuhrsche Nationalitätsidee, die sich auf gemeinsame Abstammung und gemeinsame Kulturgüter berief, war die gemeinsame Frucht der Romantik ${ }^{1}$ ) und der Erhebungszeit, und sie konnte allerdings, da sie so stark an die geschichtliche Vergangenheit der Nationen anknüpte, auch in sehr konservativem Sinne weiter entwickelt werden. ${ }^{2}$ ) Dann mußte ihr freilich jene für die legitimen Dynastien so gefährliche Spitze wieder abgebogen werden, die sie bei Niebuhr noch hatte. Sie durfte also nicht dazu benutzt werden, bestimmte Forderungen an die Politik der Einzelstaaten zu stellen, - sie durfte nicht als beherrschendes, wohl aber als tragendes Prinzip des Staatslebens verwandt werden. Tragend in dem Sinne, daß das Staatsleben einer Nation nicht minder wie ihr Kulturleben als die eigenartige Blite und Frucht des Vollssgeistes aufgefaßt wurde. Dann war nichts leichter, als alle geschichtlich iiberlieferten Einrichtungen und Daseinsformen zu rechtfertigen und zu sanktionieren durch die Berufung auf den unwillkürlich schaffenden Volksgeist, dem sie entstammten, und alle willkürlichen Eingriffe in das Stilleben der Staaten als Vergewaltigung des natiirlich Gewordenen und des echt und ursprünglich Nationalen zu ächten. Diesen durch die Romantik und durch die Schellingsche Lehre von der bewußtlosen Entwicklung

1) Fiir die besondere Einwirkung der Romantik auf Niebuhr ist z. B. bezeichnend, daß er der sächsischen Regierung als Beweis ihrer undeutschen und beschränkten Gesinnung das von ihr erlassene Verbot vorriuckt, die Volksbücher, wie die Haymons-Kinder usw., wieder zu drucken. S. 8I. Auch das Lob des, tiefsinnigen Burke, fehlt nicht. S. 96 .

2) Vgl. oben S. \$2. 
des absoluten Geistes vorbereiteten Schritt ermöglichte die historische Rechtsschule unter Führung Savignys.

Alles Recht, so lehrte er in seiner Schrift gegen Thibaut, entsteht zuerst »durch Sitte und Volksglaube; überall also durch innere, stillwirkende Kräfte, nicht durch die Willkür eines Gesetzgebers «. ${ }^{1}$ ) Oder, wie er es bei der Begründung seiner Zeitschrift für geschichtliche Rechtswissenschaft formulierte: 》Die geschichtliche Schule nimmt an, der Stoff des Rechts sei durch die gesamte Vergangenheit der Nation gegeben, doch nicht durch Willkiir, so daß er zufällig dieser oder ein anderer sein könnte, sondern aus dem innersten Wesen der Nation selbst und ihrer Geschichte hervorgegangen ${ }^{2}{ }^{2}$ )

Savigny selbst beschränkte seine Lehre damals auf sein eigenstes Gebiet, das Recht, aber auch der Staat war Recht im weiteren Sinne ${ }^{3}$, und die Konsequenzen seiner Lehre sollten bald auch für ihn gezogen werden.

1) Vom Beruf unserer Zeit für Gesetzgebung und Rechtswissenschaft 1S14, S. I4 der 2. unveränderten Auflage (von IS2S).

2) Bd. I, $6(1 \$ 15)$.

3) Das hat Savigny selbst später (um 1840) auch ausgesprochen. Vgl. Brie, Der Volksgeist bei Hegel u. in d. histor. Rechtsschule, Archiv f. Rechts- u. Wirtschaftsphilosophie 2, 199. Die Entstehung der Lehre und des Schlagwortes vom \& Volksgeiste ist seit Erscheinen der I. Auflage durch die eben genannte Arbeit Bries, die Aufsätze v. Moellers in den Mitt. d. Instituts f. österr. Geschichtsforschung 30 und Edg. Loenings in der Internation. Wochenschrift 1910 sowie durch Landsbergs Gesch. d. deutschen Rechtswissenschaft, 3. Abt., 2. Halbband, wesentlich klarer geworden, wenn auch noch manche Meinungsverschiedenheiten iibrig bleiben. Savignys Lehre, fuir die der Meister erst später von seinem Schuler Puchta das Schlagwort vom , Volksgeister iibernahm, kniipft, wie Loening und Landsberg aberzeugend dartun, innerlich weniger an llegel als an Schelling und die Romantiker an. Näher zu untersuchen wäre jetzt noch die Bedeutung Jak. Grimms für die Entwicklung der I.ehre, die er um 1815 ebenfalls sachlich schon vorträgt, ohne das Schlagwort , Volksgeist c zu gebrauchen. Meine in der I. Auflage S. 245 geäußerte Vermutung, daß Hegel zuerst das Schlagwort im Sinne der 
Dann wurde die nationale Idee gleichsam wieder zurïckverwiesen aus der Sphäre der freien politischen Tat, aus der Helle der politischen Welt, in der sie Unheil anstiften konnte, in das dunkle Erdreich der Nation. Dort aber konnte sie auch neue Kraft wieder sammeln, um abermals, nur reicher und stärker, wieder hervorzubrechen in die Welt.

historischen Schule gebraucht habe, ist von Loening berichtigt worden. Es besteht ein deutlicher Unterschied zwischen dem Volksgeiste Hegels und dem Volksgeiste Savignys und der Komantiker (S. unten S. 273). Immerhin aber ist ihnen gemeinsam das evolutionistische Element, wäbrend der liberal-politische Gebrauch des Wortes ,Volksgeist «, der in diesen Jahren schon nicht ganz selten ist, im ganzen frei davon ist. Im Kalischer Aufrufe ( Ureigener Geist des Volkesc) scheinen aber das liberale und das romantische Element zusammenzufließen. - Ein frihestes Vorkommen des Wortes, Volksgeist c hat mir Fr. Kluge aus Campe 1794, Reinigung und Bereicherung II, I, Vorrede 20, nachgewiesen: , Veredelung des Volksgeistes und des Volkssinnes 


\section{Zehntes Kapitel.}

\section{Haller und der Kreis Friedrich Wilhelms IV.}

Von den beiden großen Hauptströmungen des nationalen und nationalstaatlichen Denkens, der liberalen und der romantisch-konservativen, folgen wir von jetzt ab lediglich der letzteren ${ }^{1}$ ) und suchen nunmehr den Weg zu bestimmen, der von den Gedanken der Novalis, Schlegel, Adam Müller und Savigny und von der deutschen Politik: Steins zu den Gedanken und der Politik Friedrich Wilhelms IV. und seines Kreises führten. Da erscheint nun zunächst, fast wie quer über unsern Pfad gebaut, das System eines Mannes, der in den Friedensjahren nach I 8 I 5 einen gewaltigen Einfluß ausübte auf die romantisch und politisch zugleich Gestimmten und insbesondere auf die junge Generation derer, die einst regieren wollten, und der ihnen doch von Nation so gut wie nichts zu sagen wußte: Karl Ludwig v. Haller. Eben wegen seiner mächtigen Wirkung aber können wir ihn nicht übergehen und müssen uns mit denjenigen Seiten seines Wesens und seiner Staatslehre auseinander-

1) Die Schrift von Dock, Revolution und Restauration über die Souveränität (1900), die zuletzt ausfiihrlich die Lehren der konterrevolutionären Schule behandelt hat, ist für unsere Probleme ganz unergiebig. Sie enthält fast nur Exzerpte und ist in ihren anscheinend selbständigen Schlußausfuhrungen (S. 269) abhängig von Stahls Gedanken (Geschichte der Rechtsphilosophie VI, I; 3. Aufl. S. 548 f.). 
setzen, die das Problem der Nation und des Nationalstaates wenigstens, wenn auch zum Teil nur mittelbar, berühren.

In demselben Jahre $\mathrm{I} S \mathrm{O} S$, in dem Adam Müller seine Vorlesungen über die Elemente der Staatskunst begann, veröffentlichte Haller sein »Handbuch der allgemeinen Staatenkunde», das schon alles Wesentliche seiner Lehre enthielt. Aber stärkeren Eindruck machte er auf das Publikum erst in den stilleren Friedensjahren, als von I8I6 ab die sechs Bände seiner 》Restauration der Staatswissenschaft « erschienen. Denn in die geistige Stimmung, die den nationalen Befreiungskampf vorbereitet und getragen hatte, paßte er noch nicht recht hinein. Nichts ist zu spüren in ihm von jener hohen Überzeugung, daß die deutsche Nation eigenartige, unersetzliche geistige Werte zu verteidigen habe, nichts auch von jenem Drange nach einer inneren Nationalisierung des Einzelstaates, wie ihn die preußischen Reformer und auch die Romantiker von Novalis bis Adam Müller fühlten. Auch wo diese sich für die alten feudalen Ordnungen begeisterten, geschah es doch in einem neuen Geiste, der aus ihnen etwas ancleres machte oder sie sich wenigstens anders vorstellte, als sie wirklich gewesen waren, sie mit Idealen und Illusionen von poetischer und philosophischer Herkunft umwob. Dieser reizende Schleier fehlt dem Bilde des Patrimonialstaates, das Haller jetzt vor seine Zeitgenossen hinstellte, ganz und gar. Derb und unverblümt preist er das Glück der alten Gewalthaber, eigene Macht und eigenen Reichtum zu besitzen und frei zu genießen. Ein materialistischer und egoistischer Zug durchweht seine Lehre, und auch wo sie Gott und göttliche Dinge zu Hilfe ruft, geschieht es ohne jede Mystik und selbst ohne innere Religiosität, vielmehr in jener selbstzufriedenen Stimmung, die in dem eigenen Besitze und in der Weltordnung, die ihn verbürgt, Gottes Fügung und Segen klärlich 
geoffenbart sieht. Macht und Herrschaft sei natürliches Recht und göttliches Recht zugleich, - das ist der Kern seiner Lehre.

Eigentlich, so sagt er einmal ${ }^{1}$ ), ist es auch nicht der Mensch, der über euch herrscinet, sondern die Macht, die $\mathrm{ihm}$ gegeben ist, und wenn ihr die Sache genau und philosophisch betrachtet, so ist und bleibt Gott der einzige Herr, teils als Schöpfer, teils als Gesetzgeber und Regulator aller unter die Menschen verteilten Macht. Damit öffnete er nun freilich Tür und Tor für einen Kultus der Macht, für eine Anbetung des Erfolges schlechthin, und der Weg von ihm zur Lehre vom Kampfe ums Dasein und von der unausgesetzt vor sich gehenden Auslese der Besten ist nicht gar so weit. Wem ist denn, so ruft er den Schwachen und Beherrschten zum Troste $\mathrm{zu}^{2}$ ), die Erreichung der höchsten Stufe des Glücks auf ewig verschlossen? Sehen wir nicht in der ganzen Welt, durch die ganze Geschichte einen beständigen Wechsel aller Dinge? Reiche arm und Arme reich, Mächtige schwach und Schwache mächtig werden, dunkle Geschlechter zum Glanz emporsteigen und berühmt gewesene in Dunkelheit versinken? Seine Prämissen trugen viel weiter, als ihm lieb war, denn sein praktisches Ziel war ja, die Macht der revolutionären Gewalten zu bekämpfen und die Macht des alten Patrimonialstaates zu rechtfertigen und wiederherzustellen. Deswegen brauchte er auch den lieben Gott nicht nur, um die Macht an sich zu sanktionieren, sondern auch, um ihrem Laufe die nötigen Hemmschuhe anzulegen, damit er eben da einhalte, wo das Mittelalter stehen geblieben war. Wir brauchen uns mit diesen höchst naiven und rein gefühlsmäßigen Argumentationen und Versuchen, Grenzen zu zichen zwischen legitimer und illegitimer Macht, zwischen ihrem

1) Restauration der Staatswissenschaft I (2. Aufl.), S. $3 S 6$.

2) a. a. O.S. 387 . 
rechten und unrechten Gebrauche, hier nicht aufzuhalten, denn man wird schon gemerkt haben, daß in diesem ganzen Systeme nicht der Gedanke, sondern der Wille, und zwar ein durch traditionelle Lebensideale im höchsten Grade bestimmter Wille, spricht. Es ist die alte Zeit selbst, die ihr Haupt hier wieder erhebt in einem ihrer echtesten Söhne. Er brauchte sie nicht, wie der Romantiker, durch Phantasie und Reflexion sich erst wieder zu beleben, sondern sie war in diesem stolzen und hartköpfigen Berner Patrizier von vornherein naturhaft lebendig ${ }^{1}$ ), und auch der Anflug von Aufklärung und Rationalismus, der seiner Jugendbildung ${ }^{2}$ ) und selbst seiner späteren Theorie noch $z u$ eigen ist ${ }^{3}$ ), stand den letzten zopftragenden Generationen dieser alten Zeit gar

1) Vergleiche seine charakteristischen Worte Restaur. 6, 571 f.: Einige scheinen zu glauben, ich hätte das bisher entwickelte System bloß aus der Geschichte des Mittelalters geschöpft .... ich gestehe unverhohlen, kein einziges Buch iber das sogenannte Mittelalter gelesen zu haben .... Nicht am Alten und Unbekannten, sondern an dem, was vor unseren Augen liegt, an den alltäglichen geselligen Verhältnissen selbst haben wir jene ewigen Gesetze wahrgenommen e etc.

2) Vgl. Looser, Entwicklung und System der polit. Anschauungen K. L. v. Hallers, Berner Dissert- I 896, S. 2 ff.

3) Naturrechtlich ist seine Lehre insofern in höchster Potenz, als sie auch, wie die Naturrechtler, vom Naturzustande ausgeht und dabei eigentlich stehen bleibt und den Schritt zum Gesellschaftsvertrage, den jene tun, nicht mitmacht. Ferner seine Berührungen mit der staatsfeindlichen und rein individualistischen Richtung der Aufklärung, mit Rousseau, an dem er lucida interzalla rühmt, mit Siéyès und den Illuminaten. Sehr fein fuhlte Savigny sogleich $(\mathbf{I} 8 \mathbf{I} \gamma$ ) das rationalistische Element bei Haller heraus ( Krasser Aufklärer in Geschichte und Politik \&), Varren. trapp, Rankes Histor.-polit. Zeitschr., und das Berliner Polit. Wochenblatt, Histor. Zeitschr. 99, 40, vgl. auch Singer, Zur Erinnerung an Gustav Hugo, Zeitschr. f. Privat- u. öffentl. Recht I6, S. $2 \delta_{5}$ u. 311 . Nicht übel sagt auch Stahl (Gesch. der Rechtsphilosophie, 3. Aufl, S. 560) von ihm: , Er ist der Rationalist unter den kontrerevolutionären Schriftstellern, er verfolgt nicht wie die anderen lebendige und mannigfache Anschauungen, sondern führt gleich dem Naturrecht ein oberstes 
nicht uneben, denn er berührte gleichsam nur ihr Kostüm, nicht ihre Grundnatur. Die Berner Geschlechterherrschaft des I8. Jahrhunderts war eine kräftige, behäbige und rotbäckige Aristokratie gewesen, die sich aus einem reichen Lande nährte und ihre Untertanen durch Fiskalismus nicht zu plagen brauchte, durch Vielregiererei nicht übermäßig plagen wollte und insbesondere ihre Bauern mild und patriarchalisch behandelte. ${ }^{1}$ ) Solches Dasein konnte sich auf die angenehme Erinnerung berufen, daß es einst erworben sei durch die größere Tüchtigkeit und Kraft der Vorväter, und auf das Bewußtsein, daß man ihrer selbst nicht unwert sei, daß man also das Recht habe, es ungestört auszukosten. Und fühlte man sich nicht eben durch den Genuß der Macht auch sittlich verbessert? "Ihr werdet allenthalben, " meinte Haller, »den Mächtigeren von Natur edler, großmütiger, nuitzlicher finden. $\left.\ll^{2}\right)$ »Was veredelt denn mehr das Gemüt als das Gefühl eigener Uberlegenheit, die Abwesenheit von Furcht und die Freiheit von Bedürfnissen? $\ll^{3}$ )

Bei solcher Auffassung von dem guten Rechte und von den guten Wirkungen der Macht ist es ganz verständlich, daß sich ihm der Staat und überhaupt das ganze Leben auflöste in eine Unzahl von übereinander-

Prinzip mit logischer Folgerichtigkeit durch alle Verhältnisse durch.e Immerhin beruhte aber dieses oberste Prinzip doch, wie wir oben ausführen, auf einer lebendigen Anschauung. - Daß Haller ferner der von ihm so leidenschaftlich bekämpften Vertragstheorie Rousseaus selbst nicht entgeht, hat man auch schon frühe bemerkt. Indem er an Stelle des großen allgemeinen contrat social eine Unzahl von kleinen Privatverträgen setzte, hat $\mathrm{er}$, wie Ancillon gegen ihn bemerkte, die große Barre nur in Scheideminze ungeprägt. (Vgl. F. v. Raumer, Über die geschichtl. Entwicklung der Begriffe ron Recht, Staat und Politik, 2. Aufl, I832, S. 190.) Ähnlich auch R. v. Mohl, Geschichte und Literatur der Staatswissenschaften 2, 550.

1) Vgl. Oechsli, Geschichte d. Schweiz im I9. Jahrhundert I, 51 ff.

2) Restauration I², 382 .

s) a. a. O.S. 386 . 
geordneten Macht- und Herrschaftsverhältnissen, vom Bettler an, der wenigstens seinen Hund beherrscht, bis zum Fürsten, der »das köstliche, seelenerhebende Glücl« « genießt, ganz unabhängig zu sein, und der so die Spitze dieser ganzen Pyramide darstellt. Alles aber darf und kann, so lehrt er, nur eigene Macht sein, nicht übertragene. Die Macht, die ein Fürst selbst und zu eigenem Rechte besitzt, wird in Schranken gehalten durch das jedem Menschen ins Herz geschriebene Pflicht- und Sittengebot, das, wie wir ja wissen, dem Mächtigen besonders leicht eingehen soll. Die Macht aber, die ein Fürst oder eine Regierung angeblich in Auftrage des Staates oder des Volkes ausübt, ist in Wahrheit und bei Licht besehen auch keine übertragene, sondern immer und immer nur faktische und eigene Macht, sie verführt aber durch die Fiktion und Illusion der Übertragung zu einem greulichen Despotismus und zur Zerstörung aller schon rechtlich begründeten Macht- und Herrschaftsverhältnisse.

Es läßt sich nicht verkennen, daß hier wirklich ein gesundes, reales Verständnis für tatsächliche Machtverhältnisse mitspricht. Wann hat denn je, so fragt er nicht ganz mit Unrecht, selbst in dem revolutionären Frankreich der allgemeine Wille der Nation geherrscht? Alle Faktionen haben vielmehr ihre Macht durch eigene Kühnheit erkämpft und selbst wider den IVillen des Volkes beibehalten, und die französischen Soldaten, die den Krieg gegen die sogenannten Privilegien führten, waren die ersten Privilegierten in allen Ländern, wo sie hinkamen. Triumphierend rief er: „O unzerstörbare Natur $\ll^{1}$ ) Aber sein unbeirrbarer Sinn für die Eigenmacht wurde zum Eigensinn, der sich dagegen sperrte, daß jede reale politische Macht auch auf geistigen Zusammenhängen beruht, die

1) Restauration I ${ }^{2}, 260,265$. 
immer weiter und großartiger werden, je höher die Macht selbst herauswächst aus der engen Sphäre grundherrlichen und patrizischen Daseins, je mehr die Eigenmacht der mittelalterlichen Dynasten zur Staatsmacht im modernen Sinne wird. Er aber blieb in jener engen Sphäre stecken, weil sein ganzes Lebensgefuhl aus ihr stammte, und so leugnete und belsämpfte er alles, was uiber sie hinauslag. Wunderlich war es dabei, wie er doch schon innerhalb seines gelobten Patrimonialstaates widerwillig diejenigen Kräfte anerkennen mußte, die diesen über sich selbst hinaushoben und dem modernen Staate entgegenführten. Die Unteilbarkeits- und Primogeniturordnungen des späteren Mittelalters waren, wie man weiß, zunächst aus rein dynastischen Interessen entsprungen, aber, einmal durchgeführt, untergruben sie die familienhafte Auffassung vom Wesen der fürstlichen Herrschaft, bereiteten den Gedanken vor, daß der Staat eine geschlossene Einheit sei, die höheren Gesetzen folge als der freien Willkür der Dynasten, und schufen überhaupt die festen Grundlagen größerer politischer Gemeinwesen. Haller war für diese Wirkungen nicht blind und beklagte deswegen die Ursache. Wäre, so meinte er, Primogenitur und Unteilbarkeit nicht nach und nach überall eingeführt worden, so wuirde das Auge uiberall nur das einfache, natürliche Verhältnis eines unabhängigen Grundherrn zu seinen Hörigen erblicken, so hätten jene falschen Systeme, jene hohlen Ideen von einer sich über alles erstreckenden Regierungsgewalt nie entstehen können. In Unteilbarkeit und Primogenitur sah er demnach - durchaus mit rich-

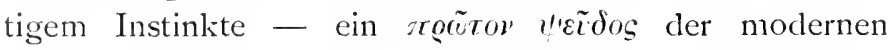
Staatsentwicklung. Und doch mußte er auf der anderen Seite zugeben, daß ein Patrimonialfürst nach seinem Herzen gar nichts Verninftigeres tun könne, als das Erworbene zu sichern durch Erstgeburtsrecht und Unteilbarkeit. So krankte sein ganzes System an dem inneren 
Widerspruche, daß die natürliche Pleonexie des Mächtigen, auf die er es doch aufbaute, zugleich die Elemente crzeugte, die es zerstörten. ${ }^{1}$ )

Kraft und Trieb zu Macht und Herrschaft sollten eben nach seiner Meinung genau da einhalten, wo sie dem patrimonialen Dasein iber den Kopf zu wachsen drohten. Folgerecht war er demnach ein Gegner der großen Staaten überhaupt. Vor den ausgedehnten Monarchien, meint er, schwindle dem Verstande der Gelehrten. »Was braucht man dergleichen engverbundene, fürchterliche Massen, der Schrecken der übrigen Welt ${ }^{2}{ }^{2}$ ) »Kleinere Staaten sind die wahre, einfache Ordnung der Natur, auf welche sie durch verschiedene Wege am Ende allemal wieder zurückführt. «3) Je mehr Staaten, um so mehr Schönheit und Mannigfaltigkeit, um so mehr Menschen, die das seelenerhebende Gut der Unabhängigkeit genießen. Wie prachtvoll war nicht Kleinasien nach der Zersplitterung der makedonischen Monarchie, wie herrlich nicht Italien, als seit dem 12. Jahrhundert die vielen unabhängigen Fïrstentümer und Republiken darin entstanden. Man wird fast an die geheime Sympathie Jakob Burckhardts für diese Gewaltmenschen an der Schwelle von Mittelalter und Renaissance erinnert, die den Staat zum Genußmittel fiir das kraftvolle Individuum machten ${ }^{4}$ ), aber freilich dabei, was Haller sich nicht sagte, auch mithalfen, den modernen Staat uberhaupt zu machen. Sie taten es, indem sie den Geist der kühlen, rationellen Realpolitik und der genauen Kal-

1) Restaur. 2, 534 ff. Auf seinen Versuch, diesen Widerspruch, den er wohl fühlte, zu verdecken, brauchen wir nicht einzugehen.

2) a. a. O. 3, 179 .

3) a. a. O. 2, 535 .

4) Die vielen kleinen Kriege Italiens im I4. und I5. Jahrhundert, sagt Haller ein andermal (2, 103), sübten nur die Kräfte und stärkten das Selbstgefühl, diese Quelle aller großen Dinge«. 
kulierung der Machtmittel aufbrachten, eben den Geist, von dem dann das von Haller und den Romantikern geschmähte Zeitalter des Absoiutismus erfüllt war und der die Staaten nicht nur äußerlich vergrößert, sondern auch innerlich gefestigt, ihnen Einheit, Persönlichkeit und Autonomie gegeben hat. Wir sahen, wie Adam Müller bis zu gewissem Grade dieser großartigen Entwicklung der europäischen Staatspersönlichkeiten hatte folgen können. Haller vermochte es nicht. "Was nützt, " fragte $\mathrm{er}^{1}$ ), »die ebenso widernatürliche als unchristliche Lehre von der unbedingten Einheit, der absoluten Isolierung und Abrundung jedes einzelnen Staats, als um alles einander feindselig gegeniiberzustellen. « Ebensowenig Geschmack konnte er der inneren Staatsbildung abgewinnen, die den Staat im Interesse seiner Macht selbst mehr und mehr zu einem wirklichen Gemeinwesen, zu einer kollektiven Zusammenfassung großer geistiger und materieller Gesamtbedürnisse erhob. Unselig war ihm die Vorstellung, daß es eine societas civilis gäbe, mit Verachtung sprach er von »sogenannten Staatszwecken", und das Wörtchen »allgemein « iberhaupt war ihm schon verhaßt. $\left.{ }^{2}\right)$

Wo er nun schon die geistige Einheit des Staates leugnete, wie sollte er da die geistige Einheit des Volkes,

1) a. a. O. 3, 179 .

2) Eine nur scheinbare Ausnahmestellung gewährte er den im 6. Bande seines Werkes behandelten Republiken, die er als , Gemein. wesen behandelte, von deren Gemeingeist er zuweilen sprach. Aber er faßte sie dabei nur als privatrechtliche Korporationen und Kommunitäten anf nnd zog, obwohl er selbst geborener Republikaner war, auch die Bilanz zwischen Monarchie und Republik zu Ungunsten der letzteren; vgl. 6, 546: จAber wie schwerfällig, wie plump und unbehilflich ist nicht ein solch kollektiver Körper in Vergleichung mit dem Individuellen des einzelnen Menschen etc.s Die Fiirstentümer seien die natïrlichsten Staaten, die Republiken dagegen künstliche Institute. 6, 10. 
der Nation anerkennen: Er spricht nicht vom Volke des Iursten, sondern von »den einzelnen Menschen, deren Inbegriff man das Volk nennt ". ${ }^{1}$ ) Er sieht sie nur, wie sic auf- und abströmen, wie sie sich da anhäufen, wo sie mehrere oder bessere Nahrung finden, die doch wieder nur, so meint er, mittelbar oder unmittelbar von der Existenz und dem Reichtume des Fürsten abhänge. »Das Volk eines Fuirsten ist eine zerstreute Menge von Menschen, ein Aggregat von abhängigen oder freiwillig dienstbaren Leuten mit unendlich verschiedenen Verpflichtungen; sie haben nichts gemeinsam, als ihren gemeinsamen Herrn; unter sich selbst aber machen sie kein Ganzes, keine Kommunität aus. « ${ }^{2}$ ) Freilich, ganz kann er den ihm so queren Begriff des Volkes und der Nation doch nicht totschlagen. Nach jener echt altständischen Denkweise, die in der Vertretung der eigenen Rechte gegenüber dem Fürsten zugleich, - ein sichtliches Zeichen der leise keimenden nationalen Idee eine Vertretung der allgemeinen Interessen sehen und die fiihrenden Schichten der Nation mit der Nation selbst identifizieren konnte ${ }^{3}$ ), bezeichnet er einmal als »Nationalschulden《 solche Schulden, die 》von der Nation, d. h. von den Ersten und Vornehmsten derselben freiwillig iibernommen " seien. ${ }^{4}$ ) Daß es »Volkskriege " geben könne, läßt er, bei seinem lockeren Begriffe von Volk, natürlich nicht gelten. $\left.{ }^{5}\right)$ Aber die natiirliche Liebe des

i) a. a. O. I, XVIII.

2) a. a. O. 2, 74 f. u. 2, II9; vgl. 2, 366: Wenn es sich um eine Anstalt zum Nutzen des Volkes handle, so werde diese sam besten und uneigennuitzigsten von ihm selbst, d. h. von Privatpersonen oder Privatvereinigungen bewerkstelligts. Seine Staatsfeindschaft bringt ihn hier in eine gewisse, aber nicht in die Tiefe gehende Verwandtschaft mit Thilh. v. Humboldt. Vgl, oben S. 39 und S. 7 I, Anm. I.

3) Vgl. oben S. 23.

4) Restaur. 2, XI.

5) Restaur. 2, VII.

Meinecke, Weltbürgertum und Nationalstaat. 2, Aut. 
Kindes zu seinem Vater, des Dieners zu seinem Herrn könne es doch bewirken, daß die Untertanen auch ohne rechtliche Verpflichtung ihrem Fürsten zu Hilfe eilen und dann mit ihm »ein Ganzes, ein Herz und eine Seele " ausmachen. „Ja! Man sah im Fall der Not oft ganze Nationen ohne Zwang herbeieilen und mit einem. unverdorbenen Ehrgefühle, einem Enthusiasmus und einer Ausdauer kämpfen, welche manchmal selbst die des Fürsten und seiner mehr verweichlichten Umgebungen übertrifft. $\ll^{1}$ ) So weht doch ab und zu aus seiner eigensinnig-egoistischen Lehre ein Hauch jenes altertumlichen Nationalgeistes, wie er in den Kämpfen der Vendéer, Tiroler und Spanier hervorgebrochen war, wie er in seinen eigenen Schweizer Landsleuten lebte. ${ }^{2}$ ) Und so spiegelt er insgesamt mit getreuer Naivität jene ältere Stufe des Nationallebens, die noch vor der Erhebung der absoluten Monarchie lag und auch unter ihr in abgelegenen Regionen sich behauptet hatte, wo die politischen Kreise klein und zersplittert waren, wo aucl die Ideen, die sie zu einem größeren Ganzen verbanden, mehr einen patriarchalisch-familienhaften Zug trugen, selten zu vollem Bewußtsein kamen, dann jedoch auch mit einer großen sinnlichen Kraft hervorbrechen konnten. Aber wie sie in ruhigen Zeiten dann wieder in Schlummer zurücksanken, so blitzen sie auch in Hallers Gedanlienwelt nur gelegentlich auf.

Haller ist also viel altertumlicher und ursprünglicher als die Romantiker und von der modernen nationalen Strö-

1) Restaur. 2, VII. und 81 .

2) Wie sich noch I 8 I $_{4}$ im gemeinsamen Aufatmen vom Drucke der Fremdherrschaft die verschiedenartigsten Geister berühren konnten, zeigt die Tatsache, daß Rottecks, Teutsche Blätter am 22. Januar I814 Hallers auf Bern und die Schweiz sich beziehenden Artikel, Was ist die alte Ordnung? als einen smit den Ansichten des Teutschen Patrioten sowie des redlichen Weltbürgers durchaus harmonierenden Beitrags wiedergaben. 
mung viel weniger berührt als sie. Weder der Gedanke der Kulturnation, noch derjenige der Staatsnation spielt in seinem Systeme eine nennenswerte Rolle, und eine weltbürgerlich-universalistische Richtung wird man bei ihm, der das Wörtchen »allgemein « haßte und so beharrlich an der Erdscholle des grundherrschaftlichen Kleinstaates haftete, erst recht nicht vermuten. Dennoch treffen wir sie auch bei ihm, und zwar in der uns von den Romantikern her wohlbekannten Form einer Idealisierung der katholischen Hierarchie. Er ist zwar erst i 820 zur katholischen Kirche übergetreten, gehörte ihr aber im Herzen, wie er selbst bezeugt, schon seit i 808 an, so daß er sein ganzes System bereits mit katholisierender Gesinnung entworfen hat. So wurzelhaft und ursprïnglich, wie seine Begeisterung für das primitive Dasein des Patrimonialstaates war, konnte sein Katholizismus freilich nicht sein. Er gewann ihn lieb und brauchte ihn vor allem, das geht aus seinen eigenen Geständnissen hervor, als wertvolle Substruktion für den Bau seines politischen Systems. Es war zunächst die gemeinsame Gegnerschaft gegen die revolutionären Ideen, die ihn mit Sympathie fuir die römische Kirche erfüllte. Aber er spiurte dann wohl bald, daß dieser Bundesgenosse mächtigere Waffen führte als er selbst. Es muß ihn etwas die Ahnung zu ihr hinibergezogen haben, daß man mit dem reinen Patrimonialstaatsgedanken und mit der Ausmalung des grundherrschaftlichen Idylls allein die Mächte der neuen Zeit nicht mehr werde bezwingen können, daß es gegen ihren berauschenden Universalismus ebenso universaler, weltumspannender Ideen bedürfe. „Ihr wollet einen Staaten-Staat", rief er, »einen sogen. Weltbürgerstaat: Wer realisiert ihn besser als die christliche Kirche : $^{1}$ ) Veiter aber: Die Kirche bot gegen das kosmopolitische

1) Restaur. 4, XVII ; vgl. 5, 369. 
Gift der Grundsätze von I789 nicht nur kosmopolitisches Gegengift, sondern eben ihre universale, übernationale und überstaatliche Autorität und Macht war eine wirksame Schranke gegen den gefährlichsten Feind seines Patrimonialstaates: den modernen Staat und die moderne Nation. Sein scharfer Sinn für die Macht und zugleich sein damit so merkwürdig verbundener Protest gegen die freie Bewegung und Entwicklung der Macht kamen hier noch einmal zur Geltung. Durch den Machttrieb, der immer weitere Kreise gezogen hatte, war der Patrimonialstaat zerstört, waren über ihn und uber den Kopf des einzelnen Machthabers hinaus neue geistige IVesenheiten geschaffen worden, zuerst der absolutistische Machtstaat, dann der nationale Machtstaat, beide von dem Drange nach innerer Zusammenschließung und äußerer Abschließung erfuiltt. So war es zu dem Zustande geliommen, den Haller bejammerte: "Die Grenzen der Staaten und Nationen sind schärfer als je gezeichnet, jecles Volk will gleichsam allein in der IVelt sein; alles ist voneinander isoliert, abgeschnitten, getrennt. «1) So war es aber gerade früher, wo die Kirche mehr bedeutet hatte, nicht gewesen. :Lagen nicht die Staaten gewissermaßen in der Kirche, gleich wie sie hinwieder in ihnen? ... Hat sie nicht, in geistigem Sinne, gleichsam die Grenzen der Staaten und Nationen verschwinden lassen:《 Sie könnte, meinte er, in Zukunft selbst ihr früheres Amt wieder aufnehmen, die Streitigkeiten der weltlichen Potentaten durch ihren freundlichen und uneigennuitzigen Schiedsspruch zu schlichten. $\left.{ }^{2}\right)$ So diente sie ihm also dazu, die Wogen des modernen Staats- und Nationallebens zu stillen.

》Ist es nicht ihr allein gelungen, « meinte er noch, "Mannigfaltigkeit in den Formen und Einheit in dem-

a. a. O. 4, XXI.

2) a. a. O. 4, XVII. 
Geist, den Patriotismus und den wahren Kosmopolitismus miteinander zu vereinigen, indem sie die Liebe des Nächsten predigt und doch ein Band der Bridderschaft zwischen allen Fürsten und Völkern knuipft ${ }^{1}$ ) Blicken wir jetzt zuriick auf alle von uns bisher behandelten politischen Denker, so sehen wir die äußersten Extreme nationalen Denkens und Empfindens vertreten, von der dumpfen Gefolgschafts- und Clangesinnung Hallers bis zur hellen Geistigkeit Fichtes. Aber auf allen diesen Stufen rief man auch immer zugleich universale Ideen zu Hilfe. Sie werden uns auch noch weiter begleiten auf unserem Wege, der uns jetzt in die norddeutsche und protestantische Welt wieder zurückfuihrt, in den Kreis der Männer, die Hailers Lehren für die preußischen Verhältnisse nutzbar zu machen suchten, die in dem Kronprinzen und späteren Könige Friedrich WVilhelm IV. den Fürsten nach ihrem Herzen und zugleich ihr ideales Parteihaupt fanden und in dem jungen Bismarck später ein auserwähltes Rüstzeug zu finden glaubten. Und da Bismarcks weitere Entwicklung einerseits zwar die Ideen dieses Kreises zersprengt hat, andererseits aber doch auch aus eben diesem Kreise heraus sprunglos sich vollzogen hat, so wird die Frage nach dem Inhalte und den Abwandlungen der nationalen und nationalstaatlichen Gedanken in diesem Kreise eine Vorfrage für die geschichtliche Leistung Bismarcks, die Begründung des modernen deutschen Nationalstaates.

Es ist reizvoll zu sehen, wie die Gegensätze und Zusammenhänge der uns beschäftigenden Ideen hier auch von einem persönlichen Sich-finden und Sich-

i) a. a. O. vgl. auch 5, XXII, 51, 96 und 372. 
trennen ihrer Vertreter, von Knüpfung und Lösung geistigen Verkehrs von Mensch zu Mensch begleitet wurden. Es war in der von Achim v. Arnim im Januar I $S$ I I begründeten 》christlich-deutschen Tischgesellschaft " in Berlin, wo zwei der von uns bisher schon behandelten Denker, Adam Müller und Fichte, zusammensaßen mit dem jugendlichen Leopold v. Gerlach, der dann in den Jahren nach I \& I 5 führendes Mitglied eines neuen Freundeskreises wurde, eben des späteren Kreises Friedrich Wilhelms IV. ${ }^{1}$ ) In der Tischgesellschaft von I8I hatten lebendige patriotische und literarische Stimmungen in mannigfacher Mischung geherrscht, und nur der Kern der Gesellschaft neigte zu einer konservativ-aristokratischen Opposition wider die nivellierenden Reformbestrebungen des Staatskanzlers Hardenberg. In dem Kreise der jungen Juristen und Offiziere, der von I 8 I 6 bis I 8 I 9 unter dem Namen »Maikäferei ${ }^{2}$ ) bestand und dort Freundschaftsbündnisse für das Leben schloß, war man mit dem bunten genialischen Durcheinander romantischer Deutschheit und romantischer Christlichkeit bald nicht mehr zufrieden. Ein charakteristischer, schlechthin übermächtiger Trieb erwachte nach Klarheit, Positivität, Scheidung der Geister. Man verzichtete nicht auf die Fluten innerer Empfindung, aber man grub ihnen feste Kanäle. So konnte man schließlich die leidenschaftlichsten Gedanken des Pietismus, einen heißen Subjektivismus, der die Extreme von Sündengefühl und Erlösungsfreuden

1) Vgl. meinen Aufsatz ïber Bismarcks Eintritt in den christlich germanischen Kreis, Histor. Zeitschrift 90, 75 f., Reinhold Steig, Heinrich v. Kleists Berliner Kämpfe, I90I und Jedele, Die kirchenpolit. Anschauungen des E. L. v. Gerlach. Tühinger Dissertation I9IO. S. 5.

2) Nach dem Wirte Mai in der Schloßfreiheit, bei dem man zusammenkam (vgl, E. Ludw. v. Gerlach I, 94 ff.). Durch seine Mitglieder Leop. v. Gerlach und Brentano, die schon der Tischgesellschaft von I 8 I I angehört hatten, konnte er sich als eine Art Fortpflanzung von dieser betrachten. 
auskostete, und einen Hang zu starren objektiven Satzungen miteinander verschmelzen. Die Art, wie man beide Tendenzen nun pflegte und zuerst durch den Genuß der inneren Gluten sich gleichgültig stimmte gegen Dogma, Kirche und Gottesdienst, und dann doch wieder diese ergriff und nach außen hin kräftig vertrat, diese Verbindung von esoterischen und exoterischen Idealen und von Schwärmerei und Selbstbeherrschung erfüllte sie mit dem Bewußtsein, etwas Besonderes und Großes zu besitzen, gab ihnen durch die fruchtbaren Reibungen, zu denen sie führte, Geschmeidigkeit und Lebendigkeit.

Solche starken inneren Ressourcen kamen auch der Kraft ihrer politischen Uberzeugungen zugute. Sie hatten aus den Feldzügen mitgebracht eine romantische Begeisterung für Deutschheit im allgemeinen, einen natürlichen preußisch-monarchischen Patriotismus und einen griindlichen $\mathrm{Haß}$ gegen alles, was aus dem revolutionären Frankreich kam. Sie haßten in diesem nicht nur den Unterdrücker der preußischen Monarchie, sondern auch den Unterdrücker ständischer Freiheiten und Vorrechte und patriarchalisch-adliger Herrschaftsformen. An Adam Müller hatten sie zwar schon einen geistreichen, aber vielleicht zu geistreichen, nicht Positives genug bietenden Theoretiker. Die ersten Bände von Hallers Restauration aber erfüllten in hohem Maße das Bedürfnis nach einer kraftvollen und handlichen Theorie der ständischen Monarchie und die zugleich auch ihrem alles Weltliche überflutenden religiösen Drange eine weite Pforte öffnete. Leopold v. Gerlach war gleich so begeistert für Haller, daß er seine Freunde ermahnte, keine Gesellschaft zu besuchen, ohne wenigstens ein Zeugnis für Haller abzulegen. ${ }^{1}$ ) »Wir versenkten uns, " erzählt sein Bruder

1) Denkwürdigk, a. d. Leben Leop. v. Gerlachs I, 6 ; Ernst Ludw. v. Gerlach I, IOI f.; Hassel, Radowitz I, I87. Wie das geschah und wie die Geister dabei aufeinander platzten, dafur haben wir in einem 
Ludwig von diesen ersten hitzigen Zeiten von $18 \mathrm{I} / / \mathrm{I} S$, »mit Liebe und Begeisterung in den heißen Kampf gegen den Rousseauschen revolutionären Staat von unten und für den Staat aus Gott.« Aber zweierlei vermißten die Freunde dabei gleich an Hallers System: Einmal, daß er nicht tief genug grabe in seiner religiösen Grundlegung, daß er den lebendigen persönlichen Gott zư riicktreten lasse hinter die von Gott geschaffene Natur; und sodann, was uns hier besonders interessieren muß, daß er den Begriff »Nation " nicht entwickelt habe, der doch eine schöne Blüte des ewigen Königtums Gottes und des Menschen sei. Wie Haller den ersten dieser Mängel durch den vierten Band seines Werkes, der von Kirche und Priesterstaaten handelte, gut zu machen suchte $^{1}$ ), haben wir schon gehört. Den zweiten Mangel auszufüllen, fühlte er weder Trieb noch Veranlassung. Wir werden davon noch zu erzählen haben. Kurz, es war in dieser preußischen Gruppe der politischen Romantik von vornherein die Tendenz da, das Hallersche System zu verfeinern und die politischen und religiösen Erfahrungen des eigenen Lebens hineinzuarbeiten.

Uber diese Weiterbildung ihrer Ansichten sind wir für die zwanziger Jahre nur ungenügend unterrich-

Briefe von Gneisenau (der damals konservative Anwandlungen hatte) an Clausewitz vom 29. März 18 IS (Pertz-Delbriick, Gneisenau 5, 300) ein hübsches Zeugnis: Hallers so viel Vortreffliches enthaltende Restauration der Staatswissenschaften einigermaßen zu loben, gilt hier fulr Blödsinn. Ich habe den Herrschsiichtigen neulich in Gesellschaft von Frauen in schäumende Wut und gräßliches Geschrei verfallen sehen als sein kleiner Schwager die Verteidigung dieses Buches unternahm. Der sHerrschsiichtige, ist Grolman, der der Schwager der Gebriider v. Gerlach war; der skleine Schwagere vermutlich Leopold selbst.

1) Freilich genügte er damit noch nicht den Wiinschen seiner preußischen Freunde, ebensowenig wie denen Adam Millers. Vergl. l. Ludw. v. Gerlach I, 127. 
tet. ${ }^{1)}$ Wohl aber haben wir für die dreißiger Jahre eine reichlich fließende Quelle in dem Berliner Politischen Wochenblatte, das vom Herbste ${ }_{3}$ I bis zum Schluß des Jahres I $84 \mathrm{I}$ erschien und eine Art Enzylilopädie der Politil in Form einer Wochenschrift darstellt. ${ }^{2}$ ) Unmittelbar unter dem Eindrucke der Julirevolution war der Plan eines konservativen Kampfesorgans gefaßt worden in den Kreisen des kronprinzlichen Hofes. Radowitz gab ihm vielleicht die praktische Gestalt und brachte seinen Glaubensgenossen, den Konvertiten Jarcke, als ersten Redakteur an (bis zum November 1832). Sein tatsächlicher Nachfolger wurde der Major Schulz, während der nominelle Redaliteur der Major a. D. Streit, seit I 839 der Hofrat Stein wurde. $\mathrm{Zu}$ ihren Mitarbeitern zählten die Brüder v. Gerlach, Leo, Haxthausen, Philipps, gelegentlich auch Haller, der hochverehrte Meister, selbst. Die Entstehung und Zusammensetzung dieses Kreises zeigt, daß er den katholischen und den evangelischen Zweig der politischen Romantik brüderlich zusammenfassen wollte. Er stand auch in geistiger Fühlung mit den gleichgesinnten Geistern in Frankreich, wahrte aber auch diesen gegenüber einen eigenen und selbständigen Standpunlt. ${ }^{3}$ )

1) Mit Ausnahme der Anschauungen ron Joseph v. Radowitz, auf die ich in der von mir übernommenen Fortführung des Hasselschen Werkes zurückzukommen habe.

2) Vgl. Varrentrapp, Rankes Historisch-polit. Zeitschrift und das Berliner Polit. Wochenblatt, Histor. Zeitschrift 99, 35 ff.; Hassel, Radowitz I, 43, 60, 212 f., 248; Salomon, Gesch. des deutschen Zeilungswesens 3, 475 ff.; Kaufmann, Polit. Gesch. Deutschlands im 19. Jahrh. S. $239 \mathrm{ff}$. Arnold, Aufzeichnungen des Grafen Carl v. Voß-Buch uiber das Berliner Polit. Wochenblatt, Histor. Zeitschr, 106, 325 ff. u. die Anmerkung auf S. 227 der ersten Auflage dieses Buches.

3) Kaufmann, Histor. Zeitschrift 88, 437, scheint uns den Einfluß der de Maistre, Lamennais etc. auf die deutschen Restaurations. politiker etwas $z u$ hoch $z u$ veranschlagen. Doch bedarf die ganze Frage der Wechselwirkung zwischen französiscber und deutscher politischer Komantik noch einer eingehenden Lntersuchung. 
Wir werden gleich sehen, daß auch in ihm selbst mannigfache Nuancen zu Worte kamen und daß er keineswegs nur die allerstrengsten Anhänger Hallers umfaßte. ${ }^{1}$ ) Wir können allerdings nur selten die Autorschaft der Aufsätze mit Sicherheit feststellen, aber es kann uns in diesem Zusammenhange auch schon genügen, den durchschnittlichen Standpunkt des Kreises zu erkennen und die einzelnen Divergenzen auch ohne Kenntnis der hinter ihnen stehenden Persönlichkeiten zu charakterisieren. Wir greifen wieder nur heraus, was mit unserem Thema, Nation und Nationalstaat, in Zusammenhang steht.

Da bemerken wir zunächst, daß der naturalistische Gedanke der Macht, der bei Haller eine, wie wir sahen, zwar erhebliche, aber inkonsequente Rolle spielte, sehr zurückgedrängt wurde zugunsten des Rechtsgedankens. Haller hatte gesagt: Der Fürst herrscht auf Grund seiner natürlichen Uberlegenheit an Macht, die aber zugleich, da Gott der Herr alles schafft und regiert, als eine von Gott gewollte anzusehen und zu respektieren ist, und seine Macht wird - so führte er weiter aus, da er doch nicht jede Macht schlechthin als Recht anzusehen wagte, - zum Rechte durch die Verjährung nicht nur, sondern auch durch die besonderen Verträge, die er mit denen, die schwächer sind als er und sich in seinen Schutz begeben, förmlich oder stillschweigend abschlier3t. Man fuhlte nun wohl, wie dünn und fragwürdig das Band zwischen Macht und Recht, das hier geknuipf wurde, und wie dürftig und dehnbar auch die transzendente, religiöse Begründung der Macht und des Rechtes hier war. Man brauchte festeren Boden, um diejenigen Gewalten, die man stützen wollte, zu stuitzen und fand ihn, statt in dem allgemeinen Theismus Hallers, in dem positiven Worte Gottes, wie es in der Heiligen Schrift offen-

1) Wie Treitschke, Deutsche Geschichte 4, 203, meinte. 
bart sei. So führte es Wilhelm v. Gerlach in den Artikeln » Was ist Recht?" im Wochenblatte von I 833 aus. $\left.{ }^{1}\right)$ Demnach beruhe das Recht der Obrigkeit auf einer speziellen göttlichen Anordnung. Sie ist eine Folge der Erbsünde und ein Zuchtınittel für die gefallene Welt, »ron Gott selbst zur Bändigung des Unrechts auf Erden eingesetzt $\ll^{2}$ ) Erst in zweiter Linie gründet sie sich auf die zwischen ihr und den Untertanen »bestehenden und entstehenden Verfassungen und Verträge, welche indessen niemals jener Hauptbasis widersprechen duirfen 8 . Damit glaubte man nun den ersehnten Ruhepunkt und die Sicherung vor dem Rechte der lebendigen geschichtlichen Entwicklung, die auch Haller nicht hatte bieten können, erreicht $\mathrm{zu}$ haben. Aber so wenig ein Haller die bestehenden Machtverhältnisse hatte fixieren und den Fluß der natürlichen Kräfte in seinem Laufe hatte aufhalten können, ebensowenig gelang es auch den Gerlachs, das Recht und insbesondere das Recht der bestehenden Obrigkeiten aus dem Strom der Entwicklung schlechthin herauszuheben und vor Umsturz und Neubildungen zu sichern. Auch Withelm v. Gerlach mußte zugeben, daß Unrecht zu Recht werden kann durch Verjährung und allmähliche Läuterung: „Das Recht wächst aus dem Unrecht hervor, wie die Blume aus dem Mistbeet. «In dem Unrecht lägen also schon unsichtbare Keime zu künftigem Rechte, die durch göttliche

1) S. 49 ff. Seine Verfasserschaft ergibt sich aus den Aufzeich. nungen seines Bruders Ludw. v. Gerlach I, 20S. - Mehr vom Burkischen Standpunkte aus kritisierte etwas später ein anderes Mitglied des Wochenblattskreises, Heinr. Leo, in seinem Lehrbuch der Universal. geschichte $6,76+f$. (1844) die naturalistische Machttheorie Hallers als eine s Karikatur der Burkischen, als eine Übersetzung der Burkischen genialen Doktrin ins Handgreifliche, Hölzerne und darum von nellem L'nwahres.

2) a. а. O. S. 60 . 
Fügung "gezeitigt « wiirden, d. h. zu ihrer Zeit zum Dasein und zur Reife gelangten. $\left.{ }^{1}\right)$ Damit war man aber gar nicht mehr so weit ab von dem, was die Gerlachs sonst als Pantheismus verdammten, von der Anerkennung des natürlichen geschichtlichen Entwicklungsprozesses. In der Tat hat denn auch ihre Partei im Laufe der nächsten Jahrzehnte fast bei jeder Um- und Neubildung politischer Autoritäten und Machtverhältnisse sich die peinvolle Frage vorlegen können, ob man sie als Unrecht zu verdammen oder als ein nach Gottes Ratschluß aus Unrecht entstehendes Neurecht anzuerkennen habe. $\left.{ }^{2}\right)$

Pantheistisch war ihnen uberhaupt alles, was sich am letzten Ende nicht auf jenseitige, sondern auf diesseitige und irdische Gründe, Zwecke und Notwendigkeiten berief. Als pantheistisch galt ihnen demnach nicht nur der Historismus, der alles geschichtlich Gewordene zu verstehen und anzuerkennen suchte ${ }^{3}$ ), sondern auch die Verherrlichung des Staates und der absoluten Staatszwecke. Hier sprach nun freilich ihr feudal-aristo-

1) a. a. O. S. 49. Ihnlich 1847 Leop. v. Gerlach (I, I19) in einer Rede, die er dem Könige in den Mund legen möchte: Denn auch aus dem Unrecht, das ist die göttliche Ordnung hier auf Erden, geht ein Kecht hervor, was ohne newes Unrecht nicht übersehen werden darf,

2) Hier nur ein prägnantes Beispiel dafür, das sich auf die im zweiten Buche zu behandelnde Oktroyierung der preußischen Verfassung vom 5. Dezenber $184 S$ bezieht. Leop. v. Gerlach bekämpfte sie zuerst natürlich, fand aber gleich hinterher, sdaß der liebe Gott mit dieser Konstitutionsurkunde den rechten Weg gegangen. Ludw. v. Gerlach war unglïcklich über diese historisch-objektiven pantheistischen Reflexionen, seines Bruders. ,So pantheisierten auch 1866 die Konservativen und wurden dadurch völlig ohnmächtig.` Ludw. v. Gerlach 2,34 .

3) Ludw. v. Gerlach 1, I02: Diese blo13 historische Lehre ron Staat und Recht (Savigny und Konsorten), welche in pantheistischer Weise, wesentlich nur aus der Individualität und Geschichte der Völker .... ilhr System aufbaute. 
kratisches Interesse mit, das in dem Absolutismus des Staates, ja auch schon allein in der Idee einer allgemeinen Staatspersönlichkeit den gefährlichen Feind der ständischen Sonderrechte erblickte und darum, genau wie Haller und geschichtlich gewiß nicht mit Unrecht, den revolutionären Macht- und Nationalstaat nur als Erben und Fortsetzer des absolutistischen Machtstaates ansah. ${ }^{1}$ ) Sollte man aber darum, wie es Haller getan hatte, den Staat ganz auflösen in ein Aggregat von privaten Machtund Rechtsverhältnissen? Friedrich Julius Stahl, der in den dreißiger Jahren in Wiirzburg und Erlangen als Lehrer des Staatsrechts und einer konservativ-geschichtlichen Staatsauffassung wirkte, wagte es, den Staat auf den Boden eines wahrhaft öffentlichen Rechtes zuriickzuführen und als Gemeinwesen aufzufassen, die Staatsidee wieder ïber die private Rechtssphäre des Fürsten zu stellen. Eben deswegen aber betrachteten ihn die Zionswächter des Wochenblattes als einen Abtrinnigen, als eine Art Wolf im Schafspelze. $\left.{ }^{2}\right)$ Er bringt uns, sagten sie, doch nur wieder den Hobbesschen Leviathan zurück, nur mit etwas höflicheren Manieren und in neumodischem Gewande. ${ }^{3}$ Und doch konnten auch sie sich nicht ganz der mächtigen geschichtlichen Erfahrung und dem Geiste des Staates, in dem sie selbst lebten, entziehen. »Der moderne Staat, "mußten sie zugestehen, »ist einmal Faktum der Weltgeschichte, man ist gezwungen, ihn anzuerkennen, denn niemand vermag unser gegenwärtiges

1) Vgl. z. B. die Artikel Jarckes iber „Revolution und Absolutismus c ic B. P. W. I\$33, 39 ff. (Verm. Schriften I, I 66 ff.)

2) Nach B. P. W. 1837,177 , lief Stahis Lehre vom Staate, die von umfassenden Aufgaben desselben und von einer über den Fürsten stehenden Staatsidee sprach, sauf eine pantheistische Vergötterıng des Staates hinaus §. Weitere Polemik (Jarckes) gegen Stahl und die historische Rechtsschule in B. P. W. 1834, 259 (Verm, Schriften 3, 10).

3) B. P. IV. 1837, S. I $\$$ I. 
Volksleben auf andere, ihm völlig widersprechende Grundlagen zu bauen «.1)

So rangen sie muihsam nach einer Grundlegung für ihren ständischen Staat, die ihrem religiösen und politischen Gewissen zugleich genügen und ihre aristokratischen Herrschaftsansprüche befriedigen sollte, die ewige Offenbarung, unabweisbare geschichtliche Notwendigkeit und robustes Standesinteresse miteinander zu verschmelzen hatte und dies allerdings nur vermochte, indem sie in den intransigenten Prinzipien des Ganzen einige schlecht verdeckte Durchlässe anbrachte.

Und nach ganz ähnlicher Methode suchten sie sich auch mit der Idee der Nation und ihrer Bedeutung für das politische Leben abzufinden. Hier war nun freilich bei jedem Zugeständnis allergrößte Vorsicht nötig, um nicht gleichsam auf dem Glatteis auszugleiten und dem verhaßten Prinzip der Nationalsouveränität zu ver-

1) B. P. W. 1 833, S. 160. Daselbst S. 150 wird ausgeführt: - Haller lebte in einer Republik, wo eine souveräne Korporation in mannigfachen privatrechtlichen Titeln einfache Untertanen gegenüber hatte, wo also die höher potenzierte Wechselwirkung fehlte, welche in Monarchien durch die Stellung eines unabhängigen Hauptes zu organisch gegliederten Ständen notwendig entsteht, wodurch allerdings andere und tiefere Beziehungen zur Erscheinung kommen, welche eben die Monarchie als die vollkommenste Gestaltung ergeben, deren das Zusammenleben der Menschen fähig ist." Auch in der Steuerbewilligungsfrage vertritt Jarcke im B. P. W. I $\$_{33}$, S. 78 (Verm. Schriften I, 192) und B. P. IV. I 837, I 29 (Verm. Schriften 3, 37 I) einen Standpunkt, der uber das starr altständische Prinzip Hallers hinaus eine Annäherung an den modernen Staatsgedanken und die Anerkennung allgemeiner Staatsnotwendigkeiten bedeutet. Noch weiter geht hierin das B. P. W. I $8_{40}$, I27 ff., wo sich u. a. der ganz unhallersche Satz findet: 2Das fürstliche Eigentum muß schlechterdings als ein solches dem allgemeinen Wohle gewidmet bleiben,e Doch sind die letzten Jahr. gänge der I3. P. W., unter den Einwirkungen des Kölner Kirchenstreites, iberluaupt gouvernementaler als die ersten gefärbt. 
fallen. Jarcke ${ }^{1}$ ) stellte bekümmert fest, daß die Gawette de France, das von ihm sehr bewunderte Organ der französischen Legitimisten, mit dem Begriffe der Nation ein gefährliches Spiel treibe und diesem zur moralischen Person erhobenen Begriffe Funktionen beilege, in denen sich zum großen Teile die revolutionären Wahnbegriffe wiederholt fänden. Er wollte wohl zugestehen, daß das Volk in gewissem Sinne eine Einheit sei, die auf gemeinsamem Wohnsitz, gemeinsamer Dynastie, gemeinsamem Recht, Sprache und Sitte und jahrhundertelangem $\mathrm{Zu}$ sammenleben in Leid und Freud beruhe, kurz, »daß allerdings ein gemeinsamer Volkscharakter erwachse, daß sich die Nationalität, als eine Einheit, die ein Volk $\mathrm{zu}$ einem Volke macht, daraus entwickle«. Allein darum sei das Volk noch lange keine juristische Person, die in rechtlicher Hinsicht einen Willen habe, keine Korporation, keine Gesellschaft usw.

Ein anderer Mitarbeiter versuchte das Auskunftsmittel, streng zu scheiden zwischen den Begriffen Volk und Nation. Volk, so wurde erklärt, sei die Masse der Einwohner eines Staates und sei als solches keine Einheit, geschweige denn ein Rechtssubjekt, sondern bestehe nur aus einer Menge einzelner Rechtssubjekte, die nicht vermögend seien, sich insgesamt zu einem lebensvollen Einzelwesen höherer Bestimmung zu vereinigen. Nationen aber wïrden gebildet durch gemeinsame Sprache und Abstammung, und der Begriff der Nation habe mit dem Staate noch weniger zu tun als der Begriff Volk; er habe vielmehr gar nichts mit ihm zu tun. Nationalität sei »ein dem Staate fremdes Element, das von diesem ebenso unabhängig ist wie der Staat, von ihm $\ll{ }^{2}$ ) »Es gibt keine Nationalstaaten $\ll .^{3}$ ) So wurde

1) B. P. W. 1832, S. 246 (Verm. Schriften I, 20 ff.); vgl, auch B. P. W. 1832, S. 3 .

2) B. P. W, $1838, S, 65$; ähnlich daselbst S. 26 I и. 1 840, S. I 3 I и. I 63.

3) a. a. O. S, 200 . 
also das, was wir Staatsnation nennen, jedes altiven, persönlichen Charakters entkleidet, jeder Möglichkeit beraubt, politischer Faktor zu werden, und das, was wir Kulturnation nennen, wurde überhaupt schlankweg aus dem politischen Leben herausdekretiert. So brach man diesem gefährlichen Begriffe den Giftzahn aus.

Aber es kam nun doch in den Spalten des Wochen. blattes noch eine andere Auffassung zu Worte, für die das Wort Nation einen wärmeren und inhaltsreicheren Klang hatte und die Staat und Nation nicht so ganz und gar voneinander trennen wollte. Wer I 8 I $3_{3}$ mit wachem Sinne und vollem Herzen. erlebt hatte, wäre sich selbst untreu geworden, wenn er vergessen hätte, was der Gedanke der Nation, der preußischen Staatsnation nicht minder wie der deutschen Kulturnation, damals fuir den Staat geleistet hatte. »Die Begeisterung jener Zeit, " heißt es einmal ${ }^{1}$ ), 》galt nicht den Theorien der Aufklärer, sondern der alten, wahren Freiheit der Väter und der in den angestammten Herrschern repräsentierten Selbständigkeit der Nationen«. Ein russischer Diplomat, den das IVochenblatt zu Worte kommen ließ, unternahm sogar einen direkten Vorstoß gegen Haller und riickte ihm vor, daß er für den Begriff der Nation taub geblieben sei. ${ }^{2}$ ) 》Der Staat des Herrn v. Haller ist nur ein Aggregat von ausgesprochenen und stillschweigenden Vergleichen ... Wie, ist dem großen Manne entgangen, daß eine Nation keine zufällige Vereinigung menschlicher Einzelwesen sei, welche ebensogut in den Bund jedes andern Volkes eintreten könnten, sondern daß sie ein organisches, mit einem belebenden Prinzip begabtes Wesen ist (Nationalität), und daß die verschiedenen Verträge nur der Körper oder die Form der Regierung sind?« Die Nationalität sei das geistige Band, das den

1) $18_{3} 6, \mathrm{~S} .57$.

2) 1834, S. $46 \mathrm{fi}$. 
Staat zusammenhalte. Alles, was positiv durch das Recht ausgedrückt sei, sei »nichts als der Stoff, welchem der schöpferische Geist der Nationalität Formen gibt, die in ihrem Ganzen die Konstitution eines Staates ausmachen «. "Die Nationalität ist die Lebensquelle jedes Volkes, und dasjenige, welches sie versiegen läßt, verdammt sich selbst zum Tode. «

Diese ganz offenbar aus Savignys Lehre schöpfenden Ideen machten auf Haller selbst gar keinen Eindruck. Er erklärte es für überfluissig, in einer bloß staatsrechtlichen Theorie zu solchen Subtilitäten, wie es die Frage nach dem verborgenen geistigen Vereinigungsgrund in den geselligen Verhältnissen der Staaten sei, heraufzusteigen, und wollte nichts davon wissen, daß die Nation ein organisches Wesen sei $^{1}$ ). Aber die Erörterung kam damit nicht zur Ruhe, und immer wieder meldeten sich ähnliche unbefriedigte Gemiiter, die mehr ron Nation, von geistigem Quellwasser für den Staat haben wollten, als Haller ihnen verabreichte. Sehr triftige politische Erwägungen drängten schon darauf hin. Man sah es doch gerade an den kleinen altertümlichen $\mathrm{Na}$ tionen Europas, wie ihr ausgeprägtes Sondertum sie immun machte gegen den liberalen und revolutionären Zeitgeist und wie sie mit massiver Geschlossenheit und erquickender Glaubenskraft an ihrer alten Kirche hingen.

1) Er berief sich kiuhl auf die dürftige von Adelung gegebene Erklärung, wonach man unter Nation nur verstehe sdie eingebornen Einwohner eines Landes, sofern sie einen gemeinschaftlichen Ursprung haben, sie mögen tibrigens einen einzigen Staat ausmachen oder in mehrere verteilt sein. A. a. O. S. 234. Eine weitere Antwort auf diese Einwände sollte dann das 92 . Kapitel in dem $\mathrm{I}_{34}$ noch erscheinenden 5. Bande seines Werkes geben. Die Frage nach dem unsichtbaren geistigen Grunde der menschlichen Gesellschaft beantwortete er hier ziemlich rationalistisch dahin, daß die Gleichlieit des Glaubens an gewisse Wahrheiten und an gewisse Pflichten ... . das urspringliche Jand der Menschens ausmache (5, 325). 
Der Zusammenhang von Nationalität und Religion, der auf den älteren Stufen des Nationallebens ja besonders intensiv und zähe ist, drängte sich auf. Als man sich die Basken, die durch ihren ritterlichen Kampf für den legitimen Fürsten Don Carlos die Aufmerksamkeit der preußischen Hallerianer auf sich zogen, näher ansah, stellte man mit Vergnügen fest, daß außer Katechismen und Gebetbüchern nicht leicht etwas in ihrer Sprache gedruckt wurde, aber daß das ganze Volk einen poetischen Sinn und ein frisches Leben habe, das den zivilisierten Pöbel von Paris und London beschämen muisse ${ }^{1}$. Ähnliche Beobachtungen machte man an den slavischen Nationalitäten. Es müsse doch, hieß es ein$\mathrm{mal}^{2}$ ), der Umstand alle Beherzigung verdienen, daß Entnationalisierung und Entkirchlichung der sicherste Weg sein würde, die Uberreste der Polen vollends in den Abgrund der dämonischen Revolution zu drängen. Man sieht hier wohl in den Boden der Anschauungen hinein, die Friedrich Wilhelms IV. polenfreundliche Politik in scinen ersten Jahren geleitet haben ${ }^{3}$ ).

Es taucht dann weiter aber auch schon einmal ein anderer Gedankengang auf, durch den dann Radowitz vor allem ergriffen und aus dem Lager der Partei schließ-

1) B. P. IV. I $8_{34}, \mathrm{~S} .86$.

2) B. P. IV. 1837, S. 300.

3) Das B. P. W. von I 841, S. 22 I ff., wendet sich zwar gegen die politischen Aspirationen der Polen in Posen, will aber ihre Nationalität durchaus geschont wissen. - Vergl. über die polenfreundliche IIaltung Friedrich Wilhelms IV. als Kronprinzen Leop. v. Gerlach I, 59, 73 und der Gerlachs 1 84 I E. Ludw. v. Gerlach I, 286; 1846 Leop. v. Gerlach I, I12. - Ganz konsequent war es, wenn das 1 . P. W. auch die Russifizierung der deutschen Ostseeprovinzen beklagte, aber bezeichnend ist es zugleich, daB es den Feind der deutschen Nationalität in diesen Provinzen nicht in der russisch-nationalen Partei, sondern im angeblich liberalen Beamtentum Rußlands erblickte (I $S_{4}$, S. 155). 
lich herausgeführt worden ist: IVar nicht der nationale Gedanke auch eine Kraftquelle für den Liberalismus, die man ihm nicht allein iberlassen durfte? Der Liberalismus, so wurde einmal gesagt ${ }^{1}$ ), geht ja, insofern er auf materialistischen Ansichten beruht, seinem Untergange entgegen. Die edleren Naturen in ihm aber fühlen das Leere, sehnen sich nach einem positiven Lebensquell und wollen das Nationale festhalten. Und nichts wiirde nun mehr die unwahren und abstrakten Vorstellungen zerstören, als $\operatorname{Sin} n$ und Interesse für die vaterländische Geschichte und die einheimischen älteren Rechtsverhältnisse. So mündete diese Erwägung gleich wieder ein in den Satz, daß Nationalität, wenn man sie recht verstehe, ein vorziggliches Mittel zur Konservierung der alten Zeit, zur Immunisierung gegen die neue Zeit sei.

Das war das Ergebnis, zu dem ein anscheinend doch nicht unbeträchtlicher Teil der Wochenblattspartei durch eigene Lebenserfahrung, Gemuitsbedurfnis und Kalkiul geführt wurde. Es war nun auch nicht so schwer, es einzuordnen in den Zusammenhang ihrer ubrigen Doktrinen uber Staat, Kirche und Gott, Irdisches und Ewiges und so nun eine reichere Skala, eine weitere Spannung der Ideen zu crhalten, als sie das simple Hallersche System bot. Obenan mußte natürlich die Offenbarung Gottes stehen bleiben, die man ja, wie wir sahen, auch schon positiver und inhaltsvoller faßte als Haller. Das Recht, d. h. das Gesetz Gottes, sollte also die Urquelle sowohl der Nationalität, als auch der positiven Verträge bleiben, aber zwischen das Gesetz Gottes und die positiven Verträge, d. h. den Patrimonialstaat, trat nun als $Z$ wischenglied eben die Nationalität als »moralisches Band, welches älter als alle positiven Ver-

1) B. P. IV. I 833, S. 244 . 
träge und gewissermaßen die Mutter derselben ist « 1 ), und demnach sei das Recht zuerst als »unverkörperter geistiger Hauch " da, bevor es in den Verträgen sichtbar werde. Umhüllt von hochuniversalen, transzendenten Ideen auf der einen, von ganz partikularen Ideen auf der anderen Seite, d. h. in einer recht mittelalterlichen Umgebung und selbst noch halb mittelalterlich gefärbt, wurde so hier der Gedanke der Nation dem politischen System des Kreises einverleibt, dem der liunftige Herrscher des preußischen Staates angehörte.

Aus welchem Boden aber dachte man sich die Nationalität, welche man anerkennen wollte, entsprossen, aus dem der Staatsnation oder dem der Kulturnation? Diese Frage hat man sich nicht mit prinzipieller Schärfe gestellt, und in den uns vorliegenden Äußerungen des Wochenblattes fließen die Vorstellungen darüber zum Teil durcheinander. Die Hauptsache war und blieb für diese überwiegend ständisch-aristokratisch interessierten Politiker, das nationale Prinzip in einer möglichst unschädlichen Form nur anzuerkennen und jede Konzession an den liberalen Nationalgedanken, der auf die abschüssige Bahn zur Volkssouveränität und Demokratie führte, zu vermeiden. Die strengeren Mitglieder des Kreises wurden darum ein gewisses Mißtrauen gegen die gefährliche Contrebande, die man aufgenommen hatte, nicht los. Sehr interessant tritt dies in den Gedanken iiber $\mathrm{Na}$ tionalität hervor, die Ludwig v. Gerlach I 844 auf der Reise von Dublin nach Liverpool unter den Eindruicken der irischen Repealbewegung niederschrieb ${ }^{2}$ ). Sie gehörte, wie die polnische, zu denjenigen Nationalbewegungen, die durch ihre bisherige kirchliche Färbung die Sympathie, aber durch die Aussicht auf deren Schwinden die Besorgnis des Kreises erregten. Ludwig v. Gerlach

1) B. P. W. I $S_{37}$, S. 299.

2) Ludw. v. Gerlach I, 397 . 
führte nun - geschichtlich vielleicht nicht ganz unrichtig - die Verklärung der Nationalitäten auf das Christentum, näher: auf die Reformation zurück ${ }^{1}$ ), denn in den früheren Weltreichen seien sie absorbiert worden. "Ausgebildet, wie sie jetzt sind, durch Sprache und Literatur, sind die Nationalitäten sehr wichtig. Sie machen der - wesentlich universalen - Kirche Gottes ihr erhabenes Amt streitig, Geist der Staaten zu sein. Deshalb ist gerade jetzt die Wahrheit so höchst bedeutend und praktisch, daß der Staat eher und mehr ist als die Nation, die aus dem Staate erst entsteht. Der Begriff Nation hat, wie alles bloße Naturtum, etwas nebelhaft Verschwimmendes, was eben darum dem heutigen pantheistischen Zeitgeiste gemuitlich ist $\left.\aleph^{2}\right)$. Auch ihm also schwankten die Merkmale der Kulturnation und der Staatsnation durcheinander, aber er entschied sich zuletzt dafür, die Nation für ein Produkt des Staates zu erklären. Dieser Ausweg, sie herabzudrücken uncl einzuengen, sagte seinem juristisch und normativ gerichteten Geiste am besten zu, aber er stand in WViderspruch mit jener vorhin charakterisierten aus Savigny und der Romantik schöpfenden Auffassung seiner Partei-

1) Ein ähnlicher Gedaukengang begegnet noch bei Heinrich Leo, der in einer Denkschrift für Friedrich Wilhelm IV. vom Herbste $1 \delta_{4} \delta$ die Entstehung der deutschen Nation auf Bonifaz und das Werk der Kirche zurückführte; die Reformation habe die nationale Bildung voltendet, aber zugleich eine Todeskrankheit in die Wurzel der deutschen Einheit selbst hineingetragen. Varrentrapp, Histor. Zeitschrift 99, $112 \mathrm{f}$.

2) Interessant ist auch eine Äußerung Ludw, v. Gerlachs aus späterer Zeit (April 1867; 2, 297) ïber die Begriffe Staat, Volk, König und Nationalität. , Diese unverstandenen Worte verwandeln sich einem unter den Händen in Natursubstanzen oder Götzen, auf welche göttliches und menschliches Recht sich nicht anwenden läßt, sondern die als monstra oder Leviathane nach ihren eigenen wunderlichen Eigenschaften beurteilt werden miissen. So entsteht, ansgebritet rom Pantheismus, das sLaster des Patriotismuss, wie mein Bruder I.copold es nannte. Wie viel Dank lin ich doch von $1 S \mathrm{I} 7$ an Haller schuldig.: 
genossen, wonach umgekehrt das positive Recht und der Staat aus der Lebensquelle der Nationalität entspringe. Und diese Auffassung war es nun doch, die sich der größeren Gunst in diesem Kreise erfreute und die stärkere Wirkung auf ihr politisches Denken ausübte. Gewiß war sie "nebelhaft verschwimmend" und konnte dem einen deshalb bedenklich, dem anderen aber gerade darum auch unbedenklich erscheinen, denn so mochte es nun gelingen, den nationalen Gedanken in der Sphäre des Unfaßbaren, des rein Geistigen festzuhalten, seinen Drang nach politischer Verkörperung in modernen Formen zu hemmen und doch zugleich alle älteren politischen Körper und Formen, die man verteidigen wollte, aus ihm abzuleiten und durch ihn $\mathrm{zu}$ rechtfertigen. Hüten wir uns jetzt aber vor ubermäßigem Rationalisieren und vergessen wir nicht, daß man die nationale Idee in dieser Form nur aufnehmen und uiber die Schwelle des Bewußtseins nur treten lassen konnte, weil sie schon davor stand und aus den großen Erlebnissen der Zeit, aus den eigenen geistigen und politischen Jugendeindrücken der Romantik und der Befreiungskriege übermächtig sich aufdrängte.

So entstand das, was wir den konservativen Nationalstaatsgedanken nennen möchten, im Gegensatz zu dem liberalen, der seine Hauptkraft aus den Ideen von 1789 zog. Hören wir, bevor wir ihn weiter untersuchen und definieren, zunächst noch ein höchst prägnantes Zeugnis aus den Spalten des Wochenblatts, das neben den uns schon genauer bekannten Zügen dieses Nationalstaatsgedankens auch diejenigen enthält, die wir uns noch klarer machen müssen. Es ist eine Rezension von Friedrich Ludwig Jahns »Merke zum deutschen Volkstum", $\left.1833^{1}\right)$. Der urkräftige Turnmeister, der hier den fran-

i) B. P. W. $1833, \mathrm{~S}, 214$. 
zöselnden Liberalen des Tages die Leviten las, war den Politikern des Wochenblattes, von denen dieser und jener selbst zwei Jahrzehnte zuvor auf den Turnplatz der Hasenheide mit hinausgezogen war ${ }^{1}$ ), nicht unsympathisch, nur hielten sie folgende Vorbehalte gegen ihn für nötig: "Wir unsererseits sind auch Deutsche, voller Liebe zu dem Vaterlande, in das uns Gott gesetzt hat, wie es jeder tiichtige Mensch sein muß, voll Begeisterung für alles Herrliche deutscher Art, Kunst und Geschichte, für die wir das Interesse nicht genug zu wecken vermögen; nur glauben wir, daß eine nichtige äußerliche Einheit Deutschlands diesen echt patriotischen Sinn gewiß eher vernichten als befördern werde und daß der Versuch uns auf diese Art zu einer sogenanuten grande nation zu machen, den schmählichsten Schiffbruch unserer edleren Nationalität zur Folge haben würde. Ja wir glauben, daß das deutsche Vaterland sein eigenstes Lebensprinzip eben in jener rechtlichen Mannigfaltigkeit habe, welche dem Trugbilde des falschen Patriotismus hingeopfert werden soll. Wir muissen ferner den Verfasser der Merke und alle ihm an gliihender Liebe für Deutschland und an unbegrenztem Haß gegen Frankreich Gleichgesinnte darauf aufmerksam machen, daß das Nationalgefühl, so wenig es an sich verwerflich, nicht das Höchste sei, ja daß es, einseitig erhoben, uns dahin bringen würde, wohin die Franzosen leider gelangt sind. Es ist dies einer der faulsten Flecke des heutigen Frankreichs, denn darin sind alle, Royalisten, Philippisten und Republikaner einig, daß die Franzosen das erste Volk der Welt seien, dem das linke Rheinufer von Rechtswegen gebihre... offenbar aber muß es etwas Höheres geben als jenes, so lange es für sich besteht, ganz heidnische Nationalgefühl. Dieses Höhere ist die Anerkennung einer auf dem Recht beruhenden

1) Vgl. mein Leben Boyens 2, 407. 
göttlichen Weltordnung auf Erden, welche jenes Gefühl läutert und heiligt. Diese Erkenntnis lehrt, daß Unrecht allemal Unrecht bleibt, welches durch keinen Vorwand, keine Sophisterei und lieine vorgebliche Begeisterung entschuldigt wird ... Sie lehrt endlich auch, daß es nicht erlaubt ist, deutsche Provinzen, welche lange Zeit vertragsmäßig undeutschen Fürsten gehört haben, unter dem Vorgeben zu überziehen, daß deutsche Erde kein fremdes Joch tragen duirfe. Wenn es auch ein Unglück für Deutschland war, daß das Elsaß französisch wurde, so ist es doch besser, daß dieses verschmerzt, als daß ohne Veranlassung ein neues Raubsystem geltend gemacht werde, zehnmal ärger als Ludwigs XIV. berüchtigte Reunionskammern . . Jagen wir daher keinen Luftgebilden nach und gönnen wir den Franzosen ihre nivellierte Einheit, ihre Departements, ihre Zentralisation und Eitellieit und bewahren wir uns das bessere Bewußtsein, Deutschlands Einheit bestehe umgekehrt gerade darin, daß in jedem, auch dem kleinsten Teile des deutschen Vaterlands, besondere Lebenspulse schlagen, die alle dem Herzen Nahrung zuführen."

Zum Wesen dieses konservativen Nationalstaatsgedankens gehört es also, daß er grundsäı zlich verzichtet auf die politische Zusammenfassung der Kulturnation, daß er aber diese als den fruchtbaren Mutterboden ansieht, aus dem vielerlei große und kleine politische Gebilde erwachsen, alle das echte Gepräge deutschen Geistes tragend. An ihren Blüten und Früchten nur kann man sie erkennen, wie sie bunt und herrlich durcheinander wachsen; sie selbst bleibt in der Tiefe dunlel und undurchdringlich, aber Lebendiges gebärend. Ohne Zweifel haben wir hier eine höchst geistreiche Konzeption vor uns, die ihren Ursprung, uber Savigny noch hinaus, aus den ersten Ideen der Frühromantik nicht verleugnet. Die IVelt, so hörten wir von dieser, ist ein Abyssus von Individualität, eine Fülle ron 
eigenartigem Sonderleben, das aber durch ein geistiges Band in sich zusammenhängt. Von dieser Anschauung aus führt ja allerdings noch kein geradliniger IVeg zu derjenigen, die wir jetzt vor Augen haben. Aber sie war doch das Mittel gewesen, um allenthalben in Leben und Geschichte geistige Einheit in dem individuell Mannigfaltigen und in dem äußerlich Getrennten innere $\mathrm{Zu}$ sammenhänge zu finden.

Der konservative Nationalstaatsgedanke sah den Nationalstaat nicht in dem nationalen Einheitsstaate, sondern in dem der Nation entsproßenen Einzelstaate. So scharf hatte ja die Frühromantik den geistigen Zusammenhang zwischen deutscher Kulturnation und deutschem Einzelstaate noch nicht betont. Sie faßte, ebenso wie Fichte und die Führer des Humanitätsideals, die deutsche Nation noch zu sehr als Menschheitsnation, zu wenig als geschichtlich bestimmte Nation auf. Aber sie hatte gerade dem Einzelstaate schon ihr besonderes Interesse zugewandt, sie hatte ihn nationalisieren, d. h. in politischem Sinne nationalisieren, mit lebendigem Gemeingefühl erfüllen und ihn so $z u$ einer in sich bewegten großen Persönlichkeit erheben wollen. Auch dieser Gedanke, den die Hallersche Lehre schon ganz zu verschütten gedroht hatte, tauchte in den Kreisen der Wochenblattspartei wieder auf. Ein Aufsatz von I8 $88^{1}$ ), der den bezeichnenden Titel »Notwendige Ergänzung der Staatswissenschaft « trug, führte aus, daß man neben Haller auch Adam Müller wieder zu Worte kommen lassen müsse, um die höhere geistige Idee in der Erscheinung des Staates $7 . u$ finden. Seine lebendige Einheit lasse sich freilich nicht mit Worten angeben, : sondern sie kann in ihrer ganzen Fülle bloß geschaut werden«. Der Staat sei ein "aus einer Wurzel, nach einer bestimmten

1) S. 2 ff. 
Richtung hin in Zeit und Raum unter göttlicher Leitung und Ordnung organisch entfaltetes universelles Menschenleben ", und es ginge nicht an, nur aus Herrschen und Dienen, aus isolierten ökonomisch-rechtlichen Interessen diese Verhältnisse zu begreifen, diese Riesenbilder, welche die Geschichte aufstelle von Fürsten und Völkern in innigster und erhabenster geistiger Verschmelzung, und die durch dies geheimnisvolle Band allein Schicksale und Kultur der Welt bestimmten.

Wenn man diese verschiedenen, aus der Romantik stammenden und durch politische Interessen und Erfahrungen weiter entwickelten Ideen neben- und durcheinander wirken sieht, so versteht man es, was wir schon oben wahrnahmen, daß man die Nationalität, die in dem Boden der großen Kulturnation ruhte, und die Nationalität, die das geistige Band des Einzelstaates war, nicht streng voneinander $\mathrm{zu}$ trennen suchte. Das war wissenschaftlich ein Mangel, aber praktisch beförderte es die Nationalisierung des Staates in der einen wie in der anderen Bedeutung. So konnte denn der deutsche Einzelstaat aufgefaßt und empfunden werden einmal als echte Schöpfung deutschen Geistes, wertvoll und eigenartig dadurch wie alles andere, was aus diesem hervorgegangen war, und sodann als lebendige, geschlossene Einheit in sich selbst. Damit erst hatte man dann eine Staatsauffassung, die den Idealen des liberalen und demokratischen Nationalstaates auch bedeutende nationale IVerte entgegensetzen konnte. Gegen die Volkssouveränität spielte so die politische Romantik den Volksgeist aus ${ }^{\mathbf{1}}$ ), gegen die geschlossene autonome Persönlichkeit der Nation konnte sie ausspielen einmal

1) Der Geist des Volkes in seiner geheimnisvollen Tiefe und Mannigfaltigkeit, wie sich Jarcke ausdrickt. B. P. W. 26. Nov, 1 $\delta_{3}$ I, S. 3 I (Verm. Schriften I, 36). Uber das Schlagwort und die Lehre rom Volksgeiste vgl. oben S. 215 und unten S. 273 Anm: 2. Jarcke ist vielleicht durch Puchta, Das Gewohnheitsrecht I (IS28) beeinfluBt. 
die phantasievolle Vorstellung der zwar ungeschlossen und unpersönlich bleibenden, aber geheimnisvoll-fruchtbar zeugenden Nationalität des gesamten Deutschlands, und dann die real-lebendigen Bilder der einzelnen Staatspersönlichkeiten Deutschlands, deren jede in säkularem Zusammenleben von Herrschern und Beherrschten entstanden war. Gegen das neue Deutschland, das der Radikalismus schaffen wollte, wurden hier die Geister Altdeutschlands und Altpreußens zugleich aufgeboten. Der liberale Nationalstaatsgedanke berief sich auf das Recht und den Willen der lebenden Nation, der konservative Nationalgedanke auf das, was sie erlebt hatte. Beide zogen dabei einen Teil ihrer Kraft aus den großen individualistischen Regungen der Zeit, aber mit dem Unterschiede, daf hier ein demokratischer und rationalistischer, dort ein aristokratischer und historisierender Individualismus standen, hier mehr das einzelne Individuum als das Atom der Gesellschaft, des Staates und der Nation, dort das Individuelle uberhaupt in den mannigfaltigen Formen des gesellschaftlichen, politischen und nationalen Lebens geschätzt wurde, hier das gleiche Recht aller im Staatsund Nationalleben, dort die besondere Funktion der Einzelnen in ihm, je nach dem Lebenskreise, in dem sie standen, gefordert wurde. Der eine setzte als Schranke gegen das Individuum den Nationalwillen, bei dessen Bildung es selbst mitwirkte, der andere sah die Schranke in dem, was die vergangenen Generationen der Nation hervorgebracht hatten. Der eine appellierte an die bewußte souveräne und regulierende Vernunft der Einzelnen und der Gesamtheit, der andere leitete die unbewußte Vernunft der Geschichte aus ihrer souveränen Regulierung durch Gott ab. Jeder vertrat dabei reale und robuste Interessen, gesellschaftlicher Klassen, jeder suchte sie aber zugleich in die Sphäre eines universalen Lebensideals zu erheben. Dem rationalistischen Univer- 
salismus der liberalen Staatsauffassung trat der religiöse Universalismus der politischen Romantik entgegen.

Diesen gilt es sich jetzt in seinen politischen Konsequenzen noch etwas deutlicher zu machen, denn wir stehen fast schon an der Schwelle der Regierung, die den pralitischen Versuch mit den Ideen der politischen Romantik machte. Wir sahen, wie sie den Gedanken der Nation vorsichtig einordnete zwischen das geoffenbarte Gesetz Gottes auf der einen und die ständische Monarchie auf der anderen Seite und so das Labile, das ihm eigen war, zu hemmen suchte durch die stabile Umgebung, in die er gestellt wurde. IVir sehen nun weiter aus der Rezension von Jahns Schrift, wie besorgt man war, den Gedanken der nationalen Macht und Größe zu dämpfen, wie man selbst einen Krieg für die Wiedergewinnung entfremdeten deutschen Landes für unerlaubt und schädlich erklären konnte, weil es besser sei, das aus friiherem Unrecht nun einmal durch Verjährung und Verträge erwachsene Recht der Nachbarnation auf das Elsaß anzuerkennen, als neues Unrecht zu verüben $\left.{ }^{1}\right)$. Damit wurde das Interesse, das Machtbedürfnis und die Selbstbestimmung nicht nur der Nation im ganzen, sondern auch des Einzelstaates eingeschränkt und ein für allemal an höhere Rechtsnormen gebunden. Es ist die alte Leugnung oder doch Abschwächung des Rechts der Staaten auf autonome Machtpolitik, die wir in immer neuen Formen wieder auftauchen sehen. Von den politischen Träumen und theoretischen Spielereien eines universalen politischen

1) Der Verfasser des Aufsatzes , Natürliche Grenzen (I. P. W. ${ }_{1} S_{3} S$, S. 65 f.), der die Nationalität iiberhaupt als ein dem Staate fremdes Element erliärt hatte (s. oben S. 239), konnte natürlich erst recht erklären: 'Die deutsche Nationalität, so hoch wir sie auch stellen, ist nicht geeignet, dem französischen Volke den moralischen Zwang des Rechts aufzuerlegen, die deutsche Grenze heilig z $\mathbf{u}$ achten. Diese Heiligkeit verleihen ihr lediglich die Territorialrechte der deutschen Fïrsten. 
Verbandes zwischen den einzelnen Staten wird ja jetzt unmittelbar nicht mehr gesprochen. Vielmehr wird der Primat des Rechtes vor der Macht und der universalen Welt- und Staatenordnung vor dem Interesse des Einzelstaates jetzt als doktrinäre Norm dem Gewissen der Staatsmänner eingeschärft. Es steht, so lehrt Wilhelm v. Gerlach ${ }^{1}$ ), mit den Verhältnissen der Souveräne untereinander genau ebenso wie mit den Rechtsverhältnissen zwischen der Obrigkeit und ihren Untertanen; das heißt, es gibt auch für sie keine Rechtsnormen, "welche der Moral und dem Christentum nicht entsprächen, ja welche mit den moralischen und christlichen nicht identisch wären; alle, auch die speziellsten, müssen daraus hergeleitet werden und sich darauf zuriickfïhren lassen; diese Rechtsverhältnisse sind nichts anderes als moralische und christliche Verhältnisse, welche nicht anders als alle andern Verhältnisse unter Menschen, nämlich lediglich nach Gottes Willen reguliert werden sollen.

Der »heidnische Nationalstolz der Franzosen war an derartige Schranken nicht gebunden. Eben das empfand man in den Kreisen des Wochenblattes als unheimlich und sündhaft, daß alle Parteien in Frankreich, die Legitimisten nicht minder als die radikalen Verfechter der Volkssouveränität, es für das selbstverständliche gute Recht Frankreichs hielten, seine Macht auszudehnen, seine wirklichen oder vermeinten Realinteressen frank und frci zu fördern. Einmiitig vertraten sie alle nach außen hin die Autonomie der Staatspersönlichkeit und bezeugten durch ihre Einmuitigkeit den inneren $\mathrm{Zu}$ sammenhang zwischen dem autonomen Machtstaate des ancien rigime und dem autonomen Nationalstaate der revolutionären Ideen. Damit hatte Frankreich einen ungemeinen politischen Vorsprung vor Deutschland, wo die Wege von Staat und Nation sich so sehr viel schwerer i) B. P. W. $18_{33}$, S. 60 . 
fanden, und wo die Autonomie des Staates wie der Nation nun auch noch gedämpft und gehemmt wurde. Deutschland und die deutschen Fürsten sollten, so hieß es, in den Machtkämpfen der Staaten untereinander gewisse Waffen nicht gebrauchen dürfen, deren ihre Nachbarn sich skrupellos bedienten.

Das also waren die Ideen über Staat und Nation und uber die Maximen ihrer Bewegung, die der Freundeslreis Friedrich Wilhelms IV. in den dreißiger Jahren sich ausbildete. Man muß sie kennen, um seine Regierung, die in Deutschlands Geschicke so tief einschnitt, zu verstehen, denn sie bildeten insgesamt einen Gedankenballast, mit dem das Schiff seiner Politik beladen und belastet blieb bis zu seinem Ende. Damit ist nun aber nicht gesagt, daß sie in allem und jedem sein eigen waren und seine Handlungen bestimmten. Diese ganze Ideenmasse der christlich-germanischen Staatslehre, die den Gegnern als eine einzige starre Einheit erschien, war es ja, wie wir schon an den von uns herausgehobenen Problemen sahen, keineswegs. Sie war reich an Varianten und Nuancen, schon weil ihre Vertreter geistreiche und scharfsinnige Leute waren und die Paradoxien liebten, durch die sie sich in ihrem engeren Kreise, man möchte fast sagen, schadlos hielten für die dogmatische Gebundenheit, die sie dem zügellosen Subjektivismus der Zeit entgegenzuhalten für Pflicht hielten. Dies Luxurieren in allerlei Einfällen und Forderungen rächte sich dann, als es zum Handeln inmitten einer mächtig bewegten Velt kam, und es sich nun herausstellte, daß man das einheitliche Handeln verlernt hatte, daß es der Wege aus ihrer Theorie zur Praxis leider zum Verirren viele gab. Wie oft schuittelte nicht Leopold von Gerlach über seinen Bruder Ludwig, und dieser über jenen, und wiederum beide iiber den König, und wohl auch dieser 
uiber jene den Kopf. Auch der einzelne machte sich selbst hinterher nicht selten den Vorwurf, falsch gehandelt, d. h. seine Theorie falsch angewandt zu haben. Der stärkste Grund dieser Zerfahrenheit aber lag in dem Charakter ihrer Theorie selbst. Sie barg in sich, wie wir sahen, den Keim zu einem politischen Quietismus und Relativismus, der ihre Köpfe und Hände, wenn es zu kämpfen und $\mathrm{zu}$ handeln galt, lähmen konnte; man bekreuzigte sich zwar uber jedes neue Unrecht der Gegner, aber man konnte sich hinterher mit dem Skrupel plagen, ob und wie weit es Gottes Wille sei, daß aus diesem neuen Unrecht neues Recht entstehe ${ }^{1}$ ).

Immerhin hielt schon der Abscheu gegen die verhaßten gegnerischen Lehren und Taten diesen Relativismus in Schranken. Nicht uberwinden dagegen konnte man die inneren Widersprïche des Systems. Eben daß man es über Haller hinaus weitergebildet hatte, war sein Vorzug und seine Schwäche zugleich. Was es an Geist und Gedanken gewann, verlor es an Kompaktheit und Derbheit, an defensiver Stärke gegenüber dem modernen Zeitgeiste. Für ein dogmatisches System wurde es zu historisch, und für eine historische Staatsauffassung blieb es zu dogmatisch. Haller hatte wohl gewußt, was er tat, als er die Gedanken der Staatspersönlichkeit und der Nation fernhielt von seinem System. Indem man ihnen, wenn auch nur vorsichtig und zögernd, Aufnahme gewährte, öffnete man das Tor den stärksten Mächten der modernen Entwicklung, eben der Entwicklung, die iber den patrimonialen und ständischen Staat mit Naturgewalt hinausführte. Sie wollten den Patrimonialstaat herstellen und gleichzeitig den Ideen der preußischen Staatspersönlichkeit und der deutschen

1) S. oben S. 236 . Diesen quietistischen, die Tatkraft lähmenden Zug der Theorie habe ich früher (Die Tagebiicher des Generals von Gerlach, Histor. Zeitschrift 70, IS92) behandelt und damals etwas zu stark unterstrichen. 
Nation, denen sie sich nicht entziehen konnten, genügen, und wollten uber das alles hinaus, um es zusammenzufassen und zu heiligen, eine oberste religiös-ethische, universale und transzendente Idee aufpflanzen, die nicht nur das Leben des einzelnen, sondern auch das Leben des Staates leiten sollte, - das war zu viel des Unvereinbaren. Und so ist die Geschichte Friedrich Wilhelms IV. und seines Kreises ein großartiger Zersetzungsprozeß, der in den dreißiger Jahren beginnt, in den Revolutionsjahren seinen Höhepunkt erreicht, aber auch nach der Zuruickdrängung der Revolution weitergeht bis zur Autlösung und Umbildung dieser ganzen Richtung durch das Zeitalter Bismarcks.

So sind denn unsere Betrachtungen, die als eine Art Einleitung sowohl zur Geschichte Friedrich Wilhelms IV. wie zur Geschichte Bismarcks gemeint sind, nicht mehr weit vom Ziele. Es genügt, mit einigen Strichen einmal den Zersetzungsprozeß der vierziger Jahre zu charakterisieren, und dann zu zeigen, wie die Idee des modernen Nationalstaats aus den Nebeln der universalistischen und unpolitischen Gedanken, von denen sie bisher umhüllt war, endlich siegreich hervorbrach.

Als Beispiel für die innere Auflösung des christlichgermanischen Staatsideals durch die Aufnahme nationalstaatlicher Elemente wählen wir zuerst die Gedanken, die Friedrich Julius Stahl in den vierziger Jahren, also in den Zeiten seiner preußischen Wirksamkeit, über das Verhältnis von Staat und Nation entwickelt hat. Wir sahen, daß er den Ultras der Hallerianer in den dreißiger Jahren als halber Abtriinniger galt. Jetzt, wo er im Berlin Friedrich Wilhelms IV. lehrte, trat dieser Gegensatz nach außen hin, wo Stahl als der wirksamste Publizist und Theoretiker der Partei erschien, uberhaupt nicht mehr hervor, aber auch in dem intimen Kreise der Gerlachs galt er als ein in der Hauptsache doch zuverlässiger 
Gesinnungsgenosse und als ein tapferer Vorkämpfer des christlichen Staates gegen Liberalismus und Revolution. Den eklektischen und rezeptiven Zug, den er von vornherein hatte, verleugnete er freilich auch jetzt nicht. Auf der einen Seite hielt er fest an der transzendenten, religiösen Grundlage des Staatslebens und an der Rechtfertigung insbesondere der ständischen Monarchie durch sie, so daß ihm also die 》historische Ordnung « zugleich die "göttlich-menschliche Ordnung « war und das »Ubermenschlich-Gefügte", das allem Menschenwerk vorangehen sollte, im historisch gegebenen Rechte und der legitimen Autorität erschien. Liberalismus war in seinen Augen zugleich religiöse Verirrung, Abfall von den Grundsätzen der Reformation, die eben allenthalben, also nicht nur in der engeren Sphäre der Religion, das UbermenschlichGegebene als das Erste und Unabweisbare predige und in der menschlichen Tat nur das zweite, nur lebendige innerliche Aneignung, nicht eigene Erzeugung sehe ${ }^{1}$ ). Aber da er selbst mehr zum Aneignen als zum eignen Erzeugen von Gedanken veranlagt war, so wollte er auch vom Liberalismus lernen. Ausdrücklich erkannte er als positive Güter, die dieser vertrete, an: „Das Recht des Menschen, die Selbständigkeit der Nation, die verfassungsmäßige Ordnung, die geistige Macht der öffentlichen Lebenswürdigung. «2) Ausdrücklich und scharf lehnte er die Hallersche Lehre ab, die die Staatsgewalt zum Privateigentum des Fürsten machte und den Staat in ein Aggregat von ubereinander geschichteten Herrschaftsverhältnissen autlöste, und bekannte mit Freuden, daß der Staat eine höhere sittliche Ordnung, ein ursprüngliches Ganzes, das sein Gesetz in sich selbst trage, sei. Er

1) Philosophie des Rechtes II., 2. Aufl. (I $\left.\$_{4} 6\right)$, S. XV ff, Die quietistische Konsequenz dieser Gedanken habe ich in meinem oben S. 255 erwähnten Aufsatze behandelt.

2) a. a. O. S. XIV.

Meinecke, Weltbürgertum und Nationalstaat. 2. Aufl. 
ist »das zur Persönlichkeit konstituierte Volk «1), und indem er ihn getragen wissen will von der lebendigen Gesinnung des Volkes und ihn selbst wieder zum Träger, Ordner und Förderer des sozialen Lebens im Volke erhebt, hat er unzweifelhaft das Bild eines echten Nationalstaates vor Augen. Eines konservativen Nationalstaates natürlich, dessen Untertanen aus bloßer Untertanenschaft zur Staatsnation sich entwickelt haben und dessen Obrigkeit auf legitimer historischer Basis beruht. Aber er ist zugleich für den moderneren Gedanken nicht unempfänglich, daß auch die Nation im weiteren Sinne, die Kulturnation, die auf Einheit des nationalen Bewußtseins, der Sitte und Sprache beruhe, nicht gleichguiltig sei für die Bildung und Abgrenzung der Staaten. »Das Volk in diesem Sinne", sagt er ausdrücklich, »ist die naturgemäße Grundlage des Staates." Es solle daher, fordert er, bei neuen Länderverteilungen, soweit nicht bestehende Rechte es hindern, der natürliche oder historische Volksverband leitende Rücksicht sein. Und es solle, wenn eine Nation, wie z. B. die deutsche, sich in Stammstaaten teilt, »eine höhere Staateneinheit, je stärker desto besser, angestrebt werden, in der das gemeinsame nationale Bewußtsein seine Manifestation und seine Sicherung erhalte. Freilich unterschied er nun gleichzeitig genau zwischen dem, was »naturgemäß «, und dem was »Recht " sei. Das Recht des Staates sei ganz unabhängig von der nationalen Zusammensetzung seiner Untertanen ${ }^{2}$ ), aber auch das »Ethos « des Staates, d. h. vor allem anderen die legitime Obrigkeit und die historisch überkommene Verfassung, sei vor und über der Nation, und sie müsse $\mathrm{ihm}$ gehorchen ${ }^{3}$ ). Da war denn allerdings die gerühmte Selbstätigkeit der Nation wieder in die Schranken des überkommenen legitimen Rechtes

$$
\text { 1) a. a. O.S. I09. - }{ }^{2} \text { ) a. a. O.S. } 134-\text { s) a. a. O.S. XVIf. }
$$


zurückverwiesen, und der für dieses Recht so gefährliche Wunsch nach kräftigerer politischer Einheit der deutschen Nation wurde zurückgedrängt in die Reihe der frommen Wünsche. Immer aber wurde er doch ausgesprochen und anerkannt und bildete so ein fremdartiges Element inmitten des konservativen Rechts- und Autoritätsstaates.

Als fremdartiges Element tritt freilich das Neue und Zukunftsreiche oft auf inmitten alter iiberkommener Gedankengänge, und es kommt darauf an, in welchem Grade es sich in ihnen lebendig zu behaupten und durchzusetzen vermag. Das sollte sich in Stahls politischer Gedankenwelt zeigen, als die Erlebnisse von I 848 sie aut die Probe stellten. Da zeigte sich vor allem, daß die dem konservativen Nationalstaatsgedanken eigene Idee der inneren Nationalisierung des historisch gewordenen Einzelstaates in ihm bis auf den Grund seines Denkens und Strebens hinabreichte. Er gehörte, wie wir im zweiten Teile dieses Buches sehen werden, zu den kräftigsten Verteidigern der preußischen Staatspersönlichkeit gegenüber den Wogen der deutschen Nationalbewegung, die als ein freundlich-feindliches Element gegen sie andrängte. Und er war auch sogar schon vor I 848 bereit zu einer konstitutionellen Reformierung des preußischen Staatswesens selbst, die zwar den reinen Parlamentarismus, die Herrschaft der Kammermehrheiten entschieden ablehnte, aber eine Einschränkung der Monarchie durch die Volksvertretung, ein Zusammenwirken des selbständigen Königtums mit dem Volkswillen rundweg anerkannte. Wünschte er auch bei der Bildung dieses Volkswillens in der Zusammensetzung der beiden Kammern die konservativen Elemente des Volkes stark vertreten zu sehen, so war doch sein Verfassungsprogramm insgesamt ein wesentlicher Schritt vorwärts zum modernen Konstitutionalismus. ${ }^{1}$ )

1) Die Revolution und die konstitutionelle Monarchie, I $8_{4} 8$. Vgl. Salzer, Stahl und Rotenhan. Histor. Vierteljahrsschr. I4, 2 I4. 
Die charakteristischen Züge des konservativen Nationalstaatsgedankens zeigen sich ferner auch in seiner Stellung zur deutschnationalen Idee. Wir sind, erklärte er $^{1}$ ), nicht der deutschen Sache, sondern nur der revolutionären Sache gram. Nur das aber könne die rechte Einigung Deutschlands sein, durch welche die echten ruhmvollen Charakterzüge deutscher Nation erhalten blieben, also Heilighaltung der erworbenen Rechte, die gegliederten Verhältnisse der sozialen Ordnung, die Selbständigkeit der kleineren Kreise gegeniber einer falschen Zentralisation, die Bande persönlicher Treue zwischen Fürsten und Völkern, die Bewahrung des christlichen Glaubens als Mittelpunkt auch für das öffentliche Leben. Man bcachte, wie hier wieder die historisch-romantische Idee des Volksgeistes, der das Eigentiumliche gebärenden Nationalität ausgespielt wird gegen die Idee der Volkssouveränität. Es war nicht nur eine geschickte Taktik. sondern es war, wie wir wissen, ein Kern von Wahrheit darin, wenn er die triumphierende Frage daran knüpfte: Sind nun nicht diese tiefsten Züge deutscher Nationalität durch das Verfassungswerk der Frankfurter vielmehr aufgehoben zugunsten kosmopolitischer Ideale: So stand es ja, daß hüben und drüben, im konservativen wie im liberalen Lager, die nationale Idee umfangen und begleitet war von universalen Vorstellungen, hier von religiös-transzendenter, dort von rational-diesseitiger Färbung.

In Stahls Nationalgedanken trat ja dies universale Moment immerhin zurück, aber es fehlte auch nicht. Ganz wie bei den Politikern des Berliner Wochenblattes diente die Aufstellung religiöser Prinzipien im Staatsleben dazu, das deutsch-nationale Prinzip in Schranken zu halten und das historische Recht der bestehenden Einzelstaaten

1) Die deutsche Reichsverfassung. 2. Aufl. IS49, S. 49. 
vor dessen Konsequenzen zu schuitzen. Und es zeigt sich nun weiter auch bei ihm, was wir so oft beobachtet haben: die Hineintragung unpolitischer Ideale in die Politik trübt die Klarheit politischer Vorstellungen überhaupt und schwächt den Sinn für das politisch Mögliche und Lebensfähige und schwächt ihn zumal da, wo es gilt, etwas Neues zu schaffen. Auf dem festen Boden des preußischen Einzelstaates bewegte sich Stahl noch mit sicherem politischen Takte, und er zeigte ihn auch in der Wahrung der einzelstaatlichen Interessen gegenüber der unitarischen Tendenz der Frankfurter Reichsverfassung Aber er war stärker in ihrer Kritik als in dem, was er nun positiv dafür vorzuschlagen hatte. Die beiden großen Hauptfragen des Verhältnisses Preußens zu Deutschland einerseits, und Preußen-Deutschlands zusammen gegen Osterreich andererseits beantwortete er mit einer auffallenden Unsicherheit und mit überaus schwankenden und haltlosen Vorschlägen. Sollte Preußen Deutschlands Vormacht sein oder nicht? Seine Antwort war ein Ja und Nein zugleich; ja sagte die preußische Seele in ihm, nein seine unpolitische und deutsche Seele. Zur Reichsvorstandschaft Preußens, wie sie durch die Dreikönigsverfassung vom 26. Mai I 849 ausgesprochen war, sagte er: „Ein solches Voraus eines Staates ist nicht das, was man als Ideal und als harmonischen Zustand der ganzen deutschen Nation gerade wünschen wird. ${ }^{1}$ ) Aber es sei allerdings, fügte er hinzu, unvermeidlich gewesen. Und ebenso sagte er Ja und Nein zugleich zur Ausschließung Osterreichs aus dem engeren deutschen Bundesstaate. Sie wäre, meinte er, in der Form wie sie das Frankfurter Parlament wollte, also unter Aufrechterhaltung eines weiteren staatenbündischen Verhältnisses zwischen Deutschland und Osterreich, nicht zu beklagen. Wenn aber,

1) a. a. O. S. 49. Salzer a. a. O. hat meine Auffassung nicht widerlegt. 
so fügte er hinzu, Österreich sich bereit erklärte, alle Verpflichtungen des neuen Bundesstaates zu erfüllen, so dürfte man ihm den Eintritt nicht verweigern, - wohl aber könnten dann die übrigen deutschen Fürsten auf Preußens Oberhauptswürde beharren, und Osterreich habe dagegen keinen rechtlichen Einspruch. Man braucht kaum darauf aufmerksam zu machen, in wie unmöglicher und doktrinärer Weise hier Rechts- und Machtfragen miteinander vermischt wurden. Und noch naiver war es, wenn er daran den Vorschlag knüpte, daß man, falls Österreich in den deutschen Bundesstaat treten und die preußische Reichsvorstandschaft anerkennen wolle, ihm einen gewissen Einfluß in Deutschland zugeben und ihm das Mitbesatzungsrecht in den suiddeutschen Festungen $u$. ä. einräumen könne ${ }^{1}$ ). Die Quelle des politischen Irrtums lag hier, wie einst bei Stein und Humboldt darin, daß man glaubte, eine politische Einheit der deutschen Nation schaffen zu können, ohne ihr die festen und scharfen Umrisse der autonomen Staatspersönlichkeit geben zu brauchen. So stark wirkte die Tatsache nach, daß die deutsche Nation ihre Einheit zuvörderst und vor allem als geistige Einheit empfunden und geschaffen hatte, - und zugleich, so müssen wir immer hinzusetzen, als eine von universalen Ideen geleitete Einheit, wo dann der Autblick zu diesen Ideen den Sinn für die Realitäten der Macht gefährdete.

Das war auch zum großen Teile das Verhängnis der deutschen Politik Friedrich Wilhelms IV. Es ist hier nicht der Ort, es aus allen den Ursachen, die man noch fassen kann, zu entwickeln und die Schwächen seines Charakters, die Widersprüche seines Wollens, die Schwieriglieiten des deutsch-preußischen Problems und die Hemmnisse der deutschen und europäischen Lage 
Preußens darzustellen. Es sollte hier lediglich der geistige Boden gezeigt werden, aus dem sein nationales Ideal stammte. In der Art, wie es seine verschiedenen Bestandteile miteinander verschmilzt, wie es alles Ideelle wie Politische mit einer Fülle von dekorativer Phantasie durchsetzt, trägt es wohl ganz den persönlichen Stempel seines Geistes; aber jene Bestandteile selbst lassen sich fast durchweg auf die Gedanken und Vorstellungen zurückführen, denen wir von der Frühromantik an begegnet sind. Obenan steht der Wunsch nach Erneuerung des heiligen römisch-deutschen Reiches mit seinem zugleich universalen und nationalen Charakter. Sein immer wieder ausgesprochener Gedanke, daß Österreich die Krone Karls des Großen wiederherstellen und tragen möchte, war doch viel mehr als ein Versuch, den deutschen Rivalen mit dem leeren Schein der Macht abzufinden und für Preußen das Wesen der Macht zusichern. Es wäre an sich schon ein traumhafter Einfall gewesen, durch eine solche Teilung von Schein und Wesen der Macht die deutsche Frage zu lösen. Aber das römischdeutsche Kaisertum war in seinen Augen auch keineswegs bloßer Schein; er nannte es wohl ein "Nebelgebilde«, erklärte es aber dessenungeachtet für eine "große Realität«1). Er würde, so erzählt Radowitz aus dem ersten Jahre seiner Regierung, für seine Wiederherstellung jedes Opfer bringen. Er erwog selbst die Möglichkeit, daß ein großer siegreicher Krieg ihm den Boden bereiten könne. „Dann ist sein Gedanke: freiwillige Unterordnung unter Ósterreichs Kaiserwürde, wo$\mathrm{zu}$ er das erste Beispiel gebe, und Herstellung eines Reichsverbandes unter Konliurrenz des Papstes." Weiter schloß sich daran »das Ideal eines großen Bündnisses aller europäischen Staaten mit dem deutlich vorgezeichneten

2) Leop. v. Gerlach I, 272 (Januar IS +9 ). 
Zwecke, gegen jeden ungerechten Anspruch, jeden Friedensbruch die gemeinsamen Kräfte zu kehren«1). Vir erinnern uns sofort, daß man Ähnliches schon bei Novalis, Friedrich Schlegel und Adam Müller lesen konnte, und gewahren leicht, daß Friedrich Wilhelm IV. damit den Dichtern und Schriftstellern vom Anfange des Jahrhunderts eigentlich näher steht als den praktisch doch schon gewitzigteren Politikern des Wochenblattes und des Gerlachschen Kreises. Es ist sehr wohl möglich, was man vermutet hat ${ }^{2}$ ), daß auch seine Idee, dem Könige von Preußen die höchste Ehre nach dem Kaiser zu geben und ihn zum Erzfeldherrn des Deutschen Reiches zu machen, auf einen Einfall mit zurückgeht, den Görres einst im Rheinischen Merkur ausgesprochen hatte? $)$.

Es kommt hier aber gar nicht einmal auf einzelne greifbare Entlehnungen und Abhängigkeiten an, wo der ganze Duft seiner deutschen Ideen auf jene tieferregte Zeit des nationalen Ungliicks und der nationalen Erhebung zuruickweist, und wo er zum Uberfluß auch selbst bezeugt, daß sie das Feuer deutscher Gesinnung in ihm entziundet habe. Selten berührt er so menschlich und auch in seinem Uberschwang so natürlich wahr, als wenn er erzählt, wie ihm die Liebe zu Deutschland von seiner

1) Aus Radowitz' Aufzeichnungen zwischen September I $\$_{4} 0$ und September IS4I. Hassel, Radowitz 1, 76.

2) Simson, Ed. Simson, S. I 72.

3) Wiederabgedruckt in Görres' polit. Schriften 2, 4r6: ,Österreich um seiner Macht und Gewalt und fruherer Verdienste willen gebiihrt die Kaiserwurde... Den nächsten Rang nach ihm sagt einstimmig das gesamte teutsche Volk Preußen zu; und weil das Haus von Ursprung an den Waffen sich ergeben und am Kriegsspiel sich erfreut, darum werde sein König zum Kronfeldherrn des Reiches erkoren.s Auch Achim v. Arnim hat, wie ich einer demnächst erscheinenden Arbeit Herma Beckers uber ihn entnehme, im Rhein. Merkur vom 21. Febr. ISI5 den König von Preußen zum Kronfeldherrn des Reiches machen wollen. 
eigenen schmerzensreichen Mutter eingepflanzt sei, daß er an Deutschland mit der Liebe hänge, mit der man am Namen seiner unvergleichlichen Mutter hänge und daß dies Wort ihn seit 50 Jahren mit den Schauern der Begeisterung durchbohre ${ }^{1}$ ). In seinen deutschen Idealen ist er zeitlebens der Jüngling geblieben, als der er sie ergriffen hatte, - ein ewiger Jüngling im guten wie im ungünstigen Sinne - und hat die zwischen Traum und Wachen schwebende Stimmung und die süßen Illusionen seiner Jugendzeit immer in sich festge. halten. Und weil in jener Zeit mit ihren überreichen geistigen Keimen und ihrer Uberfülle politisch-unpolitischer Ideale auch Ältere und Reifere als er sich ähnlichen Illusionen hingegeben hatten, so kann es nicht wundernehmen, daß in der deutschen Politik des Königs nicht nur Novalis, Friedrich Schlegel und Görres, sondern auch der Freiherr vom Stein wieder auflebt. Die Gemeinsamkeit gewisser großer Irrtümer, die sie teilten, beweist aufs stärkste die Kraft des gemeinsamen geistigen Fluidums, das zwei so grundverschiedene Menschen umfangen konnte. Zeigen wir sie jetzt noch einmal an diesen beiden eminenten Beispielen aus dem Anfang und dem Ende ihrer Entwicklung.

Gemeinsam ist beiden die zugleich universalistische und idealistische Vorstellung, daß die europäischen Staaten eine feste Gemeinschaft zu bilden hätten und auch bilden könnten gegen diejenigen Mächte, die den Frieden und das Recht gefährdeten. Der positive Kern dieser Idee war das tiefe Mißtrauen gegen Frankreich, das bei Stein aus nationaler und ethischer, bei Friedrich Wilhelm IV. aus nationaler und antirevolutionärer Empfindung zugleich floß. Gemeinsam war ferner natürlich vor allem

2) An Bunsen, 7. April I $S_{49}$, Ranke, Aus dem Briefwechsel Friedrich Wilhelms IV. mit Bunsen, S. 271 . (Sämtl. Werke 49/50, S. 51 9.) An Dahlmann 15. Mai i 848 . Springer, Dahlmann 2, 247. 
die Idee der Erneuerung des alten Reiches, und mochte diese Idee selbst bei dem einen und dem anderen mit noch so verschiedenem, hier ethischem, dort poetischdekorativem Inhalte gefüllt sein, so ist doch eine gewisse historische Grundgesinnung beiden unverkennbar gemein. Sie waren beide aufs tiefste durchdrungen von der tausendjährigen Kontinuität des deutschen Nationallebens, und daß es gälte, seine zerrissenen Zusammenhänge wiederherzustellen und es wieder, so gut es noch ging, anzuknüpfen an die größten, oder von ihnen als größte gehaltenen Zeiten seiner Vergangenheit, an die mittelalterliche Kaiserherrlichkeit. Auf sie beriefen sich beide in Stunden, die ihre deutschen Gefühle besonders mächtig erregten: Stein in der Denkschrift vom I 8. September I8I2, Friedrich Wilhelm IV., als er die Antwort an die Frankfurter Kaiserdeputation vorbereitete. Da verwies er ausdrücklich auf das »tausendjährige geheiligte Herkommen und Recht«, nach dem allein eine Kaiserwahl erfolgen dürfe. "Tausendjährig ist Ihnen zu apokalyptisch, - sagte er zu seiner prosaischer gestimmten Umgebung, - »obschon nach dem Buchstaben wahr.»1)

Gemeinsam ist ihnen weiter auch der Gedanke, daß das geschichtliche Recht darüber aussagen müsse, welcher der beiden deutschen Großmächte die Kaiserwürde gebühre. Beide entschieden sich also für Osterreich, und dies obgleich beide nach ihrer inneren Zugehörigkeit für Preußen hätten stimmen müssen. Bei Stein, dem Reichsunmittelbaren, kann man das noch eher verstehen als bei dem Hohenzollernfürsten, aber vielleicht wird diese Zurückdrängung seines eigenen preußischen Ehrgeizes auch dadurch mit verständlich, daß die zu erneuernde römische Kaiserkrone in seinen Augen nicht eine ausschließlich nationale, sondern eine zugleich auch uni-

1) Leop. v. Gerlach I, 309; v. Poschinger, Unter Friedrich Wilhelm IV. 1,89 . 
versale Würde war, die von ihm jedenfalls als Mittelpunkt des geträumten europäischen Staatenbündnisses gedacht war. Stein hatte außer dem historisch-romantischen Motiv für die Úbertragung der Kaiserwürde an Ósterreich, wie wir uns erinnern, auch noch den Grund, daß es gelte, Österreich, das mit seinen Interessen aus Deutschland hinausstrebe, gerade recht fest an Deutschland $z u$ binden. Genau denselben Gedankengang treffen wir auch bei Friedrich Wilhelm IV. „IVir müssen Ósterreich zwingen, deutsch zu sein «, erklärte er zu Beginn seiner Regierung seinem Vertrauten Josef v. Radowitz ${ }^{1}$ ), als er ihm seine Kaiserträume mitteilte. So setzte sich auch er über die Realität der undeutschen Politik Ósterreichs hinweg in dem Glauben, daß man die egoistischen Interessen des Einzelstaates überwinden könne durch große Ideen, die die Staaten miteinander verbinden, Ideen, die hier eine nationale und universale Seite zugleich hatten. Aus dieser Denkweise heraus sind auch die merkwïrdigen Widersprüche des bekannten Bundesreformprogramms, das Radowitz im Sinne des Königs am 20. November I 847 aufsetzte, zu verstehen. Denn hier wurde auf der einen Seite zwar die mißliche Erkenntnis ausgesprochen, daß Österreich zu fremd allen engeren deutschen Interessen, Freuden und Leiden sei, um mit Deutschland stehen und fallen zu können, - und doch kam der Verfasser und kam vor allem sein Auftraggeber nicht los von der Illusion, daß Österreich, Preußen und Deutsch. land insgesamt ein lebensvolles nationales Ganzes bilden könnten und müßten $\left.{ }^{2}\right)$. Wir wissen von Stein her, daß diese Illusion nicht nur geistige, sondern auch reale Wurzeln hatte in den politischen Erfahrungen und Notwendigkeiten des Befreiungskampfes von I $\delta$ I3, und so

1) Hassel I, 76 und 3 II.

2) Radowitz, Deutschland und Friedrich Wilhelm IV., Seite 44 , 50,56 . 
darf man insgesamt sagen, daß die deutsche Bundesreformpolitik Friedrich Wilhelms IV., so weit sie aus seinen eigensten Gedanken floß, ein spätes Nachspiel der großherzigen, aber Unmögliches begehrenden Nationalpolitik Steins und des Zeitalters der Befreiungskriege uberhaupt war. Wohl war sie auch zugleich schon ein Vorspiel des Zeitalters Bismarclis, da sie bereits die Keime eines hegemonischen preußisch-deutschen Ehrgeizes enthielt, aber diese wurden uberschattet und zuruickgedrängt durch jenes religiöse Ethos der Staatsidee, das nun einmal für ihn und seine christlich-germanischen Freunde von verpflichtender Kraft auch für alle praktische Politik war. Da mußten denn preußischer Ehrgeiz und deutsche Sehnsucht schweigen vor der universalen Idee des christlichen Herrschertums. So läßt Radowitz in seinen »Neuen Gesprächen", dem Epilog zu den Ereignissen von $1848 / 50$, den König sprechen: „Ich erkenne die Herstellung eines wahren Gemeinwesens als eine gerechte Forderung der Nation und als eine wahre Mission für Preußen. Aber höher als dies, höher als alles, steht mir das göttliche Gebot, daß ich meine Hand nicht ausstrecken darf nach fremdem Gute ... Ich halte die Einigung der Nation unaussprechlich hoch, ich habe es getan, seitdem ich denken und empfinden konnte, aber meine Pflichten als clristlicher König noch höher. Beide liegen so weit auseinander als Himmel und Erde. Das sind nicht Sentenzen, sondern Gebote. Hier stehe ich und kann nicht anders. ${ }^{1}$ )

Ein bisher unbekanntes Beispiel aus der deutschen Politili des Königs, aus den Monaten, die dem Zusammenbruch von Olmütz vorhergingen, möge noch einmal zeigen, auf welche Irrwege eine politische Denkweise geriet, die den Sinn für die Autonomie von Staat und 
Nation zersetzt hatte durch die Ideen einer universalen ethisch-politischen Gemeinschaft der Staaten. Es war im Fruhjahr I 850 , als man in Berlin einem Vaffengange mit Osterreich, das eigenmächtig den Bundestag erneuert hatte, ernstlich entgegensehen mußte. Radowitz tat es in der Konseilsitzung vom $2 \mathrm{I}$. April I 850, er forderte auch, daß Preußen Protest einlegte gegen das Vorgehen Ósterreichs, aber setzte sogleich hinzu: „Der Gefahr eines gewaltsamen Bruches könne aber auch in diesem Falle immer noch durch einen Kongreß3 der Teilnehmer und Garanten der Wiener Verträge unter Zuziehung der deutschen Regierungen vorgebeugt werden. Einem solchen Kongreß werde sich Preußen, unbeschadet seiner Ehre, weit eher fuigen können, als den diktatorischen Forderungen Ósterreichs und den Beschlüssen eines von Österreich der Majorität nach abhängigen Bundestages. « Und der König erklärte zustimmend in der Konseilsitzung vom 7. Mai: WVenn Preußen so handle und die europäischen Großmächte als Schiedsrichter anrufe, werde es $\gg$ den unwiderleglichen Beweis gegeben haben, daß es kein Opfer scheue, um den Frieden zu bewahren. Es werde als der Friedensbote dem Krieg drohenden Ósterreich gegenüberstehen ${ }^{1}{ }^{1}$.

Man hielt es also für einen mit der Ehre vereinbaren Ausweg, Deutschlands und Preußens Schicksal von den Mächten des Auslandes beraten und entscheiden zu lassen.

Wir haben hier nicht zu schelten, sondern zu begreifen. Wenn wir uns erinnern, daß selbst der stolze

1) Protokolle der Konseilssitzungen im Kgl. Hausarchiv. Eine Andeutung daruber bei Radowitz, Schriften 2, 249 . DaB der König immerhin der europäischen Garantie des Bundes seitens der ausländischen Mächte gewisse Grenzen stecken wollte, zeigt seine Haltung Ende IS5O, als England Miene machte, gegen den Eintritt Österreichs und Preußens in den Bund mit allen ihren Ländern $z u$ protestieren. v. Poschinger, Preußens auswärtige Politik 1850/5S, 1, 47; Leop. v. Gerlach I, 572 . 
Stein es nicht fiir verwerflich hielt, die nationale Verfassung Deutschlands unter die Garantie ausländischer Mächte zu stellen, wenn wir uns ubberhaupt den ganzen Zusammenhang dieser Gedanken noch einmal vor Augen führen, kurz, wenn wir, was wir als Betrachtende tun dürfen und müssen, hier nicht vom nationalen, sondern vom universal-geschichtlichen Standpunkt aus urteilen wollen, so sehen wir hier ein tragisches Schicksal walten, wo die Schuld die Wirkung tiefer und weitverzweigter innerer Ursachen ist. Aber es war Zeit, daß die gebundenen Glieder des Staates und der Nation endlich befreit wurden von ihren Fesseln. Fassen wir jetzt die Gedankenbewegung ins Auge, die dieses Befreiungswerk vorbereitete. 


\section{Elftes Kapitel.}

\section{Hegel.}

Die Befreiung des politischen Denkens von unpolitischuniversalen Ideen ist ebensowenig wie die ihr vorangegangene Fesselung nur das Werk Einzelner gewesen. Es handelt sich hier wie dort um allgemeine Wandlungen des Denkens und Empfindens in Deutschland, deren Fülle und Inhalt, weil es sich ja im letzten Grunde um individuelles Leben handelt, auch die weitgreifendste Geschichtserzählung nicht ausschöpfen könnte. Das Problem, das wir behandeln, ist ja auch nur ein Teil des allgemeinen, unendlich verwickelten Problems der Entstehung des modernen Geistes und insbesondere des Ubergangs vom konstruktiven zum empirischen, vom idealistischspekulativen zum realistischen Denken. Aus unzähligen Quellen rinnen die Ursachen dieser Wandlungen, aber zu ihrem stärksten Ausdrucke kommen sie erst, wenn die großen Persönlichkeiten mit ihrem Führertritt die Bruderquellen mit sich fortreißen und in ihren Schoß aufnehmen. So wagen wir als die drei großen Staatsbefreier nunmehr zu nennen: Hegel, Ranke und Bismarck.

Es scheint gewagt, den gewaltigen Systematiker und Vollender der idealistischen und spekulativen Bewegung in einem Atem zu nennen mit den beiden großen Empirikern. Aber Hegel hat es an sich, daß er das Entgegengesetzte in sich vereinigt, daß er eine Synthese aller seine Zeit bewegenden Ideen aufstellt, 
die unter seiner mächtigen Hand noch als einheitliches Gebilde volhielt, nach ihm freilich gleich wieder auseinandergehen mußte. Aber daß das Verschiedenartigste unter ihm einmal unter einem Dache beieinander war und sich häuslich vertragen mußte, hat für die Zukunft, man möchte sagen, eminent pädagogisch gewirkt. Konservative, Liberale und Radikale, historische und doktrinäre, nationale und kosmopolitische Denker konnten bei seinem System in die Schule gehen, konnten es hinterher für ihre Sonderzwecke einseitig ausbeuten und behielten dabei doch Stuicke eines ursprïnglichen Zusammenhanges mit dem, was sie dabei fallen ließen, in der Hand, die später wieder einmal als Brücke dienen konnten zu dem, was sie zunächst aufgaben und vielleicht sogar bekämpften. Hegels Anregungen konnten fruchtbar bleiben, auf welchen Boden sie auch verpflanzt wurden. Und so hat insbesondere seine Lehre vom Staate nach ganz extrem auseinanderbiegenden Richtungen hinwirken und zugleich dabei überallhin etwas von den bleibenden Wahrheiten verpflanzen können, die in ihr ausgesprochen waren. Unter den großen Denkern des I9. Jahrhunderts, die überhaupt Staatsgesinnung, Uberzeugung von der Notwendigkeit, der Größe und sittlichen WVürde des Staates verbreitet haben, steht er in der vordersten Reihe.

IVir fassen hier nur diejenigen Züge seiner Staatslehre ins Auge, die auf unsere besonderen Fragen Antwort geben. Da fühlen wir uns denn gleich in die wohlbekannte Luft der Romantik hineinversetzt, wenn wir hören, daß der Staat durchaus Individualität, individuelle Totalität sei $\left.^{1}\right)$. Es läßt sich keine Seite an ihm einzeln herausnehmen und isoliert betrachten, sondern es hängt die Verfassung

1) Über Hegels Verhältnis zur Romantik vgl, den oben S. $21_{4}$ zitierten Aufsatz von Brie S. S f. und die das Trennende wieder richtig hervorhebenden Ausfuhrungen Landsbergs, Gesch. der deutschen Rechtswissenschaft Abt. 3, 2. Halbband, S. 347 f. 
eines Volkes aufs innigste zusammen mit seiner Religion, seiner Kunst und Philosophie, und macht mit ihnen und mit allem Äußeren, als Klima, Nachbarn, Weltstellung usw. eine Substanz, einen Geist aus. Diese geistige Substanz ist im letzten Grunde, so lehrt er mit der historischen Rechtsschule, der Volksgeist, - aus ihm geht alles im Staate hervor. ${ }^{1}$ ) Aber dieser Volksgeist Hegels ist nur verwandt, nicht identisch mit dem der Romantiker und Savignys. Er wird aus dem geheimnisvollen Dunkel des Unbewußten in das helle Licht des Hegelschen Panlogismus gezogen. Er spielt nicht die Rolle der ehrfurchtig geliebten Mutter des Lebens, sondern der Gattin, die dem Könige Erben zu gebären hat. So wird er auch insofern rationalisiert, als er lediglich behandelt wird als Mittel zum Zwecke, als »ein Durchgangsmotiv zum Staate.$\left.^{2}\right)$ Staat und Volk gehören für ihn so eng zusammen, daß ihm im Dasein eines Volkes schon der substantielle Zweck zu liegen scheint, ein Staat zu sein, und ein Volk ohne Staatsbildung eigentlich lieine Geschichte hat. $\left.{ }^{3}\right)$ Er meint damit gewiß nicht, daß jede Nation, wenn sie eine Geschichte haben solle, sich einen nationalen Einheitsstaat schaffen müsse, sondern er meint offenbar im Sinne dessen, was wir den konservativen Nationalstaatsgedanken nannten, daß aus dem Volksgeiste uberhaupt irgendein ihm entsprechendes Staatsleben hervorgehen müsse. In der Würdigung des Staates aber läßt er, - wir folgen zunächst nur der einen, historischen Richtung seines Denkens - allen Schematismus, alles

1) Philosophie der Geschichte (Werke 9, $4+$ u. 50). Enzyklopädie der philosophischen Wissenschaften $\$ 540$ (3. Ausg. S. 535).

2) So Landsberg a. a. O., während Loenings Meinung (Internat. Wochenschr. I9ro, S. 84), daß der Hegelsche Volksgeist schlechthin nur der Staat sei, etwas zu weit geht und eine einzelne Wendung Hegels einseitig herausgreift.

3) Enzyklopädie \$ 549. Philosophie des Rechts $\$ 349-351$. (Werke 8, 43+ f.)

Meinecke, Weltbürgertum und Nationalstaat. 2. Auf. 
Machen und künstlich Bessern wollen der Aufklärung beiseite und erkennt die Besonderheit und Eigentümlichkeit in jeder staatlichen Bildung energisch an. "Der Staat ist kein Kunstwerk, er steht in der Welt, somit in der Sphäre der Willkür, des Zufalls und des Irrtums, übles Benehmen kann ihn nach vielen Seiten defigurieren. Aber der häßlichste Mensch, der Verbrecher, ein Kranker und Kriuppel ist immer noch ein lebender Mensch: das Affirmative, das Leben, besteht trotz des Mangels, und um dieses Affirmative ist es hier zu tun. «1) Das, was dem Staate dieses eigentiimliche, sei es schlechte, sei es gute, jedenfalls aber pulsierende Leben gibt, ist, so dürfen wir interpretieren, das nationale Prinzip, - nicht das nationale Prinzip im Sinne der Französischen Revolution, denn das Volk des demokratischen Ideals ist ihm nur ein Aggregat der Privaten, nur vulgus, nicht populus, und als oulgus nur eine unförmliche, blinde Gewalt ${ }^{2}$ ) — sondern das nationale Prinzip im geschichtlichen Sinne, indem das geistige Erbe der gesamten Vergangenheit eines Volkes mit seinen gegenwärtigen und zukünftigen Lebensbedürfnissen in ihm zusammenwirkt. Und damit er sich behaupten und weiter entwickeln könne in der Welt, gesteht ihm nun Hegel auch das Recht auf unbedingte Autonomie und Durchsetzung seiner eigensten Interessen nach außen hin zu. »Als einzelnes Individuum ist er ausschließend gegen andere eben solche Individuen. «") Im Verhältnis der Staaten zueinander gibt es keinen Prätor, der schlichtet und entscheidet, was Recht sei, sondern hier gibt es nur Selbständigkeiten gegen Selbständigkeiten, und so erhält denn endlich auch der Krieg von seiten der großen deutschen Philosophie seine unbedingte und definitive Anerkennung und seinen Platz in

1) Philosophie des Rechts $\$ 258$ (Werke 8, 320).

2) Enzyklopädie $\$ 544$.

3) Daselbst $\$ 545$; Philosophie des Rechts $\$ 330$ (Werke 8, 424). 
einer IVeltanschauung, die, wie nur irgendeine, den vernünftigen Sinn der Welt zu erkennen strebte. Demnach war ihm die Kantische Vorstellung eines ewigen Friedens durch einen Staatenbund, der jeden Streit schlichtete, nichts weiter als ein Traum, denn wie sollte eine dauernde Úbereinstimmung der Staaten möglich sein, wo in jedem Staate ein besonderer souveräner Wille lebt ${ }^{1}$ ) Und von Staatsverbindungen von der Art der heiligen Allianz urteilte er: „Diese sind immer nur relativ und beschränkt, wie der ewige Frieden. ${ }^{2}$ ) Wohl wußte und betonte er zugleich, daß es insbesondere unter den europäischen Nationen eine familienhafte Gemeinschaft gäbe, die auch auf ihr völkerrechtliches Verhältnis untereinander einwirke und ihren reinen, riicksichtslosen Interessenkampf mildere. Aber diese Milderung der Machtkämpfe bedeutet, so müssen wir ihn verstehen, keine Fesselung der autonomen Machtpolitik der einzelnen Staatspersönlichkeiten, sie ist vielmehr eine ungezwungene Folge der europäischen Kulturgemeinschaft, des »allgemeinen Prinzips ihrer Gesetzgebung, ihrer Sitten, ihrer Bildung ". ${ }^{3}$ ) Sie wird den Staaten nicht von außen, von einer uber ihnen stehenden Instanz anbefohlen, sondern sie erwächst aus ihrem eigenen inneren Leben und aus ihrer naturlichen geistig-sittlichen Verwandtschaft. So ist sie also auch im Grunde autonomen, nicht heteronomen Ursprungs.

So spricht sich in diesen Gedanken Hegels über das Verhältnis der Staaten zueinander ein echter empirischer Sinn, ein scharfes historisch-politisches Verständnis aus. Es ist wohl einer der bedeutendsten Züge seiner Philosophie, daß sie trotz ihres rationalen und konstruktiven Grundcharakters doch innerhalb ihrer Konstruktion allen empirischen, durchaus nicht immer

1) Philosophie des Rechts $\$ 333$ (Werke 8, 427).

2) Daselbst $\$ 259(\$, 321)$.

3) Daselbst $\$ 339(8,430)$. 
vernünftigen Kräften einen so freien Spielraum und eine so runde Anerkennung gewährte. »In das Verhältnis der Staaten gegeneinander, weil sie darin als besondere sind, fällt das höchst bewegte Spiel der inneren Besonderheit der Leidenschaften, Interessen, Zwecke, der Talente und Tugenden, der Gewalt, des Unrechts und der Laster, wie der äußeren Zufälligkeit, in den größten Dimensionen der Erscheinung. ${ }^{1}$ ) Ihn beirrte das nicht in seinem Glauben, daß der Verwirklichung der Vernunft schließlich doch alle Dinge zum Besten dienen müssen. Man kennt seine Geschichtsphilosophie, welche es unternimmt, in der Weltgeschichte selbst die Stufen der Entwicklung des Weltgeistes mit strengster Gesetzlichkeit nachzuweisen, den gesamten Stoff der Wirklichkeit in Geist umzusetzen, aus ihrer Bewegung die Bewegung des Gedankens selbst zu machen. So überbaute er die geschichtliche Welt mit mächtigen konstrulitiven Gedanken, und so regt sich allerdings sehr bald der Zweifel, ob er ihr nicht dadurch auf die Dauer Luft und Licht nahm, ob er nicht am letzten Ende dadurch doch der Eigenart des geschichtlichen Lebens, die er eben noch so rund anzuerkennen schien, Gewalt antut. Das läuft für uns auf die Frage hinaus, ob nicht auch in seiner Anschauung von Nation und Staat die alte universalistische Tendenz wieder durchschlägt und die reine empirische Erkenntnis wieder verdunkelt. Und das tut sie allerdings.

Schon ein Hauptgedanke jener Zeit, in der die weltbürgerlichen und die nationalen Ideen sich miteinander mischten, ist in ihm noch lebendig und nimmt in seiner Geschichtsphilosophie eine neue und eigenartige Gestalt an: das ist der Gedanke der Menschheitsnation. Nicht etwa, daß er noch wie Fichte, Schiller und in gewissem

1) Philosophie des Rechts S 340 ( $\left.8,43^{\circ}\right)$. 
Grade Humboldt und die Frühromantiker meinte, daß die deutsche Nation schlechthin die Menschheits- und Universalnation sei, sondern seine Ansicht war, daß es in jeder Epoche der Weltgeschichte ein »weltgeschichtliches Volk« gäbe als Träger der jeweiligen Entwicklungsstufe des allgemeinen Geistes. Und dieses bekomme dadurch ein absolutes Recht, gegen das die Geister der anderen Völker rechtlos seien, - jenes, das weltgeschichtliche Volk sei dann vielmehr auch das weltbeherrschende ${ }^{1}$ ). Er meinte damit nicht schlechthin das empirische Recht der Völker und die konkrete Weltherrschaft, sondern er sah die verschiedenen Nationen: gleichsam vor dem Forum des absoluten Weltgeistes versammelt und teilte von ihm aus ideale Rechts- und Herrschaftsanspriiche an sie aus. Dem rein historischen Empfinden aber nuls auch eine solche Klassifizierung und Bewertung der Nationen starr und unleidlich dünken. Denn so gewiß auch nicht alle Nationen für den $\mathrm{Hi}$ storiker gleichwertig sind, so erkennt er doch in jeder höher entwickelten Nation einen eigenartigen und unersetzlichen Wert der Geschichte, weil jede inhaltsreiche geschichtliche Individualität etwas Unersetzliches ist. Hegels Anschauung fïhrte konsequent dahin, alle Individualitäten der Geschichte ihres Eigenrechtes zu berauben, sie zu bloßen bewußtlosen IVerkzeugen und Funktionären des IVeltgeistes zu machen.

Eben das war es, was Ranke von Hegel abstieß. Alle Menschen, urteilte er einmal, wären bei dieser Ansicht bloße Schatten oder Schemen, die sich mit der Idee erfüllten, und die aufeinander folgenden Epochen und Generationen der Menschheit würden dadurch gleichsam mediatisiert und würden an und für sich eine. Bedeutung nicht haben. »Ich aber behaupte: jede

1) Philosophie des Rechts $\$ 347(8,433)$, Enzyklopädie $\$ 550$. 
Epoche ist unmittelbar zu Gott, und ihr Wert beruht gar nicht auf dem, was aus ihr hervorgeht, sondern in ihrer Existenz selbst, in ihrem eigenen Selbst. " ${ }^{1}$ )

Das galt auch von dem »eigenen Selbst « des Staates und der Nation. Hegel hatte es, mit der merkwürdigen Duplizität, die seine ganze Philosophie durchzieht, anerkannt und geleugnet zugleich, hatte ihm in der Sphäre der bewußten Wirklichkeit alle nur denkbare Freiheit gegeben, un es hinterher in der höheren Sphäre des Absoluten nur wieder aufs strengste zu fesseln. Der Staat und die geschichtliche Welt iberhaupt führt bei ihm ein Doppelleben von scheinbarer Freiheit in der Wirklichkeit und von wirklicher Dienstbarkeit in Geisterreiche. Es war ein großer Fortschritt gegenüber Fichte, daß er nicht wie dieser die geschichtliche Welt selbst zerriß in zwei Hälften, daß er vielmehr das Vernunftdasein, das dieser auf Erden schon angehen lassen wollte, in die transzendente Sphäre verlegte. Dadurch wurde, man möchte sagen, der Druck, den die Wirklichkeit von den Ideen auszuhalten hatte, vermindert dadurch konnte sie sich größerer Freiheit erfreuen. Aber diese Freiheit war doch bei Hegel nur ein prekäres Ding, nur eine Konzession gleichsam, die der Philosoph herablassend der Erfahrungswelt machte. Er selbst weilte mit seinem Herzen vielmehr in der Welt des Transzendenten und suchte auch seine Zeitgenossen zu zwingen, von ihr aus das wirkliche geschichtliche Leben zu beurteilen, mit seinen Augen es zu sehen. Es lag eine schneidende Ironie darin, wenn er es ausmalte, wie Staaten, Völker und Individuen tief in ihr Interesse versenkt dahinlebten und in Wahrheit doch nur Handlanger jenes »inneren Geschäfts « seien, »worin diese Gestalten vergehen, der Geist an und fiir sich aber den

1) Über die Epochen der neueren Geschichte S. 5 u. 7. 
Ubergang in seine nächste höhere Stufe vorbereitet und erarbeitet ${ }^{1}$ ) Wer sich ganz dem Geiste seiner Lehre hingab, stand immer in Gefahr, das Diesseits in ein bloßes Schattenspiel umzudeuten, stand in Gefahr so dürfen wir in Fortführung unseres Grundgedankens nunmehr sagen - das universale Element vorzeitig und gewaltsam in das Leben auch von Staat und Nation hineinzudenken. Denn Universalismus in der höchsten Steigerung war es, was Hegel trieb und den Weltgeist treiben ließ durch seine bewußtlosen Werkzeuge. Und so steht diese Seite seiner Lehre noch in engstem $\mathrm{Zu}$ sammenhange mit den von uns verfolgten Tendenzen.

Um dem geschichtlichen Leben seine volle Autonomie zurückzugeben, war es nicht nötig, die universalen Prinzipien, durch die es bisher eingezwängt war, ganz und gar hinauszutreiben. Es kam nur darauf an, andere und richtigere Grenzen zwischen diesen und jenem aufzurichten, den Bogen der universalen Idee so hoch und weit zu spannen, daß die Geschichte ihr volles, unverkümmertes Leben darunter führen konnte. Hegels Versuch es zu tun, war großartig und tief durchdacht, aber immer noch nicht ganz gelungen. Es war, wie Rankes Beispiel jetzt zeigen wird, möglich, noch weiter zu gehen in der Anerkennung des Eigenrechts der geschichtlichen Individualitäten, sie noch herzhafter zu umfassen und doch dabei das geistige Auge auch immer nach oben zu den ewigen Gestirnen gerichtet zu erhalten.

1) Philosophie des Rechts $\$ 3+4(S, 432)$. 


\section{Zwölftes Kapitel.}

\section{Ranke und Bismarck.}

Die »Nation " gehört zu den Grundbegriffen, mit denen die Rankische Geschichtsauffassung im großen arbeitet und die in ihr nicht zum mindesten deswegen eine so merkwürdige Fruchtbarkeit entfalten, weil er sie niemals überanstrengt, niemals zum simplen Klassifizieren des geschichtlichen Stoffes mißbraucht, weil er weiß, daß sie keine ganz scharfe Grenze der Anwendung haben, und indem er sie anwendet, auch immer ihren in das Unendliche sich verlierenden Hintergrund mitandeutet. Nur eine so eigenartige Begabung wie die seine, nur eine so zugleich empirische, philosophische und künstlerische Anschauungsweise konnte freilich, ohne verschwommen und unklar zu werden, dergestalt auf scharfe Grenzlinien und feste Kategorien verzichten. Ein mit durchschnittlichen wissenschaftlichen Mitteln unternommener Versuch kann ihrer nicht entraten und muß mit solchen Begriffen wie »Kulturnation«, »Staatsnation", » liberaler Nationalstaatsgedanke ", »konservativer Nationalstaatsgedanke« usw. operieren, die Ranke wahrscheinlich niemals in den Mund genommen haben würde, während seine Geschichtschreibung oft genug auf sie hinführt und reich an Beobachtungen ist, die unschwer in solche Kategorien sich einfügen lassen.

Es geht über den Rahmen dieser Untersuchung hinaus, seine ganze Geschichtschreibung auf die Anwendung des nationalen Gedankens hin zu prüfen. Wir 
greifen vielmehr einen Moment aus seiner Entwicklung heraus, wo er als historischer und zugleich politischer Denker in die Entwicklung des nationalen und nationalstaathichen Ideals für Deutschland bedeutend und, wie wir meinen, epochemachend eingegriffen hat. Dies geschah durch seine Aufsätze in der Historisch-politischen Zeitschrift, vor allem die über Frankreich und Deutschland « (I832), »Über die Trennung und die Einheit von Deutschland « (I832), die »Großen Mächte» (I 833) und das »Politische Gespräch « $\left.(\mathrm{I} 836) .{ }^{1}\right)$

Was er hier über das Verhältnis der Nationalität zum Staate sagt und über sein eigenes inneres Verhältnis zu diesen beiden Mächten andeutet, atmet echte Originalität, ursprüngliche Empfindung und schon allein in den gebrauchten Sprachmitteln einen unnachahmlichen Hauch. Und doch hört man, wenn man genauer hinhorcht, eigentlich fast alle die Stimmen mitklingen, die wir bisher vernommen haben. Bald glaubt man Humboldt leise zu hören, bald Fichte ${ }^{2}$ ) und selbst Schiller, bald

1) Mit Ausnahme der , Großen Mächtec, die in Bd. 24 der Werke Rankes sich finden, alle in 13d. 49/50 derselben wieder abgedruckt. Sie sind seit Erscheinen der I. Auflage von wesentlich anderen Gesichtspunkten aus untersucht worden in dem gedankenreichen Buche Otto Diethers, Leop. v. Ranke als Politiker, I9II. Während ich ein ideengeschichtliches Problem behandle, stellt er die psychologische Frage nach dem \$Verhältnis des reinen Historikers zur praktischen Politiks und kommt dann freilich auch auf diesem Wege zu geistesgeschichtlichen Ergebnissen, nach denen Ranke als der autonome, lcidenschaftslose, im Grunde unpolitische (!) Denker mehr der Welt des 18. als des 19. Jahrhunderts angehören wïrde. Ich werde mich mit dieser, eines richtigen Kernes zwar nicht entbehrenden, aber stark ibertreibenden Auffassung in der Histor. Zeitschrift auseinandersetzen und wiederhole hier im wesentlichen den Text der I. Auflage, da er diejenigen Tatsachen, auf die sich Diether stütz, schon soweit berücksichtigt, als meine Problemstellung es erfordert.

2) Ranke bezeugt bekanntlich selbst später den tiefen Eindruck, den Fichtes populäre Schriften auf ihn in seiner Jugend gemacht haben. 
die Romantiker von Novalis bis Adam Müller und Savigny, und selbst mit den Ideen des Berliner Politischen Wochenblatts, des extrem feudalen Gegenstücks zu der historisch-politischen Ruhe der Rankischen Zeitschrift, ist mancherlei Berührung da. ${ }^{1)}$ Mit gewöhnlicher literarischer Kritik und Quellenvergleichung sind diese Zusammenhänge kaum oder doch nur problematisch zu fassen. Das, worin Ranke an jene Vorgänger erinnert, braucht ihnen nirgends unmittelbar entnommen zu sein, es ist nur eben die feinste und in eine hochpersönliche Anschauung umgesetzte Quintessenz der gesamten Gedankenbewegung der letzten vier Jahrzehnte - und dieser Gedankenbewegung noch mehr wie der großen nationalen Erlebnisse der Erhebungszeit. Denn diese haben seinen Geist nicht unmittelbar und mächtig berihrt. Aber durch das Medium der Betrachtung konnten auch sie ihren inneren Gehalt ihm rein überliefern. ${ }^{2}$ )

Die ersten Elemente seiner eigenen nationalen Empfindung stammen auch nicht aus ihnen, sondern aus der ihnen vorhergehenden Zeit, wo die deutsche Nation durch ihre neue Literatur mit einem Male wieder als große Kulturnation sich fühlte. Die deutsche Literatur, sagt Ranke ${ }^{3}$ ) mit dem Tone einer ganz persönlichen Er-

Sämtliche Werke 53/54, S. 59. Literatur über den Einfluß Fichtes auf ihn bei Varrentrapp, Christl. Welt 1905 n. 23 und Histor. Zeitschrift 99, 50 Anm. Vgl, auch Fröhlich, Fichtes Reden an die deutsche Nation, S. 78 Anm. I.

1) Gar nicht unwahrscheinlich ist es, daß die dem Nationalitätsgedanken entgegenkommenden Mitglieder der Wochenblattspartei (siehe oben S. $240 \mathrm{f}$. ihrerseits von Rankes Aufsätzen schon mit gelernt haben.

2) y Sein geistiges Schicksal führte ihm das denkbar größte Erlehnis - man möchte sagen: mit ausgesuchter Rerechnung - zu mög. lichst objektiver Retrachtung ror die Seele.^ Dove, Ausgewählte Schriften S. 153.

s Trennung und Einheit S. I60. 
fahrung, »ist eins der wesentlichsten Momente unserer Einheit geworden; wir wurden uns derselben in ihr zuerst wieder eigentlich bewußt. Sie bildet nunmehr die Atmosphäre, in der unsere Kindheit erwächst, unsere Jugend aufatmet, die alle Adern unseres Daseins mit eigentiumlichen Lebenshauche beseeit. Von allen Deutschen keiner, man gestehe es, wäre, was er ist, ohne sie." Rankes deutsches Nationalgefuhl war zuerst und vor allen Dingen geistiger und nicht politischer Natur, war das Gefühl einer Inspiration, eines gänzlichen Durchdrungen- und Getragenseins, eines - so würde wenigstens Ludwig von Gerlach mißtrauisch gesagt haben pantheistischen Verhältnisses zwischen seinem Geiste und dem Geiste der Nation. Unser Vaterland ist mit uns, in uns, " heißt es im politischen Gespräch, »Deutschland lebt in uns, wir stellen es dar, mögen wir wollen oder nicht, in jedem Lande, dahin wir uns verfügen, unter jeder Zone. Wir beruhen clarauf von Anfang an und können uns nicht emanzipieren. Dieses geheime Etwas, das den Geringsten erfüllt, wie den Vornehmsten, - diese geistige Luft, die wir aus- und einatmen, geht aller Verfassung vorher, belebt und erfüllt alle ihre Formen." Hier ist das subjektive Element, das Element des eigenen bewußten IVillens, das doch sonst bei der Entstehung des modernen Nationalbewußtseins so erheblich mitspielt, von der einen Seite gesehen, gänzlich ausgelöscht. Hier heißt es nicht: Eine Nation ist, was eine Nation sein will, - sondern umgekehrt: Eine Nation ist, mögen die einzelnen, aus denen sie besteht, ihr zugehören wollen oder nicht. Sie beruht nicht auf freier Selbstbestimmung, sondern auf Determination.

So tritt jenes ältere Stadium im IVerden der $\mathrm{Na}$. tion, wo unbewußte, instinlitive, rational nicht zu fassende Lebensvorgänge in ihr dominieren und ihre Einheit und 
Besonderheit leise schaffen und erhalten, uns hier noch einmal in dem Spiegel eines genialen Geistes entgegen, und wenn wir das, was Rankes Sprache und Gedanke zu dieser Auffassung verfeinernd hinzutun konnten, abziehen, so haben wir hier genau jene Anschauung vom Wesen der Nationalität wieder, die dem konservativen Nationalstaatsgedanken eines Teiles der Wochenblattspartei zugrunde lag. Nationalität ist der dunkle, undurchdringliche Mutterschoß, ein geheimes Etwas, eine aus der Verborgenheit wirkende Kraft, an sich selbst unkörperlich, aber Körperliches erzeugend und durchdringend. Des Persönlichen und Individuellen die Fülle entspringt aus ihr, aber sie selbst bleibt, wenigstens für unsere Augen, in der Sphäre des Unpersönlichen. Jeder Versuch, sie abzugrenzen und zu bestimmen, war jhm Verengerung und Banalmachung eines Unendlichen. 》Wer darf ihn nennen und wer bekennen:" sagte er beinahe wörtlich zu denen, die die $\rtimes$ Fahne einer eingebildeten Deutschheit aufzustecken « versuchten. "Wer will jemals in den Begriff oder in Worte fassen, was deutsch sei? Wer will ihn bei Namen nennen, den Genius unserer Jahrhunderte, der vergangenen und der künftigen: Es wiirde nur ein anderes Phantom werden, das uns nach anderen falschen Wegen verfühte. $\left.{ }^{1}\right)$ Wer so die triviale Deutschtimelei abwies, mußte auch den Versuch der Wochenblattspolitiker abweisen, den ständisch-patrimonialen Staat als die besondere Blüte des deutschen Geistes, als den christlich-germanischen Staat schlechthin darzustellen. Die ganze Tendenz seiner Zeitschrift kehrte sich auch mit gegen sie. $\left.{ }^{2}\right)$ Nicht deswegen hatte er wie jene die Idee der Nationalität rein geistig und unkörperlich aufgefaßt, um hinterher damit die derbe Körperlichkeit agrar-feudaler Institutionen zu idealisieren. Nicht des-

1 Trennung und Einheit S. I72.

2) Vgl. Varrentrapp a. a. O. S. 35 ff. 
wegen hatte er dem Geiste der Nation einen so unendlichen, wir dürfen jetzt sagen, so universalen Charakter zugeschrieben, um ein so partikulares Ergebnis daraus zu gewinnen. Denn ein zarter, aber deutlicher Hauch jenes geistigen Universalismus, von dem Humboldt, Fichte, Schiller und die Frühromantiker so voll waren, schwebt noch über diesem Rankischen Nationalbegriff. Was ist hier Nation anders als eine Modifikation des geheimnisvoll-offenbaren menschlichen Daseins uberhaupt. »Die Idee der Menschheit, Gott gab ilır Ausdruck in den verschiedenen Völkern. « $\left.{ }^{1}\right)$ Und umschreibt Ranke das IVesen der Nation nicht offenbar absichtlich mit Worten, die auch für Gott als den Weltgeist gelten könnten? Name ist auch hier Schall und Rauch. Wer von dieser Idee der Nationalität erfuillt war, dem war sie nicht ein Gewicht, das auf den Boden eines begrenzten nationalen Daseins niederzog, sondern ein Fittich, der ihn in eine Höhe trug, wo er mit dankbarer Liebe auf den eigenen nationalen Mutterboden unter ihm und mit Ehrfurcht auf die unfaßbaren, unendlichen Mächte des Universums über ihm blicken konnte. Es ist eine eigene schwebende Stimmung in diesem Rankischen Nationalbegriff, so daß in ihm nicht nur, wie wir vorhin sagten, die Epoche des altertümlichen, vegetativen Werdens der Nationen, sondern auch, wie wir nun eben sahen, die universalistische Epoche der deutschen Nationalidee nachklingen kann. Ranke hat sich hier in wunderbarer Weise dem Gange der Entwicklung selbst angeschmiegt, indem ja, wie wir früher bemerkten ${ }^{2}$, die Entstehung eben jener universalistischen Epoche und ihre nationale Literaturbewegung noch einmal im großen Stile das Unbewußt-Vegetative in Werden der Nationen zeigte. Er hatte auch einen scharfen Blick dafür, wie verschieden diese Art des nationalen Werdens

1) Frankreich und Deutschland S 72 .

2) S. oben S. 27 . 
in Deutschland von der in Frankreich war, wo der bewußte IVille und die rationale Absicht dominierten. Unsere Nationalcharaktere, sagt er, sind von Grund aus verschieden, haben ganz andere Bedirfnisse, verfolgen ganz andere Gesichtspunkte. 》Jene völlige Umwälzung des Besitzes und Rechtes, jene Schöpfung einer neuen Nation und eines neuen Daseins, jene vollkommene Lossagung von aller Vergangenheit, die in Frankreich stattgefunden, bei uns ist sie nicht wiederholt worden. ${ }^{1}$ ) Hier ist der Gegensat\% zwischen deutscher und französischer Nationalentwicklung sogar überscharf charakterisiert, da die sneue Nation: der Franzosen von i 789 doch sehr viel stärker mit der alten Nation des ancien rigime zusammenhing, als man nach diesen Worten annehmen diifte, und so hat sich hier Ranke. ein seltener Fall in seinem geschichtlichen Denken, einmal von seinem eigenen deutschen Empfinden zu sehr hinreißen lassen. Sein deutsches Empfinden war hier aber zugleich auch persönliches Empfinden. Ihm selbst war die Art jener Entwicklung, wo der deutsche Geist aus ruhigen gesellschaftlichen und politischen Zuständen heraus gleichzeitig zum Bewußtsein seiner Nationalität und zu den Höhen menschlicher Ideale hinaufgestiegen war, unendlich sympathisch und kongenial.

Nan weiß, wie eng auch seine innere Fühlung mit dem Inhalte der klassisch-romantischen Literaturepoche Deutschlands war und daß insbesondere der große universalistische Zug seiner Geschichtsbehandlung aus ihr seinen Ursprung herleitet. Man pflegt dann mit Recht zu betonen, daß er zu dem universalhistorischen Erbe des is. Jahrhunderts den Sinn für das Nationale in der Geschichte hinzugefügt habe, aber indem wir uns erinnern, daß dieser Sinn für das Nationale schon in- 
mitten der universalistischen Epoche, bei Herder und Humboldt wie bei den Frühromantikern sich regte und eine scharfe Trennung beider Tendenzen unmöglich war, so werden wir nunmehr von Ranke ähnlich sagen dürfen, daß seine eigene deutsche Nationalempfindung und sein Sinn für das Universale an ihren Grenzen zusammenstoßen. Freilich, davon ist bei ihm keine Rede mehr, daß er, wie Humboldt, Fichte, Schiller und Novalis die deutsche Nation schlechthin zur geistigen Universalund Menschheitsnation steigert. Dazu war sein Sinn und der Sinn seiner Zeit schon zu real und konkret geworden, dazu hatte man zuviel erlebt, um an diese ideale, aber auf die Dauer gar zu luftige Aufgabe der deutschen Nation noch glauben zu können. Novalis' Definition, daß Deutschheit Kosmopolitismus, gemischt mit der kräftigsten Individualität sei, hätte Ranke nicht mehr befriedigen können, aber Novalis' weiteres IVort, daß alles Nationale, Lokale, Individuelle sich universalisieren lasse und daß man dem Gemeinen einen hohen Sinn, dem Bekannten die Würde des Unbekannten, dem Endlichen einen unendlichen Schein geben müsse, hat Ranlie nicht nur in seiner wissenschaftlichen Betrachtung, sondern auch in seiner eigenen nationalen Empfindung angewendet. Novalis nannte dies Verfahren ein »Romantisieren " und ließ dabei dann freilich das Endliche durch das Unendliche, das Nationale durch das Universale überstrahlen und verdunkeln. Es kennzeichnet den großen Umschwung der geistigen Stimmung, daß Ranke nicht "romantisierte", sondern die Realitäten zu ihrem Rechte kommen ließ - aber nun nicht nur, wie die Wochenblattspartei, diejenigen Realitäten, die einem besonderen politischen Interesse dienten, sondern alles, was überhaupt von dem Hauche deutscher Nationalität beseelt war. So pantheistisch seine Vorstellung vom W'esen des deutschen Nationalgeistes auch anmutet, so ist es doch 
kein mystisch-schwärmender, sondern ein realistischweltfreudiger Pantheismus, der vom Gefühle sofort zu den Tatsachen hiniiberdrängt. Denn, so meinte er, vom deutschen Genius sprechend, sehr bezeichnend, "man wird leicht eingestehen, daß es mit dem Gefühle noch nicht getan sei. Es verhält sich damit, wie mit anderen Fermenten. Sie sind da, um den Stoff zu begeistigen, seine Grundbestandteile zu entwickeln und in Gärung, in Lebensregung zu setzen; allein und abgesondert haben sie keine Bedeutung; sie würden eher eine betäubende und schädliche, als eine fördernde Wirkung äußern«. ${ }^{1}$ ) So, indem er das Reale und das Geistige immer zusammen, nie das Eine vom Andern getrennt sah, gelang es ihm auch, das Verhältnis von Nationalität und Staat und das, was wir den konservativen Nationalstaatsgedanken nannten, tiefer und reiner darzustellen, als es den befangenen Politikern des Wochenblattes möglich gewesen war. Diese seine Rechtfertigung und Verklärung des deutschen Einzelstaates haben wir nummehr ins Auge zu fassen.

Wie jene, verzichtete er damals durchaus auf eine strengere politische Einheit Deutschlands. Auch darin wird man eine Nachwirkung älterer Gesinnungen erkennen können, die den Wert einer staatlichen Einheit der deutschen Nation nicht kannten, weil sie ihn nie erfahren hatten, weil sie unter dem Eindrucke des verfallenen alten Reiches emporgekommen waren. »Glücklicherweise war das Reich nicht die Nation«, sagt Ranke von dieser Zeit ${ }^{2}$ ) und erinnert uns dadurch an das damalige Wort Schillers: „Deutsches Reich und deutsche Nation sind zweierlei Dinge. Wie merkwürdig und lehrreich biegen dann! aber die beiden, durch eine Generation getrennten Denker auseinander in den Folgerungen, die

3) Trennung und Einheit S. I 34 f.

2) Frankreich und Deutschland S. 65. 
sie daran knüpfen. Schiller fährt fort: »Die Majestät des Deutschen ruhte nie auf dem Haupte seiner Fürsten. Abgesehen von dem politischen, hat der Deutsche sich einen eigenen Wert gegründet. « Ranke aber fährt fort: »Die lebenden Kräfte der Nation hatten sich dem Reiche schon lange entzogen; sie schlossen augenblicklich zu den neuen Fürstentümern zusammen. « Schiller tröstete sich durch das, wie er glaubte, unzerstörbare Ideal der Menschheitsnation, Ranke tröstete sich durch die Anschauung der, wie er wahrnahm, unzerstörbaren politischen Lebenskraft der Nation, die nach dem Zerfall ihrer morschen untauglichen Einheit sofort sich auf den deutschen Einzelstaat warf und ihn regenerierte, nationalisierte. Was wäre aus unseren Staaten geworden, hätten sie nicht neues Leben aus dem nationalen Prinzip, auf das sie gegründet waren, empfangen : $^{1}$ ) So sei die Bedeutung der Nationalität für den Staat endlich einmal wieder in das allgemeine Bewußtsein gebracht worden.

Ist diese Nationalität, die für den Staat so unentbehrlich sein soll, nun aber ausschließlich die allgemein deutsche? Soll sie den Einzelstaat nur ebenso erfüllen, wie sie den Goethischen Faust und die Kantsche Philosophie erfüllt? Kurz, wendet er hier nur jene von der historischen Rechtsschule entwickelte Lehre vom Volksgeist an, wonach dieser, selbst unsichtbar und unpersönlich, in vielerlei sichtbaren individuellen Erscheinungen, geistigen wie politischen und gesellschaftlichen, sich offenbart? Manchmal ist das unzweifelhaft Rankes Meinung, und er pantheisiert auch hier wieder deutlich. Wie ihm die Nation eine Modifikation des menschlichen Daseins, so ist ihm der Staat, er sagt es ausdrücklich, eine Modifikation, nicht nur des menschlichen, sondern insonderheit auch des

1) Die Großen Mächte S. 93. 
nationalen Daseins, denn der Staat sei seiner Natur nach bei weitem enger geschlossen als die Nation. ${ }^{1}$ ) Er leugnete nicht - und darin zeigt sich wieder gegenuiber der Wochenblattspartei seine unbefangene historische Einsicht daß die Nationen eine Tendenz hätten zur Bildung eines nationalen Einheitstaates, aber er sah sie eigentlich nirgends, selbst nicht bei Frankreich und England, ganz verwirklicht, und er nahm sie insbesondere für die deutsche Nation nicht als sehr stark und aussichtsreich an. Die große politische Aufgabe der deutschen Nation sah er vielmehr darin, den deutschen Einzelstaat so originell deutsch, so frei von aller auswärtigen Schablone und Theorie wie nur möglich weiterzubilden. "Eine uns eigene, große, deutsche Aufgabe haben wir zu lösen: den echt deutschen Staat haben wir auszubilden, wie er dem Genius der Nation entspricht. $\left.\ll^{2}\right)$ Er verstand unter der auswärtigen Schablone, die man fernhalten müsse, vor allem den Parlamentarismus und die Lehre von der Volkssouveränität, und so protestierte er hier zugleich gegen den liberalen Nationalstaatsgedanken, insofern sich dieser auf eine universale, allgemein gültige Doktrin berief. Auch hatte er nicht etwa wie die Wochenblattspolitiker eine andere universale Doktrin über die Verfassung des Staates zur Hand, die das Absolute, Wertvolle und Allgemeinguiltige im feudalen Ständewesen erblickte, sondern seine Meinung ist, daß auch der echt deutsche Staat gar mannigfaltige Formen annehmen könne. Als Kinder einer Mutter würden, denkt er, die deutschen Staaten ganz von selbst in vielem sich ähnlich sehen, aber unmöglich sei es, allen deutschen Staaten eine und dieselbe Verfassung zu geben. ${ }^{3}$ ) In jedem von ihnen wird so-

1) Polit. Gespräch S. 326.

2 Frankreich und Deutschland S. 7 I.

3) Trennung und Einheit S. 156. 
wieder ein besonderes Prinzip wirksam, das sich auch seinen besonderen, eigentümlichen Körper baut.

Damit vervielfältigt sich nun aber auch die ursprünglich einheitliche Nationalität, der sie alle entstammen. Die nationale Grundlage, auf die Ranke den deutschen Einzelstaat stellen will, ist nicht ausschließlich der deutsche Volksgeist schlechthin, sondern fast unmerkbar differenziert sich ihm die große deutsche Kulturnation zu ebenso vielen Staatsnationen, als es lebenskräftige und selbständige Einzelstaaten gibt. Es gibt Äußerungen von ihm, bei denen er die eine ebenso sehr wie die anderen im Sinne gchabt haben muß. "Dem Ubergewicht, " heißt es z. B., »das eine andere Nation über uns zu bekommen droht, können wir nur durch die Entwicklung unserer eigenen Nationalität begegnen. Ich meine nicht einer erdachten, chimärischen, sondern der wesentlichen, vorhandenen, in dem Staate ausgesprochenen Nationalität. ${ }^{1}$ ) Ein andermal wieder hat er ausschließlich die Staatsnation im Sinne, so wenn er von der preußischen Reformgesetzgebung spricht. „Sie gründete sich auf den gesetzmäßigen Willen des Fürsten, der kein anderes Interesse hatte als das Interesse des Ganzen und der Nation. «2) Man verfolge namentlich den Gang des "politischen Gesprächs", das unter Rankes Schriften vielleicht am meisten Theorie und persönliches Bekenntnis zugleich bietet. Da tritt zuerst in leuchtender Vergeistigung das Bild der Kulturnation auf, des "geheimen Etwas", das aller Verfassung vorhergeht und alle ihre Formen erfuillt. Aus dieser dunklen Tiefe emaniert nun der Staat. Aber mit der Emanation des Staates steht es nun anders, wie mit der Emanation der Individuen aus dem Schoße der Nationalität. Bei dieser kam es, wie wir sahen, auf Wollen oder Nichtwollen nicht an; Bestimmtheit, nicht

1) An dem Schlusse der „Großen Mächte», S. IV. 49'50. S. 75.

2) Frankreich und Deutschland S. 65 . 
Selbstbestimmung walteten hier. Bei der Entstehung des Staates läßt er von vornherein beides anklingen: »Natur der Dinge und Gelegenheit, Genius und Glücl: wirken zusammen", und unter den Kräften, die den Staat dann weiter emporheben zu universaler Bedeutung, steht die »moralische Energie « - ein überaus inhaltsreicher und vielsagender Begriff bei Ranke - obenan. Von nun an fühlt sich der Hörer ausschließlich in der Luft des Staates und des in ihm lebenden besonderen Geistes. Wir spüren jetzt nicht mehr die staatsbildende Kraft der Nation, sondern die nationbildende Kraft des Staates, die "moralische Energie", die in ihm wirkt und von ihm ausstrahlt. Der »bestimmte Staat "wird zum » geistigen Vaterlande " des einzelnen ${ }^{1}$ ), und der »Geist des gemeinen Wesens", der uns nun bis zum Schlusse des Gespräches begleitet, ist ein politischer Nationalgeist, begrenzter, aber auch heller, deutlicher, persönlicher in seinem Wesen, als das "geheime Etwas", das wir in der Tiefe zurückließen. Von Nationalität erfüllt sein, heißt für den Staat voll moralischer Kraft erfüllt sein. ${ }^{2}$ )

So vollendet sich der Gang der Entwicklung, der vom Unpersönlichen zur Persönlichkeit, von der Bestimmtheit zur inneren Selbstbestimmung fuihrt. Und diese innere Selbstbestimmung des nationalisierten Staates faßt Ranke nun natürlich viel weiter als die Anhänger der Doktrinen von 1789. Der Begriff seines Nationalstaates ist so elastisch, daß er sowohl den Nationalstaat älteren, wie den modernen Gepräges einschließt. Es kommt für Ranke nicht darauf an, ob die Staatsnation in repräsentativen und deliberativen Formen an der Regierung teilnimmt, es kommt auf ihre geistige und moralische Mitwirkung am Staate iiberhaupt nur an, und die Staaten,

1) S. 333 . Das noch zweimal, S. 335 u. 336 gebrauchte Wort "Nation s bezeichnet hier unzweifelhaft die Staatsnation.

2) Die Großen Mächte S. 93. 
die nichts als Machtstaaten sind, nur auf Soldaten und Geld beruhen, läßt er als Nationalstaaten nicht gelten und bestreitet ihre Lebensfähigkeit. ${ }^{1}$ )

So gipfelt alles in dem Gedanken der aus spontanem, eigenartigem Leben entspringenden Individualität der großen Staaten. Wie anders mutet es an, als das Entwicklungsideal, das einst Humboldt in seiner Jugendschrift von I792 aufgestellt hatte. »Das Menschengeschlecht, " hatte es damals geheißen, "steht jetzt auf einer Stufe der Kultur, von welcher es sich nur durch Ausbildung der Individuen höher emporschwingen kann, und daher sind alle Einrichtungen, welche diese Ausbildung hindern und die Menschen mehr in Massen zusammendrängen, jetzt schädlicher als ehemals." Auf den ersten Blick klafft beinahe alles zwischen Ranke und Humboldt auseinander. Von der Kultur als Aufgabe der Weltgeschichte sagt Ranke: "Auch ist die oft so zweifelhafte Förderung der Kultur nicht ihr einziger Inhalt « ${ }^{2}$ ), und was drängte die Menschen mehr in Massen zusammen, als der große Macht- und Nationalstaat, in dessen Anblick Ranke schwelgt. Indessen darf man den Gegensatz doch nicht so grob fassen. Was Ranke fesselt, ist ja nicht die Zusammendrängung zu großen Massen an sich, sondern die geistige Persönlichkeit, die daraus erwächst. Individualität ist also das Losungswort beider, Humboldts wie Rankes, nur daß der Begriff der Persönlichkeit jetzt auch die großen Kollektivpersönlichkeiten mit umfaßt. Der Entdeckungszug ins Reich des Individuellen, den der deutsche Geist mit glühender Begierde unternahm, hatte inzwischen - wir sahen ja Humboldt auch noch selbst an ihm mit teilnehmen - auch die Individualität alles dessen, was die Individuen zu Massen vereinigt, zu entdecken begonnen. Und wenn nun Ranke

1) a. a. $\mathrm{O}$.

2) Die Großen Mächte S. 93 . 
von den Staaten und Nationen sagt: "Aus Sonderung und reiner Ausbildung wird die wahre Harmonie hervorgehen ${ }^{1}$ ), so klingt darin durchaus die Grundstimmung Humboldts und des klassischen Individualismus nach. Und so wird man auch in Rankes skeptischen Worten iber die "Kultur « — wie vieldeutig ist nicht schon dieser Begriff an sich - keineswegs eine Verleugnung des klassischen Humanitätsideals schlechthin zu erblicken haben. Faßt man den Begriff der Kultur « im geistigen Sinne, so ist auch der Rankische Macht- und Nationalstaat echte und edle Kultur. Denn seine Macht und sein Recht auf Persönlichkeit ist ihm nicht etwa geschenkt zu beliebigem Gebrauche, auch nicht bloß zur äußeren Fristung seiner Existenz, sondern 》die Bedingung seiner Existenz ist, daß er dem menschlichen Geiste einen neuen Ausdruck verschaffe, ihn in neuen, eigenen Formen ausspreche und ihn neu offenbare. Das ist sein Auftrag von Gott «.")

So sehen wir auch hier wieder ein universales Gebot auftauchen, das über dem Leben der großen Staatspersönlichkeiten schwebt, aber ein solches, das ihre individuelle Entwicklung zugleich in sich schließt und sie nirgends - darin sehen wir den epochemachenden Fortschritt in Rankes Auffassung vom Nationalstaate - einschränkt und schwächt. Ebenso wie Ranke das metaphysische Element aus der Geschichte zwar nicht austrieb, aber dahin verwies, wohin es gehört, an die verschwimmenden Grenzen der Erfahrung, so hat er auch das universale Element im Leben der großen Staaten nicht ausgetrieben, sondern dahin gesetzt, wo es ihre freie Bewegung nicht mehr hemmt. Ihr Ursprung in den Tiefen der Nationalität und ihr Telos also spielen ins Universale hiniiber, aber ihr Leben selbst ist reines Ausleben nur ihrer selbst. Zwar ist die Geschichtsforschung, die es betrachtet und wieder-

1) Schluß der großen Mächte. S. W. 49/50, S. 76 .

2) Frankreich und Deutschland S. 73. 
gibt, notwendig universal, insofern nichts Menschliches ihr fremd bleiben darf, aber die Objekte ihrer Betrachtung, die einzelnen Staaten, kann sie nur verstehen, wenn sie ihnen das unverkïrzte Recht läßt, nur nach ihrer eigenen Natur und Nutzen zu handeln. $\left.{ }^{1}\right)$ Was für eine großartige Antithese ergibt sich nicht daraus: Die Altion der Staaten selbst wird nicht von universalen, sondern von egoistischen Motiven getrieben, aber universal ist ihr Sinn und universal soll der Spiegel der Betrachtung sein, der sie auffängt.

Auch Hegel hatte schon, so sahen wir, diese Antithese aufgestellt, aber er hatte dabei die universale Betrachtung und Bewertung der Geschichte dermaßen auf die Spitze getrieben, daß darüber die empirische Geschichte zum Schattenspiele wurde. Ranke gab ihr das entzogene Blut wieder zurück und behandelte sie überhaupt schonender und respektvoller. Ihren universalen Sinn, den Hegel überall begreifen $z u$ können glaubte, wollte er nur anschauen und ahnen. So gelang nun endlich die richtige Grenzsetzung, durch die Ideal und Erfahrung, betrachtetes Objekt und betrachtendes Subjekt, so geschieden wurden, daß jedes zu seinem Rechte kam. Eine Grenzsetzung, darf man fast sagen, in Kantschem Geiste, obgleich es nur eine fließende und verschwimmende Grenze war. Aber dies Verfließen des Besonderen in das Universale, der Erfahrung in die Spekulation lag in der eigentümlichen Natur der Dinge selbst begriindet. Die Hauptsache, auf die alles ankam, war, daß das Reich der Erfahrung befreit, das der universalen und speliulativen Deutungsversuche weiter hinausgeschoben wurde.

Kehren wir zur Erfahrung, zum Anblick der »großen Mächte zurück. Wer kennt nicht diese mächtigen Gestalten, wie sie Rankes Skizze in atemlosen Fluge,

1) Über die Verwandtschaft und den Lnterschied der Yistorie und der Politik. S. II. 24,291 . 
aber zu unauslöschlichem Eindrucke an uns vorïberziehen läßt, wie sie sich bald in sich zusammenfassen, bald stürmend aufeinanderstoßen und durch den stürmischen Kampf selbst an Mark und Muskeln wachsen? Novalis und vor allem Adam Müller hatten ja schon eine Ahnung von diesem Anblick gehabt, aber doch mehr eine Vision als ein klares Bild, weil ihre Subjektivität noch zu viel universale Tendenzen hineintrug. Jetzt tritt uns das wahre Bild des Lebens dieser Mächte, von jedem Dunste befreit, entgegen. 》Die Eigenart, das Prinzip, welches alle ihre Organe und jede Lebensäußerung durchwaltet, - so hat Lenz sehr schön den Grundgedanken dieser Skizze wiedergegeben $\left.{ }^{1}\right)$ - »will eine jede von ihnen behaupten, alle ihre Kräfte, Stärke nach innen und außen entfalten. Vor diesem tiefsten Instinlte müssen die Gemeinsamkeiten, wie eng sie auch die Staaten miteinander verknüpfen mögen, zurïcktreten; den Bündnissen selbst, welche die Mächte miteinander eingehen, liegt er zugrunde, und er bildet die Grenze für jede Freundschaft. "Individualität und Selbstbestimmung des Staates ist im Grunde dasselbe, ebenso wie es in Rankes Sinne dasselbe sagen heißt, daß er auf »besondere Prinzipien des Daseins «, auf Nationalität, auf moralische Kräfte gegründet sein müsse, um sich und sein Selbst behaupten zu können. Diese Nationalität, Individualität und Selbstbestimmung hatten sich, wie Ranke zeigt, die großen Mächte des Abendlandes schon im ancien rigime erobert mit einer, man möchte sagen, naiven Selbstverständlichkeit. Sie war dann bedroht worden im Zeitalter der Revolution durch einen äußeren und einen inneren Feind. Der äußere Feind war der erobernde französische Nationalstaat, der, selbst aus universalen, kosmopolitischen Ideen mitgenährt, die Staaten und Völker seiner universalen

1) Die großen Mächte S. 9 . 
Herrschaft zu unterwerfen versuchte. Der innere geistige Feind waren jene universalen Ideen selbst, die allen Völkern eine einförmige Staatseinrichtung anempfahlen und sich ihnen einschmeichelten durch den Appell an die Gleichheits- und Freiheitswünsche der Individuen. So erhoben sich die in ihrer Selbstbestimmung bedrohten Staaten gegen die kosmopolitische Vergewaltigung und Uniformierung, die ihnen drohte. Sie besannen sich auf ihre eigenen tieferen nationalen Grundlagen, auf die der Staatsnation nicht minder wie der Kulturnation, und riefen deren Kräfte zu Hilfe. Aber die geistigen Kräfte, die insbesondere Deutschland seinen bedrohten Staaten zufließen ließ, waren selbst zugleich, wie wir immer wieder sahen, von universalen Ideen durchdrungen, und so war dieser innere Bundesgenosse des Staates zugleich auch ein innerer Feind seiner reinen, unbedingten Selbstbestimmung. Wir haben es an den Beispielen Steins, Gneisenaus und Humboldts gesehen, wie diese Fülle von direkt oder indirekt universalen Ideen und Voraussetzungen bis in die Kreise der praktischen Politiker hineindrang. Wir sahen, wie der damalige politische Moment selbst, der die verschiedenen Staaten und Nationen zusammenführte, die universale Idee belebte und wie der Gedanke der europäischen Gemeinschaft und der Gedanke der staatlichen und nationalen Selbstbehauptung sich gegenseitig trugen und zum Teil deckten, aber doch eben nur zum Teil, so daß auch hier wieder der Verbündete zum Feinde, die Wohltat zur Plage werden konnte. Und zu der geistigen Erbschaft der universalistischen Vorstellungen einerseits, des Erlebnisses der Befreiungskriege andererseits, kam dann als dritter Faktor das Sonderinteresse der restaurierten Gewalten in Staat und Gesellschaft. Die Anhänger des Patrimonialstaates bekämpften, wie sie selbst sagten, den Absolutismus in jeder Form, den monarchischen der alten, wie den demo- 
kratischen der neuen Zeit, - sie bekämpften, wie wir sagen können, die autonome Staatspersönlichkeit in jeder Form, sowohl den Nationalstaat älteren wie den Nationalstaat modernen Gepräges. Der nationalen Strömung selbst konnten und wollten sie sich nicht ganz entziehen und suchten sie unschädlich zu machen durch die Ausbildung eines konservativen Nationalstaatsgedankens, der den ständischen Staat verklärte als echtes Erzeugnis des Volksgeistes, der Kulturnation. Und sehr begreitlich ist es, daß sie zugleich auch, wenn auch zum Teile schon abgeschwächt, an den universalistischen Vorstellungen einer europäischen Gemeinschaft der legitimen christlichen Mächte festhielten; dieser Gemeinschaftsgedanke dämpfte ja eben den für das alte feudale Stilleben so gefährlichen Machttrieb der Staaten sowohl wie der Nationen und beschränkte die Autonomie der Staatspersönlichkeit. Der Gemeinschaftsgedanke erhielt einen positiven Inhalt durch die Aufstellung oberster rechtlich-moralischer Gebote, die allen egoistischen Machtinteressen der Staaten und Nationen vorangehen sollten, und diese Gebote wieder erhielten eine religiöse Weihe, indem man sie als Gottes Gesetz und Offenbarung verehrte.

Jetzt, im Gegensatz gegen dies aus Interesse und Ideal zusammengewebte System, wird uns die geschichtliche Bedeutung und Größe der Rankischen Konzeption erst ganz klar. Sie behielt, was fruchtbar an ihm war und was auch nicht aus ihm, sondern aus der klassischen und romantischen Bewegung herstammte, den Gedanken der Kulturnation, des Volksgeistes, der eigenartigen geistigen und neue geistige Individualitäten erzeugenden Nationalität, aber der daraus auch von ihm gewonnene konservative Nationalstaatsgedanke diente ihm nun nicht zur Beschränkung der nationalstaatlichen Autonomie, sondern umgekehrt zu ihrer Rechtfertigung und Kräftigung. Mit festen Schritten tritt sein Nationalstaat 
in die Welt und folgt in allem nur der Stimme seines inneren Genius. Die letzten Ursprünge und Ziele seiner Persönlichkeit reichen wohl in Tiefen herab und auf Höhen hinauf, wo universale Mächte wirken, aber im hellen Lichte seines Lebenstages folgt er universalen Ideen nur soweit, als sie seinem eigensten Bedürfnis entsprechen. Ranke wußte, wie Hegel, sehr wohl, daß es auch im Leben der Staaten untereinander eine »europäische Gemeinschaftlichkeit« gab, die aber das natürliche Ergebnis ursprünglicher Verwandtschaft und nachbarlichen Zusammenlebens war. Und es ist interessant, daß er die Idee der europäischen Gemeinschaftlichkeit eben gerade auch im Zeitalter der Revolutionskriege wieder wirksam sah. Aber er schränlite dieses Zugeständnis gegenüber denen, die daraus ein dauerndes universales Prinzip machen wollten, sofort wieder ein, indem er betonte, wie schwer und nur »gleichsam im Angesichte der Vernichtung sich die Staaten damals zusammengefunden hätten.\& "Nichtsdesto minder, " so ist sein Hauptgedanke hieruber, "war jeder Staat in seiner besonderen Entwicklung begriffen, und ein jeder wird, ich zweifle nicht, in dieselbe zurücktreten, sowie die Nachwirkungen der Revolutionskriege aufhören. $\left.\ll^{1}\right)$ Mit genialer Sicherheit sind hier die Gelenke der Dinge getroffen. Das Zeitalter der Revolutionskriege erscheint hier als eine Art Intermezzo europäisch-universalistischer Politik, durch das die normale Entwicklung des Staatslebens, die auf Autonomie der einzelnen Staatspcrsönlichkeiten beruht, auf kurze Zeit abgelenkt wird. Aber er sieht die Zeit mit unbedingter Sicherheit voraus, wo sie in ihr eigentliches Bett wieder zurückkehren wird. Seine Theorie wies den Universalismus der liberalen Doktrin ebenso ab, wie den der legitimistischen. Er wollte durchaus nicht zugeben, daß Europa dauernd in die

1) Polit. Gespräch S. 329. 
zwei Heerlager des guten und des schlechten Prinzips zerfallen könne, denn er wußte, daß dieselbe Zeit, die diese dualistische Vorstellung hervorgerufen hatte, auch die großen Mächte und Staatspersönlichkeiten des ancien régime mit neuem Leben erfüllt hatte. Nicht dem universalen Prinzipe, sondern der Autonomie des regenerierten Nationalstaates gehörte die Zukunft. So zerriß hier vor seinen Augen das ganze Gewölke von universalistischen Vorstellungen, in dem seine Generation aufgewachsen war, und der Historiker wurde zum vorwärtsgekehrten Propheten, der einen tiefen Blick in das Kommende tat.

Um ihn tun zu können, dazu gehörte mehr Genie als zu der Aufstellung unitarischer Ideale fur Deutschland. Wer solche aufstellte, wer den Nationalstaat für die ganze deutsche Nation verlangte, mußte von einer politischen Leidenschaft erfüllt sein, die dem schauenden Historiker nun einmal nicht zu eigen war, und so konnte es geschehen, daß er zwar in das nationale Staatsleben im großen viel weiter hinaussah als seine befangenen Zeit genossen, aber im einzelnen und im besonderen die Kraft ganz erheblich unterschätzte, die in Deutschland auf die strengere nationalstaatliche Einigung der Kulturnation hindrängte. Wir wissen heute, daß deren Boden noch mehr zu leisten und zu tragen vermochte, als den echt deutschen Einzelstaat und den losen föderativen Verband zwischen ihnen, den Ranke immerhin ja auch zu pflegen empfahl. Wir begreifen auch leicht, daß dieser ganze konservative Nationalstaatsgedanke, der mit dem vom deutschen Geiste genährten Einzelstaat zufrieden war, ein Reflex der tatsächlichen Zersplitterung Deutschlands und ein Versuch war, sie geistig zu rechtfertigen vor dem Forum des nun einmal vorhandenen deutschen Nationalbewußtseins. Aber alle derartigen Ideen sind ja abgeleitet aus einer irgendwelchen Wirklichkeit, und sie müssen es sogar sein, sie müssen möglichst viel von 
solchem Lebensblute in sich haben, wenn sie ihrerseits wieder als geistige Macht auf die Wirklichkeit zurückwirken sollen. Es war nun einmal die allerrealste Tatsache in der Entwicklung des deutschen Nationalgefühls, daß es, aus dem Bewußtsein der geistigen Einheit zu dem Wunsche nach politischem Ausdruck der deutschen Nationahität übergehend, zunächst einmal Halt machte an den Grenzen des Einzelstaates, der doch auch schon in jahrhundertelanger territorialstaatlicher Arbeit seine besondere politische Nationalität sich geschaffen hatte. Man hätte die eingewurzeltsten Empfindungen verleugnen müssen, wenn man die Nationalität des Einzelstaates nicht mit in die Wage geworfen hätte zu allen ubrigen nationalen Werten. Nicht um diese Tatsache zu beweisen, denn dessen bedarf sie nicht, sondern um ihr tieferen Sinn zu geben, erinnern wir daran, daß Humboldt und Bismarck sie übereinstimmend ausgesprochen haben ${ }^{1}$ ) - derjenige Staatsmann, der am meisten von den Ideen, und derjenige, der am meisten von den Realitäten herkam.

Zwischen ihnen - auch der Generation nach stand also Ranke, dessen Charisma es war, mehr als irgendein anderer Ideen und Realitäten zu verbinden. Dieser, man möchte wohl sagen, symphonische Zusammenhang zwischen den dreien ist ein Zeugnis, daß das wahre ideelle und das wahre reale Denken sich immer wieder finden muissen. Darauf beruht es im letzten Grunde doch auch, daß die Menschheitsnation Schillers den Nationalstaat Bismarcks hat schaffen können. $\mathrm{Zu}$ diesem hinüber suchen wir uns jetzt das letzte Stück unseres Weges.

Daß zwischen dem politischen Programm, das Ranke in den dreißiger Jahren entwickelte, und der politischen Denkweise Bismarcks eine auffallende innere Verwandt-

1) S. oben S. 193 . 
schaft besteht, hat schon ein bedeutender Forscher, der sich selbst immer gern in Beider Sphären bewegt hat, mit feinem Urteile nachgewiesen. ${ }^{1}$ ) Und er bemerkt über ihren Einfluß auf das politische Denken der Nation: "Erst sie haben für uns Deutsche in Historie und Politik Naturrecht und Romantik völlig iiberwunden. " Lenz selbst wird dieses Urteil nur cum grano salis verstanden wissen wollen, denn wo wären geistige Mächte von dieser Kraft und Fruchtbarkeit je völlig überwunden worden. Sie leben weiter in dem, was sie »überwindet«, und Ranke, Bismarck, das neue Deutschland, wir alle leben geistig noch mit von ihnen. Das ideell Wahre wie das real Lebendige, was sie enthielten, bleibt uns unverloren, auch wenn wir uns von dem abkehren, was nur noch entseelte Hülle eines fruiheren Lebens in ihnen ist. Nur um die Vernichtung solcher leeren Huillen, um die Uberwindung erstarrender Dogmen und Ideale handelt es sich also bei dem, was Ranke und Bismarck geleistet haben, aber indem man diese ihre Leistung hervorhebt, muß man im selbem Atemzuge auch auf die Kontinuität des inneren Lebens zwischen den neuen Gedanken, denen sie Raum schufen, und den alten Gedanken, deren welkes Gezweig sie entfernten, hinweisen.

Die Brücke, die von der Romantik, wie zu Ranke, so auch zu Bismarck hinüberführt, ist vor allem der konservative Nationalstaatsgedanke. Während dieser Zusammenhang bei Ranke ohne weiteres einleuchtete, sind wir gefaßt darauf, daß er für Bismarck bezweifeit werden wird. Wir konnten uns zwar schon auf die Gedanken seines Alters berufen, wo er das spezifische Wesen des deutschen Nationalgefühls darin findet, daß es nur wirksam werde durch das Medium der »besonderen Nationalitäten, die sich bei uns auf der Basis des dynastischen

1) Lenz, Bismarck und Ranke. Kleine histor. Schriften $3 S_{3} \mathrm{ff}$. 
Familienbesitzes gebildet haben « ${ }^{1}$ ) Aber zunächst ist ja diese These noch nicht schlechthin das, was wir den konservativen Nationalgedanken nannten: sie ist nahe verwandt mit ihm, aber nicht identisch. Sie verbindet auch wie dieser die einzelstaatliche Nationalität mit dem gesamtdeutschen Nationalgefühl, aber sie will damit nur das Resultat der nationalen Entwicklung, wie es Bismarck am Abend seines Lebens sah, geben und dem kommenden Geschlechte einprägen, auf welchem eigentümlichen Dualismus der nationalen Motive das neue Deutsche Reich beruhe. Der konservative Nationalstaatsgedanke der vormärzlichen Jahre dagegen kannte und verlangte kein Deutsches Reich, verlangte höchstens, wie Ranke, Radowitz und Friedrich Wilhelm IV., einen Ausbau der Bundesverfassung und war im übrigen mit dem echtdeutschen Einzelstaate zufrieden. In diesem sah er dann allerdings auch einen eigentümlichen Dualismus der nationalen Motive wirksam, die besondere politische $\mathrm{Na}$ tionalität des Einzelstaates und die geistige Nationalität des deutschen Volkstums: Man sieht also, daß die Kräfte, die gewürdigt werden, sich gleichen oder doch ähneln, daß aber der Standpunkt der Betrachtung und des Interesses verschieden ist. Bismarck erinnert die Staatsnation des neuen Reiches an die Kräfte der politischen Einzelnationalität, die in ihm walten, -- der konservative $\mathrm{Na-}$ tionalgedanke spielte gegenüber denen, die eine deutsche Staatsnation haben wollten, die Gedanken der deutschen Kulturnation und der politischen Einzelnationalität zugleich aus.

Der allgemeinere geschichtliche Zusammenhang zwischen beiden Standpunkten drängt sich aber dem Auge sofort auf. Einmal ist die neue deutsche Staatsnation ja eben geschaffen worden durch ein Zusammenwirken

1) Gedanken und Erinn. I, 293. 
der Kräfte der deutschen Kulturnation und des Einzelstaates. Und dann ist der konservative Nationalgedanke selbst eines der geistigen Mittel gewesen, um den deutschen Einzelstaat vorzubereiten für die Eingliederung in den künftigen deutschen Nationalstaat. Er hat den deutschen Einzelstaat in seiner Existenz gerechtfertigt, aber mit Gründen, die noch auf etwas Höheres sich beriefen als auf den Einzelstaat, und hat dadurch die Idee einer inneren nationalen Gemeinschaft auch in denjenigen Kreisen lebendig erhalten helfen, die voller Mißtrauen gegen die äußere politische Einheit der Nation waren. Diese Art von Rechtfertigung des Partikularismus hat gerade dazu mitgewirkt, ihn innerlich soweit zu überwinden, als es zur Herstellung des großen deutschen Nationalstaates nötig war.

Freilich hat er den deutschen Nationalstaat nicht nur vorbereitet, sondern auch retardiert. Vorbereitet hat er ihn gegen seine eigentliche Absicht, retardiert hat er ihn mit bewußter Absicht. Diese Duplizität seiner Wirkung tritt ja in der Bewegung von 1848 deutlich hervor, und hier sieht man mehr die hemmende als die fördernde Wirkung. Die partikularistischen wie die großdeutschen Gegner des Frankfurter Verfassungswerkes arbeiteten mit Argumenten, die an den konservativen Nationalstaatsgedanken deutlich anklingen, und wie insbesondere die preußisch-konservativen Gegner ihn damals als Panier aufpflanzten und ihr deutsches Gewissen damit über den Kampf beruhigten, den sie gegen die deutsche Einheit führten, haben wir schon am Beispiele Stahls gesehen.

Aber schlug auch in Bismarck, wird man zweifelnd fragen, damals ein deutsches Gewissen? Führte er nicht schlechthin nur seinen Kampf als preußischer Partikularist! »Für ihn war, \& sagt sein Biograph Lenz, »Ausland alles, was jenseits der schwarz-weißen Grenzpfähle 
lag. $\left.\ll^{1}\right)$ Als ihm ein preußischer Standesgenosse damals auf seine stürmisch reaktionären Ergüsse entgegenhielt, es sei doch in dem 》nationalen Gedanken « eine anzuerkennende Wahrheit, wies Bismarck ihn spöttisch ab: "Also sind Sie auch von dem deutschen Hunde gebissen worden $\left.\ll^{2}\right) \quad$ Wir werden es im zweiten Buche dieser Untersuchungen darzustellen haben, welche Gefahren für den preußischen Staat, für die Erhaltung seiner spezifischen Persönlichkeit und Nationalität von der damaligen deutschen Bewegung drohten. Veranlassung genug für einen Mann wie Bismarck, in dem sich die preußische Nationälität und - um mit seinen eigenen damaligen Worten zu sprechen - ihre hervorragendste Eigentümlichkeit, das kriegerische Element inkarnierte, auf den »deutschen Hund « loszuschlagen und eine Anerkennung des nationalen Gedankens, der seinen Heimatsstaat gefährdete, zu verweigern. Zwar stand nun diesseits der Kluft, die ihn von den Frankfurtern trennte, eben der konservative Nationalstaatsgedanke, und die Anerkennung der deutschen Nationalität, die dieser enthielt, war so harmlos, so ungefährlich, daß auch ein Stockpreuße wie Bismarck diese Formeln ohne Gewissensskrupel nachsprechen konnte. Wirklich haben wir auch eine Reihe von Äußerungen Bismarcks aus diesen Jahren, die neben der energisch preußischen auch eine gewisse deutsche Gesinnung atmen. Sie sind nie ganz unbeachtet geblieben und sind gewöhnlich als Reminiszenz seiner turnerischburschenschaftlichen Jugendregungen gedeutet worden. ${ }^{3}$ ) Deren Nachwirkungen brauchen nicht geleugnet zu werden,

1) Geschichte Bismarcks S. 39.

2) Ludw. v. Gerlach 2, 324 .

3, Vgl. z. B. Lenz a. a. O.S. 43 über die Rede vom 2. April i 8.8: , Es war der Gedanke seiner Jugend; er hatte ihn auch in der Revolution nicht vergessen. Aber er sah die Einheit Deutschlands doch nur in der Einigkeit seiner Fürsten.

M einecke, Weltbürgertum und Nationalstaat. 2. Auf. 
aber jene Außerungen lassen sich alle zugleich ungezwungen in den Zusammenhang des konservativen Nationalstaatsgedankens einreihen. Da erhebt sich dann freilich sofort die Frage, ob sie, insoweit sie diesen ausdrücken, echtes Stuick seiner innerlichen Gesinnung oder Anempfindung, vielleicht auch nur taktische Benutzung solcher Ideen waren, die seine Partei ohne ihn und vor ihm ausgebildet hatte.

Diese Frage wird nahegelegt schon durch die Eigenart der Stellung, die Bismarck in dem christlich-germanischen Kreise, in dem inneren Zirkel der preußischen Konservativen einnahm. Er ist nie ganz in ihm aufgegangen, er hat das religiös-politische System, das ihm hier geboten wurde, nur soweit sich angeeignet, als es in ihm auf persönlich-lebendige Erfahrungen stieß3. ${ }^{1}$ ) Vielleicht hat er niemals reiner die Sprache seiner neuen Freunde gesprochen als in der Rede über die Judenfrage, die er am I 5. Juni $1847 \mathrm{im}$ Vereinigten Landtage hielt, wo er schlecht und recht den Zweck des Staates in der Realisierung der christlichen Lehre sah. Aber wie nüchtern und praktisch denkt er über die Möglichkeit ihrer Realisierung ${ }^{2}$ ), und wie konkret-persönlich und märkisch-edelmännisch ist das Motiv, das er verrät, wenn er von seinem mit der Muttermilch eingesogenen Vorurteil spricht, wenn er erklärt, daß ihn Freudigkeit und aufrichtiges Ehrgefühl verlassen würden im Anblick eines jüdischen Würdenträgers, dem er gehorchen solle. Und so kann man bei jedem einzelnen Satze der christlich-germanischen Lehre, den er gebraucht, beobachten, wie er sich ihm im Munde umbildet und seinen theoretischen und doktrinären Klang ganz oder fast ganz verliert. So wird man

$\left.{ }^{1}\right)$ Vgl. meinen Aufsatz über Gerlach und Bismarck. Histor. Zeitschrift 72 (1893).

$\left.{ }^{2}\right)$ Er betont nicht weniger als dreimal hintereinander, daß dieser $Z$ weck nicht immer erreicht werde. 
von vornherein bezweifeln dürfen, daß seine von deutscher Gesinnung vielleicht zeugenden Worte gerade jener Theorie über das Verhältnis preußischer und deutscher Nationalität entspringen, die seine Freunde ausgebildet hatten. Sie war ausgebildet worden, wie wir sahen, auf der Grundlage der romantischen Vorstellung vom schöpferischen, Persönliches schaffenden, aber selbst nicht zur sichtbaren Persönlichkeit kommenden Volksgeiste, und diese wieder ging zum Teil zurück auf den Pantheismus und Panindividualismus der Fruhromantik, zum Teil vielleicht auch auf die Vorstellungen von der geistigen Kulturund Universalnation, die in Fichte, den Frïhromantikern und den klassischen Idealisten lebten. Man braucht diesen Stammbaum des konservativen Nationalstaatsgedankens nur aufzustellen, um zu sehen, daß er für Bismarck nichts bedeutete. Alle diese feinen und tiefsinnigen Ideen konnten inneres Erlebnis eines zum Betrachten, aber nicht eines so zum Handeln gestimmten Geistes werden, wie er es war. Aber waren nicht diese Ideen selbst immer schon abgeleitet aus dem Erlebten der Nation und war nicht insbesonders die Vorstellung vom deutschen Volksgeiste der Reflex einer kräftigen Wirklichkeit? Sie war selbst nur Reflex und Reflexion, aber was ihr zugrunde lag, war altertümliches, naives, naturhaftes Wachsen der Nation, wo sie unbewußt schon vielerlei schuf und ihrer selbst nur bewußt wurde, wenn ihr Stolz, ihre Kraft zu hassen, ihr Wille gereizt wurde. Hören wir vor allem weiterem Bismarcks Erzählung von den Eindrücken seiner Jugendreisen in Suidwestdeutschland. ${ }^{1}$ ) Sie ist aus spätester Zeit, aber sie gehört zu den Erinnerungen, die so leicht nicht durch Späteres gefärbt werden. »Beim Blick auf die Landkarte ärgerte mich der französische Besitz von Straßburg, und der Besuch von Heidelberg, Speyer und

1) Gedanken und Erinn. I, 2. 
der Pfalz stimmte mich rachsüchtig und kriegslustig." Solch elementare Empfindungen haben nichts von dem "Stadium theoretischer Betrachtungen \& an sich, in dem sich nach Bismarcks Erzählung die ersten deutsch-natio. nalen Eindrücke seiner Turnerzeit bewegten, sie sind auch ursprünglicher als der »preußische Offiziersstandpunkt im Sinne der Freiheitskriege«, auf dem er, so erzählt er ja auch, damals gestanden habe. Man wird zwar durch diese Erzählung sofort auch an die erste Rede erinnert, die er im Vereinigten Landtage von 1847 hielt, wo er es nicht fassen wollte, daß zu der Volkserhebung von I 8 I 3 auch noch andere Motive mitgewirkt haben sollten, als das ursprünglich menschliche Gefühl der "Schmach, daß Fremde in unserm Lande geboten", der » Mißhandlung und Erniedrigung «, des » Hasses gegen die Fremdlinge«. Aber kann man auch hier zweifeln, daß wir ein Stück Urgestein nationaler Empfindung vor uns haben, das selbst noch zurückliegt hinter den Gefuihlen spezifisch preußischer oder deutscher Nationalität? Es ist die geistige Welt des Volksepos, der Helden der Gudrun und der Ilias, die es auch nicht ertragen können, daß Fremde im Lande gebieten. Es ist der Drang nach nicht bloß nationaler, auch nicht bloß staatlicher, sondern nach im letzten Grunde auch heroischer Autonomie. Er war in den Tiefen seines Wollens sein ganzes Leben hindurch wirksam, hat alle seine politischen Ziele charak. teristisch gefärbt und seine Größe wesentlich mit ausgemacht.

Wesentlich, aber nicht allein; sondern es kam dazu auch ein naturhafter mächtiger Zug zu den großen, geschichtlich entwickelten Lebenskreisen hin, in denen er aufgewachsen war, ein Drang, sich mitten in sie hineinzustellen, ihr Leben zu seinem Leben zu machen und seine Autonomie mit ihrer Autonomie zu verschmelzen, als Großer zu herrschen und dem Großen zu dienen. 
Drei große Lebenskreise fand er, zum Manne heranwachsend, um sich vor, das soziale Milieu des preußischen Adels, das monarchisch-preußische Staatswesen und die deutsche Nation. Den ersten verleugnet er nie, aber dieser war damals aufs festeste verbunden mit dem zweiten, der ihn weitaus am stärksten umgab und an sich zog. Vor die Wahl gestellt zwischen dem zweiten und dritten, zwischen Preußen und die deutsche Nation, entschied er sich mit aller Kraft und Leidenschaft seiner Natur fuir Preußen. Aber die deutsche Nation war ja nicht schlechthin identisch mit dem nationalpolitischen Ideal der Frankfurter, das auf dem liberal-demoliratischen $\mathrm{Na}$ tionalitätsgedanken beruhte. Gab es nicht doch noch einen Begriff von deutscher Nation, in den er sich mitten hinein stellen konnte? Die Ideen von deutscher Kulturnation konnten es freilich, wie wir sahen, nicht sein. Von deutscher Volkssouveränität wollte er als Edelmann und Preuße nichts wissen, mit dem deutschen Volksgeiste seiner romantischen Freunde konnte er auch nicht viel anfangen, - aber hinter Volkssouveränität und Volksgeist lag noch, auch als geschichtliches Urgestein, die deutsche Volkskraft. Sie war es, die ihm gefiel.

"Ich hätte es erklärlich gefunden, « schrieb er am 20. April I 848 an die Redalition der Magdeburger Zeitung, »wenn der erste Aufschwung deutscher Kraft und Einheit sich damit Luft gemacht hätte, Frankreich das Elsaß abzufordern und die deutsche Fahne auf den Dom zu Straßburg zu pflanzen.» Kein Verständiger wird auf den Einfall kommen, daß er damit vom Fleck weg einen nationalen Eroberungskrieg gegen Frankreich habe predigen wollen. Ebensowenig freilich ist es ein bloßes keckes Kraftwort, wohl aber ein Wort der Kraft, sowohl der, die in ihm schlummerte, wie der, die nach seinem Herzen gewesen wäre. Es ist noch kein Gewitter, aber ebenso wie die verwandten Worte, die wir vorhin hörten, 
ein Wetterleuchten. Es ist ein deutsches Nationalgefühl von noch nicht politischer, auch nicht geistiger oder ethischer, aber von ausgeprägt voluntaristischer Art: Wenn Ihr denn, so klingt es heraus, durchaus Euren deutschen Enthusiasmus haben wollt, wenn Ihr nicht zufrieden seid mit dem Wohlbehagen, das Euer Heimatsstaat Euch bieten kann, so will ich Euch ein Deutschtum zeigen, das Hörner und Klauen hat, nur für ein solches wäre ich zu haben.

Der unmittelbare Zweck jenes Briefes an die Magdeburger Zeitung war, seinen deutschen wie preußischen Landsleuten die selbstmörderische Torheit klar zu machen, die sie durch Begünstigung der polnischen Bestrebungen in Posen begingen. Man wird also vielleicht einwenden können, daß er ein spezifisch preußisches Interesse durch den Appell an deutsche Empfindungen, die er selbst nicht zu teilen brauchte, fördern wollte. Aber es hieße taub sein für den Naturlaut der Empfindung, wenn man sie nicht auch in der berechneten Form, in der er sie aussprach, anerkennen wollte. Natürlich redete er nicht einer blinden, sondern einer zweckmäßigen Entfaltung deutscher Vollskraft das Wort, und diese Zwecke konnten ihm zunächst nur in der Macht und Größe seines Preußens liegen. ${ }^{1}$ ) So ist ihm also damals deutsche Nationalität auch eine große Potenz, die aber zur Erscheinung kommt nicht in einem erst zu schaffenden Einheitsstaate, sondern in der Machtpolitik des Heimatsstaates.

Auch der anderen großen deutschen Einzelstaaten? In demselben Briefe und ebenso wieder in der Rede über die Olmützer Konvention vom 3. Dezember I 850 sprach er seine Freude aus über alles, was deutsche Waffen ubberhaupt im Laufe der Jahrhunderte erobert hätten, und so auch über die Herrschaft Osterreichs in slavischen

1) So ist es auch begreiflich, daß er, wie die Dinge damals lagen, für den Krieg gegen Dänemark, der nichts filr Preußen versprach, noch nicht zu haben war. 
und italienischen Landen. Wir geben zu, daß man hier zu zweifeln beginnen kann an der Ursprünglichkeit seiner Freude, aber echt bismarckisch gedacht ist es jedenfalls, daß Osterreichs Anspruch auf den Ehrennamen einer deutschen Macht auf deutscher Herrschaft und Schwertfuihrung beruhe.

Und zum mindesten konstatieren muß man schließlich, daß sich sein damaliger deutscher Nationalbegriff nahe berührt mit dem seiner Parteigenossen Leopold und Ludwig v. Gerlach. Leopold schrieb am 24. April I 848 - vielleicht mit unter dem Eindrucke jener gleichzeitigen, ihm irgendwie wohl bekannt gewordenen Gedanken Bismarcks? - in sein Tagebuch: „Wie heuchlerisch ist ubberhaupt diese Germanomanie und was für Wunden hat sie nicht schon Deutschland geschlagen. Preußen hatte deutsche Sitte und deutsches Recht bis an den Niemen und bis an die Netze und Prosna ausgebreitet. Die Revolution gibt sich die größte Mühe, die Deutschen aus allen diesen Eroberungen treiben zu wollen. «1) Ebenso sei es mit Böhmen, Tirol und Ósterreich-Italien. "Dabei ist gar nicht davon die Rede, den Elsaß, Lothringen, die deutschen Provinzen der Niederlande, die echt deutsche Schweiz wieder mit Deutschland zu verbinden, die deutsche Nationalität in Siebenbürgen zu schützen." Ludwig v. Gerlach aber stimmte im folgenden Jahre dem Urteile Wolfgang Menzels zu, daß es die einzige deutsche Nationalpolitik gewesen wäre, Ósterreichs Kämpfe in Ungarn und Italien für eine deutsche Sache zu erklären, deutsche Truppen dahin zu senden und den Russen die bewaffnete

1) I, 155. Gerlach setzt sich hier freilich - charakteristisch fiir die Unsicherheit seines nationalen Prinzips - in Widerspruch mit sich selbst. S. oben S. 242 Anm. 3. Weiteres Material über den Nationalbegriff der Gerlachs zusammengestellt bei Liittke, Die polit. Anschau. ungen des Generals u. des Präsidenten v. Gerlach. Leipziger Dissertation 1907 . 
Einmischung gar nicht $\mathrm{zu}$ gestatten. ${ }^{1}$ ) Man bemerkt freilich sofort, wie dieselben Gedanken, die bei Bismarck einen national-heroischen Zug haben, im Kopfe der Gerlachs $z u$ einer etwas extravaganten Doktrin zu vertrocknen drohen. Bei ihnen ist es schwer, ja unmöglich, Doktrin und Empfindung zu trennen, bei Bismarck ist es schwer, ja unmöglich, Interesse und Empfindung auseinander zu halten. Dem Historiker bleibt, wenn er zwischen Hyperkritik und Gutgläubigkeit die richtige Mitte gehen will, nichts übrig, als seinem Sinne für das Lebendige zu folgen und beides jeweils neben-und miteinander anzuerkennen.

So wird also unsere Vermutung bestätigt: Bismarck stand auf dem Boden des konservativen Nationalstaatsgedankens, insoweit er von Natur und als Autochthon auf ihm stehen konnte und insoweit deutsche Volkskraft und preußisches Staatsinteresse sich finden konnten. Wo er dariber hinaus mit der nationalen Theorie seiner Freunde zusammentraf, geschah es vorwiegend aus taktischen Erwägungen des Momentes, aber zugleich mit einem Zuschuß von reckenhafter Empfindung, die ungekünstelt ihm entströmte. Seine Freude an Ósterreichs deutscher Schwertführung im Osten freilich in Taten umzusetzen und deutsche Nationalpolitik im Sinne Gerlachs zu treiben, wäre ihm schon damals nicht im Traume eingefallen. Mochte jeder deutsche Staat nur mit seinem eigenen Schwerte sich freie Bahn hauen, Ósterreich gegenüber seinen Slowaken und Magyaren, Preußen - auch dieser Gedanke blitzt ja schon in diesen Jahren auf ${ }^{2}$ ) - , indem es den Deutschen befähle, was ihre Verfassung sein solle. Wenige Tage vor der Olmuitzrede erklärte er auch im engeren Kreise seiner Parteifreunde frank und frei: Friedrich II. I740 sei sein $M M^{3}$ ster $^{3}$ ), und in der Olmützrede selbst ließ er

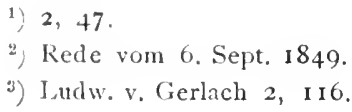


solche Gelüste wenigstens erraten. ${ }^{1}$ ) Er hielt sie nur fest im Zaume, weil für seinen Staat damals zu viele $\mathrm{Ab}$ gründe rechts und links lauerten. Immer spürt man zugleich altertümliche Heerkönigsgesinnung, die sich jeglicher Tapferkeit freut, und den modernen rationellen Realismus, der die Kraft der Elemente dem Zwecke unterjocht, der Selbstbeherrschung übt, weil er so nur auch Selbstbestimmung aus eigensten Lebensbedürfnissen heraus üben kann.

Denn in derselben Olmützrede war es, wo er die große einfache Wahrheit aussprach, die alle Nebel der politischen Romantik verscheuchte: „Die einzige gesunde Grundlage eines großen Staates, und dadurch unterscheidet er sich wesentlich von einem kleinen Staate, ist der staatliche Egoismus und nicht die Romantik, und es ist eines großen Staates nicht würdig, für eine Sache zu streiten, die nicht seinem eigenen Interesse angehört. «

Solche autonome preußische Politik nennt Bismarck ein andermal in diesen Jahren auch eine "nationale preußische Politik «. ${ }^{2}$ ) Wir würden aber auch, wenn er es nicht täte und nicht auch sonst so lebendig alle Gefühlswerte eines "spezifischen Preußentums « mitklingen ließe, den autonomen Großstaat, den er im Sinne hat, als echten Nationalstaat im politischen Sinne zu bezeichnen haben, da er das Prinzip seiner Handlungen in den inneren und äußeren Lebensbedürfnissen der politisch geeinigten Volksgemeinschaft suchen mußte. Ein Nationalstaat in diesem Sinne war das Preußen, das Friedrich Wilhelm IV. und seine romantischen Freunde im Auge hatten, nicht, denn sie hielten nicht, wie Bismarck, seinen staatlichen Egoismus für die einzige gesunde Grundlage seiner Politik. Sie banden es auch in seiner äußeren Politik an oberste sittliche

1) Richtig erkannt von Fester, Hist. Zeitschr. 85,49 f. S. oben S. 178 . Anm. 4 .

2) Rede vom 6. Sept. I 849 . 
Gebote und engten damit die Ziele seiner Macht, seine Bewegungsfreiheit und selbst schon seine Bündnismöglichkeiten ein. Durch die unstaatlichen Ziele, die sie dem Staate setzten, wandelten sie so auch die Mittel um, mit denen er arbeiten sollte, wandelten sie weiter das politische Denken, die Vorstellungen uiber das, was politisch möglich und durchführbar war, überhaupt um und schufen so eine Quelle von politischen Irrtumern, Fehlern, Mißerfolgen und Demütigungen.

Wir sind dem Ende unserer Erörterungen nahe. Lassen wir, bevor wir die letzten Umblicke tun, noch einmal die beiden Auffassungen zu Worte kommen, die an der Schwelle der neuen Zeit miteinander rangen. Jedem Kenner Bismarcks sind die Briefe, die er im Mai ${ }^{8} 57$ mit Leopold v. Gerlach gewechselt hat, und die Denkschriften, die er im Mai und Juni I 857 seiner Regierung eingereicht hat, bekannt. Man fühlt sich in ihnen in kühler Morgendämmerung und sieht den Mond erbleichen.

Da tritt noch einmal in dem Briefe Gerlachs vom 6. Mai I $857^{1}$ ) der Universalismus der Romantik, der Befreiungskriege und der Restaurationszeit auf mit dem Anspruche, das wahre Prinzip europäischer Politik zu bieten und durch die Welthistorie selbst beweisen zu können. Karls des Großen Prinzip, so beginnt er, war die Ausbreitung der christlichen Kirche. Er huldigte ihm in seinen Kriegen gegen Sachsen, Sarazenen usw. und trug guten Lohn davon, während seine Nachfolger sich prinzipienlos untereinander stritten; die großen Fürsten des Mittelalters aber blieben dem alten Prinzip wieder treu, und die Gründung der brandenburgisch-preußischen Macht beruht auf ihm, auf den Kriegen, die man gegen diejenigen Völker führte, die sich dem Kaiser, dem Vikarius der Kirche nicht unterwerfen wollten. In den

1) Bismarckjahrbuch $6,8_{3} \mathrm{ff}$. 
späteren Zeiten des Verfalls von Kirche und Reich hat nur immer wieder das alte Prinzip die Staaten in die Höhe geführt; so Osterreich und Rußland durch ihren Kampf gegen die Türken, und die Kriege des großen Kurfürsten und die drei ersten Kriege Friedrichs des Großen wahrten auch, trotz mitspielender Territorial- und Gleichgewichtsinteressen, das Prinzip, weil sie einen protestantischen Charakter trugen, und die gegen Ludwig XIV. geführten Kriege waren schon recht eigentlich Kriege gegen die Revolution. Die elendeste Zeit der preußischen Politik war die von 1778 bis zur Französischen Revolution. Das war die »Politik der Interessen, des sogenannten Patriotismus". Durch die Revolution wurden dann erst die Staaten wieder belehrt iiber das wahre Prinzip, das jetzt nur in dem Kampfe oder doch wenigstens in der Frontstellung gegen die Revolution in allen Gestalten, bis zum Frankreich Napoleons III. hin, bestchen kann. Preußen und Deutschland fuhren gut, solange dieses Prinzip galt. Keine fremde Macht hat sich von ISI5 bis I $\$ 40$ in die deutschen Angelegenheiten gemischt.

Gerlach glaubte also auch Realpolitik zu treiben, weil seine Idealpolitik angeblich auch immer ihren realen Lohn auf Erden schon fand, was er freilich ohne die gewaltsamsten Verrenkungen und Ignorierungen nicht nachzuweisen vermochte. Er scheint auch die Autonomie der Nation hochzuhalten, aber es ist nicht die echte $\mathrm{Au}$ tonomie, weil sie doch nur als die Wirkung der Eingliederung in die heilige Allianz, d. h. als Lohn für den Verzicht auf die wahre Autonomie der Macht aufgefaßt wird. Gerlachs Prinzip des politischen Handelns führte zu einer gewissen charaktervoll erscheinenden Geschlossenheit und Festigkeit, die in ruhigeren Zeiten dem Staate allerdings einen gewissen Kredit sichern konnte. »Es ist doch nicht zu verkennen, " rühmt er, »daß nur der zuverlässig ist, welcher nach bestimmten Grundsätzen und 
nicht nach schwankenden Begriffen von Interessen usw. handelt. \& Aber es bedeutete zugleich, wie alle heteronomen Prinzipien des Handelns, Einförmigkeit, Starrheit, Unfähigkeit zu lebendiger Anpassung an den Wechsel der Dinge, Unterdrückung der natürlichen Lebenskräfte und der geschichtlichen Entwicklung. Er sucht die Gesetze der Bewegung nicht in den sich bewegenden Kräften selbst, sondern in dem universalen, absoluten, transzendenten Zusammenhange, in dem sie sein Glaube sieht, In allem umgekehrt Bismarck. Seine Politik geht vom Mittelpunkte der sich bewegenden Kräfte selbst aus. ihr Wesen ist Individualität, Entwicklung und Diesseitigkeit. Sie vibriert, von der einen Seite gesehen, von Augenblick zu Augenblick, da sie bestimmt wird durch »alle die Nuancen von Möglichkeit, Wahrscheinlichkeit oder Absicht, für den Fall eines Krieges dieses oder jenes Bündnis schließen, zu dieser oder jener Gruppe gehören zu können «. ${ }^{1)}$ Aber diese Art von Bestimmtheit gehört zur wahren inneren Selbstbestimmung, wie die äußere Welt zur inneren Welt, wo diese auch nur wachsen und sich entfalten und behaupten kann durch den Kampf und Gegensatz gegen jene. Und so entbehrt auch die Bismarcksche Ansicht vom Leben der Staaten untereinander keineswegs der konstanten und beharrlichen Kräfte. Das sind die geborenen und natürlichen Interessen « der einzelnen Staaten, die durchaus nicht so schwankend sind, wie Gerlach behauptete, die sogar stärker sind als diejenigen Prinzipien, die Gerlach als fest und unverrückbar ansah. Denn sie brechen durch alle Wechsel der Regierungsform immer wieder durch und machen sich geltend, ob der Staat nun im Lager des revolutionären oder antirevolutionären Prinzipes sich befinden mag. Bismarck sagte seinem Freunde nur das Nötigste, was er ihm sagen mußte, um seine Politik der 1) 2. Mai i 857 , Kohl, Bismarcks Briefe an Leop. v. Gerlach, S. 316 . 
Selbstbestimmung, die »jede Tür offen, jede Wendung frei erhalten « wollte, zu rechtfertigen. Er ließ sich auf die Frage, ob denn der von Gerlach behauptete Gegensatz des revolutionären und antirevolutionären, des guten und des bösen Prinzips an sich und in der Wurzel berechtigt sei, nicht allzutief ein und empfand auch selbst kein Bedürfnis, seine eigene innerliche Stellung zum Liberalismus und zur Revolution zu revidieren. Sondem er handelte auch in dieser Auseinandersetzung, wie der Staat im großen, wenn er seiner Natur folgt, handeln muß: Er schaffte sich Raum für das Dringendste und Vitalste, für die größten und wichtigsten Lebensregungen der Staaten und überließ alles übrige den Flusse der Entwicklung.

Er bekämpfte die Irrtümer seines Freundes insbesondere durch den Nachweis ihrer geschichtlichen Bedingtheit. Genau wie Ranke erkannte er das Zeitalter der Revolution und Restauration als eine Art Intermezzo im Leben der Staaten untereinander und in den Maximen der sie leitenden Staatsmänner. Wenn es ein solches Prinzip gäbe, meinte $\mathrm{er}^{1}$ ), das Grundlage aller Politik wäre, wie sollte es den christlichen und konservativen Politikern, die es doch auch vor I 7 S9 gegeben habe, entgangen sein? Ich sehe nicht, daß vor der Französischen Revolution ein Staatsmann, sei er auch der christlichste und gewissenhafteste, auf den Gedanken gekommen wäre, sein gesamtes politisches Streben, sein Verhalten zur inneren und äußeren Politik dem Prinzip des Kampfes gegen die Revolution unterzuordnen und die Beziehungen seines Landes zu anderen Staaten lediglich an diesem Probierstein zu prüfen. ${ }^{2}$ ) Er suchte sich den Irrtum

1) 3o. Mai i 857 Kohl S. 328 .

2) Vgl. Sorel, L'Europe et la rev. franc. I, 7J. \' C'ne' Sainte Alliance avant 1789 est un veritable faradoxe historique. Lianienne Europe en était incapable, et il fallut la Révolution françaisr four lui in donner la notion. 
seines älteren Freundes auch im einzelnen psychologisch zu erklären. 》Mir scheint, " sagte er ihm am 2. Mai I $860^{1}$ ), daß niemand den Stempel wieder verliert, den ihm die Zeit der Jugendeindrïcke aufprägt; in dem Ihrigen steht der siegreiche Haß gegen Bonaparte unauslöschlich, Sie nennen ihn ,inkarnierte Revolution' und wenn Sie etwas Schlimmeres wüßten, so würden Sie ihn auch danach taufen. «

So holte er sich nach seiner Weise aus den Ursachen des Irrtums die konkreteste, die am frischesten erlebte heraus. Niemals wird man sie vergessen dürfen, aber unsere Aufgabe sollte es sein, auch die weiteren geistigen Zusammenhänge des Irrtums aufzuweisen. IVir suchten die tiefen Erfahrungen des Befreiungskampfes, die die europäische Staatenwelt in der Tat in zwei Heerlager zerrissen, an Stein und Gneisenau mitzuerleben, aber wir sahen, wie schon hier diese Erfahrungen auf bestimmte Kategorien des Denkens und Empfindens stießen, auf den fortwirkenden Geist des 18 . Jahrhunderts vor allem, der seine universalen Prinzipien auch auf das Staatsleben zu ubertragen versuchte, Der autonome Staat hatte mit diesen heteronomen Prinzipien einen ähnlichen Kampf zu fuihren, wie die sittliche Autonomie des Individuums mit jedweder heteronomen Moral. Der spröde Machtstaat des I8. Jahrhunderts war freilich von vornherein gegen sie fest gewesen, und selbst die aufgeklärten Herrscher des I 8 . Jahrhunderts hïteten sich wohl, zumal in ihrer äußeren Politik, sich von ihnen überfluten zu lassen. Erst durch Revolution und Befreiungskriege wurden die Zugänge im Staatenleben eröffnet, durch die eine stärkere Velle universaler und unpolitischer Ideale in die Politik hineinschoß. Insbesondere fand sie in Deutschland bereite Räume, weil hier die geistige Bildung ganz besonders unpolitisch

1) Kohl S. 347 . 
war und den universalistischen Zug besonders fein und tief ausgebildet hatte. Wohl bot nun die Romantik gegen den von ihr gehaßten rational-weltbürgerlichen Geist des I S. Jahrhunderts die Geister der Vergangenheit auf, aber weil sie selbst in jenem Geiste noch mitwurzelte, holte sie aus der Vergangenheit wieder auch das diesem Verwandte heraus. So erwachte die uralte Idee von der universalen Gemeinschaft der christlichen Staaten zu neuem Leben, und die politisch werdende Romantik wurde Weltbürgertum mit religiös-ethischem Vorzeichen. In den Ideen der Revolution und den Ideen der heiligen Allianz stießen, so sagten wir, zwei Universalismen gegeneinander. Wohl wehrte sich die kräftige Natur der Staaten gegen das fremdartige Element, das sich ihm aufdrängte und seine Glieder fesseln wollte. Nirgends siegte es deswegen ganz, aber gerade in Preußen hat es in den Tagen Friedrich Wilhelms IV. so stark die Köpfe der leitenden Persönlichkeiten beherrscht, daß es auch verhängnisvolle Wirkungen auf die praktische Politik, auf die Machtstellung des Staates hatte. So war es zuletzt wie ein Gift, das der Körper wieder ausscheiden mußte, wenn er wieder natülich funktionieren sollte. Der Arzt, der es herausbrachte, war Bismarck.

Aber es war ursprïnglich ja nicht nur Gift, sondern auch Heilmittel gewesen.

Blicken wir noch einmal zurück auf die Erhebung der Nationen gegen Napoleon, in der diese selbst in ihren mannigfachen Typen und Entwicklungsstufen erscheinen. Die einen, wie die Spanier, Tiroler und Russen, beruhten auf altertumlich-nativistischer Grundlage. Sie bedurften keines besonderen neuen Reizmittels, um sich in Feindschaft und $\mathrm{Haß}$ zu entladen gegen das napoleonische Weltreich. Es ist noch etwas von dem Fanatismus der Halbkulturvölker in ihnen, der auch die modernen Kulturelemente dieses Weltreiches von sich stieß. Ranke hat 
die tiefe Bemerkung gemacht, daß Napoleons Herrschaft da sich leichter ausbreiten konnte, "wo der Geist dazu vorbereitet war", wo die in der Revolution emporgekommenen und auch von ihm vertretenen sozialen Ideen bereits bekannt waren. Man darf hinzusetzen, daß nicht nur der soziale, sondern auch der kosmopolitische Teil der Aufklärungsgedanken ihm vorgearbeitet hat. Diese haben insbesondere die nationale Widerstandskraft Deutschlands zunächst geschwächt, dann aber gerade mitentwickeln und steigern helfen. Wir sprechen hier nur von den oberen, leitenden Schichten der Nation, denn der märkische und pommersche Bauer, der die Flinte des Landwehrmanns trug, war in der Art seiner nationalen Empfindungen nicht so sehr verschieden von dem Tiroler und spanischen Volkskämpfer. In den geistigen Führern der Nation aber war der nationale Impuls auf sehr viel kompliziertere Weise erwacht. Wir sahen, wie er hier von vornherein durchdrungen und umschlungen war von den universalen Idealen. Es war der feineren deutschen Bildung zunächst unmöglich und unerträglich, einen runden, nackten Egoismus der Nationen anzuerkennen. Ihr nationales Empfinden rankte sich empor an dem uberlieferten weltbuirgerlichen Spalier. Und die Invasion der universalen und der vergeistigt nationalen Ideen in den Staat erfolgte also gleichzeitig und in engster Verbindung miteinander. Die einen gaben den anderen Kraft und Wärme und halfen ihnen, in den Staat einzudringen. Später mußten die einen wieder ausgestoßen werden, um den preußischen Nationalstaat zum deutschen Nationalstaat weiter entwickeln zu können, aber entbehrlich waren sie nicht gewesen. Entbehrlich ist nichts, was die innere geistige Kontinuität zwischen zwei großen Epochen vermittelt. Entbehrlich ist auch nichts, was in großen entscheidenden Momenten die geschichtliche Tat befluigeln kann. Hätte wohl Stein zu Ende des Jahres I 8 I 2 den 
Zaren zur Fortsetzung des Krieges über Rußlands Grenzen hinaus bestimmen können, wenn er nicht als der europäische Staatsmann, der er damals war, neben den nationalen und staatlichen Interessen auch jene überstaatlichen und universalen Ideen in ihm hätte entflammen können? Die Sache der Nation war damals auch eine Sache der europäischen Menschheit überhaupt. So hat der Gedanke der heiligen Allianz seine größte greifbare Leistung getan, als sie noch ungeschrieben war. Denn der universale Gedanke im Staatenleben gehört eben zu den geistigen Elementen, die ihren Segen nur entfalten können, wenn sie unfaßbarer Lebenshauch bleiben. 



\section{Zweites Buch.}

Der preufsische Nationalstaat und der deutsche Nationalstaat. 



\section{Erstes Kapitel.}

\section{Anfänge des preufsisch-deutschen Problems; von Moser zu Friedrich v. Gagern.}

Die im ersten Buche behandelte Frage führt unmittelbar hinüber zu einem zweiten großen Problem der Entstehungsgeschichte des deutschen Nationalstaats, das wir schon hier und da streiften, jetzt aber näher ins Auge fassen miissen.

Wie behauptete sich, darauf lief unsere erste Untersuchung hinaus, die Idee der autonomen Staatspersönlichkeit in Deutschland innitten der Flut von neuen Ideen und Bedürfnissen, die seit dem Ende des I8. Jahrhunderts aus der Tiefe des nationalen Lebens emporstiegen und Einlaß begehrten in den Staat, insbesondere in den preußischen Staat. Er konnte ihnen den Einlaß weder ganz wehren, noch ganz öffnen. Er brauchte sie, um sich zu regenerieren, um sich mit neuen geistigen Kräften zu erfüllen - war doch die Invasion dieser Ideen im Zeitalter der preußischen Erhebung zugleich auch eine Invasion der starken Individuen in den Staat, - er konnte in seiner damaligen Not nicht nur die nationalen, sondern auch die universalen Bestandteile dieser Ideen gebrauchen, mußte dann freilich darauf bedacht sein, diese letzteren beizeiten wieder auszuscheiden, weil sie seine Autonomie schwächten. Die ersteren aber, die nationalen, durfte er, so deuteten wir an, behalten und pflegen, mit ihrer Hilfe konnte er zum autonomen deutschen Nationalstaat 
sich erheben. Jetzt gilt es, diese Meinung einzuschränken und auch die nationalen Ideen auf ihre Brauchbarkeit für den preußischen Staat zu prüfen und ob sie vereinbar waren mit seiner Autonomie und Persönlichkeit. Ja und nein zugleich, wird die Antwort sein. Ja, antwortet der geschichtliche Verlauf der Dinge im großen; das Nein zu begriinden, bedarf es einer eingehenderen Untersuchung.

Die nationale und nationalstaatliche Idee in Deutschland war ja, selbst abgesehen von ihren ursprünglichen universalistischen Begleitideen, in sich nichts weniger als eindeutig. Sie konnte, um hier nur das für uns Wichtigste zu wiederholen, erwachsen sowohl auf dem Boden des deutschen Einzelstaates, wie auf dem Boden der deutschen Kulturnation, die ihre alte politische Einheit wieder gewinnen und jetzt erst recht begründen wollte. Schon das allein konnte zu Streit und Gegensatz führen zwischen der preußischen Staatsnation und der deutschen Kulturnation, die deutsche Staatsnation werden wollte. In jener selben Schrift Friedrich Karl von Mosers vom deutschen Nationalgeist, die wir an den Eingang unserer ersten Untersuchung stellten, taucht dieser Gegensatz schon auf. Er fand seinen deutschen Nationalgeist schwer bedroht durch die "Mißgeburt einer militarisch-patriotischen Regierungsform\&, durch das neue militarische Staatsrecht«, das, so druickte er sich reichsrechtlich korrekt aus, in den ober- und niedersächsischen Landen jetzt aufgekommen sei. $\left.{ }^{1}\right)$ Er klagte über den brandenburgischen Edelmann, der den Hut in die Stirne druicke und von gar keinem deutschen Vaterlande mehr wissen wolle. ${ }^{2}$ ) Vom Standpunkte der deutschen Gesamtnation aus konnte dann der preußische Staat, wie wir hier schon 
sehen, gar nicht als echter Nationalstaat erscheinen, oder, um es paradox zu sagen, je nationaler, je geschlossener er tatsächlich in sich war, um so unnationaler konnte er die übrigen Deutschen anmuten, um so herzlicher konnten sie ihn wegwünschen. Wie kann es, fragte Fichte im Frühjahr I8I ${ }^{1}$ ), uberhaupt zu einem Volke in seinem Begriffe kommen? Griechenland, meinte er, wurde es ebensowenig wie Deutschland. Was hinderte Griechenland? »Antwort: der schon zu feste Einzelstaat. Wenn etwa, so warf er sich cin andermal in diesen Betrachtungen ein"2), Osterreich oder Preußen Deutschland eroberte, warum gäbe das nur Ósterreicher, Preußen, keine Deutsche? Wir erinnern uns, daß er die Nationalität des deutschen Einzelstaates für eine niedere, sinnliche Form der Nationalität hielt und sie nur sekundär gelten lassen oder gar ganz ausrotten wollte, damit nur die Deutschheit übrig bliebe. ${ }^{3}$ ) Als Zwingherrn zur Deutschheit aber ersah er sich zugleich keinen anderen aus, als eben den Herrscher des preußischen Einzelstaates. So sind in seinen skizzenhaften Sätzen schon alle Elemente des Gedankens vorhanden, das Dilemma zwischen dem »schon zu festen Einzelstaate " und dem Einheitspostulate der deutschen Nation dadurch zu lösen, daß der Herrscher des preußischen Einzelstaates selbst Mittel zum Zweck der neuen Deutschheit wird und - seinen alten Staat und dessen spezifische Nationalität aufgehen läßt in ihr. Denn das ist die Konsequenz, die sich aus seinen Prämissen notwendig ergibt. An der Geschichte dieses Gedankens werden wir sehen, daß es sich hier um ein ganz zentrales Problem der deutschen Einheitsbewegung handelt, und wir bewundern den Tiefblick des großen Philosophen, der seinen Grundsätzen nach eil1 un- und iberpolitischer
1) Werke 7,549.
2) 7, 570 .
3) S oben S. 93 f. und II 5 . 
Denker war, aber in sich selbst noch eine zweite Persönlichleit, die Elemente zu einem politischen Denker ersten Ranges barg.

Und wie es mit ihm persönlich dabei stand, so stand es auch mit dem Gedanken selbst. Er war aus unpolitischen Voraussetzungen geboren und barg in sich einen hochpolitischen Kern, der nach und nach sich entfalten sollte. Unpolitisch war vor allem die Voraussetzung, daß der mächtigste und festeste deutsche Einzelstaat seine Nationalität und Persönlichkeit leichthin aufopfern könne zugunsten der Deutschheit. Im ersten Buche sahen wir, wie die autonome Staatspersönlichkeit gebeugt werden konnte unter universale Gebote und Ideale. Hier sehen wir, wie man den Gedanken fassen konnte, daß sie ganz verschwinden und aufgehen solle in etwas Größerem, das sie selbst heraufzuführen habe, daß sie sich opfern solle der Idee der Nation, - eben derselben Idee, die in anderer Ausprägung gerade auch den preußischen Einzelstaat damals innerlich ergriff und stärkte. Wunderliche Durchkreuzung verwandter Tendenzen. Und doch war es zugleich ganz real und politisch gedacht von Fichte, daß die Deutschheit, die deutsche Einheit begründet werden solle durch die Macht des festesten deutschen Einzelstaates, - durch ihn, aber freilich nicht für ihn und im letzten Grunde gegen ihn. Und doch hatte auch diese an sich höchst unpolitische Zumutung an Preußen, seine Nationalität und sich selbst aufzugeben und aufzugehen in Deutschland, einen guten politischen Sinn, denn wie sollten zwei scharf ausgeprägte politische Nationalitäten neben- und ineinander bestehen, ohne sich gegenseitig zu gefährden? So ahnt man hier schon, durch welche Klippen politischer und unpolitischer Anforderungen selbst der naturgemäßeste Weg zur deutschen Einheit, die Einigung durch Preußen hindurchgehen nußte. Preußen war das Mittel und das Hindernis zu- 
gleich für die Aufgabe, die unpolitische deutsche Kulturnation zur deutschen Staatsnation zu erheben.

Manchem, der die deutsche Einheit ersehnte, konnte es auch nur als Hindernis erscheinen, das aus dem Wege geräumt werden müsse. Wie von Friedrich Karl v. Moser zum Freiherrn zum Stein überhaupt, so bemerkten wir fruher ${ }^{1}$ ), eine geistige Linie hinuberging, so auch in dieser Frage. Am I. Dezember I812, als die Morgenröte eines neuen Zustandes für Deutschland heraufzusteigen schien, schrieb er dem Grafen Münster: »Ich habe nur ein Vaterland, das heißt Deutschland ... Mir sind die Dynastien in diesem Augenblicke großer Entwicklung vollkommen gleichgültig, es sind bloß Werkzeuge; mein Wunsch ist, daß Deutschland groß und stark werde, um seine Selbständigkeit, Unabhängigkeit und Nationalität wieder $z u$ erlangen ... Mein Glaubensbekenntnis ... ist Einheit ... Setzen Sie an die Stelle Preußens, was Sie wollen, lösen Sie es auf, verstärken Sie Österreich mit Schlesien und der Kurmark und dem nördlichen Deutschland mit Ausschluß der Vertriebenen ... und machen Sie Ósterreich zum Herrn von Deutschland ich wünsche es; es ist gut, wenn es ausführbar ist." Stein schrieb das im Affekt und im Ärger dariiber, daß man in ihm den Preußen vermutet hatte. Er griff zur Hyperbel, um diesen Verdacht abzuwehren ${ }^{2}$ ), - aber es steckt auch nicht bloß Hyperbel in seinen Worten. Stein ist auch als preußischer Staatsmann, das hat uns jetzt Lehmanns Biographie wieder deutlich gemacht, nie ein unbedingter Vertreter der spezifisch preußischen Staatsidee gewesen. Wenn er Preußen diente, so wollte er Deutschland dienen, und verlangte dann auch von Preußen, daß es Deutschland diene. Wenn aber Preußen dieser Aufgabe, wie er sie faßte, untreu wurde, so lag

1) S. 26 .

9) Vgl. Lehmann, Stein 3, 197 Anm. 
ihm auch an Preußens Existenz nichts. Mag es dann, schrieb er I 809 , 》unbedauert und ohne Nachruhm untergehen «. ${ }^{1}$ ) Und darum schreckte er, wenigstens im Prinzip, nicht vor dem Gedanken zurïck, Deutschlands Einheit durch Preußens Auflösung zu erkaufen.

$\mathrm{Zu}$ den beiden Auffassungen des Problems, von denen die eine keimhaft bei Fichte, die andere momentanjähzornig bei Stein hervorbrach, trat nun auch schon in jenen Jahren noch eine dritte, die wiederum nur ganz keimhaft in Niebuhrs früher behandelter Schrift von I 8 I4 über die sächsische Frage $^{2}$ ) enthalten ist. Das war eine Auffassung, die das Problem nicht in seiner Schärfe und Spannung erkannte, die vielmehr von einer natülichen Harmonie der hier streitenden Gegensätze träumte. Die Gegensätze waren preußische und deutsche Nationalität. Niebuhr liebte die eine wie die andere, aber nur, weil die eine die Vorstufe zur anderen war, weil ihm Preußen eben nicht, so sagten wir früher, der geschlossene autonome Nationalstaat war, sondern $»$ das gemeinsame Vaterland eines jeden Deutschen «, die Quintessenz der deutschen Nation. ${ }^{3}$ )

1) a. a. O. 3, 29.

2) S. oben S. 209 .

") Eine nicht uninteressante Variante stellt das nationalpolitische Programm von Ilendrik Steffens $11 \mathrm{I} \mathrm{I}_{15 / 1} / \mathrm{f}$ dar. (Tschirch, H. Steffens' polit. Entwicklungsgang, Beitrïge zur brand. u. preuß. Geschichte (Schmollerfestschrift) S. 267.) Er fordert eine Lockerung des preußischen Staatsverbandes zugunsten provinzieller Selbständigkeit; nicht etwa, um eine strengere politische Einheit Deutschlands zu ermöglichen, sondern gerade $u m$ sie zu verhindern, um die Mannigfaltigkeit und Sonderart der kleinen Staaten $z u$ bewahren und dadurch die unsichtbare, höhere, geistige Einheit Deutschlands zu erringen, die er zugleich mit allerlei uns wohlbekanntem universalistischem Inhalte sich getiillt denkt. Hier wird also die Forderung der Schwächung Preußens er. hoben auf Grund eines gänzlich unpolitischen, rein universalistisch und kulturell gefärbten Nationalideals In diesem Zusammenhange kann man dann auch daran erinnern, daß schon Herder in den Jahren, in 
Stein und Fichte urteilten über Preußen von deutschem Zentrum aus; Niebuhr jedenfalls auch von einem mehr deutschen als preußischen Standpunkte, obgleich in seinen Augen beide zusammenfielen. Man konnte aber auch rein vom preußischen Standpunkte aus schon damals an eine deutsche Aufgabe Preußens glauben und dann allerdings nur in dem Sinne einer wirklichen Hegemonie Preußens über das übrige Deutschland oder eines durch deutsche Lande erweiterten Großpreußens, jedenfalls aber unter Erhaltung der preußischen Staatspersönlichkeit. Auch diese Politik aber mußte, wenn sie nicht schlechthin nur das Schwert des Eroberers ziehen wollte - und wie konnte das damalige schwache Preußen daran denken - zu ähnlichen Mitteln greifen, ähnliche Forderungen an Preußens inneres Leben stellen wie diejenigen, die Preußens Beruf für Deutschland von einem überwiegend oder rein deutschen Standpunkte aus ansahen. Das heißt, das gegebene Mittel war Machtsteigerung Preußens durch Nationalisierung, hier aber dann in der Form der preufischen Staatsnation, die man so kräftig und lebendig wie möglich sich wünschen mußte. Man konnte, wie Adam Müllers Beispiel uns früher zeigte, eine solche preußische Nationalität auf konservativen Wegen, durch Pflege der alten aristolratisch-agrarischen Struktur der Gesellschaft suchen, und es fehlte in den Reihen des damaligen märkischen Adels nicht an einem Manne wie Marwitz, der ein konservatives Regime im Innern mit einer ehrgeizigen preußischen Machtpolitik in Deutschland und selbst mit starken Konzessionen an die deutschnationale Idee hätte verbinden können. ${ }^{1}$ ) Aber im ganzen

denen sich seine Gedanken über nationale Kultur zu bilden begannen, den Satz gewagt hatte: „Die Staaten des Königs von Preußen werden nicht glücklich sein, bis sie in der Verbruderung zerteilt werden. (Reisejournal von 1769 , Werke hg. von Diintzer $24,425, \mathrm{vgl}$. auch 490 .) l) Vgl. mein Leben Boyens 2, $3 \mathbf{1 2}$ und IIist. Zeitschr. S2, 100. 
war das Ideal und das Interesse der damaligen preußischen Adelspartei weder auf Ausdehnung Preußens in Deutsch. land, noch auch nur auf Bildung einer einheitlichen preußischen Staatsnation, sondern auf Pflege des provinzialen Sondertums gerichtet. Denn dieses verhieß ihnen doch besseren Schutz der aristokratischen Positionen und Traditionen, als ein einheitliches preußisches Gesamtleben mit seinen zentralisierenden und darum nivellierenden, antifeudalen Wirkungen. Eine preußische Staatsnation von höherer Kraft, die von allen Ständen und von alten und neuen Provinzen zugleich getragen wurde, war ohne weitere Zugeständnisse an Bürger- und Bauernstand, ohne Weiterführung der großen Reformen der Erhebungszeit nicht wohl zu schaffen. Das war der zentrale Gedanke des damaligen Kriegsministers v. Boyen. Wenige haben so energisch wie er das Wesen der Nationalität im Politischen, in der "Ubereinstimmung des Volkes mit seiner Regierung « gesucht, und wenn er an preußische Hegemonie in Norddeutschland dachte, so geschah es in allererster Linie in nationalpreußischer Gesinnung. Preußische Machtpolitik und innere liberale Reformpolitik waren für ihn nur verschiedene Funktionen einer und derselben Idee der preuBischen Staats- und Nationalpersönlichkeit.

So trafen also die Wege der rein cleutschen, der deutsch-preußischen und der rein preußischen Nationalpolitik zusammen in der einen großen Forderung, daß Preußen in liberalem Geiste regiert werde. Alle diejenigen, die von Preußen etwas für Deutschland, oder von Deutschland etwas für Preußen erhofften, mochten sie fuir die Zukunft das preußische Sondertum wegwünschen oder erhalten wissen wollen, durften das wünschen. Vor dieser Gegenwartsfrage konnte die Zukunftsfrage, wie das Verhältnis Preußens zu Deutschland sich eigentlich gestalten solle, auch wieder ganz zurïcktreten. Wenn Gneisenau z. B. I I 4 das edel-ehrgeizige Wort aussprach, daß Preußen 
durch den dreifachen Primat in Kriegsruhm, Verfassung und Gesetzen und Pflege von Künsten und Wissenschaften in den übrigen Staaten den Wunsch erwecken solle, mit Preußen vereinigt zu sein, so machte er es sich wahrscheinlich dabei selbst nicht klar, ob das durch Aufgehen in Preußen oder durch ein enges föderatives Band geschehen solle. Aber der Gedanke, daß Preußen, um in Deutschland zu regieren, zuvörderst sich selbst liberal regieren muisse, ist fortan ein wesentliches Prinzip der preußisch-deutschen Bewegung in und außerhalb Preußens. ${ }^{1}$ ) Ihre Freunde wie ihre Feinde erkannten, daß ein $\mathrm{Zu}$ sammenhang bestände zwischen den liberalen und den nationalhegemonischen Tendenzen in Preußen. Metternich wollte, indem er Preußen von liberalen Bahnen abzuziehen bemüht war, zugleich den verborgenen deutschen Ehrgeiz in Preußen niederhalten. Umgekehrt war die Fesselung des öffentlichen Lebens in Preußen nach Pfizers Urteil im Jahre $183^{2}{ }^{2}$ ) »die Haupteinwendung, welche gegen Preußens Hegemonie von seiten des übrigen Deutschlands mit einigem Schein von Grund gemacht wird «.

Es ist nun einer der glänzendsten Züge seines an hellsichtigen Beobachtungen so reichen »Briefwechsels zweier Deutschen«, daß er hier ein Problem entdeckt, ein Dilemma des deutsch-preußischen Einheitsgedankens festgestellt hat, das tief versteckt lag, das erst gesehen werden konnte, wenn man sich das erste große Hindernis der deutsch-preußischen Einigung, das Nebeneinander zweier Großmächte im deutschen Bunde, zuvor aus dem Wege geräumt hatte, wenn man sich ein Deutschland denken konnte ohne Österreich und nun sich überlegte, wie sich Preußen und Deutschland miteinander einzu-

1) Vgl. auch meine Bemerkungen über Gruners Pläne und Harden. bergs Haltung zu ihnen: "Zur Geschichte des Hoffmannschen Bundes", Quellen und Darstellungen zur Gesch, d. Burschenschaft etc, I, $8 \mathrm{ff}$.

2) Briefwechsel zweier Deutschen I. Aufl. S. 202. 
richten hätten. Zuerst mußte es heißen und so heißt es auch bei Pfizer: Ein Bundesstaat mit zwei Großmächten im Bunde ist eine Unmöglichkeit. Dahinter aber erhob sich die Frage, ob und wie denn ein Bundesstaat mit einer Großmacht im Bunde möglich sei. Die Antwort schien zu sein: Es ist möglich, wenn Preußen sich entschließt, liberal zu werden. Aber diese Antwort enthielt eben das neue Dilemma. Gewiß, Preußen mußte, um Deutschland zu gewinnen und an sich zu fesseln, liberal werden, durfte aber nicht ganz liberal werden, wenn es nicht einen ganz neuen Stein des Anstoßes schaffen wollte. Denn es schuf diesen dadurch, daß es die Konsequenz des Liberalismus wirklich zog und sich eine konstitutionelle Verfassung gab. Dann war der preußische Staatsbildungsprozeß abgeschlossen bis zur schärfsten Spitze, dann war die geschlossene preußische Existenz noch geschlossener, als Stein und Fichte sie empfunden hatten, dann waren nicht nur Dynastie, Armee und Bureauliatie die Klammern dieses Staates, sondern es kamen nun noch hinzu die Klammern eines Zentralparlamentes und eines öffentlichen politischen Lebens auf spezifisch preußischer Basis. Das preußische Volk war clann nicht mehr bloß ein vorzügliches Substrat für die Machtpolitik seiner Lenker, es schlug dann nicht nur die Schlachten seiner Könige mit, sondern es konnte auch in deren Rate mitraten und taten. Es konnte, zur politischen Einheit zusammengefaßt, neue und eigene Gedanken und Ziele in die Politik des Staates bringen. Das übrige Deutschland hatte dann nicht nur mit dem politischen Willen der preußischen Dynastie, sondern auch mit dem politischen Willen der preußischen Nation zu rechnen. Das mußte die nationale Vereinigung Preußens mit dem ubrigen Deutschland gewaltig erschweren. Ein solches Preußen als Vormacht Deutschlands war etwas ganz anderes, als ein Staat, dessen 
Zentral- und Einheitspunkt in einer unumschränkten Dynastie lag. Von einer solchen Dynastie, die gleichzeitig Preußen und Deutschland beherrschte, konnte man hoffen, daß sie die größeren Interessen Deutschlands den kleineren Interessen Preußens überordnen würde. War sie aber genötigt, in ihrem Heimatsstaate den Willen einer preußischen Volksvertretung mit $\mathrm{zu}$ beachten, so war die Ausgleichung preußischer und deutscher Interessen viel schwieriger und waren gefährliche Reibungen zwischen dem preußischen und dem deutschen Volkswillen zu befürchten. Ein Preußen ohne Volksvertretung war ein junger Baum, der sich noch leichter in einen gesamtdeutschen Boden verpflanzen ließ. Ein Preußen mit Volksvertretung hatte schon zu starke Wurzeln dafuir.

Es ist interessant $z u$ beobachten, wie diese Gedankenreihe, die wir eben mit eigenen Worten formuliert haben, in Pfizers Geiste allmählich sich gebildet hat, wie sie in der ersten Auflage seines Buches von I83 I im Keime schon daliegt, in der zweiten, die 1832 erschien, dann klar ausgesprochen wird. Da er, eine rechte Grenzerscheinung auf der Scheide zweier deutscher Epochen, ebensosehr Philosoph als Politiker war, so begreift man es, daß er seine Gedanken in der Form einer geschichtsphilosophischen Konstruktion aussprach. Die Deutschen, so beginnt der I7. Brief seines Buches, sollen allerdings fortfahren, das geistige Prinzip der Weltgeschichte zu repräsentieren, aber damit sie das können und damit sie für ihre geistigen Bestrebungen die bis jetzt noch gänzlich fehlende Mitte erlangen, müssen sie sich in Tat und Leben zur Nation verbinden. Darauf folgt der denkwürdige und lehrreiche Satz: »Dabei glaube aber auch ich, daß Deutschland nicht umsonst so lange zersplittert und geteilt bleiben mußte, und in dieser Beziehung ist es mir höchst merkwürdig, 
daß der aus verschiedenen Stämmen zusammengesetzte preußische Staat bis jetzt noch keine allgemeine Volksvertretung, sondern bloße Provinzialstände besitzt. « Er holt dann weit aus, um diesen Satz zu begründen, verweist zuerst alle Versuche, das heilige römische deutsche Reich zu restaurieren, in das Reich der romantischen Träume, zeigt die Kluft, die zwischen Osterreich und Deutschland sich aufgetan hat, in ihrer Unüberbrückbarkeit, und lenkt dann die Blicke auf Preußen, das durch dieselben Ereignisse, die Österreichs Abtrennung von Deutschland besiegelten, näher und inniger mit Deutschland verbunden sei. Das Preußen der Reformzeit und der Befreiungskriege ist es, was ihn anzieht. Es hat, so urteilt er, sich damals einen vollgültigen Rechtstitel auf die Hegemonie erworben. Es ist auch jetzt noch ein jugendlich lebendiger, in Gesundheit und Kraft blühender Staat, aber es hat bis jetzt mehr Kraft als »Schönheit und Form der Seele», es hat ein äußeres, aber kein inneres politisches Leben. Das mußte aber auch so sein, es mußte sich alles politische Leben nach außen drängen, alle Kraft des Staates zusammengenommen werden, um sich unter den Mächten der Welt zu behaupten. So rechtfertigt er auch das jetzige absolutistische und scheinbar illiberale Preußen mit seiner $\gg$ militärischen, aber wohwollenden Diktatur «. So könne es aber nicht lange weitergehen. Preußens Macht müsse entweder zunehmen oder durch übermäßige Anstrengung sich erschöpfen, und da letzteres bei dem erwachten Selbstgefuihl des preußischen Volkes nicht anzunehmen sei, so bleibe ihm nur Wachstum ubrig, - aber, wenn seine Pläne vollständig gelingen sollten, ein Wachstum nicht in selbstsüchtigem, sondern in wahrhaft nationalem Sinne. Durch ein in solchem Sinne errungenes Protektorat über Deutschland wird Preußen einerseits seine politische Existenz in Europa auf unerschütterliche Grund- 
lage stellen, andererseits aber auch seinen bisherigen Gegensatz gegen das übrige Deutschland lösen, und so wird der Entwicklung eines öffentlichen Lebens, der Wechselwirkung und dem Kampf verschiedenartiger Kräfte im Innern Raum geschafft werden. Damit erledige sich dann jener Haupteinwand des übrigen Deutschlands gegen eine preußische Hegemonie.

Dieser Gedankengang ist nicht ganz ausgedacht, oder wenn ausgedacht, nicht ganz gesagt. Die Frage, weshalb es denn »nicht umsonst« war, daß Deutschland so lange zersplittert sein mußte, und weshalb in dieser Beziehung es merkwürdig sei, daß Preußen noch kein Zentralparlament habe, wird erst in der zweiten Auflage I 832 erschöpfend beantwortet. 》Es handelt sich ja, fügt er hier ein ${ }^{1}$ ), $\searrow$ nicht darum, dem preußischen Staate, sondern Deutschland mehr Einheit zu geben\&, und es sei alles daran gelegen, daß der preußische Staat »kein ungebührliches und schädliches Ubergewicht erhalte und die föderativ-republikanischen Elemente Deutschlands dabei geschont und erhalten werden. Eben weil ich eine kraftvolle föderative Staatsverfassung für das Ideal derjenigen Verfassung halte, nach welcher wir schon vermöge der uns eingebornen Vielheit streben müssen, möchte ich im Interesse Deutschlands beinahe wünschen, daß die preußische Monarchie keine allg e mein e Volksvertretung erhielte, sondern statt derselben Preßfreiheit und Provinzialstände, welche mehr als ein bloßes Gaukelspiel wären. Würde die preußische Monarchie im jetzigen Zeitpunkt durch die Einführung von Reichsständen vollständig zentralisiert, so könnte Deutschland leicht statt einer, seine Einheit in der Vielheit verbuirgenden präponderierenden Dynastie einen Oberherrn an dem alsdann in Deutschland übermächtigen preußischen Tolk be-

1) S. $2 \mathrm{I}_{4}$.

M einecke, Weltbürgertum und Nationalstaat. 2. Aufl. 
kommen, wovor uns Gott in Gnaden behüte. Denn es kann zwar eine herrschende Familie Gegenstand der Liebe und Verehrung eines beherrschten Volkes sein, ein herrschendes Volk aber wird dem Hasse des beherrschten, sei es früher oder später, nicht entgehen. Bleibt hiergegen der preußische Staat mehr in gesonderte Provinzen abgeteilt, so vermögen auch die andern deutschen Staaten immer noch das zur Erhaltung ihrer Freiheit nötige Gegengewicht zu bilden ${ }^{1}{ }^{1}$ )

Kurz vorher fügte er noch einen Gedanken ein, der uns hier auch interessieren muß: "So sehr ich ein Freund der liberalen Einrichtungen und des konstitutionellen Lebens bin, lieber wollte ich den gewalttätigsten Despoten zum Beherrscher Deutschlands, als die trefflichsten und vollkommensten Verfassungen ohne nationalen Zusammenhang der einzelnen kleinen Staaten. « Einen absolutistischen Herrscher, wofern er nur ein wirklich deutscher Herrscher sei, will er sich also gefallen lassen, aber nicht die Herrschatt eines konstitutionell in sich abgeschlossenen Staates und Volkes. Darin sehen wir die wichtigste Pointe dieses Satzes und nicht etwa, wie es scheinen möchte, in dem Primate des Einheits- vor dem Freiheitsgedanken. Einheit und Freiheit lagen ihm vielmehr gleichmäßig am Herzen, denn er setzte gleich hinzu: "Keine Macht der Welt ist mehr imstande, der fortschreitenden Verbreitung der freisinnigen Ideen und Institutionen Stillstand zu gebieten ", während die Begründung der Nationaleinheit allerdings gehemmt werden könne. Er war also, darf man folgern, überzeugt, daß die Hohenzollern, die als absolutistische Herrscher Deutsch-

1) Wenn Pfizer an einer späteren Stelle der 2. Auflage (im 2 I. Briefe S. 324) prophezeit, daß Preußen in 20 lahren gewiß ein konstitutioneller Staat sein werde, so will er damit gewiß nicht sein friheres Urteil modifizieren, sondern nur dem Einwurfe begegnen, daß eine Anerkennung des Konstitutionalismus von Preußen nicht zu erwarten sei. 
land einigen würden, zwar beginnen könnten wie der Principe des Machiavell, aber im wohlverstandenen Interesse ihres neuen Reiches selbst enden müßten als moderne liberale Monarchen. $\left.{ }^{1}\right)$ Fichtes Zwingherr zur Deutschheit, der mit dem $Z$ wange der preußischen Macht Deutschland einigt und $Z$ wingherrentum und Preußentum ihm schließlich zum Opfer bringt, lebt hier in merklich modernerer und realerer Form wieder auf.

Pfizer gehörte zu den Denkern, die sich in Einem großen Wurfe ausgeben. Seine späteren Schriften über die deutsche Frage geben im ganzen, trotz vieles Schönen, doch eine mattere Variation seines reichen und glänzenden Erstlingswerkes. Man versteht es, daß es ihm inmitten seiner süddeutschen Freunde und Landsleute nicht leicht wurde, die feine Linie zwischen Empfindung und Erwägung, die er sich gezogen hatte, einzuhalten. Er fühlte geradezu Gewissensnot, als man ihn in Frühjahr I 832 aufforderte, für Rankes historischpolitische Zeitschrift mitzuarbeiten, denn wie war es jetzt möglich, der Sache der Volksfreiheit, die ihn von Preußen abstieß, und der Sache der Nation, die ihn zu Preußen hinführte, gleichmäßig treu zu bleiben? Er lehnte die Aufforderung ab, weil die Zeit noch nicht gekommen sei, wo ein Süddeutscher mit Ehren und ohne Verrat an den Seinigen auf preußische Seite treten könne, und er war imstande dabei, von dem »im Grunde undeutschen Preußentum \& zu sprechen. ${ }^{2}$ ) Dann kamen die reaktionären Bundesbeschlüsse von $I_{32}$ und ${ }_{1} \$_{34}$, die seine Hoffnung auf Preußen noch mehr umdunkelten. Sein liberales Herz schlug nun wieder stärker, und er forderte 1835 , daß Preußen, um den Boden für seine

1) Vgl. auch die Ausfiuhrungen der 2. Aufl. S. 268 .

2) An Perthes 24. März I S32, mit Änderungen zuerst bei Perthes. Friedrich Perthes' Leben 6. Auf. 3, 367, nach den Resten des Originals bei Varrentrapp, Rankes Histor. polit. Zeitschr. etc. Histor. Zeitschr. 99, 70. 
künftige Hegemonie zu schaffen, zuvor reelle Garantien eines freisinnigen Regierungssystems nicht nur durch Entfesselung der Presse, sondern auch durch Einfuihrung von Reichsständen gäbe. $\left.{ }^{1}\right)$ Hat er seine frühere Befürchtung vor einem konstitutionellen Preußen schon sobald fallen lassen? Man kann es nicht mit Sicherheit sagen, da er gleichzeitig auch ${ }^{2}$ ) der Sorge der Deutschen vor einer Unterordnung unter ein herrschendes Hauptvolk wieder kräftigen Ausdruck gibt. Einige Jahre später allerdings, als er seine 》Gedanken über Recht, Staat und Kirche« veröffentlichte (1842), scheint er es wirklich getan zu haben. Er wiederholte nicht nur seine Forderung, daß Preußen zur Vorbereitung seiner küntigen Bundeshauptmannschaft zunächst im eigenen Lande freie Staatseinrichtungen gebe und sich einleben lasse ${ }^{3}$ ), sondern bekämpfte auch die Furcht vor einem Ubergewichte der Preußen in einer kïnftigen deutschen Nationalvertretung als eine Furcht der Schwäche, und, fuhr er fort, »in der Ubertragung der Bundeshauptmannschaft an denjenigen deutschen Fürsten, der allein Macht hat, sie wirksam zu handhaben, kann nur blinde Eifersucht eine Unterwerfung unter dessen Volk erblicken, indem dadurch die ubrigen Deutschen sich dem preuBischen Volk so wenig unterordnen würden, als sie im Reichsverbande den Österreichern untergeordnet waren * . ${ }^{4}$ ) Das Preußentum, vor dem man sich im übrigen Deutschland fürchte, das wie ein drohendes, den Atem hemmendes Gespenst im Hintergrunde stehe, habe - so führte er in einem interessanten Aufsatze von 1846 aus ${ }^{5}$ )

1) Über die Entwicklung des öffentlichen Rechts in Deutschland durch die Verfassung des Bundes S. 372.

2) S. 375 .

3) Bd. 2 S. $339 \mathrm{ff}$.

4) a. a. O. 2, $346 \mathrm{f}$.

5) 》Eine Stimme tiber deutsche Politik. Weil, Konstitutionelle Jahrbucher $1 \$_{4} 61,7 \mathrm{ff}$. 
- seinen Sitz doch nur in dem an Volkszahl und Ausdehnung dem übrigen Deutschland weit nachstelienden Altpreußen. Er mochte also hoffen, daß das rheinisch-liberale Neupreußen, das damals ja kräftig sich regte, das Altpreußentum in Schranken halten und so die Gefahr einer Beherrschung Deutschlands durch den konstitutionell geschlossenen preußischen Einheitsstaat zerteilen werde. So suchte er jetzt selbst die Sorge zu beschwichtigen, die er gehegt und bei seinen Landsleuten geweckt hatte. Aber ihn bewegte und erregte auch noch ein anderer und tieferer Grund. Es war ja seine Größe, daß er sich durch seine, an sich überaus lebendigen konstitutionellen Uberzeugungen und Ideale nicht den Blick für die Lebensfragen der Nation im großen trüben ließ, und er übte ferner auch schon die Kunst, die Schicksale seiner Ideale inmitten der europäischen Realitäten zu berechnen. Er sagte es sich und sagte es zugleich zur Warnung seinen Landsleuten und vor allem den Regierenden in Preußen selbst, daß, wenn Preußen seine Aufgabe in Deutschland verkenne und der reaktionäre Genosse und Diener Osterreichs und Rußlands bleibe, die übrigen konstitutionellen Staaten Deutschlands sich wohl zusammenschließen könnten und müßten, das Ende vom Liede aber ein von Frankreich abhängiges konstitutionelles Deutschland sein würde. Das hieße, so sagte er, »ein neues nationales Leben mit dem Versuche eines nationalen Selbstmordes zu beginnen ${ }^{1}{ }^{1}$ ) Um diesem furchtbaren Schicksal zu entgehen, entschloß er sich, so meinen wir, die kleinere Gefahr, die von Preußen dem übrigen Deutschland drohte, in Kauf zu nehmen. Man sieht, wie die nationale Autonomie Deutschlands im großen und die Erhaltung der preußischen Staatspersönlichkeit sich hier doch wieder gegenseitig bedingen konnten, wie

1) a. a. O. S, 126. 
man das eine bewilligen konnte, um das andere zu retten. Als er I 848 noch einmal das IVort ergriff ${ }^{1}$ ) für seine alten Ideale, die jetzt der Verwirklichung nahe schienen, forderte er von Preußen zwar gewisse, immer noch nicht geringe Opfer als Preis für seine künftige Bundeshauptmannschaft ${ }^{2}$ ), aber nicht das Opfer seiner inneren konstitutionellen Einheit. Wäre er ein Systematiker gewesen, der das Gleichgewicht der Gewalten im konstitutionellen Bundesstaate $\mathrm{zu}$ berechnen hat, so würde er wohl die Gedanken weitergesponnen haben, die er I 83 I und $I_{32}$ hingeworfen hatte. Aber das war er eben nicht, sondern ein Mensch von starker Empfindung für alles Vitale, der eine eigene, feste Grundrichtung wohl bewahren, aber auch Großes dem Größeren opfern konnte.

Mit strengerer Konsequenz entwickelten sich die Gedanken Friedrich von Gagerns, den man mit Pfizer und Welcker zu den Bahnbrechern der Bundesstaatsidee in Deutschland zu rechnen pflegt. Der Mitbegründer der Heidelberger Teutonia von I 8 I 5 hatte mit seinem Bruder Heinrich zusammen in seiner burschenschaftlichen Zeit mit einem Kreise schon Fühlung gehabt, der von einem liberalen Preußen die Einigung Deutschlands erhoffte. ${ }^{3}$ ) Mit

1) Beiträge zur Feststellung der deutschen Reichsgewalt i $S_{4} \&$ (bestehend aus einem schon vor Ende Juni 1848 entworfenen Aufsatze und aus einer Skizze der Bundesverfassung, die einen merkwürdigen Versuch enthält, den engeren Bundesstaat unter Preußen in ein näheres staatsrechtliches Verhältnis mit Österreich zu bringen).

2) Verzichtleistung auf das Recht des Krieges und Friedens, auf eigene Verfügung uber Heer und Flotte, auf das bisherige Recht der Bündnisse und Gesandtschaften, auf w $€$ sentliche Teile der Gesetzge. bung S. 9 .

3) Wentzcke, Zur Geschichte H. v. Gagerns, Quellen u. Darstellingen z. Gesch. der Burschenschaft u. der deutschen Einheitsbewegung I, $163 \mathrm{ff}$. Wentzckes Untersuchung regt überhaupt die heute noch gar nicht erschöpfend zu beantwortende Frage nach den $\mathrm{Zu}$ * sammenhängen der deutsch-patriotischen und preußisch-hegemonischen Ideen von $1 S_{14} / 15$ mit der burschenschaftlichen Früheit und mit den 
dem schnellfertigen Sinne der Jugend meinte er noch I $823^{1}$ ), daß es nur einer klugen und kühnen Politik Preußens bedürfe, um Deutschland in ein Reich zu vereinigen, daß es allerdings dann aber den preußischen Namen in dem deutschen untergehen lassen muisse. Indes verfolgte er die politischen Konsequenzen dieses Gedankens damals nicht weiter. Wohl aber stellte er ein Jahrzehnt später $^{2}$ ) ein Schema des Bundesstaates, wie er sein soll, auf, das unsere Aufmerksamkeit erregen muß. Trotz des abstrakten Standpunktes, von dem aus er sein Thema behandelt, ist es doch kein $Z$ weifel $^{3}$ ), daß er Deutschland im Auge hat, da er vorzugsweise den aus Monarchien zusammengesetzten Bundesstaat erörtert. Drei merkwürdige Forderungen stellte er für diesen. Erstens, es sei »wo nicht erforderlich, doch wünschenswert «, daß die Staaten, welche sich einer gemeinschaftlichen Oberstaatsgewalt unterwerfen, an Größe und Macht nicht zu sehr unter sich verschieden seien, weil, das ist sein Hauptgrund, »der oder die Mächtigsten dann leicht so großen Einfluß und Ubergewicht erhalten, daß die andern Genossen sich unterdrückt fühlen oder glauben, daß ihre Interessen denen der Größeren aufgeopfert werden«. Zweitens, daß der erbliche Monarch, in dessen Hand die Oberstaatsgewalt

Programmen der aus der Burschenschaft hervorgegangenen Politiker von 1848 an. Wentzcke weist z. B. S. 175 nach, daB auch Paul Pfizer schon als Tübinger Burschenschafter ${ }_{1} \$ 23$ die Notwendigkeit der preu. Bischen Führung in Deutschland gelehrt hat.

1) Dieses Datum für seine Denkschrift $»$ Von der Notwendigkeit und den Mitteln, die politische Einheit herzustellen gibt Heinrich v. Gagern, Leben Friedrich v. Gagerns I, 3 I $_{5}$ an, offenbar nach den chronologischen Anhaltspunkten der Denkschrift selbst S. $2 S_{4}$.

2) Über diese Entstehungszeit seiner Denkschrift „Vom Bundes. staat (H. v. Gagern a. a. O. I, 372 ff.) vgl. Brie, Der Bundesstaat I, 54 Anm. 14 u. Treitschke, Deutsche Geschichte 4, 260.

3, Wie auch Brie a. a. O.S. 57 urteilt; vgl. auch Jastrow, Geschichte des deutschen Einheitstraumes. 3. Auf. S. 138 . 
zu legen sei, nicht zugleich Regent eines besonderen Territoriums sein dürfe, »denn er darf kein Sonderinteresse haben, auch mit dem Regenten der Territorien in keiner Beziehung gleichstehen «. Und drittens: Im Bundesstaate sei vor allem dafür zu sorgen, daß zwischen Reichsund Landständen kein Antagonismus entstehe, »denn dieser würde die Regierung sehr erschweren und die Eintracht gefährden «.

Man sieht auf den ersten Blick hier eine Verwandtschaft mit dem Gedanken Pfizers von I83 I und I 832, die vielleicht auf unmittelbarer Einwirkung beruht. Beide erfuillt die bange Sorge vor einem Übergewichte des mächtigsten Staates, beide verlangen von dem Herrscher des Gesamtstaates, daß er aufgehe in dessen Gesamtinteresse, und die Befürchtung Pfizers vor einem Dareinreden der preußischen Reichsstände in die deutschen Dinge wird von Gagern verallgemeinert zu einer Warnung vor einer Einmischung der Landstände überhaupt. Was Pfizer lebhaft und impulsiv empfindet, wird von Gagern umgesetzt in Formeln und Paragraphen eines Systems. So künden sich bei ihm schon die Grundzüge jener von Waitz dann ausgebildeten Bundesstaatstheorie an, wonach Zentralgewalt und Einzelstaatsgewalten streng zu trennen seien, damit eine jede in ihrer eigentümlichen Sphäre ungestört lebe.

Gagern formuliert nun aber auch deswegen so scharf seine Sätze, weil sein Staatsideal überhaupt einen schärferen unitarischen Zug hat als das Pfizers. Dieser wünschte Einheit und Mannigfaltigkeit, Kraft im Ganzen und freiere Bewegung in den einzelnen Gliedern zugleich, damit »die Lebenssäfte der Nation gleichmäßig durch alle Venen und Arterien des großen Bundesstaatskörpers fließen «, und die Despotie eines einzelnen Herrschers über das Ganze betrachtete er doch nur als Not- und Ubergangszustand. Gagern dagegen war von Hause aus Unitarier 
von naiv-burschenschaftlicher Farbe, wandelte sich zwar durch reifere Erfahrung zum Föderalisten um, aber ohne seinen Ausgangspunlit ganz zu verleugnen. ${ }^{1}$ ) Die Bedürfnisse der Gesamtstaatsgewalt interessierten ihn ohne Frage erheblich stärker als die der Einzelstaatsgewalten. Wer aber sollte sie nach seiner Meinung in Deutschland übernehmen? Brie meint: „Es läßt sich nicht annehmen, daß er seiner schon im Jahre $I \$ 23$ ausgesprochenen Uberzeugung von dem Berufe Preußens, Deutschland zu einigen, jemals untreu geworden sei.« ${ }^{2}$ ) Auch wir halten das für höchst unwahrscheinlich. Auf der anderen Seite aber »scheint es, « um wieder mit Brie zu sprechen, »daß er überhaupt zweifelte, ob ein so großer Einzelstaat in einen wahren Bundesstaat sich einordnen lasse«. Denn wie soll man sich etwa die Stellung des mächtigen Königs von Preußen neben einem Kaiser, der doch nach seiner Forderung nicht Regent eines Einzelstaates sein sollte, denken? Brie hat diese Unklarheiten nicht aufzuhellen vermocht. Sie klären sich mit einem Schlage, wenn wir annehmen, daß Friedrich v. Gagern allerdings den König von Preußen zum Kaiser des Bundesstaates machen, zugleich ihn aber loslösen wollte von seiner unmittelbaren preußischen Basis und Preußen auflösen in eine Reihe ungefähr gleich großer Territorien, so daß dann, um mit seinen eigenen Worten zu sprechen, »jedes Territorium für sich einen, einer zweckmäßigen administrativen Einteilung des ganzen Bundesstaates entsprechenden Verwaltungsbezirk « bilden konnte. Ohne diese Lösung würde seine Gesamtstaatsgewalt ein leeres Abstraktum sein, würde ihr "Ansehen und Stabilität» gegenüber den

1) Vgl. Brie S. $54 \mathrm{ff}$.

2) Die von ihm nach Gagern I, $3 \mathbf{1 6}$ zitierte AuBerung F. v. Gagerns darüber saus späterer Zeit « stammt freilich nicht, wie H. v. Gagern behauptete, aus der Zeit kurz vor $\mathbf{I} \$ 4 \delta$, sondern steht in seiner Denkschrift von I $\$_{23}$, a. a. O. S. $2 S_{5}$. 
Monarchen der einzelnen Landschaften fehlen, dic Gagern mit Recht von ihr verlangte, - würde seine Denkschrift eine leere Spekulation ohne praktisches Ziel bleiben. Wir werden bald sehen, wie diese Idee, die wir hier nur durch Vermutung erschließen konnten, in dem Programme eines geistesverwandten Politikers zum unzweideutigen Ausdrucke kam. 


\section{Zweites Kapitel.}

\section{Das preufsisch-deutsche Problem vom März bis zum September 1848 .}

Die deutsche Revolution von 1848 ist, wie man weiß, ein Komplex verschiedener und verschiedenartiger Revolutionen, die zum Teil ihr Ziel erreicht haben, zum Teil aber noch heute ungelöste Probleme hinterlassen haben. Uns soll hier nur das eine Problem beschäftigen, das seitdem wirklich gelöst ist oder doch zu sein scheint: das Problem der Stellung Preußens im nationalen Bundesstaate unter preußisch-hohenzollernscher Führung.

Es gehört zu den größten und fruchtbarsten Wirkungen der Märzereignisse, daß die bisherige Scheidewand zwischen dem preußischen Staate und dem übrigen Deutschland um ein ganz wesentliches Stück verkürzt wurde, daß es mit der reinen preußischen Selbstgenügsamkeit unwiederbringlich dahin war. Aber damit ergaben sich nun Aufgaben, die durch die Losung, daß Preußen an Deutschlands Spitze gehöre, nicht beantwortet, sondern vielmehr erst gestellt wurden. Und wenn das eine große Hindernis der nationalen Vereinigung Preußens mit Deutschland, sein absolutistisches Regierungssystem, jetzt auch fiel durch den Ubergang zum Konstitutionalismus, so erwuchs eben daraus, wie wir sahen, ein neues, noch komplizierteres Hindernis, ein circulus 
vitiosus beinahe. Preußen sollte und mußte, um sich mit Deutschland innerlich auszugleichen und um es führen zu können, konstitutionell werden, aber richtete dann gleichzeitig durch sein konstitutionelles Eigenleben neue Schranken gegen das ubrige Deutschland auf.

$\mathrm{Ob}$ die Führer der nationalen Bewegung in Suidwestdeutschland, die im Februar und März 1848 ihre Blicke auf Preußen richteten, diese Schwierigkeit schon begriffen haben? Die Schriften Pfizers wurden viel gelesen, und die Gedanken Friedrich v. Gagerns sind zum mindesten seinen Brudern Heinrich und Max, die in diesen Wochen an der Spitze jener Bewegung mitstanden, bekannt geworden. ${ }^{1}$ ) Heinrich v. Gagern, der am 6. März I 848 zum leitenden Minister Hessen-Darmstadts berufen wurde, und in noch höherem Grade als er ${ }^{2}$ ) sein Bruder Max, der in nassauischen Diensten stand, waren die Seele der Verhandlungen über eine Reform der Bundesverfassung, die seit dem 7. März zuerst zwischen den süddeutschen Regierungen, dann zwischen diesen und der preußischen Regierung gepflogen wurdell. Wir müssen es uns in diesem Zusammenhange versagen, die immer noch fragmentarische Kunde, die man von ihnen hat, aufzuhellen und uns auf die Frage beschränken, $\mathrm{ob}$ in ihnen bereits die Forderung laut geworden ist, daß Preußen als Preis fur seine Hegemonie über den deutschen Bundesstaat auf seine eigene konstitutionelle Landesvertretung verzichten müsse. Offiziell ist sie jedenfalls, nach unserem bisherigen Wissen, nicht erhoben worden, aber man darf dabei nicht ibersehen, daß die nächste Aufgabe dieser süddeutschen Regierungen und Staatsmänner ja gerade die war, Preußen in die Bahnen

1) Vgl. Iliemenz, II. v. Gagern, Zeitschr. f. d. ges. Staatswissenschaften 55,532 .

2) Vgl. H. v. Gagerns Rede v. 20. März I $\$ 49$, Stenogr. Bericht der Frankfurter Nationalversammlung S. $588_{3} \mathrm{f}$. 
des konstitutionellen Systems uberhaupt erst einmal hineinzuziehen. Preußen mußte sich ihm zum mindesten, wie sich Heinrich v. Gagern am I 5. März ausdrüclite ${ }^{1}$, "möglichst bald nähern«, um das Vertrauen Deutschlands zu gewinnen. Das schließt nicht aus, daß Heinrich v. Gagern schon damals im Sinne Pfizers und seines Bruders Friedrich eine dauernde konstitutionelle Verfassung Gesamtpreußens nicht gewünscht, sondern nur vorläufige konstitutionelle Garantien verlangt hat. Sein Bruder Max, der als Führer der süddeutschen Zirkulargesandtschaft am 2I. März in Berlin eintraf, hat jedenfalls schon damals die Lockerung des preußischen Staatsverbandes als Bedingung der Kaiserkrone angesehen. Camphausen nannte später den Gedanken, daß Preußen allein an die Spitze Deutschlands treten, aber auf allgemeine preußische Stände dabei verzichten müsse, »das alte Projekt Max v. Gagerns . $^{2}$ )

War das nun auch schon der tiefere Sinn des Wortes, das der Märzminister Heinrich v. Arnim den König in der Proklanation vom 2I. März sprechen ließ, daß Preußen fortan in Deutschland aufgehe? Wiederum können wir das nicht beweisen, sondern es nur als möglich vermuten. Heinrich v. Arnim erzählte später - höchst lehrreich für die Einwirkung der Philosophie auf das damalige politische Denken -, daßihm bei dieser Stelle der Hegelsche Gedanke vorgeschwebt habe, daß eine Sache an sich aufgehoben werden solle, um als Kern einer neuen,

1) Im Gespräch mit dem preuß. Bundestagsgesandten Grafen Dönhoff ; Rachfah1, Hist. Vierteljahrsschrift I903, S. 5 16. Vgl. auch H. v. Ga. gerns Darmstädter Progranmrede vom 24. März, bei »H. v. Gagern, ein öftenti. Charakter S. $25 \mathrm{~S}$.

2) An Graf Bülow 20. Nov. 184S. Caspary, Camphausen S. 264. Meine in der I. Auflage darautbin ausgesprochene Vermutung, daß Max v. Gagern schon in den Märztagen so gedacht hat, ist mir von L. Pastor, der eine Biographie M. v. Gagerns vorbereitet, bestätigt worden. 
größeren Sache fortzuleben. ${ }^{1}$ ) Und es klingt daran deutlich an, wenn er am I7. März die »Erweiterung und Erhebung Preußens zu Deutschland « dadurch forderte, daß sein Vereinigter Landtag sich $\gg$ zum deutschen Parlament « erfülle und erhebe; durch Vereinigung mit den Volksvertretern des ubrigen Deutschland solle er zum »freien deutschen Parlamente «werden. ${ }^{2}$ ) Es war damit ja noch nicht gesagt, daß damit eine besondere preußische Reichsversammlung in Zukunft uberflüssig werden sollte, aber wir muissen doch mit der Möglichkeit rechnen, daß dies seine Meinung war. Die Proklamation des Königs vom 2 I. März beschränkte dann seinen Gedanken darauf, daß nicht der ganze Vereinigte Landtag, sondern nur »Organe «

1) Perthes, Beitr. z. Geschichte der Märztage I $\delta_{4} \delta$, Preuß. Jahrbücher 63, 541. Die Formulierung „Preußen geht in Deutschland auf", habe dann Graf Arnim-Boitzenburg gefunden, - aber sie ist nicht von diesem erfunden, sie begegnet, wie wir gleich unten sehen werden, I $S_{45}$ bei Droysen; sodann 18.47 bei (Hoefken). Fragen der nationalen Fortbildung des Zollvereins, Deutsche Vierteljahrsschrift i $\delta_{47}$, I, S. I4I : sollten aber in Preußen Gedanken nach einer politischen Hegemonie gehegt werden, so könnten sie doch nie anders als durch die Kraft der Sympathie des deutschen Volkes, mit dessen Einverständnis in Erfullung kommen, also nur durch eine deutsche Politik; dann aber wïrde nicht Dentschland in Preußen, sondern Preußen in Deutschland aufgehen.، Ferner hat Bunsen, wie Ranke S. W. 49/50 S. 472 mitteilt, schon am 19. März I $S_{4} 8$ sich des Wortes bedient: Preußen müsse im frei gewordenen Deutschland aufgehen, oder aber es werde untergehen. Lnd Bunsen bezog sich in diesen Tagen ausdrücklich auch auf den Pfizerschen Gedanken, daß der deutsche Staat, der Bundeshaupt werden solle, auf jede eigene Politik verzichten müsse, die nicht Bundespolitik sei (21. Närz; Nippold, Bunsen 2, 505 ; L'lbricht, Bunsen u. d. deutsche Einheitsbewegung S. 48). - Schlicblich findet man schon bei Karoline v. Humboldt am IS. Febr. ISI5 das ahnungsrolle Wort: Gott gebe uns Segen, reinen Willen und Gedeihen, so wird eine Zeit kommen, hoffe ich, wo der Name Preußen anfgehen wird in dem deutschen.\& Wilh. u. Karol. v. Humboldt in ihren Briefen 4, 474 .

2) Denkschrift rom 17. März. Nir war nur das in der Broschüre „Der Arnimsche l'rozeB 1852 " mitgeteilte Bruchstück zugänglich. Vgl. Rachfahl, Deutschland, Friedr. Wilh. IV. etc. S. 2SI Anm. 
Das preußisch-deutsche Problem vom März bis zum Sept. I 848.35 I

desselben mit den Fürsten und Ständen des übrigen Deutschlands zusammentreten möchten zu einer zeitweilig sich bildenden deutschen Ständeversammlung. Das wäre wohl auf die Schaffung eines provisorischen Bundesparlamentes aus Delegationen der Einzelkammern hinausgelaufen. So hatten sich auch die süddeutschen Regierungen schon die Bildung eines deutschen Unterhauses gedacht. ${ }^{1}$ ) Daran konnten sie also jetzt nicht Anstoß nehmen, wohl aber scheint ihnen die Idee Arnims, vom Vereinigten Landtage aus das deutsche Nationalparlament zu bilden, höchlichst mißfallen zu haben. „Die angedeutete Absicht, ein provisorisches deutsches Parlament auf den Vereinigten preußischen Landtag zu pfropfen, erschien als ein Mißgriff. $\left.{ }^{2}\right)$ Man sieht hier schon vielleicht eine Differenz der Wege bei innerer Verwandtschaft der Ziele. Beide, Heinrich v. Arnim wie die Süddeutschen, mochten wïnschen, daß Preußen in Deutschland aufgehe, aber es war nun eben die große Frage, ob diese Verschmelzung Preußens mit Deutschland von preußischem oder von deutschem Zentrum ausgehen sollte. Die Gestaltung der Machtverhältnisse im Innern des künftigen Bundesstaates hing davon wesentlich ab. Wie revolutionär Heinrich v. Arnim auch sonst mit den Traditionen der preußischen Politik umsprang, er wollte doch zunächst von Preußen aus das Einigungswerk versuchen. $\left.{ }^{3}\right)$

Damals, nach der Depression der Märztage und dem tiefen Sinken des preußischen Ansehens in Deutsch-

1) Punktation bei Gagern, Friedr. v. Gagern 2, 647. Vgl, auch die preußische Zirkularnote vom 25. März, Roth u. Merck, Quellensammlung zum deutschen öff. Recht I, I72.

2) H. v. Gagern a. a. O. 2, 7I2-7I4. Wir haben leider nur diese späte und vielleicht spätere Erwägungen hineinmischende Quelle.

э) Auch andere politische Kreise nahmen AnstoB an dem Gedanken, die deutsche konstituierende Nationalversammlung mit dem preußischen Landtage zu vereinen. König Friedrich August von Sachsen machte in seinem Schreiben rom 24. März an Friedr. Wilhelm IV., wie 
land, war nicht daran zu denken, daß das übrige Deutschland dem preußischen Wege, den Arnim zeigte, folgen würde, und die Verhandlungen der süddeutschen Regierungen mit Preußen verliefen nach wenigen Tagen im Sande. Die Regierungen, unklar und gespalten in sich und unter sich, ließen überhaupt nun zunächst die populare Bewegung sich über den Kopf wachsen. Nicht bei ihnen, sondern bei den Führern und Denkern dieser Bewegung müssen wir den Faden unserer Frage wieder zu fassen versuchen. Aus dem unsicheren Halbdunkel, in dem die Pläne der südwestdeutschen Politiker und Heinrich v. Arnims lagen, treten wir nun wieder in das helle Licht fester und durchdachter Programme. Und wenn wir die Verwandtschaft der Ziele und die Differenz der Mittel und Wege bei jenen nur eben vermuten konnten, so werden wir jetzt bald das interessante Schauspiel haben, daß ein und derselbe Kopf das ganze Problem, sowohl das Ziel, wie die Differenz der Wege, scharfsinnig erfaßt und durchdacht hat.

Seit Jahren schon trug Johann Gustav Droysen, der pommersche Feldpredigerssohn, der seit I 840 als Kieler Professor das deutsche Recht der Herzogtümer gegen Dänemark verfocht, das Schicksal seines preußischen Heimatsstaates und der großen deutschen Nation zugleich auf dem Herzen. Er vertrat das Ethos der preußischen Reformzeit und die Idee des auf sittliche Autonomie und Staatsbürgertum gegründeten Staates mit starker Leidenschaft und in einer ganz originellen Zuspitzung. Die preußische Monarchie, so führte er I 845 aus ${ }^{1}$ ), hat eine

Hassel, Radowitz 1, 524, berichtet, skein Hehl daraus, daß die Worte. Preußen gehe in Deutschland auf, von den Fürsten so verstanden worden seien, als ob die deutschen Einzelstaaten in Prenßen aufgehen sollten "

1) (Hallische) Allg. Literaturzeitung $\mathrm{I}_{45}, \mathrm{I} \mathrm{ff}$; vgl. G. Droysen, J. G. Droysen $1,274 \mathrm{ff}$ 
Das preußisch-deutsche Problem vom März bis zum Sept. I $\$_{4} 8.353$

Doppelnatur, sie schwankt, ob sie »Staat " oder » Macht ", ob deutsch oder europäisch, ob staatsbürgerlich oder dynastisch sein will. Durch den Wiener Kongreß habe sich Preußen für die Rolle einer europäischen Großmacht entschieden, habe dadurch erst die pentarchistische Oligarchie uiber Europa ermöglicht, zugleich aber seine eigene Entwicklung als deutscher Staat gebunden, ohne doch imstande zu sein, als wirkliche europäische Großmacht sich geltend zu machen. Wenn er die Begriffe Staat und Macht, wie er selbst sagte, "nicht ohne Spitzfindigkeit" einander gegenüberstellte, so riß er freilich unzertrennliche Dinge auseinander und bewies dadurch, daß gerade auch sein Staatsideal ein überstaatliches Leitmotiv hatte. Aber er bewies zugleich, daß er jene Fesselung der preußischen Staatsindividualität durch die europäischuniversalen Interessen der Restaurationszeit, die wir in ersten Buche unserer Untersuchungen darstellten, wohl durchschaute. Man kann an seinem Gedanken, ebenso wie früher an denen Fichtes, die innere Berührung der beiden Probleme, die wir untersuchen, ganz hell erkennen. Die europäisch-universale Fesselung Preußens verwarf er, aber seine deutsch-nationale Fesselung verlangte er. Er verlangte sie in der Meinung, daß sie keine Fesselung sei, daß sie vielmehr der innersten Autonomie der preußischen Staatspersönlichkeit entspringe. Preußen, so war sein Gedanke, muß, wenn es Staat werden, d. h. sich zu lebendigem Staatsbürgertum entwickeln will, sich mit Deutschland völlig identifizieren und $\gg$ in dem deutschen Namen aufgehen«, und das »exklusive Preußentum«, so drückte er sich in seinen $1842 / 43$ gehaltenen Vor lesungen schon aus, muß »im deutschen Namen untergehen $\left.{ }^{1}{ }^{1}\right)$ Staat zu werden fiel für Preußen nach Droysens Auffassung mit der Aufgabe zusammen, deutsch zu werden,

1) 2, 679; vgl. G. Droysen I, 348 ; in der 2. Auflage (1 $886 ; 2$, $4 \mathrm{Sz}$ ) hat J. G. Droysen diese Stelle charakteristisch abgeschwächt. 
- aber gerade um ganz deutsch zu werden, durfte Preußen nach seiner Meinung nicht ganz Staat werden! Als der Vereinigte Landtag Friedrich Wilhelms IV. I847 die liberalen Gemüter in Deutschland erhitzte, fühlte sich Droysen als der einzige Publizist, der die Frage stellte, was es denn für Deutschlands nationale Einheit bedeutet hätte, wenn Preußen statt des Vereinigten Landtages vielmehr die Hoffnungen des Liberalismus erfüllt und mit dem vollen Drittel deutscher Bevölkerung einen konstitutionellen Staat mit allen Konsequenzen des Systems gebildet hätte. ${ }^{1}$ ) Er war sehr zufrieden damit, daß Friedrich Wilhelm IV. das nicht getan hatte. Preußen, und mit Preußen Deutschland, frohlockte er, ist auf gutem Wege.

Und nun kam das Frühjahr I 848 und löste seinen verborgenen Gedanken, die sicherlich schon durch Pfizer genährt waren, vollends die Zunge.

Seine »Beiträge zur neuesten deutschen Geschichte《 ( I 849 ) beginnen mit einem Schreiben vom 6. April I 848 uber die politische Lage Deutschlands, das mit den ihm eigenen spitzen Fingern das Problem anfaßt. ${ }^{2}$ )

Es sei, sagte er, das traurigste Zeugnis der Verschliffenheit der Nation und ihrer politischen Unmündigkeit gewesen, daß sie die preußischen Vorgänge seit I 840 völlig mißverstanden habe. Man habe die Nase dariber gerümpft, daß das Patent vom 3. Februar I $\$_{47}$

1) (Hallische) Allg. Literaturzeitung I $S_{47}$, II, 230 f.; vgl. G. Droysen I, 345 .

2) Wir vermuten, daß es an Heinrich von Arnim gerichtet war. Droysen selbst sagt in seiner Vorrede vom 9. Oktober I $\delta_{49}$ : „Es wird für den Leser ohne Interesse sein, die ursprüngliche Bestimmung des Briefes, der an erster, der Denkschrift, die an letzter Stelle abgedruckt ist, zu wissen.s Diese an letzter Stelle abgedruckte Denkschrift vom 29. April 1848 aber befindet sich, von Droysens Hand (mit zahlreichen Varianten gegenuber dem offenbar nach dem Konzepte veranstalteten Drucke), in Manualakten Heinrich von Arnims (Geh. Staatsarchiv). Sie ist von diesem am 6. Mai auch an Camphausen mitgeteilt worden. 
nicht ein scharf ausgeprägtes konstitutionelles System gebracht habe. "Noch heute glaube ich wie damals, daß ein solches System eine nationale Einigung Deutschlands vorweg unmöglich gemacht hätte. Jene Formel des 3. Februar ließ einer innigen Vergliederung Preußens mit dem ubrigen Deutschland Raum. « Noch deutlicher sind die Schlußworte seiner Denkschrift vom 29. April IS4S (a. a. O. S. 55 f.): 》Preußen wird in Deutschland ,aufgehen', d. h. statt sich konstitutionell abzuschließen als Staatsindividualität, wird es durch Entwicklung der provinzialständischen Verfassung seine Vergliederung mit Deutschland und die der deutschen Staaten mit sich ermöglichen, um seine große und gesunde Machtorganisation - sein Heer- und Finanzwesen voran - als Rahmen fuir das Ganze zu bieten. "1)

In seinem Schreiben vom 6. April erwog er auch den Fall, daß die jetzige Umgestaltung Deutschlands mißlinge. „Dann allerdings, " sagte er, »muß Preußen in schärfster Weise konstitutionell geschlossen werden, muß den Kern, sozusagen das unmittelbare Reichsland, bilden, an das sich nach und nach anschließen mag, was deutsch sein will."

Man kennt die Weise der Droysenschen Geschichtskonstruktionen. Seine geistreiche, an Hegel geschulte Dialektik stellt die Dinge gern auf die Kante und berechnet die Entweder-Oder der Entwicklungen haarscharf; aber Herz und Leidenschaft sind es, die sie treiben und den Gang der Dinge mit fast atemloser Spannung ver-

1) In dem Exemplar fiir H. v. Arnim ist dieser Gedanke nur kurz formuliert: Preußen wird durch die Entwicklung der provinzialständischen Verfassung es erreichen, in Deutschland aufzugehen.` In der Vorrede des Druckes sagt Droysen: ,Der Schluß der Denkschrift blieb unausgearbeitet, nachdem drei verschiedene Entwürfe zu demselben ge. macht worden waren.e Man sieht, wie stark ihn die Formulierung des Gedankens beschäftigte. 
folgen. Das Aufgehen Preußens in Deutschland ist ihm, man möchte sagen, ein Seelenroman, der zugleich als ein logischer Prozeß verläuft. ${ }^{1}$ ) Preußen darf keine Konstitution, darf nur Provinzialstände oder höchstens einen Vereinigten Landtag haben, wenn es sich jetzt in Liebe finden soll mit Deutschland, um in dessen Konstitution ein- und aufgehen zu können, wie eine Seele aufgeht in der anderen. Gelingt das jetzt nicht, so werden die Rollen vertauscht werden, und nicht Preußen, sondern das übrige Deutsch. land wird das Opfer zu bringen, die preußische Konstitution wird den Kern der deutschen zu bilden haben. Man kann hier nicht, wie bei fast allen bisher behandelten Programmen sagen, daß der Standpunkt des Denkers ein außerpreußischer sei. An seinem glühenden preußischen Patriotismus ist gar nicht zu zweifeln. ${ }^{2}$ ) Die Existenz und die Macht des preußischen Staates wird nicht bloß als Mittel zum Zweck, geschweige denn als Hindernis des Zweckes empfunden; vielmehr fallt ihm das Endziel gesunder deutscher und gesunder preußischer Entwicklung von Rechts wegen zusammen. Aber dieses Ziel führt nichtsdestoweniger auf beiden Wegen, die er für möglich hält, zu einer Umschmelzung der ursprünglichen preußischen Staatsindividualität. Auch bei dem zweiten, mehr preußischen Wege, in seinen Augen doch eigentlich einem Notwege, bleibt Preußen nicht das alte Preußen, sondern wird »sozusagen das unmittelbare Reichsland $«$.

Wir wissen nicht, ob Droysen auch im Franlfurter Siebzehnerausschuß, dem damals vom Bundestage die

1) $\mathrm{Zu}$ dieser leisen Änderung der Formulierung der I. Auflage veranlaßt mich der anregende Aufsatz Diethers, Ranke und Droysen, Preuß. Jahrbücher Okt. Ioro, S. I9.

2) G. Droysen a. a. O. I, IV hat mich ganz mißverstanden, wenn er diese Erkenntnis bei mir vermißt hat. Treffend darüber $O$. Hintze in den Forschungen zur brand, u. preuB. Gesch. 23, 303. 
Das preußisch-deutsche Problem vom März bis zum Sept. 1 $\$ 48.357$

Ausarbeitung eines Verfassungsentwurfes übertragen wurde, diese Gedanken vertreten hat. Nötig war das in diesem Augenblicke auch noch nicht, denn sie hatten zwar eine gewaltige Tragweite fur die Zukunft, aber waren erst dann ernstlich zu verhandeln, wenn der Weg zur preuBischen Oberherrschaft von allen äußeren Hindernissen befreit war. Auch der Verfassungsentwurf der Siebzehner nimmt auf sie anscheinend keine Rücksicht. Er scheint sie sogar auszuschließen, wenn er unter den Grundrechten des deutschen Volkes auch das nennt, daß jeder Einzelstaat eine Volksvertretung mit konstitutionellen Rechten habe solle. Aber das schließt nicht aus, daß der Urheber dieses Verfassungsentwurfes, Dahlmanı, dem wir später unter den Vorkämpfern unseres Gedankens begegnen werden, ihn nicht auch schon damals erwogen haben mag. Sollte es - was man nur vermuten, nicht beweisen kann - der Fall gewesen sein, so wird er ihn als eine cura posterior behandelt haben, für die der Moment noch nicht gekommen war. Sicher ist die Forderung seines Entwurfes, daß der kiinftige Kaiser in Frankfurt am Main residieren solle, demselben Geiste entsprungen wie unser Gedanke. Sie verhielten sich zueinander wie ein milderes und ein schärferes Mittel für dasselbe Ubel, wie denn auch Pfizer selbst jetzt im Frühjahr 1848 dieses mildere Mittel anempfahl. ${ }^{1}$ ) Sicher ist ferner, daß scharf blickende Beurteiler schon aus dem Inhalte des Siebzehnerentwurfes eine Gefährdung der preußischen Staatseinheit herauslaserr. Der Breslauer Professor Braniß schrieb2): Vermutlich hätten wohl die Siebzehner den Hintergedanken, daß die Wahl des Reichsoberhauptes auf den König von Preußen fallen und dadurch der Fortbestand der preu-

1) Vgl, oben S. 342 .

2) Die deutsche Nationalverfassung und die preußische Konstitution, Breslau i\$.48, S. 16 f. 
Bischen Staatseinheit gesichert bleiben würde. »Wir stellen dies jedoch in Abrede. Auch wenn unser Monarch den deutschen Kaiserthron bestiege, ginge die preußische Staatssouveränität auf den Gesamtstaat uiber; der innere Verband unserer acht Provinzen wäre darum nicht minder aufgelöst, weil jede derselben die Ehre hätte, zur Hausmacht des Kaisers zu gehören, sie würden vielmehr dadurch nur um so entschiedener lediglich ein Verhältnis zum Reich, aber keine wesentliche Beziehung mehr zueinander haben. "Was er als Konsequenz nur erschloß, wurde von anderen nun auch schon bestimmt verlangt. Die Deutsche Zeitung, das führende Organ der südwestdeutschen Nationalpolitiker, schrieb am 2. Mai: Mehrfach sind uns mündlich und schriftlich Forderungen zugekommen, daß Preußen, danit seine Einheit nicht der deutschen Einheit zu nahe trete, seinen Vereinigten Landtag aufgebe und daß seine acht Provinzen mehr in die Reihe der übrigen kleinen Staaten Deutschlands eintreten. Sie erklärte diese Forderung noch für eine unschuldige Äußerung des Sondergeistes, meinte aber selbst am 6. Mai, daß Preußen sie wohl mit Freuden bewilligen könne, damit ein Verfließen der preußischen in die deutsche Nationalität angebahnt werde. Für unbedingt notwendig hielt sie sie noch nicht und meinte, daß die Verlegung der Residenz des Kaisers nach Frankfurt genügen würde, um ein Aufgehen Deutschlands in Preußen zu verhindern.

Am 27. Mai konnte dann die Deutsche Zeitung eine ihr zugegangene Ausfulhrung des Gedankens bringen, die sie selbst hinterher (an 3. Juni) den »liuhnnsten aller aufgestellten Pläne « nannte. Ihr Verfasser war der Freiherr v. Stockmar, damals Bundestagsgesandter für Koburg, und niedergeschrieben hat er seine Denlsschrift schon in April I 848. ${ }^{1}$ ) Hatte Droysen von deutschem

1) Jenkwürdigkeiten Stockmars S. $4 \mathrm{So} \mathrm{ff}$. 
und preußischem Standpunkt zugleich aus gedacht, so war Stockmars Standpunkt wieder schlechthin außerpreußisch, fast möchte man sagen außerdeutsch. Gewiß war Stockmar, der in der thüringischen Kleinstaaterei ursprünglich aufgewachsen war, ein warmer deutscher Patriot, aber zugleich auch ein Staatsmann der Koburger, d. h. ein Politiker, der das Staatenleben des modernen Europas als einen bildsamen, durch politische Intelligenz und aufgelilärten Liberalismus zu formenden Stoff ansah. Er diente der Monarchie, aber so, wie sie eben die Koburger repräsentierten: also weniger der alten, historisch festgewurzelten, als einer modernen, gewandt errungenen, die in geschickte Balance mit den übrigen modernen Staatskräften zu bringen ist. Prinz Albert glaubte diese Balance für Deutschland damals in der Schaffung eines Wahlkaisertums zu finden, denn nur dieses könne den übrigen Souveränen Deutschlands die Furcht benehmen, unterdrückt und vernichtet $\mathrm{zu}$ werden. ${ }^{1}$ ) Stockmar hatte 'für die Erhaltung der fürstlichen Souveränitäten in Deutschland kein besonderes Interesse, er wünschte mit Recht eine starke und mächtige monarchische Zentralgewalt für Deutschland, also keinen Turnus, auch keinen Kaiser ohne Hausmacht, aber er gab zu, daß ein Kaiser mit bedeutender Hausmacht möglicherweise der Verfassung gefährlich werden könne. Deswegen war sein Rezept: Einen Fürsten mit starker Hausmacht zum Kaiser zu erheben, ihm aber das Aufgeben seiner Hausmacht und die Verwandlung derselben in eine Reichsmacht aufzuerlegen. So kommt er von anderem, doktrinärerem Ausgangspunkte aus zu einem ähnlichen Gedanken wie Droysen: Deutschland soll zerfallen in unmittelbares und in mittelbares Reichsland. Das unmittelbare Reichsland sind die fruheren Stammlande des Kaisers. Im ganzen Reiche ubt der Kaiser mit Reichsministerium und Reichsparla-

1) Springer, Dahlmann 2, 231 . 
ment die Befugnisse aus, die der Siebzehnerentwurf der Bundeszentralgewalt zugewiesen hat. Die nach Abzug dieser Befugnisse übrig bleibenden Teile der Regierungsgewalt werden im unmittelbaren Reichslande ebenfalls rom Kaiser durch Reichsministerium und Reichsparlament ausgeubt, in den mittelbaren Reichslanden den Einzelstaaten uiberlassen. Da ihm nun Preußen durch Bevölkerung, Lage und geschichtliche Erinnerungen dazu berufen schien, den gewünschten Kern des Deutschen Reiches abzugeben, so ergab es sich, daß die bisherigen preuBischen Lande, künftigen unmittelbaren Reiclıslande, fortan nicht mehr unter preußischen Zentralbehörden, sondern unter Reichsministerium und Reichsparlament zu stehen kommen würden. Und nicht Berlin, sondern Frankfurt sollte deren Sitz sein. Auf diese Weise, meinte er, "würde das spezifische Preußentum binnen kürzester Frist verschwinden und rein deutscher $\operatorname{Sinn}$ allenthalben durchbrechen«.

Dieser Stockmarsche Plan steht unter den bisher behandelten Projekten dem Friedrich v. Gagerns geistig am nächsten. Beide sind im Grunde Unitarier und betrachten die Form des Bundesstaates nur als eine Konzession. Beide hatten auch durch ihre persönlichen Lebensschicksale den Zusammenhang niit der heimatlichen Wurzel etwas verloren und sahen auf Deutschland als Deutsche zwar, aber doch von außen. Daß sie im Anblick seines Elends ihm Einheit und Macht vor allem wünschten, versteht man ebenso, wie daß sie sich in den Mitteln dazu vergriffen. Das noch in der Luft schwebende Erbkaisertum Friedrich v. Gagerns kommt in dem Plane Stockmars zwar auf die Erde herab, um sich auf Preußen niederzulassen, aber zerdrückt es dabei zugleich. Preußen ist hier in der Tat lediglich Mittel zum Zweck. Man braucht sein Land und seine Menschen, aber den spe. zifischen Geist, der sie bisher zusammenhielt, braucht man nicht, der soll ihnen ausgetrieben werden. 
Stockmars Art war es nicht, nur publizistisch für seinen Plan zu wirken. Durch seine Beziehungen zu den Kabinetten und Staatsmännern konnte er das $\mathrm{Ohr}$ der Regierenden finden. Er teilte seine Gedanken noch im Mai 1848 an Bunsen, Heinrich v. Arnim und den König Friedrich Wilhelm IV. selbst mit. $\left.{ }^{1}\right)$ Am schnellsten ging begreiflicherweise Heinrich v. Arnim auf sie ein. Bunsen stand wohl schon auf dem Boden Pfizerscher Gedanken und hatte am 19. März vom Aufgehen Preußens in Deutschland gesprochen ${ }^{2}$ ), aber die unitarische Konsequenz erschreckte ilhn nun. "Ich meine, " antwortete er seinem Freunde Stockmar am 17. Mai, 》das Ziel wäre ein Rückschritt. Der Bundesstaat ist über dem Einheitsstaat. " Dennoch machte der Plan tiefen Eindruck auf ihn, und als er Mitte August mit Stockmar in Köln zusammentraf, ließ er, der liurz zuvor noch gegen die Medeakuren der Frankfurter Nationalversammlung gescholten hatte, sich vorübergehend impressionieren und verabredete mit ihm ein gemeinsames Programm, das dem Könige vorgelegt werde und in dem nun auch der Gedanke der unmittelbaren und mittelbaren Reichslande seine Stelle fand. Und vielleicht war es gerade Bunsen, dem dabei die behenden Einfälle kamen, ob nicht der König auf diese Weise am leichtesten aus den Verlegenheiten komme, welche die unfähige Berliner Nationalversammlung ihm verursachte, und ob ferner nicht »die Verfassung Preußens als der unmittelbaren Reichslande und die Reichsverfassung gerade diejenigen großartigeren Elemente darbiete, welche der König für sein Oberhaus wünscht «. ${ }^{3}$ ) Das hieß den König fast bei seiner

1) Denkwürdigkeiten S. 498 ff. Bunsens Leben $2,446$.

\&) S. oben S. 350 .

:) L.eben Bunsens 2, 467. Bunsen hat dann auch weiter geschwankt. Er bielt den Gedanken, Preußen durch das Reich regieren zu lassen, zunächst noch einige Wochen fest (vgl. Ulbricht a, a. O. 
schwächsten Seite packen. Ein Oberhaus sich bilden zu können mit dem glänzenden Material der ganzen ehemals reichsunmittelbaren Aristokratie, und gleichzeitig die Nöte mit der ungeberdigen demokratischen Volksvertretung in Berlin los zu werclen, das konnte ihn wohl blenden. Er hatte den Stockmarschen Plan zuerst, am 7. Juni, zwar freundlich, aber doch bestimmt zurückgewiesen ${ }^{1}$ ), aber jetzt im August, als Bunsen ihm das gemeinsame Programm vortrug, scheint er ihn nicht mehr für so ganz verwerflich gehalten zu haben. 》Das ist ein gefährlicher Köder, und hier gilt's, den Kopf oben behalten «, meinte er. ${ }^{2}$ ) Doch müssen wir erst noch weiter ausholen, bevor wir die Stellung des Königs in dieser Frage näher erörtern können.

Unsere Untersuchung will diejenigen Bestrebungen an das Licht bringen, welche Preußen zur Vormacht Deutschlands machen wollten für das $O p$ fer seiner staatlichen Persönlichkeit, welche also der hohenzollernschen Dynastie und dem preußischen Volke nicht nur etwas nehmen, sondern auch etwas geben wollten. Aber um den Boden zu verstehen, auf dem diese Tendenzen nun weiter gedeihen konnten, müssen wir auch derjenigen Versuche gedenken, welche von Preußen nur heischten

S. 64 u. 66, sein in Druck erscbienenes "Zweites Sendschreiben vom 5. Sept. und den Brief an Camphausen vom 22. Sept., Nippold 2, 479), dann aber verlangte er wieder ein eigenes preußisches Ministerium und preußisches Parlament, das freilich aus den preußischen Mitgliedern des Reichsparlamentes bestehen sollte. Ulbricht S. 64 u. 8o. Die Außerung vom 17. Aug., auf die sich Ulbricht S. 64 noch beruft, fasse ich nicht als eine Kritik des Stockmarschen Planes, sondern als eine Kritik der damaligen Rücksichtslosigkeit der Frankfurter Organe gegen Preußen auf. Über seine Vorschläge vom Januar 1849 vgl. dann unten Kap. 4 .

1) Stocknar S. $506 \mathrm{f}$.

2) Aus den eigenhändigen Randbemerkungen des Königs zu Bunsens Programm, August 1848 . Hausarchiv. 
Das preußisch-deutsche Problem vom März bis zum Sept. I 848.363

und ihm uiberhaupt nichts, oder doch zunächst nichts geben wollten. Es handelt sich hier um den großen Kampf zwischen Frankfurt und Berlin, der im Frühjahr I 848 begann, im Sommer und Herbst 1848 wogte und um die Frage gefuhrt wurde, ob der preußische Staat schon jetzt, vor der Entscheidung über die Oberhauptsfrage, der Autorität der Frankfurter Nationalversammlung und der von ihr geschaffenen provisorischen Zentralgewalt sich zu beugen habe. Während es sich in unserem eigentlichen Thema gewissermaßen um ein Handelsgeschäft, um die Bedingungen eines Fusionsprozesses zwischen dem preußischen Staate und dem übrigen Deutschland handelt, bricht in diesem Kampfe der Gegensatz zwischen Nationalsouveränität und einzelstaatlicher Monarchie ausschließlich hervor. Er hatte aber eine doppelte Spitze. Von seiten der nach links stehenden Parteien der Frankfurter Nationalversammlung wurde er gefuhrt als ein Kampf vor allem um die demokratischen Grundsätze. In der Allmacht der Frankfurter Versammlung hofften sie den Hebel zu haben, um die monarchischen Prärogativen sowohl aus dem Zentrum, als aus den Einzelstaaten Deutschlands herauszuschaffen. In den Parteien der Zentren aber, aus denen sich die spätere Erbkaiserpartei entwickelte, beteiligte man sich vor allem um der künftigen Einheit willen an dem Kampfe gegen den stärksten deutschen Partikularstaat. Auch viele derjenigen, welche in diesem den künftigen Träger der deutschen Einheit sahen oder erhofften, glaubten ihm doch um des Prinzipes willen schon jetzt während des P'rovisoriums gewisse zum Teil erhebliche Opfer an staatlicher Selbständigkeit zumuten zu müssen.

Das erste dieser Opfer, das von der Linken in Frankfurt verlangt, von den Zentren freilich bedeutend abgeschwächt wurde, muß uns hier besonders interessieren, denn es handelte sich um den kritischen Punkt, ob zwei konstituierende Parlamente in Frankfurt und 
Berlin nebeneinander tagen dürften, ob eine preußische Verfassung schon jetzt, vor der Vollendung der deutschen Gesamtverfassung, gebaut werden dirfe. Die Freunde der demokratischen Freiheit, wie die Freunde der strengeren Einheit konnten fürchten, daß das preußische Verfassungswerk durch seine Bestimmungen ihnen in die Quere kommen möchte, und diese Furcht wurde selbst von preußischen Patrioten geteilt, die ihren Heimatsstaat mit Hilfe der Frankfurter Versammlung zur Vormacht Deutschlands erheben wollten. ${ }^{1}$ ) Schon im Vorparlamente wurde der Wunsch laut, daß neben der Frankfurter Versamm. lung keine anderen verfassunggebenden Parlamente berufen würden. Der vom Vorparlamente eingesetzte Fünfzigerausschuß nahm ihn auf und ersuchte Ende April den Bundestag ${ }^{2}$ ), die Uberzeugung des Ausschusses, daß konstituierende Versammlungen in den Einzelstaaten nicht vor Vollendung des deutschen Verfassungswerkes zu berufen seien, einer Beratung und Beschlußfassung zu unterziehen.

Die preußische Regierung aber ließ sich dadurch nicht beirren, die zur Vereinbarung der preußischen Verfassung berufene Versammlung wählen und am 22. Mai in Berlin zusammentreten zu lassen - zum großen Mißvergnügen auch der preußischen Demoliraten. Heinrich Simon aus Breslau versuchte von Frankfurt aus vergebens, den Ministerpräsidenten Camphausen abzumahnen. ${ }^{3}$ ) Johann Jacoby fragte in seiner vom I $S$. Nai ${ }_{4} \&$ datierten Flugschrift 》Deutschland und Preußen « zornig $\left.{ }^{4}\right)$ : Will etwa, nachdem alle Regierungen, nur die preußische nicht, sich

1) Hansen, Mevissen 2, 373 f., 382 .

2) Wigard, Stenograph. Bericht uber die Frankfurter Nationalversammlung S. I27; Roth u. Merck, Quellensammlung zum deutschen öffentl. Recht seit $1 \$_{4} \&$ I, 333 ; Jürgens, Zur Geschichte des deutschen Verfassungswerkes I $848 / 49$ I, 66. Der Rundestag antwortete dilatorisch.

3) I. Mai 1848 ; vgl. Joh. Jacoby, H. Simon S. 233 .

4) Joh. Jacobys Reden u. Schriften II (1877) S. 12 ff. 
gefügt haben, das Ministerium den anderen deutschen Staaten das Ubergewicht Preußens bemerklich machen? In der Frankfurter Versamnlung aber brachte gleich in der zweiten Sitzung am 19. Mai Franz Raveaux aus Köln die Sache zur Sprache, er selbst noch gemäßigt, aber sein Landsmann Venedey stellte am 22. Mai den Antrag, jede Einzelverfassung, die vor Vollendung der Frankfurter beraten und erlassen werden sollte, für null und nichtig zu erklären ${ }^{1}$ ), und Robert Blum sekundierte am 27. Mai mit dem Satze: »Es ist in höchsten Grade gefährlich, daß in Preußen eine Verfassung gemacht wird, denn, wenn sie gemacht ist, sind wir nicht mehr frei. $\ll^{2}$ ) Hier wollte man also am liebsten jetzt gleich ein Joch aufrichten für den preußischen Staat und ihn seines selbständigen Konstituierungsrechtes berauben. Die besonnenere Mehrheit der Versammlung aber begnügte sich mit dem am 27. Mai schließlich beinahe einstimnig angenommenen Antrage Werner, der alle Bestimmungen der Einzelverfassungen, welche mit der von der Frankfurter Versammlung zu gründenden allgemeinen Verfassung nicht übereinstimmten, nur nach Maßgabe der letzteren als gültig erklärte. ${ }^{3}$ ) Sie konnte sich um so leichter auf diese Erklärung vereinigen, als der Camphausensche Verfassungsentwurf für Preußen selbst, der am 20. Mai veröffentlicht worden war, eine Ausgleichung etwaiger Widersprüche zwischen der künftigen deutschen und der preußischen Verfassung durch Abänderung der letzteren in Aussicht stellte.

Nirgends tauchte in diesen Verhandlungen der Gedanke auf, daß Preußen überhaupt keine Verfassung und

I) Stenogr. Bericht S. 40; vgl. auch andere, nicht ganz so weit gehende Amendements das. S. $125 \mathrm{f}$.

2) a. a. O. S. 150 .

3) a. a. O. S. 155; vgl. Mollat, Reden und Redner des ersten deutschen Parlaments S. 6 ff. 
kein Zentralparlament sich gestatten dürfe. Aber die innere Voraussetzung dieses Gedankens wirkte sich in ihnen und wirkte sich weiter auch in der Schaffung der provisorischen Zentralgewalt, die man im Juni 1848 über Preußens Kopf hinweg vornahm, schon aus. Gagern, so berichtete Usedom, der Vertreter Preußens in Frankfurt, am 4. Juni seiner Regierung, betrachtet jetzt Preußen wohl nur noch als Material für das Deutsche Reich, nicht als eigenen Organismus. Als dann das Ansehen der preuBischen Regierung durch den Berliner Zeughaussturm vom I5. Juni noch tiefer sank, mußte er am 24. Juni melden: » Man fragt sich in Frankfurt, wie es möglich sei, sich auf Berlin zu stiutzen und ob es nicht besser sei, ohne Rücksicht auf Preußen die Frankfurter Zentralgewalt so stark und einheitlich zu machen als nur möglich. Nur dadurch könne man hoffen, der wachsenden Anarchie in Deutschland zu begegnen. Die linke Seite kommt auf einem anderen Wege zu demselben Resultat, indem ihr die Schwächung und Beseitigung der preußischen Monarchie natürlich nur erwünscht sein kann.»

Wenn die Frankfurter Demokraten das preußische Landesverfassungswerk hinausschieben wollten, so geschah es, wie wir sahen, in der Hoffnung, es unter das Gesetz der erhofften demokratischen Reichsverfassung zu bringen. Johann Jacoby spielte sich allerdings bei seinem Angriffe gegen das preußische Ministerium auch als Anwalt des unitarisch-nationalen Gedankens auf ${ }^{\mathrm{I}}$ ) Während in Deutschland, sagte er, die Notwendigkeit einer vollständigen Staatseinheit fast überall anerkannt werde, rege sich in vielen Preußen wieder ein unseliger Sondergeist, ein engherziger, beschränkter Provinzialstolz, eine eigensinnige, kleinliche Souveränitätseitelkeit. Aber diese unitarische Gesinnung ging nicht tief. Nichts ist lehrreicher

1) In der oben zit. Flugschrift S. I5. 
für den eigentlichen Charakter der damaligen preußischen Demokratie, für den Primat ihres demokratischen Ideals gegenüber dem nationalen, als der Kurswechsel, den sie im Laufe des Sommers und Herbstes I $\$ 48$ vornahm. Man kann den Wendepunkt deutlich erkennen: es ist der Antrag, den Johann Jacoby am 7. Juli in der preußischen Nationalversammlung stellte. Er und seine Genossen hatten sich gefreut daruber, daß die Frankfurter Versammlung den Reichsverweser wählte, ohne die Fürsten zu fragen, sich aber geärgert daruber, daß sie ihm das monarchische Attribut der Unverantwortlichkeit beilegte, und waren vollends verstimmt, als hinterher die preußische Regierung ${ }^{\text {I) }}$ zwar die Frankfurter Wahl anerkannte, aber sich weitere Konsequenzen aus diesem einseitigen Wahlakte zu verbitten wagte. Diese verschiedenen Gefiihle faßte der Antrag Jacobys zusammen. Die preußische Nationalversammlung also sollte der deutschen Nationalversammlung zugleich ein Lob und einen Tadel aussprechen. Es wäre ein klassisches Beispiel dafür gewesen, in wie komplizierte Lagen man geraten konnte, wenn zwei mächtige Parlamente in Deutschland nebeneinander große Politik trieben. Solche Sorgen fochten die Berliner Demokraten aber nicht an. Sie wollten nur eben ungeniert heute den Frankfurter und morgen den Berliner Hebel benutzen, wenn nur möglichst viel Demokratie dabei herauskam. Damals glückte es ihnen in Berlin damit noch nicht, und Jacobys Antrag wurde am I 2. Juli mit uberwältigender Mehrheit abgelehnt. Aber diese Mehrheit hatte freilich in sich auch keinen dauernden Halt, und die ungeschulte Berliner Versammlung geriet seit dem August I $S_{4} S$ unter den Einfluß der ursprünglich in ihr wenig zahlreichen Linken. Und als nun die Berliner Demokratie entdeckte, daß die Berliner Nationalversammlung für sie brauch-

1) Erklärung des Ministerpräsidenten v. Auerswald in der Sitzung der Berliner Versammlung rom \& Juli. 
barer war als die Frankfurter, entdeckte sie auch ihr preußisches Herz wieder. Ende Juli schon hörte Gustav Rümelin in Frankfurt ${ }^{1}$ ), daß die Berliner Radikalen auf eine Verbindung mit dem Preußentume spekulierten und die preußischen Soldaten bearbeiteten, dem Reichsverweser die Huldigung zu verweigern. Im August I 848 konnte man dann in Berlin reden hören: Die Frankfurter sollten uns mit den Huldigungsparaden verschonen; die Preußen wïrden schon eine ganz gehörige demokratische Verfassung bekommen und brauchten dann kein Reichsparlament mehr für ihre Freiheit. ${ }^{2}$ ) Wie in Frühjahre Frankfurt, so wurde jetzt Berlin die Hoffnung und das Schlachtfeld der Demokratie, und zumal, nachdem sie sich bei ihrem abermaligen Versuch, in Frankfurt obenauf zu kommen, am I 8 . September blutige Köpfe geholt hatte. »Die äußerste Linke, « berichtete ein Berliner Korrespondent der Deutschen Zeitung am I 2. Oktober ${ }^{3}$ ), 》schürt jetzt überall das Feuer gegen die Zentralgewalt und gegen die Nationalversammlung, sie verschmäht es nicht, mit eben den Sonderbestrebungen sich in einen Bund einzulassen, die sie einst so bitter verfolgte."Am 23. Olitober faßte dann die preußische Nationalversammlung einen in die Verfassungsurkunde aufzunehmenden Beschluß über die Rechte der Polen in Posen, der den bereits in

1) Aus der Paulskirche S. 58.

2) Erzählung Sybels im kurhessischen Landtage, Jan. I849, bei Varrentrapp, Meinungen in Kurhessen über d. deutsche Kaisertum I $8+8 / 49$, Histor. Zeitschr. 94, 95.

3) Deutsche Zeitung vom I4. Okt. Sehr hübsch hieriiber auch W. Schrader in seinen Erfahrungen und Bekenntnissen (I900) S. IO4: - Die Ironie der Geschichte zeitigte die seltsame Umkehr, daß gerade die radikalen Abgeordneten, welche im Fruhjahr die Alleingewalt der keichsregierung am rücksichtslosesten verfochten, im Spätherbst sich gern auf die Landtage der Einzelstaaten zurückgezogen hätten, um in diesen den Widerstand gegen die ihnen mißliebige Gestalt der Reichsverfassung aufzubieten.* 
Das preußisch-deutsche Problem vom März bis zum Sept. I 848.369.

Frankfurt gefaßten Beschlüssen schnurstracks zuwiderrief, also eine gröbliche Verletzung des in Frankfurt am 27. Mai festgestellten Prinzips bedeutete. Und am 24. Oktober stellten Waldeck und d'Ester in der Berliner Versammlung den Antrag, daß diejenigen Erlasse der Frankfurter Zentralgewalt oder verfassunggebenden Versamm. lung, welche innere Angelegenheiten der einzelnen Länder zum Gegenstande hätten, für Preußen erst durch die Genehmigung der preußischen Volksvertreter gesetzliche Geltung erlangen könnten.

Es fehlte ja auch inmitten dieser sich mit einem Male so höchst preußisch gerierenden Demokratie nicht an Elementen, die preußische und demolratische Gesinnung durchaus ehrlich und kräftig verbanden und darum auch lebhaft gegen den Gedanken protestieren konnten, ihr Vaterland zu zerschlagen und provinzenweise in Deuschland aufzulösen. ${ }^{1}$ ) Aber nicht bei ihnen, sondern bei dem monarchisch-konservativen Preußentum lag der stärkere Nerv des Widerstandes gegen diese und gegen alle ihr verwandten Ideen. Und ein merkwürdiges Schauspiel war es nun, wie gleichzeitig, auch in Hochsommer und Herbste I 848 , neben dem demokratischen Preußentum auch das alte und urspruinglichere, das monarchisch-konservative Preußentum sich erhob und gegen die Frankfurter Gewalten reagierte. ${ }^{2}$ ) Auch diese Bewegung setzte ein nach der Wahl des Erzherzogs zum Reichsverweser und schwoll dann schnell

1) So Karl Gutzkow in seiner vor dem Frankfurter Septemberaufstand begonnenen und nach ihm veröffentlichten Buche: Deutschland am Vorabend seines Falles oder seiner Größe"S. I9S "Wollte Gott, das ibrige Deutschland besäße viel so feste Schwerpunkte der Einigung und der Kraft wie Preußen. Zertrümmert und zerscblagen soll nur Altpreußen als Idee werden."

2) "Les extrimes se touchent ", sagte aus AnlaB des Waldeckschen Antrages vom 24. Oktober ein Artikel des konservativen, Volksblatts für Stadt und Land 
an, als der Reichskriegsminister am I6. Juli die Huldigungsparade aller deutschen Truppen für den Reichsverweser forderte und als weiter dann noch im Juli der von Dahlmann, Beseler und Mittermaier herrührende Teil des Verfassungsentwurfs erschien, der den Einzelregierungen das Gesandtschaftsrecht entzog und die gesamte bewaffnete Macht Deuschlands der Reichsgewalt unterstellte. Der preußische General von Griesheim konnte wohl schelten, daß dadurch die preußische Armee als solche vernichtet wïrde. Seine Schrift $\gg$ Die deutsche Zentralgewalt und die preußische Armee«, datiert vom 23. Juli $1848^{1}$ ), war ein derber Protest jenes militärischen Preußentums, das die Traditionen Friedrichs des Großen und der Befreiungskriege zugleich hochhielt gegen die Vergewaltigung preußischen Wesens durch unitarische Tendenzen. Man tat der Aufsehen erregenden Schrift. unrecht, wenn man sie schlechthin reaktionär-preußisch schalt. Griesheim ließ deutlich erkennen, daß ihm eine deutsche Einheit mit Preußen an der Spitze schon behagen könne, aber allerdings: »Preußen will auch in der deutschen Einheit Preußen bleiben. " So traf sein Protest auch jene weiterzielenden Gedanken, die das Thema unserer Untersuchung sind, und traf darin zusammen mit dem zweiten Manifest des monarchischen Preußentums, der Schrift des Grafen Arnim-Boitzenburg »Die deutsche Zentralgewalt und Preußen« (August 1848). Der Staatsmann des 19. März schrieb blasser und breiter als der erzürnte Soldat, aber ließ auch keinen Zweifel daran übrig, daß Preußen sich nicht $\gg$ in eine oder einige deutsche Provinzen auflösen « lassen werde. Und was noch

Preußens zur Zentralgewalt seien jetzt äußerste Rechte und äußerste Linke einig. ,Wir sind konservative Sonderbündler. Die Linken sind revolutionäre Sonderbiindler.»

1) Üler seine Autorschaft vgl. Wentzckes Untersuchung in der Histor. Zeitschr. 106, $340 \mathrm{ff}$. 
Das preußisch-deutsche Problem vom März bis zum Sept. I 848.37 I

bedeutsamer war: Auch der künftige Träger der preußischen Krone erfaßte die Situation mit ihren für Preußen zugleich so verheißungsvollen und so bedrohlichen Perspektiven. Es wird in diesen Wochen gewesen sein, daß er zu Ernst von Saucken in Babelsberg ${ }^{1}$ ) das Wort sprach: "Preußen muß als Preußen an die Spitze Deutschlands kommen, nicht aber als Provinz in dasselbe aufgenommen werden, d. h. nicht in dasselbe aufgehen. «

Und hinter diesen hochgestellten Vertretern des preußischen Staatsgedankens regte es sich nun auch im Volke. Ein Berliner Korrespondent schickte der Deutschen Zeitung am I4. Juli schon ${ }^{2}$ ) eine drastische Schilderung des preußischen Stolzes, der sich bedroht fühlte, der zähneknirschend frage: Soll Preußen untergehen? Die Deutsche Zeitung selbst mußte am 23. Juli zugestehen, daß der Gedanke, Preußen zu vernichten, indem man es Deutschland als untertänig inkorporiere, elektrisch in den Massen gewirkt habe, und am 2 August sagte sie von dieser Bewegung: "Die Agitation in Preußen hat eine Stärke erreicht, von der unsere Freunde und Berichterstatter dort glauben, sie sei mächtiger als die Regierung selbst. $\left.\ll^{3}\right)$ Man sieht, daß die Politik der preußischen Regierung, die durch den eigenmächtigen Abbruch des Krieges mit Dänemark, durch den Abschluß des Malmöer Waffenstillstandes vom 26. August ihre Selbständigkeit gegenüber den Frankfurter Gewalten dartat, sich auch auf populare Gewalten stützen konnte. Staat

1) Prinz von Preußen an E. v. Saucken, Babelsberg, is. Nov. 1850: "Was ich Ihnen im Sommer I ${ }_{4} 8$ hier an dieser Stelle sagte, ist und bleibt mein Wahlspruch: ,Preußen muß usw." G. v. Below, Aus der Zeit Friedrich Wilhelms IV. Deutsche Rundschau, Dez. I90I, S. 3 S9.

2) S. $15 \mathrm{~S}_{7}$.

3) Vgl. auch Rümelin I 9. und 29. Juli, a a. O.S. 37 u. 49 ff., Ilansen, Mevissen 1, $568 \mathrm{ff}$. und die von Jastrow a. a. O. S. $285 \mathrm{ff}$. angeführten Zeugnisse. 
und Volk Preußens zuglejch bekundeten ihren Willen, Preußen zu bleiben.

Eben diese Erhebung des preußischen Selbstbewußtseins war es im letzten Grunde, was die politische Luft wieder klärte, die Gedanken der Erbkaiserlichen konzentrierte und das Verfassungswerk in Frankfurt in Fluß brachte. Die Nationalversammlung in Frankfurt konnte und durfte ihre unitarische Politik gegen Preußen nicht überspannen, olnne in den Strudel der demokratischen Revolution zu geraten. Sie ging schon, als sie am 5. September den Malmöer Waffenstillstand verwarf, weiter, als sie bei politischer Besonnenheit durfte, vollzog aber noch zur rechten Zeit den Bruch mit der Linken und widerrief am I6. September ihren ersten antipreußischen Beschluß in der Frage des Waffenstillstandes. Es folgte die Schilderhebung der Republikaner in Frankfurt und ihre Niederwerfung. Wenn die Frankfurter Mehrheitsparteien jetzt nicht den Boden verlieren wollten, blieb ihnen gar nichts anderes ibrig, als nach der Hand derjenigen Macht zu fassen, die sie kurz zuvor noch unter das unitarische Joch hatte beugen wollen. Camphausen, der Vertreter Preußens bei der Zentralgewalt, konnte am 3. Oktober seiner Regierung befriedigt melden: Der Kampf um den Waffenstillstand hat unwillkürlich von neuem und lebhafter das Gefühl zum Durchbruch gebracht, daß es unmöglich ist, ein einiges Deutschland zu gründen, ohne dem mächtigsten Bundesgliede eine seiner Stärke angemessene Stellung einzuräumen. $\left.{ }^{1}\right)$ Es hatte sich als schlechthin unmöglich herausgestellt, schon während des Provisoriums die strengen Forderungen des Bundesstaates auf Preußen auszudehnen, ohne ihm etwas dafuir zu geben, und so stiegen nun die Gedanken des Frühjahrs wieder empor, und die Freunde

1) Geh. Staatsarchiv. 
der preußischen Hegemonie sahen ihre gelichteten Reihen wieder sich füllen. Aber man wollte nun auch nicht bedingungslos vor Preußen kapitulieren. Die preußische Hegemonie, so war auch jetzt noch die Stimmung, darf und wird Deutschland nicht preußisch machen ${ }^{1}$, und man fühlte sich noch stark und einflußreich genug, um der preußischen Krone, die man zur deutschen erheben wollte, eine Gegenrechnung zu präsentieren. In dieser Situation wurden die Gedanken, die Stockmar zuletzt vertreten hätte, wieder lebendig, und nun nicht mehr bloß als interessante These, sondern als integrierendes Stiick eines Parteiprogramms.')

1) Vgl. Deutsche Zeitung vom 2. Sept.

2) In den Verhandlungen des Verfassungsausschusses der Frankfurter Nationalversammlung vom Sommer und Herbst i $\delta_{4} 8$ (Teil I herausg. von Droysen, I 849) wurden sie, weil man noch ungewiß war über den künftigen Träger der Reichsgewalt, nur gestreift, aber nicht eingehend erwogen. Vgl. z. B. Soirons Worte 9. August (S. I67): „Solange wir keine Einrichtung finden, die großen Staaten zu zerstören und die kleinen zu mediatisieren, solange haben wir auch die Schwierigkeit, einen Bundesstaat zu bilden aus Staaten, die zu groß selen für den Bundesstaat und solchen, die zu klein seiens etc. Droysen selbst hielt sich zurück und deutete nur an, daß man das letzte Wort uber die Form der Vereinigung Deutschlands und Preußens jetzt noch nicht sprechen könne (S. 67). - Publizistisch wurde die Forderung der Auflösung Preußens in seine Provinzen im August 1848 noch vertreten in der Flugschrift, Eine preußisch-deutsche Fantasies (Hamburg). Vielleicht, meint sie, könne dann der Preußenkönig zum (nicht erblichen) deutschen Kaiser mit republikanischer Einrichtung für das Reich gewählt werden! (Mitgeteilt von P. Wentzcke.) 


\section{Drittes Kapitel.}

\section{Heinrich v. Gagerns Werbung um Preulsen.}

`Eine baldige definitive Festsetzung der Reichsverfassung und Reichsgewalt, "schrieb der württembergische Abgeordnete Rümelin am I. Oktober aus Frankfurt an den Schwäbischen Merkur ${ }^{1}$ ), , ist die einzige Rettung Deutschlands aus der Anarchie und Verworrenheit seiner gegenwärtigen Zustände. Unter den verschiedenen Plänen und Entwürfen hierzu ist ein bis jetzt nur in kleineren Kreisen besprochener, der vielleicht eine Zukunft hat. Es ist der alte Satz: Preußen geht in Deutschland auf, in einer neuen oder wenigstens bestimmteren und anschaulicheren Form. Die Grundzüge sind folgende: Alle deutschen Staaten mit Ausschlur Osterreichs bilden das eigentliche Deutschland (mit 33 Millionen). Der König von Preußen wird König von Deutschland und residiert in Frankfurt. Ganz Preußen wird unmittelbares Reichsland, steht unmittelbar in Gesetzgebung und Verwaltung unter dem Reichsministerium und der Reichsverwaltung. Der Berliner Reichstag und das preußische Ministerium hören auf; es gibt nur noch Provinziallandtage. Gustav Rümelin, damals ein Mann zu Anfang der Dreißiger, gehörte zu den näheren Freunden Paul Pfizers"), ebenso lebendig philosophisch

l) a. a. O. S. IO2.

2) Laube, Das erste deutsche Parlament 3, 29. 
und politisch zugleich interessiert wie dieser, wenn auch als der Jüngere schon in modernerer Art. IVir brauchen deshalb nicht ängstlich zu fragen, ob er in den eben entwickelten Ideen unmittelbar auf Pfizerschem Boden steht. Jedenfalls wurzelte er in demselben allgemeinen Boden südwestdeutschen politisch-nationalen Empfindens, der ja iberhaupt die Gedanken der Erbkaiserpartei am stärksten nährte. Seine ubrigen Forderungen, die auch das Programm des weiteren Bundes zwischen Deutschland und Ósterreich schon enthalten, können wir in diesem Zusammenhange beiseite lassen. Charakteristisch ist nur, daß er unter den Schwierigkeiten, die diese Lösung der deutschen Frage zu überwinden haben werde, an erster Stelle wohl den Widerspruch Ósterreichs nennt, einen Widerspruch Preußens aber uberhaupt nicht voraussieht. Man war in dem engeren Kreise, in dem dieser Plan jetzt ernstlich erwogen wurde, vermutlich so überzeugt von dem Mehrwerte dessen, was Frankfurt der preußischen Dynastie zu bieten haben werde, daß man an ihrer Geneigtheit, den geforderten Gegenpreis zu zahlen, nicht zweifelte. War es doch immer noch ein schweres Stuick, überhaupt erst einmal in der Frankfurter Versammlung die hohenzollernsche Erbmonarchie über Deutschland durchzusetzen. Für den Fall, daß sie nicht durchzusetzen sei, daß es nur zu einer Zentralgewalt in Form einer Trias oder eines wechselnden Oberhauptes komme, dachte man auch nicht an die Grüdung von unmittelbarem Reichsland. Dieser, um mit Rïmelin zu sprechen, „große und fruchtbare Gedanke" der Verwandlung Pretßens in unmittelbares Reichsland wurde demnach im Oktober als ein strategischer Plan für die Zukunft behandelt, mit dem man erst dann hervortreten könne, wenn die preußische Zentralgewalt geschaffen sei und der auch nur unter dieser Voraussetzung Sinn und Zweck habe. ${ }^{1}$ )

1) Rümelin 29. Okt., a. a. O. S. 116. 
Aber eben in diesen Tagen, da Rümelin diese Erwägungen anstellte, trat die Frage des Verhältnisses Preußens zu Deutschland in eine ganz neue Phase durch den Konflikt zwischen der preußischen Krone und der Berliner Nationalversammlung. Berlin war, wie wir sahen, jetzt das Schlachtfeld der Demokratie; bei der Plenarberatung des Berliner Parlamentes über die preußische Verfassung, die am 12. Oktober begann, erfocht sie einen Sieg nach dem andern, inszenierte am 26. Oktober den Kongreß der deutschen Demokraten in Berlin und am 3I. Oktober die wilden Abendszenen vor dem Schauspielhause, unter deren Druck die drinnen Tagenden den Beschluß faßten, daß die preußische Regierung die Zentralgewalt zum Schutze der in Osterreich bedrohten Volksfreiheit veranlassen solle. Schon war aber auch die Gegenströmung im Flusse, um die Herrschaftsgeluiste der Berliner Versammlung zurïckzudrängen und die Macht des Königtums im Inneren der Monarchie wieder zu entfalten. Das schwache Ministerium Pfuel trat zuruick, und am 2. November erfuhr die Berliner Versammlung, daß Graf Brandenburg das neue Ministerium bilden werde, ein Ministerium ausschließlich nach dem Willen des Königs.

Bisher hatten die Frankfurter Mehrheitsparteien den Vorgängen in Berlin nur geringe Aufmerksamkeit geschenkt. ${ }^{\text {I) }}$ Das preußische Parlament galt als inferior, und sein Verfassungswerk, so sagte die Deutsche Zeitung am I 2. Oktober, sei ja doch nur ein vorläufiges, das durch die Frankfurter Beschlüsse erst bestätigt oder abgeändert werden solle. Aufmerksamer wurde man erst wieder, als die Berliner Versammlung am 23. Oktober es wagte, sich auch gegen die Autorität des Frankfurter Parlaments aufzulehnen. ${ }^{2}$ ) Das terroristische Treiben

1) Ilaym, Die deutsche Nationalversammlung von den Septemberereignissen bis zur Kaiserwahl S. I7.

2) S. o. S. $3^{6 S \text {. }}$ 
der Berliner Straßendemagogie in den letzten Oktobertagen entrüstete in Frankfurt alle Welt. $^{1}$ ) So waren denn nun Franlfurt und Potsdam eigentlich natürliche Verbindete, aber da die preußische Regierung bisher so wenig Energie gegenüber der Berliner Versammlung gezeigt hatte, so glaubten die Frankfurter, die wenige Wochen zuvor erst in der Bedrängnis der Septembertage die preußische Waffenhilfe genossen hatten, jetzt mitleidig auf das preußische Königtum herabsehen zu können. Sie fiihlten sich im sicheren Porte und sahen die preußische Fregatte draußen im Sturme umhergeschleudert. Camphausen richtete am 3. November einen ernsten Mahnbrief an die Minister in Berlin $\left.{ }^{2}\right)$ : : Seit vierzehn Tagen nimmt unser Ansehen in Frankfurt in demselben Maße ab, als man sich berechtigt glaubt, aus den Vorgängen in Berlin auf die Schwäche der Regierung zu schließen. . . Rechnen Sie es mir nicht zu, wenn ich augenblicklich der preußischen Regierung hier nicht die ihr gebührende Geltung schaffen und erhalten kann; dazu reichen der beste Wille, die größte Fähigkeit nicht aus, wenn der Vertreter nicht eine Macht vertritt, an deren Macht geglaubt wird. Der Umfang meines Einflusses in Frankfurt wird mit dem Verlaufe der Berliner Zustände gleichen Schritt halten. «

Die ernsteren Politiker in Frankfurt freilich durften sich der Befriedigung, jetzt am längeren Hebelarme zu sitzen, nicht lange ohne Sorge hingeben. Eben, Anfang November, kamen auch die Nachrichten iiber die Niederwerfung der Revolution in IVien. Osterreich also raffte sich kraftvoll wieder auf, während der erste Schritt zu größerer Energie, den das preußische Königtum durch die Berufung des Grafen Brandenburg tat, unabsehbare

1) Camphausens Bericht vom 30. Okt. G. St. A.

2) Privatschreiben an Bonin, Graf Dönhoff und Eichmann. Abschrift G. St. A. 
neue Wirren in Preußen heraufbeschwor. Hiebe und Gegenhiebe folgten sich nun schnell. Die Berliner Versammlung protestierte am 2. November gegen die Berufung eines unparlamentarischen Ministeriums, die Botschaft des Königs vom 3. November wies den Protest zurück, am 9. November erfuhr die Versammlung die Namen der übrigen neuen, zum Teil noch mißliebigeren Minister und erfuhr weiter, daß sie selbst vertagt und nach Brandenburg verlegt werden sollte. Sie protestierte gegen alles, tagte in Berlin usurpatorisch weiter. Preußen stand, so schien es, in den ersten Stadien einer neuen Revolution, die vielleicht zur Konventsherrschaft der Berliner Nationalversammlung führen konnte. Dann durfte wohl die Linke in Frankfurt, der es mehr auf die Freiheit als auf die Einheit ankam, triumphieren, aber das Verfassungswerk für Deutschland, das die Zentren betrieben, war in seinen Grundfesten erschüttert. Die Frankfurter Versammlung hatte dann einen mächtigen und siegreichen Rivalen in Berlin, und alle jene Sorgen wegen des verderblichen Antagonismus zwischen preuBischem und deutschem Parlament waren dann furchtbar gerechtfertigt. So gewann der Gedanke, dessen Geschichte wir verfolgen, mit einem Male eine ganz akute Bedeutung und wurde zu einem Motive der Entschlüsse, die nun in Frankfurt gefaßt wurden. Wenn wir uns der früheren Außerungen Rümelins erinnern, so dürfen wir die wichtigen Erwägungen, die er am I 8. November anstellte ${ }^{1}$ ), ohne Zweifel in ihrem Kerne wenigstens schon um acht Tage friiher voraussetzen. "Ein vollständiger Sieg der Berliner Versammlung, " sagte er, würde für die Bedeutung der hiesigen verderblich sein, über Deutschland das Unheil einer Spaltung und eine Partei voribergehend zum Ruder bringen, die 
in Deutschland keine Zukunft hat. Uberhaupt hat die Versammlung der Krone gegeniber weder das klare, unzweifelhafte Recht auf ihrer Seite, noch liegt es im Interesse der hiesigen Versammlung, in einseitiger Weise eine gefährliche Rivalin zu begünstigen, die von Rechts wegen hätte gar nicht zusammentreten sollen, und die es in Zukunft gar nicht geben darf, wenn in Deutschland eine vernünftige Verfassung zustande kommt. Denn das Beste wäre, wenn Preußen gar keine Gesamtverfassung, sondern nur Provinzialstände bekäme und die Landesversammlung mit dem Parlament zusammenfiele. Solange diese. zwei mächtigen gesetzgebenden Körperschaften in Deutschland nebeneinander stehen, ist eine Eifersucht und Spaltung unvermeidlich. Die Politik gebietet, auch diese Seite der Sache ins Auge $z u$ fassen.»

Die andere Seite der Sache, die von Rümelin und seinen Parteifreunden erwogen wurde, verriet er der Öffentlichkeit fast zu unvorsichtig. Es war das Bewußtsein ihrer politischen Schwäche, die Erkenntnis, daß die Allmacht der Frankfurter Versammlung ein Traum sei, daß sie nur eine moralische Macht ausüben könne, daß sie diese also möglichst vorsichtig und maßvoll ausüben müsse, um nicht eine Enttäuschung und Beschämung zu erleben. Und doch durfte sie sie andererseits auch wieder nicht $\mathrm{zu}$ bescheiden ausïben, sie durfte nicht gänzlich tatenlos zuschauen, denn von der Zukunft in Preußen hing auch die Zukunft Deutschlands ab. Immer tiefer trieb so die Wucht der Ereignisse die Uberzeugung in die Köpfe hinein, daß alles auf Preußen zunächst anliäme, daß man ohne Preußen nichts anfangen könne. "Stürzt jetzt das Königtum in Preußen, sagten die meisten Mitglieder des Zentrums, und Ihr habt mehr verloren, als gewonnen für Eure eigene deutsche Sache. ${ }^{1}$ ) Wir

1) Laube a. a. O. 3, I42. 
miissen, schrieb die Deutsche Zeitung am I3. November, anders als für Ósterreich, für Preußen alles daransetzen, weil Preußen um jeden Preis unser sein muß und wird ", darum dürfe es jetzt weder in Reaktion noch in Anarchie verfallen. Ein entschiedener, durchschlagender Sieg des Königtums in Preußen konnte also für die Frankfurter Pläne ebenso gefährlich werden, als ein Sieg der Berliner Konstituante.

Eine überaus heikele Lage also, in der Schweigen ebenso gefährlich werden konnte wie Handeln. Man mußte kunstgerecht balancieren, aber die feinsten Köpfe der Versammlung hofften nun eben durch die Kunst der Balance Großes zu erreichen. Es ist einer der interessantesten Momente in der Geschichte der Versammlung, über den uns die Geständnisse Rudolf Hayms vor allem aufklären. Unser Interesse, erzählt er ${ }^{1}$ ), war es, daß die preußische Krone nicht allein, ohne Hilfe der Frankfurter Nationalversammlung siegte: 》Ein Sieg ohne uns erschien als ein Sieg der Bajonette«, er konnte zur schroffen Realition führen. Wenn wir aber, fährt er fort, jetzt die preußische Krone entschieden unterstützten, so leisteten wir ihr eine wesentliche moralische Hilfe, weil wir dann ihren Maßregeln das Odium des Reaktionären nahmen. Unsere wirksame Hilfe aber wiederum verpflichtete die Krone zum Danke gegen uns, wir gewannen dann größeren Einfluß auf sie, und das mußte nicht nur der Sache der Freiheit, sondern auch der Einheit zugute kommen. Siegte die Krone ohne uns, dann wird 》das wiedergestärlite Preußen sich preußischer fühlen als je; es wird dem Eingehen in das Einigungswerk schwer zu überwindende Schwierigkeiten entgegensetzen. Wenn es jedoch eingestehen müßte, daß die Hälfte seiner Rettung bei uns gewesen, wie wäre es dann von neuem auf denjenigen Punkt

1) a. a. O.S. $3+\mathrm{ff}$. 
hingewiesen, aus welchem ihm ja nach unser aller Meinung in Zukunft seine Stärke und ein verjüngtes Leben quellen soll, wie wäre dann zwischen deutschem und preußischem Wesen ein neues, unzerreißbares Band geschlungen, das man menschlich ein Band der Dankbarkeit, politisch ein Band notwendiger Beziehungen nennen möchte .

Und nun darf man wohl diese Erwägungen, die Haym in seinem im Sommer I $\$ 49$ entstandenen Parteiberichte als die damaligen Leitmotive der Kasinopartei entwickelt, kombinieren mit den vorhin angeführten Erwägungen Rümelins vom IS. November. Wenn Haym auch an dieser Stelle der Forderung, daß Preußen kein Parłament haben düre, nicht gedenkt, so spielt er doch an einer späteren Stelle seines Buches (S. 227 f.) mit ausdrücklicher Billigung auf sie an. Innerlich gehören seine und Rümelins Ideen durchaus zusammen. Der Sinn dieser klugen und feinen Politik wäre es gewesen, die Macht der Imponderabilien, über die Frankfurt verfügte, mit der ponderabilen Macht des preußischen Königtums zu verschmelzen, für Herz und Kopf einen starken Arm zu gewinnen. Und man hätte die Hand des preußischen Staates genau in dem Augenblicke erfaßt, da sie am freiesten war, da sie am wenigsten durch jene Lasten beschwert war, die nach Pfizers, Droysens und Rümelins Meinung sein Aufgehen in Deutschland hinderten. Indem er eben dabei war, sein widerspenstiges Parlament zu Paaren zu treiben, war er just auf dem Wege, den jene wünschten. Bunsen hatte, wie wir sahen, schon einmal dem Könige plausibel zu machen gesucht, daß er, wenn er auf die Stockmarschen Ideen einginge, sein unbequemes demokratisches Parlament am leichtesten los würde. Jetzt war der akute Moment dafür gekommen, Sanssouci und Frankfurt hätten sich zusammenfinden können gegen Berlin, die hohenzollernsche Dynastie 
und die deutsche Volksvertretung gegen die preußische Volksvertretung, - eine ganz eigentünliche historische Perspektive voll unerwarteten Inhalts. Man sieht die Schiffe gleichsam in jäher Wendung und die Kompaßnadel in zitternder Bewegung. Wir wissen wohl, was man uns dagegen sagen wird, daß der Kompaß des preußischen Staates schon ganz von selbst gleich wieder die alte Richtung zeigen werde. Aber las hebt doch den Reiz dieser Situation nicht auf. Er besteht vor allem darin, daß die alte stolze Krone der preußischen Könige gegenüber den populären Gewalten des Tages, die sie eben bekämpfte, hier eine nicht minder populäre Allianz hätte finden können. Gegen eine Strömung, die nur Freiheit wollte, hätte sic eine Strömung benutzen können, die Freiheit und Macht zugleich wollte. Mit diesem Liberalismus, der ihr von Frankfurt aus entgegengetragen wurde und der durch den Kampf gegen den gemeinsamen demokratischen Gegner noch weiter umgebildet und auf ihre Seite gedrängt worden wäre, hätte es sich leben lassen. Die Monarchie hätte sich mit dem Zeitgeiste versöhnen können, allerdings aber, wie wir wissen, auf eine ganz neue, rein deutsche, gar nicht mehr preußische Basis stellen lassen muissen.

Das war also der Inhalt jener Politik der Balance, die wir aus Rümelins und Hayms Zeugnis erschließen können. Wir wissen nicht, von wem und wie sie im einzelnen in Frankfurt vertreten worden ist, wir können nur konstatieren, daß sie überhaupt damals gedacht worden ist. Rümelin kann nicht allein gestanden haben mit der Idee, daß man jetzt die Gelegenheit benutzen muisse zu einem Schlage gegen das rivalisierende Parlament iberhaupt, und vielleicht darf man in diesem Sinne die interessante Stelle eines Briefes, den der rheinische Abgeordnete Mevissen am 17. November aus Frankfurt schrieb, deuten: 》Hier ist die Stimmung der 
Kammer dem Könige hold und gegen die Berliner Versammlung, jedochnicht aus rechtlichen, sondern aus einheitlichen Motiven. $\ll^{1}$ )

In den bewegten Plenarverhandlungen der Frankfurter Versammlung über die preußische Frage, die in den Tagen vom I3. bis 20. November stattfanden, wurden die Rümelinschen Ideen freilich von niemandem offen vertreten. Aber der Augenblick war auch nicht angetan dazu, dies arcamum zu enthüllen. Noch war die Sorge vor einer hereinbrechenden Reaktion in Preußen zu lebhaft, noch war andererseits das Endziel des hohenzollernschen Erbkaisertums zu unsicher, als daß man jetzt schon wagen durfte, dem preußischen Volke einen Verzicht auf seine besonderen konstitutionellen Winsche zuzumuten. So kann man es nur als möglich vermuten, aber nicht beweisen, daß die kräftigen Hiebe, welche Bassermann am i $S$. November und Wilhelm Jordan am 20. November gegen die Berliner Nationalversammlung führten, nicht nur ihre juingsten Sünden, sondern ihre ganze Existenz mit treffen sollten. Aber vielleicht war cler Hintergedanke, den wir vermuten, iberhaupt auch zu fein gesponnen für diese Versammlung, zu deren Verhängnissen es gehörte, daß ihre Parteifuihrer keine Staatsmänner waren. IVir waren, klagte $\mathrm{Haym}^{2}$ ), »nur Anfänger in der Kunst, eigenes und fremdes Interesse lilug aneinander zu knüpfen, für die Freiheit die Stuitze der Macht zu gewinnen«. Schon der Antrag, den Haym und seine Parteigenossen selbst am I3. November stellten, war, $u m$ eine Mehrheit in der Versammlung finden $z u$ können, schärfer gegen die preußische Krone, als er sein

1) Hansen, Mevissen 2, 443. Ich habe, durch Küntzels Bemerkungen in der Deutschen Literaturzeitung 1908 S. 460 bewogen, diese Deutung jetzt hypothetischer gefaßt als in der I. Auflage, halte sie aber immer noch für ungezwungener als die von Küntzel versuchte.

2) a. a. $\mathrm{OS} 3 S$. 
durfte, wenn diese gewonnen und zu Dank verpflichtet werden sollte. ${ }^{1}$ ) So glitt denn die Versammlung von dem schmalen Wege, der sie vielleicht zu größerer Macht hätte emporführen können, wieder, wie so oft, hinunter in das Gebiet der Freiheitswünsche. Der Einfluß des Augsburger Hofes, der am weitesten nach links stehenden Partei der Zentren, der Biedermann und der gemütvolle Rießer angehörten, lenkte, wie es scheint, beidemal, wo die Frankfurter Versammlung über die preußische Frage votierte, den Kurs nach links hinüber. $\left.{ }^{2}\right)$ Am I 4. November, unter dem frischen Eindruck der Kunde von Robert Blums Erschießung, beschloß sie denınach, der preußischen Regierung nahezulegen, erstens, die Verlegung des preußischen Parlaments nach Brandenburg zurückzunehmen, sobald die Freiheit seiner Beratungen in Berlin wieder sichergestellt sei, zweitens, sich mit einem Ministerium zu umgeben, welches das Vertrauen des Landes besitze. Und nachdem inzwischen am I 5. November das Berliner Parlament mit dem Beschlusse der Steuersuspendierung auseinandergegangen war, erklärte zwar die Frankfurter Versammlung am 20. November diesen 》die Staatsgesellschaft gefährdenden « Beschluß für null und nichtig, wiederholte aber zugleich ihren Wunsch nach Ernennung eines anderen, volkstümlicheren Ministeriums in Preußen und warf sich zum Protektor aller dem preußischen Volke verheißenen Rechte und Freiheiten auf. Das hieß zugleich implizite dem preußischen Volke sein

1) Antrag Waitz: Stenogr. Bericht S. 3254. Er forderte an erster Stelle, „daß die preußische Krone sich mit einem Ministerium umgebe, welches das Vertrauen des Landes habe", sprach also dem Ministerium Brandenburg von vornberein ein Mißtrauensvotum aus. Vgl. Haym a. a. O. S. 22.

2) a. a. O.S. 24 u. 37. Vgl, auch Pastor, Reichensperger I, 276 und den von G. v. Below veröffentlichten Brief Sauckens vom 28. Nov., Ieutsche Rundschau, Juli 1905, S. ror 
Recht auf eine eigene Verfassung und Volksvertretung garantieren. „Ein leiser Einfluß der populären Stimmung, " schreibt Haym, »lenkte unsere Versammlung von dem Wege strengerer Klugheit ab. " Haym meint damit die Forderung des Ministerwechsels, durch die man die Regierung, die man stiitzen wollte, doch schwächte ${ }^{1}$ ), aber sein Wort gilt auch für die Preisgabe unseres Gedankens, Die liberale Forderung, die man an Preußen stellen wollte, erstickte die politische Forderung, für deren Eintreibung doch gerade dieser Augenblick, wo das preußische Parlament wie ein halb abgeschnittenes Glied am Körper des preußischen Staates hing, so unvergleichlich günstig war.

So war das Resultat dieser politischen Kampagne halb und lahm. Die abgegebenen Noten der Frankfurter Versammlung waren, wie Haym sagt, stark genug, die preußische Regierung zu verletzen, aber zu schwach, ihre demnächstigen Schritte zu dirigieren; die Hilfe, die man ihr brachte, war nicht unumwunden genug, die Unterstützten zur Dankbarkeit zu zwingen«. Der iuble Eindruck wurde noch verschlimmert durch die Proklamation des Reichsverwesers vom 21. November, die den Inhalt des Beschlusses vom 20. November gönnerhaft und anspruchsvoll breit trat. $\left.{ }^{2}\right)$ Die preußische Regierung war mit Grund darüber verstimmmt, daß das Reichsministerium diese Proklamation direkt an die preußischen Oberpräsidenten zur Veröffentlichung sandte und damit schon tatsächlich den preußischen Staat als ein

1) Es ist bemerkenswert, daß Haym, Mitglied des Ausschusses, der diesen Antrag stellte, sich von ihm ausdrïicklich ausschloß, und einen anderen Antrag anfänglich plante, der die Forderung des Ministerwechsels nicht enthielt. Stenogr. Bericht S. $3+38 \mathrm{f}$.

2) $\gg$ Preußen: Die Reichsversammlung zu Frankfurt vertritt die Gesamtheit der deutschen Nation, ihr Ausspruch ist oberstes Gesetz für allel\& u, a. m. Vgl. Stenogr. Bericht S. 3510.

Meinecke, Weltbürgertum und Nationalstaat. 2. Autl. 
Aggregat von Reichsprovinzen behandelte. Sie hätte sich ganz gern von Frankfurt aus helfen lassen, aber, so schrieb Graf Bülow, der jetzige Leiter der auswärtigen Politik, am 26. November an Camphausen ${ }^{1}$ ): Nachdem Nationalversammlung und Zentralgewalt sich halb auf Seite der preußischen Regierung, halb auf Seite der Gegenpartei gestellt haben, ist es jedenfalls der preußischen Regierung unmöglich gemacht, diese Angelegenheit im Einverständnis mit Frankfurt zu erledigen. Sie $m u B$ siejetzt alseine rein innere selbständig durchführen.

Noch konnten die Freunde einer Allianz zwischen Frankfurt und Preußen hoffen, durch persönliche Verhandlung der jetzt von Frankfurt nach Berlin entsandten Reichskommissare das Band wieder zu knüpfen. Aber da sollte sich nun herausstellen, welche Tragweite jene Worte Bülows hatten.

Dreimal eilten in diesen Wochen Vertreter der Frankfurter Gewalten nach Berlin, zuerst der Unterstaatssekretär Bassermann, der vom 9. November ab einige Tage dort weilte ${ }^{2}$ ), dann Simson und Hergenhahn, die an 20. November dort eintrafen, schließlich Heinrich v. Gagern, der Präsident der Versammlung, den Simson von Frankfurt selbst herbeiholte, vom 25. November $a b .{ }^{3}$ ) Bassermann, Simson und Hergenhahn kamen als offizielle Reichskommissare im Auftrage des Reichsverwesers, Gagern zwar mit Billigung des Reichsministeriums ${ }^{4}$ ), aber anscheinend als Privatmann. ${ }^{5}$ ) Basser-

1) G. St. A.

2) Stenogr. Bericht S. 3252 u. 3266.

8) B. v. Simson, Ed. v. Simson S. 133 f.

4) Simson a. a. O. S. 134 .

5) Darauf deutet sein Urlaubsgesuch an die Frankfurter Versammlung vom 24. Nov., Stenogr. Bericht S. 3537. 
mann ebenso wie Simson und Hergenhahn verhandelten also mit gebundener Marschroute, sie hatten lediglich die Instruktionen des von Schmerling geleiteten Reichsministeriums auszuführen und keine Politik zu treiben, die über die Regelung des Verhältnisses zwischen provisorischer Zentralgewalt und preußischer Regierung und über die Schlichtung des Konfliktes zwischen dieser und der Berliner Versammlung hinausging. ${ }^{1}$ ) Demnach erklärten denn auch Simson und Hergenhahn in der Konferenz, die sie am 21. November mit dem preußischen Ministerium abhielten, als den Zweck ihrer Sendung, darauf hinzuwirken, erstens, daß nun, wo Ruhe und Ordnung in Berlin wieder hergestellt sei, die preußische Versammlung am 27. November nicht in Brandenburg, sondern in Berlin wieder eröffnet werden möge, und zweitens, daß die Krone sich baldigst mit einem Ministerium umgeben möge, welches in höherem Grade das Vertrauen des Landes besitze. Die Frankfurter Herren hatten mit diesen liebenswürdigen Eröffnungen bei den preußischen Ministern begreiflicherweise kein Glück, aber sie erhielten bei dieser Gelegenheit eine Andeutung, welche eine ganz neue und unvermutete Perspektive auf die Lösung der preußischen Verfassungsfrage und damit auch auf das künftige Verhältnis Preußens zu Deutschland eröfnete. Graf Brandenburg sprach aus, daß die preuBische Regierung möglicherweise eine freisinnige Verfassung für den preußischen Staat oktroyieren werde für den Fall nämlich - wir folgen dem Berichte, den Camphausen über diese Konferenz von seiner Regierung

1) Ob daneben, wie Arneth, Schmerling S. 25 I zu erzählen weiß, Simson u. Hergenhahn noch eine geheime Instruktion ihrer Gesinnungsgenossen erhalten haben, sich über die Haltung Preußens zur Frage des preußisch-deutschen Erbkaisertums zu orientieren, sei dahingestellt. Die preußischen Akten enthalten nichts dariber. 
erhiclt ${ }^{1}$ ), - daß es von allen Seiten anerkannt sei, daß eine Vereinbarung mit der preußischen Versammlung namentlich jetzt, unmittelbar vor der Vollendung des Frankfurter Verfassungswerkes, als unmöglich betrachtet werden muißte. Graf Brandenburg betonte zwar, daß es sich hierbei nur um eine ins Auge zu fassende Eventualität handle. Und das war sie in der Tat auch damals nur, wie wir später sehen werden. Aber die preußischen Minister zeigten mit jener Andeutung eine Waffe, die die Frankfurter Kommissare erschreckte. Sie war es, die Simson veranlaßte, sogleich am nächsten Morgen nach Frankfurt zurückzureisen, einmal um dort nun für möglichst schleunige Vollendung des Verfassungswerkes zu wirken ${ }^{2}$ ) und sodann, um Gagern herbeizuholen und durch ihn auf die preußische Regierung einzuwirken.

Was war es, was Simson erschreckte? Sein Sohn berichtet ${ }^{3}$ ), er habe zu erkennen geglaubt, daß die Oktroyierung, wenn sie erfolge, mit einem Siege des Ministeriums auch in der öffentlichen Meinung endigen würde. Das kann es schwerlich gewesen sein, was ihm solche Sorge verursachte, daß er Gagern herbeiholte. Wenn das Ministerium sich das Vertrauen des preußischen Volkes wirklich gewann, so war damit ja auf die einfachste Weise der Wunsch der Frankfurter Versammlung vom I4. und 20. November erfüllt und der Stein des Anstoßes beseitigt, zu dessen Wegräumung die Reichskommissare entsandt waren. Näher liegt die Vermutung, daß das Oktroyieren einer Verfassung an sich ihnen mißliebig war. Oktroyieren klang als ein böses

1) Erlaß Builows an Camphausen 22. Nov. G.St. A. Vgl. Simson S. 134 .

2) Bullow beruft sich dafür auf vertrauliche Mitteilungen, die er erhalten.

3) a, a. O, S. I34. 
Wort jedem guten Liberalen ins Ohr. „Eine oktroyierte Verfassung ist gar keine Verfassung", erklärte Welcker im Staatslexikon. ${ }^{1}$ ) Die Vortrefflichkeit dessen, was oktroyiert wurde, entschädigte nicht für den gewaltsamen und despotischen Ursprung und ermangelte der Garantien für die Zukunft. ${ }^{2}$ ) Man versteht es also, daß Hergenhahn nunmehr sich eifrig für einen neuen Versuch, die preußische Verfassung auf dem Wege der Vereinbarung herzustellen, bemiihte, daß der Reichsminister von Schmerling ihn am 23. November auf Simsons Meldungen hin anwies, »jedem Gedanken einer Oktroyierung entschieden entgegenzutreten ${ }^{3}{ }^{3}$ ) Der Osterreicher Schmerling, der keine preußische Spitze über Deutschland wollte, ist frei von dem Verdachte, aus anderen als konstitutionellen Gründen die Oktroyierung bekämpft zu haben, - die Mitglieder der Kasinopartei aber sind es nicht. Man kann dringend vermuten, daß jene Bedenken gegen eine preußische Sonderkonstitution, die Rümelin am IS. November ausgesprochen hatte, jetzt hoch emporschlugen. Rümelin schrieb am 24. November kurz nach der Abreise Gagerns und Simsons nach Berlin: »Man soll eine Oktroyierung im Auge haben, was aber ein

1) IO, IOO.

2) Das führte damals, am $2 \mathbf{I}$. November, auch Radowitz im Sinne der Frankfurter Zentren dem Könige zu Gemüte. Die ganze Rechtsgrundlage für E. K. M. ist das Prinzip der Vereinbarung, sowohl im Verhältnis Preußens zur neuen Reichsgewalt, als im Verhältnis der Krone zu ihrem eigenen Volke. Nichts auf der Welt vermag den Schaden aufzuwiegen, der aus der Vernichtung dieses Rechtsbodens erwachsen würde. Wie auch die oktroyierte Konstitution materiell beschaffen sein möge, sie wird stets als ein Bruch aller rechtlichen Grundlagen und Verheißungen angesehen werden, die Krone völlig in die Luft stellen und die Kevolution verewigen. Diese Überzengung teilen mit mir hier die Männer, die wie Vincke, Schwerin, Jahlmann, Gagern sehr verschiedenartig in ihrem politischen standpunkte, doch von den red. lichsten Absichten erfijllt sind (Hausarchiv).

s) Simson a. a. O. S. 135 u. I+I Aum. 
Unglück wäre. Kein Zweifel, daß er dies Ungliuck vor allem in der konstitutionellen Abschließung Preußens sehen mußte. Bisher war der Abschluß des preußischen Verfassungswerkes im weiten Felde gewesen, man durfte hoffen, mit der deutschen Verfassung fertig zu werden vor der preußischen. Er und seine Gesinnungsgenossen konnten sich deswegen an den Frankfurter Beschlüssen vom 20. November ohne Skrupel und in der Hoffnung beteiligen, daß die Erfüllung der preußischen Freiheitsversprechungen durch eine deutsche, nicht durch eine preußische Verfassung erfolgen werde. Jetzt stand nun plötzlich die preußische Sonderverfassung drohend vor der Tür. Hergenhahn konnte zwar wenige Stunden nach Simsons Abreise von Berlin schon wieder beruhigende Nachrichten an das Frankfurter Reichsministerium erstatten, konnte melden, daß der Oktroyierungsgedanke, wenn er bestanden haben sollte, aufgegeben sei und daß er in dieser Beziehung die zuverlässigste Versicherung erhalten habe. ${ }^{1}$ ) Ohne Zweifel waren die preußischen Minister, als sie die explosive Wirkung ihrer Andeutung sahen, betroffen. Sie dementierten also, was sie 24 Stunden zuvor angedeutet hatten. Damit ist freilich nicht gesagt, daß sie den Frankfurtern Kommissaren zuliebe ihre Absicht wirklich aufgegeben hatten. Das wäre schon an sich höchst unwahrscheinlich und wird ausgeschlossen durch den Inhalt des Erlasses, der am 22. November an Camphausen abging. Auch er sollte beruhigen und die Furcht vor einer nahen Oktroyierung beschwichtigen, aber er leugnete die Oktroyierungsabsicht selbst keineswegs schlechthin, sondern stellte nur fest, daß es sich hierbei um eine auch ins Auge $\mathrm{zu}$ fassende und $\mathrm{zu}$ besprechende Eventualität« handle. Aber hatte sich vielleicht die politische Lage, aus der der Oktroyierungsgedanke entprungen war, in den 24 Stunden vom 2 I.

1) Simson a. a. O. S. I 40 Anm. 2. 
bis zum 22. November geändert, war etwa jetzt die Aussicht auf friedliche Vereinbarung mit der widerspenstigen Berliner Versammlung größer? Nicht im mindesten. Was Simson seinen Frankfurter Parteifreunden am 23. oder 24. November von der Lage in Berlin erzählte und was Rümelin daraufhin am 24. November schrieb, war demnach noch völlig richtig: »Beide Teile stehen sich noch ganz schroff entgegen; das Ministerium will nicht nachgeben, die Nationalversammlung noch weniger. Und dennoch, trotz dieser hoffnungslosen Situation, fügte Rümelin hinzu, daß die Olitroyierung »wahrscheinlich noch verhindert werden kann ${ }^{1}$ ) Worauf gründete sich nun dennoch diese Hoffnung: Sicherlich nicht auf Hergenhahns bestimmte, wenn auch, wie wir wissen, inhaltlich falsche Meldung vom 22. November, daß der Oktroyierungsgedanke überhaupt aufgegeben sei, denn hätte Rümelin diese Meldung schon gehabt, so würde er keine bloße Hoffnung, sondern eine Tatsache zu melden gehabt haben. Er muß also einen besonderen, versteckteren Grund zu seiner Hoffnung gehabt haben.

Vielleicht kommen wir der Sache näher, wenn wir annehmen, daß Simson und Gagern die Überzeugung Rümelins von der Schädlichkeit eines preußischen Parlamentes schon damals geteilt haben. Wir können diese Annahme wirklich, zwar nicht für Simson, aber, was wichtiger ist, für Gagern beweisen. Am 20. November schrieb Camphausen aus Frankfurt an den preußischen Unterstaatssekretär und Verweser des Auswärtigen Amtes, Grafen Bülow $^{2}$ ): "Das alte Projekt Max von Gagerns: Preußen an der Spitze und allein, aber ohne allgemeine Stände

1) Aus der Paulskirche S. 125.

2) Caspary, Camphausen S. 264. Schon H. v. Gagerns Worte vom 26. Okt. (Stenogr. Bericht S. 2900): "Ich bin allerdings der Meinung, $\mathrm{da} B$ an die Spitze des Bundessta ats ein einheitliches Oberhaupt gehört, was schon den Begriff einer Hegemonie Preußens ausschließt \& sind vielleicht in diesem Sinne zu deuten. 
in Preußen und statt deren Provinzialstände, wird jetzt auch von Heinrich von Gagern befürwortet. E Eine überaus gewichtige Meldung. Sollte nicht hierdurch auch Licht auf Gagerns Reise nach Berlin fallen! Simsons Absicht bei seiner schleunigen Rückreise nach Frankfurt war einmal, wie wir uns erinnern, Gagern herbeizuholen, dann aber auch auf rascheste Vollendung des Frankfurter Verfassungswerlies hinzuwirken, das heißt: das preußische Erbliaisertum sollte so bald wie möglich beschlossen werden, Gagern aber sollte, so dürfen wir uns nun den Zusammenhang herstellen, eben mit der Lockspeise dieses Erbkaisertums die preußische Regierung davon abbringen, eine konstitutionelle Verfassung fiir Preußen zu olitroyieren. Das wäre dann der Grund für jene Hoffnung Rumelins gewesen. Gagern sollte und wollte danach, so meinen wir, nicht bloß, wie man bisher annahm, gegen den illiberalen Gedanken des Oktroyierens an sich, sondern gegen eine preußische Sonderverfassung uberhaupt wirken. Erst so wird seine Mission ganz verständlich, erst so erhält sie tiefere Begruindung und inneren Zusammenhang. Bisher mußte man annehmen, daß Gagerns Reise nach Berlin zunächst durch die von Simson gemeldeten Oktroyierungsabsichten veranlaßt war und daß er diese Gelegenheit dann benutzt lıabe, um den König für die Annahme der Frankfurter Krone persönlich zu bearbeiten. Nach unserer Annahme aber steht der preußische und der deutsche Teil seiner Berliner Werbung im engsten kausalen Zusammenhange. Sein Kampf gegen die Oktroyierung war ein Kampf gegen die Schranke, die dem Aufgehen Preußens in Deutschland plötzlich entgegengestellt zu werden drohte. Dieser und gerade dieser Moment mußte ihm demnach als der wichtigste erscheinen, wo er den König persönlich auf den Berg fuihren konnte, von wo aus man die Herrlichkeit des neuen Deutschen Reiches schauen konnte. 
Am frühen Morgen des Tages, an dem der König mit Gagern sprach, fand er in den Losungen der Brüdergemeinde die Worte: "Und der Versucher trat zu ihm."1) Man weiß es, mit wie heißen Worten dann dieser Versucher in wiederholten Unterredungen den König, daß er die Kaiserkrone annehme, umworben hat, wie er ihm zugerufen hat: »Und Fluch vor allem der Geduld « $\left.{ }^{2}\right)$, wie ihn der König umarmt hat, hinterher aber doch mit einem Gemisch "von Bewunderung und Abscheu auf den Versucher zurückgeblickt hat. Hier warb, so dürfen wir nun sagen, nicht nur der Führer der Erbkaiserpartei um den Monarchen, den sie für ihre Pläne brauchte, sondern hier warb zugleich auch Deutschland um den preußischen Staat, daß er sich selbst und seine Persönlichkeit preisgebe. Man brauchte das Blut dieser Staatspersönlichkeit, um Deutschland damit zu nähren, und man meinte, daß, wenn dieser Staat sich nicht opfere, er dem übrigen Deutschland die Lebenshuft wegnehmen werde. Der preußische Staat sollte das a'er sacnum Deutschlands sein.

Doch wir hören die Stimmen derer, die von uns keine Metaphern, sondern solide Quellenzeugnisse verlangen. Wir haben bereits nachgewiesen, daß Gagern in jenem Momente der Meinung war, daß Preußen keine zentrale Volksvertretung haben solle, und wir können daraus mit voller Sicherheit schließen, daß er demnach auch ein prinzipieller Gegner der preußischen Olitroyierungsabsichten in jeder Hinsicht, nicht nur was ihre Form, sondern auch was ihren Inhalt betraf, gewesen sein muß. Schon danach kann man mit höchster Wahrscheinlichkeit weiter schließen, daß Gagern, da er eben durch die Nachricht von diesen Oktroyierungsabsichten zu seiner Reise nach Berin veranlaßt worden ist, mit der Absicht

\footnotetext{
1) Ludw. v. Gerlach 2, 32 .

2) Simson $\triangle$. I 36 .
} 
hinging, sie zu bekämpfen und für sein Programm »Preußen an die Spitze, aber ohne allgemeine Stände» zu wirken. Aber man wird fragen, ob und wie er nun in Berlin diesen Wunsch vertreten und ob er ihn wirklich rund heraus zur Bedingung fuir das preußische Erbkaisertum gemacht hat.

Fragen wir zunächst nach den Stimmen aus seinem Kreise. Man darf darauf hinweisen, daß der Frankfurter Korrespondent der Allgemeinen Zeitung, als er am 24. November die Reise Gagerns nach Berlin meldete, ihr eine unmittelbare Spitze gegen die Existenz der preußischen Nationalversammlung $\mathrm{gab}^{1}$ ): 》Auf diese Lage (nämlich der Frankfurter Verfassungsberatungen) fußend, kann Gagern dem König von Preußen neue Vorschläge wegen der vereinbarenden deutschen (so; gemeint jedenfalls: preußischen) Landesversammlung machen. Wer verhehlt sich, daß diese konstituierenden Versammlungen in den Einzelstaaten das tiefste Hindernis sind für Herstellung der Ruhe und für Herstellung der deutschen Gesamtverfassung. "Indessen, wird man einwenden, beruht diese Meldung wirklich auf Information aus dem Gagernschen Kreise und nicht vielleicht nur auf Kombination? und richtet sie sich wirklich gegen die definitive konstitutionelle Abschließung Preußens oder vielleicht nur gegen die damalige Berliner Nationalversammlung? Der reine Wortlaut spricht fuir die letztere Deutung, aber nach dem, was wir über Rümelins und Gagerns Ansichten schon wissen, dürfen wir auch die andere Deutung nicht ausschließen.

Ein weiteres, Beachtung verdienendes Zeugnis liegt vor in den sPolitischen Briefen und Charakteristiken aus der deutschen Gegenwart", die I 849 erschienen und, wie man weiß, Gustav v. Usedom zum Verfasser haben,

1) Beilage zu Nr. 333 rom 28. Nov. 
den späteren Rivalen Bismarcks, der zur Zeit der Wahl des Reichsverwesers Preußens Vertreter am Bundestage gewesen war und bei Friedrich Wilhelm IV. persona grata war. Er sagt in dem von Weihnachten 1848 datierten Schlußbriefe seines Buches ${ }^{1}$ ): ¿ Ofter schon sind Kaiseranträge von Frankfurt nach Berlin gelangt, wenn Berlin einwilligen wolle, den preußischen Staat in drei, fünf oder acht Teile zu zerschlagen, das preußische Parlament durch das Frankfurter zu ersetzen. « Da Gagerns Antrag der bedeutsamste und eindringlichste der im Laufe des Jahres 1848 von Frankfurt nach Berlin gelangten Kaiseranträge war, so liegt die Vermutung nahe, Usedoms Worte auch auf ihn zu beziehen. Indessen zwingend beweisen kann man es nicht. Erheblicher aber ist es, was der General v. Willisen, der mit einem militärischen Auftrage nach Frankfurt gegangen war, am 30. November von dort an den König schrieb. ${ }^{2}$ ) Was er ihm riet, das waren im Kerne offenbar Gedanken aus dem Kreise Gagerns. Er riet, die Versammlung in Brandenburg mit ihrer eigenen Zustimmung zu vertagen, bis die Verfassung in Frankfurt beendigt sei. »Denken wir uns am Schluß derselben Ew. Majestät an der Spitze von Deutschland, so erscheint es wirklich nicht allein nicht notwendig, sondern sogar schädlich, wenn neben dem großen Reichsparlament noch eine fast ebenso große Nationalversammlung in Preußen bestände. Beide würden nur immer in Konflikte geraten." Wir werden auf seine weiteren Vorschläge noch zurückzukommen haben. Hier galt es nur festzustellen, daß gerade seit den Tagen, wo Gagern in Berlin verhandelte, die Forderung, Preußen

1) S. 283 .

2) Hausarchiv. Die nahe Fühlung Willisens mit dem Gagernschen Kreise in Frankfurt geht auch aus seinen Schlußworten hervor: Daß Gott es gnädig gefügt habe, daß der König mit Gagern und Vincke wenigstens nicht in Unfrieden geschieden sei. 
solle auf sein Sonderparlament verzichten, auch von Frankfurt aus wieder lebhafter erscholl. Man darf geradezu von einer zusammenhängenden und planmäßigen Propaganda dafür sprechen, wenn man die Deutsche Zeitung der ersten Dezembertage liest. Sie brachte am 2. Dezember einen Artikel vom 30. November ${ }^{1}$ ), worin es heißt: 》Löse die Krone (Preußens), den Ereignissen entgegengehend, die Reichsversammlung auf, . . . . desavouiere sie die verlautenden Absichten einer Verfassungsolitroyierung, spreche sie es aus, daß sie vor der Beendigung des Verfassungswerkes in Frankfurt keine Konstituante fur Preußen anerkennen und berufen wird. « Noch deutlicher wurde sie in ihren Leitartikeln vom 5. und 6. Dezember. Wenn P'reußen, so führte der vom 5. Dezember aus, für den Preis der Bundesleitung auf die eigene Landesvertretung verzichten und mit Provinziallandtagen in seinen Bundesterritorien sich begnügen konnte, so war der heutige Konflikt vermieden und die innere Erstarkung Preußens eine Förderung der Einheit, wie sie jetzt das Gegenteil sein wird. Am folgenden Tage, in offenbar inmer bänglicher werdender Stimmung, erklärte sie: Sagen wir es frei heraus: Eine Hegemonie Preußens über Deutschland ist ebensowenig möglich, als ein Aufgehen Preußens in Deutschland, solange Preußen daneben noch eine besondere Staatseinheit bildet, solange eine Gesamtrepräsentation der Großmacht Preußen als Rivalin dasteht neben der Nationalvertretung Deutschlands.

Noch aber haben wir kein Zeugnis dafür, daß Gagern selbst in diesem Sinne in Berlin gewirkt hat. ${ }^{2}$ ) Aber

1) ,Frankfurt, Kremsier u. Brandenlurg II e. Vom Neckar. Vielleicht von Gervinus. Vgl. Nathys Nachlaß S. $451 \mathrm{f}$.

2) Die ältere Hauptquelle für Gagerns Verhandlungen in Berlin waren die Mitteilungen nach seiner mündlichen Erzählung bei Jïgens, Zur Gesch. des deutschen Verfassungswerkes I, 2 I $6 \mathrm{ff}$. Durch die neuen Veroffentlichungen Leopold $v$. Gerlach I, 253-256, Ludwig v. Ger- 
wir erinnern uns, daß die preußischen Minister es am 22. November für gut befunden haben, dem Frankfurter Vertreter gegenüber ihre Oktroyierungsgedanken z.t maskieren. Sie werden es jedenfalls auch Gagern gegenüber getan haben, so daß dieser hoffen konnte, sein Ziel, die Verhinderung einer preußischen Verfassung, vorläufig ohne Kampf erreicht zu haben. Dazu stimmt vortrefflich, was der koburgische Diplomat Meyern Mitte Dezember an Herzog Ernst schrieb: „Gagern soll in der Voraussetzung von Berlin zurückgereist sein, daß der König die preußische Verfassung bis zur Proklamation der hiesigen suspendieren werde, um sodann mit der deutschen Krone zugleich die deutsche Verfassung für Preußen annehmen zu können. ${ }^{1}$ ) Und die Kette der Beweisstücke wird aufs willkommenste geschlossen durch den Brief, den Gagern, nachdem die Oktroyierung am 5. Dezember I 848 wirklich erfolgt war, am I4. Dezember aus Frankfurt an die in Berlin zurückgebliebenen Reichskommissare Hergenhahn und Simson geschrieben hat 2): $\gg$ Mein eigenes Urteil hat sich in der Sache nicht geändert. Die oktroyierte Charte ist in sich nicht lebensfähig, in bezug auf das Gesamtvaterland unmöglich."

Also hat Gagern, wie wir nun aus seinem eigenen Munde erfahren, nicht nur das Oktroyieren an sich, sondern

lach 2, $32 \mathrm{f}$., Simson I 34 ff.) ist unsere Kenntnis durch manche charakteristische, zum Teil freilich auch zweifelhafte Züge vermehrt worden. Zweifelhaft ist vor allem die von Leop. v. Gerlach (und nach ihm von seinem Bruder Ludwig) behauptete Absicht Gagerns, Premier eines preußisch-deutschen Ministeriums zu werden. Daß dieser Gedanke iber. haupt geäußert wurde, ist sicher und wird auch durch die Deutsche Zeitung (Extrablatt vom 29. Nov. und Nummer vom 30. Nov) bestätigt durch die umgekehrte Version, daß Gagern die Bildung eines preußischen Kalsinetts abgelehnt habe. Wahrscheinlich haben Vincke und seine Freunde die Idee aufgebracht, und Leop. v. Gerlach hat sich danach das Weitere konstruiert.

1) Ernst II., Aus meinem Leben I, 323 .

2) Simson S. 146 . 
auch den Inhalt dessen, was am 5. Dezember oktroyiert wurde, verdammt, und zwar um Deutschlands willen verdammt. Etwa seines reaktionären Charakters wegen? Nun, man weiß, daß die oktroyierte Charte gerade überraschend liberal ausgefallen war. Gagern selbst gibt in jenem Briefe $z u$, daß der König im Augenblick die öffentliche Meinung dadurch gewonnen zu haben scheine. Was ihm an ihr unmöglich für das Gesamtvaterland erschien, kann also nicht ein Minus an Liberalismus, kann nur die konstitutionelle Abschließung Preußens gewesen sein.

Wir können also daran festhalten, daß es ein Hauptzweck seiner Reise nach Berlin gewesen ist, diese zu verhindern. Er ist wahrscheinlich, da der Gegner auswich, nicht zum Hiebe gekommen, und die Verbindung von Zumutung und Werbung an Preußen, die wir aus dem Zusammenhange der Sache und der Quellenzeug. nisse erschlossen, ist demnach vielleicht nicht sinnlichanschaulich geworden, aber den ideellen Hergang glauben wir richtig gesehen $\mathrm{zu}$ haben. 


\section{Viertes Kapitel.}

\section{Die Oktroyierung der preulsischen Verfassung vom 5. Dezember 1848 .}

Die Kampagne der Frankfurter in Berlin war gescheitert, Preußen erhielt mit dem 5. Dezember seine konstitutionelle Verfassung, sein Sonderparlament. Kein Zweifel, es war damit ein Keil zwischen Berlin und Frankfurt, Preußen und Deutschland getrieben worden. Die preußische Regierung hatte genau das Gegenteil von dem getan, was die Droysen, Stockmar, Rümelin, Gagern für nötig hielten, um Preußen in den deutschen Bundesstaat eingliedern zu können. Damit fallt auf die Tat vom 5. Dezember ein, wie wir glauben, wesentlich neues Licht. Ihre Bedeutung für die deutsche Frage war viel größer, als man bisher geahnt hat. Indem Preußen seinen Entschluß bekundete, unter allen Umständen, wie auch die deutsche Zukunft sich gestalten möge, eine geschlossene Staatspersönlichkeit zu bleiben, schlug es dem Frankfurter Verfassungswerke eine erste schwere, vielleicht unheilbare Wunde. Denn die Forderung der Frankfurter, daß Preußen seine staatliche Selbständigkeit aufgebe, hing, wie wir später noch zu entwickeln haben werden, aufs engste mit den Grundgedanken jenes Verfassungswerkes zusammen. Zunächst aber erhebt sich noch die Frage nach der inneren Genesis des Ereignisses vom 5. Dezember, nach seinen Urhebern und Motiven und nach dem Zusammenhang dieser Motive mit der deutschen Frage. 
Obgleich nun die Veröffentlichungen aus dem Nachlasse der Gerlachs und Otto v. Manteuffels wertvolle Zeugnisse darüber brachten, und obgleich wir uns selbst bemüht haben, alles heute erreichbare archivalische Material dafür heranzuziehen, sind wir doch noch nicht imstande, ein genügendes Bild der Vorgeschichte der olstroyierten Verfassung zu geben. ${ }^{1}$ ) Es fehlen uns vor allem die politischen Erwägungen, die im Schoße des Ministeriums Brandenburg darüber gepflogen wurden. Denn von diesem ging, wie die Aufzeichnungen Leopold v. Gerlachs beweisen, die Initiative allein und ausschließlich aus. Vom I6. November ab haben sie nachweisbar den Plan verfolgt. ${ }^{2}$ ) Sie wollten damals die Berliner Versammlung, die einen Tag zuvor ihren Steuersuspendierungsbeschluß gefaßt hatte, auflösen und den König bitten, eine Verfassung zu oktroyieren. $\left.{ }^{3}\right)$ Sie stießen damit von vornherein auf den Widerspruch des Königs,

1) Die folgende Untersuchung war schon niedergeschrieben, als Goldschmidts sich in manchem mit ihr berihrende, ubrigens nur aus gedruckten Quellen schöpfende Arbeit DDie oktroyierte preuBische Verfassung (PreuBische Jahrbiicher 125, I97 ff.) erschien. Goldschmidt hat seinerseits schon meinen Vortrag s Preußen und Deutschland im 19. Jahrhundert", Histor. Zeitschr. 97, der die Hauptergebnisse meiner Untersuchungen vorlegte, benutzen können. Da Goldschmidt und noch eindringender seitdem Seitz „Entstehung u. Entwicklung der preuß. Verfassungsurkunde i. J. $184 \mathrm{~S} \& 1909$, auch auf den Inhalt der oktroyierten Verfassung eingegangen sind, so kann ich hierfur aut diese Arbeiten verweisen.

2) Varnhagen erzählt schon am 13. Nov. (Tagebücher 5, 285) das Gerilcht, daß der König vorhabe, seine Verfassung bekannt zu machen, die alle Welt befriedigen solle durch das höchste Maß des Freisinns،. Unmöglich wäre es ja nicht, daß der Oktroyierungsgedanke der Minister schon in diese Tage zuruckgeht. Ebenso möglich ist, daß Varnhagen nur ein vages Geriicht oder eine mißverstandene Deutung von $\ddot{A} u ß e-$ rungen des Königs wiedergibt.

${ }^{3}$ ) Sie haben für diesen Fall selbst daran gedacht, ihr Verbleiben im Amte von einem Vertrauensvotum der neu zu berufenden Kammern abhängig zu machen. In den Kabinettsakten des G. St. A. befindet sich 
Die Oktroyierung der preuß. Verfassung vom 5. Dez. I $848.40 \mathrm{I}$

der geradezu leidenschaftlich wurde, als er dann - wie es scheint am 20. November - den Verfassungsentwurf der Minister wirklich in die Hand bekam. »Ich finde ihn, « erklärte er am 23. November, »über jeden Ausdruck Gefahr bringend, schlecht und unpraktisch. «1) Er hielt es mit seiner Verantwortlichkeit gegen Gott für unvereinbar, so etwas zu unterschreiben und zu beschwören.2) Man begreift seine Empörung, denn der Grundstock des ministeriellen Entwurfs war den Vorarbeiten der Berliner Nationalversammlung entnommen. ${ }^{3}$ ) Aber auch das Oktroyieren an sich erschien ihm unköniglich und nach mauvaise foi zu riechen. So wies er denn die Minister am 23. November an, es noch einmal

ein (vom November datiertes) Konzept zu einer öffentlichen Erklärung des Staatsministeriums, das vermutlich in den Tagen vom I6. Nov. ff. entstanden ist. Es rechtfertigt die bisherigen Schritte des Ministeriums, gibt $z u$, daß die unter seiner Verantwortlichkeit angeordnete Auflösung der Versammlıng und Publikation einer Verfassungsurkunde verschiedenartige Beurteilungen erfahren und vielfachen Angriffen ausgesetzt sein werde, hofft aber auf den gesunden Sinn des Volkes etc. "Die unterzeichneten Minister werden indessen den zusammenberufenen Kammern vor allen anderen Verhandlungen die Frage vorlegen, ob sie das Vertrauen derselben besitzen? und sie werden sofort S. M. um ihre Entlassung bitten, sofern diese Frage verneinend beantwortet werden sollte. Jedenfalls ist dies Schriftstück identisch mit dem ron Leop. von Gerlach am Abend des 20. November gesehenen "Ministerialerlaß, der mit einer Unterwerfung unter die Majorität der Kammer endete I, $246 \mathrm{f}$.

1) v. Poschinger, Denkwürd. O. v. Manteuffels I, 46; daß das Schreiben nicht an Manteuffel, sondern an Graf Brandenburg gerichtet war, zeigt Leop. v. Gerlach I, 249.

2) Leop. v. Gerlach a. a. O.

3) Daß Waldeck selbst an der sogen, "Charte Waldeck», dem Entwurfe der Verfassungskommission, nur einen geringen Anteil, den größeren vielmehr Peter Reichensperger gehabt hat, zeigt Seitz a. a. O. Er macht weiter S. 140 wahrscheinlich, daß die Minister die durch die Zentralabteilungen modifizierte Charte Waldeck zugrunde gelegt haben.

Meinecke, Weltbürgertum und Nationalstaat. 2. Aufl. 
mit der nach Brandenburg verlegten Versammlung zu versuchen und vor allem Zeit zu gewinnen, da die Stimmung im Lande mit jedem Tage besser werde. Dann sei "zu unterhandeln mit den Guten und Bösen, aber in Königlicher Art und mit aller Zuversicht des Siegers für alle Zeit «.

Man wird nicht irre gehen, wenn man hier den Einfluß von Radowitz vermutet. Der König hatte sich seinen Rat in der Oktroyierungsfrage ausdruicklich erbeten. $\left.{ }^{1}\right)$ Radowitz hatte ihn am 2 I. November erteilt, hatte, wie wir uns erinnern, dringend vom Oktroyieren abgeraten, weil es als ein Rechtsbruch aufgefaßt werden wiirde, und hatte auch $\mathrm{zu}$ weiteren Verhandlungen mit der Versammlung in Brandenburg zugeredet. Radowitz hatte aber auch zugleich den Blick des Königs von der preußischen auf die deutsche Frage gelenkt, hatte sich auf Gagerns und Dahlmanns Meinung berufen und ihm dringend nahe gelegt, der Frankfurter Versammlung entgegenzukommen, die jetzt ein so schweres moralisches Gewicht in die Wagschale werfe. Eben in diesem Briefe entwickelte er ihm das Programm Gagerns vom weiteren und vom engeren Bunde, und daß Preußen an die Spitze des engeren Bundesstaates kommen müsse. Sollten nicht auch diese Erwägungen seines Freundes und Ratgebers die Seele des Königs berührt haben? Wir werden es an anderer Stelle ${ }^{2}$ ) zu behandeln haben, wie Strömung und Gegenströmung in seiner deutschen Politik fortwährend wechselten. Wie er auf Gagern halb mit Sympathie, halb mit Abscheu blickte, so auch auf das Frankfurter Parlament. Ist unsere Vermutung richtig, so hätten wir in den starken Worten, mit denen der König am

2) Durch Boddien. Vgl. Leop. v. Gerlach 1, 244. Auch der Eingang des Radowitzschen Scbreibens vom 21. Nov. (s, oben S. 389) nimmt darauf Bezug.

2) In der Fortfuhrung des Ilasselschen Werkes. 
Die Oktroyierung der preuß. Verfassung vom 5. Dez. 1848. 403

23. November das Oktroyieren verdammte, zugleich auch eine erste Frucht jener Agitation zu erblicken, die in Frankfurt dagegen betrieben wurde.

$\mathrm{Ob}$ der König nun freilich auch für die weitergehenden Gedanken des Gagernschen Kreises zu haben gewesen wäre? IVir haben gesehen, durch welches Mittel Bunsen in August dem Könige den Stockmarschen Plan schmackhaft zu machen gesucht hatte. "Ja, es ist wahr, " bemerkte der König dazu ${ }^{1}$ ) und wiederholte Bunsens Argument: ,Der König kommt als Haupt Deutschlands aus den Verlegenheiten, die ihm sein e (!!!) unfähige Konstituante verursacht - denn die Reichsverfassung wird die Verfassung Preußens, als der unmittelbaren Reichslande.' Ich erkenne den ganzen Wert dieses Raisonnements. Der König hat aber (den Blick aufs Ganze gerichtet) nichts Besseres zu tun, als sich von dem SüßVerlockenden im Westen ab und gegen den Aufgang zu wenden - sprechend: Füre uns nicht in Versuchung! - Die Aussicht auf »die großartigen Elemente des Oberhauses《 verlockt den König nicht. Seine eigenen Lande bieten deren genugsam dar, um das englische Oberhaus zu überflügeln. Und der König »wün scht « dergleichen nicht um eines Haares Breite mehr oder weniger, als er überhaupt (in seinem, wie in dem gesamten deutschen Lande) die Darstellung des wirklich Bestehenden, der I 000 jährigen Gliederung wünscht, welche unser deutsches Volk, bewußt und unbewußt, jederzeit aber durch das Walten seiner Einrichtungen diesseits und jenseits des Ozeans zum ersten Volk der Welt (seit dem Untergang der Römer) gemacht hat.»

So fesselte ihn also wohl Stockmars und Bunsens Idee, aber erregte zugleich sein tiefes Mißtrauen. Mit den Grundlagen seines eigenen nationalen Ideals war sie, wenn

1) Randbemerkungen des Königs zu Bunsens Programm, August 1848, vgl. oben S. 362 . 
sie streng und genau durchgeführt wurde, unvereinbar. Jene Idee entsprang dem liberalen Nationalstaatsgedanken, dem werdenden, dem neudeutschen Volksgeiste, der nach den wirksamsten Bürgschaften nationalpolitischer Einheit suchte. Sein Nationalideal dagegen entsprang dem romantisch-konservativen Nationalstaatsgedanken und sah in den säkularen Hervorbringungen des deutschen, des altdeutschen Volksgeistes, in dem römisch-deutschen Imperium, aber zugleich auch in der Fülle der deutschen Einzelstaaten, höchste, unersetzliche Werte, die er eigentlich, wie seine Worte verraten, mehr als Kulturwerte, als herrlichste Schmuckstuicke eines geistigen Weltbildes, denn als politische Werte, als Mächte und Machtverhältnisse empfand. $\mathrm{Zu}$ den schönsten Hervorbringungen des deutschen Volksgeistes aber zählte er die eigene Monarchie; sie zu opfern dem Reichsgedanken, fiel ihm nicht ein. 》Ich weiche, « schrieb er schon am I6. Juli 1848 an Camphausen ${ }^{1}$ ), "gewissen auflösenden Anforderungen des Neu-Teutschen Wesens an Preußen keines Fingers breit. « Meine Preußen, schrieb er an Bunsen am Ostersonntage $1849^{2}$ ), sind in der uberwiegenden Masse schwarzweiß und lassen $\gg$ Teutschland höchstens als Acquisition, aber keines Weges als Gegenstand gelten, in welchem sie aufgehen sollten«. Ich wiurde, sagte er weiter $^{3}$ ), bei der Annahme der Kaiserkrone Gefahr laufen, »mich wohlfeil zu entehren, indem ich die herrliche Schöpfung Gottes durch die Geschichte ,Preußen' unwiderbringlich auflöse aus Gehorsam gegen eine Versammlung, welche die angestammten höchsten Obrigkeiten des Vaterlandes für Nichts achtet«. Aber um die Tragweite dieser Worte

1) Brandenburg, König Friedr. Wilh. IV. Briefwechsel mit L. Camphausen S. 188.

2) Ranke, Aus dem liriefwechsel Friedrich Wilhelms IV. mit Bunsen S. 273. S. W. 49/50, S. 520.

3) 1. Mai a. a. (). S. 278 bzw. 523 . 
richtig abzuschätzen, darf man nicht vergessen, daß sie aus dem Momente stammen, wo der König das Band mit den Frankfurtern zerschnitt, wo er sich alles aufs schärfste vergegenwärtigte, was ihn von jenen trennte. Er hatte im Jahre zuvor zur Frankfurter Versammlung doch innerlich merklich anders gestanden als zur Berliner. Für jene fand er mitunter im vertraulichen Gespräche freundliche Worte ${ }^{1}$ ), für diese wohl nie. Jener wollte er es im Früjahr I 848 überlassen, das künftige Unterhaus des Reichsparlaments nach eigenem Gutduinken zu konstituieren. $\left.{ }^{2}\right)$ Das war sehr viel, das hätte er einer preußischen Volksvertretung nimmermehr zugegeben. Er war also zeitweise für Deutschland zu größeren Zugeständnissen an den konstitutionellen Zeitgeschmack bereit als für Preußen. Man kann das verstehen. Deutschland war im gewissen Sinne für ihn politisches Neuland, auf dem seine politische Phantasie, so sehr sie sich auch selbst historisch band, doch sich freier bewegen konnte als auf dem altpreußischen Boden. Vor der deutschen Nation in ihrer Gesamtheit hatte er auch einen gewissen historisch-romantischen Respekt, von dem preußischen Volke dagegen verlangte er vor allem patriarchalische Ergebenheit.

Und es gab nun vielleicht eine Brücke, welche die von uns behandelten Pläne des Gagernschen Kreises mit denen des Königs hätte verbinden können. Jene wollten, daß Preußen keine Verfassung erhielte und sich mit Provinzialständen begnüge. Es war nicht aussichtslos, gerade diesen Gedanken dem Könige mundgerecht zu machen. Ähnlich wie Bunsen, versuchte das Willisen in dem schon

1) Vgl. z. B. Leop. v. Gerlach 1, 269, 270; Ludw. v. Gerlach 2, 32 ; Nippold, Bunsen 2, 491 ; Ranke, Friedr. Wilb. IV. u. Bunsen 242.

2) Als Aquivalent dafür, daß die Fürsten das Oberhaus konstituierten. An Dahlmann 3. Mai I 848 . Springer, Dahlmann 2, 241. 
erwähnten Schreiben an den König vom 30. November: »Für alles, was man Freiheit des Volkes nennen kann, wird durch das Reichsparlament hinreichend gesorgt, der Verwaltung sind so große Versammlungen eher hinderlich als förderlich. Aus allen diesen Gründen würde es dann sehr gut sein, wenn man bei uns auf Provinzialstände zurückginge. ${ }^{1}$ ) Eben nun dieser Gedanke, mit den Provinzialständen jetzt etwas zu machen, ging dem Könige selbst schon seit dem Beginn der Revolutionszeit durch den Kopf. Als es nach den Märzereignissen galt, die gesunkene Autorität des Königtums wieder aufzurichten, hatte ihm sein Freund Radowitz am 28. März als ein Hauptmittel dafür empfohlen die Wiederbelebung der Verschiedenheit und der Autonomie der einzelnen Landesteile. »Hierin läge, « sagte er, »eines der größten Gegengewichte gegen das revolutionäre Niveau. $\star^{2}$ ) Und der König ergriff lebhaft diesen Gedanken. Ich will, schrieb er dem Minister v. Auerswald am $3 \mathrm{I} . M_{\text {är }}^{3}$ ), * daß der Organisation des Landes der Vortritt vor der Konfektion einer sog. Charte gegeben werde. Mein Bemuihen seit 8 Jahren dem Lande, den einzelnen Provinzen eine Selbständigkeit in der Handhabung ihres Eignen $z u$ schaffen, kann und muß jetzt ins Leben treten und wird von jedermann verstanden und gebilligt werden. Mit einem Wort, ich will Self government, die ProvinzialStände dürfen deshalb nicht aufgehoben, nur reformiert werden.\& Wie damals, so sah er auch jetzt, wo seine Minister abermals ihm eine liberale Charte abringen

1) Er fügte hinzu: ,damit würde zugleich die Eifersucht des übrigen Deutschlands gegen das ubermächtig erscheinende Preußen beseitigt. Mit der Begeisterung, die E. M. Erhebung bervorbrächte, wäre dies alles zu machen. Jetzt mußte es aber noch nicht hervortreten.s
2) Hassel, Radowitz I, 578 .
3) a. a. O. S. 579 . 
Die Oktroyierung der preuß. Verfassung vom 5. Dez. 1848. 407

wollten, in der provinzialen ständischen Idee gleichsam das Gegengift gegen den modernen Konstitutionalismus. Wie damals an Auerswald, so schrieb er jetzt, am 23. November, den Ministern ${ }^{1}$ ): "Auf die Landesstimmung wird die Konstitution wenig oder keinen Einfluß haben. Dagegen wirkt auf die Stimmung entschieden die Verkündigung der Absicht, Selbstregierung der Kommunen, Kreise und Provinzen anzubahnen. $«$ Dem Bonner Professor Walter aber setzte er am 5. Dezember auseinander, wwie er nach der Autlösung der Versammlung auf die Einrichtung der Provinzialstände hätte zurückgehen wollen, nur so daß eine ausgedehnte breite Repräsentation der Geistlichkeit, Schule, Wissenschaft und selbst der Zenzuslosen beigemischt würde $\ll^{2}$ )

Es waren alte, immer im Grunde seiner Seele fortlebende Lieblingsideen. Er gedachte auch, nachdem er in die Bahn des modernen Konstitutionalismus hineingedrängt worden war, doch imıner mit Sehnsucht der alten preußischen Provinzialstände, an denen sich sein eigenes politisches Leben gewissermaßen emporgerankt hatte. Nach ihnen und dem aus ihnen aufgebauten Vereinigten Landtage strebte er immer zurück, wie zu seinem echten Kinde, während ihm die konstitutionelle Gesamtverfassung Preußens ein Stiefkind war und blieb. ${ }^{3}$ ) Hier war der Punkt in den Anschauungen des Königs, wo die Pläne der Droysen, Rümelin und Gagern am ersten einhaken konnten. Zwei politische Gedankenwelten berührten sich hier, aller-

1) Poschinger, Manteuffel 1, 47.

2) F. Walter, Aus meinem Leben S. 265.

3) Vgl, sein Schreiben an Großherzog Friedrich Franz von Mecklenburg-Schwerin vom 7. Januar 1849 (Hirschfeld, Friedrich Franz II. 1, 288). Er wies ihn darauf hin swie ich bei unseren ständischen und Landtagswirren es vorsichtig bis heut vermieden habe, die Auflösung der alten ständischen Verfassung auszusprechen. Man kann nicht wissen, wozu das einmal gut sein kann. Das Zerstören ist so leicht, das Zerstörte wird aber oft vergeblich zurückgewünscht 
dings von sehr verschiedenem Ursprunge. Beide hielten das englische Self government für etwas Schönes und Nachahmenswertes, wobei freilich der König durch die aristokratische, die Liberalen durch die bürgerliche Seite desselben angezogen wurden. Der König und jene Frankfurter trafen jetzt ferner zusammen in der Abneigung gegen eine konstitutionelle Abschließung Preußens, aber das christlichgermanische Staatsideal, das den einen dabei leitete, war den andcren von Grund aus fremd. Vielmehr, weil sie zugleich dem modernen Konstitutionalismus und dem unitarischen Ideale huldigten, verwarfen sie die preußische Sonderverfassung, die der deutschen Verfassung die Luft abzusperren drohte. Aber hatte nicht der König selbst schon einmal, nach den Märztagen, erklärt, »der Konstitutionalismus habe wegen Deutschland anerkannt werden muissen «? Wurde ihm nicht die Last dieser Konzession, die er damals für Preußen hatte machen müssen, erleichtert, wenn er sie jetzt nur für das gesamte Deutschland zu machen brauchte, in Preußen aber mit seinen geliebten Provinzialständen weiter leben konnte? Allerdings hätten die Frankfurter ihm in der Zusammensetzung dieser Provinzialstände Zugeständnisse machen müssen, hätten ihm ferner auch noch, um ihn zu saturieren, den Vereinigten Landtag gönnen müssen. ${ }^{1}$ ) Aber Droysens Ideen vom Frühjahr I $\$ 4 \delta$ deuteten schon an, daß der Vereinigte Landtag für gewisse beschränkte Zwecke weiter existieren könne, und Gervinus machte am I. Januar $1849^{2}$ ) den auf die Neigungen des Königs

1) Auch die Eiferer der christlich-germanischen Richtung verlangten eben damals zum Teil zu diesem zurück. Ludw. v. Gerlach 2, 26, 28 . Und auch Manteuffel erzählte später (1856), daß er im Herbste 1848 auf ihn habe zuriuckgehen wollen. Leop. v. Gerlach 2, 438.

2) Korrespondenz ,Vom Rheins in der Deutschen Zeitung vom 4. Januar 1849 . Über Gervinus' Autorschaft dieser Korrespondenzen s. Springer, Uahlmann 2, 317. 
auch nicht ibel berechneten Vorschlag, wenigstens ein Surrogat des Vereinigten Landtags zu belassen, von ähnlicher Art, wie es der König in seinen ersten Regierungsjahren selbst schon zu schaffen versucht hatte. Er führte also aus: Um dem Mißstande zweier großer Reichsversammlungen vorzubeugen, könne Preußen die Landstände rekonstruieren, sie von vier zu vier Jahren versammeln, jedes Jahr aber vereinigte Ausschüsse, aus dem achten Teile der Gesamtzahl bestehend, in Berlin zusammentreten lassen, die über die gemeinsamen Angelegenheiten zu entscheiden hätten.

Das wäre ein Mittelweg gewesen, das hätte bedeutet, daß der preußische Staatsverband in lockeren Formen erhalten worden wäre. Ein ganz verwandtes Kompromiß schlug auch Bunsen vor, als er im Januar I 849 in Berlin weilte. Er forderte nicht, daß die preußischen Kammern ganzverschwänden, sondern nur, daß sie aufhören müßten, eine politische Stellung $\mathrm{zu}$ haben, wenn das deutsche Parlament verfassungsmäßig als Darstellung des Bundes. staates dastehen würde«. Und könnte man sich auf Bunsens Zeugnis ganz verlassen, so wäre der König jetzt für diese Idee und die damit verbundene Aussicht, den konstitutionellen Apparat für Preußen selbst los zu werden, noch empfänglicher gewesen als im August 1848.1) $\mathrm{Zu}$ mehr freilich hätte er sich seiner ganzen Gesinnung nach niemals verstanden. Niemals hätte er zugegeben, daß der Name Preußen, die Krone Preußen, die Idee eines preußischen Volkes ganz verschwunden wäre. Aber daß der Mittelweg, den wir eben zeigten, solchen einleuchten konnte, die dem Könige innerlich nahe standen und die neben streng konservativer Gesinnung auch einen Funken preußischen Ehrgeizes in sich trugen, läßt sich

1) Nippold 2, 492. Bunsen zeigt sich freilich schon in seinen Aufzeichnungen über die Haltung des Königs im August is ${ }_{4} S$ (Nippold 2, 468 u. 47I) etwas sanguinisch und verschwommen. Vgl, oben S. 361. f. u. 403 . 
nachweisen. Am 26. Oktober $\mathrm{I}_{4} 8$ hieß es in der Kreuzzeitung ${ }^{1}$ ):

》Wenn Preußen, unter welchem Namen es auch sei, an die Spitze von Deutschland tritt, so übernimmt es damit auch seine Vertretung nach außen in Krieg und Frieden, und die Verbindung seiner Diplomatie und seines Heeres mit der des Reiches ist von selbst gegeben. Im Innern würde es vielleicht auf eine gesonderte Nationalversammlung verzichten müssen. Allein da diese unter den gegenwärtigen Verhältnissen ihm mehr Hemmung bereitet als Kraft verleiht, so wäre der Verlust zu verschmerzen, vorausgesetzt, daß seinen Provinzendurch diefreieste ständische undkommunale Entwicklung die wünschenswerte Selbständigkeit gesichert und die Einheit derselben sowie die Fortdauer des preußischen Namens durch kräftige, innerhalb der durch die Reichsgesetzgebung gesteckten Grenzen sich bewegende Regierung gewahrt würde.

Merkwürdige Reminiszenzen erwecken diese Gedanken. In den Jahren nach den Befreiungskriegen, als die preußische Verfassungsfrage in ihrer ersten großen Krisis stand, waren es auch die altständisch-konservativen Elemente, die sich mit Provinzialständen begnügen wollten, weil das stille provinziale Sonderleben ihnen mehr frommte, als ein kräftig zentralisiertes und energisches Staatsleben. $\left.{ }^{2}\right)$ Verzicht auf preußische liberale Zentralverfassung und Verzicht auf preußische Machtentwicklung gingen damals Hand in Hand. Diese Kombination eines zugleich inneren wie äußeren Konser-

1) Beilage zu Nr. ıоr. , Noch einmal Berlin und Frankfurt.c Von Stahl, der seine Aufsätze mit sSs zu zeichnen pflegte, dürfte der Artikel wohl nicht herruhren, und an Bismarck wird man schon wegen des Stiles nicht denken dürfen.

2) Vgl. mein Leben Boyens 2, $310 \mathrm{ff}$. u. $34 \mathrm{~S}$ und oben S. 332. 


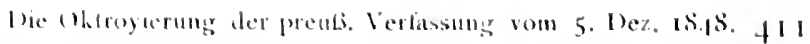

ratismus wurle atuch jetot moch von einem leile der preutisehen Konservativen, ven den ficolachs vor allem vertecten. Aber man sicht nun aus diesem Krenzzeitumssatiliel, dats atuh moch andere Kombinationen

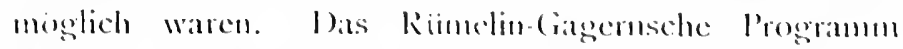

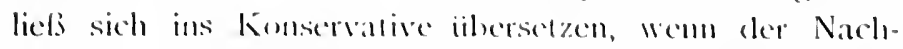
druck anf alic l'tege des provinzialen Sonderlebens ge-

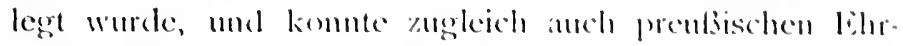

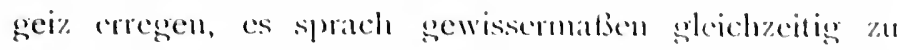

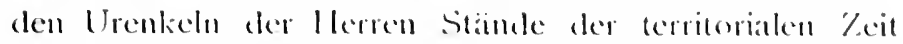
und zu den linkeln der offizicte liredrichs des Girolien umel wable sie fiir den molernen naliomalen mol liberalen

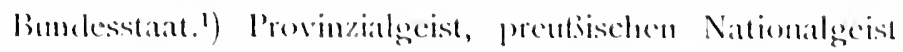

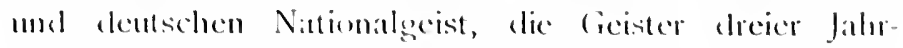
humblerte zu verbinden, dist limmle, wie wir nun selsen,

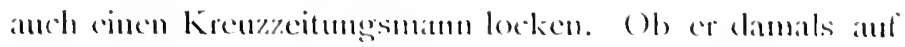

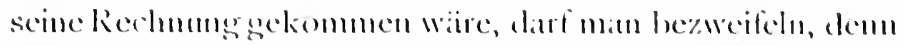

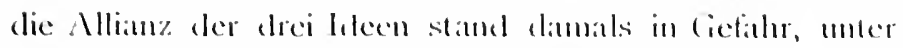

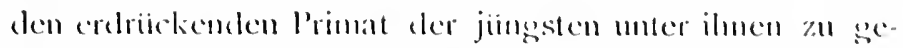
raten. Mher es wat ein tastender Ansatt zu dem, Was späler cin amelerer der damaligen Krenzocitumesmänmer, damn freilieh nuter prenbischem lerimate, hergestellt hat.

Jedenfalls diefen wir num silgen, dals die Riunclinsehen findermmen meder beim känige, now bei seinen politiselen Mammen, den prendischen Konservativen,

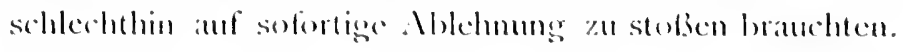

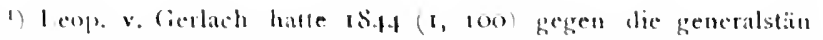
dischen l'line des kimigs gellend gemacht: D'renben halde gar nicht

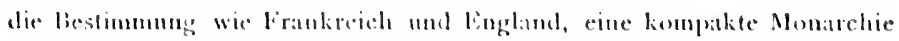

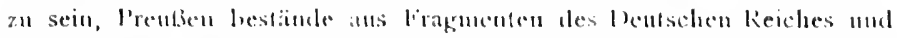

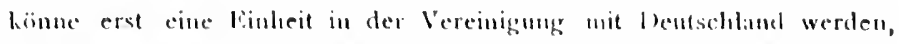

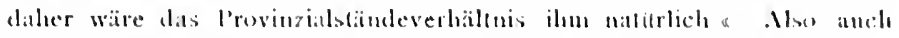
huer schon die lelee der povinzialistischen lerfasiung Prentbens ver-

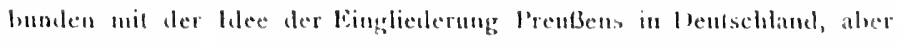
in strens und rein lionservaltiven sinne, whe die Kutat prentbischen Mathteriches, die del Kreutecilungsartiliel holt. 
Wir wissen, wieviel trotzdem einer inneren Verständigung zwischen dem Könige und den Frankfurtern im Wege stand. Wir wollten hier nur andeuten, daß sie an jenen Forderungen Rümelins und Gagerns nicht gleich zu scheitern brauchte. Wohl aber scheiterte sie damals schon an einer anderen Forderung der Frankfurter. Sie verlangten von ihm, wie wir uns erinnern, auf Grund der Beschlüsse vom I4. und 20. November, daß er das Ministerium Brandenburg, das Ministerium der rettenden Tat entlasse. Das war ein Eingriff in die Rechte des preußischen Königtums, die eben durch die Tat dieser treuen Männer wiederhergestellt worden waren. Jetzt zeigte es sich, wie verhängnisvoll jene Frankfurter Beschlüsse für die Absichten der Ruimelin und Gagern waren. Die Lage war jetzt so, daß der König zwischen Scylla und Charybdis stand, auf der einen Seite die Minister mit der widerwärtigen liberalen Charte für Preußen, auf der anderen Seite die Franlifurter mit ihrer unerträglichen Zumutung, die Minister fortzujagen. Gerlach hatte schon am 17. November die beiden Ubel gegeneinander abgewogen: "Zuletzt kam ich zu der Ansicht, daß der Weg, den das Ministerium betreten wollte, zwar ein falscher, aber doch nicht von der Art sei, um deshalb mit ihm zu brechen. ${ }^{1}$ ) Der König selbst war am 2 r. November noch unentschlossen, was er für das größere Ubel halten solle. "Er sagte, er könne sich nicht entschließen, die vollständige Desorganisation des Landes zu vollziehen - nicht nur vollziehen, beschwören soll er diesen Wisch - und könne doch auch das Ministerium nicht aufgeben. ${ }^{2}$ ) Und das Schicksal des Ministeriums hat wirklich einige Tage lang geschwankt. Manteuffel entwarf am 25. November oder kurz vorher Verordnungen, durch die der König nach dem Zusammentritt der Branden-

1) Leop. v. Gerlach I, 243 .

2) a. a. O. S. 245 . 
Die Oktroyierung der preuß. Verfassung vom 5. Dez. 1 848.4 I 3

burger Versammlung dem Lande die Entlassung des Ministeriums Brandenburg anzeigen konnte. ${ }^{1}$ ) Das Ministerium stellte also dem Könige sein Portefeuille zur Verfügung. Der König hat es ihnen gelassen; unzweifelhaft wesentlich mit deswegen gelassen, weil eine Preisgabe des Ministeriums Brandenburg in diesem Augenblicke eine Demütigung der preußischen Krone gegenüber den Frankfurter Gewalten bedeutet hätte. Es war, um mit Gerlach zu sprechen, die Frankfurter "Angriffskolonne in der Flanke«, die dem Ministerium Brandenburg Luft schaffte und seine Position beim Könige wieder stärkte. „Das ist mir klar, "sagte sich Gerlach am 25. November, »daß man das jetzige Ministerium selbst mit seinem schlechten Verfassungsprojekt halten mufs.«²) Ministerium, Kamarilla und König rückten so in diesem Augenblicke eng zusammen. Die preußische Regierung, - so schrieb Graf Bülow am folgenden Tage, den 26. November, an Camphausen - würde, wenn sie der von Frankfurt ge-

2) Drei Konzepte Manteuffels zu einer nach dem 27. Nov, zu er. lassenden Verordnung (G. St. A.). Das erste und zweite setzt den Fall voraus, daß die Versammlung am 27. Nov. in nicht beschlußfähiger Anzahl zusammentreten werde. Das erste verordnet für diesen Fall Einberufung der Stellvertreter und Vertagung bis zum I1. Dezember. Das zweite fügt hinzu, daß der König die Minister Graf Brandenburg, Ladenberg, Manteuffel, Strotha und Rintelen "auf ihr Ansuchen entlassen und die Bildung eines neuen Kabinetts angeordnet habe. Die dritte Fassung war für den Fall bestimmt, daß die Abgeordneten vollzählig erschienen und verhündete auch die Entlassung des Ministeriums und die Vertagung bis zum I I. Dezember. Die Datierung dieser drei, offenbar gleichzeitig entstandenen Entwürfe ergibt sich aus dem neben dem ersten Entwurfe stehenden Mundierungsvermerk vom 25. November. Vgl. auch des Oberstleutenants Fischer Nachrichten vom 26. November bei Caspary, Camphausen S. 266.

1) a. a. O. S. 253. Sein Bruder Ludwig bewies sich als der schlechtere Realpolitiker seiner Partei, wenn er hinterher zweifelhaft wurde, ob man recht getan habe, das Ministerium trotz seiner Ver. fassungspläne zu halten. a. a, O. S. 259. Vgl. Ludw. v. Gerlach 2, 32 u. $97 \mathrm{f}$. 
stellten Forderung nachgäbe, zugleich die Selbständigkeit Preußens gegenüber der Zentralgewalt und die königliche Autorität im eigenen Lande aufopfern. Am selben Tage noch wurde die Frage entschieden. Der König, der durch die Proklamation des Reichsverwesers noch besonders unangenehm berührt worden war ${ }^{1}$ ), schrieb ihm jetzt, daß er das Ministerium Brandenburg beibehalten werde. ${ }^{2}$ )

Und damit war nun auch das Schicksal seines Verfassungsentwurfes entschieden. Es sollte zwar nicht gleich oktroyiert werden, sondern es sollte zunächst ja noch ein Versuch mit der am 27. November in Brandenburg wieder zusammentretenden Versammlung gemacht werden. Ihr sollte, so war jetzt die Absicht, der nach den Wünschen des Königs noch mehrfach umgestaltete ${ }^{3}$ ) Verfassungsentwurf der Minister vorgelegt werden. ${ }^{4}$ ) Aber es zeigte sich nach wenigen Tagen, daß mit dieser Versammlung nichts zu machen war. ${ }^{5}$ ) Nur durch Nachgiebigkeit gegen die demokratische Mehrheit hätte man sie wieder beschlußfähig machen können. So erreichten denn die Minister am 5. Dezember gleichzeitig mit der Auflösungsorder auch die Unterschrift des immer noch schwer betrübten Königs zu ihrem Verfassungsentwurfe, der dadurch als oktroyierte Verfassung ins Leben trat.

1) Simson S. 138 ; vgl, auch die Berliner $\Delta$ Korrespondenz der I)eutschen Zeitung vom 27. Nov. u. I. Dez.

2) Leop. v. Gerlach I, 254.

s) Vgl. über diese Modifikationen Goldschmidt a. a. O. S. 204 und Seitz, Entstehung u. Entwicklung der preuß. Verfassungsurkunde i. I 1848 , S. $137 \mathrm{ff}$.

4) Das ergibt sich aus einem hiernach umredigierten Exemplar des Entwurfes, G. St. A. Ein Berliner Korrespondent der Deutschen Zeitung vom 3. Dez. (Beilage zum 7. Dez.) meint, daß es hauptsächlich infolge der Einwirkungen Vinckes geschehen sei. $̈$ hnlich eine Berliner Korrespondenz vom 7. Dez, in der Nummer vom I2. Dez.

5) DaB die Minorität der Rechten in ihr in den ersten Dezembertagen sich für Oktroyierung aussprach und wahrscheinlich durch den Einfluß des Ministeriums dazu bestimmt wurde, weist Seitz S. $128 \mathrm{f}$. nach. 
Qui trop embrasse, mal étreint. Die Frankfurter haben gerade das Gegenteil von dem bewirkt, was sie wollten. Sie haben das Ministerium Brandenburg nicht gestürzt, sondern befestigt und haben dadurch dem Oktroyierungsgedanken, den sie verabscheuten, mit zum Siege verholfen. Sie haben sogar unmittelbar dazu gereizt. „Der unerträgliche Ton, den die Zentralgewalt in allen öffentlichen Erlassen Preußen gegenüber annahm《, sei, so berichtete der russische Gesandte Baron Meyendorff aus Berlin, ein Grund gewesen, warum man mit der Heraus. gabe der neuen Charte nicht gewartet habe. ${ }^{1}$ ) Aber damit ist erst die eine Seite der Genesis des 5. Dezembers aufgehellt. Ohne die Zähigkeit der Minister wäre es zu ihm nicht gekommen, und so erhebt sich denn die Frage nach ihren Motiven jetzt mit doppelter Stärke.

Fragen wir zuerst, was uber die Haltung der einzelnen Minister bekannt ist. Zunächst wird uns bezeugt, daß Ladenberg und Rintelen fuir die Oktroyierung gewirkt haben. ${ }^{2}$ ) Der König selbst hielt Rintelen für den, der die übrigen Minister, wie er sagte, »irre mache «. ${ }^{3}$ ) Edwin v. Manteuffel dagegen sah Ladenberg noch mehr als Rintelen für das liberale Prinzip im Ministerium an. ${ }^{4}$ ) Auch der Kriegsminister v. Strotha scheint zum liberalen Flügel des Ministeriums gehört zu haben ${ }^{5}$ ), während Otto v. Manteuffel allein den rechten Flügel in ihm vertrat. Er widerstrebte dem Oktroyierungsprojekt am längsten, weniger wohl aus Abneigung gegen das $\mathrm{Ok}$ troyieren selbst, denn er wollte, wie er später erzählte, auf den Vereinigten Landtag zurückgehen, was ohne

1) Deutsche Revue Sept. 1905, S. 274.

2) Leop. v. Gerlach 1, 245, Ludwig v. Gerlach 2, 31 .

3) a. a. O. S. 250.

4) a. a. O. S. 260 ; vgl. Ludw. v. Gerlach 2, 28.

5) Nach Otto v. Manteuffels späterer Erzählung, Leop. v. Gerlach 2,438 . 
königliches Machtwort auch nicht möglich gewesen wäre. Er dachte schon daran, seinen Abschied zu nehmen, blieb aber schließlich und beteiligte sich mit der ihm eigenen bureaukratischen Geschäftsmäßigkeit auch an der Durcharbeitung des ihm unsympathischen Entwurfes. ${ }^{1}$ ) Er blieb, so erzählte er drei Jahre später, weil ihm Graf Brandenburg zu bedenken gab, daß die Personen der Minister und die Art, wie sie handelten, jetzt wichtiger sei als 》solch Wisch Papier « wie die Verfassung. Das Wort mag wohl gefallen sein und gewirkt haben. Wir wissen ja, daß auch Leopold v. Gerlach damals so dachte und sich damit tröstete, die schlechte Konstitution mit der Zeit schon wieder los zu werden. ${ }^{2}$ ) Die Erwägung, daß der Zusammenbruch des Ministeriums Brandenburg in diesem Augenblicke eine Niederlage des Königtums vor den Frankfurtern wie vor den inneren Gegnern bedeute, wird nicht nur für Gerlach und den König, sondern auch im Schoße des Ministeriums selbst von größtem Gewichte gewesen sein. Weil Ladenberg und Rintelen, von Strotha unterstuitzt, so dürfen wir vorläufig annehmen, die Verfassung so entschieden begehrten, hat sich Brandenburg auf ihre Seite gestellt ${ }^{3}$ ) und dadurch auch Manteuffel zum Bleiben bewogen.

So lenkt sich der Blick auf jene beiden Männer als die eigentlichen Betreiber des Oktroyierungswerkes. Was weiß man von ihren politischen Tendenzen? Bisher

1) Leop. v. Gerlach 1, 243, 259 f., 708, 827; 2, 438, 733; Ludw. v. Gerlach 2, 3r. Die Behauptung Poschingers I, 46, daß Manteuffel für die Oktroyierung einer liberalen Charte Propaganda getrieben habe, muß danach wohl aus der Luft gegriffen sein. Er selbst zitiert S. 56 Anm. gedankenloserweise das eine der Gerlachschen Zeugnisse, das dagegen spricht. Der Anteil Manteuffels an dem Entwurfe selbst geht aus den betr. Kabinettsakten des G. St. A. hervor.

2) a. a. O. I, $249,256$.

3) So faßt auch Ludw. v. Gerlach 2, 3 I den Hergang auf: , Brandenburg ist ihnen passiv gefolgt.c 
noch leider wenig. Ob sie wirklich, wie Gerlach meinte, für das liberale Prinzip vor allem fechten wollten, scheint uns zweifelhaft. Rintelen hatte als Abgeordneter in der Berliner Nationalversammlung wohl den konstitutionellen Staat für den besten und allein möglichen erklärt, zugleich aber gegen den Radikalismus wiederholt energisch Front gemacht. ${ }^{1}$ ) Seine Wirksamkeit als Justizminister, sein scharfes Vorgehen gegen die Vertreter der Demokratie im Richterstande ${ }^{2}$ ), macht durchaus keinen hervorstechend liberalen Eindruck. Die Idee, die ihn und Ladenberg vor allem geleitet hat, wird uns vielleicht später klar werden. Die Namen des Kultusministers und des katholischen Justizministers wecken aber noch eine andere Erinnerung, die uns zwar nicht gerade auf die wichtigste, aber auf eine doch zu beachtende Spur führt. Sollte der ominöse Artikel I 2 der oktroyierten Verfassung vielleicht eine Rolle gespielt haben? »Die evangelische und die römischkatholische Kirche, " so bestimmte er bekanntlich, »sowie jede andere Religionsgesellschaft ordnet und verwaltet ihre Angelegenheiten selbständig und bleibt im Besitz und Genuß der für ihre Kultus-, Unterrichts- und Wohltätigkeitszwecke bestimmten Anstalten, Stiftungen und Fonds. " Er war nahezu wörtlich entnommen der Fassung, den der Artikel i9 der sogenannten Charte Waldeck durch die Zentralabteilung der Berliner Nationalversammlung erhalten hatte. Er gab der Kirche die gewünschte Kirchenfreiheit zugleich mit dem von ihr gewünschten Maße staatlicher Privilegierung. ${ }^{3}$ ) Das war die große Errungenschaft, die der

1) Vgl. Seitz a. a. O. S. 132 ff.

2) Erlaß Rintelens vom 8. Dez. 1848. Deutsche Zeitung vom 23. Dez., Extrabeilage.

3) Noske, Die Entwicklung der Grundrechte des deutschen Volkes vom J. IS 4 S etc. (Greifswalder Diss. 1910) S. 103 u. I27; Schnabel, Der Zusammenschluß des polit. Katholizismus in Deutschland i. J. 1848 , S. 96. 
Ultramontanismus aus der Revolution von I 848 davon. trug. Er konnte sie klug und gewandt entgegennehmen aus den Händen des dolstrinären Liberalismus, der die Gefahren einer von ihren Fesseln befreiten römischen Kirche unterschätzte. Auch in Frankfurt hatte die ultramontane Forderung schon gesiegt, aber nicht unbedingt gesiegt. Der Artikel I4 der Grundrechte, der in erster Lesung am II. September I 848 zustande kam, verhieß zwar auch: "Jede Religionsgemeinschaft (Kirchè) ordnet und verwaltet ihre Angelegenheiten selbständig ", fügte aber zum Verdruß der Ultramontanen die Klausel hinzu: »bleibt aber, wie jede andere Gesellschaft in Staate, den Staatsgesetzen unterworfen. $\ll^{1}$ ) In der preußischen Charte fehlte dieser Vorbehalt, der die Handhabe zu einer neuen staatskirchlichen Gesetzgebung bieten konnte. ${ }^{2}$ ) So bedeutete die Verfassung voin 5. Dezember eine weitere Etappe auf dem Eroberungszuge des Ultramontanismus. Sollte nicht die Frage cui bono hier auf eine versteckte Spur führen? Ist es nicht denkbar, daß auch katholische Einfliusse bei der Entstehung der oktroyierten Charte im Spiele gewesen sind? Zwar fehlte jener den Katholiken so anstößige Vorbehalt auch schon in den Entwürfen der Nationalversammlung, an die sich die oktroyierte Verfassungsurkunde anschloß, und die Katholiken, geführt von dem unermuidlichen Erzbischof Geissel von Köln, hatten bereits in den Kommissions- und Abteilungsverhandlungen der Versammlung ihre Wünsche durchgesetzt. Aber noch mangelte ihnen das letzte Siegel, und auf dieses kam es jetzt an. Der Entschluß der

1) Bei der 2. Lesung, die im Dez. I $S_{4} S$ stattfand, wurde nur der die Katholiken besonders verletzende Zusatz , wie jede andere Gesellschaft im Staate gestrichen. Vgl. Pastor, A. Reichensperger I, $260 \mathrm{f}$.

$\left.{ }^{2}\right)$ Art. II: Den bürgerlichen und staatsbürgerlichen Pflichten darf durch die Ausübung der Religionsfreiheit kein Abbruch geschehen , war ein nur. milder Ersatz dafür. 
Minister, die Kirchenfreiheit in dem weiten Umfange, wie ihn die Entwiurfe der Nationalversammlung zugestanden hatten, in die Verfassung zu rezipieren, war unter allen Umständen ein hochpolitischer Entschluß, nach dessen Motiven man fragen muß. ${ }^{1}$ ) Daß Ladenberg, ein Pietistenfeind ${ }^{2}$ ), dem katholischen Interesse bewußt gedient habe, ist nicht anzunehmen, aber sein Ministerialrat Aulicke, der Leiter der katholischen Abteilung in Kultusministerium, war höchstwahrscheinlich dafür tätig ${ }^{3}$ ), und der Eifer, den der Katholik Rintelen für das Oktroyierungswerk entwickelie, ist auch nicht ganz frei von diesem Verdachte. $\left.{ }^{4}\right)$ Zum mindesten kann man nachweisen, daß schon gleich nach der Oktroyierung die Vermutung geheimer katholischer Nebeneinfluisse auftauchte. 》Die Kirche, « schrieb der hannoversche Staatsmann Stüve am I3. Dezember ${ }^{5}$, ist jetzt ganz für die neue preußische Verfassung. Man scheint dahin operiert zu haben, und alle Zeichen beweisen es. «

Suchen wir, da diese Vermutung einmal vorliegt, festzustellen, wie weit das, was über die Taktik der ka-

1) Dies gegen die formalistische Kritik, die Noske a. a. O. S. I27 f. an meiner Auffassung geiubt hat.

?) Wippermann, Allgem. deutsche Biogr. I7, 501.

3) Vgl die von $1 \mathrm{I}$. Oncken gesammelten Zeugnisse. Forschungen zur brand. u. preuß. Geschichte 22, 3I4. Die von ihm noch angeführte Erzählung Diepenbrocks, daß der König eigenhändig die Gewährleistung des kirchlichen Besitzes in die Verfassung hineingeschrieben habe, nachdem die Ausschüsse ihn im Entwurfe schon gestrichen hätten, scheitert an der von Noske nachgewiesenen Tatsache, daß bereits die Vorlage der oktroyierten Charte, die lieschliisse der Zentralabteilung, den betr. Passus enthalten.

4) Rintelen soll nach Ludwig von Gerlach 2, 27 nur ein snomineller Katholik « gewesen sein. Sein Sohn, der Geh. Oberjustizrat Dr. Rintelen, teilte mir dariiber freundlichst mit: ədaß mein sel. Vater bloß Namenskatholik gewesen sei, ist total unrichtig. Er war gläuliger Katholik, aber ein Kind seiner Zeit. Intensität des Glaubens war damals bei den meisten Katholiken, namentlich in Berlin, eine Seltenleit. \&

5) Briefwechsel zwischen Stive und Detmold. S. I 45. 
tholischen Kreise Preußens sonstwie bekannt ist, mit ihr $\mathrm{zu}$ vereinigen ist.

Da zeigt sich denn, daß diese Taktik zwiespältig war. Im Sommer I848, als das preußische Staatsschiff zwischen den Klippen zu schwanken schien, begrüßte die katholische Rhein- und Moselzeitung die Wahl des Erzherzogs Johann zum Reichsverweser mit Jubel und wünschte, daß er mit starker Hand die Zentralgewalt in Deutschland an sich ziehe, und da er nun eine Dotation, ein reichsunmittelbares Land brauche, so schlug sie die preuBische Rheinprovinz als passendstes Kaiserland vor. ${ }^{1}$ ) Und damit fand sie herzlichen Beifall bei ihren Lesern, und der ganze $\mathrm{Haß}$ der ultramontanen Rheinländer gegen das Preußentum entlud sich in ihren Spalten. Zum mindesten wünschte man sich hier die künftige preußische Verfassung so, daß die Rheinprovinz nicht zu eng mit den ubbrigen preußischen Provinzen verschmolzen würde, und erhoffte von einer zentralisierten deutschen Monarchie, daß sie dem preußischen Eigenwillen den Garaus mache. $\left.{ }^{2}\right)$ In den Wirren der Septembertage, als man gar von einer Soldatenemeute in Potsdam hörte, stellte sie dem preußischen Staate das Prognostikon auf baldigen Untergang. „Das Preußentum eilt mit raschen Schritten einem jähen Abgrunde zu; keine menschliche Macht vermag es in seinem Sturze aufzuhalten. ${ }^{3}$ )

Die Koblenzer Rhein- und Moselzeitung galt als Organ des niederen Klerus, während das Organ der hohen Geistlichkeit und des rheinischen Adels die in Köln

1) 2 I. Juli i 848 . Der Gedanke der Losreißung der Rheinlande von Preußen spukte schon seit den Märztagen. Vgl. Caspary, Camphausen S. I 72 u. Hist. Zeitschr. S9, 35 ; Hansen, Mevissen I, 524. Briefwechsel zwischen Stüve u. Detmold $S .43$.

2) $21,22$. 11. 27. Juli u. ö.

s) 23. Sept. 
Die Oktroyierung der preuß. Verfassung vom 5. Dez. I $\$_{4} \$ .42$ I

erscheinende $\diamond$ Rheinische Volkshalle war. $^{1}$ ) Sie spann einen feineren Faden als jene und verstand es, 》geschickt mit den herrschenden Gewalten zu transigieren«. Aber in den Stürmen der Novembertage ließ sie sich auch vernehmen ${ }^{2}$ ), daß die preußische Monarchie doch eigentlich in zwei nicht zusammengehörige Teile zerfalle, den vorwiegend katholischen Westen und den protestantischen Norden. »Statt des einen Berliner Landtags mögen zwei gesonclerte fuir Rheinland und Westfalen und für den Osten zusammentreten und auf den Grund der zu Frankfurt beratenen Gesamtverfassung sich eigentiimliche Einrichtungen geben. Dieser Plan brächte drei unleugbare und große Vorteile. Er setzt die Natur in ihre Rechte, er beugt einem sonst unvermeidlichen Zwiespalt zwischen dem Reiche und der preußischen Volksvertretung vor, er ist endlich geeignet, aus dem drohenden und furchtbaren Bruche des Königs von Preußen mit seinen Untertanen einen rettenden Ausweg zu gewähren. Rheinländer und Westfalen, tut, was in euren Kräften steht, um dieses Werk zu fördern. «

So tauchte also auch in diesem Lager der Gedanke einer staatlichen Autlösung Preußens auf, sogar zum Teil mit Verwertung derselben Argumente, die die Erbkaiserlichen im Munde führten, aber freilich doch von ganz anderen Voraussetzungen aus und mit anderen Zielen. Aber vielleicht, wird man einwenden, haben wir hier nur müßige Wuinsche und Phantasien katholischer Zeitungsschreiber vor uns, und ernsthafteren Politikern, wie z. B. den Brüdern Reichensperger, diurfe man trotz ihrer nachweisbaren Beziehungen zujenen beiden Zeitungen ${ }^{3}$ )

1) Ihre Gründung war auf einer hauptsächlich von A. Reichensperger veranlaßten Versammlung des Borromäusvereins am I I. April I $\&_{4} \delta$ beschlossen worden. Pastor, A. Reichensperger 1, 231. Schnabel, Zusammenschluß des polit. Katholizismus in Deutschland i. I. $1 \$ 48$ S. 39.

2) Deutsche Reform rom 29. Nov. (Artikel aus Köln, 26. Nov.

8) S. o. S. 421 Anm. 4 und Pastor a. a. O. 1, 230. 
nicht zutrauen, solche Gedanken geteilt zu haben. Nun, man kann zum mindesten nachweisen, daß sie sich mit ihnen beschäftigt haben, daß sie in ihnen in dem damaligen Flusse aller Dinge eine Zukunftsmöglichkeit gesehen haben. Ende Juni r 848, zur Zeit der Wahl des Erzherzogs Johann und während gleichzeitig Berlin im Stadium der Pöbclherrschaft schien, tat August Reichensperger, indem er beide Tatsachen registrierte, zugleich die Frage: $\gg$ Wie lange wird es dann wohl noch dauern, bis die Rheinlande sich reichsunmittelbar erklären ? «1) Sein Gesinnungsgenosse, der Bonner Professor Ferdinand Walter, der in der Berlincr Versammlung saß, schrieb von dort am 4. Juni ${ }^{2}$ ), wenn die Republik in Preußen wirklich proklamiert wiirde und Bestand erhielte, 》so werden wir Deputierte Rheinlands und Westfalens unsere schönen Provinzen nicht in das Schlepptau der Berliner Republik nehmen lassen, sondern nach Hause gehen und dort unsere eigene Verfassung einrichten, vorbehältlich der Rechte des Königs. Daruber sind wir einig«. Das klang recht königstreu, läßt aber, obgleich er meinte, daß es so weit nicht kommen wercle, zwischen den Zeilen zu lesen ubrig. Walter Rogge, ein dreister, aber gescheiter Publizist, dem wir manche scharfe Beobachtung verdanken, wollte wahrnehmen ${ }^{3}$ ), daß Walter noch zu Anfang September auf Losreißung der Rheinprovinz und auf einen deutschen Bundesstaat mit völliger Dezentralisation spekuliert habe. $\left.{ }^{4}\right)$ Sogar noch am

1) 29. Juni an seinen Freund v. Thimus, Pastor a. a. O. 249. V'gl. anch Böhmers Schreiben an Hurter, Frankfurt, 5. Aug. I $S_{4} S$ (Janssen, Böhmers Leben 2, 515): Wenn Brandenburg-l'reußen nit der hiesigen Zentralgewalt in Konflikt kommt, was friher oder später geschieht, wird sich die Rheinprovinz ablösen, im südwestlichen Eck könnte dann aber die Republik auflehen. $₫$

2) Aus meinem Lehen (IS65) S. ISS.

3) Parlamentar. Grölien 1, $66 \mathrm{ff}$.

4) DaB man in den von Walter selbst mitgeteilten briefstellen aus dieser Zeit nichts dariiher findet, beweist natiirlich noch nicht dagegen. 
19. November ${ }^{1}$ ) erklärte Walter selbst es für $\gg$ möglich, daß die Rheinlande der Krone durch deren beharrliches Festhalten ihrer Maßregeln verloren gehen «. Er wollte das auch jetzt zwar nicht wiinschen und schalt dabei wohl auch auf den »blinden Preußenhaß seiner Landsleute", aber man sicht doch, daß der Gedanke ihn stark beschäftigte.

Es ist keine Frage, daß sein und seiner Genossen Herz stärker für die Kirche als für den preußischen Staat schlug. Das Wichtigste an der preußischen Verfassung waren ihm nach seiner eigenen Andeutung ${ }^{2}$ ) die Kirchenund Schulparagraphen. Politisch hielten er und seine näheren Freunde sich mehr zur Sache der alten Autoritäten, gehörten sowohl in der Berliner wie Frankfurter Versammlung zu den Parteien der Rechten und warteten in dieser Position das Kommende ab. Man würde ihnen unrecht tun, wenn man sie sich nur von Taktik und Berechnung geleitet denken, wenn man nicht auch an gemiitliche Wurzeln ihres Royalismus glauben wollte. Aber das Prinzip, dem sie dienten und dem sie im Zweifelsfalle alles unterwarfen, war frei von solchen gemütlichen Banden, war an sich bündnisfähig sowohl für die konservative wie fiur die demokratische Sache. In den Rheinlanden konnte schon der Preußenhaß zur Fühlung mit der Linken führen, und iiber die oktroyierte Verfassung vom 5. Dezember fiel die Rhein- und Moselzeitung mit Argumenten her, die jeder Demokrat unterschreiben konnte. Aber schon in ihren Spalten kam nebenher noch eine andere Auffassung zu Worte. "IVas vielsagend für die Katholiken ist, " hieß es am IO. Dezember, »ist, daß die Geistlichkeit, soviel wir Gelegenheit hatten, ihre Meinung zu hören, sich unverhohlen zufrieden mit der oktroyierten Verfassung erklärt, besonders da nach den die Katholiken so sehr beengenden Frankfurter Beschliissen diese vom Könige

1) Aus meinem Leben S. 244 .

2) 22. Mai. a. a. O. S. 180. 
gegebene Verfassung der Religion ihre Rechte freigibt.k Was konnte günstiger für die Katholiken sein, als daß die alte Staatsautorität selbst ihnen die Gabe vermittelte, die sie vom neuen Liberalismus erhoffen konnten. Mochten auch einige der katholischen Politiker, wie Peter Reichensperger, ihr bedeutendster Vertreter in der Berliner Versammlung, den Modus der Oktroyierung selbst nicht billigen ${ }^{1}$ ), so fand doch gerade an ihm und an seinem Gesinnungsgenossen Walter das Ministerium Brandenburg jetzt bereite und willige Helfer. Sie, die Führer der preußischen Katholiken im Berliner Parlamente, waren es, die in offiziösem Auftrage im November und Dezember nach Frankfurt reisten und dort für die Politik des Ministeriums Brandenburg Stimmung machten. ${ }^{2}$ )

»Lassen wir, « meinte Walter Rogge, » die unerwiesenen Geriichte über bestimmte Verträge zwischen dem katholischen Klerus und der Regierung auf sich beruhen, so bleibt nur die Tatsache, daß diejenigen Deputierten zur äußersten Rechten gehörten, denen es Ernst war mit den Interessen der alleinseligmachenden Kirche. « Als die Ultramontanen eben gemerkt hätten, daß der preußische Staat nicht so gebrechlich war, wie man zuerst glaubte, hätten sie sich - so vermutete er - Konzessionen erzwungen, indem sie die Hydra der Demokratie bändigen halfen. Sollte er recht haben mit seiner Vermutung, so darf man hinzusetzen, daß nicht bloß

1) In der Schrift $₫$ Die preuß. Nationalversammlung und die Verfassung vom 5. Dez. (I 849)، S. 37 ff. (Abgedruckt auch in seinen , Erlebnissen eines alten Parlamentariers S. 239 ff., die im übrigen die deutliche Tendenz haben, seine und seiner Glaubensgenossen Verdienste um die preußische Monarchie während des Revolutionsjahres zu zeigen.) Sein Bruder August dagegen schrieb am II. Dez.: , Allem Anschein nach war dieser, kiuhne Griff" (die Oktroyierung) wirklich das beste Mittel zur Beschwichtigung des Sturmes. Pastor A. Reichensperger I, 279.

2) P. Reichensperger, Erlebnisse S. 185 ff, F. Walter, Aus meinem Leben. S. 269. 
Die Oktroyierung der preuB. Verfassung vom 5. Dez. I 848.425

die kluge Witterung der Machtverhältnisse die politisch denkenden Katholiken veranlaßt haben dürfte, ihren Kurs zu ändern. Nach den Erfahrungen, die sie in Frankfurt mit den kirchenfeindlichen Demokraten gemacht hatten, hatten sie wohl einigen Grund, deren Sieg jetzt nicht zu wiinschen. 》Wenn in Preußen, "schrieb Walter am I9. November, »das schlechte Element siegt, so ist für ganz Deutschland Bildung, Humanität, Religion auf lange Zeit verloren. ${ }^{1}$ ) Versetzen wir uns ganz auf ihren Standpunkt, so könnten wir ihnen vielleicht auch ohne quellenmäßigen Anhalt noch eine weitere Überlegung zutrauen. Friedrich Wilhelm IV. war der Herrscher, den sie brauchen konnten, der ihnen schon manches gegeben hatte und ihnen noch viel geben konnte. Zum Kaiser von Deutschland wiinschte ihn die Mehrzahl der katholischen Politiker sich freilich nicht; das hätte zu viel des preußisch-protestantischen Wesens in Deutschland werden können. ${ }^{2}$ ) Aber ihm und gerade ihm als Könige von Preußen jetzt beizuspringen, konnte als katholisches Interesse erscheinen. Und wenn sie weiter gar - was freilich nur eine ganz unsichere Vermutung ist - den Zusammenhang zwischen preußischer und deutscher Verfassungsfrage durchschauten, so konnten sie hoffen, durch die Unterstiitzung der oktroyierten Verfassung Preußens das hohenzollernsche Erbkaisertum zu erschweren.

Schon am is. November wirkte der Breslauer Bischof Diepenbrock durch einen Hirtenbrief auf die Katholiken seiner Diözese im Sinne der Regierung ein. Aber daß auch dieser milde Kirchenfürst die Unterstiitzung, dic er dem Ministerium leistete, als einen Pakt anzusehen imstande war, der geschlossen und gelöst werden konnte, zeigen seine Worte vom 22. Januar I 849: „Das sollen die

1) a. a. O. S. 247 .

2) Es ist bekannt, wie kühl die Kaiserwahl von $18+9$ in den katholischen Rheinlanden aufgenommen wurde. 
Herren nicht glauben, daß sie zum Lohne dafür, daß wir sie aufrecht erhalten haben, wieder mit uns spielen können wie die Katze mit der Maus. $\left.{ }^{1}{ }^{1}\right)$ Wir meinen damit nicht, daß die Hinwendung der preußischen Katholiken zur Regierung nichts als Pakt und Geschäft gewesen sei. Derartige Anpassungsprozesse pflegen, wir wiederholen es, nicht nur das Resultat bewußten Kalkuls, sondern des gesamten politisch-sozialen Denkens und Empfindens zu sein. Und wir räumen ferner ohne weiteres ein, daß die Rücksicht, die das Ministerium Brandenburg in der oktroyierten Charte auf die Wünsche der Katholiken nahm, nicht notwendig auf cine geheime katholische Beeinflussung deutet. Es konnte auch rein vom Standpunkt der Minister aus schon als Staatsraison erscheinen, gerade in diescm kritischen Augenblicke die katholische Bevölkerung und namentlich die unsicheren Rheinländer festzuhalten bei der Monarchie. ${ }^{2}$ )

Und iberhaupt muß man, um die Entstehungsgeschichte der Oktroyierung von Grund aus zu verstehen, doch die gesamte innere und äußere Lage vor allen würdigen. IVar es für preußische Staatsmänner damals ïberhaupt noch möglich, oder jetzt schon wieder möglich, die konstitutionelle Bahn zu verlassen, in die Preußeu seit dem I 8. März eingetreten war? Vielleicht hätte es eine robuste Persönlichkeit wie Bismarck vermocht, der damals den Rat gab, den ganzen Bauernstand gewissermaßen zu kaufen und für die Regierung zu gewinnen durch ein günstiges Ablösungs- und Rentengesetz; dann würden, meinte er, die Abgeordneten sich alles gefallen lassen, selbst eine Verfassung mit vier Ständen und einer erblichen oder ernannten ersten Kammer. ${ }^{3}$ ) Der Gedanke,

1) Reinkens, Diepenbrock S. 415 .

2) Treffend hervorgehoben von H. Oncken a. a. O. S. 3 I 5 .

3) Leop. v. Gerlach I, $24+$ (19. Nov.). Kaum vereinbar damit und jedenfalls unbeweisbar ist die Vermutung von Seitz S. 136, daß Bismarck damals die Oktroyierung der liberalen Charte gebilligt habe. 
Die Oktroyierung der preuß. Verfassung vom 5. Dez. $18+8.427$

Bauern und Gutsherrn, die gesamte Landbevölkerung unter einen Hut zu bringen und auszuspielen gegen Liberalismus und Demokratie der Städte, schmeckte mehr nach einem ganz modernen konservativen Parteifiihrer, als nach einem wahrhaft modernen lionservativen Staatsmanne. Es sei dahingestellt, ob dies sein letztes Wort wirllich gewesen wäre, wenn er verantwortlich zu handeln gehaht hätte. Nachdrücklich konstatieren muß man jedenfalls, daß seine Partei in ganzen damals ihre völlige Unfähigkeit erwies, ein positives und durchdachtes Gegenprogramm gegen die oktroyierungslustigen Minister aufzustellen. Ihr Gebahren in diesen Tagen macht den Eindruck hilfloser Konsternation. Der eine schlug den Vereinigten Landtag, der andere anderes vor, aber zu einer gemeinsamen Parole kam man nicht. "Wir waren, « klagte später Ludwig v. Gerlach ${ }^{1}$ ), „gegen die Oktroỵierung ïberhaupt, allein wir hätten doch viellejcht eine in èentum zu oktroyierende Verfassung in der Tasche haben sollen - was jedoch - so setzte er sehr charakteristisch hinzu - die Gefahr des loss of charakter und des Misverständlichwerdens nahe gelegt hätte. Man sieht hier tief hinein in die politische Impotenz des christlich-germanischen Kreises, die so nahe zusammenhängt mit den Grundlagen ihres Systems. Sie taugten mehr zur Reaktion als zur Alstion, und so versagte ihre Zunge in dem

Auch seine Meinung, daß Bismarck schon im September fur die Oltroyicrung einer liberalen Charte gewesen und vielleicht uberhaupt der Vater des Gedankens gewesen sei, steht auf sehr schwachen Fiußen. Aus der Gerlachschen Notiz 1, I00) (in Verbindung mit I, 200) läbit sich nicht mehr lierauslesen, als dab Bismarck und Gerlach im Sept. gesprächsweise neben anderen Mögliehkeiten auch die einer liberalen Oktroyierung erörtert halen; die Idee an sich lag nahe genug, und nicht auf sie, sondern auf ilıre Ausführung und Cen Geist ihrer Ausfuihrung kam es an. J lak der damalige Dismarck der Politik des 5. Dez. imerlich fern stand, ist auch die Meinung von Erich Marclis, der mir die betr. Partien seiner Bismarckbiographie ireundlichst mitgeteilt hat.

1) $2,2 \$$. 
Augenblicke, wo sie hätte sprechen müssen. So war es doch nicht bloß uiberlegte Taktik, sondern auch innere Schwäche, wenn Leopold v. Gerlach sich damals dafür entschied, daß die Erhaltung des Ministeriums Brandenburg wichtiger sei als seine papierene Verfassung. ${ }^{1}$ )

Vielleicht aber regte sich selbst in Leopold damals noch ein anderes Gefühl, ein Gefühl mehr preußischen als christlich-germanischen Ursprungs. „Der König und selbst Leopold, " so bezeugt uns sein Bruder, "trugen Scheu vor dem gänzlichen Verleugnen der Märzverheißungen. $\left.\ll^{2}\right)$ Das war die Zwangslage, in der sich alle die fühlen mußten, die damals für die Geschicke Preußens verantwortlich waren. Man konnte nicht mehr zurück, man mußte vorwärts auf der im März betretenen Bahn, um das damals gegebene Königswort irgendwie einzulösen. Graf Brandenburgs gerader und ehrlicher Charakter mag diese Verpflichtung ganz besonders empfunden haben. Er hat den Abmahnungen Leopold v. Gerlachs gegenüber sich mit Nachdruck auf das berufen, was der König vom März an habe geschehen lassen, und sein einfacher Verstand sagte ihm, daß man jetzt »nicht das Beste, sondern das Mögliche tun müsse«, um »auf dieser ersten notwendigen Grundlage dann mit Gottes Hilfe mit Mäßigung, Festigkeit und Konsequenz weiter zu bauen.$^{3}$ ) Er und seine Genossen, so mag man

1) Bezeichnend ist auch seine quietistische Bemerkung am 21. Nov. (I, 247): Manchmal denke ich, ob es nicht so kommen muß, damit der absolute Konstitutionalismus endlich einmal ein Ende nimmt.s Er glaubte auch später seine Taktik vor sich selbst rechtfertigen zu können, aber, so fragte Ludwig v. Gerlach dazu, vom Standpunkte der Partei aus nicht mit Unrecht: "Wo bleibt der Staatsmann? Das Parteihaupt? Ludw. v. Gerlach 2, 98 .

2) a. a. O. 2, 28 ; vgl, auch Goldschmidt a. a. O. S. 205 f.

3) Leop. v. Gerlach 1, 250 (24. Nov.), vgl. auch I, 261; Ludwig v. Gerlach 2, 29 f., vgl. ferner Fr. Heinemann, Die Politik des Grafen brandenburg (Berliner Dissert. 1909). 
Die Oktroyierung der preuß. Verfassung vom 5. Dez. $1 \$_{4} 8.429$

sich denken, wollten die Macht und die Autorität des Königtums und die konstitutionellen Verheißungen zugleich wahren. An der Berliner Versammlung hatten sie allen Grund zu verzweifeln. Konnte man durch bloße Auflösung und Neuwahlen in diesen aufgeregten Tagen ein besseres Resultat erhoffen? Was sollte man mit einer zweiten, ebenso widerhaarigen Versammlung anfangen? Sie würde, meinte ein Berliner Korrespondent der Deutschen Zeitung vom 3. Dezember ${ }^{1}$ ), an Machtfülle noch weit bedrohlicher sein, als die erste, vom Gipfel der Alleinherrschaft gesunkene. Die Minister mochten wohl Ähnliches fürchten und mögen so auf den gelegentlich schon früher erörterten ${ }^{2}$ ) Ausweg verfallen sein, eine liberale Charte mit monarchistischen Garantien zu oktroyieren. Es mochte ihnen als das sicherste und durchgreifendste Mittel erscheinen, einer neuen Volksvertretung gegenuiber die Krone von vornherein in Vorteil zu setzen, das Land zu beruhigen, die Reaktionsfurcht zu bannen, einer neuen Revolution vorzubeugen. „Es galt, " so motivierten sie es selbst hinterher in einem offiziösen Flugblatte ${ }^{3}$ ), : dem Absolutismus von oben und unten eine Schranke zu setzen. Die Anordnung neuer Wahlen zur Vereinbarung einer Staatsverfassung würde den Zustand, der seit März herrscht, ins Ungewisse weiter fortgesetzt haben. « Denken wir dann auch an den Moment, in dem der Oktroyierungsgedanke der Minister zuerst auftauchte, den I 6 . November. Er stand unter dem Zeichen dessen, was an Tage zuvor in Berlin geschehen war. Wird das Land, so mußten

1) Beilage zum 6. Dez.

2) Vgl. z. B. Leop. v. Gerlach I, I 99 (16. Sept.); Abgeordneter Landrat v. Moeller an Mevissen, Berlin, I I. Nov, I 848 , Hansen, Mevissen 2, 442.

s) , Warum der König also handeln mußte und daß er wohlgetan hat, eine Verfassung zu geben. Deckerschen Hofbuchdruckerei, in Akten des Ministeriums des Innern, die ich einsehen durfte. 
sich die Minister damals fragen, dem Aufrufe der revolutionären Versammlung folgen? »Bis zur Steuerverweigerung standen die Sachen für den König ganz schlecht «, - so charakterisierte ein preußischer Generalstabsoffizier die Stimmung im Lande. $\left.{ }^{1}\right)$ Der Lärm und Staub der Agitation, der über den tieferen Schichten des Volkes lag, war am 16. November noch so stark und dicht, daß man wohl zweifeln lionnte, wie es ablaufen würde. Klugheit und Loyalität also zugleich mochten damals zu dem Gedanken führen, etwaigen neuen revolutionären Ausbrüchen nicht durch ein bloßes Säbelregiment, wie man es eben in Osterreich erlebt hatte, sondern auch durch eindrucksvolle liberale Zugeständnisse zu begegnen. Daß die öffentliche Meinung solche unbedingt verlangte, konnte nicht zweifelhaft sein. 》Das ist nicht zu leugnen, « mußte auch Leopold v. Gerlach zugeben ${ }^{2}$ ), „daß sie noch immer auf der Seite des Konstitutionalismus steht. « Gewiß hätte mit dem zuverlässigen Heere, das man hatte, auch eine reine Militärdiktatur sich zunächst wohl behaupten lassen; aber zum Ruhme der preußischen Staatsmänner und Militärs fand sich niemand, der dazu raten wollte. Darf man in diesem Zusammenhange nicht auch nach den Strömungen fragen, die im Heere vorwalteten? Es versteht sich von selbst, daß das Heer keine Politik machte, aber daß es doch indirekt einwirken konnte auf die Stimmungen der leitenden Männer. Die Armee, so berichtet uns der vorhin angerufene Zeuge am $2 \mathrm{I}$. Olitober, steht natiirlich fest zum Könige und huldigt zum entschieden größten Teile zwar nicht dem Radilialismus, aber dem Liberalismus. ${ }^{3}$ )

1) 7. Dez. $184 \mathrm{~S}$ •Potsdamer u. Berliner Briefe eines preußischen Offiziers aus dem Jahre Is 4 S\&. Dentsche Runischau Bd. 2S (ISSI) S. $264 \mathrm{f}$.

2) $1,247$.

3) Deutsche Rundschan a. a. O. S. 253. 
Die Oktroyierung der preuß. Verfassung vom 5. Dez. r 848 . 43 I

Jeder weitere Tag vom I6. November ab freilich machte die politische Lage im Innern heller. Der Steuersuspendierungsbeschluß wirkte das Gegenteil von dem, was er sollte. Es ging wieder royalistischer Wind durch das Land. In den letzten November- und ersten Dezembertagen konnte man es völlig übersehen, daß die revolutionäre Versammlung keinen Boden im Lande hatte, daß neue Stürme nicht zu erwarten waren. Jetzt noch oktroyieren, hieß nicht mehr eine unmittelbare Revolutionsgefahr beschwören. Die Minister hätten jetzt, sollte man meinen, auch durch minder radikale Mittel ihren Zweck, das Land $z u$ beruhigen und $z u$ gewinnen, erreichen können. Mit jedem Tage weiter wurde der Oktroyierungsentschluß der Minister also freier von unmittelbarem Drange und Zwange, wuchs er aus der Sphäre eines momentanen Auskunftsmittels weiter hinein in die Sphäre einer organischen und großen Maßregel. Man möchte sagen, mit jedem Tage weiter wird er interessanter, und die Umgebung, innerhalb deren die Fahrtrichtung zuerst gewählt wurde, veränderte sich nicht nur dadurch, daß die ursprünglich drohenden Klippen zurückwichen, sondern auch dadurch, daß neue Gestade auftauchten, teils warnend, teils verlockend. Vom 21. November ab, wo die Frankfurter Reichskommissare den Oktroyierungsgedanken der Minister erfuhren, erhielt dieser, wie wir schon sahen, eine unmittelbare Spitze gegen das Frankfurter Verfassungswerk. Berlin, das ministerielle Berlin, stieß durch ihn hart gegen Frankfurt an, während es doch zugleich auch noch mit Potsdam zu ringen hatte. So standen die Minister jetzt in einem Kampfe gegen zwei, und wenn wir die Abmahnungen der Prinzessin und des Prinzen von Preußen vom 24. November ${ }^{1}$ ) hinzunehmen,

1) Prinzessin Augusta an Manteuffel 24. Nov. mit beigefügter Denkschrift, deren Inhalt, wie sie sagte, der Prinz, geprüft und gebilligte habe. Poschinger, Manteuffel I, $40 \mathrm{ff}$. 
selbst gegen drei Fronten. Die Prinzessin, gestuitzt auf die Unterstiitzung des Thronfolgers, wollte die Oktroyierung zwar nicht schlechthin verwerfen, erklärte sie aber für den »äußersten und gefährlichsten Schritt« und malte sich bange Bilder von innerer Zerruttung, Sturz der Dynastie und Bürgerkrieg aus. Daß die Minister sich durch alle diese Stimmen von rechts und von links nicht beirren ließen und ihren Weg weiter gingen, ist eine große politische Leistung. Und indem sie sich auch durch Gagerns verführerisches Programm nicht von dem Gedanken der preußischen Verfassung abbringen ließen, erhielt ihr Tun jetzt den Charakter einer bewußten Abwehr der Zumutung, Preußen aufzulösen in das Deutsche Reich. ${ }^{1}$ ) Der alte preußische Staatsgedanke behauptete sich kräftig gegen das moderne nationale Deutschland und tat das selbst mit modernen Waffen.

Aber in diesem seltsam verschlungenen Kampfe konnte nun das Wunder geschehen, daß die eine Hand des Kämpfers kräftig abwehrte und die andere Hand sich dem Gegner freundlich näherte. Frankfurt war fuir Berlin in diesem Augenblicke, wo Gagern in Preußen weilte und die Oktroyierung vorbereitet wurde, Feind und Freund zugleich. Schon Hermann Oncken hat in

1) Ich verkenne durchaus nicht, daß meine Konstruktion in diesem wichtigsten Punkte einen hypothetischen Charakter behält, da wir ja nicht wissen, wie weit Gagern selbst den Ministern Einblick in sein preußisch-deutsches Verfassungsprogramm gewährt hat. Bekannt aber war es ibnen ja schon, wie man stark betonen ınuß, durch die Meldung Camphausens vom 20. Nov. (s. o. S. 39I). Man kann auch darauf binweisen, daß der preußische Vertreter in Wien, Graf Bernstorff, als er mit Schwarzenberg iber die oktroyierte Verfassung und über die Anerbietungen Gagerns in Potsdam sprach, ausdriicklich dabei betonte, saß der Einfluß und die Macht Preußens in Deutschland nur dann groß sein könne, wenn es in sich und als selbständiger Staat groß und mächtig seic (Immediatbericht 9. Dez. I 848 . Ringhoffer, Im Kampfe um Preußens Ehre S. 79) - ein deutliches Echo der Gegensätze, die zwischen Berlin und Frankfurt bestanden. 
Die Oktroyierung der preuß. Verfassung vom 5, Dez. I 848.433

Erinnerung an die Vorgeschichte des I8. März die Vermutung ausgesprochen, daß die oktroyierte Verfassung den liberalen Wiinschen deswegen so weit entgegengekommen sei, weil man die Frankfurter Bundesgenossen, die man zwar nicht liebte, doch brauchte. ${ }^{1}$ ) Auf so einfachen Ausclruck läßt sich dieser Zusammenhang jetzt freilich nicht mehr bringen, denn wir wissen ja, daß die aktroyierte Charte zugleich auch einen derben Strich durch die Rechnung des Gagernschen Kreises bedeutete. Aber der hochliberale Inhalt der Charte konnte allerdings auch als eine Kompensation gelten für den Schmerz, der den Anhängern Gagerns durch die konstitutionelle Abschließung Preußens angetan wurde, und die Minister können ihn von dem Augenblicke an, wo sie jene Wünsche Gagerns erfuhren, als solche aufgefaßt haben. Der Blick der Minister muß aber auch schon vor der Werbung Gagerns auf die künftige Stellung Preußens in Deutschland gegangen sein. Von vornherein miissen sie sich das kiunftige Deutschland als einen Bundesstaat gedacht haben. Sonst würden sie in ihren ursprünglichen Verfassungsentwurf nicht die Bestimmung aus der Charte Waldeck mit aufgenommen haben, die das Vertragsrecht und die auswärtige Politik der preußischen Krone durch das künftige deutsche Bundesrecht einschränlkte. ${ }^{2}$ ) Sonst würden sie weiter auch nicht die Klausel mit aufgenommen haben, daß Abänderungen der gegenwärtigen preußischen Verfassung durch die für Deutschland festzustellende Verfassung nötig werden könnten. ${ }^{3}$ ) Auch diese

1) IIist. Zeitschrift $88,506$.

2) Poschinger, O, v. Manteuffel I, 50. Entwurf der Verfassungskommission ("Charte Waldecks) Art. 47. Auf Wunsch des Königs, der dies im damaligen Augenblicke, nicht mit Unrecht, „sehr bedenklich fand, wurde sie gestrichen.

3) Art. I I I; vgl. auch den Immediatbericht des Staatsministeriums vom 5. Dezember $\mathrm{IS}_{4} \mathrm{~S}$ (Poschinger a. a. O. S. 59 unten). Eben diese Bestimmung erregte denn auch bei dem Fürsten Schwarzenberg tiefes 
Verbeugungen vor der deutschen Zukunftsverfassung gehörten, was man nicht ubersehen darf, zu der Erfüllung jener Märzverheißungen, an die der Graf Brandenburg sich gebunden fühlte. Er hat selbst später einmal, zur Rechtfertigung seiner deutschen Politik, auf das Edilit vom 18. März sich berufen, das man »nicht ignorieren könne «.1) Sicherlich hat er es aber nicht nur aus Gewissenhaftigkeit, sondern auch aus preußischem Ehr. geize getan ${ }^{2}$ ), und die deutsche Verfassung, an die er und seine Kollegen bei der Niederschrift ihres preußischen Entwurfs dachten und der sie sich beugen wollten, kann nur eine Verfassung gewesen sein, die auch dem preußischen Stolze genügte. Das beweist die ganze deutsche Politik des Ministeriums. Hier werden wir uns mit denjenigen Zeugnissen für sie begnügen können, die aus der Zeit kurz vor und nach der Oktroyierung stammen.

Der König war am 23. November böse auf Brandenburg, daß er in der deutschen Sache nichts tun wollte. $\left.{ }^{3}\right)$ Das heißt, dieser wollte die deutsche Politik Preußens nicht, wie es der König wünschte, im Bunde mit den deutschen Königen, sondern im Bunde und mit Benutzung des Frankfurter Parlaments treiben. Er

Mißtrauen, und er bemerkte zu dem Grafen Bernstorff, daß er sich seine solche Unterordnung Preaßens in seinen eigenen staatlichen Einrichtungen unter Deutschland gar nicht anders erklären könne, als dadurch, daß die (preußische) Regierung den Wunsch und die Hoffnung nicht aufgäbe, Preußen an die Spitze Deutschlands gestellt zu sehenc. In demselben Sinne deutete man in Wien auch den liberalen Inbalt der Verfassung iiberhaupt. Bernstorffs Immediatbericht 9. Dez. Ringhoffer a. a. O. S. 78.

1) Leop. v. Gerlach I, $2 \$ 9$ (9. Febr. I $\$ 49$ ).

2) Vgl, Bismarcks Urteil uber Graf Brandenburg (Gedanken und Erinner. 1, 66): „daß sein preußischer Patriotismus vorwiegend von den Erinnerungen an I $\$ 12$ und 1 \& 3 zehrte und schon deshalb von deutschem Nationalgefiuhl durchsetzt war. Entscheidend blieb indes das dynastische und borussische Gefühl und der Gedanke einer Machtvergrößerung Preußens. 6

8) a. 2. O. S. 250 . 
Die Oktroyierung der preuB. Verfassung vom 5. Dez. $18+8.435$

gab in diesen Tagen Camphausen völlig recht, welcher ausführte, daß es jetzt, wo das Parlament durch seine Ubermacht nicht mehr gefährlich sei, nun gelte, es zu kräftigen und zugleich auf die Einzelstaten zu drücken; sonst würde deren Selbstsucht jede deutsche Verfassung und Einheit zugrunde richten. ${ }^{1}$ ) Stärksten preußischen Ehrgeiz atmet vor allem das offiziöse Flugblatt vom 6. Dezember I 848 , das die Oktroyierung rechtfertigen sollte: „Die Verfassung des Deutschen Reiches wird in wenigen Wochen vollenclet sein. Wenn dann die Blicke des deutschen Volkes spähend umherschauen, wessen Hand die oberste Gewalt am besten anzuvertrauen sei, soll dann Preußen dastehen mit halbgebrochner Kraft, zwischen Absolutismus und Anarchie noch in ungewissem Schwanken? Nein, die Lage des Vaterlandes, die IVeltlage erfordert ein starkes, ein geordnetes Preußen. Stark ist aber nur ein freies Preußen. $\ll^{2}$ ) Nicht lange darauf, wohl am 14. Dezember, sprach es Graf Brandenburg einem Freude Gagerns unumwunden aus, daß ihm allerdings Preußen an der Spitze des deutschen Bundesstaates mit einem Rate der Könige zur Seite als die einfachste und glücklichste Lösung der deutschen Frage erscheine.") Genau in dieser Stimmung fand Bunsen, als er im Januar I $\$ 49$ nach Berlin kam, die Minister: Von dem Wunsche erfüllt, Preußen als Schutzherrn an die Spitze Deutschlands zu stellen, aber höchlichst befremdet, als Bunsen meinte, daß im

1) Sybel, Begriindung des Deutschen Reiches I, 26 I.

2) a. a. O. Vgl. auch den Artikel des Preubischen Staatsanzeigers 9. Dez, bei Simson S. $143 \mathrm{f}$.

3) Simson a. a. O. S. 157. Die Datierung dieses Berichtes eines ungenannten Politikers ergibt sich vor allem aus den Worten S. I54: ,Hergenhahn wird Ihnen mitteilen, wie erwiinscht meine Nachrichten für ihn ... waren.\& Hergenhahn reiste am Morgen des 14. Dezembers von Berlin ab. (Deutsche Zeitung, Beilage zu Nr. 332.) Über die Autorschaft vgl. Hist. Zeitschr. S9, 192. 
deutschen Bundesstaate die preußischen Kammern aufhören müßten, eine politische Stellung zu haben. ${ }^{1}$ )

Fassen wir zusammen. Von vornherein ist, ähnlich wie bei der Vorgeschichte des Patentes vom 18. März, das innerpreußische Motiv verbunden mit dem deutschen Motive. Jenes ist zunächst unmittelbarer und dringender, weicht aber allmählich an Bedeutung zurïck vor dem deutschen Motive. Und nun darf man dringend vermuten, daß auch die Kunde von dem, was am 27. November in Kremsier proklamiert worden war, auf die preußischen Minister eingewirkt hat. Wenn Ósterreich seine staat. liche Einheit nicht opfern, sondern im Gegenteil enger ziehen wollte, dann erschien jetzt die Begründung des deutschen Bundesstaates ohne Ósterreich und mit Preußen an der Spitze als die durch Osterreichs Entschluß selbst diktierte Lösung. Wirklich gab Graf Brandenburg am I4. Dezember jenem Freunde Gagerns auch das zu, daß die Einigung Deutschlands zu einem Bundesstaate durch die Sonderstellung Ósterreichs nicht aufgehalten werden dürfe. $\left.{ }^{2}\right)$

Höchst eigentümlich und bedeutend erscheint doch nun, wenn wir alle Zusammhänge uiberblicken, das Ereignis vom 5. Dezember. Preußen tat eigentlich dasselbe wie Österreich am 27. November. Beide alte Mächte, siegreich über die Revolution im Innern, faßten ihre historisch erwachsene Einheit neu und fester zusammen auf neuer, konstitutioneller Grundlage und wiesen dadurch gewissermaßen den Frankfurter Verfassungs-

1) Nippold 2, 492, vgl. oben S. 362 .

2) Am Abend des 4. Dezembers kam die Nachricht von Franz Josephs Thronbesteigung. Die preußischen Prinzen sahen darin, wie Leop. v. Gerlach I, 259 erzählt, eine ,österreichische Absicht auf die Kaiserkronec. Nicht unmöglich wäre es, was ein Berliner Korrespondent der Deutschen Zeitung vom 7. Dez. (S. 2503) vermutete, daß diese Nachricht irgendwie eingewirkt hat auf die Veröffentlichung der Ver fassung am Tage darauf. Vgl, auch Walter a. a. O. S. $265 \mathrm{f}$. 
machern die Zähne, behaupteten ihre staatliche Autonomic gegenüber den Ansprüchen der Nationalsouveränität. Aber die Dinge lagen zugleich so, daß auch dieses ablehnende Nein, das sie den Frankfurtern zuriefen, dcren Verfassungswerk zunächst fördern sollte. Gerade das Kremsierer Programm Schwarzenbergs war es, was der Partei Gagerns neuen Mut zu ihrem Versuche gab, den deutschen Bundesstaat ohne Osterreich zu begründen. Ohne Ósterreich aber, das hieß mit Preußen. Wohl bedrohte nun die Erklärung Preußens, ein Einheitsstaat sein und bleiben zu wollen, die tieferen Grundlagen des Gagernschen Programmes. Die Forderung der Gagernschen Partei war ja, daß Preußen, um deutsche Vormacht zu werden, zwar liberal und konstitutionell, aber nicht ganz, nicht für sich konstitutionell werden diirfe. Der eigentümlich schwebende Widerspruch dieser Forderung kehrte sich nun gegen die, die sie gestellt hatten, sie erbielten zugleich mehr und weniger als sie gewünscht hatten. Preußen wurde so liberal, als sie es nur wünschen konnten, aber durch ein Mittel, das sie verwiinschen mußten. Und doch konnten die Frankfurter nichts dagegen machen und waren gezwungen, an Preußen festzuhalten, das sie nun einmal brauchten und das sich ja auch bereit erklärte, an ihrem Werke mitzuarbeiten. Das Spiel hatte sich ganz gewendet. Die Frankfurter gedachten Preußen auszunutzen, aber jetzt, durch die Tat vom 5. Dezember, inaugurierte Preußen eine Politik, die darauf hinauslief, die Frankfurter fuir Preußen auszunutzen. Von dem liberalen und nationalen Winde, mit dem Frankfurt fuhr, hatte Preußen so viel in seine eigenen Segel aufgefangen, daß es jetzt einmal vorauskam; und zugleich fuhr die »schmucke preußische Fregatte « dabei auf jener großen Grundströmung dahin, die sie seit den Tagen des Großen Kurfiirsten und Friedrichs des Großen trug. Die Frankfurter konnten nun gar nicht anders, sie mußten sich 
diesem Kurse anschließen. So ist schon etwas von späterem Bismarckschen Geiste in dieser Tat des 5. Dezembers. Sie war konservativ und neuschaffend zugleich, konservativ in der festen Bewahrung des preußischen Wesens, neuschaffend in der Benutzung der nationalen und freiheitlichen Kräfte. Man benutzte sie zugleich und hielt sie in Schranken, innerhalb deren sie sich mit dem geschichtlich Erwachsenen und noch Lebendigen vertragen konnten.

Ein ideales Kompromiß zwischen Altem und Neuem bedeutete die oktroyierte Verfassung, ihrem Inhalt nach betrachtet, freilich nicht. Ihr Grundstock war schematischer Liberalismus, aus Frankreich und Belgien importiert ${ }^{1}$ ), und das Verdienst der Minister bei der Ausarbeitung selbst beschränlite sich darauf, den Verfassungsentwürfen der Nationalversammlung eine Reihe von wesentlichen Vorbehalten zur Wahrung der königlichen Autorität einzufügen. ${ }^{2}$ ) Hätte man einst die Bahn weiter verfolgt, die Stein und Humboldt dem preußischen Verfassungswerke geben wollten, so hätte man wohl jetzt etwas Besseres, Organischeres, echt Preußisches schaffen können. Aber jene Entwicklung war unterbrochen, ihr Ideenschatz war den Zeitgenossen und somit auch den Männern aus dem Auge gerückt, die jetzt in diesen drang- und sturmvollen Tagen die Verfassung zu machen hatten. Sie mußten, wenn sie jetzt die liberale Forderung erfüllen wollten, beinahe notgedrungen zu dem greifen, was der Liberalismus in diesem Augenblicke und in diesem Lande verlangte. Auch Bismarck hat, als er I 866 das allgemeine Wahlrecht gab, nicht anders gehandelt.

1) Eine lehrreiche staatsrechtliche Vergleichung der endgiiltigen preußischen Verfassungsurkunde mit der belgischen gibt R. Smend: „ Die preußische Verfassungsurkunde im Vergleich mit der belgischen. ، Göttinger Preisschrift 1904.

2) Vgl. dartiber Goldschmidt a. a. O. S. 204 und Seitz S. I 37 ff, 
So war die Arbeit der Minister an sich ein Werk der Not und der Eile und darum mangelhaft. Ihr holser Wert liegt in den Zusammenhängen, in denen es entstand und in den Wegen, die es der preußisch-cleutschen Politik wies. Aber dieser beste Teil ihrer Arbeit ist in gewissem Sinne anonym. Wir können wohl nachweisen, daß die Mehrheit des Ministeriums aus Männern bestand, die die Verständigung mit Frankfurt und die Begründung des preußisch-deutschen Bundesstaates wiinschten, aber wer von ihnen der Fiihrende und Treibende war, läßt sich nicht sagen. Ganz deutlich traten uns wohl die deutschen Gesichtspunkte des Grafen Brandenburg hervor, aber wie weit er produktiv, wie weit er nur rezeptiv sie vertreten hat, weiß man nicht. Vielleicht, daß Graf Bülow, der Verweser des Auswärtigen Amtes, der mit Camphausen an einem Strange zog und in den folgenden Monaten durch den Eifer, mit dem er an der Verständigung mit Frankfurt arbeitete, des Königs Mißfallen sich zuzog, ihn beeinflußt hat. Aber auch von Rintelen wissen wir, daß er im Frühjahre I 849 frankfurtisch und erbkaiserlich gesinnt $w^{1}$ ), und Ladenberg hat später die Radowitzsche Unionspolitik mit Uberzeugung vertreten. Von Strothas Haltung in der deutschen Frage weiß man lagegen so gut wie nichts. Manteuffel hat, wie wir wissen, ubberhaupt nur widerwillig die ganze Oktroyierungspolitik mitgemacht.

Vielleicht hat aber noch ein anderer stiller Einfuß gewaltet. Der Major Edwin von Manteuffel, Fliigeladjutant des Königs, hat unzweifelhaft seine Hand mit hineingesteckt. Er fuhr in den Novembertagen hin und her zwischen Berlin und Potsdam, konferierte hier mit Brandenburg und Strotha, dort mit dem General-

1) Leop. v. Gerlach 1, 304, 306; Friedjung, Österreich von I $848-$ I 860 I, 507 . 
adjutanten von Rauch $^{1}$ ) und gelegentlich auch mit Leopold v. Gerlach. Diesen bat er am 20. November dringend, dem Könige zuzureden, sich dem Verfassungsprojekt der Minister nicht zu widersetzen, und rihmte sich, den Verfassungseid der Armee aus der Verfassung selbst herausgebracht zu haben. ${ }^{2}$ ) Er tat zu Gerlach zwar so, als handle es sich zunächst nur darum, Zeit zu gewinnen und Ruhe zu schaffen, und daß solche Verfassung noch keinen Bestand hätte. Aber wichtiger als solche argumenta ad hominem ist uns die Bemerkung, die er bei dieser Gelegenheit machte, »daß ihm der kleine Ranke a consiliis sei . Irren wir nicht, so haben wir dieses Votum Rankes in der Denkschrift, die im 49. und 50. Bande seiner Werke S. 592 ff. abgedruclit ist. $\left.^{3}\right)$ Sie ist dort auf Ende Oktober I $84 \mathrm{~S}$ datiert. Das kann nicht sein, denn sie bezicht sich schon auf Ereignisse des Novembers. ${ }^{4}$ ) Wir meinen, daß sie in denselben

1) Keck, E. v. Manteuffel S. 94.

2) Leopold v. Gerlach I, 245. Die ersten Entwürfe der Verfassung enthielten in der Tat noch den Verfassungseid der Armee (Poschinger 1, 53 unten und G. St. A.); in dem Patent vom 5. Dez. 1848 wurde in Aussicht gestellt, daß die son uns verheißene Vereidigung des Heeres aut die Verfassung unmittelbar nach erfolgter Revision stattfinden solle.

3) Ranke hat sich später (IS85) selbst tiber seine politischen Denkschriften aus jenen Jahren geänßert: ,Znweilen bin ich in ziemlich verzweifelten Augenblicken indirekt zu Rate gezogen worden ; der damalige Fliggeladjutant, spätere Feldmarschall v. Manteuffel bot sich zum Vermittler dar. Und wenigstens so viel habe ich vernommen, daß der König auf seinen Vortrag Rücksicht nahm und sich zu einer festen Haltung ermannte.\& Säntl. Werke 53/54, S. 74. Vgl. auch Wiedemann, Deutsche Revue I7, 2, S. II 3 und Varrentrapp, Histor. Zeitschrift 99, I I I.

$\left.{ }^{4}\right)$ S. 595: „Die letzten Ereignisse sind hierfür von der größten Bedeutung. Die Versammlung weigerte sich, die von der Krone gewählten Minister anzuerkennen und forderte, daß diese aus ihrer Mitte genommen würden. \& Damit kann nur der Beschluß der Versammlungr vom 2. November und die bekannte Deputation in Sanssouci gemeint 
Tagen entstanden ist, in denen der Oktroyierungsgedanke der Minister Gestalt gewann. Die »Bcstunterrichteten", sagt Ranke, "scheinen den IVeg der Vereinbarung nicht

sein. Das Ministerinm Pfuel hatte man zwar auch schon mit einem Mißtrauensvotum begrißßen wollen, es aber unterlassen. Vgl. Unruh, Skizzen aus Preußens neuester Geschichte S. 73 f. Die Denkschrift muß selbst iiber die Mitte des Novembers hinausgerückt werden, da sie von der Versammlung nur im Praeteritum spricht, bereits sich auf sdie Erklärung der öffentlichen Stimme zugunsten der Krone beruft und die Oktroyierungsgedanken schon kennt. Daß der letzte revolutionäre Akt der Versammlung vom I5. November nicht erwähnt wird, ist bei dem hohen Standpunkt, von dem aus die Lage gesclildert wird, kein Hindernis gegen diese Datierung. Diether, L. v. Ranke als I'olitiker S. 345 ff., glaubt dagegen die Denkschrift auf die Zeit zwischen 3. u. 9., allenfalls noch IO. Nov. ansetzen zu müssen. Ich will das Gewicht eines Teiles der von ihm angeführten Gräde nicht verkennen, aber er muß selbst zugeben, daß er Einzelvorgänge aus dieser Zeit, die eine »Erklärung der öffentlichen Stimme zugunsten der Kronec enthalten, nicht kenne. Ranke S. 596 aber spricht in so starken Ausdrücken von der entschiedenen und allgemeinen Meinungsäußerung der - Nation zugunsten der Krone, daß man sie nur auf den vom I6. November $a b$ einsetzenden Stimmungsumschwung beziehen kann. Mit der Wiedemannschen Notiz, auf die sich Diether vor allem beruft, ist chronologisch nichts anzufangen; sie läßt sich auch mit meiner Datherung vereinigen. Weiter wiirde es Diethers Datierung schwer fallen, die Äußerung Rankes S. 593: , Österreich kann es und scheint es in diesem Augenblicke zu wollen (sc. sich von Deutschland ausschließen)e zu erklären. Sie braucht gewiß, wie ich zu der I. Auflage S. 427 schon meinte, nicht notwendig auf das Kremsierer Programm rom 27. Nov. bezogen zu werden. Aher mein damaliger Versuch, sie zu erklären aus dem seit Mitte November in Potsdam bekannten Eintreten des damals in England weilenden Metternichs fuir Trennung von Österreich und Deutschland, genïgt mir jetzt nicht mehr. Rankes Worte , Österreich kann es und scheint cs in diesem Augenblicke zu wollen \&, müssen sich auf bestimmte, so zu deutende Akte der österreichischen Regierung selbst beziehen, und da kann als frihester und vielleicht einziger so zu deutender Akt nur die Erschießung Robert Dlums am 9. Nov. in Betracht kommen, der in Dentschland sogleich als ein Iruch mit der Frankfurter Versammlung aufgefaßt wurde. - Nicht lange danach und bald nach dem 15. Nov. also muß die Denkschrift entstanden_sein. 
für möglich zu halten und ziehen vor, eine Verfassung auf dem Grunde der gemachten Vorlagen und Entwürfe geradezu zu verleihen «. Und Ranke billigte dies Verfahren unter der Voraussetzung, daß der Begriff der Volkssouveränität dabei nicht Geltung erlange. Das war die Warnung vor einer Gefahr, die bei der Gesinnung der damaligen Minister nicht bestand, und so sollte sie wohl mehr als Beruhigung für die dienen, die vor einer modernen Konstitution iberhaupt Bedenken hatten. An diese vor allem richtete er sich: „Das konstitutionelle Wesen muß nur ohne Vorliebe und ohne $\mathrm{Ha}$ angesehen werden als eine Form, in welcher die jetzigen Menschen nun einmal leben wollen; - man muß die Verfassung so einrichten, daß man dabei bestehen kann. « Den stärksten Grund für cine konstitutionelle Verfassung Preußens aber sah er nicht in der Forderung der Zeitgenossen, auch nicht in inneren preußischen Verhältnissen, sondern in dem Verhältnisse Preußens zu Deutschland. Preußen, sagte er, kann sich nicht mehr, wie zur friderizianischen Zeit, von selber fortbewegen, ein Teil seiner Macht und seiner europäischen Bedeutung liegt jetzt in dem Zusammenhange mit Deutschland. Man müßte, wenn man sich jetzt absondern wollte, den Zollverein aufgeben. So bleibt nur die Wahl »Einfluß auszuüben oder zu erfahren «. Die Form, ihn auszuuben, sieht er nur darin, daß Preußen die erste Stelle in Deutschland einnehme. Um ihn aber ausüben zu können, muß Preußen jetzt den Gedanken der Konstitution realisieren.

Ranke kannte wohl kaum die Forderung der Rümelin und Gagern, daß Preußen diesen Gedanken nicht fuir sich, sondern fiir Deutschland realisiere, - oder er kannte wenigstens nicht den Ernst dieser Forderung. Aber er hätte sie nicht anerkannt, denn er verwirft sie implicite mit den Worten: „Das deutsche Kaisertum ist seiner Natur nach konservativ, ist es immer gewesen und wird es wieder sein. Wenn die höchste Gewalt in Deutsch- 
land nicht einen Ubergang zu republikanischem Umsturz bilden will, so muß sie sich entschlicßen, die Selbständigkeit der einzelnen Staaten und den Begriff des Fürstentums anzuerkennen «. Zu republikanischem Unsturze brauchte der Gagernsche Gedanke nun gerade nicht zu führen, aber konservativ war ein Kaisertum, das auf cler Unselbständigkeit des größten Einzelstaates beruhte, auch nicht mehr zu nennen. Und iiberhaupt der ganze Geist des Rankeschen Gutachtens atmet preußisches Selbstgefühl und Staatsbewußtsein. Es ist der alte konservative Nationalstaatsgedanke Rankes, wie wir ihn im ersten Buche kennen gelernt haben, nur auf einer höheren Stufe als damals, indem jetzt die Nationalität des mächtigsten Einzelstaates nicht mehr nur durch unsichtbare, sondern auch durch sichtbare, politisch wirksame Bande mit der umfassenderen deutschen Nationalität verknuipft wirch.

Hier haben wir nun das, was wir brauchen: eine Begrindung und Rechtfertigung der Oktroyierungspolitik, des Oktroyierens selbst, vor allem aber des zu Oktroyierenden, von großen und weiten Gesichtspunkten aus, von höchstem historisch-politischem Verstande, wie es bei einer Rankeschen Schrift selbstverständlich ist. Nicht so selbstverständlich ist, daß der große Meister hier auch seiner eigenen Zeit mitfühlend und verstehend an den Puls faßt und ihr ein Rezept verschreibt, das dem Gewordenen und dem Werdenden gleich gerecht wird. Und die Schrift ist nicht bloß ein persönliches Bekenntnis, sondern diente einem unmittelbaren politischen Zwecke, war fiir die Augen der Regierenden bestimmt und kann so als eine preußische Staatsschrift aufgefaßt werden. Denn daß Edwin v. Manteuffel, der sie jedenfalls angeregt hat, sie oder ihren Inhalt den ihm nahestehenden Ministern mitgeteilt hat, kann nach den obenerwähnten Tatsachen kaum einem Zweifel unterliegen. Ranke stand dem Kreise derer, die oktroyieren wollten, ganz nahe, - wie wäre 
es sonst möglich, daß er sich damals auch der Arbeit unterzog, eine königliche Proklamation für die Oktroyierung zu entwerfen. ${ }^{1}$ )

Wir dürfen nun nicht sagen, daß die Gedanken Rankes schlechthin die Gedanken der Minister geworden sind, aber wir dürfen sagen, daß sie der Tat der Minister ihren tieferen Hintergrund geben und unsere Auffassung von ihr bestätigen.

Und zugleich darf man wohl darauf aufmerksam machen, daß hier auch der große Gegensatz innerhalb der deutschen Geschichtschreibung des I9. Jahrhunderts, der Gegensatz zwischen Ranke und den Vertretern der sogenannten politischen Historie an einem zentralen politischen Problem hervorbricht. In den Reihen derer, die um Deutschlands willen Preußens Staatseinheit vernichten oder doch untergraben wollten, stand Johann Gustav Droysen, stand Max Duncker ${ }^{2}$ ) und stand, wie wir bald sehen

1) a. a. O. S. 598 . Die dort gegebene Datierung 5. Dez. I $\$_{4} S$ ist natiulich nur summarisch zu verstehen. Vielleicht ist der Entwurf schon gleichzeitig mit der Denkschrift entstanden, denn es fälit auf, daß die letzte Phase der Versammlung in Brandenburg und damit der letzte gescheiterte Vereinbarungsversuch nicht erwähnt ist. Gegen I) iether a. a. O. S. $357 \mathrm{Anm}$. bemerke ich, łaß ich damit lediglich eine Vermutung aussprechen will und dab die von ihm vermißte Veranlassung zur Entwerfung einer solchen l'rollamation in diescm frihen Zeitpunkte (nach 15. Nov.) genïgend vorliegt in den Oktroyierungsabsichten der Minister. Ich will aber zugleich gern auch die Möglichkeit zugeben, daß die Proklamation Anfang Dezember erst geschrieben sein könnte.

$\left.{ }^{2}\right)$ Dunckers Denkschrift üher die Oherhauptsfrage für die Kasinopartei, kurz vor Weihnachten IS 4 S verteilt (Haym, Duncker S. 9\$), auszugsweise wiedergegeben von Haym, Nationalversammlung II, 2 I 7 ff. Wird, sagt Duncker (S. 227), sdiese Situation unsererseits rasch und staatsmännisch erfaßt, so kann in diesem Bundesstaat für die zu errichtende Spitze jeder Gegensatz von Haus- und Reichsmacht aufgehoben werden. Die gefährliche Reibung einer großen Staatsvertretung neben der Reichsvertretung kann vermieden und statt der gefüchteten Hegemonie Preußens wurde vielmehr die Herrschaft Deutschlands uber 
werden, auch Dahlmann. Sie wollten Deutschland durch Preußen, aber auch auf Kosten Preußens einigen. Ranke wïnschte auch Deutschlands Einigung durch Preußen, aber unter Wahrung der historisch erwachsenen Staatsindividualität. Jene wurzelten stärker in der eigenen Zeit, indem sie von dem Ideale eines modernen deutschen Nationalstaates ausgingen und das geschichtliche, das territoriale Deutschland zwar respektierten, aber nur so weit respektieren wollten, als es ihr Begriff vom konstitutionellen Bundesstaate zuließ. Ranke schöpfte tiefer aus der deutschen Geschichte und faßte das alte deutsche, konservative Kaisertum, die territoriale Epoche und das neue, werdende konstitutionell-nationale Preußen-Deutschland zu einer zusammenhängenden, von keinem Risse unterbrochenen Entwicklungsreihe zusammen. Bei jenen ist mehr heißer Wunsch und Leidenschaft, - noch immer etwas von der Leidenschaft, mit der Stein einst Preußen zerschlagen lassen wollte, - bei Ranke verbindet sich die Ruhe historischer Kontemplation mit der Kühle realpolitischer Erwägung. Er sitzt oben auf der Warte des preußischen Staates, während jene vom Boden deutscher Nation aus heraufzustürmen versuchen. Wer vom preußischen Zentrum aus die deutsche Frage erfaßte, konnte nicht wohl so leidenschaftlich und heiß begehren wie jene, denn er hatte schon etwas, während jene nichts $z u$ haben glaubten und in ihrem Hunger nach Nation alles und darum zu viel haben wollten. Aber ohne den Hunger dieser

Preußen ... zu erlangen sein.` Vgl. uber Duncker auch Jürgens I, 481 f. - Küntzel (Deutsche Literaturzeitung r 908, S. 45S) macht wohl darauf aufmerksam, daß Duncker in seiner Schrift uber die Frankfurter Versammlung von 1849 diesen Standpunkt wieder verlassen hat, aber einmal zeigen die von Küntzel selbst zitierten Worte Dunckers (,Preußen ist im Reiche viel eher zu stark als zu schwach c) die Nachwirkung des Pfizer-Rumelinschen Gedankens, und dann haben, wie wir im 5. Kapitel ausfithren, die Erbkaiserlichen, die ihn vertraten, im Friihjalır i $\$ 49$ uberhaupt eingesehen, daß man ihn vorläufig zurlickstellen müsse. 
Nichtshaber wäre auch dem preußischen Staate gar leicht der Drang nach völliger Saturierung vergangen, wäre Preußen gar leicht nur P'reußen geblieben. Ohne die Kräfte, die jene mitschaffen halfen, hätte Ranke und hätte später Bismarck wohl kaum daran denken können, aus der preußischen Selbstgenügsamkeit herauszutreten. Wenn jene nicht mit vorgearbeitet hätten, wiirden diese nicht so weit haben schauen und so gut haben bauen können.

Noch eine Betrachtung drängt sich auf. Droysen und Duncker, die $1848 / 49$ den preußischen Staat mit auflösen wollten, wurden hinterher die borussischen

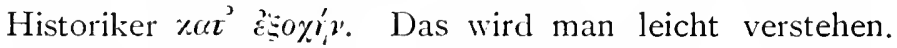
Droysen hat selbst im Fruhjahr I $\$ 4 S$ schon seine eigene Entwicklung mit antizipiert. Wir sahen, daß er damals von vornherein deutsch und preußisch zugleich dachte und die scharfe Alternative zwischen einer mehr von Deutschland oder einer mehr von Preußen ausgehenden Lösung der deutschen Frage stellte. Nachdem die erste gescheitert war, blieb er sich nur selbst getreu, wenn er in der Folgezeit entschlossen an das preußische Ufer hinubersprang. Der nuichterne Duncker tat es wohl mehr aus realistischer Anpassung an die neue Lage und weil er zu einer advokatenhaften Einseitigkeit in der Verteidigung seines jeweiligen Standpunktes neigte, während der Altmeister Ranke in ruhiger Uberlegenheit die Mär der Weltgeschichte fortspann.

Wir wagen es, diese Abschweifung vom Thema noch um einen Schritt weiter zu führen, weil sie uns sogleich zu einem neuen Ausblick auf dieses fuihrt. Steckt nicht selbst in der Art, wie Droysen dann die neue Geschichtsauffassung begründete und durchführte, noch unser Problem in verwandelter Form? Ihr Wesen war es, die preußisch-autonome Machtpolitik der vergangenen Jahrhunderte zu idealisieren, sie sich in höherem Grade beherrscht vorzustellen durch deutsch-nationale 
Ideen, als sie es wirklich war. Indem Droysen die Neigung hatte, den geschichtlichen Beruf Preußens für Deutschland aus den Zielen seiner tatsächlichen Politik nachzuweisen, verkannte er das wahre Wesen dieses Staates. $\left.{ }^{1}\right)$ Er beging damit, ohne es zu ahnen und zu wollen, denselben Verstoß gegen die Autonomie der preußischen Staatspersönlichkeit, den er mit Wissen und Willen begangen hatte, als er I $\$ 4 \&$ Preußens Auflösung zugunsten der deutschen Einheit forderte. Er löste es sich gleichsam nun geistig und für sein eigenes Gemitsbedürfnis auf, er glaubte und suchte es durch die Mittel der Wissenschaft nachzuweisen, daß Preußen schon in der Vergangenheit moralisch bis zu gewissem Grade in Deutschland aufgegangen sei. Wir sehen also, daß seine spätere geschichtliche Auffassung mit seiner Politik von I 848 genau korrespondiert. Sein borussischer Standpunkt war, bei Licht besehen, eigentlich unborussisch oder doch wenigstens überborussisch, und die »Politische Historie«, die er vertrat, hatte eine sehr unpolitische Seite. Denn unpreußisch und unpolitisch war es gedacht, dem preußischen Staate eine Politik zuzuschreiben, die nicht aus dessen eigenstem Wesen entsprang. Und man gewahrt, wenn man sich den letzten Ursprung seines Irrtums wieder klar macht, wie mächtig die unpolitische Denkweise des I8. Jahrhunderts bis in die Gedankenwelt dieses streng politisch sein wollenden Historikers hinuberwirkte, - durch eine weit hinuberschießende Welle gleichsam, die am spätesten zurückflutete und deren Grenzspuren im Boden, in den populären Nachwirkungen seiner Geschichtsauffassung, noch heute deutlich gesehen werden können.

1) Die Anfänge dieser Idealisierung kann man schon in den oben S. 353 angefuhrten Aufsätzen von $18+5$ und $1 S+7$ und in den Vor. lesungen über die Freiheitskriege wahrnehmen. 


\section{Fünftes Kapitel. \\ Von der oktroyierten Verfassung bis zur Kaiserwahl.}

Wir verlassen Berlin und Preußen und wenden uns wieder Frankfurt, der eigentlichen Stätte der von uns verfolgten Bestrebungen, zu.

Eine gewisse Duplizität gehört, wie wir schon oft gesehen haben, zu ihrem innersten Wesen, und so waren ihre Vertreter jetzt nach der Niederlage, die sie durch das Ereignis des 5. Dezembers erlitten hatten, in der glücklichen Lage, nicht nur ein Minus, sondern auch ein Plus aus ihm herauszurechnen. Jede wirkliche Kraftäußerung des preußischen Staates stärkte auch die Frankfurter Erbkaiserpartei. Camphausen konnte am I4. Dezember in einer größeren Denkschrift für seine Regierung ${ }^{1}$ ) mit Genugtuung konstatieren, daß Preußens Ansehen in Frankfurt jetzt wieder mächtig aufwärts steige, die Zahl seiner Freunde wachse, und daß die Maßregeln des jetzigen preußischen Ministeriums sehr wesentlich dazu mit beigetragen hätten. An demselben Tage stellte Heinrich von Gagern lehrreiche Betrachtungen uber Gewinn und Verlust, die durch die Oktroyierung erwachsen seien, an. ${ }^{2}$ ) Den größten und schlimmsten Nachteil sah er darin, daß nun auch die

1) G. St. A. Bruchstiicke daraus bei Caspary S. $275-277$.

2) Simson S. $146 \mathrm{f}$. 
übrigen deutschen Staaten gezwungen würden, wenigstens ebensoviel zu geben; er fürchtete namentlich, daß die Grundlagen des Wahlrechtes dadurch verschoben werden würden, d. h. offenbar, daß Beschränkungen des allgemeinen Wahlrechtes jetzt, nach dem demokratischen Vorgange Preußens, für Deutschland nicht mehr durchzusetzen sein würden. Als Gewinn dagegen konnte auch er es buchen, daß der Sieg der preußischen Regierung in der öffentlichen Meinung auf die Frankfurter Opposition gewirkt und sie zahm gemacht habe. Die oktroyierte Charte selbst verurteilte er, wie wir schon wissen, als in sich nicht lebensfähig und als für Deutschland unmöglich. Aber eben deswegen schlug er das Hindernis, das sie seinen Plänen bereitete, nicht so hoch an. Jedenfalls hielt er sie auch deswegen für schwach fundiert. weil sie nur olktroyiert, nicht regelrecht vereinbart war. »Ich hoffe also, " fuhr er fort, »sie wird nie zur Ausführung kommen, und die größere Schwierigkeit wird demnächst sein, sie wieder zu beseitigen.《

Man begreift es demnach, daß seine Partei einen unmittelbaren Kampf gegen die preußische Verfassung nicht unternahm und dem Versuche der Radikalen in Frankfurt, ihn doch zu führen ${ }^{1}$ ), sogar entgegentrat. Die Absicht war also, erst das Nötigste zu tun, das preußische Erbkaisertum durchzusetzen, danis erst hinterher und allmählich mit der preußischen Verfassung abzufahren. ${ }^{2}$ )

1) Durch den Antrag Wesendonck vom 7. Dez., die oktroyierte Charte für null und nichtig zu erklären. Noch in der Nacht vom 7 . zum 8. Dez. beschloß der Gagernsche Kreis in einer Beratung bei Beckerath, die preußische Verfassung als gültig anzuerkennen. Hansen, Mevissen 2, 48 .

2) Demgemäß gibt auch Haym den Sinn von Dunckers oben (S. 444 Anm.) erwähnter Denkschrift aus den Tagen vor Weihnachten ${ }_{1} 848$ dahin wieder, daß die Ordnung des Verhältnisses zwischen dem preußischen Einzelstaat und dem Ganzen billig der Zukunft üherlasien werden dürfe, als eine allmähliche, zugleich jedoch als eine unaus-

Meinecke, Weltbürgertum und Nationalstaat. 2. Aut. 
Wohl aber schien es den Genossen des Planes angebracht, die öffentliche Meinung Deutschlands und Preußens jetzt schon auf beides vorzubereiten, die Deutschen zu locken damit, daß die Hegemonie der Hohenzollern nicht die Hegemonie des preußischen Staates bedeuten würde, die Preußen aber darauf vorzubereiten. daß sie durch die Erhöhung ihrer Dynastie auch selbst in ein neues Verhältnis zu ihr treten würden, daß sie die unmittelbaren deutschen Reichsbürger werden würden. Das führte die Deutsche Zeitung am I I. Dezember, nachdem sie noch zwei Tage zuvor mit geschickter Taktik neben den schlechten auch die guten Seiten der Oktroyierung hervorgehoben hatte, in einem Leitartikel aus, der vielleicht die eindrucksvollste Formulierung dieser Gedanken bedeutet.

Die unabweisliche Macht der Dinge, hieß es hier, wird Preußen fruher oder später an die Spitze Deutschlands bringen. Die Frage ist nur: Wie kann es sich Deutschland organisch einfügen. Der König von Preußen wird an der Spitze des Bundesstaates sich zu ewigem Schwanken verurteilt sehen zwischen seiner doppeiten Stellung, einer doppelten Regierung, seinen zwei Parlamenten, seinen zwei Residenzen. Das geht nicht. »Preußen muß sich selbst daran geben, um sich doppelt wieder zu gewinnen." »Wer sich selbst verliert, der gewinnt die Welt. W Wir müssen in Deutschland nur eine große Regierung, nur ein Parlament haben. Zum Gluick hat Preußen sich seine Provinzialeinteilung erhalten,

bleibliche vorgestellt werden mïsse. Haym, Nationalversammlung II, 228 . In der Allgemeinen Zeitung vom I 5. Dez. heißt es zwar: , Nach Berliner Nachrichten vom IO. wären zwischen Frankfurt und Berlin ernsthafte Unterhandlungen im Gang uber ein Projekt, dem Könige von Preußen unter der liedingung eines wirklichen Aufgehens von Preußen (Verzichtung auf eine preußische Reichsversammlung, so daß nur die alten Provinziallandtage blieben) die Kaiserkrone zu ibertragene, - doch finde ich in den mir bisher bekannt gewordenen preußischen Akten keinen Anhalt dafür. 
die auf natürlichen und gesetzlichen Grundlagen ruht. Der kinftige erbliche Kaiser gewähre den acht preußischen Provinzen eine größere Autonomie unter Statthaltern aus den Prinzen seines Hauses und aus den großen Notabilitäten. Er erweitere die Kompetenz dieser nicht mehr preußischen Provinzen, sondern kaiserlichen Reichsländer bis nahezu an den Grad innnerer Selbständigkeit, der nach der zu revidierenden Reichsverfassung den fürstlichen Reichsländern noch verbleiben wird. Sein Ministerium des Auswärtigen sei das einzige in Deutschland, sein Kriegsministerium leite die mittelbaren und unmittelbaren Reichsländer, hier mehr, dort weniger detailliert; und so auch die übrigen Ministerien. Auch eine Kreiseinteilung wäre möglich, welche die zu kleinen eingliederte unter möglichster Schonung ihres gesonderten Bestehens. So denkt sich der Verfasser schließlich einen lebensvollen Einheitsstaat, gebildet aus acht unmittelbaren und acht mittelbaren Reichsländern, diese unter erblichen Regenten, jene unter abberufbaren Statthaltern. »Uns zittert das Herz vor Freude bei dem bloßen Gedanken.« Vorläufig aber sei nur zu wünschen, daß jenes ungluickselige Berliner oder Brandenburger Parlament nicht wieder zustande komme. Residenz muß auch in Zukunft Berlin sein, aber ein Jahr um das andere muß der Reichstag und während seiner Dauer die Reichsregierung in Frankfurt sein.

»Erst dadurch wird in Fürsten und Völker der volle Glaube kommen, daß sie nicht preußisch, sondern kaiserlich geworden sind."

Wir irren wohl nicht, wenn wir den jungen Heinrich Kruse, der seit dem 2. Dezember die Deutsche Zeitung redigierte und durch seine »prächtigen Leitartikel « gleich neuen Schwung in sie hineinbrachte, für den Verfasser auch dieses Artikels halten. Hinter Kruse aber stand, in der Hauptsache wenigstens, kein Geringerer als 
Dahlmann, mit dem er in regem Gedankenaustausch lebte. $\left.{ }^{1}\right)$ Auf Kruses Wunsch schrieb Dahlmann für die Deutsche Zeitung vom I. Januar eine "Neujahrsgabe", die mit markigen Worten den Sinn der Deutschen auf das große Werk hinlenkte, das jetzt in Frankfurt seiner Vollendung entgegenging. »Bei den Mächtigen suche Schutz!. . Nun steht bei Preußen bereits die Macht. Wir haben nichts zu tun, als das Werk der Geschichte anzuerkennen, welches rückgängig $\mathrm{zu}$ machen unmöglich ist. " Deutschland muß mit Preußen zusammenwachsen, aber dazu muß nun auch das preußische Volk jene Wandlung seines inneren Wesens, welche ehemals Brandenburg in Preußen umschuf, zum zweitenmal und im größeren Maßstabe bewußter vollbringen, indem es in Deutschland eingeht. Dahlmann wiederholte nun nicht nur seine alte Forderung, daß der deutsche Reichstag jedenfalls nicht auf preußischem Boden tagen dürfe, sondern fügte jetzt hinzu: „Eine preußische Nationalversammlung wird gar bald $z u$ den Undenkbarkeiten gehören; denn eine gesetzgebende Versammlung des halben Reichsvolkes hier und dann wieder des ganzen Reichsvolkes dort in Wirksamkeit setzen, hieße einen Streit von Kräften hervorrufen, die sich gegenseitig zerstören müßten. «

Was in so feierlicher Weise von dem bedeutendsten Träger der Frankfurter Verfassungsentwürfe proklamiert wurde, mußte - daran ist jetzt kein Zweifel mehr möglich - Gemeingut und Leitgedanke einer großen Gruppe der Erbkaiserlichen geworden sein. ${ }^{2}$ )

1) Springer, Dahlmann 2, 317.

2) Es genuigt, die Hauptstellen, an denen die Deutsche Zeitung in den folgenden Wochen den Gedanken noch erörterte, kurz zu zitieren: Nr. 34 vom 3. Febr. (Berliner Korresp. vom 31. Jan.); Nr. 49 vom I8. Febr.; 2. Beilage zu Nr. So vom 21. März. Auf die Polemik anderer Organe gegen diese Gedanken brauchen wir hier nicht ein- 
Am I 5. Januar I 849 begannen in Frankfurt dic Debatten über den Abschnitt des Verfassungsentwurfes »das Reichsoberhaupt ". Man wird nicht getäuscht in der Erwartung, daß unser Gedanke nunmehr ${ }^{1}$ ) auch auf der Tribüne erörtert, vertreten, verteidigt und belämpft wurde. Freilich wurde er auch jetzt von denen, die ihn aufgestellt hatten, noch nicht greifbar und präzis formuliert, und sie hatten ihre guten Gründe dazu. Man hätte sich die Aufgabe ungeheuer erschwert, man hätte vor allem die erhoffte Verständigung mit Preußen erschwert, wenn man jetzt schon die Forderung, auf das preußische Sonderparlament zu verzichten, hätte stellen wollen. Durch den 5. Dezember war das Eisen, das man schmieden wollte, wieder so hart geworden, daß man warten mußte. So waren es eigentlich mehr die Gegner, als die Freunde des preußischen Erbkaisertums, welche die Sache zur Sprache brachten, gewiß nicht ohne die Absicht, die Erbkaiserlichen aufs Glatteis zu locken und sie zu kompromittieren. Der Demokrat Schüler von Jena begann dies verfängliche Spiel am I5. Januar. ${ }^{2}$ ) Soll, sagte er, die preußische Dynastie uber Deutschland herrschen, so kann sie das nur unter der alternativen Voraussetzung, daß entweder die anderen Dynastien aufhören und ganz Deutschland preußisch

zugehen. Vgl. z. B. den Artikel der in Berlin seit Oktober erscheinenden , Deutschen Reform، vom 24. Dez. I $S_{4} S$ ( Nur, wenn Preußen in ungeschwächter Kraft bestehen bleibt, hat das neue Kaisertum einen Sinnc), die Grenzboten I $\$_{4} \&$ IV, S. 494 etc.

1) Nachdem er inzwischen im Verfassungsausschusse von Soiron und anderen vertreten worden war. Jürgens a. a. O. II, S. 323 , Haym a. a. O. II, 241; vgl. daselbst noch Jïrgens' Gegenbemerkung S. 233.

2) Er hatte schon in September $1 \$_{4} 8$ im Verfassungsausschusse eine Bestimmung beantragt, die es ermöglicht hätte, die Verfassung und Volksvertretung jedes Einzelstaates durch Reichsgesetzgebung tatsächlich zu vernichten. Droysen, Verhandlungen des Verfassungsausschusses I, 333 u. 414. 
wird, oder daß der preußische Staat sich auflöst in seine einzelnen Provinzen. Biedermann, der auf dem linken Flügel der erbkaiserlichen Parteien stand und ein etwas radikaleres Wort sich schon gestatten mochte ${ }^{1}$ ), blieb die Antwort nicht schuldig. Ich glaube allerdings, erklärte er, daß die eine oder die andere dieser beiden Alternativen wirklich werden könnte, ja daß vielleicht beide wirklich werden könnten, und ich würde der letzte sein, der darüber trauerte. Aber er setzte doch auch gleich vorsichtig hinzu, daß das Frankturter Parlament nicht den Beruf habe, jetzt schon in das Einzelgetriebe der Staaten zerstörend und umgestaltend einzugreifen. Dies Spiel wiederholte sich am folgenden Tage. Diesmal war es der Katholik August Reichensperger aus Köln, der den Ball den Gegnern zuwarf. Fast alle Verfechter des preußischen Erbkaisertums, führte er aus, sind darin einverstanden, daß die preußische Einheit zugrunde gehen müsse, wenn die deutsche Einheit aus ihr entstehen solle. Preußen soll in seine Provinzen zerschlagen werden und so das Schicksal des Greisen erleben, der sich, um sich zu verjüngen, zerhacken und in einen Zauberkessel werfen ließ. Er, als Neupreuße, sei mit vielen Altpreußen darin einig, auf dies lebensgefährliche Experiment sich nicht einzulassen. Aber sprach der Neupreuße hier wirklich als Preuße? In derselben Rede machte er auch kein Hehl daraus, daß er als Katholik Bedenken habe gegen die Hegemonie des protestantischen Nordens. So sehen wir hier wieder auf einen Moment in den merkwürdigen Zusammenhang hinein, daß die bewußten Katholiken damals für den preußischen Staatsgedanken sich einsetzen konnten, weil ihnen das Preußen

1), Er hielt standhaft die Linie ein, welche ihm seine Theorie vorzeichnete, und so blieb er besonders im ,Zentralisieren' des deutschen Staates oft allein im Augsburger Hofe, wo man nur , konzenttieren', wo man streng nur den Bundesstaat wollte.c Laube a. a. O. 3, 35. 
der oktroyierten Verfassung und der Kirchenfreiheit mehr verhieß, als ein Deutschland, dessen Kern der protestantische Norden war.

Ihm antwortete von den Erbkaiserlichen Ostendorf aus Soest. Auch dieser altpreußische Westfale leugnete nicht die geschichtliche Notwendigkeit, daß Preußen, an die Spitze Deutschlands gestellt, sich allmählich in seine Bestandteile autlösen werde, ein Ergebnis freilich, darin stimme er mit Reichensperger überein, »chas für den Augenblick weder möglich, noch auch ein Glück für Deutschland sein mag, das aber die notwendige Entwicklung der Geschichte allmählich von selbst herbeiführen wird». Welcker, der damals noch großdeutsch gesinnt war, hatte in der folgenden Sitzung vom 8. Januar guten Grund, zu spotten, daß die Erbkaiserlichen mit diesem Speck die Mäuse fangen wollten. ${ }^{1}$ )

Aber es läßt sich nicht verkennen, daß es einige Mäuse in der Versammlung gab, die diesem Specke sich neugierig näherten. Schon Schülers Rede vom I 5. Januar zeigt, daß er für das hohenzollernsche Erbkaisertum vielleicht zu haben gewesen wäre, wenn eine der beiden von ihm bezeichneten Alternativen verwirklicht worden wäre. Und zwei andere Vertreter der Linken, $\left.\operatorname{Vogt}^{2}\right)$ und Raveaux ${ }^{3}$ ), erklärten am I9. März unumwunden, daß, wenn man ihnen die Auflösung des preußischen Staates in Provinzen wirklich bieten könne, dies auch für sie ein Speck sein würde. »Es würden sich, « sagte Raveaux zum Zentrum, 》verschiedene noch von dieser Seite für das Erbkaisertum aussprechen, wenn man in dieser Beziehung dabei geblieben wäre, das zu halten, was man früher ausgesprochen hat; aber man will das nicht, man kann es nicht.《
1) Vigard S. 4770 .
2) S. $5 \mathrm{~S}_{2} \mathrm{I}$.
3) S. $5 S_{33}$. 
Während die Linken, wie wir noch sehen werden, wohl einigen Grund hatten, sich für die Auflösung des preußischen Staates zu interessieren, darf man bei den großdeutschen und partikularistischen Gegnern des Erbkaisertums von vornherein ein entschiedenes Mißtrauen gegen solche Prozedur voraussetzen. Was heute dem preußischen Staate widerfuhr, konnte morgen und übermorgen - es wurde ja deutlich genug verraten auch den übrigen Partikularstaaten Deutschlands angetan werden. Edel aus Würzburg, der zur katholischen Gruppe gehörte, war es namentlich, der am 23. Januar die unitarischen Konsequenzen des Gedankens scharf erfaßte und vor ihnen warnte. ${ }^{1}$ )

Dann aber wechselten die Großdeutschen ihre Taktik. Statt den Gedanken zu bekämpfen, nahmen sie ihn nun gerade auf. Es war eines der vielen Mittel, die sie in den letzten Tagen vor der Kaiserwahl anwandten, um dem Könige von Preußen die Reichsverfassung unschmackhaft zu machen. Der österreichische Abgeordnete Werner aus St. Pölten stellte am I9. März ${ }^{2}$ ) den Antrag, für den Fall, daß dem Könige von Preußen die erbliche deutsche Kaiserwürde angeboten würde, die Bedingung hinzuzufügen, »daß der preußische Staat als solcher sofort aufzuhören habe und in vier dem Deutschen Reiche angehörige Einzelstaaten ${ }^{3}$ ) aufzulösen sei«. Ähnlicher Tendenz war der Antrag, den der bayerische Abgeordnete Müller aus Würzburg am 20. März stellte ${ }^{4}$ ), die nötigen Abänderungen in der preußischen Verfassung, vor allem die Beseitigung des preußischen Parlamentes auf dem Wege der Unter-

\footnotetext{
1) S. 4838 .

2) S. 5834 f.

*) Unter Statthaltern, die vom Könige von Preußen zu ernennen seien - also entsprechend dem Vorschlage der Deutschen Zeitung

4) S. 5868. JJronisch-höhnend « nennt ihn Jürgens II. 2, 223.
} vom II. Dez. Is48. 
handlung mit der preußischen Regierung zu verabreden und zu sichern. ${ }^{1}$ )

Nach allen diesen Fragen und Anträgen konnte auch Gagern als Reichsminister nicht umhin, Farbe zu bekennen. „Damit bin ich vollkommen einverstanden, " sagte er in seiner großen Rede vom selben Tage $\left.{ }^{2}\right)$ : »Wenn das Kleindeutschland, wie es genannt wird, seine Aufgabe für jetzt und für die Zukunft erreichen soll, dann muß auch sein Mittelpunkt in der Mitte sein und nicht im Norden stehen. " Ein 》sehr wahr " von allen Seiten unterbrach ihn hier. "Ich gebe mich, " fuhr er freilich gleich abschwächend fort, »nicht Illusionen hin, ich glaube selbst, daß die Dezentralisierung Preußens in der Art, daß die politische Gesamtvertretung, wie sie jetzt besteht, gelöst würde, daß das nicht die unmittel-

!) In diesen Zusammenhang gehört auch unzweifelhaft die Abänderung, welche die vereinigten Großdeutschen und Linken in die Zusammensetzung des Staatenhauses ( $\$ 8 S$ der Reichsverfassung) hineinbrachten. Nach erster Lesung sollten, dem Ausschnßantrage gemäß, die Mitglieder des Staatenhauses zur Mälfte durch die Volksvertretung der Staaten ernannt werden. (Stenogr. Bericht S. 4055.) Bei der zweiten Lesung am 26. März wurde, gegen die Stimmen der Erbkaiserlichen, der Antrag der Österreicher v. Pretis, v. Mlöring, des Wiirzburgers Edel u. a. angenommen, daß in denjenigen Staaten, welche aus mehreren Provinzen oder Ländern mit abgesonderter Verfassung oder Verwaltung beständen, die betr. Mitglieder des Staatenhauses nicht von der allgemeinen Landesvertretung, sondern von den Vertrelungen der einzelnen Länder oder Provinzen (Provinzialständen) zu ernennen seien. (Stenogr. Bericht S. 6024.) Offenbar ist hier die Tendenz mit im Spiele, die Auflösung Preußens in seine Provinzen zu erleichtern. So faßte man es auch auf preußischer Seite damals auf, Die Verfassung aus Frankfurt und der preuB. Staatc, Berlin i $\$_{49}$, S. 13, ) und O. v. Manteuffel schreibt an Radowitz 16. Mai i $S_{49}$ : Die destruktive Partei sehe in $\$ 8 \&$ Alinea 2 der Reichsverfassung ein Nittel, Preußens Einheit zu zerstören. Daß die Erbkaiserlichen, obgleich viele von ihnen im Prinzipe einverstanden sein mußten, dagegen stimmten, ist von ihrem damaligen Standpunkte aus (s, das oben im Texte Gesagte) verständlich. 2) S. 5885 . 
bare Folge sein wird, wenn der Bundesstaat, Preußen an der Spitze, geschlossen würde. Daß aber ein solches Dezentralisieren, ein Aufgehen in Deutschland, die notwendige, allmälliche Folge sein würde, das kann niemand bezweifeln, der den Analogien in der Geschichte Beachtung zollt. ${ }^{1}$ )

Ihm sekundierte dann am folgenden Tage ${ }^{2}$ ) Gabriel Rießer. ${ }^{3}$ ) Preußen, meinte er, ist doch immer ein Kunststaat, Deutschland ein Volksstaat, ein Naturstaat, und so wie die Natur mächtiger ist als die Kunst, so wird auch die Naturkraft Deutschlands die künstliche Kraft von Preußen überwiegen. Dieses Übergewicht aber könne nur das allmähliche Werk der freien, edlen Hingebung Preußens an Deutschland sein, »aber nimmermehr können wir Preußen Bedingungen stellen, die seine

1) Jürgens, Zur Gesch. des deutschen Verfassungswerkes II, 2, S. I75, weiß für die Zeit vom I3. März etwa zu erzählen: >Gagern gibt jetzt unter vier Augen unumwunden $z u, d a ß$ aus der deutschen Sache eine preuBische geworden, wie er besorge, daß es nicht gelingen werde, wie es berechnet gewesen, Preußen dadurch aufzulösen, daß man seinen König zum Deutschen Kaiser inache, allein er fügt hinzu, daß ihm und vielen seiner Freunde der Zustand der Zerrissenheit und der Kleinstaaterei so unerträglich sei, daß sie eher preußisch werden... als in demselben verbleiben wollten. Obgleich Jürgens keine zuverlässige Quelle für die Äußerungen seiner politischen Gegner ist, mag man es schon für möglich halten, daß Gagern derartiges in der Leidenschaft gesagt hat. Deswegen brauchte er doch die Hoffnung nicht aufzugeben, die er in der oben angeführten Rede aus. sprach.

2) Nachdem vorher noch Schiiler seine Skepsis gegen Gagerns Vertröstung ausgesprochen hatte, S. $5 \$ 96$.

3) S. 5907. Ähnlich auch noch Rümelin im Schwäb. Merkur am IS. März. „So liegt es im Sinne der Erbkaiserlichen, daß Preußen in seine Provinzen zerfallen, als selbständiger Staat in den wesentlichsten Beziehungen aufhören solle, und dies würde auch geschehen müssen; allein es jetzt als eine sogleich auszuführende Bedingung hinzuzufügen, heißt das Ganze im Keime ersticken und soll vielleicht auch nichts anderes beiben. Aus der Paulskirche S. 199. 
Existenz aufheben; nimmermehr können wir Preußen zumuten, daß es uber Sein oder Nichtsein mit uns in Verhandlung trete; ja, ich erkiläre es offen, sowohl Deutschlands als Preußens wegen dürfen wir nicht wünschen, daß Preußen im mindesten in seinem Bestande erschuittert werde, bis Deutschland sicher und fest für die Ewigkeit gegründet ist «.

Das war das letzte erhebliche Wort, das in der historischen Redeschlacht dieser Tage darüber fiel, und zugleich der vorläufige Abschluß der Bestrebungen, die wir schildern wollten. Ihre Verfechter hatten wohl etwas gelernt im Laufe der letzten Monate. Sie verzichteten auf das aussichtslose Bemuihen, den rocher $d t^{\prime}$ bronce Preußen jetzt schon einzuschmelzen, sie verzichteten auch auf die gefährliche Taktik, durch Aufstellung bestimmterer Forderungen einen Teil der Linken und der Partikularisten für die Wahl Friedrich Wilhelms IV. zu gewinnen. Vielleicht würde diese, wenn sie jenen hierin entgegengekommen wären, mit stattlicherer Mehrheit erfolgt sein, vermutlich aber auch ein Teil der stärker preußisch gesinnten Abgeordneten abgefallen sein. Die Krone, die sie dem Könige anboten, war ohnehin schon belastet genug durch verfängliche Zugeständnisse an die Linke. Es war ja klar, daß diese den Gedanken der Auflösung Preußens ganz anders sich deutete als sie. Sie wollten, daß Preußen aufgehe in Deutschland, jene wollten, daß Preußen untergehe. ${ }^{1}$ ) Rießers Worte lassen deutlich erkennen, wie die Erbkaiserlichen jetzt spürten, daß die eine Zeitlang so kategorisch verlangte Auflösung Preußens in diesem Augenblicke wenigstens ein hochgefährliches Unternehmen sei. Die begehrlichen Blicke, welche die Linken danach aus-

1) \& Preußen wird untergehen, sobald die deutsche Nation zu neuem Leben erwacht sein wird،, hatte der Republikaner Struve schon in den 2Grundzügen der Staatswissenschaft e I, 56 (IS47) gesagt. 
warfen, waren Lehre genug für sie, behutsam vorzugehen und nicht den Wall zu zerstören, der sie jetzt und in nächster Zeit allein vor jenen schiitzen konnte.

Aber aufgeschoben wollten sie nicht als aufgehoben gelten lassen. Sie trösteten sich damit, daß das, was sie jetzt nicht verlangen konnten und durften, von der geschichtlichen Notwendigkeit selbst besorgt werden würde. So haben sie es gemeint, so haben sie das Verfassungswerk verstanden wissen wollen, so muß es auch von den Nachlebenden verstanden und interpretiert werden. Wir denken, daß damit doch ein neues Licht auf dieses fällt, wenn man sich immer gegenwärtig hält, daß die Annahme der Frankfurter Krone durch Friedrich Wilhelm IV. nach der Absicht eines großen Teiles derer, die sie anboten, über kurz oder lang zur Auflösung der preußischen Staatseinheit führen sollte. ${ }^{1}$ )

Auch führen mußte? wird man fragen. War die Hoffnung darauf, mit der jene Erbkaiserlichen sich schließlich begnügten, vielleicht nur ein billiger philosophischer Trost: Diese Frage wollen wir in den folgenden Kapiteln unserer Untersuchung zu beantworten versuchen. Hier gilt es, das, was wir bisher von den innneren Voraussetzungen wie Konsequenzen des Planes wahrgenommen haben, in einen höheren Zusammenhang zu bringen und an dem Maßstabe zu messen, den die Geschichte selbst geliefert hat, dem Werke Bismarcks.

1) Man kann also nur für einen Teil der Erbkaiserlichen es noch gelten lassen, was Baumgarten $\mathbf{I} \$ 7$ o von der Gesinnung, die der Abstimmung vom $2 S$. März I 849 zugrunde lag, sagt: Wir glaubten an Preußens dauerndes Wesen, darum hoben wir es auf den Thron " Histor. u. polit. Aufsätze S. 298. - Unter den neueren Forschern sind unsern Resultaten bisher am nächsten gekommen Lenz (I $\delta_{4} 8$, Preuß. Jahrbiicher 91, S. $5+3$ und Kleine histor. Schriften S. 394) und Laband, Das deutsche Kaisertum (Rede). Straßburg 1\$96, S. $23 \mathrm{f}$. 


\section{Sechstes Kapitel.}

\section{Von Heinrich v. Gagern zu Bismarck.}

Wir erinnern an das im Eingange Gesagte. Der Gedanke "Preußen an der Spitze Deutschlands, aber ohne Reichsstände " war unpolitisch und politisch zugleich, national und unnational zugleich gedacht. Er verkannte und vergewaltigte die Autonomie der Staatspersönlichkeit und das Lebensrecht derjenigen politischen Nationalität, die auf dem Boden des Einzelstaates erwachsen war, und zeigt darin den in der Tiefe fortwirkenden unpolitischen Geist des 18. Jahrhunderts. Aber er tat es um eines neuen politischen und nationalen Lebensbedürnisses willen, das in der deutschen Kulturnation erwacht war. Das Werdende stieß an gegen das Gewordene, der liberale Nationalstaatsgedanke, der die Souveränität und die politische Einheit der Gesamtnation forderte, gegen den konservativen Nationalstaatsgedanken, der die lebendigen politischen Gebilde der Vergangenheit schützen wollte.

Damit sind aber nur die allgemeinen Kategorien beschrieben, um die es sich hier handelt, und nicht das konkrete Leben gezeigt, das sie enthielten. Das Leben des konservativen Nationalstaatsgedankens haben wir im ersten Buche darzustellen versucht, das des liberalen Nationalstaatsgedankens bedarf jetzt noch weiterer Veranschaulichung. Wohl hat er von Natur einen Zug ins allgemeine und eine Tendenz gegen das Besondere und Indi- 
viduelle des deutschen Einzelstaates, und dieser nationalphilosophische Idealismus, der das Besondere dem Allgemeinen zu opfern bereit war, zeigte sich zumal bei denjenigen Vertretern unseres Gedankens, die, selbst aus Preußen gebürtig und voller Liebe für ihren Heimatstaat, ihn dennoch aufgehen lassen wollten in Deutschland. So die Droysen, Duncker und Haym, die bezeichnenderweise von der Wissenschaft und Philosophie herkamen und vielleicht mit Hegelscher Weltstimmung den Schritt von der niederen zur höheren Stufe des Nationaldaseins machen konnten. Wohl haben sich zeitweise, wie uns ausdrücklich bezeugt wird ${ }^{1}$ ), fast alle bedeutenden Preußen in der Versammlung und selbst solche reinen Politiker und Staatsmänner wie Vincke, Schwerin und Flottwell in den Bann der Lehre vom Opfer, das Preußen bringen müsse, ziehen lassen. Aber doch eben wohl nur zeitweise, und wäre es zum Ernste gekommen, so

1) Aufzeichnung des Abgeordneten $v$. Boddien vom 17. Januar I $\$ 49$ (für König Friedr. Wilh. IV. bestimmt, von diesem mit kandbemerkungen versehen; Hausarchiv): Wenn Männer wie Vincke, Schwerin, Flottwell etc. und fast alle bedeutenden Preußen sich entschieden für das erbliche Kaisertum erklären, so geschieht dies natiulich in der Uberzeugung, daß dasselbe nur Preußen zufallen könne. Sie sind in diese Idee so festgebannt, daß sie wiederholt erlilärt haben: Freußen werde und miisse die eigene Landesvertretung aufgeben, sein Reichstag auf Provinziallandtage reduziert werden, und so bringe Preußen, indem es an die Spitze von Deutschland träte, mit seiner Geschichte und einem integrierenden Teil seiner Selbständigkeit selbst das größte Opfer. Als Zeugnis für die Verbreitung unserer Gedanken in den Kreisen der preußischen Liberalen wird man auch, trotz ibrer Parteitendenz, die Worte benutzen dilrfen, die Kleist-Retzow in der großen Olmuitzdebatte der 2. preuB. Kammer am 3. Dez. IS50 seinen Gegnern zurufen konnte: 'Man spricht soviel von Preußens Ehre. Seh' ich mir die an, die am meisten davon reden, ... dann finde ich solche darunter, die verlangt haben, daß P'reußen in seinen Provinzen zerstitckelt würde, daB es jedenfalls unterworfen werden sollte und aufgehen sollte in außerpreußischen Kammermajoritäten.، Stenogr. Berichte S. 53 . 
wïrden die Erbkaiserlichen aus Preußen sich vermutlich gespalten haben. ${ }^{1}$ ) Uberhaupt nicht unter den preußischen Erbkaiserlichen haben wir den stärksten Herd unserer Gedanken zu suchen. Pfizer, die Brüder Gagern und Rümelin weisen uns vielmehr, wenn wir nach einer lokalen Ursprungsphäre suchen, auf Südwestdeutschland hin. Und hier sehen wir denn neben den allgemeineren geistigen Voraussetzungen des liberalen Nationalstaatsgedankens auch noch ganz konkrete und besondere Momente wirksam, die uns nun namentlich auch die Denkweise der Pfizer, Gagern und Rümelin verständlich machen helfen.

Es ist schon den Zeitgenossen nicht entgangen, welchen starken Anteil an den Führern und Ideen des Frankfurter Parlaments die Landschaften des Südwestens hatten,

1) Aus der prägnanten Charakteristik, die Radowitz an 20. März I $\$_{49}$ von den beiden Richtungen innerhalb der Erbkaiserpartei gab (Jürgens II, 2, 659), sieht man jedenfalls, daf3 auch die im eigentlichen Sinne preußisch-hegemonische oder großpreußische Richtung durchaus lebendig geblieben oder wieder lebendig geworden war. $Z u$ ihr nuß man vor allem rechnen die Gruppe der rheinisch-liberalen Führer Camphausen, Hansemann, Mevissen, über deren politisches Programm uns die neueren Veröffentlichungen über sie, vor allem Hansens Buch über Mevissen, Aufschluß geben. Sie hatten mit solchem Eifer für die Verschmelzung der Rheinlande mit dem preußischen Staate und zugleich für die Erfüllung desselben mit rheinisch-liberalen Ideen gekämpft, daß ihnen der preußische Staatsgedanke dadurch selbst ans Herz wuchs. Bei ihnen ist keinerlei Hinneigung zu den GagernRümelinschen Ideen einer Autlösung Preußens wahrzunehmen, und Hansemann hat sich auch tatsächlich gegen sie ausgesprochen. (Das preuB. u. d. deutsche Verfassungswerk I 850, S. 29 I f. u. 353 f.) Auf Gustav Freytags großpreußischen Protest gegen die Auflösungstendenz der Erbkaiserlichen hat H. Oncken in der Besprechung der 1. Auflage dieses Buches, Forsch. zur brand, u. preuß. Gesch. 22, 313, hingewiesen. Doch muB ich gegen ihn geltend machen, daß trotzdem damals auch Freytag bereit gewesen ist zu dem, Opfere, den preußischen Namen im deutschen untergehen zu lassen. 
die man einst »das Reich « nannte. $\left.{ }^{1}\right)$ Hier empfand man die territoriale Zersplitterung in Behagen wie Unbehagen beides konnte seltsam verbunden sein - am tiefsten; hier war die alte Kaiser- und Reichserinnerung noch verhältnismäßig am lebendigsten; hier war die Mischung partikularistischer und nationaler Gefühle am stärksten.

Hier konnten einst die Taten Friedrichs des Großen helle Freude und Stolz erwecken über den großen Menschen und über den neuen Lebensgehalt, der durch ihn in die nationale Kultur kam. Aber, sagt Goethe, ich war nur »Fritzisch gesinnt; denn, was ging uns Preußen an «? Man war imstande, den Genius Friedrichs des Großen und den Genius des preußischen Staates auseinander zu halten, und wer den Kaiser- und Reichsgedanken hochhielt, wie der alte Friedrich Karl Moser, konnte, so sahen wir, bei aller Anerkennung für Friedrichs Größe doch sein Werk beklagen.

Dieser alte Reichsgedanke wurde durch die Umwälzungen der napoleonischen Zeit zwar verschiuttet, aber nicht ganz ersticlit. Er modernisierte sich aber, als er wieder emporkam, und erfüllte sich mit liberalem und konstitutionellem Inhalte. Diese Kerngebiete des alten Reiches waren ja zugleich die Grenzgebiete, die den Einfluß der französischen Ideen am stärksten erfahren hatten. Man hatte an diesen neuen Freiheitsrechten oder -ansprichen nun einen Besitz, den man nicht wieder fahren lassen wollte. Um diese französischen Errungenschaften zu schätzen, brauchte man nicht französisch ge-

1), Ich bitte festzuhalten, daß die Einheitsidee Deutschlands in ihrem jetzigen Erwachen vorzugsweise in den kleinen Staaten des Südwestens ihre Heimat hat." (Usedom), Polit. Briefe u. Charakteristiken aus der deutschen Gegenwart (I849), S. I7I. Vgl. auch Jastrow, Gesch. d. deutschen Einheitstraumes, 3. Aufl., S. 277 f.; Baumgarten, Wie wir wieder ein Volk geworden sind. Histor. und polit. Aufsätze S. 244 . 
sinnt zu sein. Man konnte selbst Napoleon bewundern und eine Wiederkehr seiner Herrschaft verabscheuen. Man glaubte also auch hier wieder die großen historischen Erscheinungen trennen zu können von dem politischen Boden, dem sie entstammten. Was imponierte, eignete man sich an, olne sich denen ganz ergeben zu wollen, von denen es ausging. So war man politisch eklektisch, und die alten und neuen philosophischen Strömungen beförderten diesen Hang, die Ideen zu trennen von ihren realen Wurzeln und Früchte zu pflücken aus allerlei Gärten. Man war es eben noch nicht inne, daß die großen historischen Persönlichkeiten und die beneidenswerten politischen Institutionen bodenständig sind in ihrem Volke. Lebte man doch selbst hier in einem nichts weniger als bodenständigen Staatsleben. Alle diese Staatsgebilde Suidwestdeutschlands waren in ihrer jetzigen Gestalt künstliche Schöpfungen, die sich, nachdem sie den Druck ihres Schöpfers los geworden waren, selbst nur wieder durch einen berechnenden politischen Eklektizismus weiter halfen. Die einzige bodenständige nationale Idee, die man in Südwestdeutschland hatte, war die alte verblaßte Reichserinnerung, die aber, vage wie sie war, mehr auf die politische Phantasie als auf die politische Einsicht wirkte. ${ }^{1}$ )

Napoleon also und die Ideen von I 789 waren die Mächte, die das politische Denken Südwestdeutschlands nun vor allem beherrschten, waren die Maßstäbe, die man an Menschen und Dinge unwillkirlich anlegte. Pfizers Briefwechsel zweier Deutschen war wohl eine erste kräftige Reaktion deutschen Geistes gegen das französische Gedankengut ${ }^{2}$ ), aber wie lebte auch er noch in manchem von ihm.

1) Vgl. Baumgarten a. a. O.

2) Vgl. aucb seinen Aufsatz von I 446 (Konstitut. Jahrbucher I 846 , S. I13): 'So scheint man doch in aller Aufrichtigkeit des Herzens häufig noch zu glauben, ohne die Französische Revolution wäre die 
Wie wird man nicht gleich an Napoleon erinnert, wenn er sich vorübergehend selbst einen nationalen Gewaltherrscher gefallen lassen will.

Von allen diesen Voraussetzungen aus ermesse man nun die Stellung der Südwestdeutschen zum preußischen Staate. Friedrich der Große trat jetzt zuriick vor Napoleon, Preußen hatte seinesgleichen nicht aufzuweisen. Die Erinnerungen der Rheinbundszeit hafteten stärker in den süddeutschen Köpfen als die Zeit der Befreiungskriege, die man noch nicht halbwegs mitgemacht hatte. Und was die politischen Institutionen betraf, so sah man in Preußen trotz aller Reformarbeit doch fast nur, wie bisher, den absolutistischen Militär- und Beamtenstaat. Und wenn man die preußischen Reformideen und ihre Träger gelten ließ, unterschied man wohl auch sie wieder als etwas Vorübergehendes und nicht Durchgedrungenes von dem eigentlichen Wesen des preußischen Staates. Es ist eine alte, noch heute gehörte Rede in Süddeutschland, daß Preußen sich so viele seiner besten Köpfe aus dem nichtpreußischen Deutschland holen müsse. ${ }^{2}$ ) So war und blieb Preußen in den Augen der Süd- und Westdeutschen der künstliche Staat. Man war sich ja wohl der eigenen Künstlichkeit, des Balkens im eigenen Auge nicht unbewußt, aber man rügte nichtsdestoweniger den Splitter des Nachbarstaates. Selbst Pfizer, der ihm noch am meisten das Wort redete unter seinen süddeutschen Landsleuten, urteilte ja, daß er bisher nur ein äußeres, aber kein inneres Leben gefuhrt habe. ${ }^{2}$ ) Wer kannte uberhaupt hier Preußen aus eigener Erfahrung? Als

Zeit in Deutschland stillgestanden, und man müsse Frankreich dankbar sein, daß es nach Zerstörung aller selbständigen Entwicklung deutschen Nationallebens einige zündende Gedanken herübergeworfen, einigen Gärungsstoff nach Deutschland gebracht hat.s

1) Vgl. Denkwurdigkeiten des Fürsten Chlodwig Hohenlohe I, I 14.

2) S. oben S. 330 . 
Heinrich v. Gagern im November 1848 nach Berlin kam, um Deutschlands Werbung um Preußen anzubringen, kannte er die Braut, um die er werben wollte, eigentlich noch gar nicht, denn er war zum ersten Male in Berlin. ${ }^{1}$ ) Sehnlich rief Pfizer den Adler Friedrichs des Großen an, daß er die Verlassenen und Heimatlosen decken möge mit seiner goldenen Schwinge. Aus der Not der eigenen Staatlosigkeit streckte er seinen Arm aus nicht eigentlich nach dem mächtigsten deutschen Staate, sondern nach den Herrschern dieses Staates. Auch er war in gewissem Sinne mehr fritzisch als preußisch gesinnt. Er kämpfte für die nationale Monarchie der Hohenzollern, aber nicht für die Hegemonie des preußischen Staates. Und so nach ihm jene Führer der Frankfurter Erbkaiserpartei, die wir kennen. Immer wieder glaubte man scheiden zu können, was doch zusammengehörte. Aber welche historischen Reste stecken nicht alle, wenn wir nun zurückblicken, in ihrem denkwürdigen Irrglauben, daß man die Hohenzollern gewinnen und Preußen autlösen könne: Reichserinnerung und Kleinstaaterei, Friedrich der Große, I7 89 , Napoleon und Rheinbund, naturrechtlicher Eklektizismus und Rationalismus, - alles das nun aber verschmolzen durch die Sehnsucht, herauszukommen aus dem Leben in bloßen Fragmenten und Uberresten und ein ganzes und eigenes politisches Dasein zu gewinnen.

In hohem Grade südwestdeutsch gefärbt also war dieser Bundesstaatsgedanke von ${ }^{8} S_{4} S$. Er war statenlos in seinem Ursprunge ${ }^{2}$ ), unstaatlich in seiner Schlußforderung, und diese Unstaatlichkeit wird uns nun auch aus ganz konkreten Zuständen und Erfahrungen verständlich. Und vielleicht gibt es nun noch weitere konkrete

1) Vgl. Kaufmanns Artikel über Gagern in der Allg. Deutschen Biogr. 49, 665 .

2) Jastrow a. a. O. S. 28 . 
politische Erfahrungen, die es mit erklären, daß die von uns behandelten Ideen auch norddeutsche und selbst preuBische Köpfe ergreifen konnten.

Es ist ja kein Zweifel, daß die Bestrebungen, die wir verfolgten, einen gesunden politischen Kern hatten. Das Nebeneinander zweier großer Verfassungen, zweier mächtiger Parlamente im Rahmen desselben politischen Gemeinwesens war unter allen Umständen eine Uberlastung des politischen Lebens, und die beiden großen Triebräder nebeneinander konnten nur zu leicht sich gegenseitig reiben und hemmen. Es kann kaum eine bessere Rechtfertigung der Gagernschen Forderung geben, als daß gerade die prinzipiell preußischen Gegner seines Werkes es aus demselben Grunde mit verwarfen, der ihn und seine l'artei zu jener Forderung gefuihrt hatte. Das Gagernsche Deutschland sagte zu Preußen: Wenn du an die Spitze kommen willst, mußt du auf deine Verfassung und dein Parlament verzichten, denn zwei große Verfassungen nebeneinander sind auf die Dauer unmöglich. Das Bismarcksche Preußen antwortete: Eben aus diesem Grunde kann ich deine Kaiserkrone nicht brauchen. "Ich kann mir nicht denken, " sagte Bismarck im preußischen Landtage am 2 I. April 1849 , »daß in Preußen und in Deutschland zwei Verfassungen auf die Dauer nebeneinander bestehen können.« Just ebenso urteilte sein damaliger Parteigenosse Stahl ${ }^{1}$ ): »Ein deutsches Parlament habe ich immer fuir einen schönen, aber ohne gänzlichen Umsturz der bestehenden Verhältnisse nicht ausführbaren Gedanken gehalten «, und zwar schon deswegen, weil ilhm das Nebeneinander der Kammern der größeren Staaten und des Reichstages ohne Nebenbuhlerschaft und Kampf nicht möglich, ihre Herunterdrückung zu Provinzialständen aber unmöglich schiene.

1) Die deutsche Reichsverfassung I $\$_{49}$, 2. Aufl, S. 23. 
Hatte Deutschland I $848 / 49$ um Preußen gerungen, so rang Preußen I 866 um Deutschland. Hatte es früher seine Lebenskraft in der Abwehr jener Verbung erwiesen, so stand es jetzt vor der Aufgabe, seine Lebenskraft nicht nur durch den Sieg der Waffen, sondern auch durch die Lösung des Problems, an dem die Männer von I 848 sich vergeblich abgemuiht hatten, zu erweisen. Sofort bei der Gründung des Norddeutschen Bundes tauchte die alte Frage wieder auf. Im preußischen Abgeordnetenhause wurde sie, als das Wahlgesetz für den Reichstag des Norddeutschen Bundes am I I. und I2. September i 866 beraten wurde, von verschiedenen Rednern berührt. Twesten, der Berichterstatter der Kommission, erklärte: „Es läßt sich in keiner Weise verkennen, daß zwei Parlamente mit ähnlichen, überall ineinander greifenden Befugnissen nebeneinander auf die Dauer vollkommen unmöglich und unhaltbar sind «. Wir werden auf ein ganz neues Motiv, das in diesen Debatten zu Worte kain, noch zurickzukommen haben. Aber auch die ganz alten Stimmen von I 848 erwachten in den folgenden Jahren wieder. Ihr einstiger Führer Heinrich v. Gagern selbst meldete sich wieder und machte den uns wohlbekannten Vorschlag, die preußische Verfassung so umzuwandeln, »daß der Schwerpunkt aus dem preußischen Reichstage in die Provinziallandtage verlegt und dadurch dem Bundesparlament das Gewicht gesichert werde, welches es sonst neben einem preußischen Reichstage von politischer Bedeutung nicht gewinnen kann «. ${ }^{1}$ ) Nebenbei gesagt, sieht man daraus, daß Heinrich v. Gagern den Grundgedanken seiner Vergangenheit treuer blieb, als man gewöhnlich meint, nur daß man diese Grundgedanken etwas anders wird formulieren missen,

1) Aus dem Berichte Mohls an Freydorf 4. Mai i $86 S$ bei Lorenz, Kaiser Wilhelm und die Begriindung des Reichs, S. $589 \mathrm{ff}$. 
als es gewöhnlich geschieht. ${ }^{1}$ ) So mochte sein Gedanke jetzt wohl wie eine Stimme aus dem Grabe klingen, aber auch manche der Lebendigen dachten nicht anders. „Wie viele wackere Männer, "schrieb Treitschke ein paar Jahre später ${ }^{2}$ ), »hofften noch im Frïhjahr I $\$ 67, \ldots$ der preußische Landtag solle zerschlagen, das feste Gefüge des preußischen Staates aufgelockert und jede seiner Provinzen wie Weimar und Mecklenburg unmittelbar der Bundesgewalt untergeordnet werden." Zweierlei führte auf den Gedanken wieder hin, einmal das übermäßige Gewicht, das Preußen mit $4 / 5$ des Bundesgebietes jetzt innerhalb des Bundesstaates hatte, und dann das Bedürfnis der néu annektierten Provinzen Preußens, durch einen gewissen Grad von Autonomie ihr Eigenleben zu behaupten. So trieb man wieder heran an die $48 \mathrm{er}$ Idee vom Nebeneinander starker Reichsgewalt und starker Provinzialautonomie und von der Ausschaltung oder wenigstens Schwächung der allzustarken Einzelstaatsgewalt. Im ganzen erwog man diese Wünsche jetzt vorsichtiger, reservierter und moderner als I 848 , und so ist auch die mittlere Linie, auf der das Programm der nationalliberalen Partei vom I2. Juni i $\$ 67$ sie vereinigte, maßvoll gezogen. „Als Ziel schwebt uns vor, daß die parlamentarischen Funktionen des Staates möglichst vollständig in den Reichstag verlegt werden. Auch der preußische Landtag sollte sich nach und nach mit einer Stellung begnuigen, welche in keiner Weise geeignet sei,

1) Wentzckes oben S. 342 angefuhrter Aufsal $z$ hat inzwischen diese Kontinuität genauer nachgewiesen und insbesondere auch den $\mathrm{Zu}$ sammenhang des preußischen mit dem österreichischen Teile des Gagernschen Nationalprogrammes erläutert. Auf diesen letzteren $\mathrm{Zu}$ sammenhang sind meine Untersuchungen deshalb nicht eingegangen, weil es für sie galt, die Probleme zu konzentrieren und alles nicht unbedingt Erforderliche auszuscheiden.

$\left.{ }^{2}\right)$ Das konstitut. Königtum in Preußen. Hist. u. polit. Aufsätze 5. Aufl. 3,539 . 
dem Ansehen und der Wirksamkeit des Reichstages Eintrag zu tun. "So wurde aus einer unmittelbaren Verfassungsforderung ein allgemeines politisches Leitmotiv. Man spürte wohl, daß das Preußen Bismarcks von noch viel härterem Stoffe war als das Preußen Friedrich Wilhelms IV. Außerhalb Preußens, weiter ab von dem Felsen, den es zu sprengen galt, wagte man schon mehr zu wünschen. Der bayerische Liberale Marquard Barth stellte im September I 866 die alte Riimelinsche Forderung mit prinzipieller Schärfe wieder auf. ${ }^{1}$ ) Er hielt freilich schon einen Organisator wie Stein für nötig, um sie durchzufiihren und bewies durch diesen frommen Wunsch seinen richtigen historischen Instinkt ebensowohl wie den Instinkt des realpolitischen Zweiflers. Aber in Süddeutschland ließ man das Thema nicht fallen. Am Schlusse des Jahres I 868 wies Treitschke darauf hin, daß in der suiddeutschen Presse immer wieder das Verlangen erklinge, der preußische Landtag solle seine Funktionen an die Provinziallandtage abtreten. $\left.{ }^{2}\right)$ Von größtem Interesse ist es, daß sogar der Großherzog Friedrich von Baden diesen Gedanken ergriff und während des Kriegsjahres I 870 als Stuick seines deutschen Zukunftsideals vertrat. Er entwickelte am I2. Sept. IS70 dem oldenburgischen Kabinetssekretär Jansen ${ }^{3}$ ), daß nach seiner Meinung allerdings Deutschland dem Einheitsstaate zustrebe, zurzeit freilich für ihn noch nicht reif sei. Jetzt

1) H. Oncken in den Forschungen zur brand. u. preuß. Geschichte 22, 315 ff. u. in Leben Bennigsens 2, $105 \mathrm{ff}$. Daselbst auch des Kurhessen Fr. Oetker verwandte Wiinsche und 2, 206 M. Barths Äußerungen aus dem Dezember 1870 .

2) Zum Jahreswechsel i\$69. Zehn Jahre deutscher Kämpfe, S. 225 (3. Aufl. I, 253).

9) Jansen, Großherzog N. F. Peter von Oldenburg S. I6I. Anklingende Gedanken über Beschränkung des Partikularismus , besonders in Preußen selbst،, Reichsministerium u. deutsche Armee äußerte der Großherzog I $\$ 75$ zu Chlodwig Hohenlohe. Denkwürdigkeiten Hohenlohes 2, 153 . 
komme es vor allem darauf an, durch die Kaiseridee den ärgsten aller Partikularismen, den spezifisch preußischen, zu brechen. Unter dem Kaisertum und neben dem allgemeinen Reichstage aber werde sich ein preußisches Abgeordnetenhaus und auch wohl ein preußisches Herrenhaus auf die Dauer nicht mehr aufrecht erhalten lassen; der föderativen Befestigung der deutschen Zustände könne es nur günstig sein, wenn man sich in Preußen dazu gedrängt finden sollte, auf das System der Provinzialstände zurïckzugreifen.

Treitschke, der damals selbst in südwestdeutscher Luft lebte, wollte aus solchen Wünschen nur bewußten oder unbewußten Partikularismus heraushören, und wir wissen von $\mathrm{I} \& 48$ her und werden darauf auch noch zurückzukommen haben, daß sie allerdings auch eine partikularistische Wurzel haben konnten. Aber er erkannte doch auch selbst zugleich die Klagen über die unvermeidlichen Reibungen zwischen den beiden Parlamenten als durchaus berechtigt an. „Es bleibt rätselhaft ", sagte er unmittelbar nach den Siegen von I866, »wie ein deutsches und ein preußisches Parlament in die Länge nebeneinander bestehen sollen. ${ }^{1}$ ) Seine Bedenken erhielten neue Nahrung, als nicht der deutsche, sondern nur der norddeutsche Bundesstaat geschaffen wurde. Er meinte auch, man müsse norddeutschen Reichstag und preußischen Landtag, die doch beide wesentlich preußische Volksvertretungen seien, möglichst vollständig miteinander verschmelzen. Preußisches und norddeutsches Parlament sollten aus denselben Wahlen hervorgehen und im Verhältnis eines engeren zum weiteren Reichstage zueinander stehen. ${ }^{2}$ ) Nach den Ereignissen von I 870

1) Polit. Korrespondenz vom I0. Juli I 866 . Zelnn Jahre deutscher Kämpfe (3. Aufl. 1, 155).

2) Polit. Korrespondenz, 10. Sept. 1866, a. a. O. S. 179, vgl. auch S. 205 u. 252. Diesen Mittelweg hatte schon Bunsen 1848 (s. oben 
zog er zwar diesen Vorschlag zurück, weil er die Mittelstaaten zu schwer verstimmen würde, aber meinte doch, daß man in späterer Zeit einmal darauf vielleicht zurickgreifen könne. ${ }^{1}$ )

Und er meinte das nicht etwa nur aus politischen Zweckmäßigkeitsgründen ${ }^{2}$ ), sondern aus derselben Grund-

S. 362 Anm.) und inzwischen, I S62, auch Paul Pfizer vorgeschlagen ( daß dieselben Abgeordneten das preußische Volk in Berlin und im deutschen Parlament zu vertreten bätten ،, Zur deutschen Verfassungsfrage S. 137) und dabei auf die uns bekannten Bestrebungen von 1848/49 mit prinzipieller Billigung wieder hingewiesen. Denselben Gedanken vertrat gleichzeitg mit Treitschke auch der Abgeordnete Groote am I I. Sept. I 866 im preuß. Abgeordnetenhause und nabmen Anfang I $\$ 69$ auch die Freikonservativen und Nationalliberalen wieder auf. Antrag v. Kardorff, 2S. Jan. I S69: עDie Zusammensetzung des preuß. Abgeordnetenhauses in bezug auf Abgrenzung der Wahlbezirke, Wahlmodus und Zahl der Abgeordneten mit der des Reichstages in Einklang zu bringen und damit eine nähere organische Verbindung der beiden Körperschaften anzubahnen.s Der nationalliberale Verbesserungsantrag v. Hennig wollte, noch weitergehend, die Reform auch auf das Herrenhaus erstrecken. Stenogr. Berichte I 86869 II, S. I 29+f. lismarck bekämpfte ihn an 2S. Januar IS69 bauptsächlich mit dem Argument, daß dann das Auflösungsrecht der preußischen Krone im preußischen Verfassungsleben bedroht werden würde. Er erkannte also deutlich, daß der Antrag auf eine fundamentale Änderung in der Stellung des preußischen Fönigtums hinauslief.

1) Das konst. Königtum i. Deutschl. Hist. u. pol. Aufs. 3, 556 f.

2) Wie beide einander gegenseitig auf die Schleppe treten; wie der Landtag bei jedem Schritt Rücksichten nelımen muß auf Verhandlungen, die er nur vom Hörensagen kennt; wie keiner der beiden Volksvertretungen eine vollständige Regierung, ein vollständiges Budget gegenübersteht; wie das Volk ermüdet wird durch die allzuhäufigen Wahlen und das Verständnis verliert für die in rascher Folge sich ablösenden parlamentarischen Verhandlungen; wie die Kraft der politischen Männer vernutzt wird durch die ungebihrliche Länge der parlamentarischen Geschäftszeit, die sich in Einer Versammlung leicht abkürzen läßt; wie diese Zeitvergeudung, ohnehin die Schattenseite jedes Parlamentarismus, durch ihr Übermaß die politische Regsamkeit der Nation zu ersticken droht c etc. a. a. O.S. 556, zum Teil iibernommen aus seinem Artikel s zum Jahreswechsel is6o\&, Zehı Jahre deutscher Kämpfe. 3. Aufl, I, $251 \mathrm{f}$. 
stimmung, aus der Friedrich v. Gagerns und Stockmars Vorschläge einst hervorgegangen waren: Aus unitarischen Idealen. Der große Unterschied war nur, daß jene von außerpreußischem Standpunkte aus ihr unitarisches Ideal konzipierten, er vom preußischen aus. „Wer den Einheitsstaat und die Selbstverwaltung starker Provinzen als die Staatsform der Zukunft ansieht, der muß Preußens monarchische und militärische Uberlieferungen schonen. « ${ }^{1}$ ) Was war das im Endergebnis viel anderes als das, was Gagern und Rümelin im Grunde erstrebt hatten, was der Leitartikel der Deutschen Zeitung vom I I. Dezember I 848 ausgemalt hatte. Auch die Konsequenz der Reichsverfassung von 1849, welche die Einzelstaaten zu Untertanen der Reichsgewalt herabdrückte und ihnen nur die selbständige Pflege der territorialen Interessen ließ, wäre dahin gegangen. Aber während jene, um dahin zu gelangen, Preußen autlösen wollten, wollte Treitschke es gerade recht sorgfältig erhalten als festen Kern, an den sich die übrigen Staaten künftig einmal ankristallisieren könnten. Der Unterschied zwischen ihm und den Männern der Paulskirche lag also nicht im Ziele, sondern in den Mitteln. Jene wollten, daß Preußen in Deutschland aufginge, er dachte sich die kommende Entwicklung umgekehrt. Höchst eigentümlich verbinden sich demnach in Treitschke die Gedanken von 1848 und von I87I. Das letzte Ziel entnahm er den Idealen des älteren Geschlechtes, die den machtvollen Nationalstaat nur in der Form eines möglichst einheitlichen Staates sich denken konnten, aber sein historischer und politischer Realismus lehrte ihn, daß dies Ziel nicht vom deutschen, sondern vom preußischen Zentrum aus erreicht werden müsse. ${ }^{2}$ ) Es war die Lösung, die der geistreiche

1) Hist. u. pol. Aufsätze 3, S. 533 .

2) So schon in seiner Schrift, Bundesstaat und Einheitsstaate IS64. Hist. u. polit. Aufsätze 5. Aut. 2, I56. 
Droysen schon I 848 antizipiert hatte, als er jene Alternative aufstellte, daß, wenn jetzt die Verschmelzung Preußens und Deutschlands nicht gelinge, Preußen gerade recht fest und straff sich konzentrieren müsse. ${ }^{1}$ )

Alternative über Alternative. Die Droysen-Treitschkesche Alternative war eine solche der Mittel und Wege bei Identität des Zieles. Die Gagern-Bismarcksche Alternative von I $\$ 49$ war eine solche des Zieles: Deutschland oder Preußen hieß sie, und Bismarck entschied sich damals für Preußen. Er ließ das verzwickte Problem Deutschland damals ungelöst und war zufrieden, für Preußen gesorgt zu haben. Als er es dann i 866 und I87 I löste, hat er es aber nicht im Sinne jener Alternative, die Droysen nur hatte gelten lassen wollen, gelöst, sondern im Sinne einer Synthese. Die alte Zeit der EntwederOders, die Zeit des dialektischen Denkens und der unbedingten Ideale war vorbei, die Zeit des modern-realistischen Sowohl-Als auch beginnt. Die Bismarcksche Synthese preußischer und deutscher Verfassung, föderalistischer und unitarischer Forderungen war kein Kunstwerk politischer Architektonik, ein anscheinend unförmliches und verwickeltes, aber lebensfähiges Ding. Preußen

1) Innerlich nicht fern diesen Treitschkeschen und Droysenschen Standpunkten steht auch die Auffassung, welche Konstantin Rößler 1872 entwickelte, als er Stockmars Denkwiirdigkeiten in der Zeitschr. f. preuB. Geschichte $(9,447)$ anzeigte. Er ging sogar so weit, das sgeniale، Stockmarsche Projekt von I $\$ 4 S$ (s. oben $S .358$ ff) zu billigen, weil er annahm, daß es den preußischen Staatsorganismus nicht schädigen würde. , Im Deutschen Reich ist ein unmittelbares Reichsland bereits errichtet, und der gröiste Fortschritt, den die deutsche Reichsentwicklung nach innen machen kann, wird darin bestehen, daß der preußische Staat zum un. mittelbaren Reichsland erklärt wird. Darin liegt so wenig eine Gefahr für den preußischen Staatsorganismus, daß die bildungsfähigen unter den nichtpreuBischen Mitgliedern des Reichstages, wenn derselbe als preubisches Parlament fungiert, nur um so preuBischer, nur um so unitarischer, nur um so zentralistischer werden gesinnt werden.s Unitarischer wohl, aber ob auch preußischer? 
wie Deutschland haben ihre Verfassung und ihr Eigenparlament und haben sich miteinander eingeschüttelt. Und das ist erreicht durch ein paar einfache, aber höchst geniale Sicherungen, die Bismarck zwischen preußischem und deutschem Organismus angebracht hat.

Zwei Hauptgründe waren es, wenn wir zurückblicken, gewesen, weshalb die Forderung gestellt wurde, Preußen solle auf sein Parlament und seine staatliche Einheit verzichten. Einmal die Besorgnis, daß das preußische Parlament auf das deutsche drücken werde. Diese Besorgnis entsprang der Meinung, daß die Kammermajoritäten tatsächlich durch ihr Steuer- und Budgetbewilligungsrecht den Kurs der Regierung und die Zusammensetzung der Ministerien bestimmen würden und müßten, entsprang also der sogenannten parlamentarischen Doktrin. Zwei tatsächlich regierende Parlamente nebeneinander, mußte man sich da sagen, sind ein Unding, bringen die Maschine zum Stillstand. Dieses Vorurteil, daß Konstitutionalismus gleich Parlamentarismus sei oder sein müsse, herrschte damals fast allgemein in den Reihen derer, die iberhaupt eine moderne Verfassung wollten. Ein klassischer Zeuge dafür ist Stahl. "Es wird kaum irgendwo einen Widerspruch finden, "schrieb er $1849^{1}$ ), »daß das politische Ideal der nachmärzlichen Konservativen kein anderes ist als die parlamentarische Regierung, die Herabsetzung des Königs zum Willensvollstrecker der Kammermajoritäten. * Er selbst dachte anders, aber er fühlte sich als Ausnahme.

Dieses parlamentarische Vorurteil, wie wir es nennen wollen, ist in seiner Herrschaft über die Geister erklärlich nicht nur aus der Gewalt, mit der die liberalen Wünsche im Jahre 1848 hervorbrachen, und also nicht nur aus

1) Die deutsche Reichsverfassung 2. Aufl. S. 7. - Fiir H v. Gagerns Meinung, daß Konstitutionalismus Majoritätenherrschaft involviere, ist seine Rede vom 26. Okt. I $S_{4} S$ (Stenogr. Bericht S. 2897) bezeichnend. 
der Suggestionskraft der Revolution, sondern auch aus den Erfahrungen, die man bis dahin in Deutschland mit parlamentarischem Wesen uberhaupt gemacht hatte. Das Verfassungsleben der süddeutschen Staaten, das man vor Augen hatte, war zwar weit davon entfernt, ein Vorbild parlamentarischen Regimes zu bieten, wirkte aber eben deswegen als abschreckendes Beispiel. Man erlebte es hier, wie die bureaukratischen Ministerien sich kräftig behaupteten gegenüber den oppositionellen Kammern, wie die Bewilligung des jährlichen Budgets zur »leeren Komödie « herabsank. So drückte sich Fürst Solms 1848 aus ${ }^{1}$ ), ein früherer Hallerianer, der 1847 und 1848 als Marschall der Herrenkurie des Vereinigten Landtags fungiert hatte, und der jetzt meinte, daß eine solche parlamentarische Komödie eines Staates wie Preußens unwürdig sei. Auch er war der Ansicht, daß die Konsequenz der wirklichen, nicht nur scheinbaren jährlichen Budgetbewilligung zu einer Regierung mit Ministerien der Kammermehrheit führe.

Der unparlamentarische Konstitutionalismus der süddeutschen Staaten ${ }^{2}$ ) beruhte nicht auf der eigenen Kraft der Regierungen, sondern war nur möglich durch den Riickhalt des reaktionären Bundestages, der beiden reaktionären Großmächte, der Wiener Beschlüsse von I 834 , kurz durch das ganze Elend des vormärzlichen Deutschlands. Das klebte an ihm und machte ihn verhal3t. Weiter aber konnte das System des gemäßigten Konstitutionalismus der öffentlichen Meinung sich nur empfehlen durch

1) ,Geschichtliche Anmerlingen\&, im Novemler ${ }_{1} S_{4} S$ veröffentlicht. Vgl. über ihn, , der sich bei dem zweiten Vereinigten Landtage und in Erfurt ganz erbärmlich benommen hatte e. Leop. v. Gerlach I, 568 und G. Kaufmann, der Vereinigte Landtag in der Bewegung von I 445 . Beil. zur Allg. Zeitung 1906, Nr. 25 u. 26.

2), Eine noch unklare Mischung der altfürstlichen Herrschaft und der Volksrepräsentation. Radowitz I $S_{47}$, Gesammelte Schriften $4,17 \mathrm{I}$. 
große positive Leistungen, durch historische Taten. Wie konnten diese gedeihen in der engen Luft der Mittelstaaten. Es ist ein gewaltiger Unterschied, ob eine solche Opfer verlangende Institution von einem großen und lebendigen oder von einem kleinen Staate gehandhabt wird. Die Soldatenspielereien der Fürsten des I8. Jahrhunderts waren lächerlich und häßlich, während sie doch nur in Miniatur taten, was Friedrich Wilhelm I. und Friedrich der Große zum Respekt von Mit- und Nachwelt taten. Ohne die Feuertaufe der schlesischen Kriege würde selbst das Heer Friedrich Wilhelms I. nicht als wahrhaft große geschichtliche Leistung gelten. Ohne die Feuertaufe der Konfliktszeit und der Kriege von i 866 und 1870 würde auch der gemäßigte Konstitutionalismus in Deutschland seiner geschichtlichen Sanktion ermangeln. Durch seine Leistungen für die Nation hat Bismarck die diskreditierte Regierungsform des gemäßigten Konstitutionalismus zu Ehren gebracht und das parlamentarische Vorurteil gebrochen. So ist es möglich geworden, daß preußisches und deutsches Parlament nebeneinander existieren können, ohne sich allzustark aneinander zu reiben. Wären diese beiden Schwungräder größer, so würden sie sich berühren und hemmen. ${ }^{1}$ )

Das zweite Vorurteil, das Bismarcli brechen mußte, um die Erhaltung der preußischen Staatseinheit innerhalb des deutschen Bundesstaates zu ermöglichen, wollen wir das unitarische nennen. Es ist komplizierterer Natur, und deswegen ist auch das Heilmittel, das Bismarck angegeben hat, komplizierter.

1) Über die Entwicklung der Idee des gemäßigten Konstitutionalismus seit I 848 vgl. Koser, Zur Charakteristik des Vereinigten Landtags seit 1847 , Festschrift zu G. Scbmollers 70. Geburtstage S. $328 \mathrm{ff}$., W. Schmidt, Die Partei Bethmann-Hollweg u. die Reaktion in PreuBen I $850-1858$ S. 98 ff. u. Jellinek, Regierung u. Parlament in Deutschland 1909 . 
Wir müssen noch einmal an die Gedanken Pfizers, Friedrich v. Gagerns und Stockmars erinnern. Sie alle wollten einen Bundesstaat, dessen Zentralgewalt kein anderes Interesse kenne als das des Bundesstaates. Sie wollten wohl die preußische Macht als Substrat dafuir benutzen, aber sie wollten nicht die Hegemonie des preußischen Staates oder des Königs von Preußen als solchen. "Die Hegemonie, "sagt Treitschke noch ganz im Geiste dieser Lehre, »widerspricht dem Wesen des Bundesstaates. "1) Zwischen Treitschke und jenen Denkern steht als Verbindungsglied Georg Waitz mit seiner Lehre vom Bundesstaate, in der die Gedanken seiner Vorläufer und die Bestrebungen der Erbkaiserpartei wie in einem Sammelbecken vereinigt und gereinigt werden. Die gesamte Fülle der Staatsgewalt, lehrte er, ist geteilt zwischen der Gesamtstaatsgewalt und den Gliedstaatsgewalten. Die eine besorgt die nationalen, die anderen die territorialen Staatsaufgaben. Innerhalb ihrer Sphäre ist jede der beiden Arten von Gewalten souverän und selbständig, darum müssen sie in strenger Trennung voneinander gehalten werden. Das deutlichste Merkmal einer wahren bundesstaatlichen Verfassung sei, sagt er, daß das Oberhaupt in keiner Weise in Abhängiglieit zu den Einzelstaaten stehe. ${ }^{2}$ ) Streng genommen mußte er dann

1) Hist. u. pol. Aufsätze 5. Aufl. 3, 536. Vgl, auch > Bundesstaat und Einheitsstaat< (a. a. O. 2, 156): , Ein deutscher Kaiser und König von Preußen wird, wenn er dem deutschen Parlamente gegenuber sein monarchisches Veto ausuibt, die Interessen seines heimatlichen Staates in erster Linie bedenken.، Das aber werde sden gerechten Unwillen der übrigen deutschen Stämme erregen،.... . Einen Protektor zu ertragen, ist demuitigend für das gerechte Selbstgefühl der nicht-preußischen Stämmes Konsequenterweise meinte er dann eben, daf ein aus Mon. archien zusammengesetzter Bundesstaat nicht die Gewähr der Dauer in sich trage, sondern sich zum Einheitsstaate hinüber entwickeln werde. A. a. O. S. $143,1+6$.

2) Allg. Monatsschrift i $\$ 53$ S. 505 
auch verlangen, daß der Monarch des Bundesstaates nicht zugleich Monarch eines Einzelstaates sein dürfe, und in der Tat hat Waitz i 848 zeitweise Bedenken gegen das preußische Erbkaisertum gehabt. ${ }^{1}$ ) Indem er sie fallen ließ, tröstete er sich damit, daß eine solche Bevorzugung eines einzelnen Herrschers noch nicht eine Bevorzugung auch seines Staates bedeutete. Aber er fühlte wohl, daß die Sache damit nicht abgetan sei. „Ergreift man diesen Ausweg, " meinte er ${ }^{2}$ ), »so wird es eine erhebliche Anderung in mehr als einer Beziehung hervorbringen; es wird, wenn nicht in der Verfassung, doch im Leben, die Angehörigen dieses Staates anders stellen, als die Genossen im Bundesstaat. Man kann vielleicht nicht voraussehen, welchen Einfluß es auf die Schicksale der Nation im ganzen haben kann. Aber daß es dem Wesen des Bundesstaates widerspräche, kann ich nicht finden." Dunkle Andeutungen künftiger möglicher Entwicklungen. Wir wagen zu vermuten, daß zu den »erheblichen Änderungen", die er voraussieht, auch die Auflockerung und Erweichung des preußischen Staatsverbandes gehörte. ${ }^{3}$ ) Wie konnte es sonst erreicht werden, was er so unbedingt fordert, daß das Oberhaupt des Bundesstaates in keinerlei Abhängigkeit von den Einzelstaaten stehen dürfe? Mußte es, wenn es

1) Haym 2, 236 u. Jürgens II, I, S. 325. Waitz' Rede vom I9. März ${ }_{1} S_{49}$ (Stenogr. Bericht S. $5^{8}{ }_{3}$ ): , Ich selbst, m. H., habe geglaubt, daß ein wechselndes Oberhaupt der Natur des Bundesstaates entspreche. Aber ich bin davon zurückgekommen.e

2) Altg. Monatsschrift I $S_{53}$, S. $52 S$.

3) Die einschränkenden Worte, »wenn nicht in der Verfassung \&, stehen dem nicht entgegen. Er spricht hier nicht vom preußischen Staate als solchem, sondern von den Angehörigen desselben, und diese konnten, wenn die einzelnen Provinzen des preußischen Staates eine ähnliche Stellung wie die dibrigen Einzelstaaten erhielten, sin der Verfassunge dann als ebenso gestellt erscheinen, wie die Genossen im Bundesstaate. 
nur dem Gesamtinteresse des Bundesstaates leben sollte, denn nicht auch frei und unabhängig sein von den Einflüssen seines eigenen Einzelstaates?

Man hat die Waitzsche Bundesstaatstheorie, die bis zu Bismarck geherrscht hat, charakterisiert als eine »im wesentlichen rein doktrinäre Schablone, verfertigt nach dem Vorgange anderer «.1) Das war sie doch nicht. Sie steht vielmehr, wie wir jetzt sehen, in engstem Zusammenhange mit den Bestrebungen, die wir schilderten. Sie hat natürlich auch ihre ausländischen Vorbilder $^{2}$ ), aber sie ist doch zum guten Teil mit aus dem praktischen Problem erwachsen, wie man den preußischen Staat in den deutschen Bundesstaat eingliedern könne, ohne diesen durch jenen zu erdrücken, wie man einen Bundesstaat schaffen kïnne ohne Hegemonie des mächtigsten Staates. Dieses Problem löste er dann eben im unitarischen Sinne. Der » Gesamtstaat « im Bundesstaate ist auf den Gebieten, die ihm zugewiesen sind, ein einfacher, geschlossener Einheitsstaat, dessen Zentralgewalt einheitlich sein muß, weil sie frei sein muß in ihrer Sphäre. Dieser Waitzsche Bundesstaat ist nun gewiß nicht schlechthin identisch mit dem Frankfurter Bundesstaat von I 849 , er läßt den Einzelstaaten in ihrer Sphäre eine wirkliche Selbständigkeit, wie sie ihnen in der Frankfurter Verfassung nicht gegönnt war. Aber der unitarische Grundgedanke, eine einheitliche, von den Gliedstaatsgewalten unabhängige Zentralgewalt zu schaffen, ist ihnen gemeinsam.

Das Mißtrauen gegen den größten Staat, gegen Preußen, ist die eine Hauptwurzel dieses Unitarismus. Ebenso unzweifelhaft stecken aber in diesem Unitarismus, wie paradox es auch klingen mag, auch noch partikularistische Motive. Wir erinnern an Paul Pfizer. Er

1) Anschütz, Bismarck und die Reichsverfassung (IS99) S. I3.

2) Die nordamerikanische Bundesverfassung bzw. die Auffassung, die Tocqueville von ihr vorgetragen hatte. 
fiurchtete, die Hegemonie des preußischen Volkes werde nicht nur das übrige Deutschland im ganzen drücken, sondern werde insbesondere das berechtigte Eigenleben der einzelnen Staaten und Stämme schädigen. Bei seinem Landsmann Rümelin blickt diese Angst des Schwaben, von Preußen regiert zu werden, ganz deutlich durch. Das preußische Erbkaisertum, sagt er einmal sehr bezeichnend, ist zunächst ein kaltes Sturzbad für uns Suiddeutsche; man braucht Zeit, um sich darin wohl zu fühlen, und wir wissen, auf welche Weise er sich das Sturzbad erträglich machen wollte. Der Wunsch Friedrich v. Gagerns, daß die Gliederstaaten des Bundesstaates möglichst gleich groß seien, ist möglicherweise ebenfalls dem IVunsche mit entsprungen, den berechtigten Partikularismus der Einzelstaaten zu schonen. Vielleicht ist auch bei den Mitgliedern der Erbkaiserpartei von I $S_{4} 8 / 49$ sehr viel mehr partikularistische Unterströmung, als man meint. Ihre Beteuerungen, daß sie das berechtigte Leben der Einzelstaaten durchaus schonen wollten ${ }^{1}$ ), werden gewöhnlich nicht geglaubt, weil ihre Taten dem zu widersprechen scheinen, aber sie mußten schon auch die übrigen Einzelstaten mit herunterdrücken, wenn sie die gefährliche Ubermacht des größten Einzelstaates herunterdriicken wollten. Danı waren sie zwar alle etwas gemindert, aber der größte Staat konnte dann seine Genossen auch nicht noch tiefer druicken. Und wenn der preußische Staat gar, wie sie hofften, sich auflöste, so waren die übrigen Staaten ihren unbequemen, übermächtigen Genossen vollends los.

1. Vgl. z. B. G. Beselers Rede vom 13. Febr. I $\$ 49$ (Stenogr. Bericht S. 5IS4): ,Ich und meine Freunde sind wiederholt daruber angegriffen worden, als ob wir in dem Bundesstat nur einen Einheitsstaat wollen. Nein, meine Herren, das wollen wir nicht, aber einen kräftigen Bundesstaat, der das Gemeinsame stark und gesund mache, aber auch die Teile in ihrer Stellung gesund und kräftig lasse.» 
Wir sind zwar nicht in der Lage, diesen Gedankengang aus dem Munde von Mitgliedern der Erbkaiserpartei selbst zu belegen; daß aber die Idee der Auflösung Preußens überhaupt auch im partikularistischen Sinne gedeutet, als eine Garantie des Sonderlebens der übrigen deutschen Staaten aufgefaßt werden konnte, haben wir aus der Aufnahme gesehen, die sie selbst im ausgesprochen partikularistischen Lager gefunden hat. Der württembergische Minister Römer, der aus seinem partikularistischen Standpunkte kein Hehl machte, beklagte es am 2 I. März I 849 beinahe, daß die Erbkaiserlichen die Forderung, Preußen in Provinzen zu zerschlagen, wieder hätte fallen lassen. ${ }^{1}$ )

Es ist ja freilich, wie wir schon früher sahen, höchst zweifelhaft, ob der Partikularismus der Mittel- und Kleinstaaten dabei schließlich auf seine Rechnung gekommen wäre. Preußens Auflösung hätte eine Bresche in das System des alten Territorialstaates gerissen, durch welche die unitarische Woge mächtig hindurchgeflutet wäre. Bedenken Sie, führte Edel aus Würzburg am 23. Januar I $849^{2}$ ) mit Recht aus, welche Folgen das Aufgehen Preußens in Deutschland hat. Dann muß die Reichsgesetzgebung so umfassend sein, daß sie fuir Preußen aucn Partikulargesetzgebung wird; daraus folgt, daß die Partikulargesetzgebung auch in den ubrigen Ländern schweigt und diese mit Notwendigkeit in die preußische Gesetzgebungseinheit eingehen.

1) Stenogr. Bericht S. 5894: „Preußen soll ibberdies auch fortan ein selbständiger Staat in Gesetzgebung bleiben, somit nicht, wie man uns früher immer versicherte, in Deutschland aufgehen،, deswegen füchte er nun den preußischen Partikularismus und das Gewicht einer so mächtigen Regierung. - Auch Gervinus hat anfangs (Leitartikel der Deutschen Zeitung vom 2. Mai 1848 ) die Forderung, Preußen solle seinen Landtag aufgeben, als eine, Außerung des Sondergeistess aufgefaßt. S. oben S. 358 ; s. auch S. 472 .

2) Stenogr. Bericht S. $4 S_{3} S$. 
So wäre die Verwirklichung der Frankfurter Reichsverfassung und der mit ihr verknüpften Voraussetzungen und Erwartungen nicht der Abschluß, sondern der Anfang einer neuen, unabsehbaren Entwicklung des deutschen Staatenlebens geworden. ${ }^{1}$ ) An wieviel Problemen und Konflikten hätte man sich abzumühen gehabt, um die drei Faktoren Reichsgewalt, Preußen und Einzelstaaten in Harmonie zu bringen. Deutschlands Kraft hätte sich in diesen inneren Aufgaben verzehren können, der Machtgedanke, der die Führer der Erbkaiserpartei schon so lebendig beseelte ${ }^{2}$ ), hätte vielleicht, angespornt durch große Aufgaben, zu stärkerer Konzentrierung der Nationalkraft und damit zu schnellerer Lösung des Problems führen können, vielleicht aber auch lange schlummern müssen, bis die Evolutionen und vielleicht Revolutionen im Innern ihr Ende erreicht hätten.

Ein solcher starker, vielleicht iiberstarker Gärungsstoff war also in der unitarischen Wurzel unserer Forderung enthalten. Und doch war ihr Grundgedanke, die Einheit und Macht des Ganzen mit der Freiheit der Teile zu verbinden, durchaus gesund und richtig. Sie war durchwachsen mit partikularistischen Motiven, und das war nicht nur grunddeutsche Art, sondern diese Verbindung partikularistischer und unitarischer Lebensinteressen war eben das, was Deutschland brauchte und was Bismarck

1) Der von Waitz am 30. Jan. I\$49 erstattete Bericht des Verfassungsausschusses über den Abschnitt ,Die Gewähr der Verfassung (Stenogr. Bericht S. 4956) sagt mit Recht, daB „das Ineinanderleben des Reichs und der Staaten nicht ohne bedeutende Umwandlungen in den Verhältnissen eintreten kann und vollständig wohl erst nach längerer Zeit stattfinden wirde.

2), Denn es ist nicht bloß die Freiheit, die er meint, es ist zur größeren Hälfte die $\mathrm{Macht}$, die ihm bisher versagte, nach der es ihm gelüstet. Deutschland muß als solches endlich eintreten in die Reihe der politischen Großmächte des Weltteils.s Dahlmann, 22. Jan. I 849. Stenogr. Bericht S. 4821 . 
ihm schließlich gab. Und zwar hat er dadurch diese Verbindung hergestellt, daß er die Einzelstaaten selbst in ihrer Gesamtheit zu Trägern der Reichsgewalt machte. Das Wesen seines Werkes war es, um die vortreffliche Formulierung von Anschütz zu gebrauchen, »das gefestigte partikulare Staatsbewußtsein der deutschen Einzelstaaten als solche dem Reichsgedanken dienstbar zu machen und dies Ziel vor allem dadurch zu erreichen, daß die oberste Regierungsgewalt des Reiches den verbündeten deutschen Staatsregierungen selbst in die Hand gegeben wird ". Die Institution des Bundesrates war der Ausweg, der alle Schwierigkeiten beseitigte, mit denen die Frankfurter so schwer gerungen hatten. Jetzt konnte der Herrscher des mächtigsten Einzelstaates zum Träger der Exekutivgewalt des Reiches crhoben werden, ohne daß das übrige Deutschland und die übrigen Staaten zu fürchten brauchten, von Preußen erdruickt zu werden, und ohne daß Preußen das Opfer seiner Autlösung zu bringen hatte. Reich, Preußen und Einzelstaaten konnten nun nebeneinander ihres Lebens froh werden, jedem war das Seine gegeben. Mochte dann tatsächlich hinterher die Macht des neuen Kaisertums und damit auch des hinter ihr stehenden preußischen Staates über die Schranken hinauswachsen, welche ihr durch die Verfassung gesteckt waren, - gegen solche tatsächlichen Machtverschiebungen war kein Kraut gewachsen, da konnten nur die lebendigen politischen Kräfte entscheiden. So ist denn allerdings der Bundesrat nicht das geworden, was er werden konnte. Immer aber besaßen und besitzen die Einzelstaaten in ihm einen Damm, über den hinaus die unitarische Flut zunächst nicht schlagen kann.

Beachten wir auch, wie die Institution des Bundes. rates mit der Zerstörung des parlamentarischen Vorurteils zusammenhängt, wie sinnreich hier alles ineinandergreift. Der deutsche Reichstag kann es schon deswegen nicht 
zu einem parlamentarischen Regime bringen, weil ihm kein verantwortliches Reichsministerium, sondern Bundesrat und Reichskanzler gegenuberstehen. Bismarck hat aus vitalen Gründen die Forderung von Reichsministerien bekämpft. Sie wären, sagte er einmal ${ }^{1}$ ), »nicht anders möglich als auf Kosten der Summe von vertragsmäßigen Rechten, welche die verbündeten Regierungen gegenwärtig im Bundesrate uben. Die wesentlichsten Regierungsrechte der Bundesstaaten würden von einem Reichsministerium absorbiert werden, dessen Tätiglieit durch die Art der ihm auferlegten Verantwortlichkeit dem maßgebenden Einflusse der jedesmaligen Mehrheit des Reichstages unterliegen müßte«. Reichsministerien, hat er ein andermal im Reichstage ausgeführt ${ }^{2}$ ), die keine bestimmte Wurzel in einem Partikularstaat haben, würden geradezu zu einer Realition des Partikularismus, und zwar vor allem des preußischen Partikularismus führen; »der erste und mächtigste Widersacher des Reichsministers würde der preußische Finanzminister sein«. Das war genau auch die Sorge, welche die Rümelin und Gagern hatten. Die Schaffung von Reichsministerien würde sofort das Problem erneuern, dessen Geschichte wir erzählten.

Weshalb aber, müssen wir fragen, sind nicht schon die Männer von I 848 auf diese glückliche Lösung des Problems gekommen? Weshalb mühten sie sich so hartnäckig auf dem steilen unitarischen Wege $a b$, statt den bequemen föderalistischen Weg zu beschreiten? Weshalb waren sie so ängstlich bemuiht, die Einzelstaaten fernzuhalten von der Teilnahme an der Reichsgewalt? Wir empfangen aus ihrem eigenen Munde die Antwort: Man habe befürchtet, dadurch nur einen neuen Bundestag zu

1) Preufsische Erklärung im Bundesrat 5. April is84. Mittnacht, Erinn. an Bismarck N. F S $4 \mathrm{I}$

2) 10 März I 877 . 
schaffen. $\quad$ Wie sollte, « fragte Max Duncker ${ }^{1}$ ), »ein solches Kollegium, aus instruierten und $z u$ instruierenden Gesandten gebildet, anders regieren als der Bundestag, langsam, schleppend, elend oder vielmehr gar nicht, auch wenn die Majorität in diesem Fürstenrate entscheiden sollte?« Die Bundesfürsten, sagte Dahlmann, durften im Oberhause nicht allein stehen, »wenn nicht aus ihm ein neuer Bundestag erwachsen sollte, allen Volksbedürfnissen ein unerschütterliches Veto entgegenstellend $"{ }^{2}$ ) So steht es also mit diesem Föderalismus genau so wie mit dem gemäßigten Konstitutionalismus. Sie waren beide so furchtbar diskreditiert durch die Erfahrungen der letzten Jahrzehnte, daß man die Zukunft der Nation ihnen nicht mehr anzuvertrauen wagte. Man sieht, was wir ja eben zeigen wollten, wie die politischen Irrtümer der Denker von I 848 zum großen Teile erwachsen sind aus dem ungesunden Boden der vormärzlichen Zeit. Es waren nicht bloß Ideologien, es waren Lebenserfahrungen, die sie trieben. Die Doktrin kam allerdings gleich dazu und brachte in Formeln, was die Erfahrung verlangte oder zu verlangen schien. Ein Teil der Erbkaiserlichen war sich selbst darüber wohl klar, daß eigentlich, wie Duncker es selbst zugibt ${ }^{3}$ ), 》das Prinzip des Bundesstaates gleichen Anteil an der Regierung des Ganzen für alle Teilnehmer fordert . Aber eben weil man aus dringenden politischen Gründen den Einzelstaaten diesen Anteil an der Bundes. regierung verweigern zu muissen glaubte, wurde man, da man nun einmal einen Bundesstaat« schaffen wollte, zu

1) Zur Geschichte der deutschen Reichsversammlung in Frankfurt 1849, S. 51 .

2) Springer 2, 223. Vgl auch Binding, der Versuch der Reichsgriindung durch die Paulskirche (1S92) S. 40 : , Es ist unleugbar, daB die schlimmen Erinnerungen an den Bundestag, der schlechterdings nicht wiederaufleben sollte, die Zuerkennung der angemessenen Stellung an die Staaten und ihre Regierungen wesentlich gehindert haben.s

3) a. a. O. 
einer anderen Konstruktion des Bundesstaatsbegriffes hingedrängt - eben derjenigen, die IVaitz aufstellte und in ihren Grundzügen schon in der Rede vom I9. März I849 entwickelte. $\left.{ }^{1}\right)$ Hier haben wir also die zweite politische Wurzel der Waitzschen Theorie. Wir erkennen jetzt noch deutlicher, daß das, was er Bundesstaat nannte, eigentlich kein Bundesstaat war, sondern ein Einheitsstaat, der nur auf gewisse staatliche Aufgaben verzichtet zugunsten der von ihm im ubrigen streng getrennten Einzelstaatsgewalten. ${ }^{2}$ )

Die Waitzsche Lehre hat dann den föderalistischen Bundesstaatsbegriff so tief verschüttet, daß man wohl glaubte, Bismarck habe mit ihm etwas ganz. Neues zur Geltung gebracht. ${ }^{3}$ ) Geschaffen hat er wohl etwas ganz Neues, aber der Gedanke hat ihm schon vorgearbeitet, und es wird keine wertlose Mühe sein, seine Spuren schon in der Zeit der Märzbewegung zu verfolgen.

Man findet da zunächst, daß in den allerersten Stadien der Bewegung der Föderalismus noch gewisse Aussichten hatte. Bei jenen früher erwähnten Verhandlungen, die in der ersten Hälfte des März 1848 von den südwestdeutschen Regierungen ausgingen und an denen die Brüder Max und Heinrich v. Gagern so lebhaft beteiligt waren, haben die Bevollmächtigten von Württemberg, Hessen-Darmstadt und Nassau dem bayerischen Hofe ein Programm überreicht, das eine Zusammensetzung der Bundesbehörde aus zwei Kammern forderte, die erste gebildet durch die Stellvertreter der deutschen Bundesfürsten, die zweite aus Abgeordneten des deutschen

1) Stenogr. Bericht S. $58_{37}$

2) Er selbst half sich damit, daß er unter Bundesstaat ein $7 . u$ sammen von, Gesamtstaat und Einzelstaaten verstanden wissen wollte.

3) Anschütz S. 14; sBismarcks Tat und Verdienst nun ist es gewesen.... in der Reichsverfassung einen ganz neuen Bundesstaatsbegriff zur Geltung gebracht zu haben. 
Volkes. Jene sollten ihre Instrulition von den Fürsten erhalten, diese ungebunden sein. Um einen Beschluß der deutschen Bundesbehörde zustande zu bringen, sollte Übereinstimmung der beiden Kammern erforderlich sein. ${ }^{1}$ ) Die preußische Leitung des Bundes kann demnach nur als die einer Exelutivgewalt, nicht etwa als die eines konstitutionellen Monarchen gedacht gewesen sein. Da hat man schon einige wesentliche Grundzüge dessen, was Bismarck I 866 ins Leben gerufen hat. Ist doch auch der Deutsche Kaiser des neuen Reiches kein eigentlicher Monarch im staatsrechtlichen Sinne.

Vielleicht gehört auch das zu den schlimmen Wirkungen des IS. und I9. März, daß die günstige Stunde verpaßt wurde, wo diese föderalistische Lösung noch möglich war. In dem Programm der Heidelberger Siebenerkommission fiur das Vorparlament ${ }^{2}$ ) war noch über dem Volkshause ein Senat der Einzelstaaten vorgesehen. Ein paar Wochen darauf hat der Verfassungsentwurf der Siebzehner, den Dahlmann ausarbeitete, den verhängnisvollen Schritt getan, das Oberhaus aus Abgeordneten der Regierungen, die nicht an deren Instruktionen gebunden waren, und aus Abgeordneten der Einzelkammern gemischt zusammenzusetzen. Damit war der Anteil der Regierungen als solcher an der Gesetzgebung des Bundesstaates ausgeschaltet; sie waren zu bloßen Wahlliörpern fuir das Oberhaus herabgedruickt. ${ }^{3}$ )

1) Mitgeteilt in der Rede, die H. v. Gagern am 24 . März i $S_{4} \delta$ in der hessischen Kammer gehalten hat. H. v. Gagern, Ein öffentl. Charakter ${ }_{1} S_{4} S$, S. 264.

2) H. v. Gagern, Fr. v. Gagern 2, 750.

3) Als Mathy am 24. Juni $1 S_{4} S$ die Fortentwicklung des Pundes. tages zu einem Staatenhause verlangte (Stenogr. liericht S. 519 , vgl. Sybel I, 1SI), stand er schon ziemlich isoliert da, und doch verlangte er nicht etwa einen Bundesrat im Bismarckschen Sinne mit instruiertea Stimmen, sondern eine Versammlung, die solne besondere Weisungen 
Der föderalistische und der unitarische Gedanke, die ursprünglich noch verbunden waren, trennten sich also. Der Föderalismus wurde das Panier derer, welche auf eine Direktorialregierung oder auf einen Turnus in der obersten Leitung Deutschlands hinaussteuerten ${ }^{1}$ ), also der mittelstaatlich-partikularistischen, antipreußischen Partei. Der Unitarismus dagegen wollte sich jetzt die Stellung des erblichen Bundeshauptes nur als die eines konstitutionellen Monarchen denken, was wiederum die Föderalisten um des Prinzips willen nicht zugeben konnten. Ohne Zweifel hat, wenn auch wohl nur sekundär, die theoretische Vorliebe für die Form der konstitutionellen Monarchic mitgewirkt, um die föderalistischen Gedanken in den Hintergrund $z u$ drängen. Und $z u$ allem uibrigen kam dann die berauschende Atmosphäre, in der das Frankfurter Parlament während seiner ersten Monate lebte, der Machtduinkel, der ihr Auge trübte und die politischen Realitäten der Einzelstaaten wie mit einem Nebel ungab.

Diese eben skizzierte Entwicklungsreihe ging von Südwestdeutschland aus und mündete in Frankfurt ein, - dort ging das föderalistische Element, das sie zuerst noch mit sich geführt hatte, unter. Nicht von hier aus kamn es in Bismarcks Gedankenwelt hinübergesprungen sein. Wohl aber ist in diesen Jahren, unabhängig davon, auch auf preußischem Boden die föderalistische Lösung gedacht worden, und von hier aus kann man dann allerdings einen direkten Verbindungsfaden zu Bismarck hinuiber nachweisen.

Das früheste unzweideutige Zeugnis dafuir ist eine Schrift des jungen Grafen Robert von der Goltz, der sich später als Vertreter Preußens bei Napoleon III. einen

nach einfacher Mehrheit beschließen kanne. Vgl. ibber ähnliche Pläne noch Biedermann, Histor. Taschenbuch 1877 S. 127 u. Jurgens, Zur Gesch. d. deutschen Verfassungswerkes I, 134 ff., I 47 , I 53 , I 57 ff., I 7 I. 1) Vgl.z. B. Rotenhans Antrag vom 15. Jan. I 849 bei Binding S. 46. 
Namen gemacht hat: „Uber die Reorganisation des Deutschen Bundes. « Er will das Wesentliche seiner Gedanken schon vor dem I 8 . März niedergeschrieben haben ${ }^{1}$ ) und steht dabei eingestandenermaßen unter den Eindrücken, die er in Nordamerika erfahren hatte. Sein Vorschlag war, eine Bundesregierung zu bilden aus dem König-Protelitor (von Preußen), einem Hause der Botschafter und einem Hause der Volksabgeordneten; die vollziehende Gewalt ruhe in der Hauptsache beim KönigProtektor, die gesetzgebende bei dem aus beiden Häusern bestehenden Bundestage. Die Botschafter seien an Instruktionen gebunden, und kein Gesetz sei gültig ohne Beschluß beider Häuser und Genehmigung des König.Protektors, dessen Veto aber nur suspensiv sei. Mit einer solchen föderalistischen Strulitur konnte sich, wie wir wissen, der reine Parlamentarismus nicht vertragen, und so macht es der Einsicht des Verfassers Ehre, daß er diesen verwirft. Andere seiner Vorschläge würden allerdings die Stellung des König-Protektors und den natürlichen Einfluß Preußens im Bunde sehr geschwächt haben. $\left.{ }^{2}\right)$ Aber die Verbindung hegemonischer und föderalistischer Gedanken, die er, ein konservativer Demolirat beinahe, vertritt, ist höchst beachtenswert.

Doch auch nicht ihn wollen wir nennen als den, von dem Bismarck gelernt haben könnte. Wohl aber Stahl. In einem Leitartikel der Kreuzzeitung vom 30. August I 848 schon führte er aus, daß in Deutschland das Oberhaus nur Fürstenhaus, nicht bloßes Staatenhaus sein könne, daß die Fürsten zwar der souveränen Reichsgewalt in Deutschland unterworfen sein, aber auch ihren Anteil an dieser souveränen Gewalt und zwar als Fürsten haben muißten. Bestimmter formulierte er das dann in der

1) Die Vorrede datiert vom $S$. April i $S_{4} S$.

2) Vor allem der unmögliche Vorschlag, dab alle Staaten im botschafterhause gleiches Stimmrecht haben sollten. 
Schrift von I 849 iiber die Reichsverfassung, die wir schon kennen. Da heißt es rund heraus $\left.{ }^{1}\right)$ : Monarchische Staaten können als solche nur dadurch vertreten sein, daß die Fürsten selbst in Person oder durch ihre Gesandten, die an ihre Instrulationen gebunden sind ${ }^{2}$ ), das Oberhaus bilden. Er wünscht also etwas Ähnliches, wie das Plenum des Bundestages, nur mit anderem Stimmenverhältnis, denn in einem Bundesstaate müßten - hier geht er mit gesundem Machtgefühl über Goltz hinaus - die größeren Staaten auch besser als im Bundestage vertreten sein. Und ganz im Geiste des späteren Bismarckschen Werkes sagt $\left.\mathrm{er}^{3}\right)$ : Die Untertanen der einzelnen Fürsten werden nur dann auch der Reichsgewalt Liebe und Sympathie entgegenbringen, wenn sie ihren Fürsten an ihr beteiligt wissen. Das ist dasselbe, was Bismarck später, nur im Tone etwas kühler, in dem Kapitel »Dynastien und Stämme « ausgedrückt hat: „Deutscher Patriotismus bedarf in der Regel, um tätig und wirksam zu werden, der Vermittlung dynastischer Anhänglichkeit. «")

Nun machte ja allerdings auch die Radowitzsche Unionspolitik seit dem Mai I 849 den ernsthaften Versuch, hegemonische und föderalistische Bedürfnisse miteinander zu verschmelzen und zugleich für Deutschland wie für Preußen einen gemäßigten Konstitutionalismus anzubahnen. Das Ziel im ganzen war vortrefflich, die Elemente, die miteinander zu mischen waren, waren richtig erfaßt, aber das Verhältnis, in dem sie zu mischen waren, wurde im Rezept falsch angegeben, und so hatten Stahl und Bismarck allen Grund zu klagen, daß auch die Unionsverfassung,

1) S. $2 S$.

2) Sie dürfen aber niemals wegen mangelnder Instruktion ihre Stimne aufschieben können. Dieselbe Kautel hat Bismarck in Art 7 der Reichsverfassung angebracht.

3. S. 42.

4) Gedanken u. Erinner. I, 290. 
wie vorher die Reichsverfassung, dem preußischen Staate zu wenig gebe, ihn geradezu entwaffne zugunsten seiner schwächeren Genossen im Bunde. ${ }^{1}$ )

Dies geschah vor allem durch die höchst unguinstige Stellung Preußens in der Legislative. Die gesetzgebende Gewalt sollte vom Fürstenkolleg in Gemeinschaft mit dem Reichstage ausgeibt werden. Im Fürstenkolleg aber hatte Preußen nur eine unter sechs, oder wie es zuletzt geplant wurde, unter fünf Stimmen, war gebunden an dessen Mehrheitsbeschlüsse und hatte nur bei Verfassungsänderungen ein Veto gegen ihm nicht genehme Beschliusse des Fürstenkollegs und des Reichstages. ${ }^{2}$ ) Wenn es sich gegenuiber seinen Genossen im Fürstenkolleg behaupten wollte, so mußte es seinen Rückhalt im Parlamente des Bundesstaates suchen, lief dann aber auch Gefahr, sich von diesem in das Schlepptau nehmen zu lassen. So war die preußische Selbständigkeit hier wie dort bedroht, - hier durch die im Fürstenkolleg vertretenen föderalistischen Elemente, dort durch die im Parlamente vertretenen unitarischen und populären Elemente des geplanten Bundesstaates.

Da hat dann Bismarck am 15. April I 850 im Erfurter Volkshause einen denkwürdigen Antrag gestellt ${ }^{3}$ ): Das Fürstenkolleg, schlug er vor, sollte zu einem bloßen konsultativen Kollegium, dem »Vereinsrate« des Reichs-

I) Stahls Rede in Erfurt I2. April i 950 . Siebzehn parlam. Reden S. 150

2) Vergl. die ş 76,77,82, 99 und 194 der Dreikönigsverfassung und die erläuternde Denkschrift von Radowitz rom I I. Juni I +9 (u. a. bei Blömer, Zur Gesch. der Bestrebungen der preuß. Kegierung für eine polit. Reform Deutschlands IS49'50, S. 40). Das Erfurter Parlament verbesserte dann die Stellung Preußens, indem es durch andere Fassung der Artikel 82 und 99 das Vetorecht in der Legislative dem Reichsvorstande, d. h. Preußen, unzweideutig beilegte.

$\left.{ }^{3}\right)$ Kohl, Polit. Reden Bismarcks I, 232 ff. Er wurde unterstütat u. a, von Stahl u. Ludwig v. Gerlach. 
vorstandes (d. h. des Königs von Preußen) umgebildet werden, aber durch beständige Orientierung über alle Gegenstände auch einen gewissen, jedoch nicht bedeutenden Anteil an der von Preußen geführten Exekutive des Bundesstaates erhalten. Das Staatenhaus des Parlamentes aber. das von Radowitz nach dem Muster der Frankfurter Reichsverfassung konstruiert und demnach dem Einflusse der einzelstaatlichen Regierungen fast ganz entrückt war ${ }^{1}$ ), sollte ersetzt werden durch ein Fürstenhaus, aus den Fürsten persönlich oder aus ihren Bevollmächtigten bestehend, mit einem Stimmenverhältnis, wie das des Plenums im alten Bundestage. Die drei vitalen Organe des Bundesstaates wären danach gewesen: der König von Preußen als Vereinsvorstand mit seinen Vereinsministern, das Fürstenhaus, in dem Preußen nicht mit vertreten war, und das Volkshaus. Das Eigenartige war dabei also, daß Preußen als Vereinsvorstand strenger abgesondert wurde von seinen fürstlichen Verbündeten, als es in der Radowitzschen Verfassung und in der späteren Bismarckschen Reichsverfassung der Fall war, -- offenbar in der Absicht, sie ihm möglichst vom Leibe $\mathrm{zu}$ halten und seine Bewegungsfreiheit zu sichern. Jedes der drei Organe, Vereinsvorstand, Fürstenhaus und Volkshaus, sollte gleichen Anteil an der Gesetzgebung erhalten; aber man sieht sofort, daß diese formale Gleichberechtigung der drei legislativen Faktoren demjenigen unter ihnen am meisten frommte, der zugleich auch die Exekutive ausuibte und ubberhaupt die größte Macht hinter sich hatte. Preußen hätte es ganz anders als in der Radowitzschen Verfassung in der Hand gehabt, divide et impera zu spielen, die Fürsten gegen das Volkshaus und das Volkshaus gegen die Fürsten zu benutzen. ${ }^{2}$ ) Die Macht-

1) S. oben S. 489 .

2) Ganz genial war für diesen Zweck die Bestimmung gedacht, daß die regierenden Fürsten im Fürstenbause entweder persönlich er- 
stellung Preußens ist hier eigentlich noch stärker als in der späteren Bismarckschen Reichsverfassung, aber das war sachlich gerechtfertigt dadurch, daf in der Union zuletzt nur finf Millionen der Kleinstaaten gegen I6 Millionen Preußen standen. So wäre das Ganze hinausgelaufen auf eine Beherrschung der Kleinen durch den einen Großen, der mit ihnen im Bunde war, auf eine societas leonina. Radowitz erkannte damals diese Tendenz des Bismarckschen Antrages sehr wohl und warnte das Erfurter Parlament, daß er zu einer Mediatisierung der Kleinstaaten führen würde. So wäre Preußen bei dieser Art von bundesstaatlicher Verfassung wohl auch das unmittelbare Reichsland des Ganzen geworden, aber als mächtiger, in sich geschlossener und in seiner inneren Struktur gesicherter Kern.

"Ich finde in diesem Vorschlage, "sagte Bismarck damals, »die Erledigung eines großen Teils der gewichtigen Gravamina, welche uns Preußen, oder Wenigstens die mit mir gleichgesinnten Preußen, sagen lassen, wir wollen den Bundesstaat, aber lieber, als um den Preis dieser Verfassung, wollen wir ihn gar nicht. "Also nur einen großen Teil, nicht alle seine Wünsche wollte Bismarck durch diesen Antrag zur Geltung bringen. Man wird zunächst vermuten dürfen, daß ihm das Zugeständnis, das er hier den konstitutionellen und parlamentarischen Gedanken bringen mußte, einigermaßen sauer wurde.

scheinen oder durch einen Prinzen ihres eigenen oder eines verwandten Hauses sich vertreten lassen sollten. Nicht die Einzelstaaten, sondern die Einzeldynastien sollten also vertreten und dadurch dem Einflusse ihrer Landesparlamente möglichst entriickt werden. Bismarcks Entwurf schmeichelte dadurch den dynastischen und antiparlamentarischen Gesinnungen der Fürsten, er trieb aber dadurch einen Keil zwischen sie und ihre Landesparlamente und schwächte so auch die Parlamente und die politische Bedeutung des Fiirstenhauses, das nun, hineingestellt zwischen Vereinsvorstand und Volkshaus des Bundesstaates, seine Anlehnung naturgemäß in der Regel bei ersterem suchen nußte. 
Er wollte uberhaupt nur den Wagen von dem falschen Wege, auf den ihn die Frankfurter, die Gothaer und Radowitz gebracht hatten, abwinken und ihm einen besseren zeigen. Er tat es noch ohne besonderen Eifer, beinahe ärgerlich und mit lässiger Hand. »Wenn es doch einmal geschehen soll, «begann er seine begründende Rede, »daß wir auf den Leib der deutschen Einheit den fadenscheinigen Rock einer französischen Konstitution ziehen ...", so will ich, klingt es aus der Rede heraus, euch wenigstens sagen, wie man es allenfalls machen könnte. Er kehrte den selbstgenuigsamen Preußen heraus, der auch mit den schwarzweißen Farben seines Vaterlandes zufrieden sein wollte; aber schon die Tendenz seines Antrages läßt erraten, daß hinter der Stirn dieses anscheinend stockpreußischen Edelmannes bereits ein über Preußen nach Deutschland hinübergreifender Machttrieb lebte. Und so darf man wohl weiter vermuten, daß ihm die Stunde zu einer vollen Ausnutzung der deutschen Einheitsberegung für preußische Machtpolitik noch nicht gekommen schien, und zumal deswegen noch nicht gekommen schien, weil jene Bewegung ihm noch zu stark verquickt war mit dem ihm antipathischen liberalen Gedanken. Ihr parlamentarisches Vorurteil machte sie ihm unschmackhaft. Um es überwinden $z u$ können, mußte er selbst erst in sich das antikonstitutionelle Vorurteil überwinden. Aber den ersten Schritt dazu tat er jetzt eben durch den Erfurter Antrag, indem er durch ihn zwar unlustig, aber unzweideutig den Wunsch der liberalen Zeitgenossen nach einem bundesstaatlichen Zentralparlament erfülte. So war dieser Antrag zwar noch nicht der erste Akt, aber ein interessantes Vorspiel seiner künftigen deutschen Politik; das kommende Thema wurde hier bereits angeschlagen, das preußisch-hegemonische, das unitarisch-konstitutionelle und das föderalistische Motiv in einer Weise miteinander verbunden, daß zwar 
das erste dominierte, aber auch die beiden anderen zur Geltung kommen sollten.

Der Ausgangspunkt, von dem aus wir seinen Erfurter Antrag betrachten, war das föderalistische Motiv. Wir sahen, daß das Fürstenhaus hier tatsächlich mehr vom Scheine, als vom Wesen der Macht erhielt. Aber es erhielt doch auch vom Wesen der Macht so viel, daß die Dynastien der Kleinstaaten, auf die Preußen damals fast allein noch angewiesen war, eine gesicherte und zugleich würdige und ehrenvolle Stellung im Bundesstaate behaupten konnten. So war es ein erster Versuch Bismarcks, das Problem zu lösen, das er später durch die Institution des Bundesrates gelöst hat, - echt bismarckisch auch durch die Verbindung ron List und Liberalität in der Gabe, die er den Fürsten bot. Seine damaligen Parteifreunde mögen wohl mehr die Liberalität als die List dieser Gabe empfunden haben. Aber sie konnten sich dabei sagen und hatten dazu auch ein volles Recht, daß die bereitwillige und speziose Anerkennung des föderalistischen Elements, die Bismarcks Antrag enthielt, ein Stück ihres politischen Programmes ausführte. Hinter Bismarck ergriff am I5. April in Erfurt auch Stahl das Wort und erklärte: "Die Umgestaltung der Bundesverfassung, welche der Abgeordnete r. Bismarck rorschlägt, ist diejenige, die ich seit dem Jahre $1 s_{4} \&$ bis jetzt schriftstellerisch vertreten habe. ${ }^{1}$ )

1) Wir nennen hier auch noch eine kleine vortreffliche Schrift von Triest, Oberregierungsrat und Abgeordnetem zur ersten preuB. Kammer sowie zum Volkshause zu Erfurt: ,Das Parlament zu Erfurt, Berlin I 850 . Nach einer Notiz des Landfermannschen Exemplars, das ich benutze, muß sie anı I. Februar IS50 erschienen sein. Sie schlägt auch schon Vereinigung des Fürstenkollegs und Staatenhauses vor. 'Die Pairs des Bundesstaates sind die zum Bunde vereinigten Staaten selbst. Diese können nur angemessen vertreten werden, wenn allein die Regierungen die Abgeordneten zum Staatenhause zu ernennen haben ..... Sie erlangten damit im Staatenhause die Befugnis, gegen die gesetzgeberischen 
So haben auch die damaligen preußischen Konservativen ihren Anteil an der politischen Gedankenarbeit, die in dem späteren Werke Bismarcks steckt. Alle lebendigen Kräfte der Nation haben ihren Beitrag dazu geliefert.

Nicht aus der Zerschlagung, sondern aus der Erhaltung, nicht aus dem Tode, sondern aus dem Leben des preußischen Staates sind die Einrichtungen erwachsen, die den Wunsch Pfizers und seiner Gesinnungsgenossen erfüllten, das Sonderleben und die Mannigfaltigkeit auch in der Einheit zu schützen. Die preußischen Konservativen konnten den Dynastien und Stämmen außerhalb der schwarzweißen Grenzpfähle deswegen geben, was ihnen gebührte, weil sie selbst aus eigener Lebenserfahrung wußten, was Dynastie und Stamm in Deutschland bedeutet, - das kräftige preußische Sondertum hat sich schließlich als eine Garantie auch für das Sondertum der übrigen Stämme erwiesen.

Beschliusse des Reichsvorstandes ihr Veto einzulegen, und nichts wiirde sie hindern, ihre Bevollmächtigten zum Staatenhause mit Instruktionen zu versehen, durch welche freilich nicht ... die Beschlußnahme aufgehalten werden dürfte. 


\section{Siebentes Kapitel.}

\section{Fortentwicklung des preufsisch-deutschen Problems.}

Haben wir damit nun aber das Problem unserer Untersuchung ganz erledigt? Wir haben die Voraussetzungen sowohl der Gedanken von $\mathrm{I} \$ 48$ wie von $\mathrm{I} 866$ entwickelt, und eine Erfahrung von vier Jahrzehnten hat die geschichtliche Lebensfähigkeit der Bismarckschen Lösung erwiesen. Und doch wird man, ohne ihren politischen Wert schmälern zu wollen, gleich hinzusetzen müssen, daß an sich der durch ihn geschaffene Zustand nicht schlechthin ideal ist. Jene Treitschkesche Befuirchtung vor einem Ubermaß an parlamentarischem Treiben ist doch bestätigt worden. Unzweifelhaft liegt hier einer der Gründe, weshalb das Niveau und das Ansehen des Parlamentarismus in Deutschland gesunken ist. Sollte nicht am Ende Bismarck auch das vorausgesehen haben? Bis zu einem gewissen Grade mußte ja der Parlamentarismus eingeschränkt werden, wie wir sahen. Aber sollte Bismarck nicht auch eine weitere Minderung parlamentarischer Macht in Deutschland noch über dies Maß des Notwendigen hinaus ganz gern gesehen haben? Eben das befürchtete man nach den Siegen von I 866 im preußjschen Abgeordnetenhause, als die ersten Grundzige des neuen Zustandes an das Licht traten. Virchow meinte am II. September ${ }^{1}$ ): „Eine geschickte Regierung wird 1) Stenogr. Bericht (1866/67) 1, 288 . 
immer in der Lage sein, ein gegenseitiges Hin- und Herdrängen der Gewalten, eine gegenseitige Abschwächung der parlamentarischen Körper herbeizuführen. « Ihın schloß sich der politisch gemäßigtere Twesten am folgenden Tage an. Er besorgte als Folge des Nebeneinanders deutscher und preußischer Volksvertretung einen »Cäsarismus der Regierungsgewalt, welcher sich über die durcheinanderlaufenden Beschlüsse und Kompetenzen zweier parlamentarischer Versammlungen mit großer Leichtigkeit würde hinwegsetzen können «. ${ }^{1}$ ) Das war eine Besorgnis, die der Situation und dem Gedankenkreise von 1848 noch ferngelegen hatte. Damals kannte man in der Hauptsache nur die Extreme Absolutismus und Parlamentarismus und wollte wohl Kautelen schaffen gegen die Reibung zweier parlamentarisch regierter Staatswesen, dachte aber noch nicht an die Möglichkeit eines modernen cäsaristischen Regierungssystems in Deutschland, an die Möglichkeit, daß eine starke Monarchie auch die liberalen und nationalen Gedanken als Machtmittel ausbeuten werde und mit demokratischen und parlamentarischen Institutionen ihr Spiel treiben könne. Inzwischen aber hatte Napoleon III. gezeigt, daß dies möglich war, und Bismarck traute man $z u$, daß er auf seinen Spuren wandle. Diese Liberalen von I 866 waren ja nicht die ersten, welche Bismarck im Verdacht des Bonapartismus hatten. Zweifelsohne war er nicht so ganz unbegründet. Bismarck hat, wie man weiß, von vornherein ein merkwürdiges Interesse für Napoleon III. gehabt, in erster Linie ja, weil er ihn als Stein im Schachbrett seiner äußeren Politik brauchte. Sein Griff nach dem allgemeinen gleichen Wahlrecht - eine Ubersetzung des suffrage universel ins Hinterpommersche, wie man witzelte - aber zeigt schon, daß er auch in den Maximen innerer Politik

1) Stenogr. Bericht S. 322 . 
von ihm lernen konnte. $\left.{ }^{1}\right)$ Wenn er nun eben das Parla. ment des norddeutschen Bundes auf das demokratische Wahlrecht gründen wollte, so hat das die Besorgnisse des preußischen Abgeordnetenhauses vom Herbst I 866 nicht etwa gemindert, sondern eher gesteigert. Aus Mißtrauen gegen das, was er mit dem neuen demokratisch gewählten Parlamente vorhabe, setzte man es durch, daß diesem nur die Beratung der Bundesverfassung zugewiesen wurde, behielt man dem preußischen Abgeordnetenhause die endgültige Beschlußfassung über die Arbeit des Bundesparlamentes vor. ${ }^{2}$ )

Man hat nicht viel erreicht damit, und Bismarck hat sein Spiel schließlich durchgesetzt. Vielleicht ist doch dies Regieren mit zwei Parlamenten, dies Reiten bald auf dem deutschen, bald auf dem preußischen Pferde ein verstecktes aramum imperii Bismarcks gewesen. ${ }^{3}$ ) Er

1) Unruh, Erinnerungen S. 273, polemisiert gegen den Verdacht, daß Bismarck das Verfahren Napoleons 111, habe nachahmen wollen, und beruft sich auf eine damalige $\mathrm{Außerung}$ Bismarcks, daß von solchen Wahlkiunsten, wie in Frankreich, in Deutschland keine Rede sein könne, , das ließen sich die Deutschen nicht gefallen gesagt, sondern auch gedacht haben. Aber der Gedanke, Macht und Masse in unmitteibare Beziehung zu setzen, hat unzweifelhaft einen cäsaristischen Zug. Jie Wahlkünste Napoleons III. konnte er enthehren, weil er auf die monarchische Gesinnung der Massen und auf den sozialen Einfluß der Großgrundhesitzer auf das Landvolk vertraute (vgl. Lenz, Bismarck S. 332; Oncken, Lassalle S. 346 u. 352). Er hat damals das demokratische Wahlrecht gerade auch um der erhofften undemokratischen Resultate willen vor dem Dreiklassenwahlrecht bevorzugt. Vgl. auch die oft angefürte Stelle aus seiner Depesche an Bernstorff vom 19. April $1 \$ 66$ (Sybel 4, 31S). - Interessant ist in diesem Zusammenhange, daß Napoleon III. schon Ende IS6I der preußischen Regierung die Einfuhrung des suffrage unizersel empfohlen hat, bei dem die konservative Landbevölkerung die Lileralen in den Städten niederstimmen könne،. Ringhoffer, Im Kampfe für Preußens Ehre S. 456.

2) Sybel 5, $438 \mathrm{ff}$.

3) Es ist ja möglich, dab vorubergehend auch er an eine Vereinfachung des parlamentarischen Doppelapparates gedacht hat. V'gl. 
hat zuerst, in Erinnerung an die preußische Konfliktszeit, gehofft, mit dem deutschen Winde weiter zu kommen als mit dem preußischen, er hat das preußische Dreiklassenwahlrecht am 28. März I 867 als das elendeste aller Wahlsysteme gescholten und mit den Erwählten des allgemeinen Wahlrechts im Reichstage auch lange erfolgreich arbeiten können. Aber er hat auch keine ernstliche Miene gemacht, das Wahlrecht beider Parlamente auszugleichen ${ }^{1}$ ) und hat schließlich auch dabei seine Rechnung gefunden, als er den Kurs seiner inneren Politik wendete und das Abgeordnetenhaus nun gegen den minder gefügigen Reichstag brauchen konnte. Doch genug dieser Hinweise, die eine besondere eingehende Untersuchung verlangen.

Also e $r$ hat damit regieren können, auch seine Nachfolger konnten es und dachten ebenfalls nicht daran, auch nur den klaffenden Zwiespalt zwischen dem Wahlrecht des preußischen Abgeordnetenhauses und des deutschen Reichstages auszugleichen. ${ }^{2}$ ) Es fragt sich nur,

seine Rede vom 28. Jan. I 869 : Es hat der Königl. Regierung und den Bundesbehörden ja von Anfang an nahe gelegen, auf eine Vereinfachung des seit I 866 geschaffenen Räderwerkes hinzuwirken, und die Frage, auf welche Weise dies zu geschehen habe, auf welche Weise dies möglich sei, hat uns vielfach auch vor dieser heutigen Anregung beschäftigt.s Aber entscheidend ist, daß er diesen Gedanken nicht weiter verfolgt hat.

1) Seiner Rede vom 28, Januar 1869, in der er die Aussicht auf die Reform des preußischen Wahlrechts eröffnete, hat er keine Taten folgen lassen. Wagegen machte Bismarck in diesen Jahren, wie Oncken, Bennigsen 2, II 2 treffend bemerkt, den auf Lockerung und Dezentralisation des preußisehen Staatsverbandes gerichteten Tendenzen ein gewisses Zugeständnis durch die Begriindung des hannoverschen Provinzialfonds 1868 , die charakteristischerweise sofort von den preußischen Konservativen bekämpft wurde, - freilich wohl mehr aus allgemeinem politischen Instinkt und aus spezieller Eifersucht auf die neue Provinz, als aus Abneigung gegen provinziale Selbstverwaltung iiberhaupt.

2) Daß Kaiser Friedrich als Kronprinz deutsch-unitarischer dachte, ist bekannt und braucht in diesem Zusammenhange nur eben ange. 
ob dieser Zustand für die Regierten immer ebenso erwünscht war wie für die Regierenden. Hier liegt ein noch ungelöster Rest unseres Problems. Die unmittelbaren Friktionen zwischen preußischem und deutschem Parlament sind zwar dank jenen genialen Sicherungen, die Bismarck angebracht hat, leidlich ausgeschaltet, und uber beiden konnte nun, als die dritte und stärkste Macht, die verbundene preußische und Reichsregierung ihre Politik treiben, aber sie trieb sie nun und nußte sie treiben, man möchte sagen mehr nach den Maximen äußerer als innerer Politik. Abgeordnetenhaus und Reichstag wurden mehr und mehr zwei Mächte verschiedenen Geistes, verschiedener Willensrichtung, so daß nun die Regierung bald mit dem einen, bald mit dem andern markten mußte. A hnlich, wie es in der großen Politik zugeht, darf sie keinen zu stark, aber wohl auch keinen zu schwach wünschen, um selbst den Ausschlag geben zu können. Vieles läßt sich damit erreichen, aber eines nur schwer, was doch das Ziel einer wahrhaft inneren Politik sein muß: Einheitlichkeit auf allen Gebieten des öffentlichen Lebens. Eine beherrschende Persönlichkeit wie Bismarck war wohl imstande, für die größten und drängendsten Aufgaben seiner inneren Politik Reichsparlament und Landesparlament, deutsche und preußische Tendenzen zusammenzuspannen, aber für die Aufgaben, die dahinter und darunter lagen, für das was weniger drängte und doch in Zukunft einmal wichtig werden konnte, hat auch er oft die Dinge gehen lassen müssen, und so hat es auch unter ihm an harten Dissonanzen in der inneren Politik nicht gefehlt. Gleich schon in den ersten Jahren des Norddeutschen

deutet zu werden. Vgl. seine Frage an Chlodwig Iohenlohe an Io. Nov. I87 r sob ich glaube, daß das Reich sich konsolidiere. Die Abneigung des Kaisers, den preußischen König und das Prenßentum aufzugeben, die diese Abneigung fördernden Bemühungen des märkischen Adels flößen ihm Bedenken ein،. Hohenlohe 2, 74. 
Bundes hat man an seiner "Zweiseelentheorie» sich gestoßen, an dem Widerspruch zwischen der großartigen Reformtätigkeit seines Bundeskanzleramtes und dem reaktionären Geiste seiner preußischen Ministerkollegen Lippe und Mühler. ${ }^{1}$ ) Nach 1890 ist diese Zwitterhaftigkeit noch stärker geworden als vor I 890 . Welch ein schneidender Kontrast war es, als Caprivi in denselben Jahren die liberale Handelsvertragspolitik im Reichstage, die konservative Schulgesetzpolitik im Abgeordnetenhause machte.

Freilich rufen auch noch tiefere Gründe diese Dissonanzen hervor. Es ist nicht bloß die talitische Klugheit des divide et impera, die zum Regieren mit zwei verschiedenartigen Systemen rät, sondern die innere Genesis und Struktur der deutsch-preußischen Macht zwingt in gewissem Grade dazu. Das Deutsche Reich ist geschaffen worden mit den Kräften der altpreußischen Militärmonarchie, und die Kräfte der liberalen und nationalen Bewegung sind wohl von ihr benutzt, aber nicht als schlechthin leitend anerkannt worden. Und das Deutsche Reich ist dann im großen und ganzen bisher durch dieselben Mittel erhalten worden, durch die es gegruindet worden ist. Immer ist der preußische Militärstaat mit allem, was daran hängt, mit seinen royalistischen und aristokratischen Traditionen, mit seiner Begünstigung derjenigen sozialen Schichten, die den Kern des Offizierkorps stellen, der festeste Punkt der inneren Politik geblieben, die Zitadelle gleichsam der ganzen Festung. Immer ist man zu diesem Zeichen wieder zurückgekehrt. Und die politischen Intercssen der iibrigen sozialen Schichten hat man wohl nicht vernachlässigt, aber auch nie so zur Leitung emporkommen lassen wie jene. Man glaubt die feste Basis der Macht zu verlassen, wenn man sich ihnen ganz anvertraut, man traut ihnen

1) Oppenheim, Waldeck S. 250. Vgl. auch Aus Ed. Laskers Nachlaß 1, 52. 
nicht die unbedingte Zuverlässigleit und Leistungsfähigkeit zu, man traut ihnen nicht zu, daß sie so gute Offiziere stellen und so pünktlich alle Militärforderungen bewilligen würden. In den ersten Zeiten des Reiches konnte Bismarck wohl vorübergehend die politische Hilfe der preußischen Konservativen entbehren, weil der nationale Liberalismus ihm genug leistete. Er konnte damals gelegentlich wohl das alte Schlagwort in den Mund nehmen: "Preußen muß in Deutschland aufgehen ${ }^{1}$ ) und das neue Schlagwort erfinden, Preußen bediirfe mehr der Germanisierung als Deutschland der Borussifizierung. $\left.{ }^{2}\right)$ Er konnte, was mehr besagen will, auch einmal wirklich versuchen, seinen Schwerpunkt von Preufen auf das Reich zu verlegen, aufzuhören, wie er sagte, preußischer Ministerpräsident zu sein, weil er dachte, als Reichskanzler stark genug zu sein. Er kam ganz bald von diesem Irrtum zurück und mußte $1 \$ 77$ gestehen, daß er doch den Haupteinfluß, den es ihm gegönnt sei zu üben, »bisher nicht in der Kaiserlichen Macht, sondern in der Königlich preußischen Macht gefundei habe." Nach den Zeiten der Reichsflut sah er die Reichsebbe kommen. Und sie kam bald genug, als der Kulturkampf scheiterte, der Liberalismus versagte, die Sozialdemokratie emporkam, die Landwirtschaft aber und insbesondere der preußische Gutsbesitzerstand wirtschaftlich bedroht wurde. Die Mittel, ihm zu helfen, entsprangen demselben System, das auch dem Reiche neue Einnahmen, seinem Macht-

1) 4. Dez. I\$75. Poschinger, Bismarck und die Parlamentarier I, 75 .

2) I4. März 1 $S_{77}$. Daselbst I, 104; Kobl, Bismarchregsesten 2, 140. Vgl, auch seine Reden vom 26. April is $/ 6$, ?he Entwicklung eines Großpreußentums zum Nachteil der Keichsautorität zu bekämpfen, ist Pflicht, die mir als Reichskanzler obliegte) und ähnlich) rom Is. Nai $18 ; 6$.

3) Rede vom 10. März IS;7. Aber noch im Dezemher I $\$ 77$ konnte er $z u$ Bennigsen von der, Gefahr der Trockenlegung von Reich und Bundesrat durch den Iartikularstaat l'reußen, sprechen. Oncken 2, 327. 
bedürnisse neue Quellen verschaffen sollte. Ein Strom von preußisch-konservativem Wesen ergoß sich nun wieder über das Reich; die neudeutschen, liberalnationalen Gedanken traten zurück, das Abgeordnetenhaus kam wieder gegenüber dem Reichstage mehr zu Ehren. Das preußische Dreiklassenwahlrecht, das in den sechziger und siebziger Jahren liberale Mehrheiten hervorbrachte, ist seitdem das Wahlrecht der Besitzenden und vor allem der Grundbesitzenden geworden und hat seit den Wahlen von I $879^{1}$ ) zu leidlich festen Parteiverhältnissen im preußischen Parlamente geführt, während das allgemeine Wahlrecht des Reichstags unter dem Doppeldrucke der wirtschaftlich-sozialen und konfessionellen Kräfte eine Zersplitterung des übrigen Deutschlands hervorgerufen hat, die zur politischen Ohnmacht alles dessen, was nicht preußisch-konservativ oder was nicht konfessionell geschlossen ist, gefuihrt hat. Um so mehr Grund für die Regierenden, sich auf die zu stützen, die organisiert und geschlossen dastanden.

So wirkt hinter dem neuen Gegensatze des agrarischen und des industriellen Deutschlands in der Tiefe immer noch der alte Gegensatz zwischen Preußen und dem übrigen Deutschland fort. Pfizers Worte von I832 finden in diesem noch heute ein Echo. Es ist freilich insofern anders gekommen, als er es damals besorgt hat, als ja nicht das preußische Volk in seiner Gesamtheit es ist, das durch seine Parlamentsherrschaft das ubrige Deutschland niederdrückt. Darin teilte er damals die

i) Nach den konservativen Landtagswahlen von $18 S 2$ schrieb Treitschke: Das kunstvolle Triebwerk unseres Staates kann nicht in Gang kommen, wenn die beiden mächtigsten und repräsentativen Körperschaften des Reichs nicht von demselben Geiste beherrscht werden. Der grelle Widerspruch zwischen den Gesinnungen des Reichstags und des Landtags wird bald genug fühlbar werden.s Deutsche Kämpfe, Neue Folge S. 2 ro. 
politische Kategorien und Illusionen seiner Zeit, daß er den Begriff einer 》Volksvertretung " so ernst und wörtlich nahm und es sich nicht anders vorstellte, als daß hinter einer einheitlichen und mächtigen Vertretung auch ein einheitliches und mächtiges Volk stehen würde. Vielmehr hat die Einfuhrung parlamentarischer Institutionen in Preußen das preußische Volk in letzten Ende vielleicht mehr zersplittert als vereinheitlicht. Dic aufstrebenden Schichten sind zurückgedrängt, und die Lage im Innern wird beherrscht durch den Bund der starken Monarchie mit den stärksten sozialen und politischen Kräften ihres Heimatstaates. So schlägt durch die modernen Formen des heutigen preußischen Nationalstaates immer noch die Struktur des alten Preußens und überhaupt, um an unsere früheren Ausführungen zu erinnern, des Nationalstaats älteren Charakters durch. Und es ist ein großer Beweis für die Lebenskraft, die dieser schon entwickeln konnte, daß sie vorgehalten hat bis auf den heutigen Tag. Aber sein innerer Hait ist doch nicht mehr der alte. Wir sahen die eigenartige Doppelstellung, die die Monarchie seit den Ereignissen von I 866 und I870 einnimmt. Sie ist preußisch und deutsch zugleich, sie hat damit, wie wir bemerkten, die Möglichkeit, ihre Allianzen zu wechseln, heute mit preußischem, morgen mit deutschem Winde zu fahren. Sie kann daruber freilich selbst, und das ist vielleicht ihr eigenster Zug, zu einer inneren Einheitlichkeit nicht kommen, sie ist eine politische Gewalt mit zwei Seelen und gibt dadurch das merkwürdige Schauspiel, daß auch die Regierungen von Nationalstaaten einer doppelten Nationalität angehören können. Aber man darf deswegen eben fragen, ob dieser Zustand die Gewähr einer längeren geschichtlichen Dauer in sich trägt.

Erinnern wir uns doch: Das Ubergewicht des P'reußentums im Reiche und der altpreußisch-konservativen Ten- 
denzen in Preußen selbst beruht ja nicht auf bloßer Gewalt, ist auch nicht eigentlich die Frucht wirtschaftlicher und sozialer Verhältnisse, sondern beruht auf dem ersten und dringendsten Lebensbedürfnis, das die Regierung eines großen europäischen Staatswesens haben muß. Hier greifen die Gedankengänge ein, die Friedrich Naumann aufgestellt hat: Von dem Augenblicke an, wo der neudeutsche, liberale, bürgerlich-industrielle Boden stark genug sein würde, um die Machtpolitik und Machtbediurfnisse der Reichsgewalt zu tragen, würde der altpreußische Boden überflüssig werden, würde die Spannung zwischen dem modernisierten altpreußischen Nationalstaate und dem immer noch unfertigen und erst werdenden deutschen Nationalstaate sich lösen können.

Der reine Historiker wird zurückhaltender urteilen, als der von edelster politischer Leidenschaft erfüllte Agitator Naumann und wird auch die Symptome der juingsten Zeit, die auf eine solche Lösung hindeuten, nicht überschätzen. Die erstaunliche Lebenskraft des altpreußischen Geistes kann auch die jetzige Krisis uberstehen. Unberechenbar aber war und ist zu jeder Zeit die Einwirkung der äußeren Weltverhältnisse auf die Gestaltung des inneren politischen Lebens, und der einzelne geschichtliche Moment und die einzelne geschichtliche Persönlichkeit können - wir möchten noch einmal damit die Eingangsgedanken dieses Buches anklingen lassen - allen Formeln und Gesetzen zum Spotte der Nation ihre IVege weisen. So hat auch die geistvolle Naumannsche Konstruktion, die auf den politischen Sieg des neudeutschen Industriestaates rechnet, nur den Wert eincr Möglichkeit, aber allerdings einer sehr zu erwägenden und ernst zu nehmenden. Der konservative Agrarstaat, den die Regierung jetzt noch nicht entbehren kann, wird ja selbst auch bedroht durch die unberechenbaren Erfordernisse der Weltlage, die nun seit Jahren schon bald stärker, bald leiser oszilliert, - und 
wird weiter ständig auch bedroht durch die IVogen einer mächtigen wirtschaftlichen Umwälzung. Einmal kann diese Flut, getrieben vielleicht von den IVinden einer politischen Weltkrisis, die jetzt künstlich aufgerichteten Dämme zerreißen, und dann wird allerdings alles darauf ankommen, ob das Neuland des liberalen und industriellen Deutsch. lands die politische und nationale Festigkeit haben wird, um Ersatz für das Zugrundegehende zu bieten.

Dann wird aber auch der Gedanke, dessen Geschichte wir behandelten, noch einmal eine Zukunft wieder haben. In einem Deutschland, das seine Machtinteressen dem Bürgertum und der Industriebevölkerung anvertrauen kann und will, wircl auch der preußische Staat eine andere Stellung einnelmmen als im Zeitalter Bismarcks und seiner ersten Nachfolger. Er wird nicht aufgelöst zu werden brauchen, und es wird uberhaupt das, was wir die politische Nationalität des Einzelstaates nannten, keineswegs zu verschwinden brauchen, aber der Reichsgedanke wird den Einzelstaatsgedanken mehr und mehr überwölben, die Einzelstaaten werden clann sozusagen eintrocknen, sie werden faktisch in das Verhältnis von Reichsprovinzen heruntersinken. ${ }^{1}$ ) Sind sie es doch schon jetzt auf dem

1) Ein Anhänger Naumanns hat vor mehreren Jahren, obne zu abnen, in welchen geschichtlichen Zusammenhängen sein Gedanke steht, dies Postulat aufgestellt (Straßburger Zeitung 6. Febr. 1905): ,Wenn Graf Posadowsky gesagt hat, die Einzelstaaten würden zu Provinzen des Reichs degradiert werden, wenn man alle Resolutionen ausfiihren wolle, die der Reichstag gefaßt hat, so muß einmal offen erliärt werden, daß dies früher oder später doch kommen mub, da die jetzige Bundesstaatsverfassung die Zusammenfassung der Finanz- und Wirtschaftskräfte der Nation, die durch die volkswirtschaftliche Entwicklung gebieterisch gefordert wird, ungebührlich erschwert und sich allmählich - man denke nur an die Reichsfinanzreform - als unlialtbar erweisen wird. Preußen als Reichsprovinz würde jedenfalls fortschrittlicher regiert werden müssen, als das Königreich Preußen, der Hort der Reaktion im Deutschland der Gegenwart, zurzeit regiert wird.. - Wenn wir früher sahen, daB I $8+8+9$ auch der antipreuBische Partikularismus in 
Gebiete der spezifisch modernen, sozialpolitischen Reichsinstitutionen.

So könnte hier eine jener Verfassungswandlungen eintreten, welche die äußeren Formen der Verfassung selbst unberührt läßst. ${ }^{1}$ ) Sogar die Ausgleichung des Wahlrechts zwischen deutschem und preußischem Parlamente wäre kein unbedingtes Erfordernis dafür, daß der Reichsgedanke den Sieg über die im preußischen Staatsleben bisher vorwaltenden Kräfte davontrïge. Wohl ist der in den letzten Jahren entbrannte Kampf um die preuBische Wahlrechtsreform auch ein Kampf um dieses Ziel geworden und wird uns vielleicht ihm näher führen, aber der Historiker weiß, daß solche höheren Ziele auch dann erreicht werden können, wenn das unmittelbare Ziel, die äußere Umformung des Wahlrechts, nicht oder nur unvollkommen erreicht wird. Steht doch auch - denn man muß diese Fragen vom freiesten Standpunkte aus und den Blick auf alle sich regenden Entwicklungstendenzen gerichtet beurteilen - der Parlamentarismus im ganzen heute in einer Krisis, die für seine Bedeutung viel gefährlicher ist als für seine Formen. ${ }^{2}$ ) Es wäre

die unitarische Forderung der Autlösung Preußens mit einstimmen konnte, so kann auch hierfür wieder eine Parallele aus jüngster Zeit beigebracht werden. Am I9. Mai I goS äußerte der Kabinetsrat Schimmelpfeng auf dem Parteitage der hessischen Rechtspartei, daB seine Partei darauf rechne, sdaß das Deutsche Reich erst noch durch Entfaltung einer selbständigen unabhängigen Reichsgewalt zur Wahrheit werde, daß dann aber auch durch Auflösung des preußischen Staatsabsolutismus Raum für eine Stammesgliederung des deutschen Volkes geschaffen werde, in welcher für Hessen und sein Fürstenhaus durch Natur und Geschichte

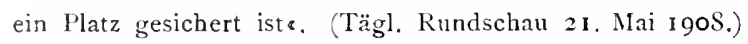

1) Vgl.Jellinek, Verfassungsänderung und Verfassungswandlung, 1906.

2) IIn der großen und unleugbaren Tatsache, welche uns die so gewaltig vorwärtsstürmende Geschichte der Gegenwart lehrt, daß uber die Parlamente, iiber diese in so vielen Staaten künstlichen Schöpfungen der neuesten Zeit hinweg, die beiden einzigen unzerstörbaren Mächte des Staates: Regierung und Volk, einander unmittelbar gegenüberzu- 
die äußere Lösung unseres Problems auch in der Weise denkbar, daß indem der Parlamentarismus iberhaupt eintrocknet, auch der Streit und Gegensatz der beiden großen deutschen Parlamente untereinander seine Schärfe verliert.

Und so würde es eine Entwicklung ohne jähen Bruch mit der Vergangenheit sein können. Das Bismarcksche Verfassungswerk ist elastisch und anpassungsfahig genug, um das zu ermöglichen. Hat es auf der einen Seite den preußischen Staat als festen Pfeiler hineingestellt in den deutschen Bundesstaat, so hat es auf der anderen Seite das preußische Königtum selbst aus der spezifisch preuBischen Sphäre hinaufgehoben, es seines ausschließlich preußischen Charakters entkleidet und ihm die Möglichkeit gesichert, in das Reich hinüberzuwachsen. $\left.{ }^{1}\right)$ Noch zaudert es am Scheidewege, wie die Geschichte der Reichsfinanzreform von 1909 gezeigt hat, aber immer wieder und immer dringlicher wird es vor die Schicksalsfrage gestellt werden. Eigene Kriegsmacht und eigene Finanzen

steben beginnen, liegt der gewaltigste Verfassungswechsel der neueren Geschichte verborgen. Jellinek a. a. O. S. So.

1) Vgl. Jellinek, Das Recht des modernen Staates I 2 (1905) S. 763 : , Da der Bundesstaat souverän ist, so gibt es für die Ausdehnung seiner Zuständigkeit gegenüber den Gliedstaaten keine Grenze: sie kann bis zur Vernichtung ihres staatlichen Charakters gehen und der Bundesstaat sich demgemäß in einen Einheitsstaat verwandeln. . Muißte ein zum Einheitsstaate neigendes Volk für alle Zeiten rechtlich die föderalistische Gestaltung seiner staatlichen Verhältnisse weiter dauern lassen? Man kann doch die Geschichte nicht durch eine Art von bundesstaatlichem Legitimismus meistern wollen.\& — Wir befinden uns gegenwärtig, urteilt ein anderer Staatsrechtslehrer (Hatschek, Bismarcks Werk in der Reichsverfassung rgo6 S. I3) , in einer Entwicklungstendenz, die uns aus dem alten Föderalismus der Reichsverfassung allmählich in un itarische Bahnen hinüberlenkte, und eindringlich fuhrt das vor allem Triepels Schrift, Unitarismus und Föderalismus im Deutschen Reiche 1907 aus (vgl. meine Bemerkungen ither sie IIistor. Zeitschr. 100, $618 \mathrm{ff}$. .) 
sind das $A$ und $O$ der Staatsgewalt. Wenn zur Reichskriegsmacht endlich einmal auch ein, in der Reichsverfassung Artikel 70) schon vorgesehenes, durchgreifendes Reichssteuerwesen käme, und wenn in dem einen wie dem anderen die gesamtdeutsche, neudeutsche Idee zum vollen Leben gelangte ${ }^{1}$, so würde die Monarchie ihren Ubergang von der preußischen auf die deutsche Basis unbedenklich vollziehen können.

Ganz ohne Sinn und Inhalt war die Meinung Treitschkes, daß das neue Deutsche Reich sich zum Einheitsstaate entwickeln werde, also keineswegs, wenn er es allerdings auch von wesentlich anderen Voraussetzungen aus prophezeit hat, als wir es heute zu tun wagen.

Doch wir erheben gar nicht einmal den Anspruch zu prophezeien. Wohl aber darf der Historiker auch die lebendigen Gewalten der Gegenwart in geschichtliche Perspektive stellen und auf die Möglichkeiten ihrer Weiterentwicklung hinweisen. Lebendige Gewalten sind heute sowohl das alte Preußen wie das neue Deutschland. Die Formen, in denen sie auf- und miteinander wirken, mögen vergehen oder mögen bleiben und sich mit anderem Inhalte füllen. Das Ziel, auf das alles ankommt, ist die volle Lebensgemeinschaft des deutschen Nationalstaats, die so stark ist, daß sie auch jede besondere Nationalität ihrer Glieder zugleich zu ertragen, zu benutzen und zu uberwinden vermag.

1) Daß auch in den staatsrechtlichen Verhältnissen des Reichsheeres noch starke Inkongruenzen $z$ wischen preußischen und deutschen Grundlagen bestehen, zeigt die lehrreiche Studie O. Bielefelds, Das kaiserliche Heer. Archiv f. öffentl. Recht XVI, 2, 2 So ff. 


\section{Personenregister.}

(Unwesentliches ist übergangen.)

Alexander I. I61, I $84,321$.

Graf Arnim-Boitzenburg 370.

A. v. Arnim 230, 264.

H. v. Arnim $349 \mathrm{ff}$.

E. M. Arndt 64 , So, 89 ff., 170.

v. Auerswald fo6.

Augusta, Prinzessin 43 I f

Aulicke 4 I9

Barth, Marquard $47 \mathrm{I}$.

Bassermann $3 S_{3},{ }_{3} 86$.

Graf Bernstorff $+32,+34$.

G. Beseler ${ }_{4} \mathrm{~S} 2$.

Biedermann $3 S_{4}, 454$.

Bismarck 193, joI ff., 426 f., 468 , $475 \mathrm{ff}$., $490 \mathrm{ff}$., $499 \mathrm{ff}$.

R. Blum $365,3^{S_{4}},+4 \mathrm{I}$.

v. Boddien 462 .

Bonald 71,126

loyen 163,332

Graf Brandenburg 376 f., $3^{S 7}$ t., 401,412 ff., $+2 S,+34 f, 439$.

BraniB 357.

Cl. Brentano 230.

Graf Bülow 386 ff, 39I, +13, 439 . Bunsen $350,361 \mathrm{ff}, 3 \mathrm{SI},+03 \mathrm{f}$, $409,435,472$.

J. Burckhardt 223 .

Burke $126 \mathrm{ff}$., 235 .
Campe 215.

L. Camphausen $372,377,386 \mathrm{f}$, $390 \mathrm{f}, 435,+38,44^{8}, 4^{6} 3$.

Dahlmann $357,380,445,452$, $4 S_{4}, 487,480$.

Diepenbrock $+19,425$ f.

J. G. Droysen 210,352 ff., 373 , 440 ff., 462,475 .

11. Duncker 444 f., $449,462,487$.

Edel 456 f., $4 S_{3}$.

d'Ester 369.

Fichte 64 , So, So ff., I 34 ff, 145 f., $148,167,230,2 S_{1}, 327$ ff. 339.

Flottwell 462 .

Freytag, Gustav 463 .

Friedrich der Große $32 \mathrm{ff} ., 65$.

Friedrich, Kaiser $502 \mathrm{f}$.

Friedrich, Großherzog von Baden $471 \mathrm{f}$.

Friedrich Wilhelm IV. S9, 220, $242,256 \mathrm{ff}, 262 \mathrm{ff} ., 303,361 \mathrm{f}$, 393 ff., too ff., $+3+$.

F. v. Gagern $342 \mathrm{fi} ., 348,360,482$.

H. v. Gagern $348 \mathrm{f}, 366,356 \mathrm{ff}$., 402 ff., $432,4+S$ if., 457 f., $467 \mathrm{ff}, 4 \mathrm{ss}$. 
M. v. Gagern 348 f., 39I, 488 .

Geißel 418 .

Gentz I 2 I, I 26 ff., I 35, I44, I 5 I, I77, I92.

Leopold v. Gerlach $230 \mathrm{ff}$., 242, 245,254 f., 3 I I, 3I+ff., 4 I I ff., $42 \mathrm{~S} \mathrm{ff.,} 440$.

Ludwig v. Gerlach 235 f., 242, $24+\mathrm{f}, 254,3$ I I f., 4OS, 4I 3, $427 \mathrm{f}$.

Wilhelm v. Gerlach 235.

Gervinus 396, 408, $48_{3}$.

Gneisenau $163 \mathrm{ff} ., 232,332 \mathrm{f}$.

R. v. d. Goltz $490 \mathrm{f}$.

Görres I44, 264 f.

v. Griesheim 370 .

J. Grimm $2 \mathrm{~J} 4$.

W. Grimm 126.

Grolman 232.

Groote 473 .

Gruner 333.

Gutzkow 369.

K. L. v. Ifaller $2 \mathrm{r} 6 \mathrm{ff}$.

Hansemann 463.

Haidenberg 166, I 69, I 80, 230, 333.

v. Haxthausen 233.

Haym $380 \mathrm{ff}, 462$.

Heeren I44, $20 \mathrm{I}$ ff.

Hegel $2 I_{4}$ f., 27 I ff., 295, 349.

v. Hennig 473 .

Herder $28 \mathrm{ff}$., $330 \mathrm{f}$.

Hergenhahn 386 f., 435 .

Hoefken 350 .

Karoline v. Humboldt 350 .

Wilhelm v. Humboldt $36 \mathrm{ff} ., 129$, I32, I 44, I 75, I 77 f., I 44 ff., $225,293,301$.

J. Jacoby $364 \mathrm{ff}$.

Jahn 246.

Jarcke 233, 237 ff., 250.

Erzherzog Johann $385,420$.
W. Jordan $3^{8} 3$.

Kant 73 .

v. Kardorff 473 .

E. v. Kleist I 68.

H. v. Kleist $122 \mathrm{ff}$.

v. Kleist-Retzow 462.

H. Kruse 45 I f.

v. Ladenberg 4I3, 4I5 ff., 439.

H. Leo $233,235,245$.

Lessing 27 .

Luden $205 \mathrm{f}$.

Machiavell $95 \mathrm{ft}$.

de Maistre 7 I, 233.

Mallinekrodt $20 \mathrm{I}$.

Edwin v. Manteuffel 415, 439 f., 443.

O. v. Manteuffel $40 S, 4 \mathrm{I} 3,4 \mathrm{I} 5 \mathrm{f}$.

v. d. Marwitz 33 I.

Mathy 489.

Metternich $200 \mathrm{f}$.

Mevissen $382,463$.

v. Meyendorft 4I5.

v. Meyern 397 .

Mirabeau 23,65.

Montesquieu 22, 25, 129.

J. Möser 28, r 29.

F. K. v. Moser $24 \mathrm{ff}, 31,326,464$.

Adam Müller I2I ff., 158, 2 I 7 , 224,230 f., 249, 264, 296, 331.

Müller, Abgeordneter 456.

Graf Münster I 58,160, I $64 \mathrm{ff}$., I 75 .

Fr. Naumann $508 \mathrm{f}$.

Niebuhr I44, I63, 207 ff. $330 \mathrm{f}$.

Novalis $5 \mathrm{~S} \mathrm{ff} ., 133,140,148,265$, $287,296$.

Oetker $47 \mathbf{I}$.

Ostendorf 455 . 
P. Pfizer 333 ff., 343, 350, 357 , 374 f., 465 f., 473,481 f., 506.

Philipps 233.

Puchtn 214, 250.

Radowitz 233, 242, $267 \mathrm{ff}, 3 \circ 3$, $389,402,406,463,492 \mathrm{ff}$.

L. v. Ranke 92, I43, I54, 280 ff., $3 \mathrm{I} 7,319,439 \mathrm{ff}$.

v. Rauch 440.

Raveaux 365,455 .

Rehberg 125.

A. Reichensperger 42 I f., 424. 454 .

P. Reichensperger 42I, 424.

G. Rießer $3 \mathrm{~s}_{4}, 45^{8} \mathrm{f}$.

Rintelen 413,415 ff., 439.

IV. Rogge $422 \mathrm{ff}$.

K. RöBler 475 .

Rotteck 226.

Rousseau 41, 220.

Römer ${ }_{4} S_{3}$.

Rümelin 9, 368, $374 \mathrm{ff} ., 3$ S9 ff., 458,482 .

Savigny I4t, 214 f., $219,241$.

Schelling 59, 126, 2 I $3 \mathrm{f}$.

Schiller $28,5+$ ff., 64. 288 f.

Schimmelpfeng 5 IO.

A. W. Schlegel 72 .

Fr. Schlegel 59, $72 \mathrm{ff}$., $79 \mathrm{ff}$,, 124 , I 40, 144, 152, 265.

Schleiermacher 64, 69.

v. Schmerling 389 .

Schüler 453, 455. 458 .

Major Schulz 233.

Fürst Schwarzenberg $433 \mathrm{f}$.

Graf Schwerin 462 .

II. Simon 364 .

Simson $356 \mathrm{ff}$.
Soiron $373,453$.

Fürst Solms +77 .

Stahl $219,237,256 \mathrm{ff}, 468,+76$, $491 \mathrm{f} ., 497$.

Steffens $330 \mathrm{f}$.

Freiherr vom Stein 26, 144, 157 ff. $265 \mathrm{ff}$, $320 \mathrm{f.}, 329 \mathrm{ff}$,

Hofrat Stein 233 .

v. Stockmar $358 \mathrm{ff}, 403.474$.

Major Streit 233

v. Strotha + I 5 f., 439 .

Struve 459

Stüve 4 ro.

Thibaut 200.

Thon $206 \mathrm{f}$.

Treitschke $110,190 \mathrm{f}, 210,470 \mathrm{ff}$. , 479, 506, 512.

Triest 497.

Twesten 469, 500 .

Usedom 366, $394 \mathrm{f}$.

Venedey 365 .

Vincke $389,395,397,4^{1} 4,4^{62}$.

Virchow $499 \mathrm{f}$.

Vogt 455 .

Voltaire 22, 25

Waitz $3 s_{4}, 479$ ff., $4 s_{4}, 488$.

Waldeck 369,401 .

Walter $407,422 \mathrm{ff}$.

F. G. Welcker 203 f.

K. Th. Welcker $389,455$.

Werner $365,+56$.

Wieland $30 \mathrm{f}$.

Wilhelm I. Prinz von Preußen) $371,43 \mathrm{I}$ f.

v. Willisen $395,405 \mathrm{f}$. 


\section{Kleine Historische Schriften}

\section{von

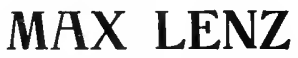

o. ö. Professor an der Universität Berlin

608 Seiten gr. $8^{\circ}$. Preis brosch. M. 9.-, elegant geb. M. 11.-

\section{Inhalts-Übersicht:}

Leopold Ranke - Zum Gedächtnistage Johann Gutenbergs - Janssens Geschichte des deutschen Volkes - Hunanismus und Reformation Die Geschichtsschreibung in Elsaß zur Zeit der Reformation - Dem Andenken Ulrichs von Hutten - Martin Luther - Luthers Lehre von der Obrigkeit - Der Bauernkrieg - Florian Geyer - Philipp Melanchthon Die geschichtliche Stellung der Deutschen in Böhmen - Gustav Adolf dem Befreier zum Gedächtnis - Nationalität und Religion - Wie entstehen Revolutionen? - Die französische Revolution und die Kirche Die Bedeutung der Seebeherrschung für die Politik Napoleons - Napoleon und PreuBen - 1848 - Bismarcks Religion - Bismarck und Ranke Otto von Bismarck und Freiherr Karl von Stein - Bismarck in Gastein Heinrich von Treitschke - Konstantin Rößler - Wilhelm I. - Die Tragik in Kaiser Friedrichs Leben - Das russische Problem - Jahrhundertsende vor hundert Jahren und jetzt - Ein Blick in das zwanzigste Jahrhundert - Die Stellung der historischen Wissenschaften in der Gegenwart.

Die vorliegenden Schriften wenden sich weniger an die Fachgelehrten, denen sie freilich auch viel Wertvolles, bisher an entlegenen Orten Verstecktes bieten, als an die große Menge der historisch interessierten Gebildeten. Max Lenz besitzt die bei deutschen Gelehrten so seltene Gabe, die Resultate tiefgreifender Studien und umfassender Forschung in gewähltester Form meisterhafter Abrundung vorzutragen: er schreibt einen Stil von so hinreißender Gewalt und so vollendeter Schönheit und - was mehr ist - er besitzt so viel originalen Geist und eine so intuitive Kraft im Erfassen und Beleuchten eines Problems, daß er den größten Essayisten unserer Literatur würdig an die Seite tritt. Es steckt eine so komprimierte Geistesarbeit, so viel förderndes und überraschend klärendes Verständnis feinster Zusammenhänge und so viel Kunst der Formulierung in diesen „Kleinen historischen Sclıriften“, daß jeder Gebildete dankbar sein wird, sie in die Hand zu bekommen. 



\title{
PLEASE DO NOT REMOVE \\ CARDS OR SLIPS FROM THIS POCKET
}

\author{
UNIVERSITY OF TORONTO LIBRARY
}




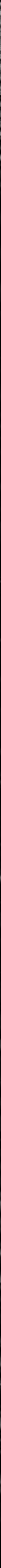

